\title{
Fossil Energy Biotechnology
}

A Research Needs Assessment Final Report

\section{November 1993}

Prepared For:

U.S. Department of Energy Office of Energy Research Office of Program Analysis Washington, D.C. 20585

Under Contract No. DE-ACO1-ER30156
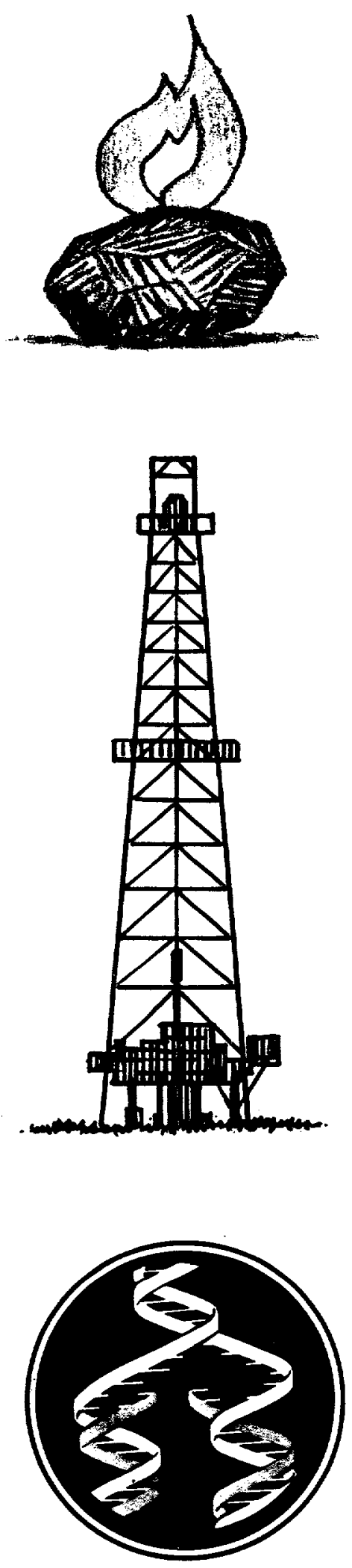


\section{DISCLAIMER}

This report was prepared as an account of work sponsored by an agency of the United States Government. Neither the United States Government nor any agency thereof, nor any of their employees, make any warranty, express or implied, or assumes any legal liability or responsibility for the accuracy, completeness, or usefulness of any information, apparatus, product, or process disclosed, or represents that its use would not infringe privately owned rights. Reference herein to any specific commercial product, process, or service by trade name, trademark, manufacturer, or otherwise does not necessarily constitute or imply its endorsement, recommendation, or favoring by the United States Government or any agency thereof. The views and opinions of authors expressed herein do not necessarily state or reflect those of the United States Government or any agency thereof. 


\section{DISCLAIMER}

Portions of this document may be illegible in electronic image products. Images are produced from the best available original document. 


\section{EXECUTIVE SUMMARY}

The Office of Program Analysis of the U.S. Department of Energy commissioned this study to evaluate and prioritize research needs in fossil energy biotechnology. The objectives were to identify research initiatives in biotechnology that offer timely and strategic options for the more efficient and effective uses of the Nation's fossil resource base, particularly the early identification of new and novel applications of biotechnology for the use or conversion of domestic fossil fuels. Fossil energy biotechnology consists of a number of diverse and distinct technologies, all related by the common denominator - biocatalysis.

The expert panel organized 14 technical subjects into three interrelated biotechnology programs: 1) upgrading the fuel value of fossil fuels; 2) bioconversion of fossil feedstocks and refined products to added value chemicals; and, 3 ) the development of environmental management strategies to minimize and mitigate the release of toxic and hazardous petrochemical wastes.

The integration of these programs as viable bioprocessing initiatives proposes an innovative and conceptual principle for the development of a "new" approach to fossil energy biotechnology. This unifying principle is NON-AQUEOUS BIOCATALYSIS. Biocatalysis coupled to conventional chemical catalysis in organic-based media offers bioprocessing options uniquely characterized by the selectivity of biocatalysts plus fast reaction rates and specificity of chemical catalysts.

The importance of non-aqueous biocatalysis lies in its ability to interface readily into most fossil fuels and chemicals processing reactor systems without major alterations or changes in the infrastructure of these in-place technologies. The supporting and enabling technologies required for the implementation of this technology are the identification and characterization of new biocatalysts or microbial consortia, strain and genetic improvements to construct the most efficient biocatalyst(s) possible, and development of on-line analytical systems to detect, monitor, and control bioprocessing systems.

New biocatalysts and microbial consortia are needed with improved target specificity to defined fossil feedstocks. Analytical instrumentation methodologies will derive significant benefits from organic solvent based fossil fuels bioprocessing systems due to advantages resulting in analytical sensitivity and precision of solution chemistry for the detection and monitoring of changes in fossil fuels substrata by biocatalysts. Non-aqueous biocatalysis reduces and potentially eliminates many concerns involving the design of expensive large volume bioreactors and associated problems of product recovery and separation by interfacing the non-aqueous biocatalytic system to existing chemical process reactors and using established industry technologies for recovery of products from organic solvent process streams.

The majority of past and present research efforts are conducted in aqueous systems. The data bases examined in this report reflect the achievements resulting from studies in waterbased media. Non-aqueous biocatalysis represents a radical departure from conventional methodologies and approaches and extends these developments into a new generation of biological systems, projecting a promising technology for the implementation of new fossil fuel bioprocessing initiatives of value and usefulness to the energy industry. 
The panel recommends the following programs as high priority initiatives for future implementation of fossil fuel bioprocessing options of value to the energy sector.

\section{BIOCATALYSIS BIOPROCESSING RECOMMENDATIONS}

1. Upgrading of Fossil Fuels.

- Biodesulfurization of organic sulfur from high sulfur coals and oils is of domestic and global importance. Heteroatom removal - desulfurization, denitrogenation, and deoxygenation in non-aqueous media. Removal of inorganic forms of sulfur from coal remains an aqueous based reaction system.

- Depolymerization of solid fuels and heavy oils by non-aqueous biocatalysis. This technology addresses issues such as coal liquefaction, beavy oil viscosity reduction, and improved feedstocks for chemical production.

- Develop new microbial systems for fossil resource applications with defined biochemical functionality in aqueous and non-aqueous media.

- Develop analytical systems for on-line detection and monitoring of bioprocesses and implement bioengineering designs to accomodate nonaqueous bioprocessing options.

2. Bioconversion of Fossil Feedstocks and Byproducts to Value Added Chemicals.

- Bioconversion of gaseous waste streams to value added products such as methane, acids, alcohols, ketones, and esters.

- Non-aqueous biocatalysis of fossil feedstocks to produce value added products such as hydroxy fatty acids, fatty alcohols, wax esters, polyesters, glycols, and hydroxylated aromatic chemicals.

- Exploit biosurfactant technology as specialty products for bioremediation, tribology, and enhanced oil recovery.

3. Bioremediation of Fossil Fuel Processing Wastes.

- Development of aerobic and anaerobic bioprocesses for biotransformation of gaseous, liquid, and solid wastes.

- Development of biological systems to metabolize low volume point source spills, oil impacted soils, slop oil emulsions, separator sludges and solids, drilling muds, and pit residues.

- Exploit the potential for bioconversion of waste streams into value added products for positive revenue return in context of non-aqueous biocatalysis.

4. Hydrocarbon and Fossil Fuel Biotransformation by Anaerobic Microorganisms.

- Assess bioprocessing of fossil feedstocks by anaerobic microorganisms in terms of upgrading, bioremediation, and added value chemicals. 


\section{EXPERT PANEL}

The following panel of distinguished scientists evaluated the research needs for fossil energy biotechnology applicable to the programs of the Department of Energy. This project was conducted under, contract to Consultec Scientific, Inc., Knoxville, TN from the U.S. Department of Energy, Office of Program Analysis.

Dr. W.R. Finnerty (Principal Investigator)

Consultec Scientific, Inc.

725 Pellissippi Parkway, Suite 110

Knoxville, TN 37932-3300

Dr. J.W. Costerton '

Department of Biological Sciences

University of Calgary

Calgary, Alberta, CANADA

T2N 1N4

Dr. Rathin Datta

Michigan Biotechnology Institute

P.O. Box 27609

Lansing, MI 48909

Dr. James R. Frank

Gas Research Institute

Biotechnology Division

8600 West Bryn Mawr Avenue

Chicago, IL 60631

Dr. Peter M. Gresshoff

Plant Molecular Genetics \& Center for Legume Research

University of Tennessee

Knoxville, TN 37996

Dr. Koki Horikoshi

Riken Institute

of Physical \& Chemical Research

Hirosawa 2-1, Wako-shi

Saitama, 351-01 JAPAN
Dr. Roger C. Prince

Exxon Research and Engineering Co.

Clinton Township, Route 22 East

Annandale, NJ 08801

Dr. Joseph M. Suflita

University of Oklahoma

Department of Botany and Microbiology

770 Van Vleet Oval, Room 135

Norman, OK 73019

Dr. Kenneth N. Timmis

Division of Microbiology

GBF

Maschroder Weg 1

3300 Braunschweig, GERMANY

Dr. David C. White

Institute of Applied Microbiology

University of Tennessee

10515 Research Drive, Suite 300

Knoxville, TN 37932-2567

Dr. J. Gregory Zeikus

Michigan Biotechnological Institute

P.O. Box 27609

Lansing, MI 48909 


\section{ACKNOWLEDGEMENTS}

Consultec Scientific, Inc. thanks the expert technical panel for their input and technical contributions to the final report. The conclusions and research priorities described in the executive summary reflect the consensus of the panel. Recognition is made to B. Ensley and B. Kelley for their contributions to the final report. The assistance and cooperation of the following scientists in providing information and documentation is gratefully acknowledged: Dr. C. Scott, Oak Ridge National Laboratory; Dr. C. Gehrs, Oak Ridge National Laboratory; Dr. P. Dugan, Idaho National Engineering Laboratory; Dr. J. Gaddy, University of Arkansas; Dr. D. Hitzman, Geo-Microbial Technologies, Inc., Ochelata, OK; Mr. R. Johnson, Morgantown Energy Technology Center; and Ms. F. Eskey, Pittsburgh Energy Technology Center. Appreciation is gratefully extended to the external expert reviewers for their incisive and insightful contributions. Special recognition is extended to Mr. Don Freeburn and Dr. Paul Scott of the U.S. Department of Energy for their support, interest and assistance throughout all phases of this study. Grateful acknowledgement is extended to other scientists and research managers consulted during the preparation of this report.

Finally, the expert technical panel acknowledges and thanks the Consultec Scientific, Inc. staff for their superb support services throughout the preparation of this report. 


\title{
TABLE OF CONTENTS
}

\author{
EXECUTIVE SUMMARY
}

Page

Chapter 1 . SUMMARY OVERVIEW OF REPORT $\ldots \ldots \ldots \ldots \ldots \ldots \ldots \ldots$

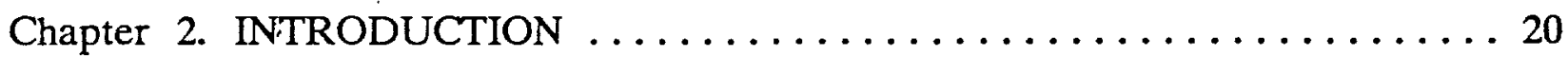

Chapter 3. BIOREMEDIATION OF LIQUID FOSSIL FUELS AND

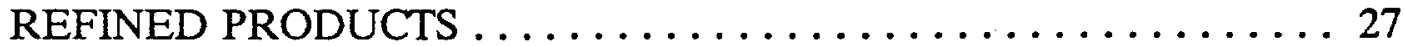

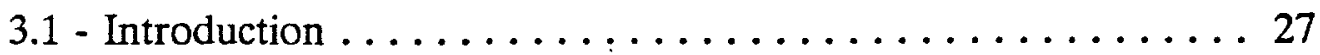

3.2 - Status of Basic and Applied Rèsearch . . . . . . . . 28

3.3 - Future Research Development and Requirements ....... 34

3.4 - Recommendations and Priority Status ............ 38

Chapter 4. BIODESULFURIZATION OF FOSSIL FUELS . . . . . . . . 40

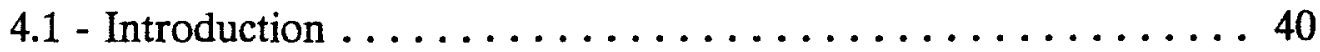

4.2 - Status of Basic and Applied Research ............ 40

4.3 - Future Research Development and Requirements ....... 45

4.4 - Recommendations and Priority Status ............ 49

Chapter 5. BIOCONVERSION OF COAL AND LIGNITE PYROLYSIS

GAS AND WASTE STREAMS $\ldots \ldots \ldots \ldots \ldots \ldots \ldots \ldots \ldots \ldots$

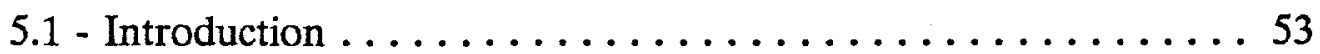

5.2 - Status of Basic and Applied Research ............ 55

5.3 - Future Research Development and Requirements .......6 63

5.4 - Research Needs and Limitations ................ 64

5.5 - Recommendations and Priority Status ............ 67

Chapter 6. ANAEROBIC BIOTRANSFORMATION OF FOSSIL FUEL

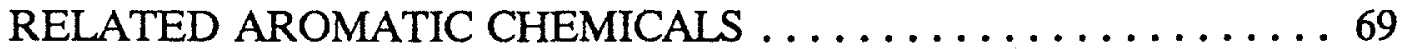

6.1 - Introduction . . . . . . . . . . . . . . . . 69

6.2 - Status of Basic and Applied Research . . . . . . . . 70

6.3 - Future Research Development and Requirements ........ 99

6.4 - Recommendations and Priority Status ............. 101

Chapter 7. BIOCONVERSION OF HYDROCARBONS TO ADDED

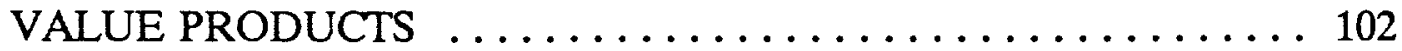

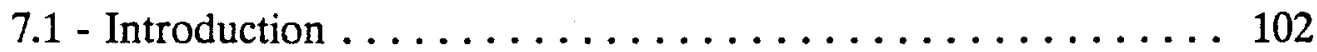

7.2 - Status of Basic and Applied Research ............ 103

7.3 - Future Research Development and Requirements ...... 117

7.4 - Recommendations and Priority Status ............ 120 
Chapter 8. GENETIC STRATEGIES FOR THE DESIGN AND

CONSTRUCTION OF MICROORGANISMS ABLE TO

EFFICIENTLY BIOCONVERT AROMATIC HYDRO-

CARBONS TO ADDED-VALUE CHEMICALS .......... 122

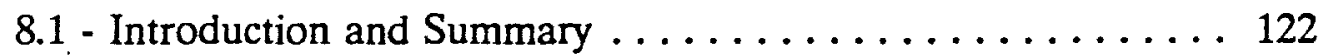

8.2 - Status of Basic and Applied Research . . . . . . . . 124

8.3 - Future Research Development and Requirements ....... 139

8.4 - Recommendations and Priority Status . . . . . . . . . 141

Chapter 9. STRATEGIES AND DEVELOPMENT OF NEW

MICROORGANISMS POSSESSING SPECIALIZED

PHYSIOLOGICAL ATTRIBUTES FOR THE

BENEFICIATION OF FOSSIL FUELS $\ldots \ldots \ldots \ldots \ldots \ldots \ldots \ldots 142$

9.1 - Introduction . . . . . . . . . . . . . . . . . . 142

9.2 - Status of Current Research on Solvent-Tolerant

Microorganisms .................... 143

9.3 - Future Research Development and Requirements ...... 146

9.4 - Research Needs and Limitations .............. 147

9.5 - Recommendations and Priority Status ........... 148

Chapter 10. USE OF METHANE IN WATER TREATMENT $\ldots \ldots \ldots \ldots \ldots 150$

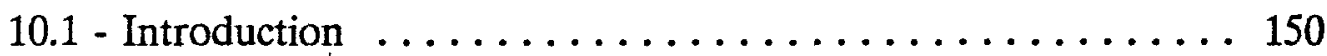

10.2 - Status of Basic and Applied Research ...............151

10.3 - Future Research Development and Requirements ...... 156

10.4 - Recommendations and Priority Status .......... 158

Chapter 11. MICROBIOLOGICALLY INFLUENCED CORROSION

IN THE NATURAL GAS INDUSTRY $\ldots \ldots \ldots \ldots \ldots \ldots \ldots . \ldots 159$

11.1 - Introduction . . . . . . . . . . . . . . . . . 159

11.2 - Status of Basic and Applied Research ............ 161

11.3 - Future Research Development and Requirements ....... 165

11.4 - Recommendations and Priority Status ............ 166

Chapter 12. SUBSURFACE MICROBIOLOGY IN THE NATURAL

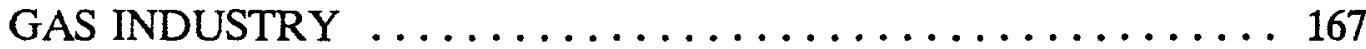

12.1 - Introduction . ...................... 167

12.2 - Status of Basic and Applied Research ............ 170

12.3 - Future Research Development and Requirements ....... 174

12.4 - Recommendations and Priority Status ........... 175

Chapter 13. CHEMICALS FROM METHANE $\ldots \ldots \ldots \ldots \ldots \ldots \ldots \ldots$

13.1 - Introduction . ........................ 176

13.2 - Status of Basic and Applied Research ............ 179

13.3 - Future Research Development and Requirements ....... 181

13.4 - Recommendations and Priority Status ........... 182 
Chapter 14. PHYSICAL DELIVERY OF MICROBIAL ACTIVITY AND APPLICATION TO FOSSIL FUEL BIOTECHNOLOGY. . . . . 183

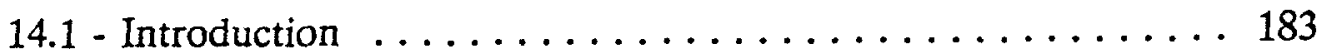

14.2 - Status of Basic and Applied Research . . . . . . . . 184

14.3 - Future Research Development and Requirements ....... 194

14.4 - Recommendations and Priority Status ............ 194

Chapter 15. ANALYSIS OF BIOENGINEERING/BIOREACTOR TECHNOLOGY APPLICABLE TO THE BIOPROCESSING

OF FOSSIL FUELS . . . . . . . . . . . . . . . . . . . 195

15.1 - Introduction and Summary $\ldots \ldots \ldots \ldots \ldots \ldots \ldots \ldots$

15.2 - Status of Basic and Applied Research . . . . . . . 197

15.3 - Future Research Development and Requirements . . . . . 200

15.4 - Recommendations and Priority Status . . . . . . . . . 201

Chapter 16. APPLICATION OF ANALYTICAL INSTRUMENTATION

TO FOSSIL FUELS $\ldots \ldots \ldots \ldots \ldots \ldots \ldots \ldots \ldots \ldots \ldots \ldots \ldots$

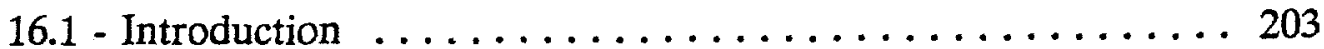

16.2 - Status of Basic and Applied Research ............ 204

16.3 - Future Research Development and Requirements in

Analytical Technologies ................... 214

16.4 - Recommendations and Priority Status .......... 217

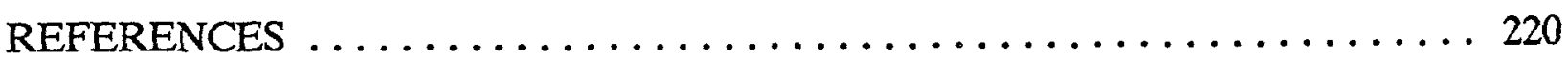

APPENDIX 1 - PRIORITIZED PROGRAM RECOMMENDATIONS ....... 276

APPENDIX 2 - FEDERAL LABORATORY PROGRAMS

IN FOSSIL ENERGY BIOTECHNOLOGY . . . . . . . . 290

APPENDIX 3 - EXTERNAL PEER REVIEWERS . . . . . . . . . . . . . . . 297 


\section{Chapter 1}

\section{SUMMARY OVERVIEW OF REPORT}

Fossil energy biotechnology will play a significant role in the development of viable options for improving the use of fossil feedstocks and assuring a cleaner environment. The majority of the world's energy comes from depleting fossil resources, with these resources and the energy derived from them representing the lifeblood of economies worldwide. Conventional estimates predict a two- to four-fold increase in energy consumption over the next fifty years, with these projections becoming possibly larger as developing nations emerge as signficant energy consumers. This increased energy demand requires strategies today to circumvent the many problems associated with fossil resource-based energy systems. It seems imperative that new technologies and products address environmental concerns as well as improved energy efficiency. It could also develop that at some future time fossil resources will become too valuable to burn. Such options depend on other energy-yielding alternatives such as biomass, solar, hydroelectric, nuclear and geothermal. A balanced portfolio of research initiatives, which includes fossil fuels, will serve to provide viable options in securing cleaner and abundant energy supplies for different and, perhaps, difficult future global scenarios.

The Department of Energy recognizes that biotechnology can impact on its mission to improve and foster technologies that support its goals of enhancing the more efficient utilization of the nation's fossil resources, whether solid, liquid, or gaseous fuels. The mission of the Office of Fossil Energy is to support research programs which allow the Department of Energy to understand and anticipate future developments in biotechnology which will offer timely and strategic options for the more efficient and effective uses of our fossil resource base while protecting the environment. The unique capabilities of the Department to address and solve the numerous and complex problems arising from the expanded utilization of fossil resources will be targeted more effectively by an early recognition of the advantages offered by focused biotechnological initiatives in the bioprocessing of fossil fuels. Biotechnological scenarios offer a subtle, sophisticated alternative approach to addressing a myriad of past, present, and future issues ranging from the upgrading of fossil resources, the production of specialty chemicals, environmental management strategies, innovative and integrated engineering designs, and the development of environmentally acceptable technologies.

The U.S. Department of Energy, Office of Program Analysis has directed the completion of this study for long-term research needs in fossil energy biotechnologies. The growing importance of biotechnology worldwide prompted an analysis of biotechnology initiatives which can or will become available to the domestic fossil energy resource base over the next 2-3 decades. Of special importance is the identification of those technologies which will impact positively on future uses of these resources, with early identification of new and novel 
applications of biotechnology for the use or conversion of domestic fossil resources to fuels and chemicals. Domestic fossil energy biotechnology R\&D initiatives are largely centered within DOE regional research centers, with other programs located at universities and the private sector.

The research recommendations of the panel are presented in context of three broad-based technology programs which cross-cut and integrate multiple biological options. They stem from the determination of the most fruitful way to foster the exploitation of the marvellous advances of modern biology in processing fossil fuels to meet the Nation's needs. The rationale behind each recommendation is based on two factors. First, each major recommendation exhibits elements of technical feasibility, although for individual programs a more substantial base of fundamental knowledge is necessary to move the technology forward. Secondly, each major recommendation offers promise for commercial implementation, provided the basic science is scientifically sound and technically feasible.

\section{A. Implement biological upgrading of fossil fuels to improve their characteristics.}

Areas for mid- to long-term applications include:

- Microbial removal of sulfur and other heteroatoms from solid and liquid fuels

- Microbial depolymerization and viscosity modification of solid and liquid fuels

- Microbial upgrading of the fuel value of syngas.

These areas offer substantial opportunities for commercialization, but further developments are required in the fundamental biology and bioengineering of these processes before progress will occur. Emphasis is placed on retaining and enhancing the fuel values of the resources during upgrading; for example, the removal of organic sulfur should not involve the complete mineralization of the host compound, and depolymerization should not be emphasized at the expense of downgrading fuel value. Promising technologies include anaerobic transformations for the removal of heteroatoms (Chapters 4 and 6), the applications of biosurfactants for viscosity modification (Chapter 7), and the biological conversion of gases to methane or alcohols (Chapter 5). New conceptual advances in bioreactor technologies will be required for fossil fuels bioprocessing (Chapter 15), as well as the interactive integration of sophisticated analytical systems to effectively detect and monitor changes occurring in structurally complex fossil substrates (Chapter 16). Environmental considerations will offer further opportunities for the biological processing of fuels (Chapters 3 and 6).

B. Exploit the recent developments that allow microorganisms and enzyme systems to function in organic-based media for chemicals production.

Revolutionary developments are occurring in the development of biocatalysts which function with specificity and selectivity in the biotransformation of diverse hydrophobic substrates non-aqueous biocatalysis. We recommend the development of improved and enhanced biocatalysts that offer future economic and performance potential in the bioprocessing of 
fossil resources (Chapters 7 and 8). Chemical manufacturing, whether specialty, fine, or commodity, involves a process infrastructure based on organic solvents. The known ability of biological processes to function in organic media offers a totally new, exciting and innovative approach to the bioconversion of fossil feedstocks and refined petrochemicals for the efficient production of "old" and "new" chemicals not heretofore possible with existing technology (Chapter 7). We recommend that programs be initiated to expand our knowledge of the total potential of global metabolic diversity to better recognize and target those microbial activities of value to the fossil resource industry (Chapter 8). Immediate goals for implementation within a five-year time frame are applications of biosurfactant technology, biopolymer production, and the development of sophisticated chemo-enzymatic bioconversions of fossil feedstocks for the production of chemicals for established product lines and the development of new product lines (Chapters 7 and 8).

\section{Develop environmentally-compatible waste management programs that integrate into the existing infrastructure of fossil fuel industries.}

The panel recognizes that the fossil fuel industries generate a variety of complex waste streams of solid, liquid, and gaseous forms. Biotechnological efforts must be directed toward the dissipation and disposal of such wastes in an environmentally-compatible manner. Waste stream processing strategies are to be integrated into the overall use of fossil energy reserves, ranging from production through processing of fossil feedstocks to minimize and eliminate waste generation. It is possible and environmentally expedient to develop added value products from waste stream feedstocks through bioprocessing (Chapters 3, 5, 6, and 7).

The panel further recognizes that fossil fuels and waste streams will inevitably reside in environmental compartments deemed unacceptable. Bioremediation technologies offer the potential for the efficacious beneficiation of such contaminated environments. Approaches to the restoration of contaminated areas will assuredly be as diverse as the environment and pollutants under consideration, with treatments being site specific. The panel recommends that such approaches continue to evolve with the development of protocols and standards for reliably assessing the efficiency and efficacy of such remedial actions (Chapter 3 ).

Lastly, the panel recommends that aggressive programs be implemented concerning pollution prevention. The report does not address prevention, rather focusing on "cure" technologies for existing environmental threats. The development and implementation of future biotechnological strategies aimed at prevention will promote the goals of a cleaner environment as well as the improved utilization of our fossil resources. The costs associated with the restoration of polluted environments are significantly greater than costs incurred in the prevention of ecological insults. This is particularly evident when the potential is recognized for the generation of added-value byproduct credits derived from the bioprocessing of waste streams. Biotechnological approaches for the prevention of pollution associated with the extraction, transport, storage and processing of fossil fuels are achievable goals. 
Three additional recommendations are offered in context of support sciences which relate directly to the ability of any bioprocessing program to achieve future success, and to provide the Department of Energy with an armamentarium of biological systems from which to exercise options in the development of viable bioprocessing programs. These recommendations concern the expansion of our knowledge base in the understanding and appreciation of the total spectrum of global microbial diversities, particularly as they relate to fossil substrates, the development of interactive analytical systems which enable on-line detection and monitoring of specific changes occurring in biologically-treated fossil fuels and the development of novel bioreactor-bioengineering systems to accommodate the required large volume bioprocess technologies.

\section{A. Expand our understanding of global microbial diversities that relate to fossil fuel substrates.}

The panel recommends the establishment of programs which significantly expand our insight and understanding of the total potential within the microbial world that addresses the beneficiation of fossil fuel substrates. For example, it has been recently proven that a sulfate-reducing microorganism can oxidize a long-chain alkane with the concomitant reduction of sulfate to sulfide, a claim that has been in contention for over 50 years. The past decade has provided irrefutable evidence that anaerobic microorganisms do metabolize aromatic compounds with the potential for such biotransformations only beginning to emerge and be recognized as a valuable biological tool (see Chapters 5 and 6). Further, by expanding our knowledge of the microbial and metabolic potential, real advantages and opportunities arise in the potential to target microbial activities with recognized value to specific fossil resource technologies. The establishment of an expanded microbial armamentarium will expedite the implementation of strategies for future progress in fossil resource bioprocessing.

\section{B. Bioreactor-Bioengineering Design.}

It is essential that as fossil energy bioprocessing programs evolve into scientifically sound and technically substantiated technologies, the development of integrated, innovative bioreactor strategies must occur. The bioprocessing of extremely large masses and volumes of fossil substrates in economical and quality-controlled processing systems is mandatory for the future integration of bioprocessing options into the fossil fuels industry (Chapter 15).

\section{Analytical Instrumentation.}

The success of any bioprocessing initiative is dependent on our ability to detect and monitor specific changes in structurally complex fossil substrates. To date, biologists have concentrated their efforts on the microbial transformations of structurally simple hydrocarbons or surrogates of more structurally complex fossil constituents, primarily for reasons involving the availability of analytical systems with which to assess those changes occurring through biological processes. The bioprocessing of more complex substrates such as coal and the heavy ends of oil will require a significantly greater level of analytical 
sophistication to detect and monitor specific changes occurring in the complex fossil substrates than is currently available to the general biological community. Such on-line, nondestructive systems must be adaptable to bench level studies as well as large scale bioreactors. It is noteworthy that few high-quality reports exist in the literature describing the changes which occur in complex fossil substrates as the result of bioprocessing and even these reports have limitations due to the lack of suitable analytical systems. We recommend the development of analytical systems which relate to and integrate with biological studies and systems.

\section{GENERAL BACKGROUND}

This study represents an independent assessment of the research needs for the application of biotechnology to the conversion and use of the nation's fossil energy resources. The direction, content and priority of research activities for the long term (15-30 years) are addressed with emphasis on the identification of new applications and potential opportunities, including radically different approaches from the direction of current applied research in fossil energy biotechnology. The fossil resources of interest are coal, natural gas, heavy oils, tar sands, and oil shales. Enhanced oil recovery and gas production/recovery were specifically excluded from this research needs assessment.

A time frame of 15-30 years was considered, which includes both short-, mid-, and long-term needs. Short-term R\&D (up to 10 years) should focus on applied technologies through pilot plants and the establishment of commercial feasibility; mid-term R\&D (10-15 years) develops emerging basic programs into applied programs; and long-term $R \& D$ (15-30 years) develops and integrates new knowledge and emerging concepts as the basis for future bioprocesses. Research priorities were established based on each program's perceived importance and probability of obtaining technical feasibility, reliability and potential for commercial implementation.

An eleven-member expert panel developed and prioritized $R \& D$ recommendations listed herein for fossil resources biotechnology. This study was conducted over an eight-month period involving four days of panel meetings and attendance at national and regional meetings relevant to the study. Further, independent peer reviews of the report were obtained from eminent researchers to provide proper perspective and commentary.

A diverse list of technical subjects was organized into a generalized format which allowed a meaningful analysis of complex, interrelated technical areas in functional industry-relevant process technologies.

\section{Definitions of Process Technologies:}

Extraction Biological processes that upgrade and/or modify the physical and/or chemical properties of fossil fuels in situ.

Transport Biological processes that upgrade and/or modify the physical and/or chemical properties of fossil fuels during transportation. 
Storage Biological processes that upgrade and/or modify the physical and/or chemical properties of fossil fuels during storage.

Processing Biological processes that result in the bioconversion of fossil fuels or derived fractions thereof into added-value products.

Waste Biological processes that are performance-effective in bioremediation strategies.

Fossil energy biotechnology encompasses a number of diverse and distinct technologies, all related however, by the common denominator-biocatalysis. Specific fossil energy biotechnological needs and R\&D initiatives to be addressed within this report include:

- bioremediation

- biodesulfurization of fossil fuels

- bioconversion of coal and lignite pyrolysis gas and waste streams

- anaerobic biotransformations of fossil fuel-related aromatic chemicals

- added-value chemicals from petrochemical feedstocks

- genetic strategies and constructs for fossil fuel biotechnology

- solvent-tolerant microorganisms biocorrosion and microbial contamination control in fossil industries ultramicrobacteria

- bioengineering and bioreactor technologies for fossil fuels bioprocessing

- improved analytical techniques and instrumentation applicable to fossil fuels

The research needs assessment for fossil energy biotechnology emphasizes three points concerning future research developments, recommendations, and priority status:

1. R\&D initiatives are developed in context of short-, mid- and long-term programs. The near-term programs represent a high probability of success in establishing early credibility for the application of biological processes for the fossil resources industry.

2. The infrastructure for oil, gas, and coal production, transport, storage, and processing are well-established, in-place technologies developed and improved over many decades. Biological processes and technologies must interface with these existing systems with minimum impact on or affecting their established function.

3. We are forced to assess technology development in context of databases and knowledge that exists today. The next two to three decades will realize significant advances in our understanding of the chemistry and physics of fossil fuels plus, most certainly, significant advances in all phases of modern biology. Accordingly, some license is granted to exercise forward thinking in developing biological scenarios of import to the futuristic bioprocessing of fossil resources. 


\section{ORGANIZATTON OF REPORT}

This document represents the results of bringing together a diverse group of scientists and engineers to address the future of biotechnology in the fossil fuel industry. Chapters 3-16 represent the results of their efforts to address what were seen as the principle issues of fossil energy biotechnology. The diverse topics, contents, and styles of these chapters highlight the diverse expertise of the panel, and provide a detailed overview of the current position of the field.

This document is, however, much more than the sum of these individual chapters. In assembling the panel for its point sessions, the synergisms between the various areas became very apparent from the viewpoint of addressing the major areas of potential importance. Three major areas stood out; upgrading the fuel value of fossil fuels, converting fossil fuels to alternative, high value products, and environmental management to minimize and mitigate any environmental harm caused by the use of fossil fuels. In this section we briefly highlight how future progress in these three areas will require an integrated approach that cuts across the technical areas defined herein where scientific advances in one area impact on other technical areas.

FUEL UPGRADING. The fossil fuel industry has already used much of the most readily available and most easily refined resources, and there is an increasing need for innovative approaches to extracting and using the remainder. At the same time, increasing environmental awareness mandates the specific removal of certain components of the fuels. Among the most promising area that the panel recommends for support are the biological removal of heteroatoms, such as sulfur from solid and liquid fuels, the biological removal or conversion of undesirable compounds, such as aromatics, from liquid fuels, the biological liquefaction of solid fuels providing this is done with minimal loss of fuel value, the biological approaches to decreasing the viscosity of heavy liquid fuels, either by microbial transformations or the application of biosurfactants, and the biological conversion of syngas to reduce toxicity, improve its fuel value or convert it to oxygenated additives for liquid fuels.

The achievement of these goals will require an interdisciplinary approach that will foster an understanding of the fundamental biological phenomena, the successful scale-up of the processes to commercial scale, and integration of the processes into the existing infrastructure of the fossil fuel industry.

For example, progress to a commercialization of desulfurization of fossil fuels, dealt with in some detail in Chapter 4, will require substantial use of the advanced analytical techniques discussed in Chapter 16; improvements in understanding the basic biology of the phenomenon, and improving the biocatalysts for commercial exploitation (Chapters 6, 7, 8, and 9), and new conceptual developments in bioreactor technology (Chapter 15). In this case it is clearly premature to progress to large scale bioreactors until a better understanding of the basic processes exists. 
CHEMICALS PRODUCTION. The emerging opportunities in the bioprocessing of fossil feedstocks for chemicals manufacturing cross-cut the diverse technologies that characterize fossil energy biotechnology. For example, the development of biosurfactant technology impacts on the upgrading of fossil fuels to enhance the bioavailability of solid and liquid substrates, biosurfactants will form oil/water or water/oil emulsion systems in which to catalyze specific reactions, and offer applications to hazardous and toxic waste sites for stimulating the rates of biodegradation and improving the bioavailability of waste materials to the indigenous microflora. Biosurfactant technology offers a commercially viable product for reasons of low manufacturing costs including no downstream recovery or purification as well as being an environmentally acceptable and non-polluting additive to diverse ecosystems for directed beneficiation strategies. New developments in bioreactor-bioengineering design are not required for implementation of this technology.

The development of solvent-tolerant biocatalysts (Chapter 9) offers a radically different approach to chemicals production (Chapter 7), bioremediation (Chapter 3), bioreactor design (Chapter 15), and fossil fuel upgrading (Chapters 4, 5, 6 and 8). The importance of this potentially new technology lies in its ability to interface readily into most fossil fuels and chemicals processing systems without major alterations or changes in the infrastructure of these in-place technologies. A scientifically sound data base exists concerning the ability of biocatalysts to function efficiently in organic-based media. With new developments appearing regularly, the level of this technology has changed from an empirical science to a predictive science in our ability to predetermine and target the functional properties of biocatalysts in various organic solvents (Chapters 7, 8, and 9).

ENVIRONMENTAL CONSIDERATIONS. The application of biotechnology strategies to mitigate and beneficiate environmental insults resulting from fossil fuels production, transport, processing, and storage involves the integration of diverse cross-cutting bioprocessing options. For example, waste streams resulting from coal processing contains a wide variety of phenolic compounds (Chapter 4 and 5). Solutions to such problems involve mineralization (Chapter 3), and bioconversion to added-value fuels (Chapter 5) and chemicals (Chapter 7). The ability to redirect waste streams to profit-deriving process streams offers potential economic incentives to the fossil fuel industry. Inherent to any viable bioprocessing option is the concurrent development of bioreactor-bioengineering designs (Chapter 15) coupled to sophisticated interactive, on-line analytical systems (Chapter 16).

The beneficiation of hazardous and toxic wastes through either oxidative (Chapter 10) or reductive (Chapter 6) metabolic processes dictates similar concerns for improved bioreactor and analytical instrumentation needs to meet the requirements of process efficiency and efficacy. The potential of aerobic and anaerobic microorganisms to beneficiate wastes is receiving increased attention and appears to represent the technology of choice for future bioremediation initiatives (Chapters 3, 6 and 8).

A rigorous quantitative rating of the subjects was not possible, because of the interdependencies that existed between subjects and, more importantly, the interrelationships 
that exist where technological improvements made in one subject area will impact directly on other related subject areas. For example, the development of solvent-tolerant microorganisms (biocatalysts) would impact beneficially on biodesulfurization, syngas bioconversions, bioremediation strategies, and bioreactor/bioengineering designs. Each subject area offers recommendations for further R\&D needs and priority status. Specific prioritized and detailed project recommendations for each subject area are listed in Appendix 1.

A summary of specific program recommendations follows, addressing the technology in the context of PROBLEMS, SOLUTIONS AND EVALUATIONS.

BIOREMEDIATION (Chapters 3 and 10).

\section{Problems:}

The presence and accumulation of toxic and hazardous chemicals originating from diverse point sources has become a global problem of major importance. This encroaching aspect of general pollution impacts on all aspects of our surrounding environment.

- Air quality (gases)

- Water quality (liquids)

- Soils (solids)

Therein lies the problem of designing efficient and effective bioremediation strategies that address restoration of our environment to more pristine conditions.

\section{Solutions:}

- Controlled or stimulated biodegradation technologies

- Physical delivery and stimulation of microorganisms

- Indigenous microorganisms

- Ultramicrobacteria

- Spores

- Solvent-tolerant microorganisms

- Microbial oxygenases and oxidoreductases

- Genetically engineered microorganisms
Time Frame

Short to Mid

Short

Short to Mid

Short

Short to Mid

Short to Mid

Mid to Long

\section{Evaluation:}

Current remediation methods encompass physical (adsorption, filtration, extraction), chemical treatment, thermal pyrolysis, and biological treatments. Bioremediation is a recent technological development which is rapidly becoming the treatment of choice due to low costs and the ability to process dilute waste streams when compared with other technologies. Bioremediation occupies a small share of the larger and diverse environmental management and remediation market, but is considered one of the fastest growing technologies in this area. In 1991, bioremediation technologies are estimated to yield $\$ 60$ million growing to $\$ 150$ million by 1995 . These biotechnologies fall into 3 general categories: (1) land 
treatment, (2) bioreactors and (3) in situ treatment. The oil-industry uses land treatment and oxidation lagoons for treatment of refinery wastes, although such treatment methods face certain restrictions under RCRA land disposal regulations. Bioreactors, whether in situ or ex situ, offer a potentially effective means of degrading wastes. Above-ground bioreactors of either fixed or portable design afford on-site treatment, although $e x$ situ bioreactors are more cost-intensive due to capital, maintenance and operating costs. In situ bioreactors offer a technology for stimulating indigenous microflora through the injection of nutrient feedstocks. The implementation of efficient bioremediation strategies is not as dependent on the biology component as it is on the design engineering of various bioreactor systems. Laboratory testing has been highly successful although the real test lies in implementing these technologies into field situations and realizing the desired level of remediation.

Competition. The feasibility of using bioremediation technologies is based on its ability to reduce costs and time, in addition to conforming to ever increasing regulatory constraints and standards. Numerous new biotechnology companies offer remediation services ranging from nutrient stimulation, bioaugmentation to site-specific biorestoration. In many cases proof of principle, treatment efficacy and mass balance analyses are yet to be documented.

A number of applied $R \& D$ initiatives are presently in progress. Bioremediation is an immature technology, although rapid and innovative progress will develop in this attractive technology.

\section{FOSSIL FUEL UPGRADING (Chapters 4 and 6).}

\section{Problems:}

- Fossil resource heteroatom removal $(\mathrm{S}, \mathrm{N}, \mathrm{O})$

- Upgrading crude oil, heavy oil, coal, tars, shales

\section{Solutions:}

- Develop physiologically specialized microorganisms

- Biodepyritization of coal

- Biodesulfurization of organosulfur in oil and coal

- Aerobic systems

- Anaerobic systems

- Biodenitrogenation of fossil fuels

- Anaerobic systems

- Biodeoxygenation of fossil fuels

- Anaerobic systems

Time Frame

Short to Mid

Short

Mid to Long

Mid to Long

Mid to Long

Mid to Long

\section{Evaluation:}

Heteroatom removal from the organic matrix of high-sulfur fossil fuels requires extensive indepth basic research. The exception is the biodepyritization of coal, which is a technology that has advanced to pilot stages with detailed process engineering and economic assessments. The biological removal of organic sulfur, nitrogen, and oxygen is less well understood and requires the development of a more rigorous basic data base before 
considering applied bioprocessing programs. Current deficiencies in heteroatom removal are a lack of definitive organisms and the absence of enzymological and metabolic pathway data for the abstraction of organosulfur. Recent studies indicate the anaerobic conversion of fossil resource organosulfur to hydrogen sulfide, possibly a preferable technology over sulfate as an end product for large volume processing of high-sulfur fossil fuels.

Competition. Postcombustion scrubbers for coal-fired boilers and hydrodesulfurization units for high-sulfur oils are current technologies for the removal of sulfur. Postcombustion scrubbers are in-place technologies with developments occurring regularly to improve efficiencies and operating costs. Hydrodesulfurization units are few, although plans are underway for the construction of new high-volume HDS units. Once these technologies are installed and capitalized, new emerging biotechnology developments will experience little interest from the industry.

\section{SYNGAS BIOCONVERSIONS-C1 FEEDSTOCKS (Chapter 5).}

\section{Problems:}

- Organism tolerance to products and toxic process streams

- Efficient mass transfer of gaseous feedstocks

- Cell retention in bioreactors

- Product recovery from dilute process streams

- Biotreatment of waste streams

- Sulfur and nitrogen in waste streams

\section{Solutions:}

- Product and feedstock tolerant microorganisms

- Cell retaining bioreactors

- Membrane-based separations for product recovery (Integration of separation with bioconversion)

- Phased waste stream biotreatment systems

- Aerobic systems

- Anaerobic systems

- Microbial-based processes for flue gas desulfurization and $\mathrm{NO}_{\mathrm{x}}$ removal

Time Frame

Short to Mid

Short to Mid

Short to Mid

Short

Short to Mid

Short to Mid

\section{Evaluation:}

Competition. Syngas as an industrial feedstock for chemical processing is an attractive alternative to current petroleum-based oxychemical and fuel production. Specific drawbacks to catalytic conversions are the required removal of catalyst poisons $\left(\mathrm{H}_{2} \mathrm{~S} \& \mathrm{COS}\right)$. These purifications are energy intensive, adding to product cost, particularly for coals of high sulfur content.

Product Value and Market Niches. Key advantages to bioprocessing are: anaerobic bioconversion conserves the energy content of the syngas, converting it to longer chain 
oxychemicals and methane; sulfur removal from the feedstock is not required, reducing processing costs; generation of higher value products; and, anaerobic bioreactors operate under milder reaction conditions offering potential savings. Market niches currently exist for the integration of products.

Scale Up Feasibility. Anaerobic bioconversion of syngas represents a technology ready for scale up R\&D. This technology is borderline in terms of economics, mainly due to microbiological and engineering shortcomings. Further work is needed in strain(s) improvements to industrial grade productivity and the development of high productivity bioreactors and product recovery systems. Larger scale R\&D will offer more precise economic projections with sensitivity analyses targeting those cost-sensitive steps requiring attention, expediting the commercial implementation of this technology.

\section{ANAEROBIC BIOTRANSFORMATIONS OF AROMATIC HYDROCARBONS (Chapter 6).}

Problems:

- Biodegradation of petrochemical and refinery wastes

- Desulfurization, denitrogenation, and deoxygenation of fossil fuels.

- Low capital cost bioreactors

- Low energy requiring bioreactors

Solutions:

- Anaerobic biodegradation of petroleum and coal wastes

- Anaerobic bioconversion of fossil feedstocks

- Anaerobic biodegradation of toxic process solvents

- Anaerobic bioconversion to added value products

- Anaerobic upgrading of fossil fuels

- In situ beneficiation of fossil resources
Time Frame

Short to Mid Short to Mid

Short to Mid

Short to Mid

Mid to Long

Mid to Long

\section{Evaluation:}

Anaerobic metabolism of aromatic substrates is an immature field of investigation with the metabolic potential of this technology far from being fully understood or appreciated. Future $R \& D$ efforts should develop the basic parameters underlying the anaerobic metabolism of fossil fuels and derived products. These programs should address the isolation of microorganisms, identify metabolic intermediates and pathways, establish the enzymology of these pathways, and determine the genetic elements encoding these enzymes and their regulation. Advantages of anaerobic biobeneficiation of fossil resources are: lower processing economics, added value fuels (methane), fossil resource upgrading, in situ biotransformations (coal), and bioliquefaction of low rank coals. Opportunities in the anaerobic bioprocessing of fossil resources are substantial, offering innovative technologies that are potentially performance-effective and economic. 


\section{ADDED VALUE PRODUCTS-BIOSURFACTANT AND SYNTHON TECHNOLOGY (Chapters 7, 8, and 13).}

\section{Problems:}

- Transport of heavy crude oil

\section{BIOSURFACTANTS}

- Oil mobilization (tar sands, shales, reservoirs)

- Bioremediation strategies

- Enhanced bioavailability of fossil feedstocks

- Pollutant mobilization

- Borehole deparaffinization

- Enhanced biodegradation

- Corrosion control

\section{SYNTHONS}

- Biocatalyst sensitivity to substrate concentration

- Biocatalyst sensitivity to products

- Biocatalyst sensitivity to chemical-physical environment

- Low biocatalyst efficiency, stability, and product yield

- Lack of organic solvent-based bioconversions

Solutions:

- Purified biosurfactants

- Crude biosurfactants

- In situ biosurfactant generation

- Semisynthetic biosurfactants

- Develop solvent-tolerant biocatalysts

- Improve biocatalyst properties through

- Protein engineering

- Reactor technology

- Genetic engineering

- Integrate conversion and separation technology

- Integrate chemo-enzymatic conversion technology
Time Frame

Short to Mid

Short to Mid

Mid to Long

Short to Mid

Mid to Long

Short to Long

Short to Long

Short to Long

Short to Mid

Short to Mid

\section{Evaluation:}

Competition. Synthetic surfactants are an established chemical commodity with annual global sales exceeding $\$ 10$ billion dollars. These products are manufactured economically in large volume and offer a broad array of physico-chemical performance characteristics for diverse end uses and applications. Biosurfactants are a relatively new class of bioproducts produced by microorganisms exhibiting performance properties that are equal, if not superior, to synthetic surfactants. Currently, large scale manufacturing of biosurfactants for specific market niches do not exist, although new biotechnology companies are developing this technology for oil and bioremediation technologies. Present cost estimates indicate that crude biosurfactants can be produced for $<\$ 5.00 / \mathrm{lb}$ for field applications in enhanced oil recovery with added costs of $<\$ 1.00 / \mathrm{bbl}$ of new oil produced. These projected estimates are 
made possible due to low critical micelle concentration and ultra low interfacial tension values characteristic of newly developed biosurfactants plus the elimination of downstream processing costs by using the spent culture broth as the surface-active solution.

Hydrocarbon bioconversions of value to the chemical and pharmaceutical industries offer strong potential for the manufacturing of new and novel chiral, stereo-, and regio-selective products not possible through synthetic organic chemistry. The application of the principles of solvent engineering for biocatalysts will serve to expedite the integration of biocatalytic conversions into the existing chemicals manufacturing infrastructure. The importance of chemo-enzymatic conversions will acquire greater relevance as new insights emerge from future studies into microbial and metabolic diversity.

Process catalysts appear to be experiencing increasing demands for manufacturing chemicals and polymers, for fuels from oil, and for biological materials. The current worldwide market for catalysts is valued at $>\$ 5$ billion with principal uses in 3 major industries: chemicals production, petroleum refining, and pollution control. Catalyst consumption by the U.S. and Western Europe is dominated by petroleum refining, accounting for $>90 \%$ of the total catalyst volume used. Environmental control catalysts are projected to increase dramatically, increasing from $<\$ 1$ million in 1991 to $>\$ 2$ billion by 2000 . Biocatalysts currently play a minor role in the total catalyst market, being used industrially for sugar transformations, semisynthetic antibiotics and steroid conversions with annual sales estimated for 1991 at $\$ 100-150$ million. Barriers to biocatalysts include high cost, heat lability, $\mathrm{pH}$ sensitivity and solvent, feedstock and product inhibition. Organic solvent engineering of biocatalysts can well improve the competitive position of these biocatalysts as industrial catalysts due to their ability to function more efficiently in organic media with fewer reaction limitations.

Industrial exploitation of microbial oxygenases and dehydrogenases has been a major incentive for intensive research over the past 2 decades to generate added value specialty and fine chemicals. Major advantages of bioprocesses over chemical syntheses are mild reaction conditions, and stereo- and regio-selectivity. The chemical and pharmaceutical industries presently have not exploited this technology extensively. Future developments will depend on the needs for specialty or fine chemicals not available by conventional chemical means.

\section{GENETIC STRATEGIES (Chapter 8).}

\section{Problems:}

- Strain improvements to commercial activity levels

- Lack of focus on pathways critically important to the fossil fuel industry

- Lack of integration of genetic strategies with separation science and engineering

Solutions:

- Molecular genetics

- High level biocatalyst synthesis
Time Frame

Short to Mid 
- Coordinate expression of genes from different pathways

- Construction of new metabolic routes

- Improve metabolite flow

- Expand knowledge of global microbial and metabolic diversity

Short to Mid

Short to Mid

Short to Mid

Short to Long

\section{Evaluation:}

The range of possible chemical products originating from biological systems is determined by a combination of the range of natural metabolites produced by such systems, the ability of the geneticist to introduce unnatural substrates into metabolic pathways and route them through different pathways to particular compounds, and the ability of the chemist to isolate and chemically transform such metabolites and compounds to desired products. The expansion of our information/experience base needed for optimal exploitation of biotransformations include exploration of metabolic diversity, characterization of the genetics of metabolic networks and their regulation, and development of the "new" synthetic chemistry based on combined biochemical and chemical strategies.

\section{ORGANIC SOLVENT TOLERANT MICROORGANISMS (Chapter 9).}

\section{Problems:}

- Toxicity of substrates and products to microorganisms

- Bioavailability of fossil feedstocks

- Aqueous bioprocessing streams

- Product in dilute aqueous streams

- Biocatalyst stability

- Industry processing infrastructure in organic media

Solutions:

- Development of organic solvent tolerant biocatalysts

Time Frame

Mid to Long

\section{Evaluation:}

The development and applications of organic solvent-tolerant microorganisms with specialized physiological attributes directed to specialized areas of fossil fuel processing is a new concept with long-term importance. The biocatalytic treatment of fossil fuels and refined products in an organic medium presents opportunities for process initiatives not previously possible. It is now possible to develop immobilized biocatalysts exhibiting enhanced reaction rates, absence of substrate or product inhibition, selective specificity, and enhanced stability for fossil fuel upgrading in heteroatom removal, bioremediation strategies, and added value specialty chemicals. Recent advances in organic solvent engineering of biocatalysts from an empirical to predictive technology lends further support to the importance of this technology in fossil fuel bioprocessing technologies. 


\title{
BIOCORROSION AND CONTAMINATION CONTROL IN FOSSIL FUEL INDUSTRIES (Chapters 11 and 12).
}

\author{
Problems: \\ - Internal pipeline corrosion \\ - External corrosion: coatings, metallurgy \\ - Reservoir souring and product souring \\ - Detection and monitoring corrosion rate
}

Solutions:

- Chemical control and effect on microorganisms and biofilms

Time Frame

- Biological control of biofilm formation

- Probes for monitoring

- Microorganisms

- Metabolic activity

Short

Short to Long

- Products formed

- Rate of corrosion

Short to Mid

Short to Mid

Short to Mid

Short to Mid

- Materials that prevent biofilm formation

- Biosurfactants

Short to Mid

- Targeted treatment of microbial consortia

Short to Mid

\section{Evaluation:}

Corrosion and souring contamination of fossil fuels are a major cost to most industries in terms of replacement materials, down-time, safety, and liabilities. The cost estimates for all forms of corrosion worldwide are approximately $\$ 126$ billion annually. It is clear that microbial biofilms play an important role in the initiation of underdeposit pitting corrosion, while the role of biofilms in later stages of the corrosion process are less well-established, suggesting that prevention and mitigation at early stages of corrosion are critical. Research needs for microbiologically-influenced corrosion (MIC) $R \& D$ require new methodologies for on-line measurement of corrosion rates. It is essential to identify other chemical phenomena and target chemicals that indicate susceptibility or initiation of MIC. Sulfate-reducing bacteria as indicators of MIC may have limited value in some applications. New approaches for modifying biofilm-forming microbial consortia through changes in the physical environment or the seeding with antagonistic microorganisms merit further study. The nature and micro-composition of solid surfaces serving as initiation foci for microbial colonization are poorly understood. It is appropriate to develop alternatives to current technology employing biocide control of MIC, such as heat treatment and biocide-conjugated antibodies for targeting specific microbial consortia. Little is known about the environmental impact of biocides, corrosion inhibitors, and other chemicals employed in corrosion control. Programs to determine the environmental effects resulting from chemical treatment will become of importance.

A major outcome of biocorrosion studies is the integration of physical, chemical, electrochemical, biochemical, and genetic probes for improved understanding of the microbial ecology of biofilms on surfaces. Understanding how bacteria interact with chemicals in soil environments is a fundamental issue in bioremediation. An improved 
knowledge/experience base in MIC will lead to advances in corrosion mitigation and bioremediation and will affect all fossil-related industries.

\section{ULTRAMICROBACTERIA (Chapter 14).}

\section{Problems:}

- Physical delivery of targeted biocatalysts

- Breadth of physiological/biochemical activities with ultramicrobacteria.

Solutions:

- Ultramicrobacteria

- Delivery of biocatalysts with predetermined catalytic properties

- In situ nutrient stimulation of indigenous ultramicrobacteria
Time Frame

Short to Mid

Short to Mid

\section{Evaluation:}

Ultramicrobacteria are small, dormant bacteria which penetrate into and through silicoclastic and carbonate formations and soils without adhering to inert surfaces. These dormant bacteria are regenerated by nutrient stimulation to physiologically-active bacteria. To date, ultramicrobacteria have been investigated principally to exploit slime production. Whether other physiological activities can be induced is unknown. An area requiring further definition is the ability to enrich naturally-existing ultramicrobacteria populations by appropriate nutrient stimulation to produce specific and desirable biocatalytic reactions. Ultramicrobacteria technology poses a potentially cheap and effective technology for introducing bacteria into solid matrices for biotransformation of organic materials, introduction into aquatic systems for bioremediation applications, effecting biotransformations in surface deposits of processed fuels (coal), biobarrier formation to contain pollutants, and possibly to effect in situ fossil resource upgrading prior to recovery. The future applications of ultramicrobacteria technology requires the development of a strong basic biology component with respect to physiological attributes other than slime production.

\section{BIOENGINEERING/BIOREACTOR TECHNOLOGY (Chapter 15).}

\section{Problems:}

- Mass transfer of gaseous and hydrophobic substrates

- Cell retention in bioreactors

- Product recovery from dilute process streams

- Integration of separations with bioconversions

- Bioreactor designs to process large volume fossil feedstocks at low cost 
Solutions:

Time Frame

- Development of low capital cost bioreactors and bioconversions

- Non-sterile processes

Short

- Non-corrosive systems

Short to Mid

- Aerobic systems

- Anaerobic bioconversions

Short to Mid

- In situ bioconversions

Short to Mid

Mid to Long

- Development of low energy bioreactors requiring

- Anaerobic processes

Short to Mid

- Non-sterile processes

Short to Mid

- Development and integration of low energy separations with bioconversions

- Membrane-based processes: electrodialysis, pervaporation, micro- and ultrafiltration

- Novel separations integrated with bioconversion

Short to Mid

Short to Mid

- Development of integrated processes and systems

- Bioconversions with separations

- Bioprocessing within industry infrastructure

Short to Mid

Short to Mid

Evaluation: ,

The two major bioengineering components of bioprocessing are bioreactors and separation technologies. Successful development and integration of both components are required for commercial viability. Bioreactor designs are either single phase or multiphasic systems with basically 3 types under development for fossil resource bioprocessing: 1) solid, liquid, and gas 3-phase systems; 2) solid-liquid or gas-liquid 2-phase systems; and 3) single phase systems-liquid only. Bioreactor design R\&D for fossil resources is an active program at many academic and government laboratories. Applications of bioprocess technologies to fossil resources beneficiation require large scale reactors with low operating costs. Large scale bioprocessing has 3 primary cost centers: capital costs, process energy costs, and raw materials cost. Future R\&D initiatives must address the reduction of these cost centers to obtain a viable commercial technology. Separation technologies are often large cost centers in bioprocessing which can potentially be reduced through membrane-based technologies. Bioengineering of fossil resource bioprocessing technologies will be process specific with each exhibiting certain physical requirements and constraints characteristic of that process. It is cautioned that bioengineering of fossil bioprocessing programs must proceed synergistically with the development of the biology of the system.

\section{ANALYTICAL INSTRUMENTATION (Chapter 16).}

\section{Problems:}

- Structure elucidation of oil

- Structure elucidation of coals

- Nondestructive methods for on-line analyses of complex substrata undergoing biological modification(s) 
- Destructive methods coupled to smart detector systems for on-line analyses of complex substrata undergoing biological modification(s)

Solutions:

- Nondestructive analytical systems

- Destructive techniques coupled to smart detectors

- Coupling of nondestructive and destructive systems to enhance information densities
Time Frame

Short to Long

Short to Long

Short to Long

\section{Evaluation:}

Advances in analytical instrumentation are usually evolutionary, not revolutionary. Breakthroughs in the knowledge of matter occur regularly. However, translation of this knowledge into sophisticated analytical systems is time-dependent. Structure analysis of complex fossil resources is an active, on-going area of difficult and tedious programmatic R\&D. Numerous new and sophisticated analytical instruments are available, or will become available, to the biological community. The biologist needs to interface more closely with the analytical chemist to exploit these new technologies in bioprocessing programs. The closer cooperation of biologists with chemists will expedite more rapid and definitive progress in determining the efficacy of bioprocessing initiatives. The development of biosensor technology will play a critical role in bioengineering and bioremediation technologies. New and innovative fossil fuel biotechnology initiatives will develop synergistically with the development of improved and sophisticated analytical capabilities to better monitor and assess quantitative and qualitative changes occurring from the bioprocessing of fossil substrata. 


\section{Chapter 2}

\section{INTRODUCTION}

\section{BACKGROUND.}

Energy in all its forms is the motive sustenance of modern, industrialized societies. Its use and availability' determines social stability, economic viability, and power in terms of competing international economies and geopolitical affairs. The U.S. Administration's National Energy Strategy presents four broad-based initiatives addressing the development of our future energy independence. These strategies serve to increase energy and economic efficiency; secure future energy supplies; enhance environmental quality; and fortify foundations in R\&D. The future impact of this "Energy Policy" intends to decrease U.S. dependence on imported foreign oil through greater domestic production, emphasizes technological fixes through $R \& D$ to develop more efficient uses of domestic fossil resources, and to enhance environmental quality caused by the burning of fossil fuels. Currently, crude oil reserves are estimated in excess of one trillion barrels of oil worldwide.

Oil. Global crude oil reserves are estimated in excess of one trillion barrels with more than one-half of this resource located in the Middle East.

North America and Mexico
South and Central America
Western Europe
USSR and Eastern Europe
Africa
Persian Gulf
Far East and China
Australia and New Zealand

\begin{tabular}{c} 
Billions of bbls \\
\hline $139-281$ \\
$75-136$ \\
$48-78$ \\
$130-274$ \\
$89-159$ \\
$483-620$ \\
$81-198$ \\
$4-13$ \\
$1,049-1,759$
\end{tabular}

Major oil-producing areas of the U.S. are East Texas, Alaska, off-shore Louisiana, West Texas-Oklahoma, and California. Thirty-one states have some oil and gas but the above listed states produce over $81 \%$ of the total U.S. oil. East Texas fields have produced over 4 billion barrels with remaining reserves in excess of 2 billion barrels. The Bay-MarchaudTimbalier-Calliou Island complex in the Gulf of Mexico is the world's largest salt-dome reservoir containing 3.4 billion barrels. The Prudhoe Bay field on the North Alaska coast is the largest U.S. field, estimated at 20 billion barrels. The Arctic National Wildlife Refuge is attracting considerable interest from the oil industry and environmentalists. The Department of Energy estimates over 3.5 billion barrels of untapped oil with the coastal plain region holding as much as 30 billion barrels of new oil. Untapped large oil resources, which include the Canadian tar sands, U.S. oil shales, and Venezuela's Orinoco Basin oils, are not included in the above listed estimates of known reserves. 
U. S. oil imports have risen steadily since the 1950 s, approaching almost 20 million barrels per day in the 1990s. Domestic oil production peaked in the 1970's and has been in a steady decline since then, with increased oil imports making up the difference in domestic supply and demand. This fact places the U.S. in a particularly vulnerable position with regard to its own welfare, nationally and internationally.

Oil Sands. The total U.S. oil sands resource is estimated at 54 billion barrels with 22 billion of known reserves, 31 billion of speculative oil sands and 1 billion barrels as minor deposits. The geographical distribution of oil sands deposits in the domestic U.S. are (in billion barrels):'

$\begin{array}{lccc}\text { A. Major deposits } & \text { Measured } & \text { Speculative } & \text { Total } \\ \begin{array}{l}\text { ( 100 million barrels }) \\ \text { Alabama }\end{array} & 1.8 & 4.6 & 6.4 \\ \text { Alaska } & - & 10.0 & 10.0 \\ \text { California } & 1.9 & 2.6 & 4.5 \\ \text { Kentucky } & 1.7 & 1.7 & 3.4 \\ \text { New Mexico } & 0.1 & 0.2 & 0.3 \\ \text { S. Oklahoma } & - & 0.8 & 0.8 \\ \text { Texas } & 3.9 & 0.9 & 4.8 \\ \text { Tri-State } & 0.2 & 2.7 & 2.9 \\ \text { Utah } & 11.9 & 7.5 & 19.4 \\ \text { Wyoming } & 0.1 & 0.1 & 0.2\end{array}$

B. Minor deposits

(10-100 million barrels)
Alabama
$-\quad 0.1$
0.1
California
0.2
0.2
Utah
0.1
1.0

Source: Major Tar Sands \& Heavy Deposits of the United States, Interstate Oil Compact Commission, Oklahoma City, OK, 1984

The offshore California coast is expected to yield new oil sands and heavy oil deposits. The deposits listed above are significantly larger than past estimates because of more precise quantification of oil content and the identification of new deposits. Future studies, such as offshore areas of California and Alaska, may add significant amounts of new oil sands to the U.S. resource base.

In North America, Canada implemented a program in 1973 to recover bitumen from oil sand deposits in Alberta province. By 1984, the production of a synthetic crude oil (SYNCRUDE) yielded 129,000 bbls/day. The Athabasca deposits are the largest, with initial in-place reserves estimated in excess of 1,260 billion barrels. The average overburden depth is 15 meters with an average oil sand depth of 42 meters. Economical recovery depends on the thickness of the oil-bearing strata, size of the deposits, degree of bitumen saturation, and depth of overburden. Surface mining requirements involve the removal of the overburden and oil sand recovery with bucketwheel excavators or draglines. The oil sands are 
transported to processing facilities on conveyors and the bitumen is separated by a caustic, hot water flotation process. The extraction facility processes $11,800 \mathrm{tons} / \mathrm{hr}$ of oil sand to produce 2050 tons $/ \mathrm{hr}$ of froth. The froth treatment plant produces $676 \mathrm{dm}^{3} / \mathrm{second}$ of diluted bitumen which is converted to coke, naphtha and gas-oil. The latter 2 fractions are hydrotreated to remove sulfur, nitrogen and oxygen and the naphtha and oil-gas fractions blended to form SYNCRUDE. This product is pipelined to refineries for processing to higher value fuels. Currently, no oil sands operations are functional in the continental U.S.

Heavy Oils. The majority of heavy oil deposits are in California (356 deposits), Texas (350 deposits), and Arkansas (120 deposits). Heavy oils are defined as exhibiting an API gravity between 10-20. Such oils constitute an important and challenging U.S. resource target that requires further definition as to in-place and recoverable deposits. Approximately $25 \%$ of the 100 largest fields in the U.S. are heavy oils. Current production technologies recover $<20 \%$ of the heavy oil, leaving behind the great bulk of this resource. Although heavy oils are less attractive and less valuable to refiners, they are already a liquid fuel, thus, less costly to convert to refined products than coal. The U.S. heavy oil resource base needs further study to fully establish, define, and compile information on this important resource.

Oil Shales. The Green River Formation occupies approximately 16,500 square miles in the states of Colorado, Utah, and Wyoming and is estimated to contain $80 \%$ of the world's 2.5 trillion barrels of in-place shale oil. Deposits range from surface outcroppings to depths of $2000 \mathrm{ft}$. The Piceance Creek Basin deposits of Colorado are estimated to contain a potential fossil resource exceeding $10^{6} \mathrm{bbl} /$ day for 500 years! The recovery of oil shales has involved a complex interplay of technical, economic; social, and political considerations. The demise of oil shale recovery programs appears largely due to economic, technical, and environmentally-unfriendly factors. Oil shales are a dolomitic marlstone containing varying percentages of kerogen and waxes. Oil shales, unfortunately, lie in deposits which exhibit little or no permeability or porosity. The past $R \& D$ initiatives for in situ recovery assumed that solutions to the permeability problem would occur. Currently, no known oil shale recovery operations are functional in the domestic U.S.

Coal. U.S. coal reserves are estimated by the Department of Energy at 268 billion tons, an available energy resource capable of lasting another 2 to 3 centuries. Coal generates $44 \%$ and $75 \%$ of the world's electricity and steel, respectively. A 5-phased clean-coal program initiated in 1986 by a joint Department of Energy-industry cooperative program stated the goal of providing the U.S. with advanced, efficient, and environmentally-friendly acceptable coal-consuming technologies. Coal combustion has major disadvantages affecting its use including effects on air quality, acid rain depositions from sulfur emissions, global warming from $\mathrm{CO}_{2}$ release to the atmosphere, and localized pollution from particulate emissions. The coal-burning industry has spent $>\$ 250$ billion to control emissions since 1970 , resulting in a dramatic decrease in $\mathrm{SO}_{\mathrm{x}}$ emissions. The new $\mathrm{SO}_{\mathrm{x}}$ and $\mathrm{NO}_{\mathrm{x}}$ air-quality compliance regulations will cost the electric power industry $\$ 4-5$ billion annually until the year 2000, at which time the level of $\mathrm{SO}_{\mathrm{x}}$ emissions will be capped. Concern over air pollution from coal-fired power plants is additionally directed at $\mathrm{CO}_{2}$ emissions, which are apparently linked to global warming trends. The Department of Energy estimated that in 
1986 the U.S. contribution to total global $\mathrm{CO}_{2}$ release was $22 \%$, of which $35 \%$ was from electric power generation, $30 \%$ from transportation, $24 \%$ from industry and $11 \%$ residential and commercial sources. The future mitigation of $\mathrm{CO}_{2}$ emissions is one of the clean-coal programs' principal objectives. It may be that future biotechnological solutions to the problem of $\mathrm{CO}_{2}$ emissions from coal combustion can impact positively through the development of greatly enhanced methanogenic systems for the efficient conversion of ' $\mathrm{C}-1$ feedstocks to methane and added value oxychemicals. The clean-coal program consists of 3 categories: improved coal preparation, improved coal combustion, and removal of coalderived pollutants. Coal preparation may be physical or chemical with physical methods limited to impurity removal, accomplished by washing methods to separate pyritic sulfur and mineral inclusions with up to $90 \%$ removal of pyritic sulfur. The biological removal of pyritic sulfur is currently in pilot plant R\&D and is expected to offer an economic and efficient biotechnological alternative to physical methods of coal preparation for removal of pyrite. Chemical cleaning, including the use of biological agents, is a considerably more challenging problem in context of organic sulfur removal. Precombustion biodesulfurization technology may develop in the long-term, assuming effective biocatalysts are identified and bioengineering strategies emerge that allow for large volume bioprocessing treatments. A number of advanced combustion methods and equipment improvements are in development, including fluidized-bed combustion, combined-cycle processing, mild gasification, magnetohydrodynamic technology, coal liquefaction and coprocessing. A combination of pre- and post-combustion technologies are in various phases of development to produce advanced technologies for coal utilization that are cost and performance effective. It would appear that the physical and strictly chemical advanced technologies are developing faster than potential biotechnology alternatives. Once these physical and chemical technologies are in place, biotechnological alternatives will face difficult odds in securing commercial implementation unless they are exceedingly cost-effective, highly reliable process technologies.

Global Competition: The importance of appreciating the competitive position of American science lies in recognizing the ability of U.S. science to compete successfully in commercial biotechnology in future years, especially at the international level. The U.S. science establishment is extremely competent in the conduct of basic science. Innovative and cutting-edge progress occurs almost daily in the basic sciences. Unfortunately, new knowledge and concepts generated at the basic level are rarely carried the next step towards applications and engineering for the real world. Often, our best basic science ends up in other countries undergoing applications development and commercialization. This is perhaps best illustrated by the findings of a special scientific task force analyzing bioprocess engineering programs in Japan conducted under the auspices of the National 'Science Foundation's Japanese Technology and Evaluation Center (JTEC Panel Report on Bioprocess Engineering in Japan, May 1982). An overall comparison of Japan's competitive position in biotechnology with that of the United States is summarized for targeted biotechnology areas. 
Competitive Position - Comparison of Japan \& the United States Position

\begin{tabular}{|c|c|c|c|c|c|c|c|c|}
\hline $\begin{array}{l}\text { Molecular } \\
\text { Biology }\end{array}$ & $\begin{array}{c}\text { Produ } \\
\text { Now } \\
-\end{array}$ & $\begin{array}{l}\text { iscovery } \\
\text { Future } \\
y\end{array}$ & & $\begin{array}{l}\text { ics } \\
\text { Future } \\
x\end{array}$ & & & & \\
\hline \multirow[t]{3}{*}{ Microbiology } & \multicolumn{2}{|c|}{ Screening } & \multicolumn{2}{|c|}{$\begin{array}{c}\text { Strain } \\
\text { Development }\end{array}$} & \multicolumn{2}{|c|}{ Fermentation } & & \\
\hline & Now & Future & Now & Future & Now & Future & & \\
\hline & + & $\pi$ & + & $\pi$ & + & $\nearrow$ & & \\
\hline \multirow[t]{2}{*}{$\begin{array}{l}\text { Upstream } \\
\text { Processing }\end{array}$} & \multicolumn{2}{|c|}{$\begin{array}{c}\text { Process } \\
\text { Development }\end{array}$} & \multicolumn{2}{|c|}{$\begin{array}{l}\text { Engineering } \\
\text { Science }\end{array}$} & \multicolumn{2}{|c|}{$\begin{array}{c}\text { Monitor \& } \\
\text { Control }\end{array}$} & \multicolumn{2}{|c|}{$\begin{array}{l}\text { Bioreactor } \\
\text { Scale-Up }\end{array}$} \\
\hline & & $\begin{array}{c}\text { Future } \\
\rightarrow\end{array}$ & $\begin{array}{l}\text { Now } \\
-\end{array}$ & $\begin{array}{c}\text { Future } \\
y\end{array}$ & $\begin{array}{c}\text { Now } \\
+\end{array}$ & Future & $\begin{array}{c}\text { Now } \\
-\end{array}$ & $\begin{array}{c}\text { Future } \\
y\end{array}$ \\
\hline \multirow[t]{4}{*}{$\begin{array}{l}\text { Downstream } \\
\text { Processing }\end{array}$} & \multicolumn{2}{|c|}{$\begin{array}{l}\text { Solid-Liquid } \\
\text { Separation }\end{array}$} & \multicolumn{2}{|c|}{$\begin{array}{c}\text { Cell } \\
\text { Disruption }\end{array}$} & \multicolumn{2}{|c|}{$\begin{array}{l}\text { Membrane } \\
\text { Technology }\end{array}$} & \multicolumn{2}{|c|}{$\begin{array}{c}\text { Affinity } \\
\text { Chromatography }\end{array}$} \\
\hline & & $\begin{array}{l}\text { Future } \\
\rightarrow\end{array}$ & $\begin{array}{c}\text { Now } \\
0\end{array}$ & $\underset{\rightarrow}{\text { Future }}$ & Now & $\underset{\rightarrow}{\text { Future }}$ & $\begin{array}{l}\text { Now } \\
-\end{array}$ & $\begin{array}{c}\text { Future } \\
\chi\end{array}$ \\
\hline & \multicolumn{2}{|c|}{$\begin{array}{l}\text { Ion-Exchange } \\
\text { Chromatography }\end{array}$} & \multicolumn{2}{|c|}{$\begin{array}{l}\text { Size Exclusion } \\
\text { Chromatography }\end{array}$} & \multicolumn{2}{|c|}{ HPLC } & \multicolumn{2}{|c|}{$\begin{array}{l}\text { Protein } \\
\text { Refolding }\end{array}$} \\
\hline & Now & $\begin{array}{l}\text { Future } \\
\rightarrow\end{array}$ & $\begin{array}{c}\text { Now } \\
0\end{array}$ & $\begin{array}{l}\text { Future } \\
\rightarrow\end{array}$ & $\begin{array}{c}\text { Now } \\
0\end{array}$ & $\stackrel{\text { Future }}{\rightarrow}$ & Now & $\begin{array}{c}\text { Future } \\
\rightarrow\end{array}$ \\
\hline \multirow[t]{3}{*}{ Biocatalysis } & \multicolumn{2}{|c|}{$\begin{array}{c}\text { Enzyme } \\
\text { Discovery }\end{array}$} & \multicolumn{2}{|c|}{$\begin{array}{l}\text { Enzyme } \\
\text { Science }\end{array}$} & \multicolumn{2}{|c|}{$\begin{array}{l}\text { Enzyme } \\
\text { Engineering }\end{array}$} & \multicolumn{2}{|c|}{$\begin{array}{c}\text { Industrial } \\
\text { Implementation }\end{array}$} \\
\hline & Now & Future & Now & Future & Now & Future & Now & Future \\
\hline & + & $\lambda$ & - & $\lambda$ & + & $r$ & + & $\lambda$ \\
\hline \multirow[t]{3}{*}{$\begin{array}{l}\text { University } \\
\text { Government }\end{array}$} & \multicolumn{2}{|c|}{$\begin{array}{l}\text { University } \\
\text { Industry }\end{array}$} & \multicolumn{2}{|c|}{$\begin{array}{l}\text { University } \\
\text { Government }\end{array}$} & \multicolumn{2}{|c|}{$\begin{array}{l}\text { Government } \\
\text { Industry }\end{array}$} & \multicolumn{2}{|c|}{ Overall } \\
\hline & Now & Future & Now & Future & Now & Future & Now & Future \\
\hline & + & $\pi$ & + & $\pi$ & + & $\nearrow$ & + & $\nearrow$ \\
\hline
\end{tabular}

Symbol Legend: $(+)=$ Japan ahead; $(-)$ Japan behind; $(O)=J a p a n$ cven $(->)=$ Japan will be further ahead; $(<-)=$ Japan will fall further behind

Major conclusions noted by the JTEC task force were:

- Japan has and will continue to lead in the area of biocatalysis.

- Applied research initiatives represent a major focus in government, academic and industrial programs in Japan.

- There is the strong participation of industrial scientists and foreign investigators in targeted development of scientific programs in Japan.

- Strong industrial collaborative interactions exist with universities in Japan.

- Strong support of university science programs by government and industry in Japan.

- Funding resources are available for both basic and applied sciences in Japan.

- The government is a very visible partner in Japan's biotechnology initiatives with established long range policy commitments to the implementation of biotechnology in diverse market sectors. 
Of interest is that Japan is predicted to fall behind in very few technical and policy areas over the next several decades. Energy R\&D was notably absent from the report, especially considering the total dependence of Japan on foreign energy imports. A minor comment did address biodesulfurization activity, although no details were available from the panel. Either little energy R\&D is in progress or there was no discussion of energy, in as much as the panel bias did not include energy matters, nor did they address questions concerning energy-based R\&D efforts currently under intensive development in Japan. A similar analysis of biotechnology initiatives for other developed countries would be of interest.

Oil and Energy Trends. An overview of the scope of U.S.-based fossil industries is of value for understanding the magnitude of processing technologies that will be required of future bioprocessing initiatives. A number of crucial factors required of biotechnology programs include low cost, absolute biological fidelity/reliability, fast reaction rates and low residence times, efficient and low cost separation and recovery methods, ability of the technology to conform to existing process infrastructures and, most importantly, the ability to offer distinct and clear advantages over present technologies for industry acceptance and implementation. Future energy demands and trends are unknown. But, certainly energy demands will not drastically decrease. Global energy demands and usage are constantly in flux, with adequate oil supplies an unknown quantity, regardless of known sources. The following data illustrate the types of fossil fuels activity currently practiced in the United States (source: Oil and Energy Trends, February, 1991).

\section{Summary}

Crude oil \& NGL production - 1990

Natural gas production - 1990

Coal \& lignite production - 1990

Product demand - 1990

Net oil imports - 1990

9693 thousand barrels/day 49536 million cubic feet/day 707 million metric tons 16977 thousand barrels/day 7283 thousand barrels/day

Production from Refineries - 1990 (tho"sand barrels/dav)

$\begin{array}{lll}\text { LPG }-535 & \text { Mogas - 6960 } & \text { Naphtha - 134 } \\ \text { Aviation Fuel }-1463 & \text { Kerosene }-73 & \text { Gas/diesel oil - 2927 } \\ \text { Residual oil }-948 & \text { Other }-2265 & \text { Total - 15305 }\end{array}$

Oil Demand by Product Category - 1989 (thousand barrels/day)

\begin{tabular}{cccccr}
\hline Gasoline & Kerosene/Jet & Fuel Diesel/Gas Oil & Hy Fuel & Oil LPG & Other \\
7327 & 1365 & 3158 & 1371 & 1666 & 2441
\end{tabular}




\section{Gross Imports of Crude Oil to U.S. by Country of Origin - 1990}

$\begin{array}{ll}\text { Algeria }-60,000 \mathrm{~B} / \mathrm{D} & \text { Norway }-124,000 \mathrm{~B} / \mathrm{D} \\ \text { Indonesia }-157,000 \mathrm{~B} / \mathrm{D} & \text { Saudia Arabia }-1,115,000 \mathrm{~B} / \mathrm{D} \\ \text { Iran - } 0 & \text { UAE }-21,000 \mathrm{~B} / \mathrm{D} \\ \text { Iraq }-438,000 \mathrm{~B} / \mathrm{D} & \text { United Kingdom - } 163,000 \mathrm{~B} / \mathrm{D} \\ \text { Kuwait }-154,000 \mathrm{~B} / \mathrm{D} & \text { USSR }-0 \\ \text { Libya }-0 & \text { Venezuela }-495,000 \mathrm{~B} / \mathrm{D} \\ \text { Mexico }-714,000 \mathrm{~B} / \mathrm{D} & \text { Other }-1570 \mathrm{~B} / \mathrm{D} \quad \text { B/D=barrels/day } \\ \text { Nigeria - } 795,000 \mathrm{~B} / \mathrm{D} & \end{array}$

Gross Exports of Solid Fuels from U.S. to other Countries - 1989

$\begin{array}{lr}\text { Canada } & 16,309,000 \text { metric tons } \\ \text { Japan } & 12,219,000 \text { metric tons } \\ \text { Belgium } & 5,165,000 \text { metric tons } \\ \text { France } & 6,223,000 \text { metric tons } \\ \text { W. Germany } & 385,000 \text { metric tons }\end{array}$

For many years, the United States enjoyed a raw materials and energy advantage, but this advantage is no longer in existence, in as much as the U.S. has become dependent on foreign oil imports to support its economic viability. The energy advantage now lies in the oil-rich, developing countries where industrialized, developed countries are now required to share fossil resources witt. national oil companies at a price. An exception to this situation in the U.S. is coal, with large known reserves. The U.S. chemical industry, being dependent on oil for chemicals production, must identify new strategies if it is to thrive and perhaps "survive". Value-added strategies for product lines of both old and new chemicals must be developed rather than the construction of expensive, inflexible engineering edifices churning out old product lines. The capability of generating new products of superior quality and performance characteristics will require innovative thinking and management to capitalize on and exploit new technologies. The past several decades have focused on molecules and molecular properties. The future appears to lie in materials and material sciences where the materials of tomorrow are not going to be simple ones and two monomer conversions but, rather, improved composites derived from diverse sources, including biotransformations of petro-chemical feedstocks. Health-related biotechnology is now a multi-billion dollar success story. Fossil energy-related biotechnology has the potential to become a similar success story over the next 2 to 3 decades with proper implementation of R\&D initiatives. 


\section{Chapter 3}

\section{BIOREMEDIATION OF LIQUID FOSSIL FUELS AND REFINED PRODUCTS.}

\section{$3.1 \quad$ INTRODUCTION.}

Bioremediation may be defined as the process of encouraging the natural process of biodegradation to clean up spills and other environmental problems caused by humankind's activities. The widespread use of one particular type of bioremediation, in this case the application of appropriate fertilizers, to the Exxon Valdez oil spill has helped to bring the idea to the public's notice, but, in fact, the enhancement of biodegradation has been an important part of people's activities for a long time, and no self-respecting gardener would be without a compost pile.

The amount of petroleum used daily in the U.S. is truly staggering. According to Bauman (1989), the daily average consumption was almost 500 million gallons of refined products (gasoline, fuel oil and aviation jet fuels) per day in 1986. Despite the best efforts of the petroleum industry and regulators, some of this is spilled, either before refining, at the refinery, in subsequent shipping, in storage, or during and after final use. Many of these releases require some action to minimize or mitigate their impact on shorelines, soils and groundwater.

Massive releases, such as those following tanker accidents or tank ruptures get the most public attention, but, in fact, these probably represent only a small proportion of the total release into the environment. For example, the National Research Council (1985) estimated that the total input of petroleum from all sources into the sea is between 1.7 and 8.8 million metric tons per annum, with a best estimate of 3.2 million metric tons. Of this, only 0.4 million metric tons was attributable to tanker accidents, comparable to natural sources, principally seeps, at 0.25 million tons. Total input from transportation was 1.47 million metric tons, compared to a total of 1.18 million metric tons from municipal and industrial wastes and runoffs. In this perspective, the largest tanker spill to date, 244,000 tons following the total loss of the Amoco Cadiz in 1978, was only $8 \%$ of the amount entering the sea that year (or 28 days worth), albeit in a very small area (Gundlach et al., 1983). The 1989 Exxon Valdez spill, of only a portion of its cargo, was only one-sixth the size of the Amoco Cadiz spill (Harrison, 1991). Similarly, infamous terrestrial spills are only a minor portion of the total. For example, the diesel fuel tank rupture at the Ashland oil terminal on the Monongahela River, PA, in 1988, was only 13,500 metric tons (Miklaucic and Saseen, 1989). While such spills have serious environmental impacts on their immediate surroundings, many more people are likely to be affected by individually smaller spills such as those from leaking underground storage tanks.

With the ever-growing awareness of the extent of pollution emanating from all aspects of our use of petroleum has come an ever increasing political requirement to ameliorate the 
problem. Coupled with increasingly sensitive analytical tools has come the requirement for cleaning contaminated sites to very clean levels. Traditional methods involving excavation and shipment to hazardous waste sites are increasingly being viewed as merely moving, not solving, the problem, so the time is ripe for alternative approaches to remedying the problem. Bioremediation is one attractive option (see Preslo et al., 1989), and indeed this perception is widely shared; a recent conference organized on this topic, "In situ and on site bioreclamation" by Battelle in San Diego in March 1991 attracted almost four times as many attendees as expected, and many had to be turned away at the door.

\subsection{STATUS OF BASIC AND APPLIED RESEARCH.}

\section{BACKGROUND.}

Crude oils and their refined products are inherently very biodegradable, although some constituents degrade at very slow rates (Leahy and Colwell, 1990). Unfortunately, this fact, and the fact that crude oil is a natural product, truly organic in all senses of the word, is often ignored by the general public. The National Research Council report (1985) estimates that 0.25 million metric tons of crude oil enter the marine environment every year from natural seeps and by erosion, and it is clear that the majority of this oil is removed from the environment by natural processes. Evaporation plays an important immediate role, responsible for perhaps $15-50 \%$ of the hydrocarbon in different source oils, but even this material eventually returns to the biosphere, where it is degraded by microbial activity. Similarly, some components of the oil dissolve into the sea, but again these molecules all seem to be biodegradable in the long term. The remainder of the un-evaporated, un-dissolved oil is subject to biodegradation wherever it is deposited, and it is likely that only a few truly recalcitrant molecules are completely inert to biodegradation over centuries (Requejo and Halpern, 1989).

\section{CURRENT RESEARCH STATUS.}

\section{BASIC.}

Tre biodegradation of oil and refined products is principally by microorganisms, especially bacteria, and the study of microbial oil degradation has been an important area of microbiology for at least 50 years .(Zobell, 1946; Atlas, 1984; Snellman et al., 1988; Leahy and Colwell, 1990). The question of whether oils and their refined products are biodegradable is no longer an issue, at least under aerobic conditions. While there are still many areas where our understanding of the microbial ecology, biochemistry and physiology is very incomplete (Leahy and Colwell, 1990), the basic processes are either understood, or at least demonstrated. The important area of research, in terms of developing bioremediation, is in demonstrating effectiveness in the field, and in understanding the rates and effectiveness of biodegradation under field conditions. At the same time, microbiology must progress to an understanding of the processes occurring in the field, where mixed populations act on mixed substrates. It is already abundantly clear that while laboratory studies with pure cultures on simple substrates have allowed the elucidation of some of the fundamental pathways of biodegradation, the interactions between species in the real world may provide rather more effective and total removal of pollutants than has sometimes been imagined. 
The one area where our understanding is not yet very advanced and where there is room for extensive basic research, is that of anaerobic degradation of crude oils and refined products. Bertrand et al. (1989) have recently reviewed this topic and concluded that anaerobic hydrocarbon metabolism has been demonstrated under fermentative and denitrifying conditions, and Edwards et al. (1991) have presented some evidence that sulfate can act as the terminal electron acceptor. However, the range of compounds degradable under such conditions has not been determined, and the microorganisms responsible for these processes still need to be isolated and identified. The biochemical mechanisms of their metabolism are completely unknown. These are all important for bioremediation, since spilled oil does get into anaerobic environments, and current efforts to stimulate anaerobic degradation are only just beginning (Gersberg et al., 1989; Al-Bashir et al., 1990; Ball et al., 1991; Barbaro et al., 1991; Edwards et al., 1991; Evans et al., 1991; Flyvbjerg et al., 1991; Hutchins and Wilson, 1991; Jorgenson et al., 1991; Olsen et al., 1991; Reinhard et al., 1991).

\section{APPLIED.}

Two basic scenarios may be envisioned for a successful bioremediation strategy: either encourage the native microbial flora to degrade the pollutant more rapidly, or add effective microorganisms where there is not an effective indigenous flora. The latter process is sometimes called bioaugmentation. Both have been suggested and tested in the field.

The rationale for applying nutrients is that the normal (pre-spill) microbial flora is adapted to low levels of the pollutant of concern, either from chronic low-level pollution or by normal growth on similar natural foodstuffs (e.g. plant oils, etc.; Button et al., 1981). Under such conditions, oil degradation would be expected to be essentially substrate-limited. Any oil spill is likely to change the system dramatically so that the organisms are now presented with a surfeit of carbon. Under these conditions, their growth would be expected to be limited by the supply of some other nutrient, perhaps nitrogen, phosphorus, iron, or oxygen. Simple experiments to identify the limiting nutrient, followed by its careful application, would be expected to stimulate the rate of biodegradation.

The rationale for adding organisms is that the normal microbial flora is unused to the presence of the pollutant in the environment, so there are probably few hydrocarbon degrading organisms in the natural population to exploit the spill. Such a scenario may be particularly appropriate when considering spills from leaky storage tanks or pipeline breaks, where the pollutant is entering a previously undisturbed environment, with a relatively inactive microbial population. Alternatively, the particular pollutant(s) of concern might be degradable only by engineered organisms. In either case, the addition of active microbial populations would be expected to stimulate biodegradation. Additional nutrients would probably also be required.

It should be noted that the two alternatives are not necessarily mutually exclusive, and that either or both could be considered for broad application to an undisturbed spill site, or for application in bioreactors where the contaminated material is put in an enclosed reactor and the bioremediation is carried out inside the reactor. The former is simpler and cheaper, 
while the latter is more amenable to the containment of pollutants and organisms and the manipulation of temperature, $\mathrm{pH}$, oxygen, surfactant (Oberbremer et al., 1990), etc. Also, the direct and indirect environmental and human health aspects of nutrients, biomass, or other amendments must be carefully considered before use.

\section{The addition of microbial cultures for bioremediation.}

Numerous vendors provide cultures of bacteria for bioremediation, usually in some form that provides a reasonable shelf-life. In general the documentation of such preparations is part of glossy promotional booklets with no information other than boldly asserted "facts". Not much work has appeared in the refereed literature concerning such products. Molnaa and Grubbs (1989) claim several successes with commercial products, but there is not enough information to assess the claims.

Vecchioli et al. (1990) mixed aromatic hydrocarbon storage tank residues with soil, with and without nutrients and an inoculum from a petroleum waste land-treatment unit. They found some stimulation by the autochthonous organisms at the end of one month, but still found substantial degradation by the indigenous organisms in the previously uncontaminated soil.

Dott et al. (1989) tested nine commercially available microbial strains as amendments to domestic sewage sludge for stimulating oil biodegradation in batch culture. While all the products contained viable cultures of oil degrading organisms, the products had no beneficial effect on the overall process. They concluded that fuel oil degradation in domestic sludge is catalyzed effectively by naturally occurring bacteria and does not depend upon the application of highly adapted commercially available cultures.

The Oil Spill Intelligence Report International Oil Spill Control Directory (1991) lists several companies who have microbial cultures for cleaning oil spills. Venosa et al. (1991) tested several of these in laboratory experiments that aimed to determine whether there might be any benefit to adding them to oiled shorelines in Prince William Sound, Alaska, following the Exxon Valdez spill; they found little improvement over the rates catalyzed by the indigenous organisms.

Jones and Greenfield (1991) tested the addition of nutrients and bacteria to soils contaminated by a number 6 fuel oil in Florida. They found that the addition of nutrients (ammonia and phosphate) markedly stimulated biodegradation, but that there was no additional benefit from adding cultures of bacteria isolated from the site.

An obvious criticism of these experiments is that they were additions of microbial cultures to environments already loaded with indigenous organisms. Although this is indeed the mode of application suggested by the vendors, one might ask the question "how would the products perform if there were no indigenous organisms present?" The effectiveness of such products is readily shown in the laboratory under sterile conditions (e.g. Venosa et al., 1991), but is this a realistic scenario in the field? It seems very unlikely that any surface-accessible environment will lack oil-degrading microbes in some numbers, and one might expect that 
the indigenous flora would always predominate over added organisms in such environments. But what of, for example, subterranean environments with possibly reduced bacterial populations? Here the problem is likely to be one of access; if one can readily add autochthonous cultures, one would expect that there would already be an indigenous population, and the obvious corollary is that if there are no bacteria present, this probably indicates that there are serious barriers to colonization. It may be possible, however, to introduce microorganisms into previously sterile zones using ultramicrobacteria (see Chapter 14). An exception to this might be the seeding of oil slicks at sea, which achieved some notoriety after the spills from the Mega Borg in the Gulf of Mexico and the Apex barges in Galveston Bay in 1990 (Greene, 1991). There is not enough information to assess the effectiveness of these applications, but the EPA is addressing the issue of designing protocols for future testing of microbial additions to spills in open water. It should be noted, however, that proposals for seeding oil slicks at sea are not new; US Patent 4,146,470 was issued for the use of microorganisms in combination with surface active agents to synergistically disperse oil slicks in 1979 (Mohan et al., 1979).

The general conclusion seems to be that for most scenarios the indigenous populations of microorganisms are probably adequate for effective biodegradation if supplemented with appropriate nutrients (see below). There may, however, be an important role for microbial inocula under some special conditions. For example, if the concentration of pollutant is so high as to be toxic to the indigenous strains, or if the pollutant of concern is not degraded by the indigenous organisms. In such cases, it may be appropriate to consider using engineered strains in the field, providing the political questions surrounding the release of genetically engineered organisms are settled. For example, Diels et al. (1991) have isolated heavy metal-resistant, polychlorophenol-degrading Alcaligenes strains by mating strains with the individual characteristics. Solvent-tolerant microorganisms may have also an important application here (see Chapter 9). Another concern is that organisms capable of degrading particular pollutants might not do so under stress conditions. Little et al. (1991) have reported the construction of organisms where the toluene degradation pathway is under the control of specific stress-promoters, so that active degradation continues even in the absence of growth. Such experiments are in their infancy, but they may point the way to specific strains of organisms for specific applications.

Perhaps the most likely application of bacterial cultures is in those situations where the contaminated material is enclosed in a bioreactor, and the bacterial environment can be more readily manipulated. Little has been published on this topic in the refereed literature. Several groups (e.g. van den Munckhof and Veul, 1991; Stegmann et al., 1991) claim excellent degradation of oil in a rotating bioreactor using only indigenous organisms supplemented with appropriate nutrients, while other groups have also included inoculum (e.g. Ahlert et al., 1991; Yare, 1991).

The addition of nutrients to stimulate biodegradation.

As discussed above, the indigenous microbial population of a contaminated site may well be capable of degrading the pollutant, but be limited in this activity by the availability of 
essential nutrients. In surface situations, the limiting nutrients are likely to be nitrogenous compounds, phosphate, or some other mineral nutrients. This was thought to be the case in Prince William Sound after the spill from the Exxon Valdez (Pritchard and Costa, 1991) and indeed was borne out by both field and laboratory testing (Prince et al., 1990; Chianelli et al, 1991; Tabak et al., 1991).

The approach of adding nutrients to stimulate oil degradation is not new, indeed it is the basic rationale of "land-farming" for the destruction of oily waste (see Bartha and Bossert, 1984). It has been widely used for terrestrial remediation (see for example, Bossert and Bartha, 1984; Fogel et al., 1989; Block et al., 1990; Song et al., 1990; Ladousse and Tramier, 1991) and tested on a small scale for dealing with oil spills that affect shorelines (Lee and Levy, 1991; Jones and Greenfield, 1991). Until the spill from the Exxon Valdez, however, it had not been used on a substantial marine spill with the single exception of a spill in Spitzbergen (see Ladousse and Tramier, 1991).

Under some circumstances it may be beneficial to consider adding a readily degradable carbon source along with the inorganic nutrients. Inipol EAP22 contains oleic acid as a major component (Ladousse and Tramier, 1991), and Lindstrom and Brown (1989) found that amino acids, specifically valine, stimulated the biodegradation of toluene. Ying et al. (1990) report an increase in the biodegradation of a heavy oil by adding molasses and proteins along with inorganic nutrients.

In subsurface environments the limiting factors for biodegradation may still be nutrients, or they may be terminal electron acceptors. Oxygen has often been thought to be a limiting factor, and the provision of forced air flow through contaminated zones is one approach to removing this limitation (Dineen et al., 1990). An alternative approach is to inject hydrogen peroxide into the contaminated zone (see Raymond et al., 1986; Lawes, 1990); this decomposes to provide oxygenated water with hundreds of $\mathrm{ppm}_{2}$. Yet another alternative is to strip the pollutant out of the soil so that it can be biodegraded in a reactor on the surface (Diks and Ottengraf, 1991; Armstrong et al., 1991).

In recent years it has become apparent that at least some biodegradation can occur coupled to the reduction of alternate electron acceptors, especially nitrate and sulfate (Gersberg et al., 1989; Al-Bashir et al., 1990; Ball et al., 1991; Barbaro et al., 1991; Edwards et al., 1991; Evans et al., 1991; Flyvbjerg et al., 1991; Hutchins and Wilson, 1991; Jorgenson et al., 1991; Olsen et al., 1991; Reinhard et al., 1991). This is a promising approach, although its limits have not been defined.

With any nutrient addition, there will be concern that the nutrients may be contaminants in their own right. A substantial program of ecological monitoring and testing for potential acute toxicity accompanied the bioremediation of the Exxon Valdez oil spill (Prince et al., 1990; Pritchard and Costa, 1991), and it is likely that at least some form of monitoring will be required in any surface spill application. Subsurface applications will presumably raise different concerns, especially if nitrate is used in substantial quantities. Concern will also be raised if bioremediation involves the reduction of sulfate to sulfide, and it is clear that 
progress in application technology must be accompanied by progress in environmental monitoring.

International Research Initiatives.

Work on bioremediation of crude oil and refined products is a truly international enterprise, and there is substantial activity in both research and application in many countries. This is exemplified by an analysis of the list of presenters at the 1991 International Symposium on in situ and on site bioreclamation organized by Battelle in San Diego in March 1991; there were speakers from Australia, Belgium, Canada, Denmark, England, France, Germany, India, Israel, Japan, the Netherlands, New Zealand, South Korea and Thailand. Research at universities and national laboratories is sponsored by government and industry, and there are a plethora of small companies actively engaged in carrying out bioremediation.

\section{Commercial Developments.}

There has been substantial patent activity in the field, and a few representative patents are listed in Table 1 . It is not clear how many have been actively practiced; some, such as US 4,460,692 which covers compositions such as Inipol EAP22, clearly have.

Table 1.

SOME REPRESENTATIVE US PATENTS ON BIOREMEDIATION OF FOSSIL FUEL SPILLS.

Bacterial method and composition for degrading hydrocarbons. (1990)

Vandenburgh, P.A., US 4,910,143

Microorganisms for biodegrading toxic chemicals. (1989)

Portier, R.J., US 4,859,594

Stimulation of biooxidation processes in subterranean formations. (1986)

Raymond, R.L., Brown, R.A., Norris, R.D. and O'Neill, E.T., US 4,588,506.

Microemulsion of nutrient substances. (1984)

Tellier, J., Sirvins, A., Gautier, J. and Tramier, B., US 4,460,692

Use of microorganisms in combination with surface active agents to synergistically disperse oil slicks. (1979)

Mohan, R.R., Robbins, M.L., Laskin, A.I. and Naslund, L.A., US 4,146,470

Biodegradation of oil on water surfaces. (1976)

Bartha, R. and Atlas, R.M., US 3,959,127

Material for biological degradation of petroleum. (1975)

Townsley, P.M., US 3,883,397 
There are probably hundreds of small companies offering bioremediation services to the oil industry in the U.S., and several large ones such as duPont. The majority are very young, and it is too early to say whether the market place is best served by so many companies. Many offer bacterial cultures, either alone or as part of packages including bioreactors, and many offer bioengineering skills. Only a single oleophilic fertilizer is currently commercially available, Inipol EAP22 (Ladousse and Tramier, 1991), but many slow release fertilizers are available (see Pritchard and Costa, 1991).

\subsection{FUTURE RESEARCH DEVELOPMENT AND REQUIREMENTS.}

Relevance and justification.

Bioremediation is on the verge of becoming a well accepted adjunct to more traditional waste-treatments, and it is very much in the public eye as a "green" alternative to other technologies perceived as more dangerous, such as burning or burying. The USEPA has identified bioremediation as a very important potential option for cleaning hazardous waste sites of all kinds and is undertaking a major research initiative to support this. This includes the partnership with the University of Pittsburgh Trust known as the National Environmental Technology Applications Corporation (NETAC) to assess bioremediation products (see Venosa et al., 1991).

Research needs and limitations.

Enough is known about the processes of microbial biodegradation that bioremediation is already being used in the field. Nevertheless, there are still several areas of research that should have a very high priority. These fall into two broad categories; more clearly defining the scope and limitations of present ideas and elucidating fundamentally new biodegradation processes.

\section{Well-documented proof of principle.}

The use of bioremediation as part of the cleanup of the Exxon Valdez spill was accompanied by a substantial monitoring program to address safety and efficacy (Prince et al., 1990). While it was relatively easy to demonstrate the biodegradation of crude oil and its refined products in the laboratory, under conditions which simulated conditions in the field (e.g. Tabak et al., 1991, Chianelli et al., 1991) there was strong pressure from many quarters to demonstrate effectiveness in the field. This turned out to be a non-trivial exercise. The inherent variability in oiling of the shoreline sediment made it very difficult to assess the amount of oil in the sediment, so addressing the rate of its disappearance could not be determined by simple gravimetric comparisons. The rate of degradation was determined using $17 \alpha(\mathrm{H}), 21 \mathrm{~B}(\mathrm{H})$-hopane as an internal standard which was assumed to be resistant to biodegradation on the timescale of relevance to the cleanup and using an artificially weathered oil as a surrogate for oil that initially landed on the shoreline. The annual rate of biodegradation could then be determined as $2.2 \mathrm{~g}$ oil $/ \mathrm{kg}$ sediment in surface sediments 
and approximately half this in the subsurface $(30 \mathrm{~cm}$ lower). Furthermore, the use of the internal standard allowed the estimation of maximal degradation already accomplished; the most degraded samples had already lost approximately $80 \%$ of their oil, by biodegradation, by the summer of 1990 , some 16 months after the spill. But the sensitivity of the analysis, which had to compare any sample with the amount of oil in the sample at beaching, could not address the question of whether fertilizer applications had stimulated biodegradation in the short period of the monitoring program with the relatively small number of samples. Evidence for this came from radiorespirometric measurements with radiolabelled hexadecane and phenanthrene; these showed a substantial stimulation, some three to fourfold after a single application and five to tenfold after two applications approximately a month apart. Only by combining the two sets of information could the conclusion be drawn that the treatment was indeed effective.

Small spills will not warrant such a massive and expensive monitoring program. There is a real need for a few well documented bioremediation applications in the field to establish the effectiveness and limitations of the technique. These should include fertilizer application and the application of autochthonous organisms.

\section{Internal markers for estimating biodegradation.}

As discussed above, the heterogeneity of oiling in shorelines of Prince William Sound prohibited meaningful comparisons of the amounts of oil in different sediment samples at different times, and the only way estimates of biodegradation could be obtained relied on using a conserved internal standard. Crude oil contains a range of steranes and terpanes that are potentially appropriate for this role, but what could be used if monitoring a refined product? Clearly work is needed to identify appropriate internal markers and then to develop standard protocols for their measurement.

\section{Protocols for testing bioremediation products.}

Faced with a spill that needs bioremediation, the spiller is faced with a plethora of products from the many small companies in the market offering bioremediation products and services. Given the importance of appropriate cleanup, it is essential that there be some objective criteria that the various products and services be judged on. As discussed above, USEPA and NETAC are currently designing protocols for testing bioremediation products for use on oil spills. While still under discussion, there are plans to first assess information provided by the vendor (Tier I). This information must include the chemical composition, some estimate of efficacy, and data on acute or chronic toxicity. Appropriate candidates would then undergo a formal screening involving laboratory (Tier II) and microcosm (Tier III) tests. Finally, a protocol is being developed to conduct limited field trials of the most promising candidates (Tier IV) (see Venosa et al., 1991). It is recognized that Tiers III and IV may be prohibitively expensive for some small vendors, and discussions are underway to share costs with EPA and the oil industry, but whether these will be fruitful remains to be seen. Current plans call for the development of protocols for open water, beaches, wetlands, and soils. 
Many issues remain to be worked out. One strange outcome of the first round of testing (Venosa et al., 1991) is that the results are available, but the products tested are anonymous.

Fundamental limits to biodegradation.

It is widely perceived that some components of crude oil are more readily biodegradable than others. But how important is this? Laboratory experiments with isolated microbes indicate a strict preference, for example, for linear over branched alkanes, even though both are eventually consumed (Pirnik et al., 1974). In the field, however, although the preference is seen, it is not so dramatic (Prince et al., 1990). If there is merely a slight preference for some compounds over others, then some components of the oil will undergo preferential degradation, but the oil will eventually be completely consumed. But if some compounds are only consumed adventitiously, or as co-metabolites, along with the more readily degradable materiali (Perry, 1979), then their degradation will cease when the readily degraded components are depleted.

There is evidence that most of the components of crude oil are indeed biodegradable in the long term (see Prince et al., 1990; Chianelli et al., 1991), but many questions remain. Little work has been done on the biodegradation of the different components of heavy fuel oils, such as Bunker oils, but they are quite recalcitrant (Song et al., 1990), and many of the saturated, poly-condensed components used in lubricating oil may be quite resistant to biodegradation.

This is an important question for the future of bioremediation. If biodegradation ceases before all the pollutants of concern are degraded, then bioremediation will be a less appealing option for cleaning spills.

Is there a role for adding inducer compounds or alternate growth substrates?

Many degradation pathways are under genetic control so that they are only induced under appropriate conditions. In some cases only a few of the compounds degraded by a particular pathway are capable of inducing its synthesis (Bauer and Capone, 1988; Abramowicz, 1990). Might this be exploited, at least in bioreactors, to stimulate the degradation of relatively recalcitrant molecules?

The question of alternate or additional growth substrates is a related one. Inipol EAP22 contains oleic acid as its principal component (Ladousse and Tramier, 1991), offering the surprising paradox that the fertilizer adds carbon to stimulate the degradation of carbon. Lindstrom and Brown (1989) found that amino acids, specifically valine, stimulated the biodegradation of toluene, and Ying et al. (1990) report an increase in the biodegradation of a heavy oil by adding molasses and proteins along with inorganic nutrients, yet Bauer and Capone (1988) found no benefit in adding low concentrations of glucose to stimulate the biodegradation of anthracene or naphthalene. Clearly more work needs to be done to understand these phenomena. 
Does emulsification help or hinder biodegradation?

Dispersants are often considered as the first response to an oil spill, although a reluctance to authorize their use has developed in the U.S. (Cunningham et al., 1991). Would their use compromise subsequent biodegradation? Oberbremer et al. (1990) found that the hydrocarbon degradation rate was doubled by the addition of sophorose lipids as biosurfactants, whereas Foght et al. (1989) found that Emulsan, a rather different biopolymer, retarded the rate of biodegradation by mixed cultures.

This is an important question if bioremediation is to be fully integrated into spill response. One approach to such an integration has been suggested by Bronchart et al. (1985), who have developed an oil dispersant that contains oleophilic nutrients, so that the subsequent biodegradation of the dispersed oil would be enhanced.

Unfortunately there is not a good fundamental understanding of what role dispersion and the production of biosurfactants play in biodegradation. This is an area where there is a real need for some basic investigations.

Alternative delivery systems for bioremediation nutrients.

The simple concept of adding nutrients to stimulate biodegradation acquires some complexity when it comes to actual practice. Oil-degrading organisms are not the only organisms presented with an unlimited supply of carbon, but limiting nitrogen and phosphorus; at least in surface applications, the same is true of photosynthetic organisms. The application of nutrients thus has to selectively supply the oil-degrading community without stimulating the photosynthetic one. Furthermore, the nutrients must not cause acute or chronic toxicity to the other indigenous biota. The EPA tested several alternative slow release formulations of fertilizer as part of the bioremediation program for the Exxon Valdez spill (Safferman, 1991), but there is clearly a substantial opportunity to develop alternative delivery systems.

Are there adverse ecological effects associated with bioremediation?

Typical surface applications of nutrients as part of bioremediation will most likely be occasional discrete applications rather than continuous ones, and as such the environmental impact of careful designed programs is likely to be minimal. But what are the effects? What should be measured? What will be the effect of prolonged delivery of nutrients to the subsurface? If microorganisms are added to the environment, how will their longevity be assessed?

What is the fate of the pollutant after biodegradation? Presumably a goodly portion is mineralized to $\mathrm{CO}_{2}$ and $\mathrm{H}_{2} \mathrm{O}$ by microbial activity, but some of the carbon must end up as microbial biomass. In some cases this carbon, or the nitrogen of the fertilizer, may have a different isotope signature from the undisturbed biosphere. Can this be detected moving up through the trophic levels? 
Are there roles for microorganisms as catalysts for degradation?

The general view of bioremediation tends to envision the growth of bacteria on the offending pollutant, although it is clear that some degradation only occurs as an adjunct to growth on other substrates. For example, while the biodegradation of PCBs is a well documented phenomenon (Abramowicz, 1990), there are apparently no organisms that can grow on PCBs as sole source of carbon and energy. Prior sections have addressed the potential benefits of adding additional growth substrates, but are there potential benefits to growing the organisms in batch culture and then immobilizing them as catalysts for a flow-through system? If such a system could be designed to be robust enough for field use, it might have several potential benefits in terms of requirements for on-site equipment and containment.

\section{Reactor design and operation.}

There will be a range of situations where it will be appropriate to dig up the contaminated soil and bioremediate it in a reactor. Such bioreactors will need to be optimized for stimulating biodegradation without, for example, liberating pollutant into the atmosphere, and clearly there is a need for standards within the industry. This research will also influence the design of waste-treatment facilities for waste streams from coal liquefaction and gasification plants as well as from the petro-chemical industry.

Anaerobic biodegradation of crude oil and refined products.

As discussed above, this area is almost completely unexplored, yet it may have substantial potential for remediating spills in anoxic zones. Basic research at many levels is required to delineate the phenomenon and characterize the microbial ecology, physiology, and biochemistry of the process.

\subsection{RECOMMENDATIONS AND PRIORITY STATUS.}

Bioremediation is on the verge of becoming a major treatment for the remediation of hazardous waste, and the foregoing review has discussed several areas where research and development is needed for effective development of the technology. Some are already being actively worked on by other agencies, especially the USEPA, but there are good reasons for DOE to be involved as well. A very important role would be played by providing test sites for the thorough testing and documentation of the effectiveness of bioremediation on terrestrial and freshwater sites. The paucity of well documented "proof of principle" success is probably the major obstacle in the way of widespread use and acceptance of bioremediation.

Many commercial companies are ready to provide bioremediation services to the public, but they are unlikely to come up with the fundamental information needed to advance the technology to its full potential. DOE could play an important role by funding research into the more basic aspects of anaerobic degradation of hydrocarbons, bearing in mind that such 
research will probably also have an impact on our understanding of what may be dccurring in petroleum reservoirs and pipelines. An understanding of anaerobic hydrocarbon degradation might also provide new insights into how such reservoirs are filled in the first place and thus provide new insights into petroleum exploration.

- Establish "proof of principle" for various bioremediation strategies by providing test sites for the thorough testing and documentation on the effectiveness of these biological-based technologies in terrestrial, fresh water, and marine environments.

- Identify internal marker standards and establish standard protocols for estimating rates of biodegradation and bioremediation effectiveness. This type of standardization will aid in the direct comparison of results obtained by different investigators.

- Establish protocols to be used for the testing of bioremediation products and establish acceptable analytical procedures for measuring small concentrations of contaminants in environmental samples.

- Determine fundamental limits of oil biodegradation.

- Define the role(s) of synthetic surfactants and biosurfactants in bioremediation strategies for terrestrial, fresh-water, and marine environments.

- Provide basic answers to the question "is there a role for inducers or alternative growth substrates?" in bioremediation technologies.

- Investigate alternative delivery systems for the addition of nutrients serving to stimulate rates of biodegradation.

- Analyze possible adverse ecological effects resulting from implementation of bioremediation strategies.

- Evaluate the potential for the use of microorganisms as nongrowing, immobilized biocatalysts in bioremediation.

- Assess anaerobic biodegradation of crude oil and refined products. 


\section{Chapter 4}

\section{BIODESULFURIZATION OF FOSSIL FUELS.}

\subsection{INTRODUCTION.}

Sulfur is an undesirable component of fuels, since its combustion products (oxides) are important pollutants that lead to acid rain (Manowitz and Lipfert, 1990). There are two obvious options for limiting the impact of the pollutant if it is present in the fossil fuel: remove it prior to use, or remove the oxides after combustion. The former is particularly appropriate for transportation fuels, while the latter is an increasingly important option for already operating power generation facilities. Indeed both alternatives are followed, principally by chemical and physical treatments. It is noteworthy that the production of elemental sulfur during the refining of petroleum now exceeds that conventionally mined and dominates world supply (Buchner et al., 1989).

It is widely appreciated that biological processes might be employed as an adjunct to the chemical and physical processes for removing sulfur, or perhaps they might even replace them. While there has been much research both in the United States (Table 1) and abroad (see Table 2), and a large number of patents have been filed (Table 3 ), there has not been to date a significant commercialization of biological processes for sulfur removal. While it is possible to envision biological processes for the removal of sulfur oxides from flue gasses (Sublette et al., 1990), most work on potential biological processes has focussed on removing sulfur prior to combustion, and it is this work which forms the basis of this review. Much of the literature covers the removal of inorganic sulfur from coal, with more recent work emphasizing the removal of organically bound sulfur from both coal and petroleum. This paper is not an exhaustive review of the earlier literature, which can be found elsewhere (Monticello and Finnerty, 1985; Finnerty and Robinson, 1986; Kawatra et al., 1987; Bos and Kuenen, 1990); rather it attempts to integrate current work to provide guidance for the future.

\subsection{STATUS OF BASIC AND APPLIED RESEARCH.}

\section{BACKGROUND.}

Sulfur is present in both inorganic and organic forms in most fossil fuels. As we shall discuss below, the techniques for identifying the forms of organic sulfur in complex mixtures are still being developed, and there is much still to learn about the heterogeneity of organic sulfur species in fossil fuels. Rather more is known about the inorganic material, which is principally the sulfides pyrite and marcasite in coal and shale, and $\mathrm{H}_{2} \mathrm{~S}$ in natural gas and 
liquid fuels. There has been a question as to whether elemental sulfur is a significant component of fossil fuels, and it now seems that coals, at least, do not contain elemental sulfur unless they have been subjected to chemical and/or biological oxidation (Friedman, 1990; Stock and Wolny, 1990). Organic and inorganic sulfur species are fundamentally different, and quite different biological processes have been developed or suggested for their removal.

The removal of inorganic sulfur from solid fossil fuels.

Sulfide minerals are typically removed from coal prior to combustion by grinding the coal and separating the denser sulfide minerals. This only works, however, when the sulfides are present as rather coarse particles (Palowitch and Deurbrouck, 1979). A range of physical treatments have been proposed for the removal of more finely divided particles, such as froth flotation, high gradient magnetic separation, electrostatic separation and chemical processes (see Bos and Kuenen, 1990), and these all work better the finer the coal. It is here that alternative biological processes are perhaps nearest to commercialization.

The susceptibility of sulfide minerals to biological oxidation has long been recognized in the problem that it causes: acid mine drainage. Aerobic chemoautotrophic organisms such as species of Thiobacillus and Sulfolobus are able to oxidize pyrite and marcasite using atmospheric oxygen to produce sulfates and sulfuric acid; they use the energy to fix atmospheric $\mathrm{CO}_{2}$ for growth (Khalid et al., 1989; Norris, 1990). For example, Thiobacillus ferrooxidans catalyses the following process:

$$
4 \mathrm{FeS}_{2}+15 \mathrm{O}_{2}+2 \mathrm{H}_{2} \mathrm{O} \rightarrow 2 \mathrm{Fe}_{2}\left(\mathrm{SO}_{4}\right)_{3}+2 \mathrm{H}_{2} \mathrm{SO}_{4}
$$

Since such organisms can grow without the need for an organic carbon source, they need only a mineral nutrient medium for growth on pyrite. Furthermore, at least in principle, they do not degrade the organic part of coal, and so, again at least in principle, they do not degrade the potential available heat in the coal. The concept of exploiting this process for the removal of inorganic sulfur from coal is more than thirty years old (Zarubina et al., 1959), and it has long been noted that the coal would need to be finely pulverized, mixed with water, and provided with a ready source of air for the process to work. In fact, early processes for the desulfurization of coal differed little from proposals for using microbes in mineral leaching processes.

In a rather thorough recent review, Bos and Kuenen (1990) point out that while the process has been widely seen as a major solution to eliminating acid rain resulting from coal combustion, there are several disadvantages.

1. The process is comparatively slow and will require huge reactors or a lot of space to treat a bulk commodity such as coal.

2. Conditions amenable for sulfide removal are probably the antithesis of those required for the potential removal of organic sulfur from coal (see below). 
3. The microbial process produces a very acidic wastewater laden with iron and other metals. Disposing of this waste, perhaps by neutralization and precipitation, would be rather expensive.

Nevertheless, there is a substantial literature of laboratory scale experiments to examine the potential feasibility of the process, and this reports substantial success with a variety of bituminous and subbituminous coals and even lignites (e.g. Bos and Kuenen, 1990).

The typical organisms used in laboratory scale bioremoval of inorganic sulfides are mesophiles such as Thiobacillus, but extreme thermophiles such as Sulfolobus have also been considered (Norris, 1990; Khalid et al., 1989), as have been moderate thermophiles (Norris, 1990; Bos et al., 1990). In theory, there might be some benefit to using moderate or extreme thermophiles to obviate the need to cool the desulfurization process, but Bos et al. (1990) conclude that the potential benefits are outweighed by the drawbacks of inorganic precipitation at the higher temperatures, and they intend to use mesophiles in an upcoming pilot plant to be built in Italy.

The removal of organic sulfur from solid fossil fuels.

In the last few years there has been much interest in the potential for biological removal of organic sulfur in a variety of fossil fuels, including both coal and petroleum. Unfortunately, while timely when viewed from an environmental perspective, the work has been somewhat premature in a technological sense since the identity of the organic sulfur in the fossil fuels remains unresolved. The vast majority of workers have used dibenzothiophene as a model compound, and there is now a considerable literature on the biodegradation of this compound (Foght et al., 1990). The majority of isolates that can degrade dibenzothiophene do so by the initial oxidation and cleavage of one of the aromatic rings, and in so doing initiate the complete degradation of the molecule to $\mathrm{CO}_{2}, \mathrm{H}_{2} \mathrm{O}$ and $\mathrm{SO}_{4}$. While this is an important pathway for the complete biodegradation of the compound and is clearly important for bioremediation, it is not an appealing pathway for commercial exploitation in desulfurization since it degrades the fuel value of the resource. Nevertheless, work on organisms that catalyze the complete degradation of dibenzothiophene should give insights into biological sulfur chemistry, and there are attempts to use isolated enzymes from such organisms to desulfurize coal (Nochur and Kitchell, 1990).

Recent work, principally from the Institute of Gas Technology (Kilbane, 1990) and ARCTECH (Harding et al., 1990), has identified an alternative pathway of degradation that selectively removes sulfur from the organic material and leaves the carbon skeleton essentially intact. A similar finding was reported to occur under anaerobic conditions (see chapter 6). The pathway of degradation apparently involves direct oxidation of the sulfur through the sulfoxide and sulfone to sulfate. Unfortunately, little of this work is in refereed journals, and the published work, principally in conference proceedings, leaves many questions unanswered. Nevertheless, there is published confirmation of at least parts of the pathway (van Afferden et al., 1990). This work is potentially very important because it identifies a pathway that could be used to desulfurize fuels without substantial degradation 
of their fuel value. While some of the organisms that use this pathway can grow at the expense of dibenzothiophene for their sole source of carbon, sulfur and energy (van Afferden et al., 1990), it seems that the strains isolated by Kilbane (Rhodococcus rhodochrous IGTS8 and Bacillus sphaericus IGTS9) utilize dibenzothiophene solely as a source of sulfur (Kilbane, 1990). Furthermore, the enzymes appear to be associated with the cell wall, so it becomes feasible to consider growing the bacteria on a substrate other than a fossil fuel and then using the organisms as a catalyst. Kilbane (1990) reports decreasing the organic sulfur content of Illinois No. 6 coal from 2.25 to $0.205 \%$ after 212 days in a bioreactor, which represents a $91 \%$ removal. Several questions remain, however, in particular the thermodynamics of the sequential oxidation of the organic sulfur are puzzling (Datta et al., 1991).

Perhaps surprisingly, given the only tenuous understanding of the sulfur-centered oxidation of organic sulfur species, there are already attempts to manipulate the genomes of organisms apparently capable of catalyzing this pathway, with the intention of combining the genes for organic sulfur removal with those of inorganic sulfur removal to create organisms capable of complete biodesulfurization (e.g. Kilbane and Bielaga, 1990; Roberto et al., 1990). While this may well yield powerful insights into the biochemistry of the process, it is hard to be optimistic that manipulated organisms will have any role in commercial processes in the near future.

The removal of inorganic sulfur in liquid and gaseous fossil fuels.

The principle form of inorganic sulfur in liquid and gaseous fuels is hydrogen sulfide, and this is readily removed during processing. Nevertheless, there are potential opportunities to remove sulfide by biological means, perhaps most prominently in secondary stripping applications. Sublette (1988) has discussed the feasibility of removing $\mathrm{H}_{2} \mathrm{~S}$ from coal-derived synthesis gas using Thiobacillus denitrificans under both aerobic and anaerobic conditions. Maka (1990) has described processes utilizing Thiobacillus thioparus or the photosynthetic Chlorobium limicola $f$. thiosulfatophilum. There are, perhaps, important applications for biological removal of $\mathrm{H}_{2} \mathrm{~S}$ from waste water streams. On a quite different note, Jannasch (1979) has proposed using hydrogen sulfide in gas streams to drive chemosynthetic aquaculture.

The removal of organic sulfur in liquid fossil fuels.

Much of the work on removing organic sulfur from coal can be readily applied to the desulfurization of liquid fuels (Foght et al., 1990; Fedorak, 1990), although the chemical technology to do the job is well entrenched (Buchner et al., 1989). As with coals, the majority of recent laboratory work has examined the desulfurization of dibenzothiophene even though, as Fedorak (1990) points out, there are many other organic sulfur compounds present in oil. Most work has utilized aerobic oxidation (Fedorak, 1990), but Kim et al. (1990) suggest a novel combination of microbial- and electro-chemistry for anaerobic reduction of organic sulfur to hydrogen sulfide. 
Applications of biodesulfurization technologies.

There is quite a body of literature on potential reactor design for the biological removal of inorganic sulfur from coal. These range from discussions of simple heap leaching to remarkably sophisticated reactor designs (Andrews, 1989; Bos and Kuenen, 1990). Knott and Sproull (1989) have described a fluidized bed bioreactor, Andrews and Quintana (1990) an aerated trough bioreactor, and other models, including pipe-reactors (Rai, 1986) have also been discussed. Briganti et al. (1990) have described a combined chemical and biological process, where pyrite is removed from the coal by chemical extraction with a mixture of ferrous and ferric iron, and the spent liquor is then regenerated by a biological process using Thiobacillus. A pilot plant with a capacity of $10 \mathrm{Kg}$ coal per hour has been run successfully in Italy.

One appealing scenario is to combine desulfurization with transport of coal as a coal slurry (Rai, 1986). While at first sight this seems a neat solution to the problems of the volume and time requirements for the process, the requirement for an acid $\mathrm{pH}$ and the need for adequate aeration, perhaps at intermediate pumping stations, suggest that it will not be simple to operate.

If the potential corrosion problems can be adequately addressed, recycling the aqueous phase back to the source of coal production could aid the microbial process by providing the appropriate $\mathrm{pH}$ for the growth of the acidophilic bacteria and fulfill the apparent political requirement that water not be consumed on a massive scale in the process.

At present, there appear to be no commercially viable coal biodesulfurization operations, although the literature is replete with hints that commercial scale bioreactors will be built in a few years (e.g. Bos et al., 1990). Similarly, there appear to be no commercially viable oil or petroleum biodesulfurization operations, although there are anecdotal reports that there may be such processes in eastern Europe. There are certainly plenty of patents on desulfurization, some dating from the 1950 s (Table 3), but none seem to have been practiced on any significant scale.

According to Bos and Kuenen (1990), microbial pretreatment of coal to reduce the mineral sulfur content so that post-combustion scrubbing was unnecessary was perhaps feasible with low sulfur coals $(<1 \% \mathrm{~S})$ when regulations allowed the combustion of coal with $0.8 \%$ sulfur. However, future regulations will mandate more stringent control of emissions, and this will require coal with a sulfur content of $<0.35 \%$, and there are few coals with such a low level of organic sulfur. Of course, microbial desulfurization still might have a role to play in reducing sulfur emissions but probably only in combination with physical and chemical processes.

International research initiatives.

Research into biodesulfurization of fossil fuels is truly an international concern (Table 2), and there are significant research activities underway in Italy (e.g. Briganti et al., 1990), 
Germany (e.g. Uhl et al., 1989, van Afferden et al., 1990), Sweden (e.g. Olsson et al., 1989), and Korea (e.g. Kim et al., 1990). In general, this work seems to be well-integrated into that going on in the U.S., and foreign workers are frequent attendees at U.S. symposia. The vagaries of international tax laws make it quite likely that economic and legislative incentives for fuel desulfurization will be quite different in different countries.

\section{Commercial developments.}

As described above, there are no commercially viable operations using biodesulfurization of fossil fuels at this time, although it is widely thought that coal desulfurization might be viable soon. Debus (1990) has discussed the economic hurdles to the commercialization of biological coal desulfurization in comparison to the situation in the copper ore industry, where biological beneficiation is important in $>25 \%$ of U.S. production. In short, his conclusion is that efforts based on speeding up the biological process may not be well founded, and that efforts to commercialization should look for in situ opportunities where investment in equipment and/or bioreactors is low. If this could be run profitably and in an environmentally sound way, even on a small scale, the chances of using biological processes on a broader front would undoubtedly be dramatically enhanced.

\subsection{FUTURE RESEARCH DEVELOPMENT AND REQUTREMENTS.}

\section{RELEVANCE AND JUSTIFICATION.}

The relevance of research into desulfurization technologies has never been greater. With the ever increasing political requirement for cleaner air, and the ever decreasing supply of low-sulfur fuels, there is a real need to deliver commercially viable fuel-desulfurization technologies for coal, oil and gas (Manowitz and Lipfert, 1990). On the other hand, there is a moving and ever decreasing target in that the requirements for the extent of desulfurization are continually becoming more stringent. Furthermore, the window of opportunity for direct desulfurization by any process is narrowing. For example, if government regulations specify sulfur-emission levels in the near future based on the best technology available now, the industry will probably install scrubbers. Once that investment is made (with a probable payoff estimate of 20 years or so), there will be little incentive for desulfurized coals or oils unless the price is competitive with current feed. Of course, there may still be some advantages, for example, partial desulfurization prior to combustion would lengthen the lifetime of scrubbers, but the overall picture is clear. If biodesulfurization is to achieve its full potential it needs to be commercialized before alternative approaches are installed.

It is widely appreciated that biology may have much to offer in the search for appropriate desulfurization procedures, since it is clear that microbes can carry out desulfurization reactions. The major question is whether such reactions can be carried out on a large enough scale, and whether biological processes can be integrated into the already mature energy supply industry. Chemical and physical processes are already widely used, and the potential for improving these technologies, and their fundamental limits, are quite well 
understood. A major question for biological processes thus becomes "how efficient are they?", which translates to "what is their cost?"; it is here where there is a major research need.

\section{RESEARCH NEEDS AND LIMITATIONS.}

There are always unanswered questions left by research and development, but in the case of the biodesulfurization of fuels there are several areas where there are important gaps in our knowledge. These are found in both the basic and applied arenas, and yet they should not be thought of as entirely independent. The field of biodesulfurization is leaving the period when it was essentially documenting a phenomenon for a period on the threshold of commercial application. This is an exciting time, but it will require some important changes of approach.

\section{An understanding of the forms of organic sulfur in coal.}

The principal gap in our current knowledge of biodesulfurization of organic sulfur is in the forms this sulfur takes in fuels. This limitation is widely appreciated (Friedman, 1990), but its implications for biological processes are rather profound. Chemical and physical desulfurization processes are well understood, and while they would perhaps be aided by a better understanding of the nature of sulfur in fuels, the processes are sufficiently generic, and the products sufficiently simple, that their efficiency is readily determined. Biological processes, on the other hand, are well known to often be very specific. If one is to make a decision on whether biodesulfurization is truly viable, it is very important to understand whether a process which is currently able to remove say $50 \%$ of the organic sulfur is in fact removing $50 \%$ of all the organic sulfur or $100 \%$ of a form which makes up $50 \%$ of the total. The implications are clear; in the former case it is likely that process improvements could be made to asymptotically approach $100 \%$ removal, while in the latter it is clear that an alternative, perhaps novel, approach will be required.

Fortunately we are on the threshold of a much better understanding of the forms of organic sulfur in complex materials (George and Gorbaty, 1989; Huffman et al., 1989a, 1989b; George et al., 1990, 1991; Gorbaty et al., 1990a, 1990b). X-ray absorption and X-ray photoelectron spectroscopies have a powerful potential to discriminate the different forms of sulfur in complex organic materials, and the availability of beamlines at synchrotrons is becoming ever greater (e.g. the Stanford Synchrotron Radiation Laboratory, California, and the National Synchrotron Light Source at Brookhaven National Laboratory, New York). While there are still developmental issues, for example how to deal with the concentration effects in heterogeneous materials, it is clear that the next few years will see a major improvement in our understanding of the forms of organic sulfur in complex materials such as fuels. Further improvements are also being made in the detection of compounds eluting from gas chromatography columns (Johansen and Birks, 1991). If this work can be integrated into the ongoing biobeneficiation research enterprise, we can expect significant progress. 
An understanding of the chemistry involved in the oxidation of organic sulfur.

The recent elucidation of sulfur-centered oxidation in organic materials is potentially very important, as discussed above. But how generic is the process? Most work has focused on dibenzothiophene as substrate, but what of other forms of organic sulfur? What of more sterically-hindered molecules? Research into this area is important if the process is to be important on a commercial scale, since unsubstituted dibenzothiophene is not the only or even the major organosulfur compound in fossil fuels.

Future research should be aimed at understanding both the phenomenology of the process and the enzymology. Interesting work is already underway on the pathway from dibenzothiophene (Kilbane, 1990; van Afferden et al., 1990), and this could be usefully extended to other organosulfur compounds and to model mixtures. Nothing is known of the sorts of enzymes involved, and this could be approached by both classical enzymology and by molecular genetics approaches. Some of the latter is underway (Kilbane and Bielaga, 1990; Roberto et al., 1990), but its current focus seems to be more on developing transgenic organisms for processes (a very long shot) rather than at understanding the fundamental process to see whether it has the essential attributes needed for commercialization. The isolation of enzymes active in desulfurization should be an important goal, since understanding their mode of action might provide important guidance in process design.

Future research must also include the acquisition of a molecular material balance for the process. Does the organically bound sulfur indeed end up as sulfate? This is a vital piece of information if one is to understand the phenomenon.

Are there anaerobic processes that can result in the desulfurization of fossil fuels?

For obvious reasons, most of the work on biodesulfurization of fossil fuels has focussed on aerobic oxidation. Unfortunately such processes, even when not aimed at the carbon matrix, are likely to modify the carbon molecules and thereby degrade the fuel value. Furthermore, if microbial growth is to be encouraged during the bioprocessing, aerobic conditions are likely to stimulate the partial degradation of the fuel. Kim et al. (1990) have discussed an anaerobic mechanism for the removal of sulfur from petroleum, and extensions of this work to solid fuels should be investigated.

\section{Need for rigorous peer review.}

While this may seem a curious item to identify as a research need, it is worth considering. Much of the literature on fuel biodesulfurization is in unrefereed conference reports, and the rigor of the analytical work often leaves much to be desired. For example, of the 142 references cited by Bos and Kuenen (1990), only approximately one third are to refereed primary sources. Similarly, the references cited in this review are predominantly in conference proceedings, because so little is published in refereed journals. This is most unusual in a scientific field and seems to reflect either its youth or a general lack of 
appreciation for the benefits of the peer-review system. Rigorous reviewing would undoubtedly benefit both the individual scientists and the whole research endeavor.

\section{Integration of biology with chemistry.}

The field of biodesulfurization has matured from one merely documenting a phenomenon to one hoping for commercial vindication in the near future. It is thus imperative that biologists collaborate with chemists to understand the total changes occurring during biological processing. Unfortunately this is not yet the norm. Very few papers attempt a realistic chemical analysis of the coal before and after desulfurization, and there has been little work to determine the heating value of the microbially treated coal to determine whether there has been any serious oxidation of the organic part of the coal during the process. As discussed by Friedman (1990) in a recent polemic, coal is notorious for binding adventitious material, and very careful analysis is required to ensure that desulfurization has indeed occurred, rather than merely dilution by adsorption. Integrating the best biological approaches with the best chemical and spectroscopic analyses is a sine qua non for future progress.

\section{Mass transfer issues.}

Little work has been directed at understanding the issues of a biological process interacting with either a solid (coal) or immiscible (oil) substrate on an industrial scale. Coal is typically ground to a small particle size, but what are the operating limitations imposed by particle size? What are the potentials for large scale operation? Do the microbes have to have a close physical contact with the substrate, or are soluble extracellular enzymes involved? Similar questions are applicable to desulfurizing oil; how will the oil be presented to the microorganisms?

\section{Separation of biomass from the fuel.}

The goal of biodesulfurization is to remove sulfur from the fuel stock so that combustion does not result in the production of sulfur oxides. If the biological process removes the sulfur from the organic matrix of the fuel but incorporates it into biomass that cannot then be separated from the fuel, no progress has been made.

\section{Forms of disposal.}

The commercialization of any desulfurization process will have to include the environmentally sound disposal of the sulfur removed from the fuel, yet little work has addressed this problem. The release of soluble sulfate into the environment on a large scale is unlikely to be acceptable, and of course it is the limitation of gaseous emissions which is driving the desulfurization in the first place. Perhaps the solution is to make gypsum and store it back in the mines from which the coal was removed, but in any case the environmentally sound and economic disposal of the removed sulfur should have a very high priority. 
An initial commercialization.

As discussed above, the fossil fuel industry is a well-integrated mature edifice which does not yet see the commercial possibility of biological processes, except in waste-treatment. Furthermore, biological processes are unlikely to be so dramatically cost-effective that they will replace current technologies. What is possible, however, is that a biological process can be added to current technology for a small gain. If this could be achieved it would be much more likely that step-out biological technologies would be accepted. So what is needed is a small success. Debus (1990) has discussed this, and it warrants further discussion and work. Some progress is being made in Europe (Bos et al., 1990), but success is by no means assured. As discussed above, if utility companies make substantial investments in scrubbers in the near future, progress in desulfurization for power generation will be somewhat moot.

\subsection{RECOMMENDATIONS AND PRIORITY STATUS.}

The section above has discussed some of the research needs for the near future. Some are simple for DOE to implement, such as requiring publication in refereed journals as part of documented progress. Others are underway, such as new approaches to understanding the forms of organic sulfur in complex materials, and DOE can encourage this by its support of the synchrotron resources and of those groups doing the work. It should also encourage the interaction of these groups and of other analytical spectroscopists, with biologists and fuel scientists.

Other decisions will be harder to make but should reflect a more realistic approach to what is needed for commercialization. It is unlikely that genetically engineered organisms or isolated enzymes will have any role to piay in viable technologies in the near term because of their inherent fragility. This does not mean that work on such systems is not of value in the basic understanding of the process, but rather that the research should be directed at this fundamental understanding, rather than at a dubious possibility of a worthwhile process. Similarly, there is no point in designing reactors or treatment regimes if the fundamental fuel value of the bioprocessed material has not been characterized.

A number of initial "milestones" must occur prior to developing cost-effective and performance-effective fossil fuel desulfurization biocatalysts. In the near term, research should be focused to the following goals:

- Isolation of definitive microorganisms which possess the biochemical ability to abstract organosulfur from target fossil fuels without downgrading the fuel value.

- Establish the absolute chemistry of pathways involved in organosulfur abstraction from target fossil fuels.

- Determine the enzymology involved in the organosulfur abstraction pathway.

- Identify the genetic determinants which encode these enzymes and their regulation. 
Once these basic mechanisms are established in fact, not fancy, it is possible to consider commercial potential and to initiate development strategies relevant to strain(s) improvements, isolation of specific genes, gene cloning, gene amplification and consideration of alternate hosts and expression systems which will improve the overall process efficiencies and economics. The development of production strain(s) requires an exhaustive database to insure biological reliability/fidelity with the production strain(s) and absolute genetic stabilities. The processing of high-sulfur coals or oils to low-sulfur products is a large volume process technology where residence time and stability of the biocatalyst become parameters of importance.

The bioprocessing of fuels is on the horizon; it will be the research of the next decade that will decide whether it will be commercialized or fade as an unattainable dream.

The priority status of R\&D initiatives in fossil fuels (oil and coal) biodesulfurization is longterm. The following recommendations specify initiatives which will place this important technology development on a scientifically rigorous foundation.

- Accelerate R\&D efforts in the analytical characterization of organosulfur in complex fossil fuels.

- Develop programs into the basic physiology and biochemistry of microbial interactions with high-sulfur coals and oils. The major objectives are to establish large culture collections of aerobic and anaerobic microorganisms that upgrade fossil fuels through biodesulfurization, biodenitrogenation, bioleaching, biodeashing and bioliquefaction and are available to the scientific community.

- Correlate the physical/chemical forms of organosulfur existing in fossil fuels to specific biological systems that catalyze "biodesulfurization". It is essential to understand whether a biodesulfurization process can potentially remove all organosulfur in a fossil fuel, or only specific species.

- Foster R\&D programs that integrate biology with chemistry.

- Establish the absolute chemistry and enzymology involved in microorganisms which catalyze beneficial reactions.

- Evaluate biobeneficiation of high-sulfur coals and oils with defined solvent-tolerant microorganisms where biocatalysis proceeds in an organic solvent reaction medium.

- Evaluate "soluble coal" for large volume bioprocessing of coal. Enzymatic reactions involving hydrogenase in a hydrogen atmosphere solubilize bituminous and subbituminous coals.

- Address technical issues concerning mass transfer on industrial scales, and separation of biomass from the fuel. Immobilized desulfurization biocatalysts functioning in a 
$100 \%$ organic solvent-based reaction medium may prove beneficial to bioprocessing strategies.

- Design new bioreactor systems consisting of immobilized biocatalysts which function in $100 \%$ organic solvent systems.

- Develop strategies for disposal of sulfur wastes that will be generated in large scale biodesulfurization technologies.

Table 1.

ORGANIZATIONS PURSUING WORK ON BIODESULFURIZATION OF FUELS IN THE USA, BASED ON RECENT PUBLICATIONS

ARCTECH

Brookhaven National Laboratory

Bruceton Research Center

DynaGen Inc.

Idaho National Engineering Laboratory

Institute of Gas Technology, Chicago

J.K. Research, Bozeman, MT

Johns Hopkins University

Montana College of Mineral Science and Technology Debus, 1990

New York State University, Buffalo

Northeastern University

Oak Ridge National Laboratory

Ohio State University

Pittsburgh Energy Technology Center

Purdue University

Southern Illinois University, Carbondale

State University of New York, Binghamton

Texas A\&I University

University of Colorado at Colorado Springs

University of Kentucky

University of Mississippi

University of Southern California

University of Tulsa

Virginia Polytechnic Institute and State University

Washington University, St Louis

Kargi, 1987
Harding et al., 1990

Krishna and Francis, 1988

Hyman et al., 1990

Nochur and Kitchell, 1990

Roberto et al., 1990

Kilbane, 1990

Runnion and Combie 1990

Peeples et al., 1990

Andrews et al., 1989

Ngaisa and Wise, 1988

Faison et al., 1990

El Zeky and Attia, 1986

Hyman et al., 1990

Narayan and Ho, 1988

Clark, 1989

Lazaroff et al., 1990

Rai, 1986

Schwartz et al., 1990

Huggins et al., 1990

Ward et al., 1990

Lee and Yen, 1988

Sublette, 1988

Yoon et al., 1990 
Table 2

\section{COUNTRY OF OQRIGIN OF REPRESENTATIVE WORK ON BIODESULFURIZATION $\mathrm{OF}$ FUELS OTHER THAN THE USA}

$\begin{array}{ll}\text { Bulgaria } & \text { Groudev and Genchev (1979) } \\ \text { Canada } & \text { Bhadra et al. (1987) } \\ \text { Germany } & \text { Uhl et al. (1990) } \\ \text { India } & \text { Chandra et al. (1980) } \\ \text { Italy } & \text { Pietropoaolo (1990) } \\ \text { Korea } & \text { Kim et al. (1990) } \\ \text { Netherlands } & \text { Boogerd et al. (1990) } \\ \text { People's Republic of China } & \text { Xu et al. (1990) } \\ \text { Poland } & \text { Gawdzik and Farbiszewska-Bajer (1990) } \\ \text { Sweden } & \text { Olsson et al. (1989) } \\ \text { Turkey } & \text { Ozcengiz et al. (1988) } \\ \text { USSR } & \text { Zarubina et al. (1959) } \\ \text { Yugoslavia } & \text { Vrvic et al. (1988) }\end{array}$

Table 3.

REPRESENTATIVE PATENTS CLAIMING BIODESULFURIZATION

Desulfurization of coal.

US Patents

Madgavkar, A.M.

Steven, S.E. and Burgess, W.D.

Isbister, J.D.

Atia, Y.A. and Elzeky, M.A.

Kopacz, E.P.

International Patents

Whellock, J.G. and Goodbody, J.

Adami, M., DiGiorgio, G. and Levi, G.

Combustion Engineering Inc.

Shell

SOHIO

ARCTECH

Ohio State U.

ARCO
(1989) US 4861723

(1989) US 4851350

1989) US 4808535

(1988) US 4775627

(1986) US 4632906

(1990) GB 2225256

(1989) EP 341222

(1988) EP 244659

Desulfurization of Petroleum.

US Patents

Hitzman, D.O.

Zobell, C.E.

Strawinski, R.J.

International Patents

Pifferi, P.G., Iranzarini, G., Matteuzzi, D.,

Zecchin, A. and Leoncini, S.

Kim, B.H., Kim, T.S. and Kim, H.Y.

Cosmo Shokuhinin

Eckart, V., Hieke, W., Koehler, M.,

Genz, I., Bauch, J. and Gentzsch, H

Phillips

Texaco

Texaco

Enichem

(1989) EP 401922

(1989) EP 323748

(1987) JP 62106822

VPS

(1981) DD 147365 


\section{Chapter 5}

\section{BIOCONVERSION OF COAL AND LIGNITE PYROLYSIS GAS AND WASTE STREAMS}

\section{$5.1 \quad$ INTRODUCTION.}

Coal, which is aerived from lignin, is largely recalcitrant to direct anaerobic mineralization, presumably because of its high molecular weight property (Zeikus, 1981; Zeikus et al., 1982). Therefore, coal must be significantly solubilized before it can be a substrate for bioprocessing. High temperature gasification of coal or lignite produces gas mixtures with high concentration and yields of $\mathrm{CO}, \mathrm{H}_{2}$, or $\mathrm{CO}_{2}$. Typical raw gas compositions and gasification (energy) efficiencies of oxygen or steam blown coal gasifiers are shown in Table 1 . Syngas (i.e., $\mathrm{CO}$ plus $\mathrm{H}_{2}$ ) can be readily and inexpensively converted to methanol by copper-zinc chromite-containing catalysts (Collman and Hegedus, 1980). Thus, $\mathrm{CO}, \mathrm{H}_{2}$, and $\mathrm{CH}_{3} \mathrm{OH}$ are the inexpensive and principal coal derived substrates for either microbial or chemical conversion to higher value products (Zeikus, 1980; Datta and Zeikus, 1983).

Table 1

GAS COMPOSITION AND EFFICIENCY OF COAL GASIFICATION

\begin{tabular}{|c|c|c|}
\hline Gasifier & Shell-Koppers & BGC Lurgi \\
\hline Feed & Ill. \#6 Coal & Ohio \#9 Coal \\
\hline Gasification Temperature & $1500-1800^{\circ} \mathrm{C}$ & $1100-1900^{\circ} \mathrm{C}$ \\
\hline \multicolumn{3}{|c|}{ Raw Gas Composition (vol. \%) } \\
\hline $\mathrm{CO}$ & 65.0 & 55.5 \\
\hline $\mathrm{H}_{2}$ & 32.1 & 28.3 \\
\hline $\mathrm{CO}_{2}$ & 0.8 & 5.1 \\
\hline $\mathrm{CH}_{4}$ & -- & 6.3 \\
\hline $\mathrm{C}_{2} \mathrm{H}_{4}$ & -- & 0.1 \\
\hline $\mathrm{C}_{2} \mathrm{H}_{6}$ & -- & 0.4 \\
\hline $\mathrm{N}_{2}$ & 0.5 & 4.0 \\
\hline $\mathrm{H}_{2} \mathrm{~S} \mathrm{COS}$ & 1.4 & 2.0 \\
\hline $\mathrm{H}_{2} \mathrm{O}$ & -- & -- \\
\hline \multicolumn{3}{|l|}{ Cold Gas Thermal } \\
\hline Efficiency \% & 83. & $76-85$ \\
\hline
\end{tabular}

From Datta and Zeikus (1982). 
The commercial Monsanto process chemically converts methanol and carbon monoxide to acetic acid on homogenous catalysts. The conversion of syngas to methane and higher hydrocarbons (Fischer Tropsch) occurs in the presence of iron-cobalt or nickel containing catalysts. Chemical catalysts require expensive sulfur removal from syngas to a parts per million level (Rostrup-Nielsen, 1971) while anaerobic microorganisms are unaffected by $\mathrm{H}_{2} \mathrm{~S}$ and carbonyl sulfide (COS) at parts per hundred or roughly the gas composition of sulfur in raw synthesis gas. Thus, microbes could use raw synthesis gas as a carbon and energy source without expensive sulfur removal. Microbes would further consume the sulfur for cell carbon synthesis.

Both aerobic and anaerobic microorganisms consume syngas and methanol as carbon and energy sources for growth. Aerobes convert these coal derived substrates into cell biomass which in itself cannot economically compete with soy beans as a protein product. Bioconversion of syngas to specialty chemicals is not a target because such chemicals are expensive and technology for their production from glucose is economical. Commodity chemicals have moderate value and they are a biotechnology target for syngas bioconversion because syngas is considerably cheaper than glucose per pound. Anaerobes can convert syngas and methanol to methane and/or several organic acids and alcohols which are commodity products with large volumes and require a substrate less expensive than glucose for manufacturing.

Methanogenic and acetogenic bacteria grow and conserve energy on these simple substrates as a consequence of favorable chemical thermodynamics (Thauer et al., 1977) and their unique metabolic machinery (Zeikus, 1983a; 1983b; Datta and Zeikus, 1983; Zeikus et al., 1985). Biomethanation of syngas (i.e., the biological conversion of $\mathrm{CO}+\mathrm{H}_{2}$ into $\mathrm{CH}_{4}+\mathrm{CO}_{2}$ ) upgrades the BTU content of the gas and removes toxic CO (Wise et al., 1978). Bioconversion of syngas and methanol to certain organic acid and alcohol feedstocks is thermodynamically feasible and can be achieved in high molar conversion efficiencies.

The higher value organic chemical feed stocks derived from anaerobic bacterial growth on $\mathrm{H}_{2} / \mathrm{CO}_{2}, \mathrm{CO}$ and $\mathrm{CH}_{3} \mathrm{OH}$ (i.e., unicarbonotrophy) include: $\mathrm{CH}_{4}$, acetic and butyric acids, ethanol and butanol and organic esters chemically derived from these acids and alcohols (or methanol). These feedstocks can be used in a variety of products including: butanol, ethanol or methylbutyrate as octane enhancers for liquid fuel additives; calcium magnesium acetate as biodegradable and non-corrosive road salt (a mixture of acetic acid and dolomite); direct commodity chemical uses of these feedstocks; use of methane as natural gas; and, specialty chemicals such as the microbial cells for animal feed additives high in vitamin $B_{12}$ content.

Anaerobic fermentation technology for deriving these higher value products from syngas and methanol is not yet economical because of present microbiological and engineering research shortcomings. First, a lack of robustness of the present microbial strains (i.e., they are not yet improved to the industrial grade level in terms of final product concentration and chemical yield). This requires further biocatalyst development. Second, high productivity reactors for bioconversion of gases and cost-effective product recovery systems for organic 
acid and alcohol removal from dilute aqueous streams are just now emerging process development arenas for fermentation technology.

Associated with coal gasification are high strength waste waters and blow down from cooling towers and boilers. The composition in these high strength waste waters includes: oils, phenols, $\mathrm{H}_{2} \mathrm{~S}, \mathrm{NH}_{3}, \mathrm{SO}_{4}, \mathrm{HCN}$, and diverse soluble polyaromatic hydrocarbons. These waste streams are amenable to both aerobic and anaerobic biological waste treatment systems. Anaerobic biotreatment systems, unlike aerobic processes, do not produce high sludge levels that require further treatment. Furthermore, anaerobic treatment yields the by-product methane as a vendable energy source and is less energy and capital intensive than aerobic biotreatment processes; however, anaerobic degradation requires advanced reactor designs and control and monitoring systems for the more sensitive biocatalysts.

\section{SUMMARY.}

Coals and lignites are readily and economically gasified to syngas and further industrially converted into methanol and acetic acid via chemical catalysis. During the gasification process high strength phenol wastewaters are also generated. Thus, simple coal pyrolysis feedstocks (i.e., $\mathrm{CO}, \mathrm{H}_{2}, \mathrm{CO}_{2}$, and $\mathrm{CH}_{3} \mathrm{OH}$ ) and the derived wastewaters are substrates for further bioconversion to higher value products and waste bioremediation by anaerobic microorganisms. The higher value products include: liquid fuel additives, noncorrosive road salt, commodity chemicals, natural gas and specialty feed additives and vitamins. Figure 1 presents an overall scheme for bioconversion of coal gasification products and wastes. Research to date has established the feasibility that novel anaerobic biocatalysts can derive energy from conversion of coal gasification feedstocks and wastes into diverse higher value products, methane and $\mathrm{CO}_{2}$. Considerably more work on biocatalyst development and process development is required before an economical and environmentally sound biotechnology exists to utilize coal and lignites in this manner.

\subsection{STATUS OF BASIC AND APPLIED RESEARCH.}

\section{BACKGROUND.}

Diverse species of acetogenic and methanogenic bacteria have been described that grow on $\mathrm{CO}, \mathrm{H}_{2}-\mathrm{CO}_{2}$ or methanol. Basic research has defined the general metabolism and biochemical routes for conversion of these single carbon substrates to methane, organic acids or alcohols. Applied studies have demonstrated fermentation process feasibility for conversion of syngas (i.e., $\mathrm{CO}+\mathrm{H}_{2}$ ) or $\mathrm{CO}$ to methane by pure cultures and consortia or into organic acids and alcohols by pure culture. Consortia have been developed which can degrade a variety of phenolic wastes including those derived from coal gasification. A granular activated carbon-based fluidized bed reactor with an anaerobic bacterial mixed culture biofilm has been tested on coal gasification wastewaters. 
Substrate

Coal

Lignites
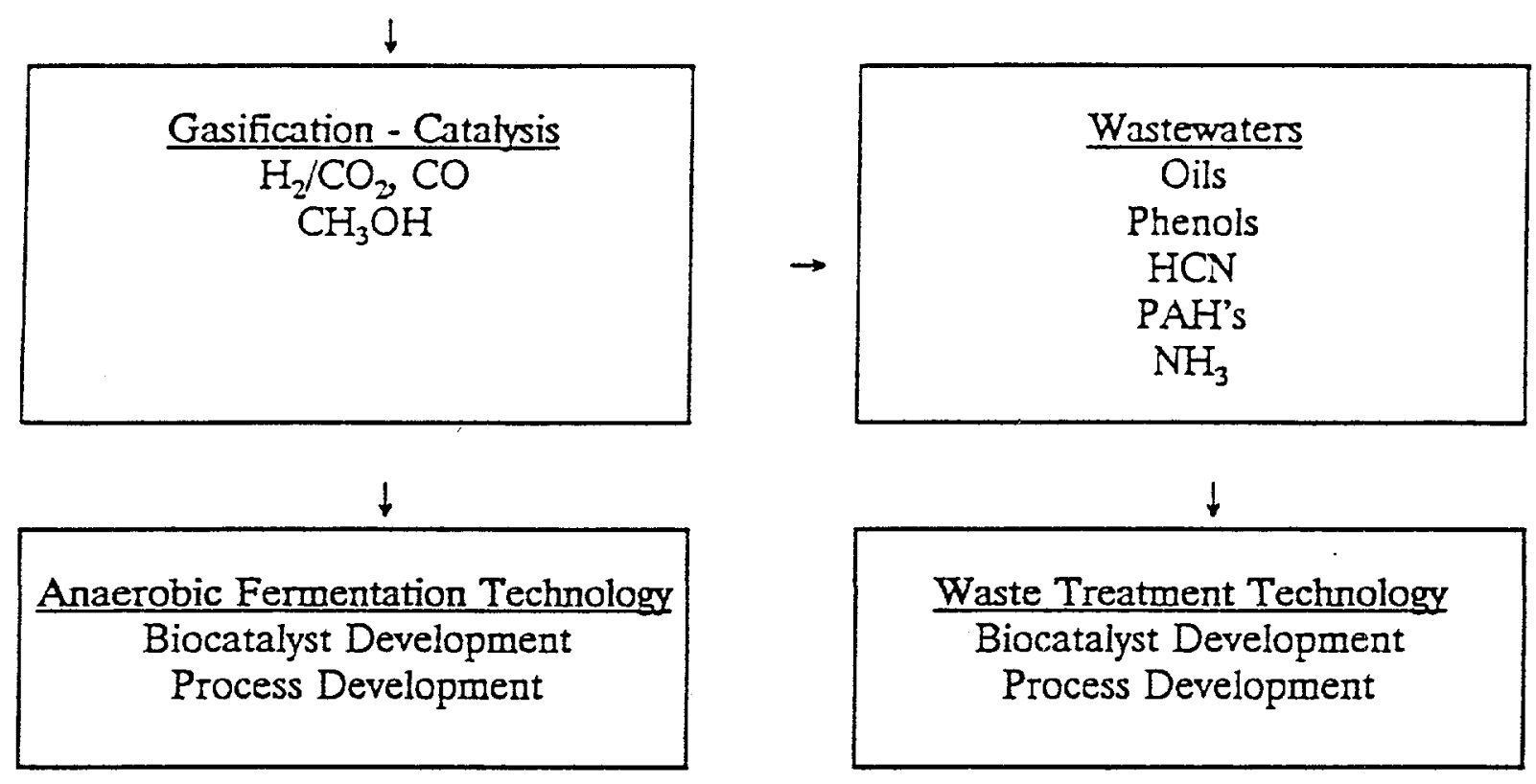

$\downarrow$

Organic Chemical Feedstocks

Solvents

Acids

Esters

Methane

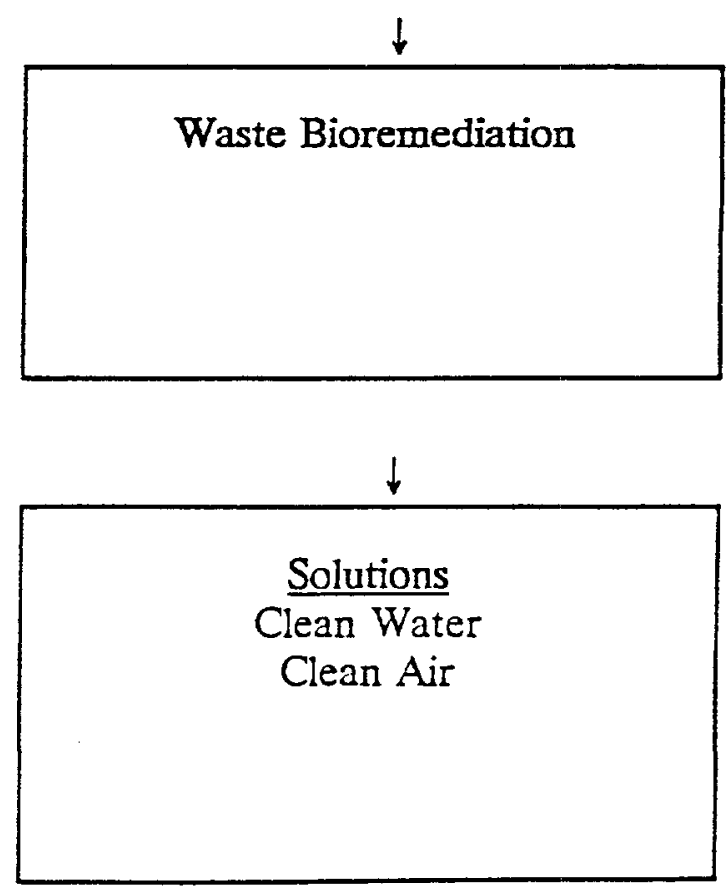

Bioconversion of Coal and Lignite to Higher Value Products with Waste Stream Bioremediation.

Figure 1 


\section{CURRENT RESEARCH STATUS.}

Basic research on anaerobic methanol and syngas fermentations is being undertaken at MSU/MBI (Jain, Zeikus and colleagues on methanogens and acetogens). Basic research on the biochemistry of $\mathrm{CO}$ and methanol conversion to acids or alcohols by the University of Georgia (Ljungdahl), Case Western Reserve (Wood), and MSU/MBI (Zeikus and Jain), work on the genetics and biochemistry of $\mathrm{CO}$ conversion to acetic acid is under study at the University of Wisconsin (Ragsdale). The biochemistry of syngas conversion to methane is under study at MSU as well. Several other labs are studying the CO dehydrogenase and hydrogenase of methanogens (Ferry, VPI; Daniels, University of Iowa; Reeves and Krzycki, Ohio State University). Basic research on the microbiology of anaerobic phenol degradation is under study in many other laboratories (see Chapter 6).

Applied research on the conversion of $\mathrm{CO}$ or syngas to octane enhancers is being performed at the University of Arkansas for ethanol production (Gaddy) and at MBI butanol and ethanol or methylbutyrate (Jain, Worden and Datta). These same workers are working on syngas fermentations for organic acid and non-corrosive road salt products. Applied research on biomethanation of phenolic wastes is carried out by Young at New York University and Grbic'-Galic' of Stanford University (see Chapter 6). Work on anaerobic reactors for degradation of phenolic coal wastes is being done by Suidan (University of Cincinnati) and Pfeffer (University of Illinois).

\section{BASIC.}

Table 2 summarizes the diversity of anaerobic bacteria which metabolize CO. Carbon monoxide metabolism by anaerobic bacteria has been documented for Rhodopseudomonas gelatinosa (Uffen, 1976), four species of Clostridia, Clostridium thermoaceticum and $\mathrm{Cl}$. formicoaceticum (Diekert et al., 1985; Kerby and Zeikus, 1983), Cl. pasteurianum (Fuchs et al., 1974) and Cl. ljungdahlii (Barik et al., 1988; Tanner and Yang, 1990), Butyribacterium methylotrophicum (Lynd et al., 1982), Acetobacterium woodii (Kerby et al., 1983), Eubacterium limosum (Genthner and Bryant, 1982), Peptostreptococcus productus (Lorowitz and Bryant, 1984), and several methanogens (Klyuver and Schnellen, 1947; Daniels et al., 1977; O’Brien et al., 1984).

Some of these organisms such as B. methylotrophicum, E. limosum, $P$. productus, $C$. thermoaceticum, C. ljungdahlii, and Methanosarcina barkeri have the ability to utilize $\mathrm{CO}$ as energy source while others such as $C$. pasteurianum can metabolize $\mathrm{CO}$ but growth occurs only in the presence of additional energy sources. B. methylotrophicum was isolated from a sewage digester in Marburg, Federal Republic of Germany. Initially the Marburg strain did not grow on $\mathrm{CO}$ alone but did consume $\mathrm{CO}$ during growth on a variety of substrates in the presence of a $100 \%$ CO gas phase. However, Lynd et al. (1982) selected a strain (CO strain) that grew vigorously on $\mathrm{CO}$ alone. The ability of the $\mathrm{CO}$ strain to grow on $\mathrm{CO}$ was stable through multiple transfers in the absence of $\mathrm{CO}$. A sheep rumen isolate, E. limosum, 
Table 2. Carbon Hitonoxide Uilizing Anaerobic Bacleria

\begin{tabular}{|c|c|c|c|c|c|}
\hline Organism & Subsliales & $\begin{array}{c}\text { CO Fermenlation } \\
\text { Producls }\end{array}$ & Isolation/l labilals & $\begin{array}{c}\text { Optimum } \\
\text { Growli Condilions }\end{array}$ & Relerences \\
\hline $\begin{array}{l}\text { Rhodopseudomonas } \\
\text { gelotinosa (now } \\
\text { Rlodocyclus } \\
\text { gelalinosus) }\end{array}$ & $\begin{array}{l}\text { CO, pyruvale, glucose, } \\
\text { Iruclose }\end{array}$ & $\mathrm{CO}_{2}, \mathrm{H}_{2}$ & lake and pond sedimenls & $30^{\circ} \mathrm{C} . \mathrm{p} / \mathrm{6} .0 .8 .5$ & $\begin{array}{l}\text { Ullen, 1976; } \\
\text { Daschehvice and Ulien, } \\
1979\end{array}$ \\
\hline $\begin{array}{l}\text { Clostridium } \\
\text { thermoacelicum }\end{array}$ & glucose, $\mathrm{CO}_{2}+\mathrm{ll}_{2}, \mathrm{CO}$ & acelale, $\mathrm{CO}_{2}$ & horse mariure & $55 \cdot 60^{\circ} \mathrm{C}, \mathrm{p} / 17.0 \cdot 7.2$ & $\begin{array}{l}\text { Keiby and Zeikus, 1987. } \\
\text { Dickent and Ilwaer. } \\
1978\end{array}$ \\
\hline Cl. Iormicoacelicum & $\begin{array}{l}\text { Iruclose, ribose, } \\
\text { pyruvale, CO }\end{array}$ & acelale, $\mathrm{CO}_{2}$ & $\begin{array}{l}\text { sowage, pond and dilch } \\
\text { mud }\end{array}$ & $37^{\circ} \mathrm{C}, \mathrm{pH}$ 7.0.7.2 & $\begin{array}{l}\text { Dickell and Hiaver, } \\
\text { 1978; Andreesen el al, } \\
1970\end{array}$ \\
\hline Cl. paslauianum & glucose, pyuuvalo, CO & & soil & $37^{\circ} \mathrm{C} \cdot \mathrm{pH} 7.0 \cdot 7.2$ & Fuchis el al, 1974 \\
\hline Cl. ljungdalilii & CO, Irucloso & ellianol, acelale & chicken waslo & $37^{\circ} \mathrm{C}, \mathrm{p} / 14.0 .5 .0$ & $\begin{array}{l}\text { Barik el al, 1988; Veya } \\
\text { el al. } 1909\end{array}$ \\
\hline $\begin{array}{l}\text { Bulyribacierium } \\
\text { mellylolrophicum }\end{array}$ & $\begin{array}{c}\text { glucose, melhanol, } \\
\text { lormale, } \mathrm{CO}\end{array}$ & $\begin{array}{l}\text { acelale, bulyrale } \\
\text { bulanol, ellianol }\end{array}$ & sewage digestor & $37^{\circ} \mathrm{C}$, pll 7.0.7.2 & $\begin{array}{l}\text { Lynd el al . 1982; } \\
\text { Worden el al. 1989. } \\
\text { Grelldein el al. } 19(\mathrm{~m})\end{array}$ \\
\hline Acelobaclerium woodii & $\begin{array}{c}\text { luclose, glucose, } \mathrm{CO}, \\
\text { melhanol }\end{array}$ & acelale & $\begin{array}{c}\text { aqualic and marine } \\
\text { anaerobic sediments }\end{array}$ & $30^{\circ} \mathrm{C}, \mathrm{p} / \mathrm{l} 6.6 .6 .8$ & $\begin{array}{l}\text { Brown, 1987; Bikli el } \\
\text { al., } 1977\end{array}$ \\
\hline Eubacterium linosum & $\begin{array}{c}\text { glucose, methanol, } \\
\text { formale, CO }\end{array}$ & acelale, $\mathrm{CO}_{2}$ & sheep rumen & $37^{\circ} \mathrm{C}, \mathrm{p} / \mathrm{l} 7.0 .7 .2$ & $\begin{array}{l}\text { Genllmer and Biyanl. } \\
1982\end{array}$ \\
\hline $\begin{array}{l}\text { Peplosireplococcus } \\
\text { produclus }\end{array}$ & $\begin{array}{l}\text { glucose, fruclose, } \\
\mathrm{H}_{2}+\mathrm{CO}_{21} \mathrm{CO}\end{array}$ & acolale, $\mathrm{CO}_{2}$ & $\begin{array}{l}\text { sewage digeslor, luunan } \\
\text { colon and leces }\end{array}$ & $37^{\circ} \mathrm{C}$, pll 6.5.6.0 & $\begin{array}{l}\text { Lorowilz and Biyamil. } \\
\text { 1901; Geedlings el al., } \\
1987\end{array}$ \\
\hline Medhanosarcina barkeri & acelale, $\mathrm{II}_{2}+\mathrm{CO}_{2}, \mathrm{CO}$ & melhane, $\mathrm{H}_{2}$ & $\begin{array}{c}\text { sewage digeslor, animal } \\
\text { waste lagoons, } \\
\text { fresliwaler and maine } \\
\text { mud }\end{array}$ & $30.40^{\circ} \mathrm{C}, \mathrm{p} / 16.8 .7 .2$ & OBien el al., 198.1 \\
\hline $\begin{array}{l}\text { Alcllianobacleria } \\
\text { Hhermoautolrophicum }\end{array}$ & $\mathrm{II}_{2}, \mathrm{CO}_{2}, \mathrm{CO}$ & $\mathrm{CH}_{2}, \mathrm{H}_{2}$ & $\begin{array}{c}\begin{array}{c}\text { Houmal spilings } \\
\text { sewer }\end{array} \\
\end{array}$ & $70^{\circ} \mathrm{C} .10116 .0 .7 .2$ & Danicls el al. 1977 \\
\hline
\end{tabular}


which resembles $B$. methylotrophicum, is capable of growth on $\mathrm{CO}$ but its growth has not been tested beyond $75 \% \mathrm{CO}$ in the gas phase (Genthner and Bryant, 1982). P. productus $\mathrm{U}-1$ was isolated from an anaerobic sewage digestor; it grew rapidly with $\mathrm{CO}$ as the energy source. Recently, $\mathrm{Cl}$. ljungdahlii was isolated from chicken waste; it metabolized $\mathrm{CO}$ at a lower $\mathrm{pH}$ (Vega et al., 1989).

Anaerobic $\mathrm{CO}$ fermentations are preferable for the production of relatively reduced biochemicals, since no available electrons are lost to oxygen. These fermentations typically yield carbon dioxide, cell mass, and a relatively reduced product such as $\mathrm{CH}_{4}, \mathrm{H}_{2}$, acetate, or butanol. Among the anaerobic microorganisms able to metabolize $\mathrm{CO}, B$. methylotrophicum is noteworthy because of its metabolic diversity. Prolific growth with carbon monoxide as the only apparent source of carbon and energy qualitatively distinguishes $\mathrm{CO}$ utilization by $B$. methylotrophicum from $\mathrm{CO}$ utilization by methanogens and CO-utilizing clostridia. The principal difference between the $\mathrm{CO}$ metabolism of $B$. methylotrophicum and $R$. gelatinosa is that acetate is the principal reduced catabolic product in the former, whereas the latter forms $\mathrm{H}_{2}$ (Uffen, 1976; Lynd et al., 1982). B. methylotrophicum can convert $\mathrm{CO}$, as the sole carbon and energy source, to either acetate or butyrate. The ratio of acetate to butyrate produced during the stationary phase can be controlled by $\mathrm{pH}$ (Worden et al., 1989). This organism has also been shown to produce butanol and ethanol directly from CO (Grethlein et al., 1990). The doubling time of $B$. methylotrophicum on $100 \% \mathrm{CO}$ is about 12 hours (Lynd et al., 1982).

$P$. productus strain U-1, isolated from an anaerobic sewage digestor (Lorowitz and Bryant, 1984), grows rapidly with $\mathrm{CO}$ as the energy source. The doubling time with up to $50 \% \mathrm{CO}$ was 1.5 hours with acetate and carbon dioxide as the major products. The production of acetate and carbon dioxide during growth with $\mathrm{CO}$ yielded a stoichiometry similar to that reported for other acetogenic CO-utilizers (Fuchs et al., 1990; Lynd et al., 1982):

$$
4 \mathrm{CO}+4 \mathrm{H}_{2} \mathrm{O} \rightarrow 2 \mathrm{HCO}_{3}^{-}+\mathrm{CH}_{3} \mathrm{COO}^{-}+3 \mathrm{H}^{+}
$$

with a $\Delta \mathrm{G}=-165.4 \mathrm{KJ}$ per reaction. Tolerance to levels of $\mathrm{CO}$ of up to $90 \%$ were achieved at the expense of a higher concentration of yeast extract in the medium. $P$. productus requires methionine in much higher quantity (medium containing $0.01 \%$ yeast extract) than other amino acids for complete utilization of $\mathrm{CO}$ present in the culture flask (Vega, 1989). Another strain of $P$. productus, strain Marburg, was also isolated from a sewage digester. It grew on $\mathrm{CO}(50 \%$ at $200 \mathrm{kPa})$ as the sole energy source with a doubling time of 3 hours (Geerligs et al., 1987). The carbon monoxide was converted to acetate and carbon dioxide. Optimal growth rates were observed with $50-70 \% \mathrm{CO}(200 \mathrm{kPa})$ while at higher concentrations the growth rate decreased.

C. ljungdahlii, originally isolated from chicken waste (Barik et al., 1988), produces ethanol from $\mathrm{CO}, \mathrm{CO}_{2}$, and $\mathrm{H}_{2}$ in the synthesis gas at low $\mathrm{pH}$. However, under optimal growth conditions, the organism produces acetate in favor of ethanol with acetate: ethanol product ratios as high as 20:1 (Vega et al., 1989). C. thermoaceticum was culturally adapted to grow 
on $\mathrm{CO}$ as the energy source (Kerby and Zeikus, 1983). E. limosum metabolizes $\mathrm{CO}$ as an energy source under low $\mathrm{CO}$ (below $0.75 \mathrm{~atm}$ ) partial pressures (Genthner and Bryant, 1982).

Acetogenic bacteria, which grow on $\mathrm{CO}$ as the sole energy source, contain carbon monoxide dehydrogenase $(\mathrm{CODH})$, and these bacteria have been used as a tool to understand the role of $\mathrm{CO}$ as the precursor for the synthesis of the carboxyl group of acetate. Carbon monoxide in a bound form (rather than formate) was suggested as an intermediate in the biosynthesis of the carboxyl group of acetate (Diekert et al., 1984, 1985, 1986; Zeikus et al., 1985; Fuchs, 1986). The function of $\mathrm{CODH}$ in acetogens in vivo appears to be more extensive than the oxidation of $\mathrm{CO}$ to $\mathrm{CO}_{2}$ (Kerby et al., 1983; Kerby and Zeikus, 1987; Lynd and Zeikus, 1983; Wood and Ljungdahl, 1991; Diekert and Ritter, 1983) as indicated by (1) in vitro results indicating that $\mathrm{CODH}$ is one component necessary for the conversion of methyl-THF and either $\mathrm{CO}$ or the carboxyl group of pyruvate into acetyl-CoA; (2) higher specific activities of the enzyme found when $B$. methylotrophicum was grown with methanol rather than $C O$ as the energy substrate and the presence of significant amount of the enzymes in all acetogens tested, regardless of the growth substrates; and (3) preferential in vivo incorporation of $\mathrm{CO}$ into the acetate carboxyl group by $A$. woodii and $B$. methylotrophicum. Furthermore, the effects of removal of nickel on the fermentation of fructose by $A$. woodii are consistent with a role for $\mathrm{CODH}$ in the synthesis of the acetate carboxyl group (Diekert and Ritter, 1983). Preliminary experiments with cell suspension of $P$. productus incubated in the presence of labelled $\mathrm{CO}$ and unlabelled $\mathrm{CO}_{2}$, or vice versa, indicated that this organism mediates the incorporation of $\mathrm{CO}$ in the free form into acetate (Diekert, 1987). Figure 2 summarizes the proposed path of $\mathrm{CO}$ conversion into acetate, butyrate, ethanol, and butanol by $B$. methylotrophicum and indicates the known microbial catabolic diversity for syngas and methanol conversion. Methanogens convert $\mathrm{CO}$ into $\mathrm{H}_{2}$ and $\mathrm{CO}_{2}\left(\mathrm{O}^{\prime} \mathrm{Brien}\right.$ et al., 1984; Krzycki et al., 1985; Bhatnagar et al., 1987) which is then converted to methane via the unique one carbon metabolism discovered by Stadtman, Wolfe and colleagues. This catabolic route involves methanopterin, coenzyme $\mathrm{M}$, and vitamin $\mathrm{B}_{12}$ (Zeikus et al., 1985; Bhatnagar et al., 1991).

Genetic studies aimed at cloning the genes for key enzymes involved in syngas and methanol metabolism in methanogens and acetogens have just been initiated. Methyl CoM reductase was cloned into $E$. coli from $M$. voltae (Konheiser et al., 1984), M. barkeri (Bokranz and Klein, 1987), and M. thermoautotrophicum (Bokranz et al., 1988). Reeve et al. (1989) have recently cloned genes encoding the methyl viologen reducing hydrogenase from $M$. thermoautotrophicum into $E$. coli. Cloning and expression of a gene cluster encoding key proteins involved in acetyl CoA synthesis in $C$. thermoaceticum including $\mathrm{CO}$ dehydrogenase has been reported by Roberts et al., (1989).

Obligate anaerobic bacteria which degrade phenolic components have not been isolated and described in pure culture. However, they have been detected in mixed methanogenic cultures (Grbic'-Galic', 1989; Bhatnagar et al., 1989). Aromatic compound degradation including benzoate metabolism by pure and mixed cultures of anaerobic bacteria has been reported (Haddock and Ferry, 1990; Fuchs et al., 1990; Young et al., 1988) (see Chapter 6.) 


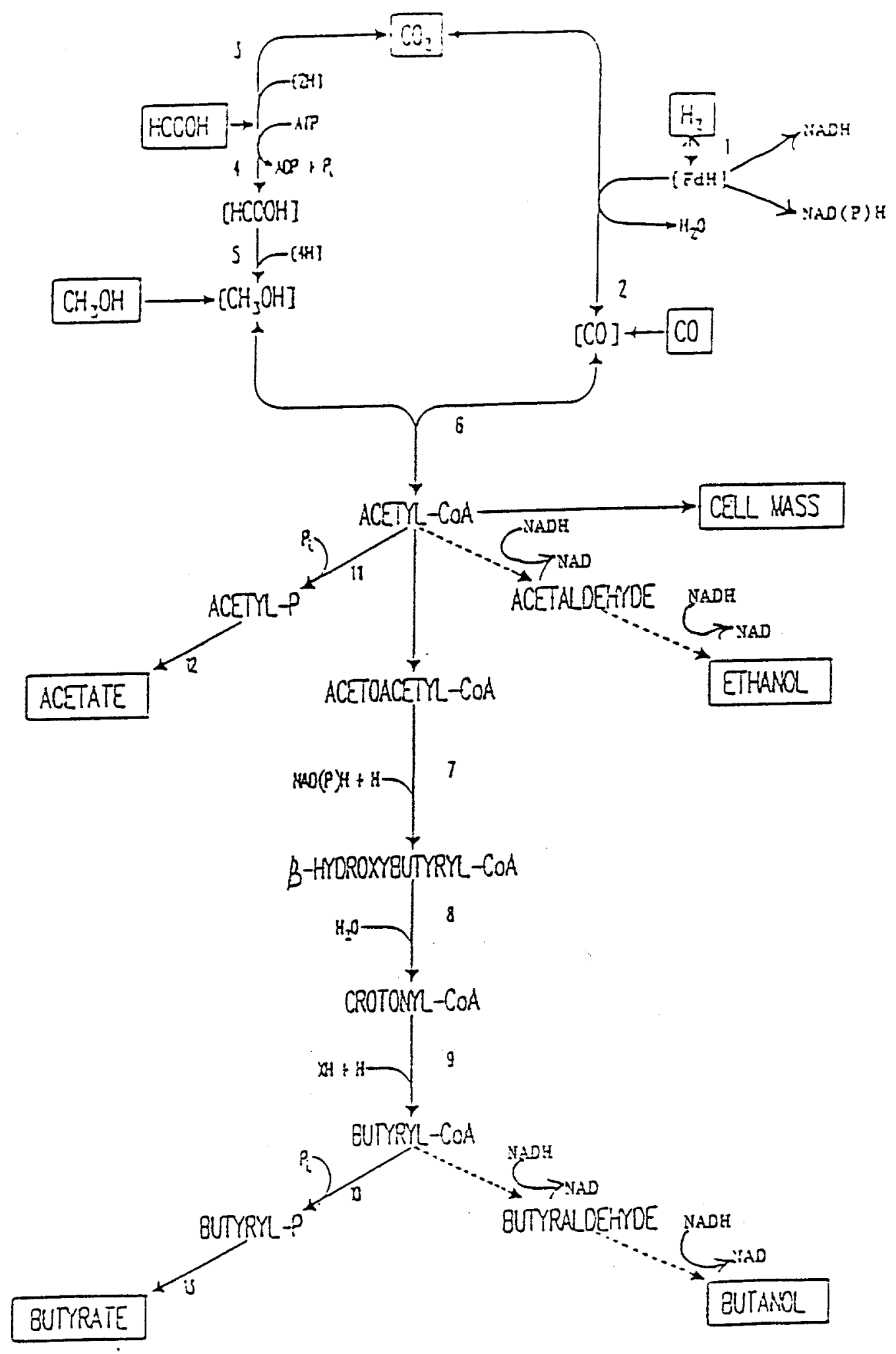

Figure 2 


\section{APPLIED.}

Syngas represents a cheap feedstock for microbial conversion to higher value commodity products. Specialty products are not a target for syngas fermentation because their higher price makes glucose a preferable substrate. Initial studies on syngas fermentation (Wise, $1978 ; 1983$ ) were focused on upgrading the BTU value of the gas and converting toxic CO into methane by mixed methanogenic cultures. Recent research on syngas biomethanation (Darek et al., 1990) have not focused on strain or reactor improvements but have shown that mixed methanogen cultures can convert over $90 \%$ of the $\mathrm{CO}$ and $\mathrm{H}_{2}$ into $\mathrm{CH}_{4}$ and $\mathrm{CO}_{2}$.

Current research is aimed at syngas fermentation to liquid fuel additives. The feasibility of ethanol production from syngas fermentation by C. ljungdahlii (Barik et al., 1990) and ethanol plus butanol production by B. methylotrophicum (Grethlein et al., 1990) has been established. However, chemical yields are low and the final concentration of alcohol is less than $1 \%$, making product recovery uneconomical.

Relatively little work has been done on the degradation of the phenolic wastes derived from coal gasification. Suidan et al. (1988) demonstrated that a granular activated carbon bed with a non-defined microbial biofilm could degrade greater than $70 \%$ of the phenolics in simulated coal gas wastes. Young et al. (1988) demonstrated the feasibility of a two-phase anaerobic-aerobic system for destruction of phenolic organics and $\mathrm{NH}_{3}$ in coal processing wastes.

Interestingly, UASB reactors which are in widespread industrial use for treatment of diverse organic wastes and, whose granular sludges can degrade phenolic compounds in olive processing wastes, pulp and paper wastes and even pentachlorophenol itself (Lettinga et al., 1980; 1983; Bhatnagar et al., 1989) have not been adapted to treatment of coal gasification wastes.

A need exists for new technology that removes sulfur and nitrogen oxides from concentrated flue gas streams and dilute gas streams. A biological approach to reducing these oxides has been shown to offer potential (Lee and Sublette, 1990 and 1991). A potential process is the simultaneous combined removal of $\mathrm{SO}_{2}$ and $\mathrm{NO}_{\mathrm{x}}$ from flue gas by contact with cultures of sulfate-reducing bacteria and Thiobacillus denitrificans as cultures-in-series or in coculture in a single contacting stage.

\section{FOREIGN RESEARCH INITIATIVES.}

Basic studies on anaerobic fermentation of syngas and methanol are taking place largely in Germany (Prof. Thauer, Marburg and Prof. Drake-Beyreuth and Prof. Deikert, Marburg) and the Netherlands (Prof. Vogels, Neijmegen and Prof. Harder, Gronigen). Applied research on anaerobic degradation of phenolic wastes is taking place in Germany (Prof. Schink, Tubingen) and in Japan (Aqua Renaissance Project, Fermentation Institute, Tscuba). Fermentation of syngas to higher value products is also taking place in Germany (Prof. 
Ringpfeil, Berlin). Anaerobic degradation of phenolics associated with coal processing wastes has been primarily studied in Alberta, Canada (Fedorak and Hrudey).

\section{COMMERCIAL DEVELOPMENTS.}

Aside from the suggestion to commercialize the fermentation of pretreated lignites into methane in underground salt caverns (Leuschner et al., 1990), no commercial activity on syngas fermentation processes for commodity chemicals production or anaerobic digestion systems for coal gasification have been reported. More microbiological and engineering research is needed before cost effective bioprocesses are developed for producing oxychemicals or fuels from syngas or in the bioremediation of coal gasification wastes.

\subsection{FUTURE RESEARCH DEVELOPMENT AND REQUIREMENTS.}

\section{RELEVANCE AND JUSTIFICATION.}

The use of coal and lignite derived synthesis gas as an industrial feedstock for chemical processing has provided an increasingly attractive alternative to present petroleum-based oxychemicals production stemming from recent developments in $C_{1}$ chemistry and gasification technology. One of the major drawbacks with utilizing coal-derived gases for chemical and fuel production is the required removal of catalyst poisons such as hydrogen sulfide $\left(\mathrm{H}_{2} \mathrm{~S}\right)$, carbonyl sulfide (COS), and other trace contaminants from the synthesis gas. The levels of sulfur gases are relatively high, and these gases must be removed prior to catalytic conversion. These purification steps are energy intensive and add significantly to the product costs, particularly for coals having a high sulfur content (Wilson et al., 1988).

Biological conversion of synthesis gas offers some key advantages over more conventional chemical processing routes. Anaerobic bioconversion conserves the energy content of the synthesis gas and converts it into longer chain oxychemicals. The most attractive advantage is that sulfur-gas removal will not be required. With highly sulfur-tolerant microorganisms, the $\mathrm{H}_{2} \mathrm{~S}$ and $\mathrm{COS}$ gases will pass through the process as inert components. Thus, the capital and operating costs associated with conventional gas separation and upgrading equipment could be avoided. If need be, $\mathrm{H}_{2} \mathrm{~S}$ and $\mathrm{COS}$ can be removed from the waste gas after the $\mathrm{CO}$ and $\mathrm{H}_{2}$ have been reacted. Because a smaller volume of more concentrated gas would remain, the cost of sulfide removal will be reduced. Catalytic processing often requires strict $\mathrm{CO} / \mathrm{H}_{2}$ ratios in the synthesis gas to maintain a particular product mix, necessitating gas recompression and shift reaction conversion operations. Because the $\mathrm{CO} / \mathrm{H}_{2}$ ratio is not a key factor in biological conversion with respect to product formation, gas-shift operations would be unnecessary. As with most biological reactions, $\mathrm{CO}$ fermentations exhibit a high degree of selectivity and efficiency and occur at relatively low temperatures and pressures, at least an order of magnitude less than in conventional gas-phase catalysis. The milder processing conditions may reduce both operating and capital costs. These key advantages distinguish the biological synthesis gas conversion concept and offer a unique and important niche for production of liquid fuels via fermentation of coal-derived synthesis gas. 
Anaerobic digestion of high strength organic wastewaters is superior to aerobic bioprocessing of wastewaters because it generates less sludge for disposal, is less capital intensive, and yields energy as methane instead of requiring energy for aeration. An aerobic step is necessary in addition to an anaerobic step to convert $\mathrm{NH}_{3}$ to $\mathrm{N}_{2}$ and to degrade some recalcitrant polyaromatics present in the coal gasification wastewaters. The future switch from a petroleum to a coal-based feedstock for chemicals and energy production in the United States will demand environmentally sound bioprocessing of waste streams regardless if syngas fermentations are used for the production of higher value oxychemicals and fuels.

\subsection{RESEARCH NEEDS AND LIMTTATIONS.}

\section{APPLIED.}

\section{BIOCATALYST DEVELOPMENT.}

1. Microbiological and genetic strain improvements of model syngas and methanol consuming anaerobes that form organic acids and alcohols aimed at production of higher yields and concentrations of end product.

2. Isolation and characterization of new organic acid and alcohol producing bacteria from acidic marine and hypersaline environments that grow at high salt and low $\mathrm{pH}$. Strains that grow at high salt could produce higher concentrations of organic acid salts to aid in product recovery. Strains that grow at, low $\mathrm{pH}$ would favor higher alcohol yields and concentrations.

3. $\mathrm{H}_{2}$ itself is not a useful product for $\mathrm{CO}$ bioconversion as it has less value than methane or organic molecules and has low BTU content.

4. Development of active anaerobic consortia that degrade coal gasification wastes and which form either a stable granular sludge or a stable biofilm on sand or activated carbon.

\section{BIOPROCESS DEVELOPMENT.}

1. Two-phase systems for biomethanation of syngas. This can be achieved by coupling a first-phase conversion of $\mathrm{CO} \rightarrow \mathrm{H}_{2}+\mathrm{CO}_{2}$ by non-methanogens to a second phase conversion of $\mathrm{H}_{2}+\mathrm{CO}_{2} \rightarrow \mathrm{CH}_{4}$ by methanogens. This would overcome the inhibition of methanogens by high $\mathrm{CO}$ levels.

2. Two-phase systems for conversion of syngas to alcohols (see Figs. 3 and 4). This can be achieved by coupling a first-phase conversion of $\mathrm{CO}$ to organic acids by acetogens (e.g., B. methylotrophicum) to a second-phase conversion of organic acids plus $\mathrm{H}_{2}$ into alcohols by solventogens (eg., C. acetobutylicum). This may work because $C$. acetobutylicum readily converts $\mathrm{H}_{2}$ and acetate and butyrate into ethanol and butanol and has high $\mathrm{CO}$ tolerance (Kim et al., 1984; Kim and Zeikus, 1985). Thus, C. acetobutylicum would be coupled to consume the excess 
organic acids produced from syngas by B. methylotrophicum and this would result in net higher yields of alcohol and decreased levels of organic acid byproducts.

3. Develop co-culture systems for improved alcohol production from syngas using co-cultures of $B$. methylotrophicum and $C$. acetobutylicum for ethanol and butanol production or $C$. ljungdahlii and $C$. beijrienkia for ethanol and isopropąnol production.

4. Integration of syngas fermentation processes for organic acid and alcohol production with continuous removal of organic acids by membrane electrodialysis systems or with continuous removal of alcohol by using a membrane-based perevaporation system coupled to IHSOR advanced distillation technology for energy efficient recovery of $100 \%$ alcohol at $1 \%$ fermentation broth concentrations.

5. Development of high pressure fermentation reactors for bioconversion of syngas.

6. Development of a three-phase anaerobic-aerobic fluidized bed process for destruction of organic and nitrogen compounds in coal gasification wastewaters with retention times below 2 hours (see Fig. 5).

7. Development of a UASB anaerobic treatment system for rapid destruction of coal pyrolysis waste at high loading rates and retention times of 1 day or less.

8. Development of a process for conversion of syngas to cheap acetate for making calcium magnesium acetate-based roaḍ deicers.

9. Evaluate the fate of coal based PAHs in anaerobic and aerobic ecosystems.

\section{BASIC.}

1. Characterize the diversity and taxonomy of anaerobes which degrade syngas, methanol, phenolics, soluble aromatic compounds, and $\mathrm{HCN}$.

2. Characterize the biochemical routes and genes encoding the rate-limiting enzymatic steps in syngas and methanol conversion into organic alcohols and acids.

3. Develop genetic systems in model anaerobes that ferment syngas into organic alcohols, organic acids, or methane for enhancement of rate-limiting systems.

4. Determine microbial electron transport chain and energy conservation mechanisms associated with anaerobic catabolism of $\mathrm{CO}$ and phenols.

5. Determine mechanism of cell adhesion in anaerobic biofilm and granular consortia that degrade phenolics. 
Acidogenic Siage

$$
4 \mathrm{CO}+1.6 \mathrm{H}_{2} \mathrm{O}+.4 \mathrm{H}^{*}-.-3.3 \mathrm{CH}, \mathrm{COOH}+.3 \mathrm{C}, \mathrm{H}, \mathrm{COOH}+2.2 \mathrm{CO} \text {, }
$$

Solventogenic Stage

$$
\begin{aligned}
& .2 \mathrm{CH}_{3} \mathrm{COOH}+.4 \mathrm{H}_{2} \cdots .2 \mathrm{C}_{2} \mathrm{H}_{3} \mathrm{OH}+.2 \mathrm{H}_{2} \mathrm{O} \\
& .1 \mathrm{CH}_{3} \mathrm{COOH} \cdots .05 \mathrm{CH}_{3} \mathrm{COCH}_{3}+.05 \mathrm{CH}_{2}+.05 \mathrm{H}_{2} \mathrm{O} \\
& .3 \mathrm{C}_{3} \mathrm{H}_{7} \mathrm{COOH}+.6 \mathrm{H}_{2} \cdots .3 \mathrm{C}_{4} \mathrm{H}_{9} \mathrm{OH}+.3 \mathrm{H}_{2} \mathrm{O}
\end{aligned}
$$

Total Bioconversion

$$
4 \mathrm{CO}+1 \mathrm{H}_{2}+1.05 \mathrm{H}_{2} \mathrm{O}+.4 \mathrm{H}^{*}-.2 \mathrm{C}_{2} \mathrm{H}_{3} \mathrm{OH}+.05 \mathrm{CH}_{3} \mathrm{COCH}_{3}+.3 \mathrm{C}_{4} \mathrm{H}_{2} \mathrm{OH}+2.25 \mathrm{CO}_{2}
$$

Figure 3. Bioconversion Reactions of Synthesis Gas to Mixed Solvents (Provided by Dr. M. K Jain)

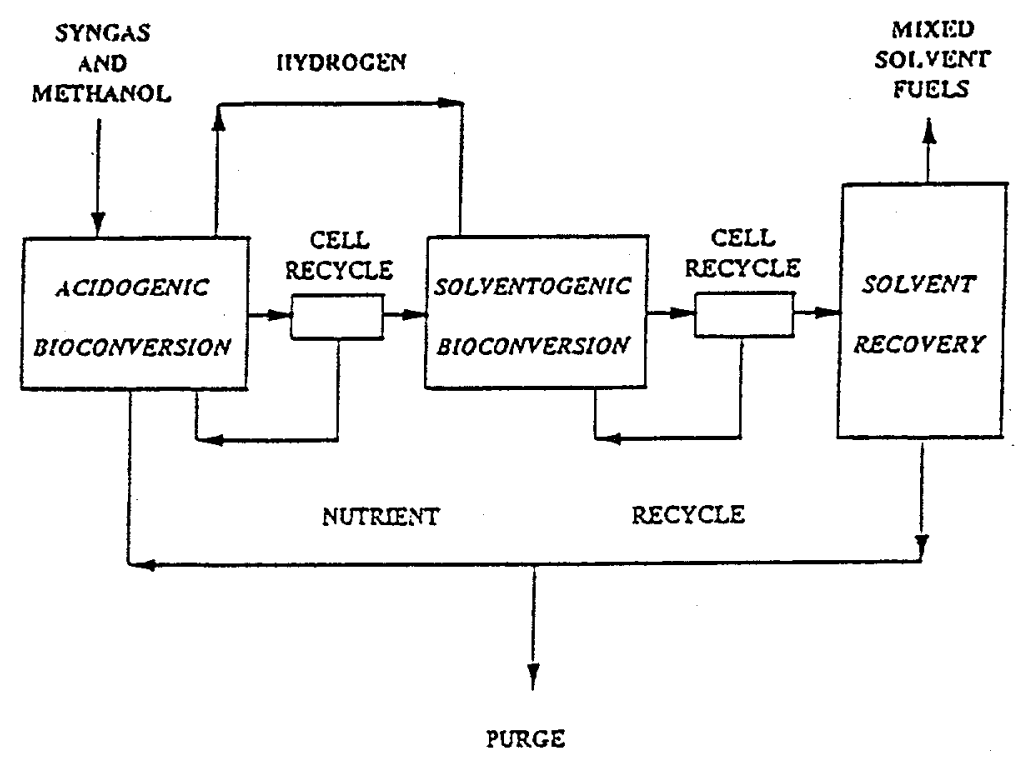

Figure 4. Two-Stage Bioconversion of Coal Derived Gases.

(Provided by Dr. M. K Jain) 


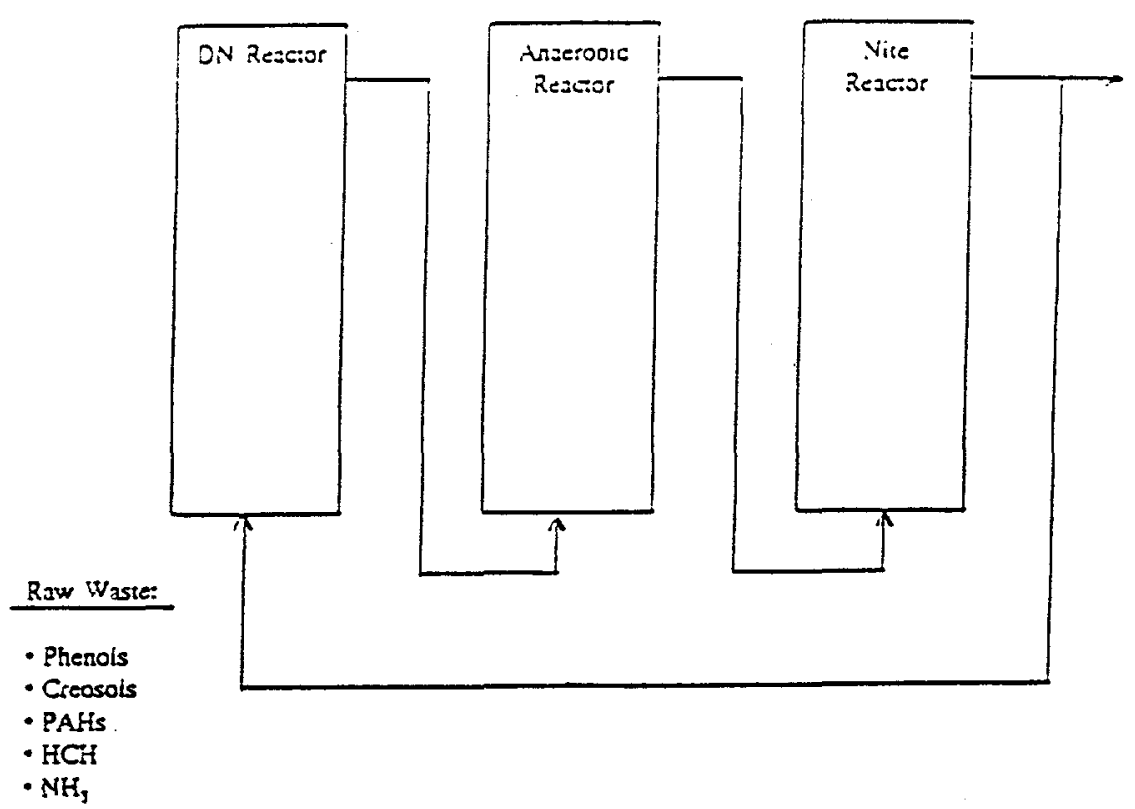

Figure 5. Proposed Fluidized Biotreatment Scheme for Integration Advantageous Features of Anaerobic with DN/Nite Treatment Options.

(Provided by Dr. R. Hickey)

5.5 RECOMMENDATIONS AND PRIORITY ORDER (listed in decreasing importance).

- Development of anaerobic fermentation processes for conversion of synthesis gas and methanol to higher value organic solvents, organic acids, and methane. (These are in decreasing order of importance.) Table 3 presents a comparison of the octane value of organic solvents that could be generated from syngasderived fermentation products.

- Development of a fluidized bed-biofilm reactor and UASB reactor system with active granular sludge for treatment of coal pyrolysis gas wastes with preference for UASB systems.

- Development of microbial consortia that anaerobically degrade phenolic coalbased gasification wastes and which form stable biofilms or granules.

- Development of new biocatalysts by isolation or genetic improvements of existing strains that convert syngas and methanol to economically recoverable levels of organic alcohols, organic acids, or methane (in order of priority).

- Isolation of anaerobic acetogens (i.e., sulfate reducers or syntrophiles) that degrade phenolics, coal-based soluble aromatics, and $\mathrm{HCN}$ into organic acids and $\mathrm{H}_{2}$. 
- Development of bioreactor technologies for retention and recycling of biocatalysts.

- Development of separation technology for recovery of organic acids or alcohols from dilute solutions (emphasis on membrane separations).

- Identification of physiobiochemical tolerance mechanisms of syngas fermenting organisms to organic solvents and acids.

- Identification of biochemical rate-limiting steps in anaerobic digestion of phenolic-based coal pyrolysis wastes.

Table 3

APPROXIMATE AVERAGE OCTANE BLENDING VALUES OF SOME COMMON OXYGENATES.

\begin{tabular}{|c|c|c|c|}
\hline Compound & $\begin{array}{l}\text { Average }^{I} \\
\text { ROM }\end{array}$ & $\begin{array}{l}\text { Average } \\
\text { MON }\end{array}$ & $\begin{array}{l}\text { Average }^{3} \\
\text { OIBV }\end{array}$ \\
\hline Methanol & 124 & 94 & 106 \\
\hline Ethanol & 125 & 96 & 108 \\
\hline Isopropanol & 119 & 100 & 109 \\
\hline t-Butanol & 107 & 98 & 104 \\
\hline \multicolumn{4}{|l|}{ Methyl t-butyl ether } \\
\hline $\begin{array}{l}\text { (MTBE) } \\
\text { Methyl t-amyl ether }\end{array}$ & 117 & 99 & 107 \\
\hline (MTAE) & 111 & 95 & 102 \\
\hline (ETBE) & 117 & 102 & 109 \\
\hline Ácetone & 109 & 98 & 104 \\
\hline \multicolumn{4}{|c|}{ Methyl isobutyl ketone } \\
\hline (MIBK) & 108 & 103 & 107 \\
\hline Methyl acetate & 110 & 100 & 106 \\
\hline Ethyl acetate & 117 & 100 & 108 \\
\hline Methyl propionate & 113 & 99 & 106 \\
\hline Methyl butyrate & 110 & 100 & 106 \\
\hline Methyl isobutyrate & 110 & 99 & 105 \\
\hline \multicolumn{4}{|c|}{1 RON - Research Octane Number } \\
\hline \multicolumn{4}{|c|}{2 MON - Motor Octane Number } \\
\hline 3 OIBV-Octane 1 & & & \\
\hline
\end{tabular}

Table provided by Dr. R. Datta. 


\section{Chapter 6}

\section{THE ANAEROBIC BIOTRANSFORMATION OF FOSSIL FUEL RELATED AROMATIC CHEMICALS}

\section{$6.1 \quad$ INTRODUCTION}

Fossil fuel reserves like oil, coal, tar sands, and shale oil represent important energy resources for this country. Such reserves are complex materials composed of carbon, hydrogen, oxygen, nitrogen, and sulfur combined in various functional groups together with lesser quantities of other inorganic and organic constituents. The ways in which these elements combine influence the stability and reactivity of the material as well as its susceptibility to microbial attack. For example, to convert a large heteropolymer such as coal into a liquid or gaseous fuel by microbial action, it is often necessary to convert the insoluble material into soluble, usually smaller compounds, that allow for more efficient microbial attack. The products then serve as the carbon and energy sources for metabolism by heterotrophic microorganisms. The susceptibility of various coals to microbial metabolism varies substantially. In general, however, coal represents a rather inhospitable habitat for the proliferation of microorganisms (Couch, 1990).

There are many areas of fossil fuel beneficiation where biotechnology could conceivably reduce the costs associated with such processing and render the product more environmentally acceptable. These include fossil fuel solubilization, gasification, denitrogenation, and desulfurization. However, progress in any one of these areas requires information on the requisite microorganisms, the metabolic pathways, the catabolic enzymes involved and their genetic control. All of these topics are, in turn, dependent on a clear description of the chemistry of fossil fuels. While much progress is evident in the latter discipline, much remains to be accomplished. It is clear that all fossil fuels possess a wide variety of aromatic chemicals.

For instance, the chemistry associated with a complex three dimensional polymer like coal is only poorly understood. Coal resources can be categorized as lignite, subbituminous, bituminous, and anthracite. The formation of coal is generally viewed as a continuum, ranging from relatively recent living material (likely lignin-like) to lignite to bituminous to anthracite. The degree of change of chemical composition in coal is called the rank of a coal. Lignite is the lowest rank and anthracite is the highest rank coal. The factors that lead to the change from low to high rank coals are temperature, pressure, and time (Hatcher and Johnson, 1990). All ranks of coal have a very large aromatic character. Lignite, the lowest rank coal, appears to be most amenable to microbial attack, whereas anthracite, with its highly condensed aromatic ring network, appears to be least susceptible to biological attack. 
As a fossil fuel, coal is a very significant energy source for the United States. Lignite, in particular, represents just less than one third of the estimated U.S. coal reserves (Hatcher and Johnson, 1990). However, lignite can contain as much as $50 \%$ ash and moisture and can also harbor substantial amounts of sulfur, reducing the value of this energy source. Anaerobic biological treatment of coal provides a mechanism for potentially converting coal into a more acceptable energy form such as methane gas. Anaerobic processes produce about $11 \mathrm{X} 10^{6} \mathrm{BTU}$ of methane for each ton of COD in coal. In contrast, a typical aerobic biological process consumes $9 \times 10^{6}$ BTU of energy per ton COD removed (Hergenroeder, et al., 1976). The potential ability to recover methane from the anaerobic treatment of coal is certainly worthy of biotechnological consideration.

The molecular structure of lignite is a large aromatic ring polymer joined together by mostly carbon-carbon and ether linkages. The polymeric network of lignite is generally too large to permit much transformation, although some may be possible (see below). However, the chemical or biological pretreatment of pulverized lignite fractionates the polymer into simpler materials and introduces more oxygen in the products. The products are lower in molecular weight, and many are soluble in an aqueous matrix. The aromatic products frequently contain carboxyl and hydroxy functional groups, exhibiting a marked phenolic and benzoate character.

Recent studies indicate that hydrolyzed lignite represents a suitable substrate for methanogenic fermentations (Leuschner et al., 1990; Oren, 1990a, 1990b; Lapin and Matson, 1990; Cohen,1990). However, it should be clear that the anaerobic destruction of coal is a science which is still in its infancy. This report will focus on the aromatic chemicals that are commonly found in coal as well as other fossil fuels. Relative to knowledge based on the aerobic metabolism of these materials, little is known about the anaerobic destruction of fossil fuel related chemicals. Further, little is known about how anaerobes participate in processes such as gasification or the removal of undesirable nitrogen, oxygen, and sulfur moieties from fossil fuel reserves. It is felt that a review of the current state of knowledge will logically lead to a clearer appreciation for areas where anaerobic biotechnology can play an increasingly important role in harnessing this nation's energy reserves.

\subsection{STATUS OF BASIC AND APPLIED RESEARCH.}

\section{PRINCIPLES OF ANAEROBIC METABOLISM}

Heterotrophic bacteria oxidize organic compounds to obtain energy. In the process, electrons or reducing equivalents from the substrate are transferred to and ultimately reduce an organic or inorganic electron acceptor. During this electron transfer process, usable energy is recovered via a series of complex redox reactions by the formation of energy storage compounds or electrochemical gradients.

Under anaerobic conditions and in the presence of suitable electron donors, microbial electron transfer and respiration can proceed if suitable exogenous electron acceptors are 
available. The potential energy available from the oxidation of a particular substrate coupled with the reduction of various electron acceptors varies considerably. In an ecosystem, higher energy yielding processes tend to predominate (but do not exclude other processes) until a favored electron acceptor is consumed (Grbic'-Galic', 1991). Nitrate is energetically the best electron acceptor under anoxic conditions and will be utilized preferentially by complex microbial communities containing appropriate denitrifying microorganisms (Knowles, 1982). Oxidized nitrogen utilization will be followed by ferric iron respiration (Lovley, 1987) and manganese respiration (Lovley and Phillips, 1988). Once sufficiently low redox potential levels have been reached, other anaerobic processes, such as sulfate reduction, fermentation, and $\mathrm{CO}_{2}$ reduction will occur (Widdel, 1988; Zehnder and Stumm, 1988).

Under anaerobic conditions, microorganisms may enter into very tightly linked metabolic consortia. Consequently, the anaerobic biotransformation of aromatic chemicals is fundamentally different from the aerobic microbial metabolism of these compounds, in that a consortium of interacting microorganisms represents the catalytic entity. Fermentative bacteria convert such compounds eventually to $\mathrm{CO}_{2}, \mathrm{H}_{2}$, and a variety of organic acids and alcohols. These latter compounds are often substrates for the proton reducing syntrophic bacteria that convert them to suitable methanogenic precursors. The acetogenic bacteria can convert $\mathrm{H}_{2}$ and $\mathrm{CO}_{2}$ or, as indicated later, polyhydroxylated or methoxylated aromatic compounds directly to acetate. The nutritionally limited methanogenic bacteria are then able to make methane from the small molecular weight products of the initial bioconversions such as methanol, acetate or $\mathrm{H}_{2}$ and $\mathrm{CO}_{2}$. The basic reason for the required interaction in anaerobic metabolism is that the bioconversions tend to be thermodynamically unfavorable unless the concentration of $\mathrm{H}_{2}$ is maintained very low $\left(10^{-3} \mathrm{~atm}\right)$. In anaerobic microbial communities, this low $\mathrm{H}_{2}$ concentration is maintained by methanogens, sulfatereducing bacteria, or other bacteria such as the iron reducers, depending on the availability of a suitable electron acceptor. Methanogenesis, coupled to fermentation, will usually occur after sulfate reserves have been exhausted (Oremland, 1988), because sulfate reducers can successfully outcompete methanogens for common electron donors such as acetate and $\mathrm{H}_{2}$. This sort of metabolism is correctly called "coupled" fermentation because of the species interaction required to initiate the reaction. In a coupled fermentation, the terminal $\mathrm{H}_{2}$ consuming step can essentially pull along the degradation of the original substrate; thus, the terminal step may be the key rate controlling step for the entire anaerobic degradation process. This coupling would be expected to be the case for any metabolism in which electrons must be disposed of by a NADH-linked hydrogenase.

It is generally assumed that only a few similar metabolic pathways are employed among anaerobic microorganisms. This is because metabolic pathways tend to represent a unifying feature of life. On the biochemical level, pathways for the cycling of carbon and energy tend to be similar among diverse lifeforms in spite of great differences in individual catabolic or biosynthetic abilities. Undoubtedly, this fact reflects a common ancestry. With this perspective, it is not astonishing that microbial degradation information gleaned from the study of one type of anaerobic condition can at least provide a prospectus of the types of transformations that might reasonably be expected under other types of anaerobic 
conditions. Regardless of the electron acceptor employed, this review will attempt to characterize the progress on the major mechanisms involved in the anaerobic metabolism of aromatic chemicals that are important to the fossil fuel-related industries and to highlight promising areas for future research endeavors.

Therefore, this review is arbitrarily subdivided according to chemical class. For the most part, repetition has been avoided for compounds that could fit into several categories. The reviewed evidence includes both field and laboratory investigations for which anaerobic degradation of a substrate by microbial action provides a reasonable explanation for the observations.

\section{Benzene}

The simplest aromatic chemical is benzene. Until recently, benzene was believed to be completely resistant to microbial attack under anaerobic conditions. This view was supported by the common occurrence of benzene in fossil fuel deposits many millennia old. In fact, decreased dissolved oxygen concentrations in the terrestrial subsurface is associated with a diminution in benzene biodegradation in the field (Chiang et al., 1989; Barker et al., 1989).

However, in a subsurface field study of the Leiduin dune site in Amsterdam, Piet and Smeek (1985) reported that a variety of low boiling aromatic compounds, including benzene, were reduced in concentration relative to the infiltration water. Under so called "deep anaerobic" conditions, benzene concentration was reduced by $95 \%$ in 3 weeks. However, only slight experimental detail is given as well as ill-defined anaerobic conditions. In this case, the significance of anaerobic metabolism versus other potential removal mechanisms is impossible to evaluate. Similarly, Batterman and Werner (1984) showed the disappearance of benzene in an aquifer bioremediation field project where nitrate was provided as a potential electron acceptor. Within six months, the benzene concentration in one of the contaminated wells decreased from about $1 \mathrm{mg} / \mathrm{l}$ to nondetectable levels. It is equally unclear in this report whether anaerobic metabolism is truly involved in the benzene removal process. This is no doubt due to the difficulties of assessing such a metabolic process in the field.

Laboratory investigations also failed to present a convincing argument for benzene biodegradation in sediments under anaerobic conditions. Wilson et al. (1986) report that after 120 weeks of incubation, $>99 \%$ of the original amount of added benzene disappeared in microbiologically active aquifer microcosms, while only $30 \%$ was removed from autoclaved controls; the difference being attributed to biodegradation. Such studies are difficult to interpret since no benzene metabolites were detected in these studies and no indicators of anaerobiosis (i.e. methane production, indicator dyes, etc.) were included in the experimental protocols. A similar investigation employing defined anaerobic conditions in the author's laboratory was unsuccessful in showing any evidence for anaerobic benzene metabolism within a 64 week incubation period (unpublished data). 
Nevertheless, the possibility of benzene biodegradation in anaerobic environments must not be completely discounted. For instance, the findings of Ward et al. (1980) indicated that a small amount (up to $2 \%$ ) of ${ }^{14} \mathrm{C}$-labeled benzene could be converted to gaseous endproducts following prolonged incubation in anoxic marine sediments contaminated with oil. Further, the aquifer field study by Major et al. (1988) suggested that benzene could be transformed under denitrifying conditions. However, the possibility of trace oxygen contamination in the latter study cannot be ruled out. In fact, the recent article by Hutchins et al. (1991), where more rigorous anaerobic conditions were employed, indicates that the metabolism of benzene linked to denitrification could not be attained.

Significant insight on the possibility of anaerobic benzene biodegration is contributed by the unambiguous studies of Grbic'-Galic' and Vogel (Vogel and Grbic'-Galic', 1986; Grbic'-Galic' and Vogel, 1987). Using a mixed methanogenic culture enriched from sewage sludge for its ability to mineralize ferulic acid, ${ }^{14} \mathrm{C}$-labeled benzene was converted to ${ }^{14} \mathrm{CO}_{2}$. Intermediates formed during benzene metabolism were detected by GC/MS, indicating an initial oxidative attack of the ring to form phenol (Grbic'-Galic' and Vogel, 1987). Cyclohexanone was tentatively identified as a ring saturation product of the phenol intermediate, and methane was formed as an end product. Using ${ }^{18} \mathrm{O}$-labeling studies, the same authors showed that the source of the oxygen on the phenolic intermediate produced during benzene metabolism originated from water (Vogel and Grbic'-Galic', 1986).

Therefore, in the strict sense, the anaerobic microbial destruction of benzene is no longer contentious. However, little is known of the requisite microorganisms, the catabolic enzymes involved, the regulation of such biotransformations, or the ecological significance of such findings. It may be that these organisms will eventually prove extremely useful for the biotechnological processing of fossil fuels.

\section{Benzoic Acid, Phenol, and 4-Hydroxybenzoate}

Benzoate and phenol are structural components of a wide variety of both naturally occurring and xenobiotic substrates. Even a cursory examination of the ensuing sections of this article will reveal that the degradation pathways associated with many diverse substrates seem to converge on these two compounds. For these reasons, it is important to understand the anaerobic metabolism of these chemicals. Benzoate is one of the first aromatic compounds that was shown to be degraded under anaerobic conditions (Tarvin and Buswell, 1934). To date, anaerobic benzoate metabolism has been demonstrated under photosynthetic conditions (Procter and Scher, 1960; Dutton and Evans, 1968; Dutton and Evans, 1969; Dutton and Evans, 1976; Guyer and Hegeman, 1969; Whittle et al., 1976; Hutber and Ribbons, 1983; Harwood and Gibson, 1986), denitrifying conditions (Williams and Evans, 1973; Williams and Evans, 1975; Evans, 1977), sulfate-reducing conditions (Bak and Widdel, 1986), and methanogenic conditions (Balba and Evans, 1977; Grbic'-Galic' and Young, 1985; Chen et al., 1985; Ferry and Wolfe, 1976; Fina et al., 1978; Fina and Fiskin, 1960; Gibson and Suflita, 1986; Healy and Young, 1979; Keith et al., 1978; Mountfort and Bryant, 1982; Mountfort et al., 1984; Novelli and Zobell, 1944; Shelton and Tiedje, 1984a; Shlomi et al., 1978; Slea and Robinson, 1983; Tarvin and Buswell, 1934). Similarly, phenol 
decomposition has been demonstrated with syntrophic co-cultures (Barik et al., 1985) under denitrifying (Bakker, 1977) sulfate-reducing (Gibson and Suflita, 1986; Bak and Widdel, 1986b) and methanogenic conditions (Balba and Evans, 1979; Chemielowski et al., 1964; Boyd et al., 1983; Fédorak and Hrudey, 1984; Gibson and Suflita, 1986; Healy and Young, 1978; Healy and Young, 1979; Shelton and Tiedje, 1984; Suflita and Miller, 1985; Young and Rivera, 1985; Szewzyk et al., 1985; Dwyer et al., 1986). The anaerobic degradation of benzoate and phenol have been extensively reviewed in recent years (Evans,1977; Young,1984; Sleat and Robinson,1984; Berry et al., 1987; Evans and Fuchs, 1988; Haddock and Ferry, 1990) and will not be reiterated here. This section will focus on some of the general metabolic features associated with the anaerobic degradation of these substrates and to highlight the information which has appeared since the publication of these other fine reviews.

The generalizing features of the anaerobic decomposition of benzoate appear to involve several ring reduction steps to form cyclohexanecarboxylate. Subsequent transformations of this intermediate result in the formation of ring cleavage precursors. However, recent evidence with Rhodopseudomonas palustris indicates that this organism produces benzoate CoA synthetase activity in response to benzoate (Hutber and Ribbons, 1983). In fact, the uptake of benzoate by this organism is closely coupled to the formation of benzoyl-CoA (Harwood and Gibson, 1986). It appears, therefore, that the actual substrate for ring reduction is the thioester of benzoate rather than benzoate itself. The types of intermediates produced as products of ring cleavage reactions are varied and depend on the organism or enrichment and the type of incubation conditions employed in the study. In general, the ring cleavage products most often detected include a number of carboxylic acids such as pimelate, adipate, heptanoate and caproate. The subsequent anaerobic metabolism of these compounds appears to involve their conversion to central metabolic intermediates through $\beta$-oxidation reactions.

In comparison, the pathways for phenol decomposition by anaerobic microorganisms have received much less attention. The degradation of phenol under denitrifying conditions has been shown by Bakker (1977). A ring reduction mechanism of phenol to cyclohexanone was suggested, and subsequent transformations of this intermediate resulted in the formation of caproate. A similar ring reduction mechanism was also indicated when cyclohexanone was identified as an intermediate formed during the methanogenic fermentation of phenol (Balba and Evans, 1979). However, adipate was identified as a ring cleavage product in the latter case.

Several groups have also evaluated the anaerobic biotransformation of phenol in recent years. Knoll and Winter (1987) found benzoate accumulating in sewage sludge cultures when phenol degradation was decreased by an artificial increase in the pool size of hydrogen and carbon dioxide. Benzoate was also found in non-inhibited cultures, suggesting that this compound is an intermediate formed during the anaerobic decomposition of phenol. The same authors isolated a syntrophic bacterial consortium that catalyzed this reaction (Knoll and Winter, 1989). The reaction apparently proceeded via a carboxylation of phenol with $\mathrm{CO}_{2}$. Similarly, in several methanogenic sediment incubations, phenol is converted to 
benzoate via a carboxylation reaction (Sharak-Genthner et al., 1989a, 1989b, 1989c; Wiegel et al., 1990). Zhang et al. (1990) have shown that ${ }^{13} \mathrm{C}$-1-phenol is transformed to ${ }^{13} \mathrm{C}-4$ benzoate via carboxylation in the position para to the hydroxyl group. This information agrees with recent findings regarding the anaerobic decomposition of phenol (Suflita, unpublished results). Another carboxylation of phenol has been described by Tschech and Fuchs for phenol metabolism under denitrifying conditions (Tschech and Fuchs, 1987) and suggested by Lovely and Lonergan (1990) for phenol metabolism by an iron-reducing bacterium. The former authors have isolated two pseudomonads that were able to convert phenol to $p$-hydroxybenzoate and to couple the mineralization of the latter with the consumption of nitrate or nitrite. Benzoate could also serve as a suitable electron donor to support anaerobic respiration by these organisms.

The formation of $p$-hydroxybenzoate as an intermediate in the pathway of phenol metabolism deserves special attention. In fact, $p$-hydroxybenzoate has been recognized as an intermediate common to a wide variety of anaerobic metabolic pathways (Bossert and Young, 1986; Harwood and Gibson, 1988; Knoll and Winter, 1989; Neilson et al., 1988; Tschech and Fuchs, 1987; Vogel and Grbic'-Galkic', 1986; Young and Frazer, 1987; Smolenski and Suflita, 1987; Lovely and Lonergan, 1990). p-Hydroxybenzoic acid can be metabolized via a direct ring reduction pathway without the prior conversion to benzoic acid. Separate pathways for the metabolism of $p$-hydroxybenzoate and benzoate have been found in the photosynthetic bacterium Rhodopseudomonas palustris. Harwood and Gibson (1988) found a specific coenzyme ligase for $p$-hydroxybenzoic acid and benzoic acid and thus suggested at least two major routes for the anaerobic degradation of aromatic compounds in this organism.

The continued study of the microbiology, biochemistry, and genetics associated with even these simple aromatic compounds will reveal that anaerobic microorganisms are much more metabolically diverse than originally believed.

Obviously, much remains to be learned about the metabolic sequences employed by anaerobes for the biotransformation of benzoate, phenol and $p$-hydroxybenzoate. Progress with this type of research tends to be painstakingly slow. Given the importance of these compounds as intermediates in a wide variety of anaerobic biodegradation pathways, the research effort is easily warranted.

\section{Hydroxylated Benzenes}

A variety of hydroxylated benzenes (phenolic compounds) are important products from the chemical or biological pretreatment of coal. Compounds such as the cresol, xylenol, and ethylphenol isomers as well as phenol itself have been associated with underground coal gasification activities (Humenick et al., 1982). Phenol is also an intermediate common to many anaerobic biodegradation pathways (see above). Information on the anaerobic bioconversion of this group of contaminants has steadily emerged in recent years. 
Field evidence for the anaerobic biodegradation of the phenolic material found in creosote is included in studies of two contaminated subterranean environments; one in St. Louis Park, MN, the other in Pensacola, FL. Creosote is a complex mixture of hydrocarbons containing from 2 - 17\% phenolic compounds. The initial findings of Ehrlich et al. (1982) demonstrated that total recoverable phenolic compounds decreased in a contaminated aquifer relative to a conservative tracer. Over $95 \%$ of the phenolic compounds were removed within $1000 \mathrm{~m}$ of the contamination source. This level of reduction would not have been expected if only physicochemical processes were involved in the attenuation process. Sorption of the phenols on the aquifer sediments was shown to be insignificant. Methanogenic fermentation of the creosote constituents was suggested since methane and methanogenic bacteria were found only in ground water samples collected from contaminated portions of the aquifer, but not in unimpacted regions (Ehrlich et al., 1983). Further, in laboratory experiments, anaerobic incubations evolved methane when creosote polluted ground water was inoculated with microorganisms obtained from the contaminated aquifer zone.

In a comparison of field and laboratory findings, Godsy and co-workers (Godsy et al., 1983), found that phenol, $o$-cresol and $m$-cresol apparently degraded during transport through anoxic portions of the contaminated aquifer, while a variety of xylenol isomers, as well as triand tetramethylphenols were not substantially removed. Laboratory digestors inoculated with contaminated well water, were only able to mineralize phenol and $m$-cresol but not $o$ cresol. The efficiency of conversion of the phenolic substrates to the theoretical amount of methane was calculated to be about $70 \%$.

Similar findings were also noted by Goerlitz et al. (1985) while studying a Florida aquifer contaminated with creosote chemicals. By monitoring a series of multilevel wells along the waste plume for $\mathrm{O}_{2}, \mathrm{H}_{2} \mathrm{~S}$, and $\mathrm{CH}_{4}$, it was evident that oxygen was completely consumed in the aquifer and that sulfate-reduction and methanogenesis were likely the terminal metabolic processes governing the flow of carbon and energy. Phenol, $0-, m$-, and $p$-cresol were disproportionately decreased downgradient from the waste introduction point. Evidence for the degradation of the phenolic compounds was supported by the detection of high methane levels only in contaminated portions of the aquifer. However, more highly substituted alkylated phenols as well as other creosote constituents were degraded slowly or not at all. $o$-Cresol was apparently more resistent to anaerobic mineralization relative to the other cresol isomers since it migrated the greatest distance downgradient before it was removed below detection limits. Using the same type of logic, $p$-cresol was the most susceptible to methanogenic fermentation.

This same pattern of selective degradation was also noted by Smolenski and Suflita (1987) in a laboratory study of cresol biodegradation in samples obtained from a shallow aquifer polluted by municipal landfill leachate. In both methanogenic and sulfate reducing incubations, $p$-cresol persisted for 46 days and less than 10 days, respectively, before significant substrate disappearance was noted. However, under the same two incubation conditions, $o$-cresol metabolism required over 90 days to commence. 
Interesting results have been obtained by Kuhn et al. (1988) with columns of aquifer material that were originally used in studies of xylene and toluene biodegradation under denitrifying conditions (see below). When the microorganisms in these columns were provided with the cresol isomers as a source of carbon, $o$-cresol persisted while $m$ - and $p$ cresol were removed. Electron balances suggested that these two substrates were at least $70 \%$ mineralized.

Clearly, cresols are examples of substrates which are known to degrade under anaerobic conditions. However, different cresol isomers vary in their susceptibility to anaerobic decay and in the pathways for their decomposition. For example, the metabolism of $p$-cresol proceeds through the initial oxidation of the aryl methyl group under methanogenic (Senior and Balba, 1984; Smolenski and Suflita, 1987), sulfate-reducing (Smolenski and Suflita, 1987; Suflita et al., 1989), nitrate-reducing (Bossert et al., 1986; Bossert and Young, 1986; Tschech and Fuchs, 1987) and iron-reducing conditions (Lovley and Lonergan, 1990). In fact Bossert et al., (1986) have isolated a pure culture denitrifying organism (PC-07) from polluted river sediments that was capable of anaerobically converting $p$-cresol to $p$-hydroxybenzoic acid. This organism lives syntrophically with another denitrifying organism that could utilize the $p$-hydroxybenzoic acid produced by strain PC-07. Mass spectral evidence was used to confirm the identity of the PC-07 metabolic endproduct. In a similar fashion, $o$-cresol is anaerobically oxidized to $o$-hydroxybenzoate (Suflita et al., 1989). The reaction mechanism in these cases presumably involves the incorporation of water via a methyl hydroxylase (Hopper, 1978; Vogel and Grbic'-Galic', 1986).

Other pure cultures of anaerobes are also known to metabolize methylated phenols. For instance, Bak and Widdel (1986b) and Lovley and Lonergan (1990) have reported on pure cultures of sulfate- and iron-reducing bacteria, respectively, that catalyze p-cresol metabolism. Similarly, Schnell et al. (1989) isolated several strains of sulfate reducing bacteria that could use either $p$ - and/or $m$-cresol but not $o$-cresol as electron donors and carbon sources.

Much less is known about the pathway for $m$-cresol metabolism in anaerobic environments, but there is no doubt that it can be biodegraded in the laboratory under a variety of conditions (Bossert et al., 1986; Bossert and Young, 1986; Boyd et al., 1983; Fedorak and Hrudey, 1986; Roberts et al., 1988; Smolenski and Suflita, 1987; Suflita et al., 1989; Tschech and Fuchs, 1987) and in the field (Goerlitz et al., 1985). The small amount of evidence which does exist suggests that the degradation of $m$-cresol does not proceed through aryl methyl-group oxidation (Fedorak and Hrudey, 1986). For instance, Roberts (Roberts et al., 1987 ) found that the methyl group of $p$-cresol was predominantly oxidized to $\mathrm{CO}_{2}$ while that of $m$-cresol was largely recovered as $\mathrm{CH}_{4}$. The only reports describing a pathway for anaerobic $m$-cresol metabolism are those of Roberts et al. (1990) and Ramanand and Suflita (1991). These groups demonstrated that the metabolism of $m$-cresol by either methanogenic or sulfate-reducing enrichment cultures proceeded through the initial carboxylation of the parent substrate. The subsequent steps in the transformation of the carboxylated intermediate (4-hydroxy-2-methylbenzoic acid) have yet to be delineated, but both groups reported that the parent substrate is completely mineralized. 
Information on the biodegradation of more complex hydroxybenzenes has also grown recently. Low molecular weight phenols of this type might be expected as the products of previous microbiological or chemical alterations associated with the degradation of natural polymers like coal, lignin, phytoalexins, and bioflavanoids (Pridham, 1965; Simpson et al., 1969). The first organisms capable of fermenting phloroglucinol (1,3,5-trihydroxybenzene) were the rumen isolates Streptococcus bovis and a Coprococcus sp. (Tsai and Jones, 1975). The degradation of this substrate appeared to involve the direct reduction of the ring. In fact, Patel et al., (1981) have partially purified a reductase from the Coprococcus which catalyzed the conversion of phloroglucinol to dihydrophloroglucinol with NADPH as the source of reducing equivalents.

Schink and Pfennig (1982) found that, when aquatic muds were amended with pyrogallol (3,4,5-trihydroxybenzene) or phloroglucinol, pure cultures of strictly anaerobic bacteria were eventually enriched. The organisms were assigned to the genus Pelobacter, and they fermented several trihydroxylated substrates including gallate (3,4,5-trihydroxybenzoate), 2,4,6-trihydroxybenzene, as well as the enrichment substrates to acetate and $\mathrm{CO}_{2}$. Pelobacter acidigallici also possesses NADPH-dependent phloroglucinol reductase activity (Samain et al., 1986).

Interestingly, the anaerobic metabolism of pyrogallol involves the initial transformation of the substrate to phloroglucinol (Samain et al., 1986; Krumholtz and Bryant, 1986). The pyrogallol-phloroglucinol isomerase responsible for this bioconversion has been partially purified from Eubacterium oxidoreducens and characterized (Krumholz and Bryant, 1988). The mechanism of the reaction involves the oxidation of the pyrogallol followed by the introduction of water. The benzenetetrol intermediate thus formed is reduced and dehydrated to phloroglucinol.

In Eubacterium oxidoreducens, the subsequent degradation of phloroglucinol proceeds through the generation of a dihydrophloroglucinol intermediate via an NADPH-linked reductase (Krumholz et al., 1987). This intermediate could then be hydrolyzed to 3-hydroxy5 -oxohexanoate. This six-carbon ring cleavage product then presumably is broken down by a series of reactions similar to $\beta$-oxidation. Such reactions converted the six-carbon acid to 3-hydroxybutyryl-coenzyme A, resulting in acetate and butyrate as endproducts.

The isolated sulfate-reducing bacteria referred to above for their ability to metabolize cresol isomers could also degrade a variety of other aromatic compounds. One organism, Desulfobacterium anilini, was isolated from marine sediment for its ability to anaerobically degrade aniline (Schnell et al., 1989). The organism could also use the following hydroxylated aromatic compounds as both electron donors and carbon sources when sulfate served as the electron acceptor : pyrogallol, catechol, phenol, 2-, 3-, and 4-hydroxybenzoate, 4-hydroxyphenylacetate, and 3,4-, 2,4-, and 2,5-dihydroxybenzoate. Similar enrichments by these authors with the three dihydroxybenzene isomers as the substrates resulted in the isolation of three different strains of sulfate reducers; each of which could grow only with the dihydroxybenzene used for enrichment. However, one catechol-degrading sulfate 
reducer obtained in this manner could grow with as many as 18 other aromatic compounds while a resorcinol-metabolizing isolate could also utilize 2,4-dihydroxybenzoate.

Another versatile organism (strain PA-1) was isolated from a sludge digester using phenylacetate as the enrichment substrate. The organism was obtained in pure culture but was found to require co-culture with a $\mathrm{H}_{2}$-consuming organism (Wolinella $\mathrm{sp}$.) in order to degrade a variety of aromatic compounds (Barik et al., 1985). These compounds included resorcinol, gallate and several other benzenoids.

Enrichments from anoxic sediments amended with resorcinol resulted in the isolation of two defined cultures containing Clostridium species which fermented this substrate to either acetate and methane or acetate and butyrate (Tschech and Schink, 1985). While the pathway of decomposition for this compound is not clear, Tschech and Schink (1985) speculated that the two hydroxyl groups of resorcinol may influence the aromatic $\pi$-electron system sufficiently to stabilize a cyclohexenedione tautomer which after reduction to cyclohexanedione could be susceptible to hydrolysis. It was noted by these authors that cyclohexanedione served as a growth substrate for some of the defined cultures.

Other dihydroxybenzenes microbiologically transformed under anaerobic conditions include catechol and hydroquinone. Catechol is an important intermediate in the anaerobic degradation of plant materials (Kaiser and Hanselmann, 1982) and is also formed during the aerobic degradation of benzene. Several reports allude to the likely anaerobic biodegradation pathway for these compounds. Catechol has been found to be quite resistent (Healy and Young, 1978) or even stable under anaerobic conditions (Kaiser and Hanselmann, 1982). However, Szewzyk et al. (1985) and Balba and Evans (1980b) have found catechol degradation in methanogenic enrichments. Both groups identified phenol as a metabolic intermediate while the latter group presented evidence that this conversion proceeds through cis-benzenediol. Phenol was also identified as an intermediate formed during hydroquinone metabolism. Thus, the initial bioconversion for both of these dihydroxybenzenoid substrates may involve a reductive dehydroxylation.

The fermentative degradation of hydroquinone was detected in sludge samples (Young and Rivera, 1985) and was noted in enrichment cultures (Szewzyk et al., 1985). Insight into a different pathway for hydroquinone metabolism that does not involve phenol as an intermediate is provided by Szewzyk and Schink (1989). They isolated an anaerobic fermenting bacterium that degraded hydroquinone and gentisate in pure culture. These cultures also degraded benzoate in coculture with a hydrogen scavenging bacterium. Benzoate was formed and accumulated as a reduced endproduct of hydroquinone and gentisate fermentation. The authors speculated that hydroquinone is metabolized via gentisate; thus, the first step likely involves an aryl carboxylation reaction. The subsequent metabolism of gentisate could be the reductive elimination of the hydroxyl groups to form salicylate and eventually benzoate.

Interesting results have been reported by Szewzyk and Pfennig (1987) in their studies of catechol degradation by a sulfate-reducing bacterium that can use nitrate as well as a variety 
of oxidized sulfur species as electron acceptors. Desulfobacterium catecholicum can metabolize catechol, resorcinol, and hydroquinone, but not phenol. This is in contrast to the methanogenic enrichments of Szewzyk et al. (1985) that degraded catechol, hydroquinone, or phenol but not resorcinol, and the resorcinol-degrading bacteria of Tschech and Schink (1985) that failed to degrade catechol, hydroquinone or phenol. As noted above, two different degradation pathways were proposed for these substrates; the direct reduction to cyclohexadione derivatives for resorcinol and the reductive dehydroxylation to phenol for catechol and hydroquinone. Since this novel organism degraded all the dihydroxybenzenoids, it is possible that a different metabolic pathway is operative, or that the previously established pathways exist, and the organism simply lacks a phenol uptake mechanism. This organism also utilized phloroglucinol, pyrogallol, benzoate, p-hydroxybenzoate, protocatechuate, and 2-aminobenzoate as electron donors to support dissimilatory sulfatereduction.

The anaerobic degradation of phenol has already been discussed (see above). It has not yet been possible to isolate a pure culture that is capable of fermenting phenol, but cultures have been obtained on the di- and trihydroxybenzenes. Insight on the reasons for these observations is provided in the review by Haddock and Ferry (1990) and their comparison of the energetics of fermentation of hydroxybenzenoid substrates (Kaiser and Hanselmann, 1982). Equations [1] to [3] show the effect of the number of aryl hydroxy groups on the change in free energy for the fermentation.

$$
\mathrm{C}_{6} \mathrm{H}_{5} \mathrm{OH}+5 \mathrm{H}_{2} \mathrm{O}-\mathrm{CH}_{3} \mathrm{COO}^{-}+3 \mathrm{H}^{+}+2 \mathrm{H}_{2} \quad \Delta \mathrm{Go}^{\prime}=+6.55 \mathrm{~kJ} / \mathrm{mol}
$$

$$
\mathrm{C}_{6} \mathrm{H}_{4}(\mathrm{OH})_{2}+4 \mathrm{H}_{2} \mathrm{O} \ldots>3 \mathrm{CH}_{3} \mathrm{COO}^{-}+3 \mathrm{H}^{+}+\mathrm{H}_{2} \quad \Delta \mathrm{Go}^{\prime}=-78.1 \mathrm{~kJ} / \mathrm{mol}
$$

$$
\mathrm{C}_{6} \mathrm{H}_{3}(\mathrm{OH})_{3}+3 \mathrm{H}_{2} \mathrm{O}-\cdots>3 \mathrm{CH}_{3} \mathrm{COO}^{-}+3 \mathrm{H}^{+} \quad \Delta \mathrm{Go}^{\prime}=-158 \mathrm{~kJ} / \mathrm{mol}
$$

It is evident from such a comparison that the fermentation of phenol to acetate and hydrogen is thermodynamically unfavorable and would require the coupling of a phenol degrading organism with a hydrogen-utilizing organism. However, the negative delta Go' values for the dihydroxy and trihydroxy derivatives suggest that they may be fermented by pure cultures.

\section{Carboxylated Benzenes and Related Compounds}

Carboxylated benzenes are an important class of substrates in nature and may be anticipated as products resulting from the chemical or biological decomposition of humic materials, coals and lignaceous polymers. Carboxylated benzenes can also be formed during the breakdown of phthalic acid esters. The latter compounds are ubiquitous contaminants in the environment and are widely used as plasicizers in a variety of industrial processes. (Giam et 
al., 1978; Mathur, 1974; Mayer et al., 1972; Peakall, 1975). Microbial esterases involved in the hydrolysis of phthalic acid esters do not have a requirement for oxygen (Engelhardt and Wallnofer, 1978; Benckiser and Ottow, 1982; Shelton et al., 1984). Therefore, the aerobic and anaerobic biodegradation of such molecules results in the production of carboxylated benzene derivatives. Cleavage of the ester bonds is faster for butyl-, ethyl-, and methyl-substituted phthalates compared with the n-octyl derivative (Shelton et al., 1984).

There is a rapidly growing literature on the fate of carboxylated benzenes in anaerobic environments. This information has been steadily reviewed in recent years, and the reader is referred to the work of Evans (1977); Young (1984); Sleat and Robinson (1984); Berry et al. (1987); Evans and Fuchs (1988); as well as Haddock and Ferry (1990) for exhaustive summaries of the anaerobic bioconversions associated with this class and related classes of aromatic compounds.

The picture that emerges from such studies suggests that carboxylated benzenes (and related substrates) may undergo initial modification reactions (Figure $X$ ) and/or aryl removal reactions (Figure $\mathrm{Y}$ ) that serve to convert the parent substrate to a metabolite that can be subsequently metabolized via several known anaerobic biodegradation pathways.

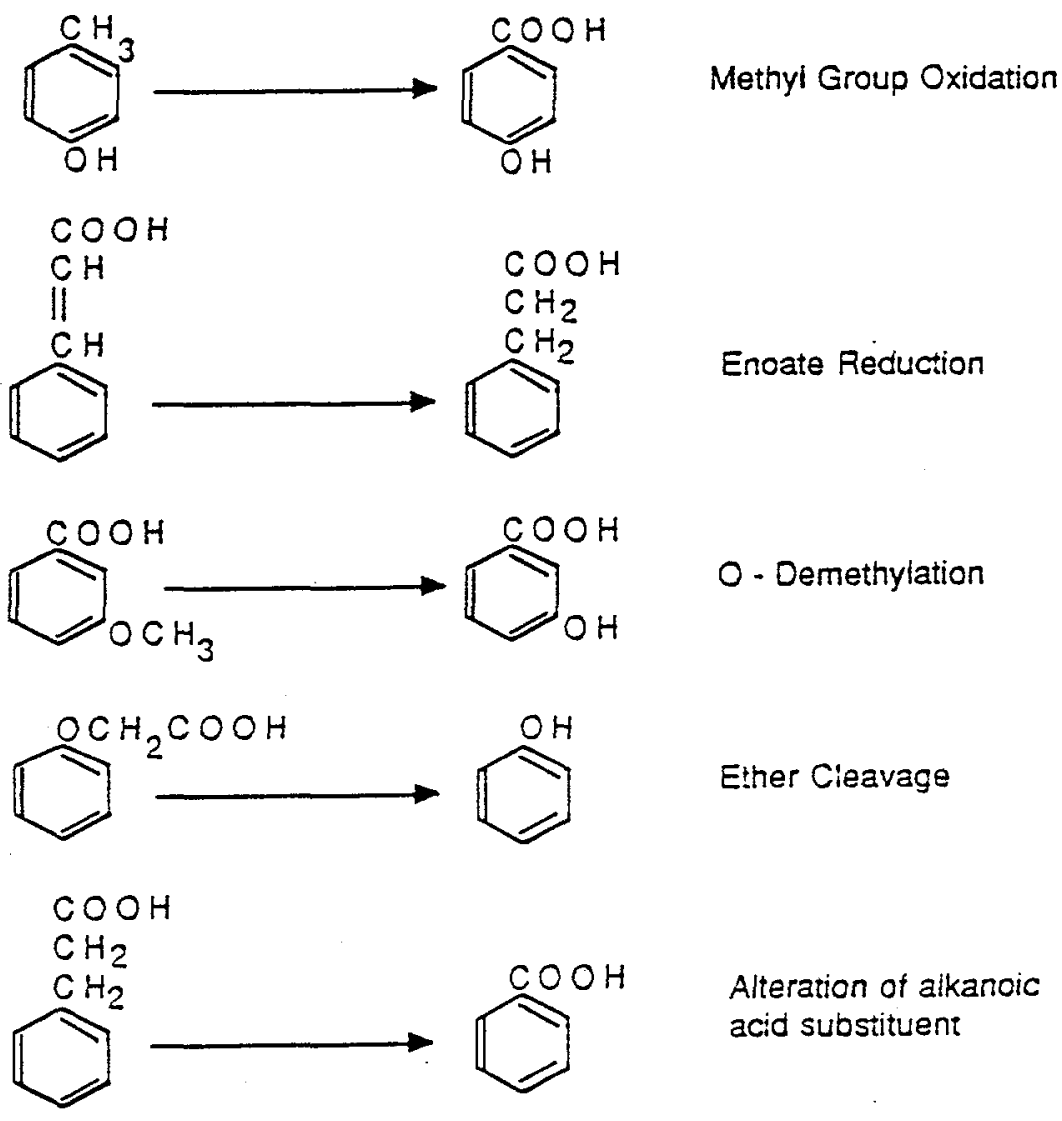

Figure X. Modifications of Aryl Substituents Catalyzed by Anaerobic Microorganisms 
With some notable exceptions (see below), the primary degradative events and even subsequent ones do not necessarily involve the destruction of the aromatic moiety. The substituent modification reactions listed in Figure $X$, and the substituent removal reactions illustrated in Figure $Y$, generate intermediates that subsequently are most frequently able to enter the anaerobic biodegradation pathways associated with benzoate, phenol, $p$ hydroxybenzoate, resorcinol, or phloroglucinol.<smiles>O=C(O)c1cc2cc(c1)Oc1ccccc1O2</smiles><smiles>O=C(O)c1cccc(C(=O)O)c1C(=O)O</smiles><smiles>NC(=O)c1ccccc1CCc1ccccc1C(=O)O</smiles><smiles>[Y][R10]([H])([H])c1ccccc1CCc1ccccc1C(=O)O</smiles>

Dehalogenation

Figure Y. Substituent removal reactions catalyzed by anaerobic microorganisms

However, the metabolic pathways for aromatic compound degradation associated with anaerobic bacteria are more diverse than once believed, and much remains to be discovered. Several notable exceptions to the above generalizations can be found in the literature. For instance, experiments with 3,5-dihydroxybenzoate resulted in freshwater, marine and sludge enrichments which could mineralize this substrate to acetate and methane (Tschech and Schink, 1985). Substrate metabolism by these enrichments depended on syntrophic cooperation with methanogenic or homoacetogenic bacteria. However, these cultures did not grow at the expense of resorcinol, hydroxybenzoate or benzoate. Therefore, it is unlikely that the cells catalyzed a decarboxylation or dehydroxylation reaction as the initial step in the degradation of the parent molecule. 
The same authors also suggested an initial anaerobic bioconversion in which the aromatic moiety did not remain intact (Tschech and Schink, 1986). Defined cultures originally isolated from freshwater sediment and sludge metabolized $o$-hydroxybenzoate. However, unlike the other hydroxybenzoate isomers, neither benzoate nor phenol could be demonstrated as likely degradation intermediates. The authors suggested that $o$ hydroxybenzoate converged with the benzoate degradation pathway without substituent removal and after ring saturation. An intermediate possessing a hydroxylated and fully saturated ring system was proposed.

This speculation prompted a study by Kuhn et al. (1989) on pathways for the destruction of hydroxybenzoate isomers. A wide variety of carboxylated and hydroxylated chemicals are eventually converted to one of the hydroxybenzoate isomers over the course of their anaerobic destruction. However,' instead of examining enrichment cultures, Kuhn et al. (1989) examined the fate of hydroxybenzoate isomers in aquifer slurries held under denitrifying, sulfate reducing and methanogenic conditions. They found the same metabolites formed from a given hydroxybenzoate isomer under the latter two conditions. Benzoate was detected as an intermediate of all three hydroxybenzoate isomers suggesting that aryl dehydroxylation reactions are independant of the relative substitution pattern under these two incubation conditions. However, while benzoate was the major degradation product detected with the ortho and meta isomers, it proved to be only a trace metabolite when aquifer slurries were amended with $p$-hydroxybenzoate. Rather, phenol proved to be the major metabolite of this substrate when sulfate or carbon dioxide served as the major terminal electron acceptor. Phenol was also identified as an intermediate formed during the metabolism of all the hydroxybenzoate isomers in denitrifying aquifer slurries. While these results do not contradict a direct ring reduction mechanism for $o$-hydroxybenzoate metabolism, they do demonstrate that substituent removal mechanisms should not be overlooked.

Numerous bacteria have been described that can utilize hydroxybenzoate isomers under anaerobic conditions. Several are also able to metabolize benzoic acid but not phenol. These include the nitrate-reducing Alcaligenes xylosoxidans subsp. denitrificans, formerly Pseudomonas PN-1 (Taylor et al., 1970), the phototrophic Rhodopseudomonas palustris (Harwood and Gibson, 1988), Desulfobacterium catecholicum (Szewzyk and Pfennig, 1987), Desulfococcus multivorans (Widdel and Pfennig, 1984), Desulfosarcina variables (Widdel and Pfennig, 1984), Desulfonema magnum (Widdel and Pfennig, 1984), and Desulfotomaculum sapomandens (Cord-Ruwisch and Garcia, 1985). It may be that these organisms are able to reductively dehydroxylate the hydroxybenzoate isomer to form benzoate, which would then be anaerobically metabolized via ring reduction and cleavage reactions. Alternate explanations for such observations could involve the initial decarboxylation of the hydroxybenzoate isomer to phenol followed by the conversion of the latter compound to benzoate (see above).

Decarboxylation of hydroxybenzoates is well known. Hsu et al. (1990) described a thermophilic homoacetogen, Clostridium thermoaceticum, that decarboxylates $p$ - 
hydroxybenzoate to phenol and 3, 4-dihydroxybenzoate to catechol. Similarly, Zhang and Wiegel (1990) describe another Clostridium sp. that catalyzed the same bioconversions. Such decarboxylation reactions are common. Martin (1982) described the decarboxylation of phenolic acids to simple phenols by rumen organisms. Such reactions may be a useful source of energy for the requisite micoorganisms. Hilpert et al. (1984) and Dimroth (1987) describe the $\mathrm{Na}^{+}$ion-dependent decarboxylation reaction as an energy conservation mechanism.

Several other organisms, such as Desulfobacterium phenolicum (Bak and Widdel, 1986b) and Desulfobacterium anilini (Schnell et al., 1989), are able to metabolize hydroxybenzoate, phenols and benzoates. These are some of the most metabolically diverse anaerobes that are known.

The anaerobic metabolism of more complicated hydroxylated aromatic compounds is also known. For instance, Sembring and Winter (1989) and Liu et al. (1991) were able to demonstrate the anaerobic bioconversion of 2-hydroxybiphenyl under methanogenic and sulfate-reducing conditions, respectively. Both studies suggested that the compound was mineralized. Thus, the anaerobic degradation of aromatic substrates containing multiple ring systems is known, but the pathways involved have yet to be established (see below).

\section{Other Nonoxygenic Aromatic Hydrocarbons}

Several investigators have recently shown that nonoxygenic aromatic hydrocarbons can also be metabolized under anaerobic conditions. Ward et al. (1980) reported the formation of small amounts of carbon dioxide and methane from radiolabeled toluene and benzene in laboratory sediment incubation systems. Field evidence also argued that hydrocarbons could be transformed anaerobically. Schwarzenbach et al. (1983) described the behavior of toluene and alkylated benzenes in a river water to ground water infiltration area at an anaerobic site in Switzerland. The decrease in toluene and $m$-xylene was attributed to microbial degradation. This suggestion was confirmed in subsequent laboratory investigations which revealed that the metabolism of these materials was linked with nitrate as the terminal electron acceptor (Kuhn et al., 1985). Similarly, Reinhard et al. (1984) reported that xylenes were selectively removed relative to other contaminants from an anoxic aquifer in Canada that was polluted by landfill leachate. Laboratory studies with polluted aquifer slurries by Wilson et al. (1986) suggested that toluene, benzene, ethylbenzene and $o$-xylene could be slowly metabolized under methanogenic conditions.

An aviation gasoline contaminated aquifer in Traverse City, Michigan has become an instructive site for understanding the fate and transport of hydrocarbons in the terrestrial subsurface (Wilson et al., 1987). The anaerobic center of the gasoline plume possessed high concentrations of alkyl benzenes and dissolved methane, while another portion of the contamination plume was high in methane content and low in alkyl benzenes but had high concentrations of phenols, aromatic alcohols, aldehydes, acids, and alicyclic compounds (Grbic'- Galic', 1990). The latter compounds were presumably transformation products of the gasoline components. Aquifer slurries made from the anaerobic aquifer material 
exhibited relatively rapid degradation of benzene, toluene and xylene isomers (Wilson et al., 1987). Recent evidence has suggested that the addition of nitrate as an electron acceptor further accelerated the anaerobic biotransformation process (Hutchins et al.,1991).

Yet another hydrocarbon-contaminated field site is in Bemidji, Minnesota. The contamination plume contained high concentrations of benzene and alkylbenezenes in addition to phenols, aromatic acids, alicyclic compounds, and aliphatic acids which were not original components of the pollutant, nor were they normally present in the aquifer. The anaerobic destruction of these contaminants may be linked with various microbiological processes including iron and manganese reduction as well as methanogenesis (Baedecker et al., 1989).

Vogel and Grbic'-Galic' (1986) offered proof for the methanogenic degradation of toluene and benzene. By using ${ }^{18} \mathrm{O}$-labeled water, these authors showed that the heavy isotope was incorporated into $p$-cresol or phenol when toluene or benzene were the parent compounds, respectively. Thus, the transformation was oxidative with the oxygen functionality derived from water. Later, Grbic'-Galic' and Vogel (1987) established a mass balance relationship between the substrate and final degradation products with ${ }^{14} \mathrm{C}$-labeled parent material. In addition, $p$-cresol, $o$-cresol, and benzyl alcohol were detected as early toluene transformation intermediates. A similar mechanism for toluene degradation has been suggested under denitrifying conditions (Kuhn et al., 1988) and for an isolated toluene-degrading, ironreducing bacterium (Lovley and Lonergan, 1990). The methanogenic degradation of other aromatic hydrocarbons, including styrene (Grbic'-Galic' et al., 1990), naphthene and acenaphthene has also been noted (Grbic'-Galic, 1989). The initial transformation of styrene involves the addition of water across the double bond in the unsaturated side chain of the molecule to result in the formation of phenylethanol. The degradation of styrene results in the formation of a variety of fatty acids as well as carbon dioxide, but methane formation tends to be inhibited (Grbic'-Galic', 1989).

The degradation of more complicated structures, such as the polynuclear aromatic hydrocarbons under anaerobic conditions, appears to resemble the transformation of the monocyclic aromatic hydrocarbons. That is, early transformation reactions result in the initial oxidation of a ring with a hydroxyl functional group derived from water. The degradation of naphthalene and acenaphthalene is complete with the stoichiometric conversion of these materials to carbon dioxide and methane (Grbic'-Galic', 1990).

A creosote contaminated aquifer in Pensacola, Florida, was used as inoculum in experiments designed to probe the anaerobic degradation of polynuclear aromatic hydrocarbons, such as indene and naphthalene (Grbic'-Galic', 1990). Indene was mineralized within two months of incubation with the stoichiometric production of carbon dioxide and methane. The same incubations completely degraded naphthalene in less than a month. The initial acclimation period prior to the onset of indene degradation was about 1.5 months, whereas, naphthalene transformation started after two weeks. Interestingly, the anaerobic transformation of these chemicals could not be demonstrated in small incubation systems (150 grams of aquifer solids; 100 milliters of microbiological medium), while larger ones (400 grams of aquifer 
solids, 250 milliters of medium) were successful. The effect of the size of the incubation system for such anaerobic metabolic processes is as yet unexplained. Naphthalene and acenaphthalene degradation have also been noted in studies conducted under denitrifying conditions (Mihelcic and Luthy, 1988a, 1988b), but the pathway of biotransformation was not explored.

\section{Nitrogen and Sulfur Substituted Benzenes}

Very little is known about the susceptibility of nitrogen and sulfur substituted benzenes to anaerobic metabolism. Aniline and toluidines can be detected in the waste waters from coal gasification sites(Stümer et al., 1982). Under reducing conditions, nitroaromatic substrates tend to be readily reduced to anilines, presumably by way of the corresponding nitroso and hydroxylamino compounds (McCormick et al., 1976). Even several common aerobic microbial systems possess nitroaryl-reductase activity which is capable of converting multiple aromatic nitro substituents to amino groups (McCormick et al., 1976). Anilines are also produced as intermediates during the aerobic biodegradation of numerous phenylurea, phenylcarbamate and acylanilide pesticides and result from the anaerobic microbial reduction of azo dyes (Wuhrmann et al., 1980).

Once formed, anilines can often become strongly bound to matter. Hsu and Bartha (1976) have delineated several mechanisms for such immobilization. Regardless of the mechanisms, such binding processes tend to reduce both the mobility and the mineralization of aniline residues once they are released in the environment.

Information on the anaerobic biodegradation of anilines is particularly sparse. An early report of aniline metabolism under anaerobic conditions was given by Bollag and Russel (1976). They document that the degradation products resulting from the anaerobic metabolism of 4-chloroaniline by a Paracoccus sp. are different from those found in aerobic incubations. Substrate removal by this organism was actually faster under reducing conditions. However, the metabolites produced under anaerobic conditions were not identified.

As already noted, Schnell et al. (1989) described a metabolically versatile sulfate-reducing bacterium enriched for its ability to grow with aniline as a substrate. Substrate induction experiments suggested a common pathway for the degradation of aniline and 4aminobenzoate (Schnell and Schink, 1991). Like several other anaerobic bioconversions (phenol, $m$-cresol and hydroquinone), the degradation of aniline was $\mathrm{CO}_{2}$-dependent, although this dependency was not evident with 4-aminobenzoate. Extracts of aniline- or 4aminobenzoate-grown cells exhibited 4-aminobenzoate-CoA synthetase activity, and benzoate was detected as an intermediate during 4-aminobenzoate metabolism. Schnell and Schink (1991) also found that 4-aminobenzoyl-CoA was converted to benzoyl-CoA by cell extracts in the presence of low potential electron donors. Thus, aniline is degraded by this organism by carboxylation of 4-aminobenzoate which is subsequently activated to the CoA derivative and further metabolized by reductive deamination to benzoyl-CoA which enters the benzoate degradation pathway. 
Kuhn and Suflita (1989a) tested a total of 24 model compounds representing four different groups of chemicals for their biodegradability in aquifer slurries held under sulfate-reducing or methanogenic conditions. The nitrogen-substituted compounds included anilines and benzamides while the sulfonated benzenes include sulfonic acids and sulfonamides. They found that the aminosubstituted benzenes were relatively easily biodegraded when the aromatic nucleus was substituted with a carboxy group. This is in contrast to aniline and the methylated anilines (toluidines) which proved much more recalcitrant. Methane formation from all three aminobenzoic acids could be demonstrated in methanogenic incubations, but the same could not be said when either aniline or any of the methylated anilines were incubated in the same type of aquifer slurries. Aniline and $m$-toluidine were partially transformed in sulfate-reducing aquifer slurries (Kuhn and Suflita. 1989a).

Anthranilic acid (2-aminobenzoate) has been the aniline most intensely investigated under anaerobic conditions. At least three different metabolites of anthranilate have been detected in various incubation systems, including benzoate, salicylate and aniline. The detection of benzoate as the initial metabolite would indicate a very interesting reductive deamination reaction. In contrast, the observation of salicylate as the initial intermediate suggests the addition of water across an imino double bond and the hydrolytic elimination of ammonia (Balba and Evans, 1980a). However, these two pathways may be related in that benzoate could be formed from salicylate via a reductive dehydroxylation reaction (Balba and Evans, 1980a; Balba et al., 1981). Another interesting transformation is the conversion of anthranilate to aniline in mixed microbial communities containing sulfate-reducing bacteria (Balba et al.,1981; Senior and Balba, 1984). It is as yet unclear what role, if any, the sulfate-reducers have in this decarboxylation reaction. Anthranilate is also degraded under denitrifying conditions by an as yet unknown mechanism in which the amino group of the parent molecule could be detected as ammonia (Braun and Gibson, 1984).

In general, aminobenzoic acids can be anaerobically degraded under denitrifying (Braun and Gibson, 1984), sulfate-reducing (Bak and Widdel, 1986a; Kuhn and Suflita, 1989a) and methanogenic conditions (Balba et al., 1981; Senior and Balba, 1984; Kuhn and Suflita, 1989a). The anaerobic pathway of aminobenzoic acid decomposition is not clear. As noted, decarboxylation and deaminations have been suggested as initial transformation mechanisms for such substrates. In addition, the formation of the CoA derivative of anthranilic acid was demonstrated in cell-free extracts (Ziegler et al., 1987). Much remains to be learned about this interesting group of substrates. This work is particularly important since it is conceivable that the aminobenzoates are intermediates formed during the degradation of numerous other compounds.

In their survey of the biodegradability of $\mathrm{N}$ - and S- substituted benzenes, Kuhn and Suflita (1989a) found that benzeneamide and p-toluamide were relatively easily biodegraded in anaerobic aquifer incubations. However, when the nitrogen atom was substituted with a single methyl group, the biodegradability of the resulting $\mathrm{N}$-methylbenzamide decreased in methanogenic aquifer slurries, although this compound was degraded in comparable sulfate reducing slurries. A second $\mathrm{N}$-methyl group rendered the respective molecule highly persistent under both sulfate-reducing and methanogenic conditions. 
Conceivably, an $\mathrm{N}$-demethylation reaction might be postulated under anaerobic conditions. $\mathrm{N}$-dealkylation reactions are known degradation pathways for various nitrogen containing aromatic compounds. Whether the substituted benzamides are metabolized through a similar initial reaction sequence under anaerobic conditions is unknown. In this context, it is interesting to note that alkylamino hydrolase (dealkylaminase) activity was observed in cell-free extracts of a Pseudomonas sp. strain under both aerobic and anaerobic conditions (Cook et al., 1984). The enzyme activity was detected during the degradation of $\mathrm{N}$ cyclopropylmelamine. Obviously, other biotransformation reactions must also be considered, and this type of chemical must be more closely investigated.

To date, there appears to be only a single report that considers the anaerobic metabolism of aryl sulfonates (Kuhn and Suflita, 1989a). In this study, only one model compound, $p$ benzosulfonic acid, was biotransformed. Notably, this chemical possesses an aryl carboxy group. As with other classes of substrates (anilines, phenols, heterocyclic compounds etc.), the presence of an aryl carboxy group makes the resulting molecule much more susceptible to anaerobic microbial attack. Generally, however, the benzene sulfonic acid derivatives must be considered highly recalcitrant under anoxic conditions.

The carbon-sulfur bond of the sulfonate group attached to either an alkane or an aromatic ring is thermodynamically far more stable than the sulfate ester bond (C-O-S). This is reflected in the rarity of naturally occurring sulfonates and the increased biological recalcitrance of such compounds (Cain, 1981). To illustrate, alkylsulfatase activity (sulfate ester cleavage) could be found in 12 anaerobic bacteria including members of genera such as Clostridium, Lactobacillus, Peptococcus, and Eubacterium (Van Eldere et al., 1988). No mineralization of alkylsulfonates or alkylbenzenesulfonates could be detected in methanogenic sewage sludge incubations, whereas, the same inoculum could anaerobically biodegrade dodecylsulfate (Wagener and Schink, 1987).

Benzenesulfonamides proved to be more recalcitrant in anaerobic aquifer incubations when the substrate was alkylated at the $\mathrm{N}$-atom (Kuhn and Suflita, 1989), but benzenesulfonamide itself and $p$-toluenesulfonamide were transformed under anaerobic conditions. The mechanisms associated with these transformations are as yet unknown.

In this respect, it is interesting to note the work of Köhler et al. (1984). They observed the anaerobic degradation of dibenzylsulfide by a Desulfovibrio sp. Toluene and benzylmercaptan were detected as intermediate metabolites and ${ }^{35} \mathrm{~S}$-sulfide was produced from ${ }^{35} \mathrm{~S}$ dibenzylsulfide.

Much remains to be learned about the prospects and limits for the anaerobic destruction of $N$ - and S-substituted benzenes. Such bioconversions may be important for the denitrogenation and desulfurization of fossil fuels. A research effort focused on this general topic appears easily justified. 


\section{Methoxylated Benzenes}

Methoxylated benzenes are formed during the aerobic and anaerobic destruction of lignin or lignin-related structures by microorganisms (Crawford, 1981; Colberg and Young, 1985). As mentioned, it is believed that lignaceous material is structurally similar to that of the younger and softer coals. The aryl methoxy groups associated with some coals could conceivably represent an important $C_{1}$ carbon source for microbial metabolism.

There are many examples of studies that clearly show the anaerobic decomposition of lignoaromatic substrates belonging to this chemical class(Kaiser and Hanselmann, 1982a, 1982b; Sharak-Genthner and Bryant, 1987; Healy et al., 1980; Healy and Young, 1979; Grbic'-Galic'and Young, 1985; Grbic'-Galic', 1983). Early studies generally employed complex mixed cultures of microorganisms, but much progress has been made in isolating the bacteria resposible for methoxybenzene metabolism. Generally, the defined bacterial cultures capable of utilizing these substrates fall into two general categories; the obligately anaerobic bacteria that convert the aryl substituent to acetate or other short chain fatty acids and the facultative anaerobes such as the Enterobacteriaceae or denitrifying pseudomanads.

Acetate is apparently not formed during the metabolism of methoxybenzenoids by the Enterobacteriaceae, thus suggesting a fundamentally different mechanism of biodegradation relative to the obligately anaerobic acetogenic bacteria (Grbic'-Galic', 1986). However, thus far, all bacteria that are able to anaerobically metabolize methoxylated benzenes share the common feature that the primary degradative event results in the conversion of the parent substrate to the corresponding hydroxylated derivative (Table X). Subsequent metabolism of the O-demethylated intermediate by pure cultures may range from the reduction of a double bond in those lignoaromatic substrates that have an acrylate side chain to reductive dehydroxylation of the resulting aromatic intermediates, to aryl decarboxylation reactions sometimes followed by ring cleavage reactions (see previous sections). The mechanisms of the latter reactions are largely identical to the metabolic processes previously discussed. The reduction of the acrylate side chain of some substrates may result in a greater overall free energy change (Tschech and Pfennig, 1984). Generally, the sequential removal of aryl substituents proceeds until the parent substrate can enter one of the common degradation pathways such as those associated with the degradation of phenol or benzoate (see above). 
Table X. Selected Examples of the Anaerobic Metabolism of Methoxylated Benzenes by Defined Cultures

\begin{tabular}{|c|c|c|c|c|}
\hline \multirow{2}{*}{$\begin{array}{l}\text { Benzene } \\
\text { substrate }\end{array}$} & \multicolumn{4}{|c|}{ 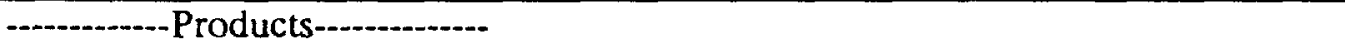 } \\
\hline & Aromatic & Fatty acid & Organism & Reference \\
\hline \multicolumn{5}{|c|}{ 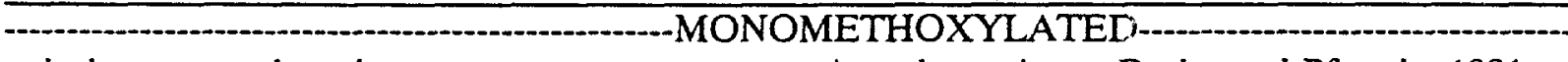 } \\
\hline anisol & phenol & acetate & Acetobacterium & Bache and Pfennig, 1981 \\
\hline \multirow[t]{6}{*}{ vanillic acid } & protocatechuate & acetate & Strain TH-001 & Frazer and Young, 1985 \\
\hline & & acetate & Acetobacterium & Bache and Pfennig, 1981 \\
\hline & & unknown & Alcaligenes"*” & Taylor, 1983 \\
\hline & & buttyrate & Clostridium & Krumholz and Bryant, 1985 \\
\hline & & acetate & Syntrophococcus & Krumholz and Bryant, 1986 \\
\hline & & mixtures & Strain FD & Mountfort and Asher, 1986 \\
\hline \multirow[t]{4}{*}{ vanillin } & 3,4-dihydroxy- & & & \\
\hline & benzaldehyde & acetate & Acetobacterium & Bache and Pfennig, 1981 \\
\hline & & butyrate & Clostridium & Krumholz and Bryant, 1985 \\
\hline & & acetate & Syntrophococcus & Krumholz and Bryant, 1986 \\
\hline \multirow[t]{8}{*}{ ferulic acid } & hydrocaffeic & acetate & Strain TH-001 & Frazer and Young, $1985^{\circ}$ \\
\hline & & acetate & Acetobacterium & Bache and Pfennig, $1981^{\circ}$ \\
\hline & & not acetate & Enterobacter & Grbic'-Galic', 1986 \\
\hline & & not acetate & Escherichia & Grbic'-Galic', $1986^{*}$ \\
\hline & caffeic acid & unknown & Alcaligenes ${ }^{* *}$ & Taylor, 1983 \\
\hline & & butyrate & Clostridium & Krumholz and Bryant, 1985 \\
\hline & & acetate & Syntrophococcus & Krumholz and Bryant, 1986 \\
\hline & & mixtures & Strain FD & Mountfort and Asher, 1986 \\
\hline \multicolumn{5}{|l|}{ 3-O-methyl- } \\
\hline & & & & \\
\hline \multirow[t]{3}{*}{$\begin{array}{l}\text { 3-methoxy- } \\
\text { benzoic acid }\end{array}$} & $\begin{array}{l}\text { 3-hydroxy- } \\
\text { benzoate }\end{array}$ & unknown & Alcaligenes ${ }^{* * *}$ & Taylor, 1983 \\
\hline & & unknown & Eubacterium & DeWeerd et al, 1988 \\
\hline & & unknown & Desulfomonile & DeWeerd et al, 1988 \\
\hline $\begin{array}{l}\text { 3-methoxy- } \\
\text { cinnamic } \\
\text { acid }\end{array}$ & $\begin{array}{l}\text { 3-hydroxy } \\
\text { hydrocin- } \\
\text { namic acid }\end{array}$ & acetate & Acetobacterium & Bache and Pfennig, $1981^{\circ}$ \\
\hline
\end{tabular}

syringic acid gallate acetate acetate unknown butyrate
Strain TH-001 Acetobacterium Alcaligenes ${ }^{* *}$ Clostridium
Frazer and Young, 1985

Bache and Pfennig, 1981

Taylor, 1983

Krumholz and Bryant, 1985 
acetate

mixtures

acetate

unknown

guaiacol

catechol

3,4,5-trihydroxy-

3-phenylpropionateacetate

3,4,5-trihydroxy-

cinnamate

mixtures

acetate

Syntrophococcus

Strain FD

Acetobacterium

Alcaligenes ${ }^{\cdots \bullet}$

Acetobacterium

Strain FD

2,4-dimethoxy-2,4-dihydroxy-

benzoic acid benzoate

3,4-dimethoxy- 3-hydroxy-4-

benzoic acid methoxybenzoat

unknown

Alcaligenes***

Taylor, 1983

3,5-dimethoxy- 3,5-dihydroxy-

benzoic acid benzoate
Krumholz and Bryant, 1986

Mountfort and Asher, 1986

\begin{tabular}{|c|c|c|c|c|}
\hline $\begin{array}{l}\text { 3,4,5-trimeth- } \\
\text { oxycinnamic } \\
\text { acid }\end{array}$ & $\begin{array}{l}\text { 3,4,5-trihydroxy- } \\
\text { 3-phenylpropionat } \\
\text { 3,4,5-trihydroxy- } \\
\text { cinnamate }\end{array}$ & mixtures & $\begin{array}{l}\text { Acetobacterium } \\
\text { Strain FD }\end{array}$ & $\begin{array}{l}\text { Bache and Pfennig, } 1981^{\circ} \\
\text { Mountfort and Asher, } 1986\end{array}$ \\
\hline $\begin{array}{l}\text { 3,4,5-trimetho } \\
\text { benzoic acid }\end{array}$ & $\begin{array}{l}\text { 3,5-dihydroxy- } \\
\text { benzoate }\end{array}$ & $\begin{array}{l}\text { acetate } \\
\text { butyrate } \\
\text { acetate } \\
\text { acetate } \\
\text { unknown }\end{array}$ & $\begin{array}{l}\text { Acetobacterium } \\
\text { Clostridium } \\
\text { Syntrophococcus } \\
\text { Desulfotomaculum } \\
\text { Alcaligenes }\end{array}$ & $\begin{array}{l}\text { Bache and Pfennig, } 1981 \\
\text { Krumholz and Bryant, } 1985 \\
\text { Krumholz and Bryant, } 1986 \\
\text { Klemps et al., } 1985 \\
\text { Taylor, 1983** }\end{array}$ \\
\hline
\end{tabular}

Evidence to date indicates that the conversion of methoxybenzenoids to hydroxybenzenoids by acetogenic bacteria involves an O-demethylation reaction. DeWeerd et al. (1988) studied the ability of several such bacteria to metabolize 3-methoxybenzoic acid which was labeled in the methoxy substituent with ${ }^{18} \mathrm{O}$. Isolation and mass spectral characterization of the resulting 3-hydroxybenzoic acid product conclusively demonstrated that the heavy isotope was retained. These results are consistent with the findings of Frazer and Young (1986). 
Using a representative acetogen grown with vanillic acid containing a ${ }^{14} \mathrm{C}$-methoxy substituent, they demonstrated that for every $\mathrm{O}$-methyl carbon converted to ${ }^{14} \mathrm{C}$-acetate, two were oxidized to ${ }^{14} \mathrm{CO}_{2}$. The specific activity of the ${ }^{14} \mathrm{C}$ in acetate suggested that only one carbon of this product was derived from the aryl methoxy substituent. The other apparently was formed in part by the fixation of unlabeled $\mathrm{CO}_{2}$. It will prove interesting to determine if similar mechanisms are also operative in those microorganisms that do not produce acetate or produce other fatty acids as endproducts of the fermentation of aryl methoxy groups.

\section{Nitrogen Heterocyclic compounds}

Nitrogen-containing heterocyclic aromatic compounds are commonly found in fossil fuels (Ho et al., 1980; Later et al., 1981; Novotny et al., 1981) and in the aqueous effluents of coal mining and processing operations (Dailey, 1981). These compounds are also important industrial chemicals and are common components of creosote (National Research Council Committee, 1945). Heterocyclic compounds tend to be more susceptible to anaerobic metabolism than their homocyclic aromatic counterparts because of the instability that the heteroatom imparts to the ring structure (Grbic'-Galic', 1990). The distortion of the $\pi$ electron cloud in heterocyclic compounds facilitates protonation and nucleophilic attack by water.

The anaerobic metabolism of nitrogen heterocyclic compounds has been known for some time (Harary, 1957; Hunt et al., 1958; Pastan et al., 1964; Tsai et al., 1966; Holcenberg and Stadtman, 1969), with interest in this group of chemicals being renewed from the recognition that two-thirds of the estimated 4 million known organic compounds are heterocycles (Wang et al., 1984; Berry et al., 1987; Kuhn and Suflita, 1989b). Even nonoxygenated heterocyclic compounds are susceptible to anaerobic microbial metabolism (Wang et al., 1984; Berry et al., 1987). Berry et al. (1987) examined the anaerobic biotransformation of indole, a constituent of creosote, demonstrating that indole was converted to oxindole under methanogenic conditions. Thus, the primary degradation event involved a hydroxylation reaction. Indole was eventually mineralized to carbon dioxide and methane, and anthranilic acid was suggested as an intermediate in this metabolism. Madsen et al. (1988) suggested that the anaerobic oxidation of indole could also proceed under denitrifying conditions.

Bak and Widdel (1986) enriched for sulfate-reducing bacteria that metabolized skatole, indole, quinoline, and pyridine. An isolate, Desulfobacterium indolicum, was characterized as using indole and quinoline as electron donors and carbon sources. Anthranilic acid and several other nonaromatic compounds were also utilized by this organism. It may be that such materials are intermediates of indole metabolism.

Several research groups (Godsy et al., 1987; Grbic'-Galic', 1990; Pereira et al., 1987a, 1987b) have studied the field evidence for the methanogenic degradation of creosote compounds, includirig quinoline, isoquinoline and 4-methylquinoline. Godsey et al., (1987) measured the concentration of creosote constituents in an aquifer, downgradient from a contamination source, noting that microbial metabolism could account for the removal of 
about $25 \mathrm{mg} / \mathrm{l}$ quinoline and $2 \mathrm{mg} /$ isoquinoline with $47 \mathrm{~m}$ between sampling wells. Moreover, this removal process could not be attributed to sorption of the materials on aquifer solids. Subsequent laboratory studies confirmed that quinoline and isoquinoline were completely degraded in less than 30 days at $25^{\circ} \mathrm{C}$ (Grbic'-Galic', 1990). The primary degradation products of these substrates included quinolinone and isoquinolinone. The latter compounds persisted until the 150th day of incubation before being degraded. Acetate was detected as a transient intermediate, and stoichiometric amounts of methane and carbon dioxide were eventually measured as a result of these bioconversions. Hence, it is conceivable that the volatile fatty acids, acetate and methane detected in the ground water at the site were the result of the degradation of the creosote constituents. A pathway for the methanogenic degradation of quinoline has been proposed (Grbic'-Galic', 1990). Quinoline may be initially oxidized by a hydroxylase to 2-oxoquinoline which is the precursor of several intermediates detected in the culture fluids (e.g. aniline, benzoic acid and phenol). These compounds are then subsequently mineralized. In addition to the monoaromatic intermediates, 2, 3-dimethylpyridine was detected, but its subsequent metabolic fate is unclear. This compound could have been formed through the oxidation of the homocyclic ring of quinoline, followed by ring cleavage. This mechanism presumes a hydroxylated precursor was formed, but as yet, one has not been found.

In contrast to these experiments, Periera et al. (1987a, 1987b) did not observe complete degradation of quinoline, isoquinoline or methylquinoline under anaerobic conditions, observing instead the hydroxylation of the heterocycles to the corresponding oxo derivatives and subsequent $\mathrm{N}-, \mathrm{C}-$, and $\mathrm{O}$-methylation. The discrepancy between the results of these two sets of investigators utilizing the same aquifer material is difficult to interpret but may attest to the metabolic diversity of anaerobic microbial communities. In a recent study, Pereira et al. (1988) used ${ }^{18} \mathrm{O}$ to demonstrate that the oxygen for the hydroxylation of quinoline was derived from water.

The methanogenic degradation of indole has been detected in enrichments from sewage sludge, soils and sediments (Wang et al., 1984; Baldwin et al., 1966; Madsen et al., 1988). Denitrifying soil and sediment enrichments as well as sulfate-reducing enrichments from sludge and marine muds have also proved successful in this regard (Madsen et al., 1988; Bak and Widdel, 1986). Such evidence suggests that this type of metabolism is widespread among anaerobic microbial communities. Similarly, quinoline has been degraded by sulfatereducing enrichments obtained from sludge and marine mud (Bak and Widdel, 1986) and methanogenic incubations derived from aquifer material (Godsy et al., 1987; Pereira et al.,1987a,b). Similarly, isoquinoline is degradable under methanogenic conditions in ground water aquifer samples (Godsy et al., 1987; Pereira et al., 1987a, 1987b; Riley, et al., 1976).

Grbic'-Galic' has noted that the fusion of the benzene ring of indole with the simple heterocyclic pyrrole ring generally increases its chemical stability, but indole can undergo abiotic electrophilic substitution, preferentially on the hetercyclic ring. The favored position for the abiotic substitution is carbon-3 (Streitwieser and Heathcock, 1976). However, the preferred position for substitution in biologically mediated systems is carbon-2 (Berry et al., 1987; Madsen et al., 1988; Grbic'-Galic', 1989). This difference from abiotic reaction systems 
might possibly be a function of the steric requirements of the enzymes involved in the microbial versus chemical production of oxyindole.

Quinoline and isoquinoline are benzopyridines that are oxidized in an anaerobic microbial community to produce hydroxyquinolines which tautomerize in aqueous solutions to form oxoquinolines (Pereira et al., 1987). As mentioned, the mechanism for nitrogen heterocyclic compound oxidation is believed to be similar to homocyclic aromatic compounds (Grbic'Galic', 1989). Therefore, the likely intermediates to be produced would be those oxidized on the heterocyclic ring. However, as pointed out, some of the intermediates of quinoline transformation include those that were oxidized at the benzene moiety. Presumably, this reflects the production of oxoquinoline as an intermediate.

The higher reactivity of heterocyclic aromatic hydrocarbons compared to their homocyclic counterparts is reflected in a generally faster rate of microbial transformation (Grbic'-Galic', 1989). Other nitrogen heterocyclic compounds shown to be metabolized under anaerobic conditions include 4-methylquinoline (Pereira et al., 1987b) and acridine (Knezovich et al., 1990). With acridine, a large number of oxidation products were detected including 2methylquinoline, phenyl-delta-oxopentanoic acid, N-methylanthranilic acid, 3hydroxyanthranilic acid, phenylpropionic acid, benzyl alcohol, benzaldehyde, benzoic acid, 1,2-dimethoxyethylbenzene, phenylacetic acid, $p$-cresol, 4-methoxybenzoic acid and phenyl-2pentenoic acid. In addition, ethyl-, propyl- and hexylbenzene were also detected in experimental incubations, but not in controls. Knezovich et al. (1990) proposed a pathway that involved an initial hydroxylation of acridine at the 3, 4, or 9 position. While the initial oxidation products were not detected, their speculations seem reasonable, based on the nature of the proposed intermediates. It seems clear that not only the heterocyclic ring, but also the homocyclic ring of such condensed structures can undergo the initial oxidative attack. The mineralization of 4-methylquinoline was not detected under methanogenic conditions (Pereira et al, 1987b) while the degradation of acridine was noted under denitrifying, sulfate-reducing, and methanogenic conditions (Knezovich et al., 1990).

Kuhn and Suflita (1989b) found that nicotinic acid was more susceptible to anaerobic metabolism in either methanogenic or sulfate-reducing aquifer slurries than the methylated (picoline isomers) or unsubstituted (pyridine) analogues. In methanogenic incubations, about $46-67 \%$ of the expected amount of carbon in pyridine, 4-picoline and nicotinic acid was recovered as methane. In the same study, no significant degradation of either 2- or 3picoline was evident under methanogenic conditions. However, pyridine, 2-picoline and nicotinic acid were relatively easily degraded under sulfate-reducing conditions, as verified by the loss of the parent substrate and the depletion of the near expected amounts of the terminal electron acceptor. The 3- and 4-picoline isomers were more recalcitrant than the other test nitrogen heterocycles under sulfate-reducing conditons.

As mentioned earlier, the primary degradative event for these compounds likely involves the hydroxylation of the ring with $\mathrm{H}_{2} \mathrm{O}^{\prime}$ at a position adjacent to the nitrogen heteroatom. This transformation has been suggested for nicotinic acid (Hirschberg and Ensign, 1971), purines (Vogels and Van der Drift, 1976), pyrimidines (Vogels and Van der Drift, 1976), quinoline 
(Pereira et al., 1988), and indole (Berry et al., 1987). The hydroxylation of nitrogen heterocycles with water can occur even in the presence of molecular oxygen (Pereira et al., 1988; Dagley and Johnson, 1963). The anaerobic bacterial metabolism and growth on purines and pyrimidines is known for various fermenting organisms, including several clostridia (Vogels and Van der Drift, 1976). Bak and Widdel (1986) demonstrated that sulfate-reducing bacteria could utilize nitrogen heterocylic compounds including quinoline, pyridine, indole and skatole (3-methylindole) as sole sources of carbon and energy. Even larger molecular weight alkyl pyridines may be subject to removal mechanisms under anaerobic conditions (Rogers et al., 1985). Collectively, these investigations indicate that the complete mineralization of many nitrogen heterocyclic compounds that may be in fossil fuels is at least possible under anaerobic conditions. The limits of this type of metabolism need to be fully explored as a potential method of fossil fuel beneficiation.

\section{Sulfur Heterocyclic Compounds}

There is much concern with the presence of organic sulfur in fossil fuels. As pointed out by Foght et al. (1990) and Fedorak (1990), organosulfur compounds in fuels can exist in many forms. The prospects for the anaerobic desulfurization of fossil fuels has virtually been ignored. However, several lines of evidence indicate that anaerobes may have some potential in this regard.

For instance, Eckart et al. (1986) examined the anaerobic biodesulfurization of a crude oil. Mixed cultures grown with lactate as the electron donor and sulfate as the electron acceptor were employed in these experiments. Desulfovibrio spp. were the predominant members of the microbial community. When the $\mathrm{pH}$ was controlled to maintain circumneutral conditions, desulfurization of 26 to $40 \%$ was noted after 48 hours.

The microbial metabolism of thiophene under aerobic conditions appears to be quite difficult (Fedorak, 1990). However, the anaerobic metabolism of this compound has been reported by Kurita et al. (1971). Hydrogen sulfide was detected as a metabolic product, but $\mathrm{C}_{1}-\mathrm{C}_{4}$ hydrocarbons could not be found. The bacterial cultures in this study were obtained from oil sludges and were grown with polypeptone.

Kuhn and Suflita (1989) compared the potential for the anaerobic biodegradation of 12 heterocyclic model compounds containing either an oxygen, nitrogen or sulfur heteroatom. They found that the nitrogen and oxygen heterocyclic compounds were more amenable to destruction in either sulfate-reducing or methanogenic aquifer incubations compared to analogous sulfur heterocycles. No evidence was found for the microbial removal of thiophene, and 2-, or 3-methylthiophene following a three month incubation period. However, 2-thiophenecarboxylic acid was susceptible to anaerobic degradation and $65 \%$ of the theoretically expected amount of methane could be recovered after an eight month incubation. Generally, the three classes of heterocyclic compounds were more susceptible to anaerobic decay when carboxylated rather than when methylated or unsubstituted. 
More complex organosulfur compounds also appear to be somewhat susceptible to anaerobic microbial attack. Kurita et al. (1971) found that benzothiophene could yield hydrogen sulfide as an anaerobic endproduct as well as several unknown carbon compounds. Similarly, Maka et al. (1987) reported that benzothiophene was anaerobically degraded by a mixed culture obtained from soil at a coal storage site. A methanogenic consortium derived from a contaminated aquifer in Pensacola, Florida was able to metabolize benzothiophene, and numerous intermediates were detected. These metabolites included thiophene-2-ol, 4-hydroxybenzene sulfonic acid, 2-hydroxyphenylacetic acid, benzyl alcohol, styrene, phenylacetic acid, 2-oxophenylacetic acid, toluene, phenol, benzoic acid as well as several nonaromatic alcohols and acids (Godsy and Grbic'-Galic', 1989; Grbic'-Galic', 1990). Grbic'-Galic'(1990) suggested that 2-oxobenzothiophene or 7-oxobenzothiophene might be the initial oxidation products of the parent substrate. Thus, the detection of the oxidized intermediates suggests that the initial anaerobic transformation mechanism for benzothiophene might be analogous to that found for the nitrogen heterocyclic compounds (Grbic'-Galic', 1991).

Köhler et al. (1984) and Maka et al. (1987) have reported the anaerobic destruction of dibenzothiophene. In the former study, this compound was dissolved in paraffin oil and added to a sulfate-reducing mixed culture. Under these conditions, about $16 \%$ desulfurization was evident after 6 days of incubation. In the latter study, $60-80 \%$ removal of dibenzothiophene was detected within 2 weeks.

These findings are interesting in light of the results of Kim et al. (1990). They studied the degradation of organosulfur compounds, including several nonaromatic thiols, aromatic sulfides and both benzothiophene and dibenzothiophene. The desulfurization reaction system consisted of harvested Desulfovibrio desulfuricans M6 cells suspended in a sulfate-free medium to which methyl viologen and a $2 \%$ organosulfur substrate in dimethylformamide was added. The reaction was carried out under a hydrogen atmosphere and the standard incubation was at $30^{\circ} \mathrm{C}$ for 5 days.

The greatest amount of removal was observed with benzothiophene (96\%) although dibenzothiophene was also metabolized ( $42 \%$ removal). The reaction product associated with dibenzothiophene was identified by thin layer chromatography and mass spectral evidence as biphenyl. Thus, the organism apparently only cleaved the carbon sulfur bond and left intact the two aromatic nuclei. This has important implications since the fuel value of the chemical would largely be unaffected by such a process. The same authors were also able to modify this system to demonstrate the desulfurization of a Kuwait oil (as evidenced by $\mathrm{H}_{2} \mathrm{~S}$ evolution) using electrochemically supplied electrons (Kim et al., 1990).

\section{Lignoaromatic Compounds and Coal}

Lignin is a three dimensional polyphenolic material that is believed to be somewhat structurally similar to soft coal. Lignin is the most abundant naturally occurring source of aromatic compounds and second only to cellulose as the most abundant organic carbon source on earth. The randomness of the lignin structure and the presence of multiple C-C 
and $\mathrm{C}-\mathrm{O}$ bonds linking phenylpropanoid residues makes lignin highly resistent to anaerobic microbial attack (Zeikus et al., 1982). Many of the aromatic rings of lignin are substituted with methoxyl groups.

Nevertheless, there is little doubt that lignin is substantially modified under anaerobic conditions (Young and Frazer, 1987; Colberg, 1988). Colberg and Young (1982; 1985a, 1985b) prepared radiolabelled carbohydrate-free, soluble lignin fractions of reduced molecular weight that could be characterized by gel permeation chromatography. The incubation of this material with a methanogenic mixed culture enriched from a digester for its ability to utilize lignin, led to the release of labeled carbon as mineralized endproducts (i.e. $\mathrm{CO}_{2}$ and $\mathrm{CH}_{4}$ ) and a shift in the chromatographic profile of the material, indicating the preferential utilization of the lower molecular weight compounds. In fact, the subsequent fractionation of the lignin into three size classes which varied according to their molecular weight range revealed that the fraction containing the largest lignin components (MW > 1000 ) was least susceptible to anaerobic decay and yielded less $\mathrm{CO}_{2}$ and $\mathrm{CH}_{4}$ than other fractions containing smaller molecular weight materials ( $\mathrm{MW} \leq 700)$. The authors concluded that the size of the lignin fragments could potentially limit the rate and extent of anaerobic degradation.

The same authors (Colberg and Young, 1985b) also showed that smaller molecular weight lignin "monomers" and a variety of fatty acids could be released from a soluble lignin fraction that possessed an initial molecular weight of 600-700 (approximately two to four monomer units). The release of this level and range of monomers from the oligomers suggested that the most prevalent $\beta$-aryl-ether bond in lignin is not completely inaccessible to attack by anaerobic microorganisms.

The mechanism of this attack is not clear. Zeikus et al. (1982) examined the anaerobic degradation of radiolabled lignin model dimers and observed the production of labeled $\mathrm{CO}_{2}$ and $\mathrm{CH}_{4}$. Simiarly, Chen et al. (1985a, 1985b) studied the catabolism of veratrylglycerol- $\beta$ guaiacyl ether and dehydrodivanillin by rumen microorganisms. In the latter studies, clear evidence for the metabolism of the parent substrate materials was observed, and a number of intermediates were identified. However, it is not clear whether such materials are anaerobically metabolized one ring at a time, as seems to be the case for more complex polynuclear aromatic hydrocarbons, or if the $\beta$-aryl-ether bonds or other intermonomer linkages are cleaved prior to the metabolism of the aromatic nuclei.

The anaerobic degradation of higher molecular weight lignin is certainly more difficult than the smaller lignin monomers and oligomers. Nevertheless, the anaerobic modification of lignin should not be dismissed as insignificant. Akin (1980) provided electron microscopic evidence for the delignification of Bermuda grass by a rumen isolate. Similarly, Butler and Buckerfield (1979) used bacteria that are normally found in the hindgut of a termite to demonstrate the mineralization of ${ }^{14} \mathrm{C}$-lignin to ${ }^{14} \mathrm{CO}_{2}$. The recovery of the radioactivity as $\mathrm{CO}_{2}$ was greatest when the label was in methoxyl groups and least when present in aromatic rings. 
The anaerobic sulfate-reducing bacterium Desulfovibrio desulfuricans could be grown on a medium supplemented with either Kraft lignin or lignosulfonate (Ziomek and Williams, 1989). Interestingly, lignosulfonate contributed to the growth of the organism by replacing sulfate as an electron acceptor. Spectrophotometric and elemental analysis showed that both lignin preparations could be transformed by this organism. This transformation included the partial depolymerization of the polyphenolic backbone as well as the lignin functional groups.

The contribution of microorganisms to the decomposition of lignin in anoxic sediments has also been addressed by Benner et al. (1984). Lignin derived from Spartina, Juncus, Carex, and Rhizophora were used for these experiments. Using radiolabeling procedures and a nine month incubation at $21^{\circ}-30^{\circ} \mathrm{C}, 1.5 \%$ up to $17 \%$ of the various lignins were mineralized to gaseous endproducts. A thermophilic enrichment $\left(55^{\circ} \mathrm{C}\right)$ was able to mineralize lignin about 10- to 15-fold faster (Benner and Hodson, 1985). Thus, while the anaerobic rates of lignin metabolism were substantially slower than that which could be achieved aerobically, these authors clearly showed that anaerobic biodegradation of lignin is far from insignificant.

The salient features surrounding the anaerobic biodegradation of lignin have been summarized by Young and Frazer (1987). First, the susceptibility to anaerobic decay is influenced by the size of the lignin fragments. While high molecular weight lignins are not totally recalcitrant, the lower molecular weight oligomers and monomers are much more readily metabolized. Secondly, the role for anaerobic microorganisms in lignin degradation seems to be as secondary degraders. That is, the anaerobes act on the fragments of lignin that are released during primary microbial or chemical attack on lignin. In addition to the complete mineralization of some lignin fractions, anaerobes can also release soluble lignin components as a consequence of their metabolic activities. This soluble fraction can be quite substantial and range from $18 \%$ to $74 \%$ of the total amount of lignin (Young and Frazer, 1987).

The generalizations concerning anaerobic lignin biotransformations will probably also prove true when one considers the bioconversion of soft coals to methane. That is because softer coals like lignite possess a structure that is similar to lignin and consists of large aromatic ring polymers joined together by C-C and C-O linkages (Leuschner et al., 1985). The U.S. has coal reserves that are the equivalent of 750 billion barrels of oil, or a 300-year supply (Barik et al., 1990). Subbituminous and lignite coals account for about $60 \%$ of these reserves; the latter represents slightly less than one third of U.S. reserves. The simplest method of using coal is to burn it to recover the energy content. However, the sulfur, nitrogen and ash content of this coal is often so high that environmental concerns are associated with coal combustion (i.e. acid rain). Lignite also has a tendency to smolder in open railroad cars and is thus difficult to transport to remote facilities. If coal is to be a major source of both fuel and commodity chemicals, such problems must be overcome. One possibility is to convert coal to a cleaner fuel such as methane.

A frequently suggested approach is to biologically or chemically solubilize coal to simpler materials that are easier to transport, more water-soluble and often more suceptible to anaerobic decay than the untreated coal. The solubilization products of coal vary in 
molecular weight. In general, very slow degradation rates have been detected with natural samples of soft coals, except with a highly oxidized North Dakota lignite (Scott et al., 1986). Often pretreatment of lignites and subbituminous coals lead to increased depolymerization rates (Scott et al., 1986; Wyza et al., 1987). The methods for the solubilization of various coals remains an extremely active area of research. The methods for such conversions are beyond the scope of this article. However, there is little doubt that such solubilized products can be converted to methane (Davison et al., 1991; Leuschner et al., 1990; Lapin and Matson, 1990; Oren, 1990). The mechanism of such bioconversions, the nature of the solubilized products, and the most efficient means of biological or chemical pretreatments remain far from clear. Moreover, the chemical diversity of coals, even within broad classifications, appears to be quite large and thus generalizations on biodegradability may be difficult to extrapolate between different coals.

Another approach is the direct anaerobic conversion of coal without pretreatment. While rarely studied, Barik (1990) has demonstrated the anaerobic biodegradation of both a North Dakota and a Texas lignite to water soluble products. The rates of biodepolymerization were not measured since these soluble products were rapidly converted to methane gas. Up to $10 \%$ of the total coal carbon in the North Dakota lignite and up to $50 \%$ of the Texas lignite could be converted to methane.

As with the other organic materials mentioned in this review, much remains to be learned about the mechanism of direct coal bioconversion, the kinetics of coal methanogenesis, the scale-up of such processes and the economic feasibility of such a process. A complete assessment of these issues is therefore tied to the lack of understanding about the organisms involved, their ecology, physiology, biodegradation pathways, biochemistry, and genetics. Further research is needed to establish the basic scientific foundation upon which the solution to the very practical challenges associated with the biotechnological utilization of fossil fuels such as coal must be built.

\subsection{FUTURE RESEARCH DEVELOPMENT AND LIMTTATIONS.}

Predictably, most work on fossil fuel beneficiation to date has focused on aerobic microorganisms, since they are easy to handle, grow relatively rapidly, and the majority of microbiologists are skilled in their manipulation. However, this review has demonstrated the potential for the anaerobic metabolism of diverse aromatic substrates. This research area is still in its infancy, and the limits associated with anaerobic bioconversions are far from being fully appreciated.

Therefore, an area of fruitful future investigation will be the exploration of the metabolic limits associated with anaerobic metabolism of fossil fuels. This initiative would include the generation of information on the types of organisms involved and an appreciation for their ecology. It should be remembered that the pursuit of such an objective is not merely defining the metabolism of aromatic chemicals in the absence of oxygen. Rather, a clear effort must be made to define the type of anaerobic conditions under which such metabolism occurs. 
It is quite likely that rapid progress in this area will come from the collaboration of anaerobic microbiologists and organic chemists. The latter will help identify solubilized starting materials and synthesize the necessary substrates or intermediates. Collectively, they can begin to systematically correlate the structure of a substrate with its susceptibility to anaerobic decay under defined conditions.

A corollary to the above recommendation is the establishment of the various metabolic pathways associated with anaerobic metabolism. This task needs to be done in a rigorous fashion to clearly delineate rate limiting steps. Inherent in this recommendation is the isolation of the requisite microorganisms and microbial consortia, the identification of the metabolic intermediates, the isolation of the enzymes involved in such bioconversions, and an appreciation of the genetic factors controlling this metabolism.

The anaerobic beneficiation of fossil fuels has several advantages over aerobic methods. First and most obvious, the expense associated with aeration is eliminated. This fact will have a large impact on the economic feasibility of any biotechnological process. Secondly, it is clear that many of the bioconversions can conceivably result in the recovery of a valuable fuel in the form of methane gas. This will also influence the economics of fossil fuel processing. Moreover, as the pathways of anaerobic metabolism become better appreciated, it may be that anaerobic reactions can result in products that retain their fuel value. An example is the desulfurization of dibenzothiophene by sulfate-reducing bacteria (see above). In this reaction, the almost exclusive removal of the sulfur heteroatom leaves the basic carbon skeleton of the molecule and associated fuel value essentially intact. From an economic standpoint, this would be considered quite desirous. The limited amount of scientific literature on the anaerobic metabolism of heterocyclic compounds allows one to speculate that analogous reactions may also occur with nitrogenous heterocycles. Therefore, anaerobic denitrogenation reactions may also prove useful. Such bioconversions (desulfurization, denitrogenation, deoxygenation, etc.) should be sought. An economic assessment of anaerobic fossil fuel beneficiation should also be compared to aerobic methodologies.

The point of fossil fuel processing where anaerobic techniques are employed also needs consideration and economic analysis. For instance, it may be possible to introduce desirable microorganisms either before or after the fossil fuel is collected. In the former case, it may be possible to leave the material in place for extended periods of time in order to slowly effect the desired process. After that time a more desirable product can be harvested in typical fashion. Anecdotal evidence of the progressive souring of oil fields suggests that anaerobic processing in the field is not beyond the realm of possibility.

Another area for intense investigation is the solubilization of insoluble fossil fuels such as coal. This has been attempted numerous times with varying degrees of success, but seemingly few generalizations have emerged on the most efficient ways of accomplishing this task. A concentrated research effort on the chemical and biological mechanisms of coal solubilization should be undertaken with the ultimate objective of increasing the susceptibility of the initial substrate to methanogenic fermentation. Methods to accurately assess this type 
of fossil fuel processing should also be developed. In this fashion, the solubilization procedures can be contrasted with approaches designed for the direct methanogenic fermentation of coal.

The prospects for the anaerobic metabolism of fossil fuel hydrocarbons are truly enormous. It is hoped that research efforts in the immediate future will be designed toward extending the fundamental knowledge base on the mechanisms of anaerobic bioconversion. Ultimately, this knowledge base will serve as a solid foundation upon which biotechnological solutions to fossil fuel beneficiation will be built.

\subsection{RECOMMENDATIONS AND PRIORITY STATUS.}

\section{HIGH-PRIORITY}

- Explore the limits of anaerobic metabolism and its potential in the liquefaction, desulfurization, denitrogenation, and deoxygenation of fossil fuels.

- Identify metabolic pathways and their regulation.

- Focus on bioconversions that retain the fuel value in the product.

- Explore in situ methodologies for the beneficiation of fossil fuels.

- Correlate structure of fossil fuel substrates with their susceptibility to anaerobic decay.

- Develop solubilization with the aim of increasing the susceptibility of the products to methanogenic fermentation.

\section{LOWER-PRIORITY}

- Isolate effective microorganisms and/or consortia

a) select for efficient fossil fuel utilization

b) nutritionally characterize the isolates.

- Economic assessment of aerobic versus anaerobic beneficiation processes.

- Explore the direct conversion of soft coals to methane. 


\section{Chapter 7}

\section{BIOCONVERSION OF HYDROCARBONS TO ADDED-VALUE PRODUCTS.}

\subsection{INTRODUCTION.}

The chemical industry uses petroleum and natural gas as primary feedstocks for the manufacture of numerous organic chemicals. The manufacture of organic chemicals exists within an established and well-integrated industry with large scale facilities capable of producing high purity chemicals at relatively low cost. Accordingly, the ability to maintain low production costs plus low pricing structures serve as significant barriers to new production routes, particularly those involving bioconversions of various petro-feedstocks. A particularly interesting argument has been advanced for the production of organic chemicals through bioconversion of biomass (Leeper and Andrews, 1991). Such alternatives for the production of chemicals currently encounter highly unfavorable economics, failing to realistically compete with traditional, petroleum-based manufacturing processes for commodity chemicals.

The development of biological processes for the bioconversion of fossil fuels to commodity chemicals merits little serious attention at this time, due primarily to existing low cost structures and the expected future price increases in feedstocks over the next 10-30 years. However, bioconversions of fossil fuels or refined hydrocarbon feedstocks offer opportunities for the development of specialty chemicals with high-added value to compete in existing markets and to develop new market niches for new products with superior performanceeffectiveness over existing product lines. An added incentive for the development of such specialty chemicals resides in the ability of biological systems to catalyze stereo and regio selective reactions coupled to high efficiencies, offering potential new biocatalytic routes for the cost-effective production of new specialty chemicals plus improving existing specialty chemical manufacturing processes.

This treatise addresses the development of specialty chemicals through bioconversion of fossil fuel feedstocks in the context of new technologies such as nonaqueous reaction mixtures, immobilization of either intact microorganisms or isolated enzyme systems which maintain functional biocatalytic activities in hydrophobic media, and genetic engineering technology. 


\subsection{STATUS OF BASIC AND APPLIED RESEARCH.}

Hydrocarbon microbiology has compiled comprehensive data-bases concerning the biotransformation of various paraffinic and aromatic hydrocarbons. Reviews concerning developments in hydrocarbon microbiology have appeared at regular intervals, with a general emphasis on the physiology and biochemistry of hydrocarbon-utilizing microorganisms (Ratledge, 1980; Buhler and Schindler, 1984; Singer and Finnerty, 1984b). Exploitation of various facets of hydrocarbon microbiology are few, with developments in the application of hydrocarbon-utilizing microorganisms and their physiological processes suggesting a potential for commercialization of useful products (Finnerty and Singer, 1983). Numerous products resulting from hydrocarbon oxidations appear of importance as value-added articles of commerce. This chapter discusses the use of hydrocarbon-utilizing microorganisms in the production of specialty chemicals, the development of biosurfactants, and single cell protein and single cell oil technologies. Emphasis is directed to those aspects of hydrocarbon microbiology amenable to technology development and, where possible, an examination of the economics and technical constraints associated with such applications.

\section{SPECIALTY CHEMICALS.}

The seventies witnessed intensive research into the development of chemicals from microorganisms. The production of unique products and biochemicals by hydrocarbonutilizing microorganisms was recognized early because of their metabolic potential to effect special biotransformations of an unusual nature and specificity. The use of hydrocarbonutilizing microorganisms for the production of bioproducts has certain attractive features meriting commercial interest. Advantages noted are the specificity of the primary oxidative attack on hydrocarbons yielding products difficult to obtain by other means and the ability of such biological systems to operate at ambient temperatures and pressures with low activation energies and high turnover numbers per catalytic site (May, 1979; Drozd, 1980). Disadvantages associated with hydrocarbon fermentations are: the poorly understood enzymological parameters of many of the reactions, the products released into a dilute aqueous stream making recovery difficult and expensive, and the many products which are toxic to the producing microorganism. Nevertheless, the development of hydrocarbon fermentations has produced commercial scale production facilities capable of significant output. Today, few chemicals are manufactured commercially by hydrocarbon fermentations. The production of various bioproducts from specific hydrocarbons has generated an extensive diversity of products (Abbott and Gledhill, 1971; Bird and Molton, 1972; Miall, 1978; Ratledge, 1980; Buhler and Schindler, 1984; Singer and Finnerty, 1984b). Numerous publications and patents emerged on the production of amino acids, fatty acids, vitamins, flavor enhancers such as 5'-nucleotides, polyhydroxy alcohols, pigments, antibiotics, wax esters, tricarboxylic acid cycle intermediates and enzymes, all of which are related to expanding the potential of single cell protein technology for added-value economic benefits. 


\section{General Aspects of Hydrocarbon Oxidations}

The metabolic capacity of bacteria, yeasts, and fungi to utilize hydrocarbons as sole sources of carbon and energy is of ubiquitous distribution in nature. The pathway of alkane oxidation is:

$$
\mathrm{RCH}_{2} \mathrm{CH}_{3} i+\mathrm{O}_{2} \rightarrow \mathrm{RCH}_{2} \mathrm{CH}_{2} \mathrm{OH} \rightarrow \mathrm{RCH}_{2} \mathrm{CHO} \rightarrow \mathrm{RCH}_{2} \mathrm{COOH}
$$

These oxidations are obligately $\mathrm{O}_{2}$-dependent reactions, catalyzed by monooxygenases or dioxygenases. Variations on this reaction sequence are known, representing diterminal and subterminal oxidations (Singer and Finnerty, 1984b).

$$
\mathrm{HOOCCH}_{2}\left(\mathrm{CH}_{2}\right)_{\mathrm{n}} \mathrm{CH}_{2} \mathrm{COOH}<-\mathrm{CH}_{3} \mathrm{CH}_{2}\left(\mathrm{CH}_{2}\right)_{\mathrm{n}} \mathrm{CH}_{2} \mathrm{CH}_{3} \rightarrow \mathrm{CH}_{3} \mathrm{CH}_{2}\left(\mathrm{CH}_{2}\right)_{\mathrm{n}} \mathrm{COCH}_{3}
$$

In all instances, fatty acids or methyl ketones arise and either undergo further degradation, are assimilated into the cellular lipids, or accumulate as extracellular products. Qualitative and quantitative differences occur in the products resulting from alkane metabolism as compared to more conventional substrates. A relationship between the chain length of the alkane substrate and the chain length of cellular and extracellular fatty acids has been demonstrated in certain bacteria (Makula and Finnerty, 1968; Dunlop and Perry, 1975). In general, the growth of microorganisms on alkanes as a sole source of carbon and energy reflects the following characteristics:

1. Even numbered carbon alkanes $\left(\mathrm{C}_{12}, \mathrm{C}_{14}, \mathrm{C}_{16}, \mathrm{C}_{18}\right)$ yield even carbon fatty acids with the cellular fatty acid composition reflecting the alkane carbon number.

2. Odd numbered carbon alkanes $\left(\mathrm{C}_{11}, \mathrm{C}_{13}, \mathrm{C}_{15}, \mathrm{C}_{17}\right)$ yield odd carbon numbered fatty acids with the cellular fatty acid composition reflecting the alkane carbon number.

Studies describing the quantitative and qualitative changes that occur in the cellular and extracellular lipids of Acinetobacter species HO1-N have been reported (Makula et al., 1975; Singer et al., 1985). These results are summarized in Table 1 to demonstrate the effect of substrate on lipid production and composition. The cellular phospholipids, mono-and diglycerides increase 3-, 18- and 50-fold, respectively, in alkane- and fatty alcohol-grown cells. Extracellular lipid accumulation is significantly increased in alkane- and fatty alcohol-grown cells with the fatty acid carbon number representing $>95 \%$ 16-carbon fatty acids in hexadecane- and hexadecan-l-ol grown cells. Alternate alkane substrates $\left(\mathrm{C}_{13}, \mathrm{C}_{14}, \mathrm{C}_{15}, \mathrm{C}_{17}\right)$ reflect the same relationship between alkane carbon number and the carbon number of the resulting fatty acids. Such substrate directed physiological relationships offer the ability to tailor-make lipids with specific fatty acid compositions and high added-value potential through hydrocarbon fermentations. 
Table 1

CEILULAR AND EXTRACELLULAR LIPIDS OF ACINETOBACTER

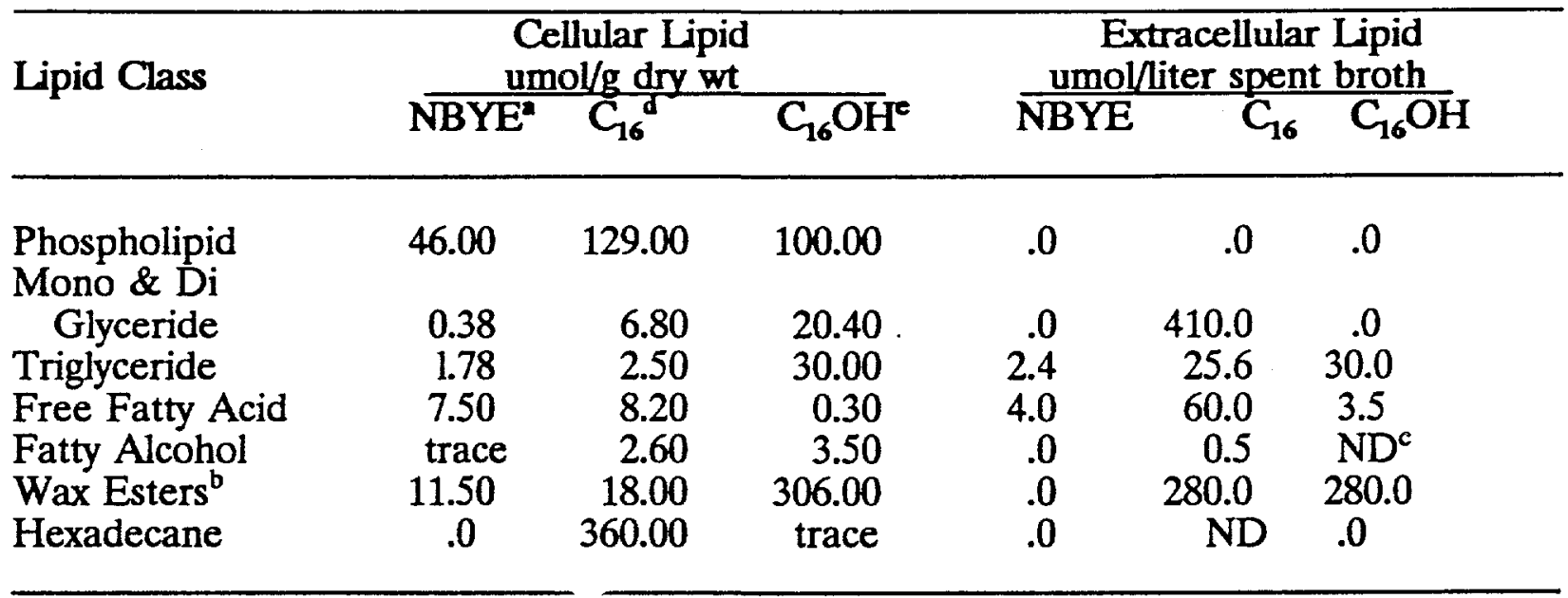

a) $\quad N B Y E$ is $0.8 \%$ nutrient broth- $0.5 \%$ yeast extract growth medium.

b) Esters derived from $N B Y E$-grown cells were low molecular weight, water-soluble esters. Esters derived from hexadecane and hexadecanol-grown cells were 32 carbon esters.

c) ND is not determined.

d) $C_{16}$ is hexadecane grown cells.

e) $C_{10} \mathrm{OH}$ is hexadecan-1-ol grown cells.

The oxidation of aromatic hydrocarbons has always been thought to be an obligately $\mathrm{O}_{2}$ dependent reaction found in bacteria, yeasts and fungi capable of utilizing substrates such as benzene, naphthalene, anthracene, and phenanthrene as sole sources of carbon and energy. Recent information indicates significant rates of aromatic hydrocarbon biodegradation under anaerobic conditions (see Chapter 6). The generalized pathway of aerobic aromatic hydrocarbon oxidation is:

\section{BENZENE $\rightarrow$ BENZENE-DIHYDRODIOL $\rightarrow$ BENZENE-1,2-DIOL $\rightarrow$ MUCONIC ACID}

The bioconversion of simple-, substituted-, and polycyclic-aromatic hydrocarbons is welldocumented in the microbiological literature (Abbott and Gledhill, 1971; Cain, 1980; Cerniglia, 1984; Sariaslani, 1989). The biotransformation of methylbenzenes to corresponding acids, dihydroxy derivatives, methyl-substituted muconic acid, dihydroxy-ptoluic acid, and salicylate are a few examples of conversions effected to date. The genetics of aromatic hydrocarbon oxidation is particularly well-studied in comparison to the genetics of alkane oxidations (Singer and Finnerty, 1984a). The involvement of plasmid-localized genes coding for aromatic hydrocarbon oxidations and the ability to manipulate these genes into expression vectors containing strong promoters offers exciting possibilities for the development of cost-effective processes in the use of genetically-engineered microorganisms for the production of value-added specialty chemicals (see Chapter 8 for details).

Biotransformation of Alkane Analogues.

The oxidation of an homologous series of symmetrical dialkyl ethers varying in carbon number from $\mathrm{C}_{14}$ to $\mathrm{C}_{20}$ was studied in Acinetobacter species HOl-N (Modrzakowski et al, 
1977; Modrzakowski and Finnerty, 1980). These substrates were selected on the basis of their structural similarity to alkanes of identical carbon number, differing only by the presence of an ether oxygen positioned in the middle of the molecule. This study described a new pathway in prokaryotic bacteria involving an internal carbon-carbon scission reaction, resulting in the formation of a homologous series of alkoxyacetic acids as nonmetabolizable extracellular endproducts. These products accumulate in the culture broth in direct stoichiometric relationship to the disappearance of the dialkyl ether substrate. Concomitantly, an alkanedioic acid is formed which serves as the sole source of carbon and energy for growth of the organism (see Table 2). The pathway of dialkyl ether metabolism is:

$$
\begin{gathered}
\mathrm{CH}_{3}\left(\mathrm{CH}_{2}\right)_{\mathrm{n}} \mathrm{O}-\left(\mathrm{CH}_{2}\right)_{\mathrm{n}} \mathrm{CH}_{3}+\mathrm{O}_{2} \rightarrow \mathrm{CH}_{3}\left(\mathrm{CH}_{2}\right)_{\mathrm{n}}-\mathrm{O}-\left(\mathrm{CH}_{2}\right)_{\mathrm{n}} \mathrm{COOH} \\
\mathrm{CH}_{3}\left(\mathrm{CH}_{2}\right)_{\mathrm{n}}-\mathrm{O}-\mathrm{CH}_{2} \mathrm{COOH}+\mathrm{HOOC}\left(\mathrm{CH}_{2}\right)_{\mathrm{a}} \mathrm{COOH}
\end{gathered}
$$

These studies were extended further to examine the types of endproducts resulting from the oxidation of phenoxy-substituted fatty acids, n-fatty acids, and alkanes (see Table 2). The nature of products arising from the oxidation of such substrates indicates a novel pathway involving the scission of carbon-carbon bonds. In all examples cited in Table 2, three facts emerge which are of fundamental importance: 1) a short-chain alkane, a phenoxysubstituted short-chain acid or an alkoxy-substituted short-chain acid results from the oxidation of alkanes, fatty acids, phenoxy-substituted fatty acids and alkoxyalkanes; 2) alkanedioic acids are produced which constitute the sole source of carbon and energy for cell growth; and 3) the ether oxygen of the dialkyl ether is metabolically refractory. Such studies illustrate the potential that exists for future basic research initiatives that offer biotechnological opportunities for the production of cost-effective, high value-added specialty chemicals.

Table 2

PRODUCTS FROM OXIDATION OF DIALKYL ETHERS, ALKANES, FATTY ACIDS AND SUBSTITUTED FATTY ACIDS

\section{Substrate}

Diheptyl ether

Dioctyl ether

Dinonyl ether

Didecyl ether

Pentadecane

Hexadecane

Heptadecane

Pentadecanoic acid

Hexadecanoic acid

Heptadecanoic acid

Phenoxy-11-undecanoic acid

Phenoxy-12-dodecanoic acid

\section{Products}

Heptoxy-2-acetic acid; glutaric acid Octoxy-2-acetic acid; adipic acid Nonoxy-2-acetic acid; pimelic acid Decoxy-2-acetic acid; suberic acid Pentane; 1,10-decanedioic acid Hexane; 1,10-decanedioic acid Heptane; 1,10-decanedioic acid Pentane; 1,10-decanedioic acid Hexane; 1,10-decanedioic acid Heptane; 1,10-decanedioic acid Phenoxy-3-propionic acid; 1,8-octanedioic acid

Phenoxy-4-butyric acid; 1,8-octanedioic acid 


\section{Specialty Chemicals From Hydrocarbon Fermentations.}

A summary discussion follows to document the various initiatives occurring in hydrocarbon microbiology and commercial development over the past several years and to indicate, where possible, the reasons for the absence today of viable full-scale production of specialty chemicals through hydrocarbon fermentations. Programs for the development of specialty chemicals through biological processes developed in the United States, Japan, England, Germany, and Russia in the sixties and seventies. Hydrocarbon fermentations for the production of extracellular amino acids developed early in Japan, although efficient chemical syntheses exist for most of the important amino acids. Chemical syntheses, however, yield racemic mixtures which are usually difficult and expensive to separate; whereas, biological systems offer advantages in producing almost exclusively the L-isomer of amino acids. Comprehensive reviews detail the production of amino acids by hydrocarbon fermentations (Abbott and Gledhill, 1971; Kinoshita and Nakayama, 1978; Fukui and Tanaka, 1980).

Tricarboxylic acid (TCA) cycle intermediates have been produced through hydrocarbon fermentations employing paraffinic substrates. However, only citric acid production reached serious levels of consideration for commercial development. The increases in crude oil prices that developed in the late seventies made further commercial development not economical and projects were canceled. Other TCA cycle intermediates such as malate, fumarate and succinate are either of marginal commercial importance or are synthesized more economically by chemical means. Early patents concerning citric acid production from the fermentation of paraffin mixtures $\left(\mathrm{C}_{9}\right.$ to $\left.\mathrm{C}_{20}\right)$ by Yarrowia lipolytica taught reduced fermentation residence time and increased product yields. However, the simultaneous production of isocitrate reduced citric acid yields. Later work focused on successfully reducing the conversion of citrate to isocitrate with mutants blocked at aconitate hydratase, competitive inhibitors and uncoupling agents. Currently, the production of citric acid through hydrocarbon fermentations is not practiced on a commercial scale, probably for reasons of the associated economics in using hydrocarbon feedstocks.

The production of specific fatty acids through directed hydrocarbon fermentations offers some possibilities for the development of added-value products. The major difficulty in the microbial production of fatty acids resides in the fact that few microorganisms accumulate significant amounts of free fatty acid as either cellular or extracellular products. In addition, if accumulation does occur, product buildup becomes toxic to the microorganism. However, the long-chain fatty acids and alkanedioic acids, and omega-1 hydroxy fatty acids and primary and secondary alcohols can be produced through directed hydrocarbon fermentations in low yields without degradation of the parent alkane carbon chain. Such products have commercial applications due to their surface activity and ability to stabilize emulsions as well as uses in the formulation of plasticizers, synthetic resins and polymers, lubricants and cosmetics.

Extracellular wax esters are produced by Acinetobacter, Moraxella and Nocardia species grown on alkanes. Alkane-grown Acinetobacter species HOl-N produces extracellular wax esters, the composition of which depends on the chain length of the alkane substrate (see Table 3). Interestingly, hexadecan-l-ol-grown cells produced a total of $273 \mathrm{mg}$ of cetylpalmitate/liter as compared to $138 \mathrm{mg}$ cetylpalmitate/liter for hexadecane-grown cells 
(Makula et al., 1975; Singer et al., 1985). Similar studies were reported where wax ester yields were $275 \mathrm{mg} /$ liter from a mutant of Acinetobacter unable to degrade the wax ester product (Geigert et al., 1984). Interest in microbially-produced wax esters stems from the possibility of developing alternate sources of cetylpalmitate, which is currently obtained from the sperm whale, and for developing long-chain, di-unsaturated wax esters as jojoba oil substitutes.

Table 3

EXTRACELLULAR WAX ESTERS PRODUCED BY ACINETOBACTER

$\underline{\text { Substrate }}$

Decane

Dodecane

Tetradecane

Pentadecane

Hexadecane

Heptadecane

Octadecane

Hexadec-1-ene

Octadec-1-ene

\section{Product}

Decylhexadecanoate

Dodecylhexadecanoate

Tetradecylhexadecanoate

Pentadecylhexadecanoate

Hexadecylhexadecanoate

Heptadecylhexadecanoate

Heptadecylheptadecanoate

Heptadecyloctadecanoate

Octadecylhexadecanoate

Octadecyloctadecanoate

Hexadec-15-enylhexadecanoate

Octadec-17-enylhexadecanoate

Octadec-17-enylheptadecanoate

Octadec-17-enyloctadecanoate

The production of biologically-derived polyesters through polymerization of hydroxy fatty acids has attracted attention for years. These biological polyesters are biodegradable, unlike the synthetic polymers derived from petrochemicals. Serious attention is currently focused on the commercial development of poly- $\beta$-hydroxybutyrate (PHB) as a biodegradable, thermoplastic polyester with properties similar to polyethylene and polypropylene. Commercial applications suggested for PHB are degradable sutures, controlled drug release and biodegradable wrappers. Full-scale commercial production of PHB is under evaluation, although a production fact of considerable economic magnitude is that 2.5 tons of glucose are required to produce 1 ton of PHB. Again, the economics of production becomes a contributing factor to success or failure, with success depending on improvements to the production process and the price the market is willing to pay for a biodegradable polyester product.

The modification of polyester synthesis has been explored by employing alternate secondary substrates for the formation of different poly-hydroxyalkanoates (PHA). Reports have appeared on the synthesis of poly- $\beta$-hydroxyoctanoate and poly-B-hydroxypentanoate following growth of PHB-producing microorganisms on decane (deSmet et al., 1983) and 
valerate (Doi et al., 1987), respectively. These polyesters are produced along with $\mathrm{PHB}$, the ratio of PHB to PHA being dependent on the concentration of the secondary substrate. Syntrophomonas wolfei grown on crotonate produced PHB containing only the D-isomer of $\beta$-hydroxybutyrate; whereas, when grown with trans-2-pentenoate or other hexenoates, produced PHB containing $\beta$-hydroxypentanoate or $\beta$-hydroxyhexanoate, respectively (Amos and McInerney, 1991). The PHB-PHA heteropolymers exhibit improved properties suitable for plastic molding and appear certain to secure a favorable market niche due to their biodegradability.

The formation of alkanedioic acids has been frequently reported as extracellular products resulting from the microbial oxidation of alkanes. A mutant strain of Torulopsis candida was reported as producing decanedioic acid when grown on decane with yields increasing to 33 g/liter of decanedioic acid (Kaneyuki et al., 1980). Recently, a mutant strain of Candida tropicalis was reported as producing dodecanedioic acid when exposed to dodecane (Hill et al., 1986). High yields of alkanedioic acids resulted from the oxidation of $C_{12}$ to $C_{16}$ alkanes. Another laboratory has reported on alkanedioic acid formation by $C$. tropicalis yielding tridecanedioic acid and dodecanedioic acid from the oxidation of tridecane and dodecane, respectively, (Yi and Rehm, 1982a, 1982b, 1982c). A biotransformation of alkanes to alkanedioic acids was developed employing $C$. tropicalis immobilized in carrageenan (Yi and Rehm, 1982d).

Several process patents have appeared concerning the production of alkanedioic acid (Buhler and Shindler, 1984). An example of one patent concerns a process whereby a mutant strain of $C$. tropicalis is grown on a carbohydrate-containing medium and then transferred to a non-growth medium containing hexadecane or hexadecan-l-ol. These substrates are oxidized to hexadecanedioic acid with yields approaching $4 \mathrm{gm} / \mathrm{liter}$, representing a $40 \%$ conversion of substrate to product (Phillips Petroleum Co, 1976). Commercial production of tridecanedioic acid from tridecane is operated by the Nippon Mining Company, Japan, at a scale of 150 tons/year (Uemura et al., 1989). The process employs a mutant of $C$. tropicalis with production yields of $70 \%$ alkanedioic acids resulting from the oxidation of alkanes. In China, an omega-oxidation system derived from C. tropicalis has been studied which yields $75 \mathrm{gm} / \mathrm{liter}$ of 1,13-tridecanedioic acid and $109 \mathrm{gm} / \mathrm{liter}$ of 1,15pentadecanedioic acid from tridecane and pentadecane, respectively (Chiao, 1988). This system was extended to the oxidation of long-chain, unsaturated fatty acids to prepare unsaturated dicarboxylic acids, preparatory intermediates for large alicyclic compounds such as muscone. There are no other commercial operations known in this area, due mainly to the marginal cost-effectiveness in comparison to chemical syntheses.

\section{MICROBIAL BIOSURFACTANTS.}

Biosurfactants are surface-active agents derived from biological sources which, like synthetic surfactants, exhibit characteristic physical and chemical properties. Structurally, surfaceactive molecules contain hydrophilic and hydrophobic components, a property which enables such molecules to concentrate at interfaces of air/water or oil/water and thereby reduce surface tension and interfacial tension, respectively. This, in turn, produces effects including solubilization, emulsification/deemulsification, dispersion/flocculation, wetting/dewetting, 
foaming/defoaming, and detergency. At the critical micelle concentration (CMC), surfaceactive molecules form micellar aggregates with surface activity reduced to minimum values. Surfactants and biosurfactants are classified into four groups based on charge-type: anionic, cationic, nonionic, and amphoteric. A number of surface-active microbial products which exhibit surface activity have been identified. However, limited information exists on the definitive chemical and physical properties of these surface-active products or on the types and distribution of surfactant-producing microorganisms.

In industrial applications, surfactants are used either as essential additives or processing aids, or as a minor component of a particular system of formulation. In such cases, the surfactant is regarded as a true "performance" or "effect" chemical where detailed knowledge of its structure and physical properties are essential for selection of the optimum surfactant system for specific end uses. In other cases, a single surfactant is unable to provide all the physical properties required or desired, and two or more surfactants are formulated to provide the desired set of properties and effects.

Biosurfactants have become recognized as important products arising from diverse biological sources. The physical properties of these biosurfactants are potentially important to a number of industrial and consumer applications and processes. Biosurfactants represent effective replacements, as well as enhancers, to synthetic surfactants due to their physical and chemical properties, potential low toxicity, biodegradability, and specificity. Comparative physical properties of selected proprietary biosurfactants developed by Finnerty Enterprises, Inc. to selected synthetic surfactants are:

Biosurfactants

FEI-2230

FEI-197-M

FEI-92-A

FEI-109-O

FEI-305-H

FEI-100-R

FEI-81-Q
Interfacial tension $(\mathrm{mN} / \mathrm{m})$

1.00

$0.02-0.0004$

6.8

0.01

0.008

0.001

0.0004
0.03

0.30

0.018

0.160

$\mathrm{CMC}(\mathrm{mg} / \mathrm{ml})$

0.005

0.075

\section{Synthetic Surfactants}

Sodiumlaurylsulfate

0.02

Cetyltrimethylammonium bromide

Tween 20

5.80

0.60

Petroleum sulfonate

$<1.0$ 
A number of advantages reside in the development of biosurfactants as specialty chemicals and marketable articles of commerce for target markets. These advantages are reflected in the unique solution properties associated with biosurfactants such as:

1. Unique structural and physical properties which are equal, if not superior, to synthetic surfactants with respect to minimum interfacial tension values at significantly lower CMC values.

2. Biological characteristics of biosurfactants that offer potential commercial opportunities as specialty chemicals include antimicrobial, antiviral, anticancer, and immunostimulatory activities of interest to health care and pharmaceutical applications; the fact that most biosurfactants are extracellular products which affect downstream process economics; and the fact that biosurfactants can be "tailor-made" with specific physical properties through physiological manipulations to match specific application targets. Additionally, biosurfactants have numerous functional groups which can serve as chemical modification sites to produce a large array of semisynthetic biosurfactants from a single biologically-derived product. The successful marketing of semisynthetic products is well-established in the drug industry.

3. Biosurfactants are biodegradable and, accordingly, offer low toxicity profiles to the environment. The structural constituents of biosurfactants consist of molecular species for which well-established pathways of metabolism exist. This fact offers an advantage in terms of the ultimate positive environmental impact resulting from field applications of biosurfactants.

\section{Microbial Sources.}

Biosurfactants are produced by a variety of microorganisms including bacteria, yeasts, and fungi (Table 4). The topic of microbial biosurfactants and bioemulsifiers, their occurrence, chemistry and surface properties has been reviewed (Zajic and Panchal, 1976; Cooper and Zajic, 1980; Zajic and Mahomedy, 1984). The term bioemulsifier refers to biologicallyproduced emulsion stabilizers which may or may not exhibit surface activity. Biosurfactants have generally been associated with the growth of microorganisms on alkanes. Most of the biosurfactants listed in Table 4 were discovered as products of alkane metabolism with a physiological role related to the transport and uptake of alkane by the microbial cell.

Biosurfactants, in certain cases, are produced during the growth of alkane-utilizing microorganisms on nonhydrocarbon substrates. Sophorolipids are produced by Torulopsis species during growth on alkanes or on glucose supplemented with vegetable oil. Rhamnolipids are produced by Pseudomonas species on both alkane and nonalkane growth substrates. Acinetobacter calcoaceticus RAG-l produces an emulsion stabilizer on either alkane or nonalkane growth substrates. Biosurfactants produced by nonhydrocarbon-utilizing microorganisms include surfactin by Bacillus subtilis, sophorolipid by Candida bogoriensis from a glucose-yeast extract medium and a surface-active lipopeptide from Bacillus licheniformis grown on sucrose. 
Table 4

\section{MICROBIAL BIOSURFACTANTS AND BIOEMULSIFIERS}

\section{Microorganism}

Torulopsis species

Pseudomonas species

Rhodococcus erythropolis

Rhodococcus species Hl3-A

Candida species

Candida bogoriensis

Acinetobacter species

Corynebacterium lepus

Candida petrophilum

Bacillus subtilis

Bacillus licheniformis

Candida tropicalis

Corynebacterium hydroclastus
Biosurfactant/Bioemulsifier

Sophorolipids

Rhamnolipids

Trehalose lipids

Trehalose mycolates

Sucrose \& fructose lipids

Trehalose lipids

Mannosyl erythritol lipid

Sophorolipid

Fatty acid, glycerides, emulsan

Corynemycolic acids

Peptidolipid

Cyclic lipopeptide

Cyclic lipopeptide

Mannan-fatty acid complex

Proteo-lipid-carbohydrate complex

Microbial biosurfactants are lipoidal molecules which include glycolipids, neutral lipids, lipopeptides, fatty acids, phospholipids, and high molecular weight polymers such as lipoproteins, lipopolysaccharide-protein complexes and polysaccharide-protein-fatty acid complexes. Corynemycolic acids are $\alpha$-branched, B-hydroxy long-chain fatty acids produced by Corynebacterium species as cellular or extracellular products. Sophorolipids are extracellular anionic glycolipids produced by Torulopsis bombicola and Candida bogoriensis. The Torulopsis glycolipid consists of sophorose and 17-hydroxyoctadecanoic acid plus esterified acetate; whereas, sophorolipid produced from $C$. bogoriensis contains sophorose glycosidically linked to docosanoic acid with acetate esterified to the 6 and 6 ' hydroxyls of sophorose. Rhamnolipids are anionic extracellular glycolipids produced by Pseudomonas species consisting of 2 molecules of $L$-rhamnose and 2 molecules of $B$-hydroxydecanoic acid. Trehalose dimycolate is a cell-bound glycolipid produced by Rhodococcus erythropolis. This glycolipid consists of $\alpha$-branched, $B$-hydroxy mycolic acids esterified to the 6 and 6 ' hydroxyl of trehalose. Surfactin is an extracellular lipopeptide produced by Bacillus subtilis. Surfactin is a cyclic lipopeptide containing seven amino acids which are amide-linked to Bhydroxyisopentadecanoic acid at the glutamate residue and ester-linked to the fatty acid at the leucine residue. 


\section{A Biosurfactant Case Study.}

A soil microorganism was isolated and identified as a Rhodococcus species which produced an extracellular biosurfactant when grown on long-chain alkanes or high-paraffin based crude oils (Finnerty and Singer, 1984; Singer and Finnerty, 1990). Characterization of this extracellular surface-active product established the chemical and physical properties of the molecule. The product is an anionic glycolipid consisting of trehalose and a complex mixture of fatty acids and mycolic acids. The biosurfactant exhibits a CMC of $1.5 \mathrm{mg} / \mathrm{ml}$ with minimum interfacial tension values of $0.02 \mathrm{mN} / \mathrm{m}$ and $0.00006 \mathrm{mN} / \mathrm{m}$ in the presence of a coagent (Singer et al., 1990). The surface activity is not significantly affected by brine, extreme $\mathrm{pH}$ values, divalent cations, or temperature. The biosurfactant forms stable oil-inwater emulsions and exhibits phase behavior with the formation of a middle phase.

The application of this biosurfactant to heavy oils such as Venezuelan Monogas and Cerro Negro crudes, Westminster crude and California crudes having API gravity values between 8 to 15 , results in the formation of stable oil-in-water emulsions with a greater than $95 \%$ reduction in their relative viscosities. Characteristics of the treated oil were: 1) formation of a stable emulsion containing approximately $30 \%$ water; 2) improved rheological properties with flow characteristics significantly improved from the original crude oil, including reduced adherence to surfaces; and 3) destabilization of the emulsion by increases in temperature to $60^{\circ} \mathrm{C}$. This biosurfactant exhibits a potential for the pipeline transportation of heavy crude oils, a technology that currently depends on the use of gas distillates, a commodity of ever-increasing value.

Studies were conducted on the application of this biosurfactant as an effective chemical enhanced oil recovery agent for displacement of oil from a rock matrix. Core flood studies employed a radial core configuration consisting of Berea sandstone. The biosurfactant was injected at a rate equivalent to $1 \mathrm{ft} /$ day to displace the residual in-place oil following core saturation and water flooding. Tertiary oil recovery was approximately $15 \%$ of the in-place oil with the loss of $\mathrm{pH}$ control and biosurfactant fractionation within the core matrix. However, greater than $95 \%$ of the biosurfactant injected was recovered from the core, indicating insignificant losses due to adsorption to the rock matrix. Preliminary studies indicate a potential for the application of biosurfactants as chemical enhanced oil recovery agents in the tertiary recovery of known oil deposits (Finnerty, 1987). A biosurfactantproducing Bacillus licheniformis has been described which mobilized crude oil with oil bank formation in sand packs (Jenneman et al., 1983). The reader is referred to a comprehensive treatise offering additional information and details on the subject of biosurfactants (Kosaric et al., 1987).

\section{SINGLE CELL PROTEIN AND SINGLE CELL OIL.}

The subject of single cell protein production through fermentation of hydrocarbon feedstocks as the sole source of carbon and energy has attracted industrial interest for decades as a source of supplementary protein for various end uses. The technical feasibility for large 
scale, continuous or batch fermentations is a well-researched, proven fermentation technology which yields a high-quality protein product. Despite the existence of this exploitable commercial technology, the industrial use of hydrocarbon feedstocks for single cell protein or other products is largely nonexistent within the industrialized world. Historically, the successes and failures of single cell protein as a viable commodity on the world market appear to relate directly to the changes in oil pricings that have characterized the last few decades (Shennan, 1984). Other factors contributing to the demise of single cell protein are market acceptability and competition from soy and fish meal as protein supplements. There existed, however, intense activity in basic and applied research where achievements in process design and bioengineering accomplished the construction of 100,000 tons per year single cell protein production facilities. A voluminous literature exists on developments in single cell protein production. The reader is advised to consult the authoritative review of Shennan (1984). Single cell protein production is a major scientific and technical success of the twentieth century, reflecting the achievements that are possible through concentrated efforts in bioengineering and biotechnology.

Alternatives to paraffin-based single cell protein technology have used gaseous alkanes as feedstocks. Numerous problems are encountered in the process engineering of gaseous alkanes such as mass transfer and mixing of the heterogeneous mixture of methane, oxygen and liquid medium. Most pilot plant studies utilized relatively pure methane; whereas, commercial scale plants would employ natural gas. Commercial scale single cell protein production from natural gas should be of interest to Middle East countries such as Saudia Arabia due to large feedstock supplies.

A nontraditional feedstock for single cell protein production has been methanol. ICI, Hoechst and Phillips Petroleum Co. have developed a highly efficient methanol-based single cell protein production technology. These more progressive commercial projects have attempted to develop processes that yield products other than SCP, hopefully to improve on the overall process economics. The Phillips high-density yeast process technology illustrates developments in the current state-of-the art in single cell protein production. This fermentation process develops extremely high cell mass yields per liter of fermentation broth (see Table 5). The growth medium is fed to the fermenter at a rate designed to maintain the cell density and productivity at the desired level with the process adaptable to either batch or continuous fermentations. The high cell density simplifies downstream recovery processes, eliminating centrifugal recovery of biomass in many applications and making it possible to directly spray dry the product with advantages occurring in production economics. This high density process technology has been successfully applied to the growth of Bacillus subtilis, Bacillus megaterium, Methylomonas species, and Escherichia coli K-12 yielding dry cell yields (in $\mathrm{g} / \mathrm{liter}$ ) of $57,110,114$ and 110 , respectively. These specially engineered fermenters are licensed to Daniel International Corporation to manufacture and feature Phillips proprietary high density design which results in high rates of oxygen transfer and heat transfer. 
Table 5

BIOMASS YIELDS FROM VARIOUS FEEDSTOCKS

Cell Productivity

Feedstock: Microorganism

Methanol: Pichia pastoris

Ethanol: Pichia pastoris

Candida utilis

Sucrose: Candida utilis

Saccharomyces cerevisiae

Beet-molasses: Candida utilis

Cane molasses: Candida utilis

Whey permeate:

Kluyveromyces fragilis

Glucose: Candida utilis
(G/Liter)

126

108

122

150

138

160

118

132

136
Dry Cell Yield

(G/Liter/H)

12

11

33

25

28

27

19

22

27

Improvements in the high cell density process have been achieved through molecular genetics. An expression system was developed with Pichia pastoris for production of recombinant DNA proteins. The first enzyme in the methanol oxidation pathway is an alcohol oxidase. Several genes in the pathway were cloned into a Pichia expression vector including the regulatory regions (Ellis et al., 1985). These cloned DNA fragments have been sequenced and used to construct expression vectors which are tightly regulated in the expression of recombinant proteins. Two types of expression vectors have been constructed: 1) autonomously replicating sequences; and 2) integrative vectors. The integrative expression vectors offer long-term stability in continuous fermentation applications. Applications of these expression vectors have been successfully developed for the production of human necrosis factor, streptokinase, hepatitis B surface antigen, and invertase. With the strong alcohol oxidase promoter controlling expression, high levels of specific protein production coupled to high cell density results in increased levels of recombinant protein per fermenter volume. This high yield of recombinant protein results in lower production costs by combining single cell protein production with other byproducts of commercial value. The application of high cell density process technology to other fermentation scenarios such as sucrose, ethanol, molasses, and whey feedstocks has been successfully developed for the production of useful food products (Shay and Wegner, 1985; Shay and Wegner, 1986).

Single Cell Oil. The production of single cell oil was selected as a target for industrial development over fifty years ago. Renewed interest developed in the seventies due to technological improvements in full-scale single cell protein production and the possibility of deriving new or added-value products from single cell protein production. Ratledge has championed and researched the subject of single cell oil for several years (Ratledge, 1984; Ratledge, 1989). Interest in single cell oil is related to economic forecasts of increased future demands for plant derived oils in the face of developing shortages on the world market. The 
bulk of edible oils and technical grade oils (over $80 \%$ ) is derived from plant seeds, the remainder coming from animal and fish sources. In Europe, up to 10 million tons of oils are imported with a predicted shortage of 18 million tons/year by the early 1990s. The pricing for such oils is highly variable with supply and demand fluctuating widely from year to year. However, world wide demand is increasing on an annual basis, and traditional sources of oils may well be unable to supply the volume demand. Accordingly, single cell oil coupled to single cell protein production may well have a future (Moreton, 1989).

Single cell oil production based on current pricing and associated economics offer only a negative forecast with respect to economic viability. If one assumes, however, that significant technological achievements can be made through basic research to increase single cell oil yields than perhaps economic viability would more closely approach parity. Precedents do exist for the improvement of single cell protein production as well as with other microorganisms where doubling and tripling of the cellular lipid content was achieved through genetic manipulations. We have seen where substrate choice significantly influenced the total lipid content of hydrocarbon-utilizing microorganisms. Further examples of producing high value-added oils include the synthesis of gamma-linolenic acid from decanegrown Mortiella isabellina and $M$. vinacea (Yokochi and Suzuki, 1984) and the commercialization of gamma-linolenic acid production by fungi (Suzuki, 1989). Such high value specialty oils could well stimulate further commercial development in the production of single cell oil.

Microorganisms involved in considerations of single cell oil are the oleaginous yeasts and fungi (Ratledge, 1989). The oleaginous yeasts as a group are a relatively small group with the oleaginous fungi representing a considerably largeer number of organisms. Additionally, the fungi synthesize a considerably broader diversity of fatty acids than the oleaginous yeasts, possibly impacting on their potentially greater economic value. Single cell oil is generally considered to represent lipid accumulation in the form of triacylglycerols. Oleaginous microorganisms accumulate such lipids in ranges varying from $20 \%$ to over $85 \%$ of the total biomass. The attractiveness of single cell oil centers on the nature of the fatty acids in the triacylglycerols. Most yeast fatty acids are not particularly unusual and are generally similar to fatty acids present in seed oils. Yeast fat, with a high stearate content, is a potential target of interest due to its similarity to cocoa butter - the most expensive of all bulk commercial oils at $\$ 5500 /$ ton.

The advantages of using fungi rather than yeasts for single cell oil production stems from the ability of the fungi to utilize a wider diversity of waste materials than yeasts and in the ability of the fungi to produce a wider spectrum of fatty acids, particularly polyunsaturated fatty acids. Generalizations that can be stated about the fatty acids of oleaginous microorgansims are:

1. Fungi exhibit more diversity of fatty acids than yeast.

2. Higher amounts of the polyunsaturated fatty acids $18: 2$ and $18: 3$ occur in the fungi than in yeasts. 
3. The genus Mucorales uniquely contains gamma-linolenic acid [18:3(6)] as the sole $18: 3$ fatty acid rather than the usual $\alpha$-linolenic acid [18:3(3)].

4. The highly polyunsaturated fatty acids such as arachidonic acid [20:4(w6)] and eicosapentaenoic acid [20:5(w3)] are found in the fungi but not in the yeasts.

5. A number of unusual fatty acids including branched-chain and B-hydroxy fatty acids occur in the fungi but not in the yeasts. Biotechnological exploitation of certain oleaginous fungi are under development for the production of single cell oil rich in gamma-linolenic acid: for example, by J. and E. Sturge Company, United Kingdom and Idemitsu Co., Japan.

\subsection{FUTURE RESEARCH DEVELOPMENT AND REOUIREMENTS.}

Enzymes used in the oxidation of various organic molecules include laccases, lignin peroxidases, tyrosinases, monooxygenases and dioxygenases. These oxido-reductases are important for maintaining the global carbon cycle as well as being involved in the transformation and/or biodegradation of numerous synthetic chemicals and pollutants. Such oxidative enzymes can also be viewed as potential biocatalysts for the synthesis of chemicals that are difficult to prepare by conventional chemical means (Sariaslani, 1989).

Enzyme systems which oxidize hydrocarbons are classified as either monooxygenases or dioxygenases. The monooxygenases catalyze the insertion of one atom of oxygen into the substrate, the second oxygen atom being reduced to water. Two general types of monooxygenases are recognized: internal and external monoxygenases. In "internal monooxygenases" systems the substrate serves as electron donor and oxygen acceptor. The majority of monoxygenases are the external type requiring the participation of external electron donors (e.g. $\mathrm{NAD}(\mathrm{P}) \mathrm{H})$. Monooxygenases require cofactors such as copper, flavins, pteridine, heme or non-heme iron for catalytic activity. The diversity that exists within the flavin-or iron-containing monooxygenases is illustrated by the following classification of different monooxygenase systems.

Table 6

Classification of Monooxygenases

FLAVIN MONOOXYGENASES

Aromatic Hydroxylases

Ketone Monooxygenases
IRON MONOOXYGENASES

Non-Heme Iron Monooxygenases

Omega-Hydroxylases

Aromatic Monooxygenases

Heme-Dependent Monooxygenases

Secondary Amine Monooxygenases

Cytochrome P-450 
Dioxygenases catalyze the incorporation of both oxygen atoms into the substrate molecule and are classified as listed in Table 7.

Table 7

Classification of Dioxygenases

Aromatic Ring Dioxygenases
Non-Heme Iron Dioxygenases
Heme-Containing Dioxygenases
Aromatic Ring Cleavage Dioxygenases
External Flavoprotein Dioxygenases
Copper-Containing Dioxygenases
Intra- and Extradiol Cleavage Dioxygenases

The monooxygenases and dioxygenases represent powerful enzymatic tools for generating useful chemicals - both old and new. The potential for exploiting such enzyme systems for chemicals production through biocatalysis has gained importance worldwide. However, applications of such enzyme technology requires further development, addressing such problems as multicomponent enzyme systems, cofactor recycling requirements, and substrate/product solubility. For example, hydrophobic substrates such as hydrocarbons, crude oil and/or refined oil fractions and coal liquids generate water-insoluble emulsions or 2-layered, biphasic systems in water-based media. The efficiency of such systems is most often self-limiting, proving generally ineffective for large scale manufacturing process technology.

The past decade has witnessed astounding developments with the introduction of organic solvents into water-based enzymatic transformations. This new organic solvent based technology takes advantage of one principle; namely, that very little water is essential for enzymes to retain their catalytic activity. If this essential layer of water is maintained intact around the enzyme, the rest of the water can be replaced by organic solvent without interferring with the reaction. To date, enzyme systems such as oxido-reductases, isomerases, esterases and peptide- and ester-bond synthesis have performed efficiently in organic solventbased media (Klibanov, 1986; Deetz and Ruzzell, 1988; Laane et al., 1987).

Different approaches are used for nonaqueous reaction mixtures such as water-miscible solvents, two-phase systems and non-aqueous systems. In two-phase systems, a waterimmiscible solvent is added to the aqueous reaction mixture, generating an organic phase and an aqueous phase, where the product partitions into the organic phase, simplifying product recovery (Aldercreutz and Mattiason, 1987). Selected examples of reaction mixtures containing organic solvents are the regio- and stereospecific oxidoreduction of the hydroxylketo groups of steroids by steroid dehydrogenase in ethyl and butyl acetate (Carrea et al., 1988), site specific hydroxylation of N-acetyl-p-hydroxy-phenylglycine (Antonini, 1981), and the use of Pseudomonas putida for epoxidation of alkenes (Harborn, 1986). 
Oxidative enzymes in organic solvents can be used with free or immobilized intact organisms or isolated enzymes, with immobilization often enhancing enzyme stability (Doddema, 1988; Fukui and Tanaka, 1982; Chubata et al., 1985). A number of immobilization techniques are available: carrier-binding, cross-linking and entrapment. Laccase immobilized on celite catalyzes the oxidation of chlorophenols, methylphenols and methoxyphenols (Shuttleworth and Bollag, 1986). Alginate and carrageenan immobilized alkene-utilizing bacteria converted propene to 1,2-epoxypropane (Habetz-Crutzen et al., 1984). Phanerochaete chrysosporium immobilized on agarose (Linko et al., 1986), nylon (Linko, 1988) or polyurethane foams produced lignin peroxidases (Kirkpatrick and Palmer, 1987).

The application of classical genetics and modern molecular genetics has developed specific mutants for the production of specialty chemicals (Zeya et al., 1985; Ley et al., 1987; Johnston and Rangathan, 1987; Ley and Sternfield, 1988; Rossiter et al., 1988; Spain and Gibson, 1988). Imperial Chemical Industries, United Kingdom have developed special mutants of $P$. putida lacking benzenedihydrodiol dehydrogenase (Ballard et al., 1983; Taylor, 1985; Taylor et al., 1987). The oxidation of benzene by these mutants produces cis-benzene dihydrodiol, a product that is difficult to synthesize by ordinary chemical means. This product is then used to produce a new polymer-polyphenylene. The cloning and expression of naphthalene dioxygenase in Escherichia coli resulted in the production of indigo (Ensley et al., 1983).

Oxidative enzymes in wild type or recombinant organisms have been viewed as candidates for the treatment of environmental pollutants such as halogenated benzenes and biphenyl derivatives (Renganathan, 1989; Mondello, 1989) and trichloroethylene (Eaton, 1985).

Scientific progress over the past 10-15 years has witnessed the evolution of biocatalytic processes occurring in 1) water-based systems containing low organic solvent concentrations 2) to two-phase organic/aqueous reaction mixtures 3) to enzymes in reverse micelles to enzymatic transformations in organic solvents containing low water activity. Today, enzymatic conversions occur in anhydrous organic solvents (Duarte, 1988; Tanaka and Fukui, 1985; Klibanov, 1986). Klibanov (1989) has defined a set of "rules" governing the use of organic solvents for enzymatic transformations. Such rules are essentially empirical, determined through successful experimentation. Klibanov has coined the term "solvent engineering" for developing organic-based biotransformations. Advantages characterizing this new technology offer heretofore unavailable opportunities into high performance bioprocessing of hydrophobic materials. The ability to direct substrate specificities in terms of regio- and stereo-selectivity, minimizing undesirable side reactions, enhancing thermal stability, alteration of enantiomeric selectivity and reaction equilibria, elimination of diffusional limitations involved in aqueous reactions mixtures, control of toxicity profiles associated with substrates and products and recovery of products offers unprecedented opportunities for the development of new bioprocessing scenarios for the production of added-value specialty chemicals. 
New studies at Oak Ridge National Laboratories by Dr. C. Scott indicate enzymes function in anhydrous organic solvents without the requirement for essential water. Such developments indicate the near term technical capability for engineering advanced biocatalytic reactors, which operate totally in organic solvent systems. The next 5-10 years will realize the development of major new industries employing enzymatic and chemoenzymatic transformations of hydrophobic substrates. Table 8 lists selected examples of enzymatic biotransformations conducted in organic solvents.

Table 8

Organic Solvent Based Enzymatic Reactions

\begin{tabular}{lll} 
APPLICATION & ENZYME & SOLVENT \\
\hline cholesterol oxidation & oxidase & carbon tetrachloride \\
cholesterol transformation & Rhodococcus & 1,1,1-trichloroethane \\
D-phenylglycine synthesis & subtilisin & methylisobutylketone \\
l-menthol production & lipase & heptane \\
l-menthol production & lipase & cyclohexane \\
aspartame synthesis & thermolysin & ethylacetate \\
oil interesterification & lipase & hexane \\
glyceride synthesis & lipase & benzene
\end{tabular}

\subsection{RECOMMENDATIONS AND PRIORITY STATUS.}

\section{NEAR TERM-HIGH PRIORITY.}

The applications of solvent engineering for directed biocatalytic transformations of hydrocarbons is positioned to exploit opportunities in the area of fossil fuel biotechnology. New and novel bioengineering/bioreactor strategies are emerging which will allow for costeffective and performance-effective bioprocessing of hydrocarbon feedstocks. Commercial realization of these bioprocessing innovations are beginning to develop in other countries. It is hoped that the United States will develop meaningful R\&D initiatives in this 21st century technology and exercise scientific leadership in the implementation. A few selected examples of directed hydrocarbon biotransformations that will impact on the food, health, energy, pharmaceutical, and chemical sectors follow: 
- Alkanes and Alkenes $\longrightarrow>$

- Simple Aromatics $\longrightarrow$
Fatty Acids, Fatty Alcohols, Fatty Aldehydes, Mono- and Poly Unsaturated Fatty Acids, Hydroxy Fatty Acids, Saturated and Unsaturated Wax Esters, Short and Long-Chain Dicarboxylic Acids, Methyl Ketones, Alkoxy Fatty Acids, Polyhydroxy Fatty Acids, Biosurfactants, Amino Acids, Vitamins, Flavor Chemicals, TCA Cycle Intermediates, Epoxyalkanes, Glycols

1,3,5-Trihydroxybenzene, Benzene Catechol, Muconic Acid, Toluene Phenol, Succinic Acid, Anthracene Polyphenylene, 1- and 2-Naphthols, Phenanthrene 1, 2-Dihydroxy Naphthalene, Salicylic Acid, Salicylaldehyde, Coumarin, Naphthoquinones, Hydroxy Naphthoic Acids, Benzyl Alcohol, Benzylaldehyde, 1,2-Dihydroxy Toluene, Benzoic Acid, Poly(methyl)toluene, 3Methyl Catechol

- Alkyl-Substituted Aromatics->Phenylacetic Acid, Cinnamic Acid (Alkylbenzene) Phenylpropionic Acid

- Expedite the development of hydrocarbon biotransformations in organic media through "solvent engineering".

- Initiate focused programs for the further development of definitive databases in the genetics and enzymology of long-chain alkane and aromatic hydrocarbon oxidations for production of value-added chemicals.

- Generate expanded databases on all types of oxidoreductases with potential for fossil fuels beneficiation.

- Develop biosurfactant technology for applications in fossil energy heavy oil pipeline transportation, bioremediation, emulsifiers/deemulsifiers, wetting/dewetting agents, flocculation/deflocculation, solubilization/detergency, foaming/defoaming agents, and corrosion control chemicals.

- Evaluate the potential for high cell density petro-chemical feedstock fermentations (single cell protein) for the production of specialty chemicals and enzymes.

- Analyze the growth of fungi on petro-chemicals for the production of added-value polyenoic fatty acids such as gamma-linolenic acid, eicosapentaenoic acid, and arachidonic acid. 


\section{Chapter 8}

\section{GENETIC STRATEGIES FOR THE DESIGN AND CONSTRUCTION OF MICROORGANISMS ABLE TO EFFICIENTLY BIOCONVERT AROMATIC HYDROCARBONS TO ADDED-VALUE CHEMICALS.}

\section{$8.1 \quad \underline{\text { INTRODUCTION }}$}

The exploitation of microorganisms for the conversion of certain organic chemicals into more desirable or valuable compounds has been practiced for as long as man has produced alcoholic beverages and fermented foods. Microorganisms currently known to us produce a vast array of industrially interesting organic chemicals and since "known" microorganisms may only constitute some $10 \%$ of those present in the biosphere, the spectrum of chemicals of biological origin thus far identified represent just a fraction of the totality. Moreover, biological catalysts often exhibit relaxed substrate specificities and many are able to transform compounds other than their natural substrates. Compounds of non-biological origin may thus be transformed by biological catalysts to useful products.

Despite the wealth of microbially-produced chemicals, relatively few are commercially manufactured by biotechnological processes. The principal reasons for this are on one hand the innovativeness of organic chemists in devising new synthetic routes, and on the other the fact that biochemical reactions usually operate in aqueous solutions at low reactant concentrations, which means that reaction volumes are large (and thus capital investment costs are high), and products must be recovered from dilute aqueous solutions. However, a variety of factors, including growing environmental awareness and political and legislative actions to diminish environmental pollution and the toxicity of human medicaments and other products for human consumption, are stimulating a growing interest in the development of new chemicals and new processes for chemical production either to replace existing compounds with better alternatives, to assure greater purity of an active ingredient of a mixture, or to satisfy new needs and applications.

The search for new products is accompanied by an increasing number of constraints, including higher levels of quality control (product purity) and environmental protection measures. The high selectivity and specificity of biochemical reactions that can produce particular stereoisomers in high yield and the "softness" of such reaction technology that does not involve harsh conditions of temperature and pressure or caustic or corrosive reagents represent significant advantages from the points of view of the range of molecules that can be produced and of the environmental friendliness of biotechnological processes.

Moreover, recent exploration of the activities of enzymes and whole cells maintained under nonphysiological conditions has shown that biological catalysts are sometimes able to 
function well under conditions more favored by industrial processes, e.g. in organic solvents or two-phase systems, at high substrate concentrations and at higher than physiological temperatures. Even when this is not attainable with some native catalysts, it may be possible to selectively improve them by genetic engineering so that they acquire properties such as increased thermostability, stability in solvents, resistance to end product inhibition, etc., desirable for technical processes. Genetic engineering can also of course be used to increase the ratio activity: mass of the catalyst through the selective augmentation of expression of the cellular components that catalyse the desired reactions. And, perhaps most importantly, genetic engineering allows the custom designing of multistep metabolic routes such that a whole new range of possible substrate-product transformation routes not restricted to existing pathways becomes available.

\section{SUMMARY}

The high rate of technological change and development in our society, coupled with an increasing awareness of the need to permit such development within the context of preserving and improving environmental quality, is driving the search for a wide range of new chemicals that permit and facilitate the development of environmentally-friendly products and processes. Many chemicals with desirable properties are chiral in nature, and the production of the required enantiomer by purely chemical means is at present often difficult, if not impossible. Biochemical reactions, however, often catalyse the selective formation or transformation of a particular enantiomer and thus can be harnessed for the production of chiral products or synthons. There is a wealth of experience on simple biotransformations involving single step transformations of substrates to related but more desirable products. Such reactions may be carried out by purified enzymes as well as whole cells containing the enzymes. More familiar but at least as important in the long term are complex biotransformations involving multiple step pathways that convert a substrate to an often chemically-unrelated product.

The multienzyme pathways involved in the degradation of aromatic hydrocarbons can be genetically manipulated to obtain value-added products from aromatic hydrocarbons. Recombinant microorganisms can offer a number of advantages over wild type bacteria or mutants obtained by chemical or physical treatment. The use of cloning vectors with well characterized, regulated expression systems permits operator control of expression of a metabolic pathway. The use of strong promoters results in high-level expression of the desired enzymes, leading to high metabolic rates. A regulated expression system can also be made resistant to repression of enzyme synthesis by molecules such as glucose or by the desired end product of the reaction sequence, thereby permitting growth of microorganisms on well-defined growth substrates and also allowing conversion to high endproduct concentrations without danger of product repression. Genetic engineering techniques may also be used to add genes to and delete them from a particular metabolic pathway. Deletion of unwanted genes ensures stable accumulation of desired pathway intermediates, since the organism lacks the genetic material necessary for subsequent metabolism, and reversion of 
mutants is impossible. Addition of extra genes to metabolic pathways (enzyme recruitment) permits contruction of hybrid pathways with entirely new end products, as exemplified by the harnessing together of pathways for naphthalene and tryptophan metabolism to produce the textile dye indigo from glucose and the channelling of alkylaromatics into ordinarily nonproductive ortho-cleavage pathways to yield alkyl-cis, cis-muconic acids and alkyldienelactones. Enzyme recruitment also provides the opportunity of introducing into natural or constructed pathways genes encoding enzymes with greater stability, broader substrate specificity or higher reaction rates.

The diversity of metabolic activities in the microbial world which offers a wealth of novel and commercially interesting chemicals, coupled with our increasing ability to genetically optimize production of selected metabolites, provides the basis of a much greater commercial exploitation of microbial products than has hitherto occurred. Maximal exploitation of these possibilities will, however, necessitate concentrated research efforts in the areas of (1) characterization of microbial and metabolic diversity, (2) analysis of metabolic networks and regulatory hierarchies, (3) development of genetic tools for analysis and expression of genes encoding desirable activities in poorly characterized organisms, and (4) development of integrated, interdisciplinary programs involving chemists, biochemists, microbiologists and geneticists to explore novel and innovative mixed biochemical-chemical routes from inexpensive feedstocks to high value products.

\subsection{STATUS OF BASIC AND APPLIED RESEARCH}

\section{The Genetic Tools}

The cloning of genes and gene clusters is routine methodology. Cloned genes can be inserted downstream of strong promoters and efficient translation initiation regions such that they become transcribed and translated at high rates into the desired catalysts (e.g. Schauder et al, 1987). The use of well-regulated transcriptional promoters enables elimination of natural control systems and the institution of new regulatory circuits that can be activated at the discretion of the operator. Such regulatory systems can also be made resistant to repression of enzyme synthesis by molecules such as glucose or by the desired end product of the reaction sequence, thereby permitting growth of microorganisms on well-defined growth substrates and allowing conversion to high end product concentrations without the danger of product repression. As a complement to the use of foreign promoters, genes can be transfered to high copy number plasmids leading to gene dosage effects and potentially high levels of enzyme activity (Frey and Timmis, 1985).

A variety of strong transcriptional signals have been incorporated into cloning vectors designed for high level gene expression in E. coli K-12 (Sambrook et al., 1989). Some of these, however, require particular genetic backgrounds or physiological conditions or the addition of chemicals having a significant cost so that they have only limited application in commercial biotransformations. The bacteriophage lambda $\mathrm{P}_{\mathrm{L}}$ promoter, which is activated 
by a temperature shift from $30^{\circ} \mathrm{C}$ to $42^{\circ} \mathrm{C}$, is readily and inexpensively exploited under process conditions.

E. coli has its limitations as a biocatalyst, although these limitations may well be less than initally suspected (see below), and active gene expression signals that function well in organisms likely to perform satisfactorily under process conditions are needed. The lambda $P_{L}$ promoter: $C_{I}$ repressor control system has been shown to function in some non- $E$. coli hosts, but its activity range has not been systematically examined. Pseudomonas sp. exhibit a wide range of interesting biochemical reactions and are considered to $x$ promising biocatalysts for the production of a variety of organic chemicals. The Pm promoter - XylS regulatory system of the $P$. putida TOL plasmid has excellent gene regulation characteristics has little-to-no activity under non-inducing conditions, high activity under inducing conditions, induction with low concentrations $(\mu \mathrm{M})$ of inexpensive benzoate inducers, and functions in a wide range of Gram-negative bacteria. It has been incorporated into a number of plasmid and transposon cloning vectors designed primarily for use in non-enteric Gram-negative bacteria (Mermod et al., 1986; Ramos et al., 1988; de Lorenzo et al., submitted for publication).

Although the translation of mRNA in $E$. coli $\mathrm{K}-12$ is well characterized, it has not been extensively studied in other prokaryotes. High levels of gene expression in non-coli bacteria often requires optimization of the translation signals of the genes of the relevant enzymes for such bacteria. Other factors influencing the activity of biocatalysts include the stability of the mRNA and of the gene products. Where these are found to be important, they need to be individually addressed by appropriate genetic engineering strategies and utilization of appropriate mutant host bacteria (e.g. mutants deficient in specific RNAases, proteases).

Hybrid plasmids containing genes of desired enzymes are often not inherited stably, particularly if the encoded enzymes are expressed at high levels, as is often the case with high copy number vectors. Instability of the plasmid in the culture means reduced yields and ultimately total loss of the catalytic activity. The problem is particularly acute in continuous processes, in which bacterial growth and enzyme production are coupled, but is also relevant to batch processes (Kula et al, 1986). To stabilize introduced genes, it is generally better to integrate them into the chromosome which, by definition, must be inherited stably by a growing culture. Versatile transposon cloning vectors that greatly facilitate the cloning of genes and their random insertion into the chromosomes of a wide range of Gram-negative bacteria were recently described (Herrero et al., 1990; de Lorenzo et al., 1990).

\section{Genetic Strategies}

High level catalyst synthesis uncoupled from biomass production.

Microorganisms cultivated for biotransformations may be unstable with regard to the catalytic activity of interest, and this instability is often exacerbated by improvements in yields of catalyst per unit biomass. In some instances, for example where the catalytic 
activity involves integral membrane proteins, high level production of the catalyst results in slower microbial growth rates and thus constitutes a selective pressure for genetic inactivation of the catalyst (Herrero et al., 1990). High level production of the catalytic proteins can often be accomplished without accompanying instability if (1) the determinants of the catalyst are placed under the control of a strong but tightly regulated promoter so that little expression occurs until a specific signal is given by the operator, and (2) this signal is withheld until late in the growth phase of the culture so that biomass production and synthesis of the catalytic proteins are uncoupled (Frey and Timmis, 1985). The metabolic load on the cell which constitutes the selective disadvantage of the catalytic activity is thereby confined to that part of the growth phase in which little or no cell division occurs and in which genetic instability is not significantly manifested.

Although a number of strong transcriptional signals are available for obtaining high induced levels of expression of cloned genes, a number of these give significant levels of basal expression in the absence of the cognate inducing signal, which may cause problems. particularly when present on high copy number plasmids. The Pm-XylS regulatory circuit (Mermod et al., 1986) is one expression system that gives extremely low basal levels of expression. Where even these levels are too high, regulatory circuits specifically designed to give total shut-down of gene expression can be employed. One such system uses antisense RNA to block unwanted transcription of cloned genes (O'Connor and Timmis, 1987).

\section{Coordinated expression of genes originating from different pathways.}

As we emphasize below, some of the most exciting possibilities for transformations lie in the selective combination of enzymes from different pathways to produce novel routes through which feedstocks can be channeled to added-value products. Genes of different pathways are subject to different regulatory controls which are, for the most part, inappropriate for the new activity. Coordinated regulation of genes from disparate pathways can be achieved either through their separate cloning into expression vectors having the same regulatory elements or, usually better, through their combination to form a hybrid operon in which they are all read from a single promoter.

Bottlenecks in a new pathway arising from imbalance in the component activities of the pathway and that can be eliminated by selective hyperexpression of one of the genes may be alleviated by a number of strategies including expression of the relevant gene from a stronger promoter and elevating its translation by modifiying its translation initiation signals (Shine-Dalgano sequence; secondary structure of the ATG-containing region of the mRNA).

\section{Construction of new metabolic routes.}

There are two basic strategies to develop a biotransformation route that is not already known. If a metabolic route exists for transformation of an analog of the target substrate, then this route can be biochemically analysed, non-permissive steps for the target substrate or intermediates thereof identified, and these non-permissive steps sequentially eliminated, 
either by a mutational broadening of the substrate specificity of the enzyme in question or by replacing it with an analogous broader substrate enzyme from another pathway. This strategy is illustrated in the modification of a toluene/xylene catabolic pathway (Fig. 1) to enable it to transform 4-ethyltoluene (in this case to Krebs cycle intermediates and hence to $\mathrm{CO}_{2}$, rather than to an added-value chemical, although the principles are the same). The sequential elimination of bottlenecks for 4-ethyltoluene existing in the toluene pathway involved (1) mutational broadening of the substrate specificity of the first enzyme xylene monooxygenase, (2) mutational broadening of the effector specificity of the XylS regulator, one of the two regulators of transcription of the pathway enzyme genes, and (3) mutational reduction of the sensitivity of the ring cleavage enzyme, catechol-2,3-dioxygenase, to inactivation by the suicide substrate 4-ethylcatechol (Ramos et al., 1986; Ramos et al., 1987; Abril et al., 1989).

If no metabolic route for the desired transformation is known, then a new route may be conceived and realized through the judicious combination of different enzymes from different pathways. One such example of the "patchwork assembly" of new pathways, again a degradation pathway but nevertheless with intermediates such as alkylmuconic acids and alkyldienelactones of potential interest, is the construction of an ortho-cleavage pathway for the degradation of mixtures of chloro- and methylbenzoates and of chloro- and methylphenols (Rojo et al., 1987). The enzymes of this pathway were derived from three different organisms and from 4 or 5 different pathways (Fig. 2). Clearly, this approach is more arduous than the straightforward restructuring of an existing, well-characterized pathway but has infinitely more potential since it is not restricted to known routes and is hence limited more by our imagination than anything else.

\section{Improving metabolite flow.}

In many instances, a particular product will be made either by a single-step transformation or by a multiple-step transformation effected by a single pathway or part thereof. In other instances, however, the route from substrate to product will be more complex, involving more than one pathway and perhaps coupling biosynthetic and degradative pathways, as for example in the case of indigo in which segments of four pathways are involved - glucose assimilation, tryptophan biosynthesis, tryptophanase, and naphthalene degradation. In such cases, pathway branches may siphon off metabolites at various stages, thereby reducing product yields. The sequential "tying off" of non-essential branches by genetic inactivation of key enzymes acting at the branchpoints can in some cases significantly improve metabolite flow through the hybrid pathway and accomplish higher product yields (Bailey, 1991). 

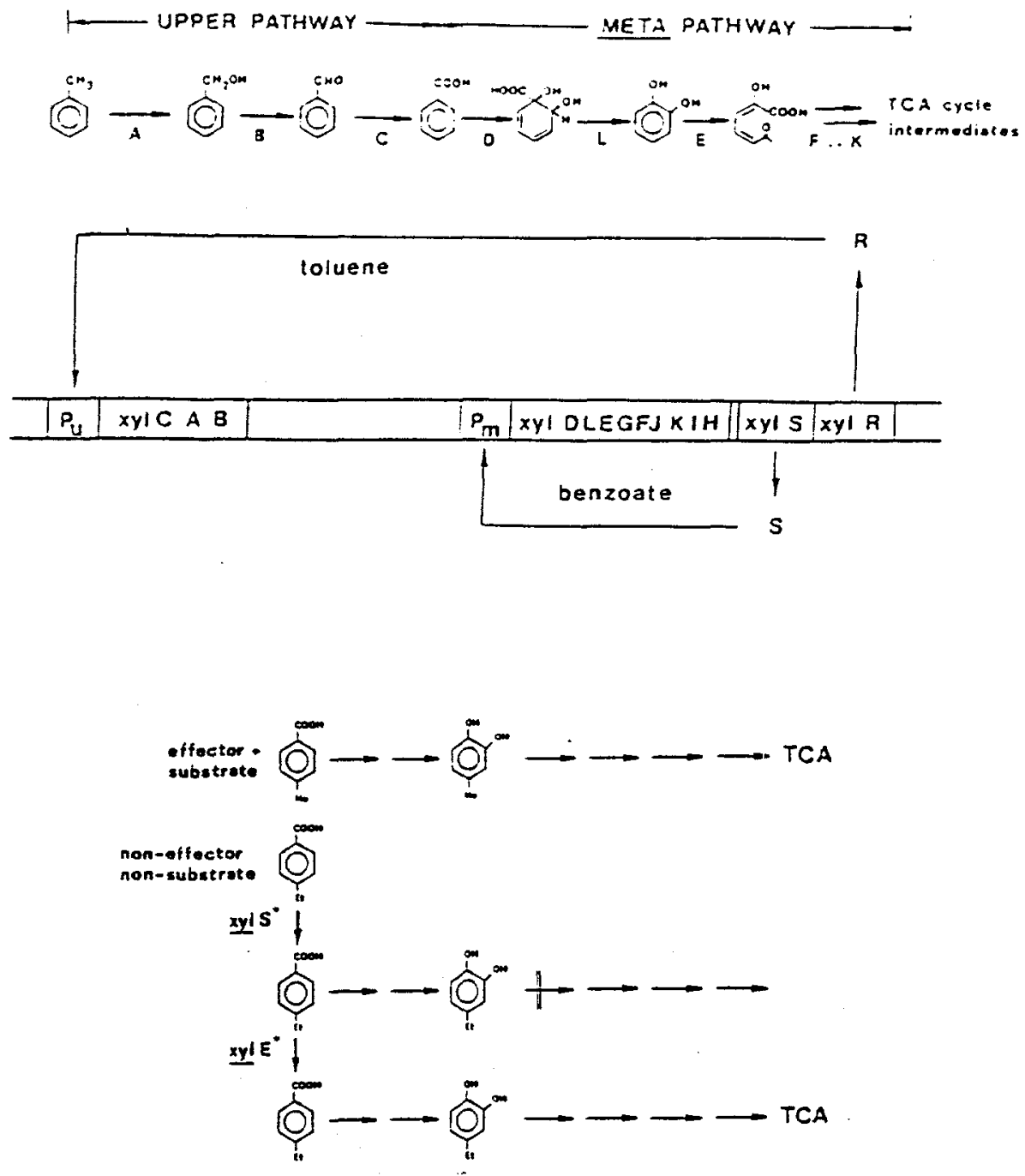

Figure 1. The TOL plasmid-encoded pathway for the degradation of alkylbenzenes and the experimental broadening of its substrate range. $(A)$ The TOL catabolic pathway is shown for the substrate toluene, and 3-and 4-methyltoluene ( $m$ - and p-cresol, respectively,) 1,3,4-trimethylbenzene, and 3-ethyltoluene are degraded in a similar fashion; 4-ethyltoluene is not, however, a substrate of pathway. The organization into two operons of the genes encoding the catabolic enzymes is shown, as are the regulatory circuits controlling transcription of these operons. They XylS positive regulator stimulates transcription of the meta operon when activated by benzoate or alkylbenzoates (i.e., the substrates of the meta operon), whereas the XylR positive regulator stimulates transcription of the upper operon when activated by toluene or another upper operon substrate. $(B)$ 4-Methylbenzoate is both an effector molecule that activates the XylS protein, as well as a substrate for the meta pathway. 4-Ethylbenzoate does not serve as an effector for the XylS protein regulator of the catabolic operon promoter Pm, and thus fails to induce synthesis of the catabolic enzymes. Isolation of a mutant that produces a XylS protein analogue which is activated by 4-ethylbenzoate results in the synthesis of all catabolic enzymes in response to the presence of 4ethylbenzoate in the bacterial culture medium. However, this compound is then only metabolized as far as 4ethylcatechol, because the latter inactivates the ring cleavage enzyme catechol-2,3-dioxygenase (C230). The isolation of a mutant that produces a C230 analogue resistant to inactivation by 4-ethylcatechol eliminates this metabolic block and permits complete degradation of 4-ethylbenzoate through the meta pathway. Analysis of the substrate specificities of the enzymes of the upper pathway revealed that the initial enzyme xylene monooxygenase does not attack 4-ethyltoluene but that the neat two enzymes, both dehydrogenases, have relaxed substrate specificities. Xylene monooxygenase mutants that oxidize 4-ethyltoluene were readily isolated and permitted complete degradation of this substrate through the restructured pathway (Ramos et al., 1986, 1987; Abril et al., 1989). 
A

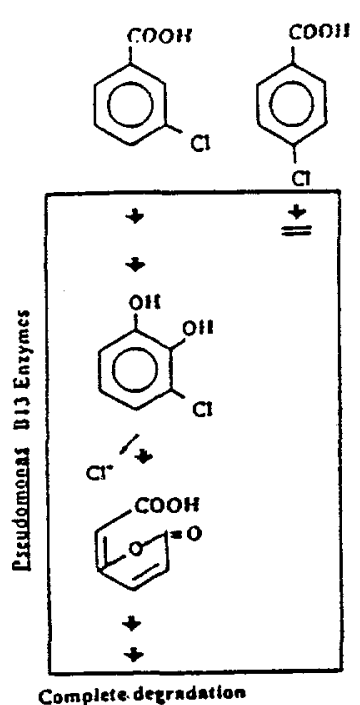

B

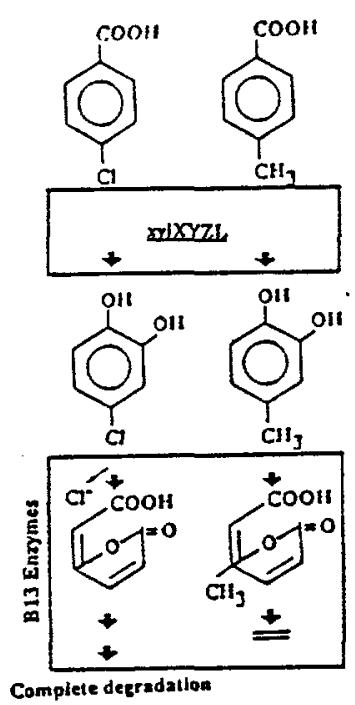

C

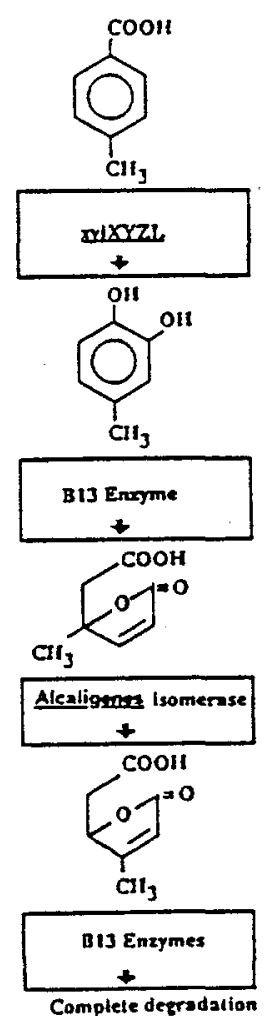

D

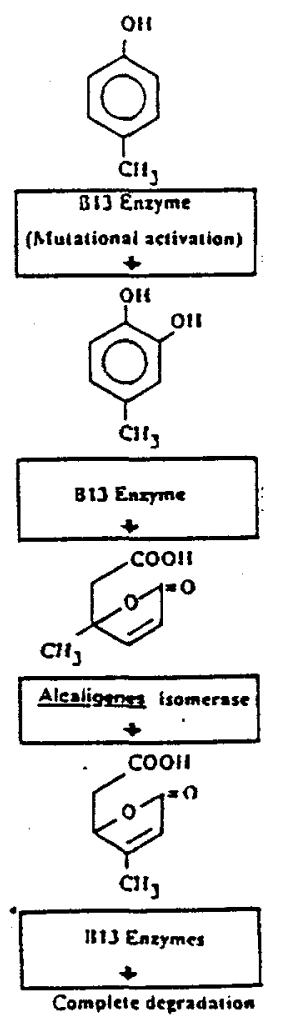

Figure 2 Constructed pathwcy for the simultaneous degradation of chloro- and methylaromatics. The route is based on the modified ortho pathway for 3-chlorobenzoate of Pseudomonas sp. B13 (A). Introduction into B13 of the TOL plasmid genes coding for toluate 1,2-dioxygenase (xyLXYZ, which also has the single allele designation $x y(D)$ and dihydroxycyclohexadiene carboxylate dehydrogenase (xylL), together with that of the positive regulator of the xylDL operon (xylS), expands the degradation range to include 4-chlorobenzoate and permits transformation of methylbenzoates to methyl-2-enelactones, which are accumulated as dead-end metabolites $(B)$. Recruitment of a 4-methyl-2-enelactone isomerase form Alcaligenes eutrophus allows the transformation of 4-methyl-2enelactone (the intermediate of 4-methylbenzoate catabolism) to 3-methyl-2-enelactone (bottom right), which is completely degraded by other enzymes of B13 $\quad$ (C). Mutational modification of the expression of the phenol hydroxylase of $B 13$ further extends the degradation capacities to chloro- and methylphenols $(D)$. The final routeis thereby composed of five different pathway segments derived from three different organisms. 


\section{Production of Added-Value Chemicals by Biotransformation.}

Biotransformations expand the range of compounds that can be generated by classical chemical methods. Enzymes often exhibit high selectivity for substrates and may exhibit high regioselectivity within a substrate. Since they catalyse transformations under mild reaction conditions, they can be used to obtain compounds that would otherwise be destroyed under the harsh conditions employed for chemical syntheses. Moreover, and most importantly, many high value chemicals are chiral molecules, only one enantiomer of which may possess the desired property. In some instances, other stereoisomers that may be present in a racemic mixture may simply be inert and hence represent a waste of material, but in other instances they may have undesirable activities. Synthesis strategies are designed, where possible, for the production of required enantiomers and for the avoidance of others. Such syntheses are greatly simplified if chiral starting materials are used. Since many enzymes transform substrates to chiral products, often in high enantiomeric excess, biotransformations are becoming increasingly attractive for the production of enantiomerically pure synthons, as well as end products (Ribbons et al., 1990). Biotransformations should not, however, be viewed as an alternative or competing technology to chemical synthesis but rather as a complementary technology that can produce a wider ranger of products, improve the selectivity and specificity of reactions and provide improved feedstocks for efficient chemical synthesis strategies.

Although the literature on biotransformations is extensive (Sariaslani, 1989), the production of high value chemicals by enzyme catalysts is in its infancy, and only a few types of reactions have been studied extensively, mainly oxidations and hydroxylations. This review cites examples of simple aromatic substrate oxidations, but it is clear that a wide range of other types of enzyme-catalysed reactions will be exploited in the near future.

\section{Biotransformations of Aromatic Compounds.}

Oxidative pathways for the degradation of aromatic compounds have considerable potential for the synthesis of added-value chemicals. Already the initial attack of aromatic substrates, either by monooxygenases or dioxygenases, can yield interesting products. Toluene monooxygenase of Pseudomonas mendocina, for example, catalyzes the positionally-specific oxidation of toluene to para-cresol (Fig. 3; Whited et al., 1986). The positional specificity of this oxygenase presents several opportunities for the synthesis of value-added chemicals (Table 1). In addition, further oxidation of para-cresol by this system results in the formation of molecules such as para-hydroxybenzaldehyde and para-hydroxybenzoic acid. These molecules are also of commercial interest and a multi-enzyme system for the oxidative conversion of toluene to these various specialty chemicals may be economically viable, provided that problems associated with enzyme induction and accumulation of the desired products to high levels can be solved. The toluene monooxygenase system of Pseudomonas mendocina is only induced after bacterial growth in the presence of toluene, and the enzyme is rapidly turned over following toluene removal. These characteristics present obstacles to the commercial application of the wild-type microorganism. The genes encoding the toluene monooxygenase system from $P$. mendocina organism have, however, been cloned into 
regulated expression vectors in $E$. coli $\mathrm{K}-12$ (Winter et al., 1989). The recombinant $E$. coli displays toluene monooxygenase activity similar to those observed in the wild-type organism after induction by a temperature change or addition of the lactose analog IPTG.

Table 1

\section{SYNTHESIS OF PHENOLIC COMPOUNDS BY TOLUENE MONOOXYGENASE}

$\begin{array}{ll}\text { Substrate } & \text { Product } \\ \text { toluene } & \text { p-cresol } \\ \text { acetanilide } & \text { acetaminophen } \\ \text { fluorobenzene } & \text { fluorophenol } \\ \text { methylphenylacetate } & \text { hydroxyphenylacetate } \\ \text { ethylbenzene } & \text { ethylphenol }\end{array}$

Wild-type Pseudomonas mendocina and recombinant $E$. coli were incubated with the listed substrates for periods of up to 24 hours. The reaction products were extracted and either identified directly or as phenolic compounds using a phenol assay.

Bacterial dioxygenation of the aromatic ring of benzene, toluene, etc. involves the regio- and enantioselective incorporation of both atoms of molecular oxygen into the aromatic nucleus to yield cyclohexadines containing two hydroxylated asymmetric carbon atoms (Fig. 4; Gibson et al., 1970). Ordinarily, further metabolism leads to dehydrogenation of the cis-dihydrodiols and rearomatization of the ring to yield catechols, which are then oxidatively ring cleaved. Prevention of dehydrogenation, either by genetic inactivation of the dihydrodiol dehydrogenase or through the cloning of the dioxygenase determinants, can lead to bacteria able to accumulate and secrete dihydrodiols in quantity. In addition to their high regio- and enantiomeric selectivity, some aromatic ring dioxygenases are able to attack a wide range of substituted aromatics, yielding many prochiral compounds with different substituents, some of which are very difficult to synthesize chemically (Ribbons et al., 1990; Gibson et al., 1990). Benzene-cis-dihydrodiol, for example, is a starting material in the synthesis of polyphenylenes, polymers which have novel properties and electrical and electronic applications. Polyphenylene can be made by a mixed biochemical-chemical synthesis, involving derivatization of the cis-diol, polymerization and rearomatization (Ballard et al 1983), thereby avoiding solubility problems associated with the purely chemical synthesis of the polymer. Hybrid biochemical and chemical synthetic routes will undoubtedly be increasingly exploited in the synthesis of chemicals from basic hydrocarbon feedstocks. 
Toluene Oxidation in Pseudomonas mendocina<smiles>Cc1ccccc1</smiles>

Tolvene<smiles>Cc1ccc(O)cc1</smiles>

p-Cresol<smiles>OCc1ccc(O)cc1</smiles>

p-Hydroxybenzyi alcohol<smiles>O=Cc1ccc(O)cc1</smiles><smiles>O=Cc1ccc(O)c(O)c1</smiles>

Protocalechuate

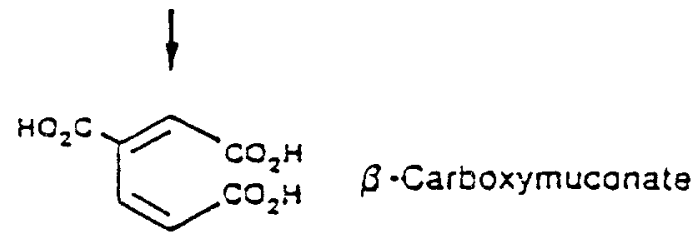<smiles>[3H][3H]</smiles><smiles>C=CC(C)(C)C(=O)O</smiles>

p-Hydroxybenzaldehyde

p-Hydroxybenzoate<smiles>O=C1CC2=CCC(=O)C(C2)O1</smiles><smiles>C[13CH3]</smiles><smiles>CCOC(=O)CC(=O)CCCC(=O)O</smiles>

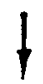

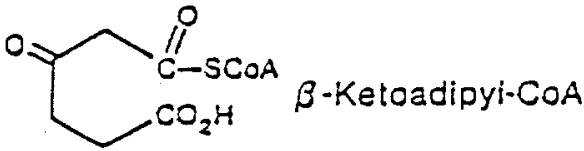<smiles>[3H][3H]</smiles>

Succinyl CoA acetyi COA

Figure 3. Pathway for Toluene Oxidation by Pseudomonas mendocina 


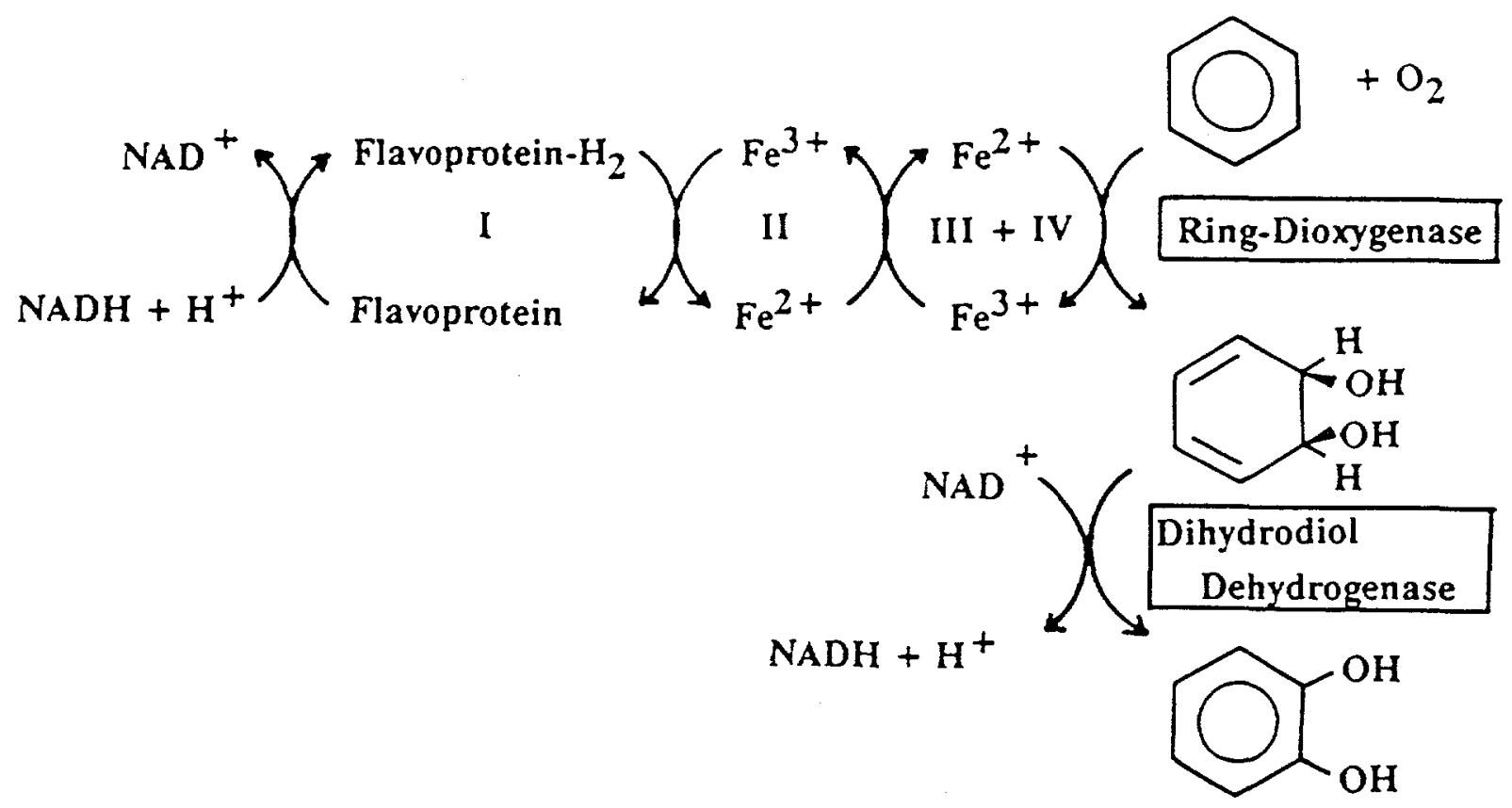

Figure 4. Formation of ditydric phenols catalysed by ring-hydroxylating dioxygenases and dihydrodiol dehydrogenases. Ring-hydroxylating dioxygenases produce dihydrodiols by introducing two atoms of oxygen into the aromatic ring. They consist of three or four polypeptides which together form a short electron transfer chain that transfers electrons from NADH to oxygen. Component I is a flavoprotein and has NADH oxidase activity; II is a ferredoxin and contains one ( $\left.2 \mathrm{Fe}-2 S^{*}\right)$ cluster ( $S^{*}$ is the inorganic sulphur in the iron-sulphur cluster). In dioxygenases which oxidize benzoate, components I and II comprise one polypeptide. Components III and IV form the terminal oxygenase and contain $\left(2 \mathrm{Fe}-2 \mathrm{~S}^{*}\right)$ clusters. The molecular weights of polypeptide subunits of different ring dihydroxylating dioxygenases are similar: the terminal oxygenases gernally consist of two polypeptides of 20 and $50 \mathrm{kD}$, and their ferredoxins are usually small polypeptides. Dihydrodiols are oxidized to dihydric phenols by dihydrodiol dehydrogenases which are single component enzymes.

Toluate-1,2 dioxygenase is also able to attack a range of substituted benzoates (Fig. 1), particularly meta- and para-substituted molecules, and also some disubstituted compounds, to form 1,2-cis-dihydroxycyclohexa-3,5-diene carboxylic acids (Reineke and Knackmuss, 1978, 1979; Harayama et al., 1986). The determinants of toluate-1,2-dioxygenase, together with their promoter and the gene of the positive regulator of this promoter, were cloned on a high copy number broad host range plasmid and introduced into $E$. coli $\mathrm{K}-12$, Pseudomonas putida, and $P$. oleovorans, an organism particularly suited to hydrocarbon biotransformations in two-phase bioreactor systems (Lehrbach et al., 1984; Zeyer et al., 1985; Wubbolts and Timmis 1989, 1990). All recombinant strains were able to produce corresponding cis-diols from a range of substituted benzoates (Table 2), with the $P$. oleovorans strain giving yields $50 \%$ higher than those of $P$. putida and $150 \%$ higher than those of $E$. coli. 
Table 2

\section{BIOCONVERSION OF DIFFERENT SUBSTTTUTED BENZOIC ACIDS BY Pseudomonas oleovorans DERIVATTVE GPo12(pWD15)}

\begin{tabular}{lcccccccccc} 
Position $^{\mathrm{a}}$ & \multicolumn{8}{l}{ \% Conversion with the following substituents } \\
& $\mathrm{H}$ & $\mathrm{F}$ & $\mathrm{C} 1$ & $\mathrm{NH}_{2}$ & $\mathrm{OH}$ & $\mathrm{CH}_{3}$ & $\mathrm{Br}$ & $\mathrm{OCH}_{3}$ & $\mathrm{C}_{2} \mathrm{H}_{5}$ \\
& 100 & 64 & 0 & $\mathrm{ND}^{\mathrm{c}}$ & 300 & 300 & 9 & 1 & $\mathrm{ND}$ \\
ortho & 100 & 100 & 61 & 52 & 16 & 100 & 53 & 81 & $\mathrm{ND}$ \\
meta & 100 & 94 & 46 & 11 & 98 & 100 & 31 & 8 & 73 \\
para & 100 & & & & & & & & &
\end{tabular}

a Relative to the carboxyl group.

b Conversion of benzoic acid derivatives and concomitant accumulation of cis-diol carboxylates was determined by reversed-phase HPLC analysis (13) of culture supernatants of GPo12(pWD15) isolates grown overnight in minimal medium (21) in the presence of $5 \mathrm{mM}$ o-toluate (inducer) and $5 \mathrm{mM}$ substrate. The amount of substrate converted to the corresponding cis-diol is expressed relative to the amount of substrate remaining in medium to which no cells were added.

c ND, Not determined

Transformation of cis-diols to further intermediates or products can be determined by either chemical or biochemical processes. Dehydration of substituted cis-diols under acidic or basic conditions produces substituted phenols. Dehydrogenation of cis-diols either chemically or biochemically produces catechols, chemical moieties found in many pharmacologically active compounds. Benzene cis-glycol has been used as precursor not only of polyphenylenes but also of ( \pm )-pinitol and inositol-1,4,5-triphosphate (Ley et al., 1987), and toluene cis-glycol has been transformed to precursors of terpenoids, prostaglandins and cyclohexane oxides (Hudlicky et al., 1988; Ribbons et al., 1990).

The cis-diols and catechols are just two of the many intermediates in pathways for the degradation of aromatic components. Catechols are substrates for cleavage of the aromatic ring, the carbon skeleton of which is successively dismantled and fed into the Krebs cycle. Catechol may be either ortho or meta cleaved (Fig. 5), according to the type of substituent present on the aromatic ring. Some of the intermediates of the ortho-cleavage pathway, particularly the ring cleavage products, cis,cis-muconic acids, and the lactones formed from them, have potential commercial applications. Several reports describing bioconversions of toluene or benzoic acid to cis,cis-muconate, which can subsequently be chemically hydrogenated to adipic acid, a polymer precursor, have been published in recent years. Nature has optimized catabolic pathways for the benefit of microorganisms, not the biotechnologists. A number of feedstocks that would be interesting to convert to cis, cismuconic acids or dienelactones are, because of their substitutents, cleaved in the meta- 
position and thus channelled away from the desired pathway. Genetic manipulation techniques, however, permit us to channel chemicals from one pathway into another and thereby circumvent the constraints of available routes. Rojo et al. (1987), for example, created an ortho-cleavage route for methylaromatics, which are normaly degraded through a mesa-cleavage route, by introducing into an organism expressing only an ortho-cleavage route for catechol just that part of a meta-cleavage pathway which leads to the production of catechol (Figs. 1, 5).

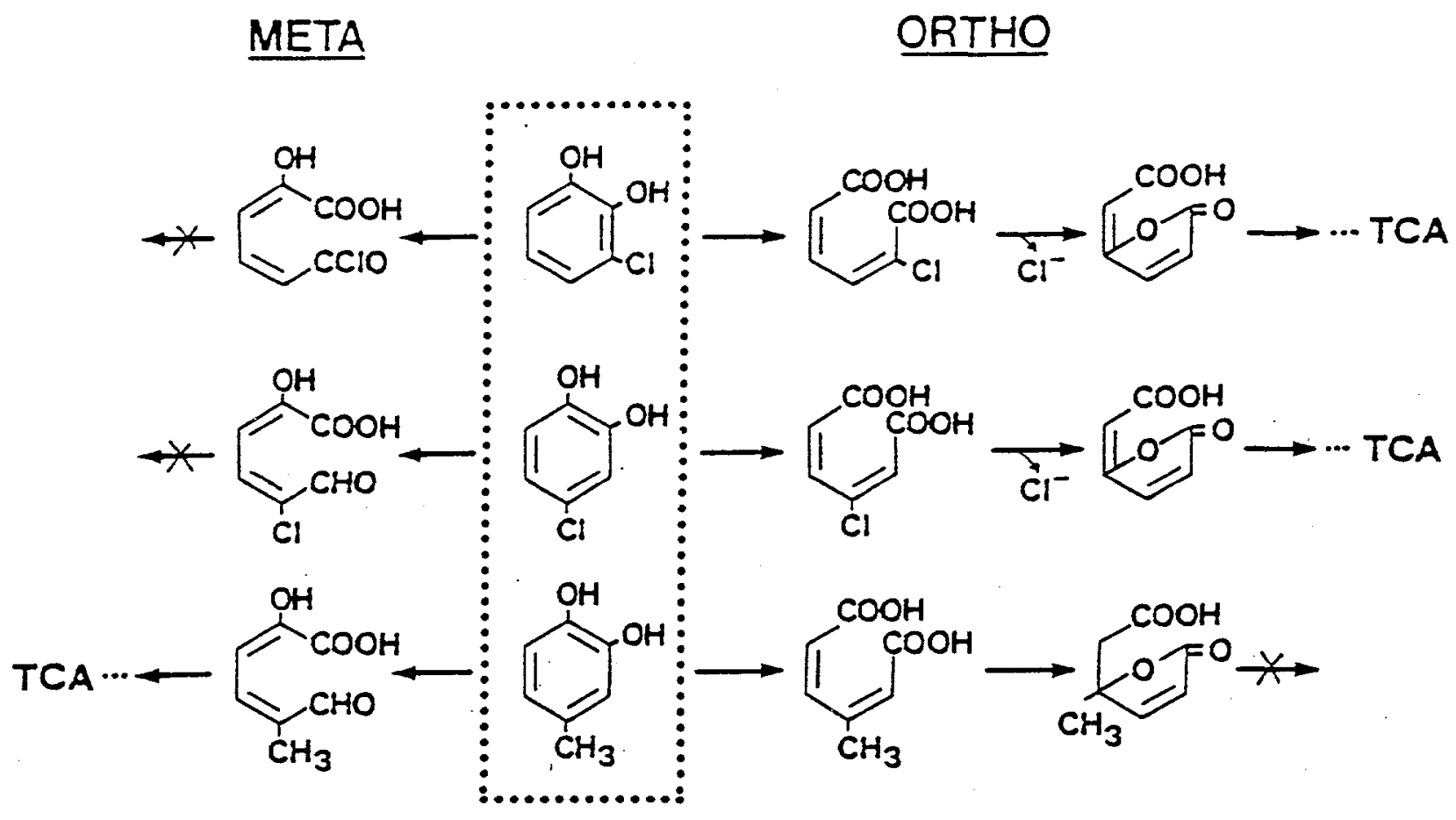

Figure 5. Ortho and meta cleavage of catechol In nature, catechol and halocatechols are normally degraded by ortho-cleavage pattiways via cis,cis-muconate and dienelactones, whereas alkylcatechols are degraded by metacleavage pathways via hydroxymuconic semialdehyde. Pathway selection is made by regulatory systems that activate transcription of the appropriate pathway genes. The ring cleavage enzymes, however, once synthesized are able to cleave both alkyl- and halocatechols, albeit channelling the "wrong" substrates into dead-end products, e.g. methyllactones. Although this "incorrect" channelling is unproductive biologically, it car be very productive from a biotransformation viewpoint.

The oxidation of naphthalene to value-added products has been of industrial interest for many years. One intermediate in the microbial degradation of naphthalene is salicylic acid (Fig. 6). Attempts have been made to manipulate culture conditions so that microorganisms accumulate salicylate from naphthalene (Ishikura et al., 1968) and the formation of the 
stereochemical product cis-1,2-dihydroxy-1,2-dihydronaphthalene using mutants (Cos et al, 1980). These efforts met with limited success due to low concentrations of product formed or to genetic reversion of the production strain leading to undesired further metabolism of the product. Cloning of the naphthalene oxidative pathway in E. coli (Ensley et al., 1983) and characterization of the naphthalene operon (Fig. 1; Yen et al., 1988) permitted the functional transfer of the genes encoding naphthalene dioxygenase (NDO) activity into a temperature-regulated, high-level expression vector that functions well in $E$. coli, resulting in substantially higher levels of synthesis of NDO activity in this organism than observed in wild type organisms (Table 3 ). This recombinant $E$. coli offers the advantage that the organisms can be grown rapidly on a simple carbohydrate such as glucose without catabolite repression of the NDO activity. In addition, the strong $\mathrm{P}_{\mathrm{L}}$ promoter of the expression system is well-regulated by the use of temperature: a $12^{\circ}$ change in the fermentation temperature results in rapid induction of the pathway and high level synthesis of NDO activity. The recombinant organism is genetically stable and lacks the genes encoding further metabolism so the dihydrodiol accumulates stably to high levels. The rate of transformation displayed by this organism, one gram of product per gram (dry wt.) of microorganism per hour, compares favorably with some chemical catalysts and could potentially lead to a commercially viable process for the synthesis of this chiral molecule.

Table 3

EXPRESSION OF NAPHTHALENE DIOXYGENASE

\begin{tabular}{llllcc}
\hline & & & & \multicolumn{2}{c}{ NDO Activity* } \\
Plasmid & Host & Promoter & Inducer & Uninduced & Induced \\
NAH7 & $P$. putida & Nah & Salicylate &.-- & 90 \\
pBR322 & E. coli & Nah & Salicylate & 8 & 8 \\
pKC101 & E. coli & $\mathrm{P}_{\mathrm{L}}$ & Temperature & 16 & 400 \\
pUC9 & E. coli & lac & IPTG & 9 & 140 \\
\hline
\end{tabular}

nmoles of naphthalene oxidized/min/mg protein (Ensley, Gibson, Laborde, 1982)

Naphthalene oxidation was measured by the assay described previously (Ensley et al., 1982). The Pseudomonas putida was grown in minimal salt broth with salicylate as the sole carbon and energy source. The $E$. coli was grown in Luria broth with the listed inducers at one to five $\mathrm{mM}$ concentrations.

In addition to the genetic manipulation of catabolic pathways to achieve higher catalytic activities or to cause accumulation of desired intermediates through elimination of unwanted reactions, and to combine catabolic pathways to channel substrates from one into another, it is possible to combine biosynthetic with catabolic pathways. This is of great interest because it enables the biological synthesis of valuable substrates from simple inexpensive materials like hydrocarbons and their direct bioconversion into desired products. This has been convincingly demonstrated in the biological production of indigo from glucose (Ensley et al., 1988). Many aromatic ring dioxygenases (Ensley et al., 1983; Eaton and Timmis, 
1986) and even the enzyme xylene monooxygenase (Mermod et al., 1986) are able to oxidize indole to indoxyl which spontaneously oxidizes in air to the dimeric structure indigo, an important textile dye (Fig. 7). Naphthalene dioxygenase is particularly efficient in this reaction. The introduction of the ndo gene in $E$. coli results in the production of blue colonies as a result of indigo formation. High level expression of the naphthalene dioxygenase resulted in greater yields of indigo but the supply of indole became limiting. Indole exists as indole 3-glycerol phosphate (IGP) or as a side chain of tryptophan and is formed by cleavage of IGP by the enzyme tryptophan synthetase to glycerol-3-phosphate and indole, the latter of which is normally condensed immediately with serine to form tryptophan. High level expression of a mutant tryptophan synthetase resulted in the release of significant levels of free indole. Tryptophan then became limiting. Manipulation of the tryptophan regulatory system then overcame the final bottleneck and high rates of synthesis of tryptophan from glucose were achieved with almost quantitative conversion to indole and thence indigo (Ensley et al., 1988).

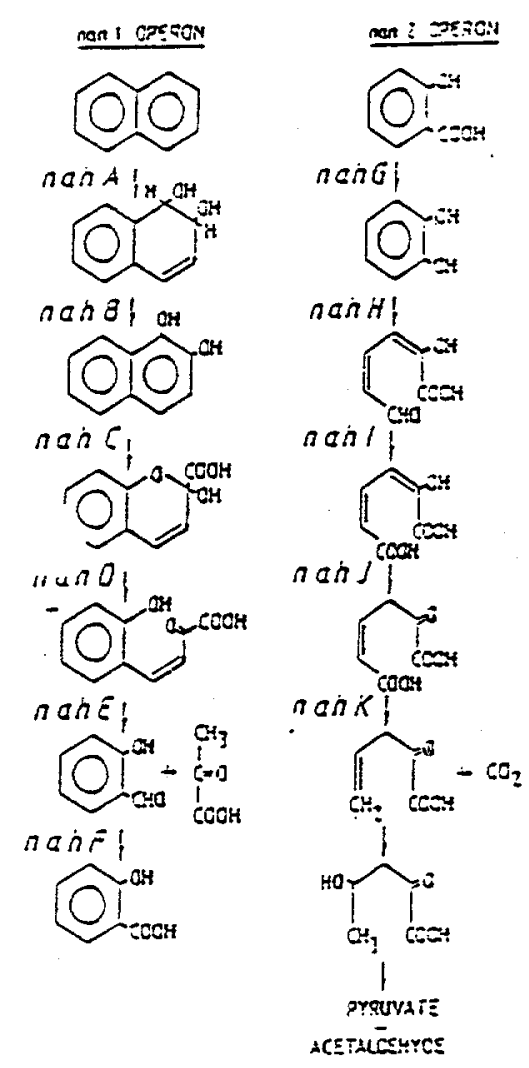

Figure 6. Catabolic pathway and genes of NAH plasmid NAH7. A to $K$ indicate gene designations of the corresponding enzymes. For NAH enzymes: A, naphthalene diangenase; $B$, cis-dihydrodiol naphthalene dehydrogenase; C, 1,2-dihydroxynaphthalene diangenase; D, 2-hydroxychromene-2-comaxylate dehydrogenas; $E, 1,2-d i$ hydraxybenzylpyruvate aldolase; $F$, salicylaldehyde dehydrogerase; $G$, salicylate hydraxylase; $H$, catechol 2,3-dioxygenase; $N$, hydroxymuconic semialdehyde hydrolase; I, hydroxymuconic semialdehyde dehydrogenase; $J$, 4-axalocrotonate isomerase; $K$, 4-axalocrotonate decarboxylase, $L, 2$-axopent-4-enoate hydratase; M, 2-axo-4 hydrary-pentanoate aldolase. Pathway intermediates that have been proprased as products for commercial biotransformations include naphthalene cis-diols and salicylate, the product of enzyme $F$. 


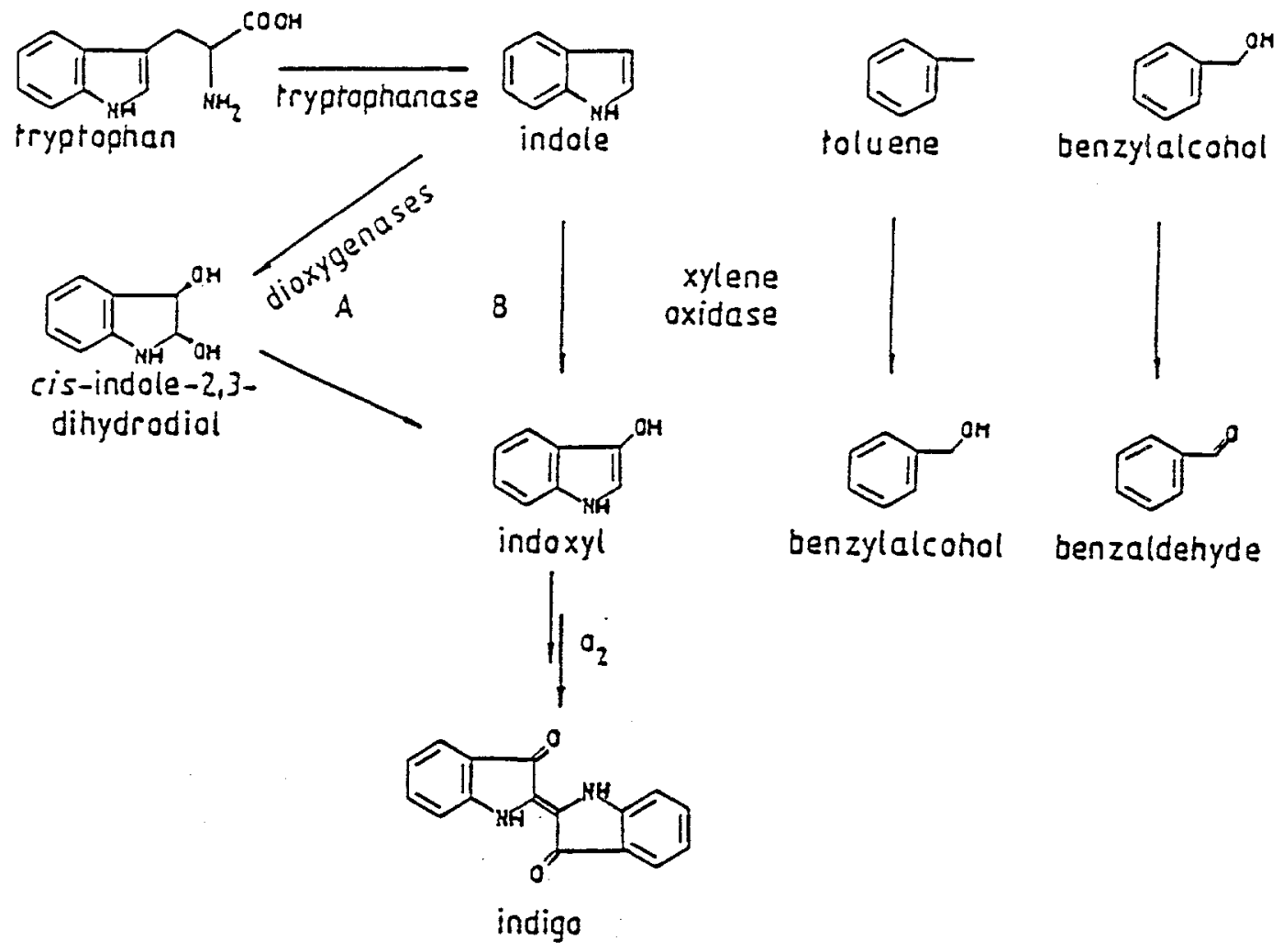

Figure 7. Proposed pathways for indigo production from indole mediated by dioxygenases and monooxygenases. Dioxygenases are thought to form cis-indole-2,3-dihydrodiol from indole, which spontaneousty dehydrates to indoxyl which in turn oxidizes rapidly in air to form indigo (Ensley et al., 1983) Monooxygenases are thought to form indoxyl directly (Mermod et al, 1986a)

The designing of new metabolic routes based on the chiannelling of sibstrates through different biosynthetic and degradative pathways is an extremely powerful strategy to obtain novel products that could never be produced chemically from the chosen substrates. In the case of indigo production given above, although glucose was the substrate employed, it could with appropriate pathway design be any other assimilatable organic molecule whose carbon skeleton can be dissassembled and reassembled into tryptophan. 
The range of possible chemical products that can originate from biological systems is determined by a combination of the range of natural metabolites produced by such systems, the ability of the geneticist to introduce unnatural substrates into metabolic pathways and route them through different pathways to particular compounds, and the ability of the chemist to isolate and chemically transform such metabolites and compounds into desired products. The expansion in our information/experience base needed for optimal exploitation of biotransformations includes exploration of metabolic diversity, characterization of the genetics of metabolic networks and their regulation, and development of the "new" synthetic chemistry based on combined biochemical and chemical strategies.

(a) Microorganisms inhabit an incredible spectrum of environments ranging from relatively constant, nutrient-rich ones like the animal intestine to extremely hostile ones (such as those characterized by temperatures exceeding $100^{\circ} \mathrm{C}$, high pressures and low nutrient content, as, for example, in deep sea thermal vents) that higher - organisms are unable to tolerate. This collective ability of microorganisms to exploit almost all environments on and in the earth's surface is possible because of their collective enormous metabolic diversity, which is not found in higher organisms. It is this microbial diversity which provides the opportunity for the development of new biotransformations (Bull and Hardmann, 1991).

Current estimates indicate that only about $10 \%$ of the members of the microbial world have been cultivated and characterized. Of the $10 \%$ we know, we only have very fragmentary information about their metabolic networks and the regulation of these networks. Thus, major resources need to be mobilized to get to grips with the problem of microbial and metabolic diversity, in other words to search for, isolate and characterize new microorganisms and to analyse the metabolic activities and potential of representatives of the major new groups, in order to be able to better exploit biochemical reactions.

(b) As Bailey (1991) emphasizes in his excellent review, the metabolic activities of microorganisms are effected by a regulated, highly coupled network of approximately one thousand enzyme-catalysed reactions. This network accomplishes certain types of reactions much more effectively than current chemistry permits, but often not sufficiently well for practical processes. Metabolic networks that have evolved in natural habitats are not genetically optimized for the objectives or conditions central to applications and hence can generally be improved for this purpose, often substantially, by selected genetic modifications of the microorganisms. Though our knowledge of gene expression mechanisms and of the factors influencing heterologous gene expression are substantial and generally permit or facilitate the development of single step biotransformation processes, our understanding of cellular metabolic networks, and of the regulatory hierarchies of the cell, is still fragmentary and 
ordinarily inadequate for the rapid development of effective multistep processes, particularly those involving several pathways. Thus a major effort needs to be invested in characterizing microbial metabolic networks, their control and the consequences of deliberate alteration of metabolite levels and balances, so that the manipulation of metabolite flow for biotechnological purposes moves increasingly from empirical to predictive rational science.

(c) Dogma has it that multistep metabolic transformations involving pathways from nonenterics are best caried out in such organisms or their close relatives, rather than in E. coli K-12. Recent data indicate, however, that some biotransformations effected by soil bacteria can be conveniently and effectively carried out in E. coli $\mathrm{K}-12$. Obviously, the extensive body of knowledge on $E$. coli $\mathrm{K}-12$ make it the organism of choice for genetic manipulations and if it or other well characterized laboratory strains can be exploited effectively for biotransformations, this will greatly simplify the construction of useful strains and obviate the need to develop appropriate genetic tools for every new organism exhibiting a useful metabolic property. Thus, it is important to extend our experience on the utility and drawbacks of laboratory strains for carrying out interesting biotransformations.

(d) Though it may well turn out to be the case that many useful biotransformations can be carried out with laboratory strains, it is to be expected that others will require the special structural, physiological or metabolic characteristics of the strains in which the pathway elements naturally reside. In these instances it will be necessary to effect the required genetic manipulations in such strains. There is therefore a pressing need to develop new genetic tools that are useful for the analysis and manipulation of groups (rather than individuals) of poorly characterized but biotechnologically interesting organisms. The development of such tools will require detailed characterization of gene expression and regulation in these groups of organisms. Particularly important here will be mRNA translation efficiency and protein stability in such organisms, and factors affecting these, about which we know essentially nothing at this time. The development of genetic tools must of course go hand in hand with the exploration of microbial diversity; as new groups of organisms are discovered that exhibit novel activities of biotechnological interest, the genetic tools needed for exploitation of these activities must be rapidly developed. 


\subsection{RECOMMENDATIONS AND PRIORITY STATUS.}

\section{HIGH-PRIORITY: NEAR MID-LONG TERM.}

- Develop greater insights into global microbial and metabolic diversity to better exploit biochemical reactions in targeted biotechnological applications.

- Develop and characterize microbial metabolic networks, their control and the consequences of deliberate alteration of metabolite levels and balances, so that manipulation of metabolic flow for biotechnological purposes moves increasingly from empirical to predictive science.

- Extend our knowledge on the utility and drawbacks of laboratory strains for carrying out interesting biotransformations.

- Develop new genetic tools that are useful for the analysis and manipulation of groups (rather than individuals) of poorly characterized but biotechnologically interesting organisms.

- Design new metabolic routes using different biosynthetic and degradative pathways to obtain novel products that are impossible to chemically synthesize - for example, indigo production from four different pathways: glucose assimilation, tryptophan biosynthesis, tryptophanase and naphthalene oxidation. Such strategies are applicable to any assimilatable organic molecule whose carbon skeleton can be disassembled and reassembled into new products.

- Develop high level enzyme(s) synthesis which is uncoupled from biomass production.

- Construct new metabolic routes for product synthesis from either known pathways or non-existing pathways.

- Develop the coordinate expression of genes originating from different pathways.

- Improve metabolite flow by inactivaton of key enzymes acting at branchpoints. 


\section{Chapter 9}

\section{STRATEGIES AND DEVELOPMENT OF NEW MICROORGANISMS POSSESSING SPECIALIZED PHYSIOLOGICAL ATTRIBUTES FOR THE BENEFICIATION OF FOSSIL FUELS.}

\section{$9.1 \quad$ INTRODUCTION.}

Research and development on new microorganisms possessing specialized physiological properties, such as tolerance to organic solvents, would contribute to fossil fuel biotechnology initiatives. Specific objectives in the development of solvent-tolerant microorganisms for fossil energy R\&D initiatives are biotransformations, bioremediation, waste treatment, denitrogenation, deoxygenation, and biodesulfurization. There are limitations under which microorganisms can exist in the presence of specific solvent concentrations (Haggin, 1989). The development of solvent-tolerant microorganisms is considered to offer significant potential for improving as well as solving specific problems that exist in the biological processing of various fossil fuels. The application of solvent-tolerant microorganisms to oilcontaminated sites and/or oil spills may potentially expedite the bioreclamation of such sites with a minimum of environmental threat. The biotransformation of specific water-insoluble components present in fossil fuels to high-added value products with solvent-tolerant microorganism offers advantages in the development of process technologies, both downstream and upstream.

To date, little research has been accomplished on microorganisms which grow in high concentrations of organic solvents. The isolation and development of solvent-tolerant microorganisms offers the potential for utilizing organic solvents as new environments for biological functions rather than representing inhibitory substances. The isolation of solventtolerant microorganisms will require rigorous characterization with respect to cultural properties, solvent tolerance mechanisms plus the analysis of the genetic basis for these physiological properties. The scientific and technological achievements accruing to the development of solvent-tolerant microorganisms will serve to establish new frontiers in the areas of applied microbiology and biotechnology.

This review will focus on recent progress in the development of organic solvent-tolerant microorganisms plus the applications of these microorganisms for the beneficiation of fossil fuels. 


\section{SUMMARY.}

Organic solvent-tolerant microorganisms are potentially useful tools for biotechnological applications to fossil fuels. One strain of Pseudomonas has been isolated which grows in high concentrations of toluene, an organic solvent which is highly toxic to other microorganisms. In addition, an aromatic compound-utilizing microorganism, Pseudomonas putida, has been mutagenized to acquire toluene tolerance, suggesting solvent-tolerant microorganisms can be obtained by genetic methods as well as by screening methods.

Advantages for the application of solvent-tolerant microorganisms include an increase in the solubility of water-insoluble substrates where reactions are conducted in organic solvents, favorable shifts in chemical equilibria, reduction of substrate and product inhibition and simplication of product separation and recovery from reaction mixtures. Potential applications of solvent-tolerant microorganisms include several aspects of fossil fuel beneficiation including: biodesulfurization, coal liquefaction, viscosity reduction of heavy oils, waste treatment, bioremediation of toxic chemicals, and biotransformations.

\subsection{STATUS OF CURRENT RESEARCH ON SOLVENT-TOLERANT MICROORGANISMS.}

\section{BACKGROUND.}

Organic solvents are generally toxic to microorganisms, inhibiting growth and metabolism. Some organic solvents, such as ethanol and toluene, are used as bactericidal or bacteriostatic chemicals. Among the various organic solvents, simple hydrocarbons in particular, an elevated toxicity towards microorganisms is manifested, with many becoming bacteriocidal at concentrations of less than $0.1 \mathrm{vol} \%$. Accordingly, no reports have appeared describing microorganisms which are tolerant to high concentrations of organic solvents and able to maintain normal growth and metabolism.

A number of microorganisms assimilate organic solvents as growth substrates such as normal alkanes (pentane through eicosane), benzene, toluene, xylene, cyclohexane, and others. However, all of these microorganisms exhibit a tolerance to only low concentrations of hydrocarbons (vapor or at most $1.0 \mathrm{vol} \%$ ). Apart from the recent work by Inoue and Horikoshi (1988) and Shima et al. (1991), no reports describe microorganisms with organic solvent-tolerance greater than $3 \%$. Table 1 lists representative hydrocarbon-assimilating microorganisms and the maximum solvent concentrations which allow growth.

Microorganisms growing in the presence of organic solvents are considered to show specific adaptations in physiological characteristics and cell surface structure. However, due to the lack of solvent-tolerant microorganisms, little progress has been made in determining the nature of these adaptations. Detailed studies on these organisms will provide new information and technologies for applications in the fossil fuel industry. 
Table 1.

SOLVENT'-ASSIMILATION OF SELECTED MICROORGANISMS.

\begin{tabular}{lll}
\hline Microorganisms & $\begin{array}{l}\text { Concentration } \\
\text { Organic Solvent }\end{array}$ & $(\% \mathrm{v} / \mathrm{v})$ \\
\cline { 2 - 3 } Bacterium JOB5 & Dodecane & 0.300 \\
Pseudomonas oleovorans & Octane & 1.000 \\
Nocardia spp. & Hexane & 0.250 \\
\hline Acinetobacter cyclohexanophilus & Cyclohexane & 0.100 \\
Mycobacterium spp. & Cyclohexane & 0.200 \\
Nocardia spp. & Cyclohexane & 0.200 \\
\hline Arthrobacter spp. & Cyclohexane & 0.100 \\
Pseudomonas aeruginosa & Benzene & 0.200 \\
Mycobacterium rhodochrous & Benzene & 0.200 \\
\hline Achromobacter spp. & Benzene & 0.100 \\
Pseudomonas putida & Toluene & vapor \\
Achromobacter spp. & Toluene & 0.100 \\
\hline Pseudomonas desmolytica & Xylene & 0.200 \\
Nocardia coralitis & Xylene & 0.002
\end{tabular}

\section{CURRENT RESEARCH STATUS.}

As mentioned, little research has been reported on solvent-tolerant microorganisms, even though extensive data bases exist on the assimilation/dissimilation of various organic solvents by microorganisms. Therefore, our recent experimental results on toluene-tolerant bacteria will be reviewed (Inoue and Horikoshi, 1989; Shima et al., 1991).

\section{A Pseudomonas thrives in high concentrations of toluene.}

Although toluene is highly biotoxic, killing most microorganisms at a low concentration ( 0.1 vol\%), a variant strain of Pseudomonas putida isolated from soil grew in culture media containing more than $50 \%$ (vol/vol) toluene, cyclohexane, xylene or heptanol. Table 2 summarizes the solvent tolerance of strain $\mathrm{IH}-2000$ plus the tolerance level of other microorganisms. Although the bacterial strains tested showed tolerance to some solvents, their tolerance was limited to low polarity solvents. In Table 2, polarity (P) is the partition coefficient of a given solvent in an equimolar mixture of octanol and water, where $P$ represents a quantitative index of solvent polarity. Strain $\mathrm{IH}-2000$ is resistant to solvents 
with $\log \mathrm{P}$ values greater than or equal to 2.4 (e.g., heptanol, $\log \mathrm{P}=2.4$; toluene, $\log \mathrm{P}=2.8$; octane, $\log P=4.9$ ). In contrast, strain $\mathrm{IH}-2000$ does not grow in fluorobenzene, benzene and butanol which have $\log P$ values of $2.3,2.1$ and 0.8 , respectively. The concept of such a tolerance limit can be extended to the growth capabilities of other microbial strains in a high solvent environment; e.g., Pseudomonas putida exhibits tolerance to xylene $(\log \mathrm{P}=3.1)$ but not to styrene $(\log \mathrm{P}=2.9)$

Table 2.

SOLVENT TOLERANCE OF BACTERIAL STRAINS AND MUTANTS.

\begin{tabular}{|c|c|c|c|c|c|c|c|c|}
\hline & $\log P$ & $\begin{array}{l}\text { IH- } \\
2000\end{array}$ & $\begin{array}{l}\text { mut } \\
-1\end{array}$ & $\begin{array}{l}\text { mut } \\
-2\end{array}$ & $\begin{array}{l}\text { mut } \\
-3 \\
\end{array}$ & $\begin{array}{c}\mathrm{P} \\
\text { putida } \\
\text { IFO3738 }\end{array}$ & $\begin{array}{c}\text { E.coli } \\
\text { IFO } \\
8 \quad 8306 \\
\end{array}$ & $\begin{array}{l}\text { B.sub. } \\
\text { AHU } \\
1219\end{array}$ \\
\hline Dodecane & 7.0 & + & + & + & + & + & + & + \\
\hline Decane & 6.0 & + & + & + & + & + & + & + \\
\hline Octane & 4.9 & + & + & + & + & + & + & + \\
\hline Isooctane & 4.8 & + & + & + & + & + & + & - \\
\hline n-Hexane & 3.9 & + & + & + & + & + & + & - \\
\hline Propylbenzene & 3.8 & + & + & + & - & + & + & - \\
\hline Cyclohexane & 3.4 & + & + & + & - & + & - & - \\
\hline p-Xylene & 3.1 & + & + & - & - & + & - & - \\
\hline Styrene & 2.9 & + & + & - & - & - & - & - \\
\hline Toluene & 2.8 & + & - & - & - & - & - & - \\
\hline Heptanol & 2.4 & + & - & - & - & - & - & - \\
\hline Benzene & 2.1 & - & - & - & - & - & - & \\
\hline
\end{tabular}

Genetic engineering of toluene-resistant Pseudomonas.

Three toluene-sensitive mutants derived from the toluene-resistant Pseudomonas strain IH2000 were obtained by chemical mutagenesis to study the mechanism of toluene resistance. These mutants, IH-2124T, IH-2124TX and IH-2124TXC were tolerant to styrene, cyclohexane and hexane, respectively (Table 2 ), and exhibited a back-mutation frequency 
of less than $10^{-7}$. Genetic analysis of strain $\mathrm{IH}-2000$ indicated that genes conferring toluene tolerance were localized on the chromosome, suggesting that microbial tolerance to organic solvents is genetically determined.

Toluene-resistant mutants of Pseudomonas putida.

Pseudomonas putida showed relatively high resistance to p-xylene but not to toluene (Table 2). To obtain toluene-resistant mutants, p-xylene-resistant $P$. putida was grown and spontaneous mutants were selected that were resistant to toluene. One mutant strain was obtained after incubation with saturated toluene for 3 days. This toluene-resistant strain maintained the toluene tolerance phenotype for several weeks in the absence of toluene with a back-mutation frequency of less than $10^{-8}$, suggesting a stable mutation.

\subsection{FUTURE RESEARCH DEVELOPMENT AND REQUIREMENTS.}

\section{RESEARCH NEEDS AND JUSTIFICATION.}

Since toluene-resistant microorganisms were isolated from soil, it is highly probable that other organic-solvent tolerant microorganisms exist, whether the solvents are crude oils, refined oil fractions, coal liquids or conventional organic solvents. It will become possible to carry out various chemical reactions currently considered impossible, difficult or even impractical through the development of these types of microorganisms. In the energy industry, possible applications of solvent-tolerant microorganisms include biodesulfurization, bioconversion to added-value products and bioremediation.

There are four major problems that have so far prevented or thwarted the application of biological processes in the fossil fuel industry. The first problem is the maintenance of $\mathrm{pH}$, temperature and a supply of abundant amounts of water in reaction mixtures. The amount of water needed will be greatly reduced by the use of solvent-tolerant microorganisms. For instance, IH-2000 grows in 30 volume\% of toluene. Considering that ordinary microorganisms survive only up to $0.3 \%$ toluene, this indicates a 100 -fold reduction of reaction volume. The second problem is the low concentration of substrates available for these reactions, due to limited substrate solubility in a water-based medium. Accordingly, reaction conditions can be significantly improved with solvent-tolerant microorganisms through the replacement of water with organic solvent as the reaction medium. Further, high concentrations of organic solvent can potentially serve to reduce and/or eliminate product inhibition, another problem in the application of biological technologies. The partitioning of products by two-phase separations, depending on charge and solubility coefficients, would impact significantly on the downstream process economics. The fourth problem concerns aseptic conditions in bioreactors. Since solvent-tolerant microbial technology allows for high concentrations of organic solvents, the reaction mixture could be considered as sterile for most other microorganisms. 


\section{General Perspectives.}

There are two major research needs for implementing the application of solvent-tolerant microorganisms in the fossil fuels industry:

1. Inherent genetic stability of solvent-tolerant microorganisms to solvent tolerance. It is necessary to develop genetically-stable microorganisms exhibiting high levels of tolerance to mixtures of various organic solvents, crude oils as well as heavy metals for application to fossil fuel treatments and/or transformations. The two approaches for developing solvent-tolerant microorganisms are selection through screening of soil microorganisms and mutagenesis of existing microorganisms. New microorganisms can be expected through screening, although the risk of failure is high.

2. Solvent-tolerant enzyme systems should be developed and should be of value to fossil fuel process technology. It is impossible at present to apply the toluene-tolerant bacterium, IH-2000, as a practical tool due to lack of useful enzymatic properties. It appears necessary to screen for solvent-tolerant microorganisms which possess biotransformation enzyme systems which are solvent-tolerant.

Even though solvent-tolerant microorganisms can be useful in various stages of fossil fuel technologies, certain limits exist. All biological entities need nutrients, exhibit optimal temperature and $\mathrm{pH}$ limits and require the presence of water. The extent of these limitations are presently unknown and offer real opportunities for the development of performance-effective and cost-effective biotechnology initiatives.

\section{Biodesulfurization and bioliquefaction of coal.}

Chemical desulfurization processes are presently under intensive study by the petrochemical and coal industries, due to increasingly stringent regulatory pressures. However, severe technical constraints exist due to limitations in commercially available technology (Schwartz, 1990; see Chapter 4).

Since coal is expected to be a major future energy source, biodesulfurization and bioliquefaction of coal are important technologies for the future (Haggin, 1989). The use of solvent-tolerant microorganisms engineered to contain the enzyme systems capable of organic sulfur removal from coal offers a potentially advantageous new technology. The solubilization of the coal in an organic solvent system would allow for enhanced rates of biodesulfurization, making large scale process technology more feasible. 


\section{Bioremediation.}

Bioremediation occurs in field situations involving the reclamation of waste disposal sites or cleanup of oil spills. It is possible that such bioremediation processes could be significantly improved through the use of solvent-tolerant microorganisms which could survive and grow in the presence of high concentrations of oil-derived wastes (see Chapter 3).

Generally, the solubility of organic pollutants in water is low, making it difficult for microorganisms to efficiently biodegrade such wastes (Haggin, 1989). Problems encountered in such systems are high molecular weight polycyclic aromatic hydrocarbons which exhibit limited solubility in aqueous media, which aggregate into macromolecular complexes in hydrophilic environments and which are generally metabolized quite slowly due to limited bioavailability. Such problems might be overcome by extraction of pollutants into organic solvents and treatment with solvent-tolerant microorganisms or through the addition of organic solvents to isolated polluted soil systems and treatment with solvent-tolerant microorganisms.

\section{Biotransformation.}

Biotransformation represents the most promising field for the application of solvent-tolerant microorganisms in the conversion of fossil fuel feedstocks to high-added value chemicals (see Chapter 7). Impressive advances have occurred in the area of biotransformations carried out in organic solvent systems or organic solvent-water, two-phase systems (Antonini et al., 1981; Deetz and Rozzel, 1988; Laane and Tramper, 1990) (see chapter 7). Enzymatic biotransformations in organic solvents have inherent disadvantages such as catalyst denaturation, catalyst regeneration and limitation of co-factors (Laane and Tramper, 1990). In contrast, biotransformations catalyzed by solvent-tolerant microorganisms could occur in continuous bioreactors with less regard for denaturation and catalyst regeneration, since the microorganisms would grow in high organic solvent concentrations. Also, solvent-tolerant microorganisms would be able to replenish essential co-factors.

\subsection{RECOMMENDATIONS AND PRIORITY STATUS.}

\section{NEAR-TERM INITIATIVES}

Two immediate research objectives should be considered as near-term R\&D initiatives, regardless of specific fields of fossil energy applications.

1. The isolation and characterization of stable solvent-tolerant microorganisms which exhibit broad tolerance to organic solvents should be developed. Considering the practical industrial applications for solvent-tolerant microorganisms, genetic stability and wide-range solvent tolerances of solvent-tolerant microorganisms are critical to 
implementation. Solvent-tolerant microorganisms can be acquired through screening and by mutation of existing solvent-tolerant microorganisms. These laboratory procedures do not require specialized expertise, utilizing basic microbiological methodologies which can be accomplished in the short-term.

2. Genetic engineering of solvent-tolerant microorganisms. The ability to catalyze specific chemical reactions must be present in solvent-tolerant microorganisms, either through selection, mutagenesis or cloning of specific genes with amplification. It has been demonstrated that toluene-resistant strains can be derived through such procedures. Of concern are the numerous regulations and restrictions applying to the release into the environment of genetically-engineered microorganisms. Therefore, it is recommended that bacterial strains be used where extensive genetic data-bases exist and for which precedents support the environmental application of such microorganisms.

\section{MID-TERM INITIATTVES}

The application of solvent-tolerant microorganisms in biotransformations and bioremediation technologies should be considered as mid-term initiatives, since these fields offer significant potential for commercial exploitation. Solvent-tolerant microorganisms will allow for higher efficiences in bioprocessing technologies with higher substrate concentrations and improved product yields. Most importantly, such reaction systems may likely develop new reactions and products not previously possible. The development of suitably gene-engineered solventtolerant microorganisms represents priority status.

\section{LONG-TERM INITIATTVES}

\section{Biodesulfurization of fossil fuels.}

Microbial desulfurization of fossil fuels, particularly coal, appears feasible. The importance for the application of solvent-tolerant microorganisms to fuel biodesulfurization is emphasized. The basic laboratory scale techniques can be developed in a relatively short time frame; however, the R\&D for large scale applications of solvent-tolerant microorganisms would require a longer time frame.

\section{Biodesulfurization of coal.}

One of the disadvantages of coal as an energy source is its solid character. Several reports detail coal biosolubilization by various microorganisms such as fungi (Odom et al., 1990), bacteria (Crawford et al., 1990), and enzymes (Scott et al., 1990). The significant advantage for solvent-tolerant microorganisms would be the tolerance of microorganisms to liquid coal and their ability to carry out specific bioconversions to upgrade coal quality, such as biodesulfurization and/or biodenitrogenation. Research in biodesulfurization will bear more importance in the future, especially for countries like Japan which may be forced to import such high-sulfur coal to compensate for fuel shortages. 


\section{Chapter 10}

\section{USE OF METHANE IN WATER TREATMENT.}

\section{$10.1 \quad$ INTRODUCTION.}

In 1985, Wilson and Wilson reported the aerobic microbial degradation of trichloroethylene (TCE) as a result of adding $0.6 \%$ natural gas in air to the atmosphere of a soil column. Subsequently, it has been shown that mixed cultures of methane or propane-utilizing bacteria are capable of degrading a variety of halogenated hydrocarbons in addition to TCE (Fogel et al., 1986; Henson et al., 1988). Since 1985, significant effort has been expended on developing both above-ground and in situ remediation methods using methanotrophic bacteria, and has led to bioremediation experiments to evaluate the in situ degradation of TCE (Roberts et al., 1989). The Deep Subsurface Program sponsored by DOE conducted investigations of subsurface microbial populations and activity at an underground aquifer at Savannah River Research Laboratory, demonstrating that large populations of diverse microorganisms exist in subsurface environments, including methanotrophs (Phelps et al., 1990), which did not decrease with depth (Levine and Ghiorse, 1990) and which exhibited metabolic activities (Fliermans et al., 1988; Phelps and White, 1990).

After five years of research and development, laboratory systems have achieved the performance parameters needed to compete with air stripping and carbon adsorption, the technology currently used to remove TCE from groundwater. Major commercial firms and national laboratories are developing processes which will be tested at Savannah River Laboratories and possibly other sites in the next two years. In addition, in situ bioremediation field experiments are underway which will be using methanotrophic systems at both Savannah River Laboratory and possibly other sites.

\section{BACKGROUND.}

Trichlorethylene (TCE) is a halogenated aliphatic organic compound widely used as a degreasing agent and ingredient in industrial cleaning solutions. TCE and perchloroethylene are among the most frequently detected volatile organic chemicals in groundwater in the United States (Westrick et al., 1984; Fischer et al., 1987; Russell et al., 1991). The presence of TCE has led to the closing of water supply wells on Long Island and in Massachusetts (Josephson, 1983). About $20 \%$ of 315 wells sampled in a New Jersey study contained TCE or other volative organic chemicals above the $1 \mathrm{ppb}$. detection limit (Fusillo et al., 1985). While TCE itself is not carcinogenic, it is believed to become a human health hazard after processing in the human liver (Bartseh et al., 1979). It is suspected that epoxidation by liver oxidase enzymes results in a possible carcinogen (Tu et al., 1985). The anaerobic reductive 
dehalogenation of TCE may possibly result in the production of vinyl chloride which is a known carcinogen.

Current technology has utilized air-stripping to effectively remove TCE from contaminated water. This process only shifts the TCE from a liquid medium to the atmosphere, and such venting is becoming restricted by new regulations (Russell et al., 1991). As a result, air stripping is often combined with granulated activated carbon adsorption. Granulated activated carbon adsorption has two limitations: a limited capacity for sorption of a given contaminant so that once the limit is reached breakthrough occurs; and the carbon must be disposed of, replaced or regenerated. Adsorption of TCE to granulated activated carbon, based on equilibrium concentrations of $1 \mathrm{ppm}$ at neutral $\mathrm{pH}$ and $20 \mathrm{C}$, is $28 \mathrm{mg} / \mathrm{gm}$ (Amy et al., 1987). Another limitation is that dissolved organic carbon (DOC) and other contaminants can compete with TCE for the binding sites on carbon (Russell et al., 1991). A concentration of $10 \mathrm{ppm}$ natural organic matter in river water has been shown to reduce TCE adsorption by up to 70\% (Amy et al., 1987). Another issue is that, while TCE is extremely volatile and hence amenable to air stripping, other halogenated hydrocarbons are less volatile. Using air stripping followed by granulated activated carbon as current technology for TCE removal from groundwater, a study conducted by the Radian Corporation estimated that, if conservative performance goals for an above-ground methanotrophic reactor system could be met, it could be 40 to $60 \%$ cheaper to build and operate. One of the most cost-sensitive components of the methanotrophic reactor was found to be the cost of methane with a reduction in the amount of methane used a major goal of the research program.

The methane-oxidizing bacteria were identified in 1905, and the first was isolated at that time (Kaserer, 1905; Hutton and Zobell, 1949). A second methane-oxidizing bacterium was isolated in 1966 (Foster and Davis, 1966). New isolation techniques and extensive examinations of numerous environments resulted in the isolation of several hundred methanotrophs of ubiquitous distribution throughout the biosphere (Hansen, 1980; Malashenko, 1987; Sieburth, 1987). In some cases, they have been reported to comprise up to eight percent of the total heterotrophic microbial population (Higgins et al., 1981). These organisms are of interest for a number of reasons. Besides having an important role in the cycling of methane, carbon, and nitrogen (Higgins et al., 1981), their energy source, methane, is the lowest cost carbon substrate by a cost factor of at least ten (GRI, unpublished data). In addition, the methanotrophs have simple growth requirements, they exhibit relatively rapid growth, and they synthesize a methane monooxygenase in either particulate or soluble form. Many of the details of this system are reported in Chapter 13 on the use of methane for chemical production.

\subsection{STATUS OF BASIC AND APPLIED RESEARCH.}

\section{BASIC RESEARCH.}

The use of methanotrophs to degrade TCE and other halogenated hydrocarbons followed the discovery that an atmosphere of $0.6 \%$ natural gas in air could stimulate the degradation 
of TCE (Wilson and Wilson, 1985). Subsequent experiments with a mixed culture showed that, while methane stimulation was needed, it did not need to be in the headspace for degradation to occur (Henson et al., 1988). In bioreactors containing aerobic mixed cultures, Phelps et al., (1990) showed that over $90 \%$ of the TCE present was degraded utilizing either propane or methane plus propane as the energy source. When methane was used alone, the total amount of TCE degraded decreased by approximately $60 \%$, suggesting that either the consortia used propane more effectively, or that methane is a more effective competitive inhibitor of methane monooxygenase. This competitive inhibition effect has been confirmed by Broholm et al. (1990), with the conclusion that total inhibition is observed at $13 \mathrm{mg}$ TCE/liter, which corresponds to a concentration in soil of $2.6 \mathrm{mg} / \mathrm{kg}$, assuming a distribution coefficient of 0.2 liter $/ \mathrm{kg}$, a representative value for sandy soils with a low content of organic carbon. This inhibitory soil concentration is not unrealistically high and may be exceeded at or close to the source of contamination.

This inhibition by TCE of naturally-occuring microbial populations is consistent with the observations by Phelps and White (1990), that negligible bacterial activity and biomass were detected in sediments severely contaminated by TCE. Similiarly, Jewell at al. (1991) reported that prolonged exposure to vinyl chloride concentrations above $5 \mathrm{mg}$ per liter, or dissolved methane concentrations greater than $0.5 \mathrm{mg}$ per liter in the headspace of the expanded bed reactor, result in a reversible inhibition of the methanotrophic culture and inhibition of vinyl chloride degradation, respectively. Nichols et al. (1985) and Henry and Grbic'-Galic' (1991) suggest that TCE degradation is positively correlated with high storage polymer-phospholipid fatty acid ratios, indicative of nutrient stress. Oldenhuis et al. (1991) suggest that acute toxicity to TCE or degradation products can be reduced by adding activated carbon. This activated carbon presumably aids by adsorption and slow desorption. Activated carbon is also described as a suitable supporting material for microorganisms, resulting in stable bioreactor systems (Bouwer and McCarty, 1983).

A minimum threshold TCE concentration of approximately $0.5 \mathrm{mg}$ per liter at influent methane concentrations between 20 to $50 \mathrm{mg}$ per liter is reported by Phelps et al., (1990). Similar thresholds have been reported using trickling filters (Strandberg et al., 1989). Even though there appears to be a lower threshold, stable TCE degradation was sustained for over 6 months at utilization rates of 50 to 150 mole of methane per mole of TCE degraded or 15 to $80 \mathrm{mg}$ of TCE per gm (dry weight) of biomass per day (Phelps et al., 1990). Jewell et al. (1991) observed a TCE threshold of approximately $0.1 \mathrm{mg}$ per liter in batch runs in a high-rate expanded bed reactor. Subsequent work has indicated that the addition of activated carbon can reduce the effluent concentration of TCE to below $0.01 \mathrm{mg}$ per liter.

Anaerobic transformations of these pollutants is also known to occur (Bouwer et al., 1981). In general, anaerobic transformations of halogenated alkanes and alkenes lead to the production of a wide variety of less-halogenated products (Bouwer and McCarty, 1983; Roberts et al., 1989). In these systems, TCE and perchloroethylene are reduced sequentially to form 1,2-dichloroethene and then vinyl chloride. Vinyl chloride can also be transformed anaerobically, but the rate is very slow. Roberts et al. (1989) and others have suggested 
that an initial anaerobic transformation in a reactor or aquifer may be desirable, followed by a methanotrophic process for the destruction of vinyl chloride. Jewell et al. (1991) have demonstrated, during continuous flow operation of his expanded bed reactor, vinyl chloride removal efficiencies as high as $99.9 \%$ and effluent concentrations of vinyl chloride as low as $1 \mathrm{ppb}$ during an operation with an influent vinyl chloride concentration of $2000 \mathrm{ppb}$. Economic analyses have indicated that coupling anaerobic dechlorination of TCE and perchloroethylene with methanotrophic destruction of vinyl chloride could significantly reduce methane use and process cost.

Studies on another methanotrophic application for removing nitrogen and phosphorus from sewage effluents have been initiated. Previous work attempted to use a methanotrophic system to denitrify wastewater with methane, but was unsuccessful (Jewell et al., 1991). The experiments indicated, however, that both nitrogen and phosphorus could be removed from the sewage effluent by assimilation into the methanotrophic biomass in a high rate system. Results indicate that all forms of nitrogen can be removed to relatively low values (less than $1 \mathrm{mg} / \mathrm{l}$, and phosphorus can be simultaneously removed to values less than $1 \mathrm{mg} / \mathrm{l}$. Subsequent testing has showed that the ratio of nitrogen to phosphorus removed reflects the theoretical ratio in the methane-oxidizing cell mass that is approximately a nitrogen to phosphorus ratio of $6: 1$. Therefore, in most cases, while most nitrogen would be removed, only 50 to $75 \%$ of the phosphorus would be removed from typical domestic sewage without supplying additional nitrogen (Jewell et al., 1991). The possible advantages of such a system over other tertiary treatment methods are under investigation.

\section{APPLIED RESEARCH.}

\section{Above-ground Bioreactor.}

At many contaminated sites in the U.S., there is a need to contain pollutant movement as well as reduce concentrations of in-place pollutants. Containment is often achieved by hydraulic interdiction of the pollutant plume through wells linked to a pump-and-treat system. Such a system usually involves treatment with air stripping and/or granular activated carbon (GAC) followed by discharge to surface waters; the use of activated carbon for direct water treatment or for capture of pollutants from the effluent air stream of the air stripper causes treatment costs to rise dramatically to the range of $\$ 1-3 / 1000$ gallons or more for the treatment of water streams containing more than $10 \mathrm{ppm}$ chlorinated hydrocarbons. Since the amount of GAC employed in interdiction systems is a major cost factor, there exists a need to develop methanotrophic above-ground processes capable of destroying TCE in water with minimal need for adsorbents.

In a survey of $77 \mathrm{U}$. S. groundwater interdiction and treatment systems that used air stripping, it was found that more than $90 \%$ of the "pump-and-treat" units operated at flow rates of more than $350 \mathrm{gal} / \mathrm{min}$ and at concentrations of less than $10 \mathrm{ppm}$. Since most groundwater pollutant containment systems involve the treatment of high flows of water at low pollutant, it was logical that attached film reactors be evaluated and developed for methanotrophic treatment by bacteria concentrations. However, a number of considerations 
were required in the development of the reactor. First, the reactor needs to be compatible with a methane and oxygen feed and cometabolism of the pollutant while controlling the effects of competitive inhibition between methane and the pollutant, as previously observed in basic research studies. Secondly, methane demand must be limited to below 3,000 scf/lb of TCE to be competitive with GAC costs of conventional treatment systems. Lastly, reaction rates in methanotrophic treatment reactors are likely to be either limited by biotransformation kinetics or by mass transfer of the feed gases to the biofilms. In view of these considerations, two types of fixed film bioprocesses were selected for development: 1) the methanotrophic attached film expanded bed reactor (MAFEB) and 2) the rotating biological contactor.

The MAFEB was selected to compensate for low specific unit rates of TCE oxidation (i.e. mg TCE oxidized/gm cell mass/day) that may arise from the innate biotransformation capability or from competitive inhibition. The MAFEB is a type of fluidized bed process whereby biofilms attached to solid particles, such as diatomaceous earth or granular activated carbon, are fluidized in a column that is fed with a pollutant stream. The waste streams are circulated through methane and oxygen contactors to provide the required oxidant and supplemental substrates for pollutant removal. Hydraulically, this type of reactor is capable of operating at retention times of less than 5 minutes without washout while maintaining concentrations of 30-70 $\mathrm{g} / 1$ compared to conventional activated sludge microbial mass concentrations of 1-3 $\mathrm{g} / 1$, which are maintained under much longer hydraulic retention times of 6-8 hours. If the overall kinetic rate of substrate oxidation is second order and a function of substrate and cell concentration (i.e. $\mathrm{dC}_{\mathrm{s}} / \mathrm{dt}=\mathrm{KC}_{\mathrm{s}} \mathrm{C}_{\mathrm{b}}$, where $\mathrm{C}_{\mathrm{s}}=$ substrate concentration, ppm; $\mathrm{C}_{\mathrm{b}}=$ cell mass concentration, ppm; and $\mathrm{K}=$ first order kinetic constant), then the ability of the reactor to concentrate cell mass to twenty times that of suspended culture systems should reduce kinetic limitations. The challenge with this type of reactor is to provide sufficient methane and oxygen to the liquid phase of the reactor to match the potentially high volumetric rates of TCE destruction.

Jewell et al. (1991) report the first attached film methane oxidizing bioreactor. It was found, due to unexpectedly high densities of methanotrophic films, that maximum concentrations of microbial mass are nearly three times the predicted maximum based on characteristics of aerobic films developed in other studies. The film appears tough and dense, unlike other aerobic films that usually have low densities and are relatively weak and easy to dislodge into suspension. The films are more characteristic of anaerobic films which may be due to the small size of the bacteria. Maximum microbial concentration achieved in an attached film was $25 \mathrm{~g} \mathrm{VS/L}$ of reactor, and the film was maintainable for extended periods at high liquid flow rates. The reactor was highly stable and easy to control with hydraulic retention times of 0.6 to 3.6 minutes. Later studies showed that continuous flow TCE degradation rates of 0.9 and $0.4 \mathrm{mg}$ TCE/g VS-d were observed at operating concentrations of 0.7 and $0.2 \mathrm{mg}$ TCE/L. Copper inhibition of methanotrophic TCE degradation was also investigated by monitoring influent and effluent copper concentrations. Yeast extract in the feed was identified as the primary source of copper, but no effect on TCE degradation was observed over a range of 0.004 to $0.016 \mathrm{ppm}$ copper. A continuous flow expanded bed system was run with an influent vinyl chloride concentration of $20 \mathrm{mg} / \mathrm{L}$. Under these conditions, there 
was an average effluent vinyl chloride concentration between 0.001 and $0.01 \mathrm{mg} / \mathrm{L}$, representing a removal efficiency of $99.9 \%$. The unoptimized methane requirement for vinyl chloride degradation was about $40 \mathrm{gm}$ of methane per gm of vinyl chloride.

One of the problems with TCE degradation is the residual effluent concentrations. Economic analyses have shown that adding an activated carbon cleanup to the residual effluent is a cost-effective approach. Work is underway, however, on adaptations of commercially available high rate granular activated carbon fluidized bed bioreactors which are currently being developed for benzene (BTEX) removal in oil and gas industry applications. Recent applications have demonstrated removals of influent concentrations of from 250 to $1000 \mathrm{ppb}$ BTEX from wastewater containing triethylene glycol to 1.4 to $9 \mathrm{ppb}$ in the effluent at retention times of 5 minutes. Similar results have been found for degradation of polyaromatic hydrocarbons in other related studies. It is anticipated that this system will be adapted for methanotrophic applications and will be ready for field trials in 1992. One of the major issues is expected to be how methane and oxygen will be delivered to the system.

The rotating biological contactor was selected to address the possibility that gas mass transfer to the biofilms may be limiting the overall volumetric rate of TCE destruction (mg TCE destroyed/l reactor/day). This reactor design is comprised of a tank through which water is passed, a rotating drum of solid support media on which biofilms are grown that is partially submerged in the water, and a cover over the tank to allow control of gases in the headspace above the water. During continuous operation the groundwater to be treated is passed through the tank while air with a small fraction of methane is passed through the headspace. As the biofilm on the drum is slowly rotated through the water, methanotrophic consortia in the biofilm oxidize pollutants in the water and, when rotated into the gas phase, the biofilms are regenerated. This process potentially offers advantages of enhanced gas mass transfer through direct contact of biofilms with the gas phase while separating methane from pollutant destruction by-products, thereby reducing opportunities for competitive inhibition. The disadvantage of the process is that cell mass concentrations are not nearly as high as the MAFEB, but reduced competitive inhibition may compensate at least partially for the lower cell mass concentration.

A rotating biological contactor has been proposed by Fogel and is being developed by Combustion Engineering, Inc. This is a rotating biological contactor in which bacteria are fed a mixture of $2-15 \%$ methane and $2-20 \%$ oxygen. TCE removal on a single pass is reported to be $90 \%$. A possible advantage of a rotating biological contactor is that gas transfer through liquid is no longer needed, allowing for more economical gas transfer. Field trials are anticipated in the near future. Additional field trials of a continuous stirred tank reactor developed by Battelle for the U.S. Army and a trickling filter developed by Oak Ridge National Laboratories are anticipated as well. Field trials will be carried out at a well characterized site at the Savannah River Laboratories from 1991 to 1993. 
Additional research is examining the advantages of anaerobic pretreatment of TCE and perchloroethylene followed by methanotrophic degradation of vinyl chloride. Other concepts, involving the use of methane-fed "mother" reactors, are also being considered. Gas phase systems are also being considered in combination with air stripping or vacuum extraction.

In situ

The first in situ test of a methanotrophic system was initiated by P. McCarty and co-workers at Moffet Field (Semprini et al., 1987; Roberts et al., 1989). The objective was to increase transformation rates in a treatment zone by stimulating a large population of bacteria through the addition of methane and oxygen. It was shown in this study that methane utilization began within ten days when the system was first biostimulated and within 1 day in subsequent experiments. Biotransformations of the target organic compounds (e.g. TCE, dichloroethene and vinyl chloride) started immediately and were in steady state within two weeks. Extent of transformation at steady state was approximately $95 \%$ for vinyl chloride, $85 \%$ for trans-dichloroethene, $40 \%$ for cis-dichloroethene, and $20 \%$ for TCE. This occurred in a relatively small zone with travel distances of 1 to 4 meters and residence times of 8 to 25 hours. Models, based on theoretical considerations and laboratory experiments, proved to be a good description of field study results (Roberts et al., 1989). In addition, the models were used to predict the behavior of combined in situ/above-ground systems. An EPAsponsored field test at a Michigan industrial site is anticipated as a follow-up to these initial experiments.

A second large-scale field test is underway under joint GRI/SRL sponsorship at the Savannah River Laboratories. This system uses an adaptation of technology developed by the gas/oil industry called "horizontal drilling". Two wells have been placed on site at SRL. The lower well is approximately 125 feet deep, where the water table is at 100 feet, and the upper horizontal well is at 75 feet. The upper well is a withdrawal well and is connected to a vacuum extraction system, and the lower well is the injection well.

Initial studies with vacuum extraction show that approximately 7 times more TCE can be removed than from an equivalent vertical well. In 1990, air was injected into the system, with preliminary analyses indicating that bacterial populations increased by two orders of magnitude. In the summer of $1991,4 \%$ methane in air will be added and the microbial populations monitored. This experiment should provide a useful feasibility test for this approach.

\subsection{FUTURE RESEARCH DEVELOPMENT AND REQUIREMENTS.}

\section{RELEVANCE AND JUSTIFICATION.}

The development of methanotrophic systems represents a potentially feasible option for in situ bioremediation since methane (or propane) is a carbon source amenable to such 
applications. It would appear that methanotrophic bioremediation has features which are complementary to other anaerobic or aerobic bioremediation strategies, such as the ability to rapidly degrade vinyl chloride. There may be other applications as well. The importance of this technology is evident by the speed with which it is being evaluated as a bioremediation technology. For the natural gas industry, the use of methane for bioremediation represents an added-value for its product, a potentially significant market, and a possible bioremediation tool for some oil and gas industry applications. Some of the research conducted in this program has already led to other potential applications, such as benzene or polyaromatic hydrocarbon removal, and these are becoming increasingly important.

\section{RESEARCH NEEDS AND LIMITATIONS.}

Research needs include further performance testing of methanotrophic reactions at actual sites to better assess and understand the effects of complex environments on above-ground and in situ systems. Such field experiments and the standardization of testing protocols will aid in developing more realistic and reliable concepts for the application(s) of methanotrophic systems in waste water treatment initiatives. Further studies are required for evaluating the temperature ranges under which TCE degradation occurs. This need is based on the work of Jewell et al. (1991), indicating that TCE degradation decreases by $70 \%$ when temperatures are shifted from $37^{\circ} \mathrm{C}$ to $21^{\circ} \mathrm{C}$. A major concern in methanotrophic systems is gas mass transfer limitations. This issue will probably form the basis for future work on above-ground bioreactors. Approaches include decreasing methane input through improvements in bioreactor design or through the addition of an anaerobic pre-processing step. Any above-ground or in situ system requires a design restriction that ensures zero methane release to the environment. Studies to date indicate that the relatively small quantities of methane added as substrate to methanotrophic systems are rapidly metabolized. Bioreactors must be designed to elimminate possible leakages of methane. The design of bioreactor systems capable of gas phase methanotrophic reactions combined with air stripping and extraction are desirable. Work on such design concepts are in progress. Finally, improved methods are needed for the on-line measurement(s) of in situ pollutant and nutrient concentrations. The ability to differentiate between pollutant removed by airstripping and through bioremediation strategies is critical to the development of effective bioremediation systems. 
NEAR-TERM-HIGH PRIORTTY.

- Determine the technical goals needed to achieve economic competitiveness of methanotrophic systems.

- Develop systems which achieve low effluent concentrations of pollutant either by adding a granulated activated carbon component or by developing the granulated activated carbon fluidized reactor.

- Establish pollutant degradation rates of methanotrophic systems at ambient temperatures.

- Improve gas mass transfer in above-ground bioreactors designed for methanotrophic systems.

- Design above-ground and in situ bioreactors for methanotrophic systems that release zero methane to the atmosphere.

- Develop systems capable of gas phase methanotrophic reactions with air stripping and vacuum extraction.

- Develop new methods for on-line measurement of in situ pollutants and nutrient concentrations.

\section{MID AND LONG-TERM-HIGH PRIORITY}

- Develop improved methods for the detection of microorganisms and targeted chemicals.

- Initiate R\&D programs for developing a better understanding of the biochemistry and genetics of microbial-mediated pollutant biodegradation.

- Develop improved models for groundwater hydrology and biogeochemical reactions.

- Establish a better definition of priority pollutants and risk assessment. 


\section{Chapter 11}

\section{MICROBIOLOGICALLY INFLUENCED CORROSION (MIC) IN THE NATURAL GAS INDUSTRY.}

\subsection{INTRODUCTION.}

Corrosion is a major cost to most industries, including fossil fuel industries, in terms of replacement materials, down-time, safety, and liabilities. Fontana (1986) reported estimates for the costs of all forms of corrosion (worldwide) up to $\$ 126$ billion annually. Some investigators working on stainless steel and other alloys in the chemical and nuclear industries have estimated that MIC may be involved in $10-30 \%$ of the corrosion with the natural gas industry estimates being slightly higher. In the natural gas industry, work has focused on anaerobic underdeposit pitting corrosion of mild carbon steel.

The previous 50 years of research on MIC focused primarily on the roles of sulfate-reducing bacteria. Contemporary work examines the roles of microbial consortia and their ability to initiate electrochemical corrosion processes as well as translating information about MIC mechanisms into more effective mitigation measures. Methods for testing the mitigation of MIC and the early detection of MIC are receiving renewed interest. At present, most of the techniques used by industry for detection and evaluation depend on classical microbiological methods. Newer detection methods are based on applied immunoassays and gene probes. Many of the new assays target sulfate-reducing bacteria, although the development of probes to other microbial targets are needed. A major limitation in assessing MIC is the inability to measure corrosion rates directly using on-line measurement techniques. Several approaches using electrochemical impedance techniques are currently being investigated.

The study of biocorrosion has witnessed the integration of the physical, chemical, electrochemical, genetic, and biochemical sciences for developing a more detailed understanding of the microbial ecology of biofilms on surfaces. The melding of classical corrosion techniques with biotechnology should improve the understanding of bacterial interactions on metal surfaces and aid in our overall understanding of such interactions with other environments. For example, an understanding of how bacteria interact with chemicals in soil environments is a fundamental issue in bioremediation. Unlike soil, however, there is a detailed science for the detection of electrochemical and metallurgical features on metal surfaces. This knowledge will help us to understand microbial interactions in biofilms, on surfaces and in soils. An improved understanding of MIC, therefore, should lead to advances in other important environmental applications such as corrosion mitigation and bioremediation, which could affect all fossil fuel industries. 


\section{BACKGROUND.}

Despite considerable research on MIC in gas and oil production operations in Europe between 1950 and 1984 (Tiller, 1985), MIC was not systematically investigated by the U.S. natural gas industry until 1986. The few natural gas pipeline companies investigating MIC prior to 1986 included Tokyo Gas, British Gas, and Nova Husky (Canada); (Kasahara and Kajiyama, 1985; Lake et al., 1986; Worthingham and Jack, 1985). In addition, there has been work on the mechanisms of biological sulfur cycling (Orr, 1974; Grinenko and Ivanov, 1983; Herbert, 1987; Rosanova and Nazina, 1979; Zobell, 1957). Some studies have investigated methods of controlling $\mathrm{H}_{2} \mathrm{~S}$ production by sulfate-reducing bacteria through chemical treatments and preventing MIC by the application of cathodic protection (Tiller, 1975; Jones, 1987; Lunden and Stastny, 1985; Sanders and Stott, 1987; Herbert, 1987; Stott, 1987; Herbert and Stott, 1983; Herbert et al., 1985; Somerville, 1984). Considerable interest has been generated in sulfate-reducing bacteria related $\mathrm{H}_{2} \mathrm{~S}$ production and consequent corrosion due to the souring of large waterflood operations in the North Sea (Cochrane et al., 1988) and elsewhere. The focus on MIC in pipelines is relatively new since, until recently, there were no methods available for differentiating between MIC and "classical" corrosion mechanisms. The discovery by Pope et al., (1987) of a distinct metallurgical "fingerprint" characteristic of MIC attack on carbon steel has been a critical advance.

In contrast to investigations of MIC at oil fields in Europe, there has been little investigation of MIC related to gas transportation and storage systems in the United States, in spite of the large scale use of biocides and corrosion inhibitors to control sulfate-reducing bacteria and associated $\mathrm{H}_{2} \mathrm{~S}$ production and corrosion (Kelley, 1977, 1980; Orton, 1978). In most gas pipeline and storage operations, bacteria were suspected if hydrogen sulfide odors were detected and if microbiological media (based on API-RP38) turned black (from iron sulfide production) when inoculated with samples from the system. Treatments were generally based on the effects of biocides on Desulfovibrio species in an artificial brine having approximately $30,000 \mathrm{mg} / 1$ total dissolved solids. Bacteria were exposed to the test chemicals for 18 hours at $100^{\circ} \mathrm{F}$ and then transferred to API sulfate reducer media (Johnston, 1969). Sometimes biocides were applied in a methanol carrier to remove water blockage of gas, reduce hydrate freezing problems, and distribute the biocide over a wider area (Wright and Kepley, 1967). Unfortunately, the effectiveness of such treatments in controlling MIC was difficult to assess, since there was no known metallurgical method to differentiate biological from non-biological corrosion of carbon steel. Instead, biocorrosion was "controlled" when sulfate-reducing bacteria were killed in the condensates or water phase or $\mathrm{H}_{2} \mathrm{~S}$ production decreased.

The relatively primitive approaches presently available for detecting and controlling microbial corrosion in industry reflect the difficulties encountered in understanding the mechanisms whereby MIC occurs. This difficulty is exemplified by the preoccupation with the roles of sulfate-reducing bacteria and the "classical" theory of MIC. This "classical" theory postulated that sulfate reducing bacteria accelerate corrosion by removing cathodically produced hydrogen, using their hydrogenase enzymes (Von Wolzogen Kuhr and Van der 
Vlugt, 1934). The completeness of this theory has been challenged by many investigators who have shown that hydrogenase-negative organisms may also be involved in MIC (Miller and King, 1975). Some studies have indicated that the role of iron sulfide may be more important than the role of hydrogenase (King and Miller, 1971; Mara and Williams, 1972). Other investigators believed that the major mechanism was the fluctuation in some environments between anaerobic and aerobic conditions and the subsequent oxidation of sulfide to elemental sulfur (Schauchl, 1980). Herbert and Stott (1983) showed in an oil field injection system that hydrogenase activity decreased with increased pressure while corrosion rates increased as sulfide concentrations increased. A major cause of uncertainty has been the observation that corrosion rates are higher in the presence of sulfate-reducing bacteria than with sulfides alone. Herbert and Stott (1983) and Jack (1985, 1990) proposed that localized pitting corrosion is initiated by the bacteria because of enhanced contact between anodic areas of the metal surface at the FeS cathode and the build-up of high levels of cathodic reactant under the film, suggesting the importance of that biofilm structure (Tiller, 1985). A major problem with the referenced studies is that corrosion rates observed in laboratory experiments using sulfate-reducing bacteria in anaerobic conditions did not approach the rates found in the field (Tiller, 1985). The role of anaerobic/aerobic cycles in aeration cells did produce corrosion rates closer to field conditions, but this explanation is difficult to apply to internal corrosion of natural gas pipeline systems in which the environment is clearly anaerobic.

\subsection{STATUS OF BASIC AND APPLIED RESEARCH.}

\section{BASIC RESEARCH.}

In 1986, the U.S. natural gas industry initiated a program through the Gas Research Institute to determine whether MIC was as important in gas industry operations as it was in other industries. Initial field investigations were unable to correlate the numbers of sulfatereducing bacteria in the corrosion product with failures due to corrosion. Most of the bacteria present were, however, capable of producing organic acid metabolites (Pope et al., 1987). Concurrently, Pope et al., (1987) examined over 150 samples of external corrosion from several pipeline companies and was able to identify a metallurgical "fingerprint" which was believed to be a result of MIC. This metallurgical pattern was characteristic of underdeposit acid attack, often aggravated by chloride. This pattern had not been observed previously by researchers because acid attack was not recognized as important in MIC mechanisms. Field methods for cleaning pipeline samples prior to metallurgical examination had generally obliterated the "MIC" pattern in previous studies. This distinctive metallurgical pattern has now been recognized worldwide as a characteristic of underdeposit acid attack type MIC of carbon steels, and many investigators and industries now use this characteristic as definitive for MIC on carbon steel. Subsequent laboratory experiments with a three member microbial community consisting of Enterobacter aerogenes, a slime forming acid producer; Clostridium acetobutylicum, a strictly anaerobic acid producer; and a Desulfovibrio species, a sulfate-reducing bacterium, demonstrated that acetic acid is a principal product of community metabolism and is an important part of the MIC mechanism (Pope et al., 
1987). When these bacteria were cultured separately on carbon steel coupons, lesser amounts of lactic, butyric, and acetic acid were produced. Furthermore, the corrosion seen with the complete microbial community duplicated the appearance and rates of corrosion observed in field samples (Pope et al., 1990).

Since this initial work, several important corrosion mechanisms associated with MIC have been identified. These include the formation of an occluded area on the metal surface which can lead to oxygen or ion concentration foci as suggested by previous researchers (Tiller, 1985). Recent studies by Franklin and White (1989) using a scanning vibrating electrode in an aerobic system graphically demonstrates how bacteria may "fix" the anode by localizing pitting under the bacterial colony. A plastic embedding technique for fixing field samples for scanning electron microscopic examinations, developed by $\mathrm{H}$. Aldrich, University of Florida, has shown that pits appear to form under bacterial colonies within hours of exposure (Pope et al., 1990). Organic acids are also known to be early metabolic products of the microbial communities attached to the metal surface. Short chain fatty acids such as acetic acid are very aggressive to carbon steel when concentrated under a colony or other such deposits, as first demonstrated by Pope et al., (1987). Acetogenesis was confirmed under field conditions with the use of radioactive tracers (Pope et al., 1990). Using aerobic systems with nickel or other metals as the substrate, other studies have confirmed the role of organic acids in MIC (Little et al., 1986, 1987). Dias and Bromel (1989) hypothesized that acid production might be involved in MIC on carbon steel, based on the presence of acid-producing bacteria on the metal surface but failed to prove that organic acid accounted for the observed corrosion. The organic acid mechanism may also account for the corrosive effect of chloride. The addition of chloride to acetic acid converts the weak organic acid to a strong acid, $\mathrm{HCl}$, and may allow the $\mathrm{pH}$ to drop below 4 , a $\mathrm{pH}$ below which corrosion products of iron are soluble. Another factor in determining the severity of corrosion may be the specific microbial consortia involved. Using electrochemical impedance to monitor corrosion rates, a MIC community consisting of $E$. limosum, an acetic acid-producing bacterium and Desulfovibrio species had a higher bacterial population and corrosion rates than $E$. limosum alone. When a hydrogenase-negative species of Desulfobacter 2ac9 was added, corrosion rates increased significantly (Pope et al., 1990). This work suggests that the composition of a microbial community could have an impact on corrosion rates. Pope et al. (1990) also showed that low nutrient levels resulted in increased levels of organic acids by a three member microbial community with increased pitting rates.

These studies have led to revisions of the "classical" models of MIC and appear to be consistent with observations of the biological, chemical, and physical characteristics of MIC seen in field investigations. The current model has three major phases. Phase I is the attachment of bacteria to specific sites. There is some evidence that microbes will preferentially attach to some metallurgical features (e.g. manganese inclusions) or other features such as preexisting corrosion, weld beads, or organic materials. Phase II is the formation of a microbial community as a biofilm or nodule. Organic acids are produced, organic acid anion moieties are consumed, and chloride, sulfate, and other anions enter the crevice to neutralize the excess protons, leading to crevice corrosion. In Phase III, the pit is mature and corrosion may be driven by $\mathrm{HCl}$. The pit $\mathrm{pH}$ is probably less than 4 , making 
the pit and most of the nodule unsupportive of most biological growth (Pope et al., 1990). Scanning electron microscope studies indicated that in Phase III, active bacteria principally colonize outer edges of the corrosion product in a manner reminiscent of coral reef growth. This would be consistent with the hypothesis of Jack (1985) that FeS deposition increases the surface area of the cathode enormously. Such a biofilm is considerably different, however, from the classical models of biofilms generally used to study MIC in the laboratory (Little et al., 1990).

\section{APPLIED RESEARCH.}

Most of the applied research conducted between 1988 and 1990 was focused on improving chemical treatment methods for MIC. Internal MIC was the primary focus because of the importance of internal corrosion in offshore pipeline systems and because chemical mitigation, moisture control, and pigging are practical mitigation approaches. In contrast, external corrosion is often detected as wall thinning using "smart pigs", and the pipe is repaired or replaced. Pipeline coatings were believed to inhibit corrosion except where coatings disbonded in which case cathodic protection was thought to provide protection against corrosion, including MIC (Pope et al., 1990).

Initial studies of internal corrosion investigated the effects of commonly used biocides on MIC communities. The results indicated that few biocides were effective, even at slug dose levels (Pope et al., 1987, 1989, 1990a, 1990b). Only the aldehydes had a significant effect on both the surface and fluid phase populations under the conditions tested. These experiments were followed by experiments at gas company field sites using glutaraldehyde in specially designed test loops using spool pieces of actual pipe and liquids from the actual operating system (Pope et al., 1987, 1990). The results showed that slug doses with 1000 ppm glutaraldehyde for one hour eliminated surface populations, however, MIC surface populations approached control levels within 8 hours after treatment. A protocol for establishing appropriate levels of control was developed (Pope et al., 1987, 1990). In the case examined, the system was treated at $100 \mathrm{ppm}$ glutaraldehyde for 1 hour out of every 8 hours. Another approach was the investigation of "targeted" treatment protocols. These studies were done in offshore pipeline systems which had high levels of bacterial contamination. It was shown that major bacterial growth sites were often localized in one or two separators and that treatment of the inlet side of the separators could reduce the bacterial levels in downstream facilities. In one system, treatment of the separator reduced the cost of biocide application to the system to $\$ 7 /$ day (Pope et al., 1990). Subsequent work by a pipeline operator indicated that corrosion rates were also reduced. Another possible approach which, if effective, could reduce the use of chemicals in some systems is heat treatment. It was shown in field studies that temperatures from $130^{\circ}$ to $150^{\circ} \mathrm{F}$ for 5 minutes can kill over $99 \%$ of the surface associated bacteria (Pope et al., 1990). It is not yet known whether this approach will be effective in some pipeline systems since, unlike chemical treatments, heat treatment would not leave active residuals in the pipeline system. 
Work on external MIC suggests that different grades of metal and types of coatings have varied susceptibility to MIC under identical conditions (Pope et al., 1990). Cathodic protection greater than $-0.95 \mathrm{~V}$ versus $\mathrm{CuSO}_{4}$ was previously believed to ensure protection from MIC (Horvath and Novak, 1961) and was used as the industry standard when MIC was suspected. The efficacy of this treatment was confirmed in laboratory studies by King and Miller (1975) and on North Sea sediments and muds by Fischer (1985). However, it has been shown that cathodic protection is not uniformly effective when pipeline coatings have disbonded. In fact, cathodic protection may provide some nutrients (e.g. hydrogen), resulting in the growth of bacteria on the pipeline surface.

Another important component of MIC-related research is the measurement of important physical, chemical, and biological parameters in both biofilms and on metal surfaces. Most of the studies conducted in the field have utilized relatively unsophisticated microbiological techniques. This is because these methods work in the presence of materials such as hydrocarbons, biocides, and corrosion inhibitors and are easily used by field personnel. Generally, fluorescent dyes and fluorescently labeled antibodies were used to identify the numbers and types of bacteria attached to surfaces. Media used to culture the MIC community were a departure from the "selective" media used in protocols such as API RP-38 (Pope et al., 1990). Fatty acid analyses were also utilized but sometimes encountered interference due to the presence of hydrocarbons (D. White, personal communication). In the laboratory, these methods are particularly useful for detecting difficult to culture organisms such as Desulfovibrio. Radioactive tracer techniques were used to confirm that acetate metabolism was taking place in samples from actual pipeline systems.

A major problem limiting studies of corrosion is the on-line measurement of corrosion rate. Extensive work has been done using alternating current impedance. Application of the scanning vibrating, electrode was mentioned previously. Another promising approach is the use of electrochemical noise, proposed initially by Iverson (1974). More recently, electrochemical noise detection coupled to sophisticated computer analyses showed that the level of low frequency noise increased dramatically as growth of MIC bacteria occurred on the metal surface (Pope et al., 1990). Such a technique could be configured in a probe that could be placed in a side-stream device or at "worst case" points in a system.

Biotechnology is beginning to play a role in detection of MIC. Methods for detecting sulfate-reducing bacteria using a gene probe have been developed. This gene probe (GENPROBE Inc.) detects ribosomal RNA specific to sulfate-reducing bacteria and then uses a chemiluminescent acridinium ester which produces light when reacted with hydrogen peroxide. Only the hybridized probe is chemiluminescent, resulting in light emission which is proportional to the concentration of the bacteria. Another recent approach is the immunoassay developed by Conoco, Inc. which detects sulfate-reducing bacteria (Tatnall et al., 1988). These commercial products are noteworthy, being the forerunners of a number of biotechnology products applicable to environmental applications. Some applications using these tools appear promising but issues such as interference from various chemicals and environmental parameters needs to be determined. In addition, the focus on the detection 
of sulfate-reducing bacteria may limit the application. Undoubtedly, the approaches which have been developed will be extremely useful as our understanding of the mechanisms of MIC increase and other targets or organisms are identified.

\subsection{FUTURE RESEARCH DEVELOPMENT AND REQUIREMENTS.}

\section{RELEVANCE AND JUSTIFICATION.}

Corrosion of carbon steel is a major cost to many industries including the fossil fuel industries. It is now clear that bacteria play an important role in the initiation of underdeposit pitting corrosion. Their importance at later stages of the corrosion process are less well established. This implies that prevention and mitigation at early stages of the corrosion process are critical. Work on MIC in the natural gas industry has advanced the corrosion field by identifying interactions between classic corrosion processes and bacteria. These advances have been made in part because pipelines represent closed systems where some control methods are more feasible. Additionally, the cooperation by the gas industry in providing materials and sites and allowing field and laboratory research has stimulated and expedited progress in basic and applied problem-oriented research programs. While methods have been developed which allow pipeline operators to test the efficacy of suggested treatments and reduce costs by targeting chemical applications, there is still a need for methods which do not require chemical applications or which prevent problems through the choice of appropriate materials and operational practices.

\section{RESEARCH NEEDS AND LIMITATIONS.}

Research needs for microbiologically influenced corrosion R\&D include the development of new methodologies for the on-line measurement of corrosion rates. Electrochemical methods such as alternating current impedance spectrometry and electrochemical noise analysis represent promising approaches, but unambiguous interpretation of the electrochemical signals remain difficult. It is essential to identify other target chemicals which will indicate susceptibility to MIC or treatment effectiveness. Sulfate-reducing bacteria as indicators of MIC may have a limited usefulness in some applications. The development of biochemical or genetic probes are considered targets for early detection and monitoring of MIC activity. Such on-line detector systems coupled to electrochemical or fiber optic devices are considered feasible. However, testing of such instrumentation is required under diverse field conditions; and the design requirements for such probes to be simple and inexpensive need to be met. New approaches to modifying biofilm-forming microbial consortia through changes in the physical environment or seeding with antagonistic microorganisms merit further study. Preliminary studies have suggested that changing the composition of the microbial community could influence corrosion rates. The nature and micro-composition of solid surfaces which serve as initiation foci for microbial colonization are poorly understood. The development of model systems more closely approximating real field conditions will expedite the basic understanding of MIC mechanisms and offer new insights into possible control mechanisms presently unrecognized. It is alto appropriate to develop alternatives to current technology employing biocide control of MIC. Such alternate 
approaches include heat treatment and biocide-conjugated antibodies for target ing specific microbial consortia. Little is known of the environmental impact of biocides, corrosion inhibitors and other chemicals employed in corrosion control. Programs to determine the environmental effects resulting from treatment with these chemicals will become of future importance.

\section{$11.4 \quad$ RECOMMENDATIONS AND PRIORITY STATUS.}

\section{NEAR-TERM.}

Since near-term is defined as $5-10$ years, subjects listed below are ranked "high priority". New non-chemical or targeted chemical treatments will depend on the results of these research needs.

- Develop on-line methods for the measurement of corrosion rates and associated chemical reactions.

- Improve the understanding of MIC mechanisms to identify other target chemicals or bacteria.

- Develop biochemical and genetic probes to increase the speed and decrease the cost of field detection of MIC.

- Test and develop alternatives to biocide applications for the control of MIC.

- Evaluate the environmental effects of biocides and other chemicals used to control MIC.

\section{MID-TERM and LONG-TERM.}

These suggestions are possible approaches for the control of MIC. Long-term research is merited, however, since it could lead to non-chemical or highly-targeted control technologies not currently possible. Basic research leading to these developments will be important for the recommended near-term research.

- Develop biochemical and genetic on-line probes for key environmental and bacterial targets - high priority.

- Develop methods to modify microbial populations in actual field situations - high priority.

- Develop realistic models of biofilms in the natural environment which can be used diagnostically - high priority.

- Identify methods of corrosion treatment which apply chemicals only to the affected sites (e.g. antibody carriers). 


\section{Chapter 12}

\section{SUBSURFACE MICROBIOLOGY IN THE NATURAL GAS INDUSTRY.}

\subsection{INTRODUCTION.}

The effects of subsurface activities by microorganisms on gas and oil industry operations is still largely unexplored except for the effects of sulfate-reducing bacteria. These microorganisms are known to contribute to serious problems including: 1) corrosion of steel due to microbiologically influenced corrosion; 2) contamination of gas or stored fuel oil with $\mathrm{H}_{2} \mathrm{~S}$, resulting in added costs due to requirements for $\mathrm{H}_{2} \mathrm{~S}$ removal, replacement of materials with those suitable for "sour service", safety, and environmental liabilities; 3) plugging of formations by slime formation, ferrous sulfide precipitation, and production of other corrosion products all of which can reduce injectivity and potentially decrease gas/oil reserves.

This section will focus primarily on $\mathrm{H}_{2} \mathrm{~S}$ production by sulfate-reducing bacteria, the biology of sulfate-reducing bacteria, field experiences with biological $\mathrm{H}_{2} \mathrm{~S}$ production, biological methods of removal or control, and their impacts on gas/oil operations. The increasing liabilities associated with environmental awareness and regulations will require that chemical inputs to production systems and the effects of mixing injected fluids with formation waters will need to be better understood and controlled to reduce downstream problems and costs.

\section{BACKGROUND.}

In the U.S., approximately $22 \%$ of the natural gas produced contains hydrogen sulfide levels exceeding 4 ppmv, the pipeline specification for hydrogen sulfide (Darymple et al., 1991). The same study estimates that $74 \%$ of this $\mathrm{H}_{2} \mathrm{~S}$-contaminated gas falls in the range of 4 to $10,000 \operatorname{ppm}(\mathrm{v})$. These estimates are probably low since the databases used to compile this information had few results for $\mathrm{H}_{2} \mathrm{~S}$. Also, some of the $\mathrm{H}_{2} \mathrm{~S}$ data provided are unreliable due to the methods used (Orr, 1977; Darymple et al., 1991). The estimates given are, however, consistent with world-wide estimates that less than half of presently produced gas is sour and most of the sour gas contains 10,000 to $50,000 \mathrm{ppm} \mathrm{H}_{2} \mathrm{~S}$ (Orr, 1977). Another complication arises from the fact that gas composition may vary considerably in different wells from the same field and with time from the same well due to changes in downhole pressures and production practices (Orr, 1977).

Microbial reduction of sulfate is probably the most common source of low concentrations of hydrogen sulfide in petroleum reservoirs. Orr (1977) believes that most of the hydrogen sulfide found in oil and gas reservoirs was formed in the subsurface after deposition. Most investigators also believe that $\mathrm{H}_{2} \mathrm{~S}$ concentrations greater than $10 \%(10,000 \mathrm{ppm})$ are not the result of current microbial production. At one time it was thought that non-biological sulfate reduction could not occur at temperatures below $250^{\circ} \mathrm{C}$. However, a number of 
geochemical mechanisms have since been identified which could generate or release hydrogen sulfide in reservoirs with temperatures as low as $100^{\circ} \mathrm{C}$ or less (Herbert et al., 1985; Herbert, 1987). These include release from pyrite during acidification procedures used to improve injectivity (Bourgeois et al., 1979), thermochemical oxidation of hydrocarbons by anhydrite or gypsum (Eliuk, 1984), sulfur reduction by disproportionation (Belkin et al., 1985), thermochemical sulfate reduction in the presence of organic matter (Orr, 1977) or light hydrocarbon gases (Krouse et al., 1988), reaction of pre-existing elemental sulfur with organic matter (Orr, 1977), and thermal decomposition of organic sulfur compounds during maturation (Orr, 1977). These processes can sometimes be distinguished from biological sulfate reduction through the sulfur isotope ratios of biological or geological sulfide (Krouse et al., 1988). In general, analyses of the ratio of sulfur isotopes in the $\mathrm{H}_{2} \mathrm{~S}\left({ }^{34} \mathrm{~S}:{ }^{32} \mathrm{~S}\right)$ show "del" values of -40 to $+10 \%$ or -10 to $+35 \%$ for biologically and non-biologically derived hydrogen sulfide, respectively (Cochrane, 1988; Krouse et al., 1988). If, however, both processes are concomitant, "del" values may be intermediate and hence difficult to interpret.

Biological hydrogen sulfide production is an important consideration in production operations requiring water injection and in storage field operations where water movement from surrounding groundwater occurs. While some sour gas fields (with up to $80 \%$ hydrogen sulfide content) are in successful production (some as a result of sales of sulfur as a byproduct), it is the possibility of souring sweet reservoirs which is of principal concern (Herbert, 1987). Since greater than $300 \mathrm{ppm}$ of hydrogen sulfide concentration could result in sulfide corrosion, the extensive replacement of steel components with expensive hydrogen sulfide-resistant steels would be required (Herbert, 1987). Other problems associated with souring include personnel safety (at $\geq 100 \mathrm{ppm}$ ) and air quality issues ( $\geq 170 \mathrm{ppm}$ ).

Major complications in assessing $\mathrm{H}_{2} \mathrm{~S}$ production are that $\mathrm{H}_{2} \mathrm{~S}$ levels can be affected by a variety of production factors (Orr, 1977), including sulfide mineral formation (e.g. pyrite) which is largely controlled by reservoir lithology; the solution of hydrogen sulfide in water, oil, or condensates which is dependent on mixing and mass transport as well as temperature and pressure and the potential for the presence of an oxidizing environment. As a result of these factors, the balance between hydrogen sulfide formation and removal determines abundance in produced gas and fluids. Therefore, hydrogen sulfide levels can respond to many common production practices which affect temperature, water, $\mathrm{pH}, \mathrm{Eh}$, and salinity.

Sulfate-reducing bacteria are morphologically diverse, strictly anaerobic bacteria that utilize sulfate, other oxidized sulfur compounds, or elemental sulfur as electron acceptors. Sulfatereducing bacteria differ with respect to their utilization of organic compounds. Habitats are varied and include anaerobic sediments of freshwater, brackish water, and marine environments and the gastrointestinal tracts of mammals including man (Widdel and Pfennig, $1984)$. Both mesophilic $\left(20^{\circ}\right.$ to $\left.40^{\circ} \mathrm{C}\right)$ and thermophilic $\left(50^{\circ}\right.$ to $\left.70^{\circ} \mathrm{C}\right)$ species have been isolated from oil field environments (Cord-Ruwisch et al., 1987; Cochrane et al., 1988; Stetter et al., 1983; Herbert, 1987). Most investigators agree that sulfate-reducing bacteria are introduced into a gas or oil field, or into a gathering system, through the use of water that contains bacteria from surface or groundwaters (Cord-Ruwisch et al., 1987; Lake et al., 1986). They have also been found, however, in cores from oil wells, in produced waters, and 
in drilling muds at depths of $6000-12,000$ feet and temperatures of $60^{\circ}-105^{\circ} \mathrm{C}$ (Zobell, 1958; Iverson and Olsen, 1983). Rozanova and Nazina (1979) isolated thermophilic sulfatereducing bacteria in gas and oil bearing strata in Apsheron and Western Siberia. At temperatures above $80^{\circ} \mathrm{C}$, Desulfovibrio thermophilus was predominant, while at lower temperatures $\left(60^{\circ}-70^{\circ} \mathrm{C}\right)$ Desulfotomaculum nigrificans predominated. Contamination may occur during drilling, perforation, hydraulic fracture, squeeze jobs, hydrostatic testing of pipelines, or water injection for pressure maintenance and enhanced recovery (Lake et al., 1986). The greatest concern is the possibility that sulfate-reducing bacteria can migrate beyond the well-bore area into producing strata. This is of particular concern when drilling mud is "lost" into the producing formation, or when produced water or contaminated water is injected. Laboratory studies indicate that sulfate-reducing bacteria can move through cores of oil-bearing sands at average rates of $0.7-13 \mathrm{~m} / \mathrm{yr}$ (Zobell, 1958). Field studies indicate that organisms from drilling mud can be carried into storage strata in an aquifer gas storage field (Pankhurst, 1968).

There have been many instances in which sweet fields subjected to water injection and storage became sour. For example, $\mathrm{H}_{2} \mathrm{~S}$ was detected in associated gas from the Wilmington oil field in California only after secondary recovery was initiated (Gates and Parent, 1976; Bleakley, 1972). At another site, $\mathrm{H}_{2} \mathrm{~S}$ did not appear in the associated gas until 9 years after the first well had been drilled and thereafter rose to $0.15 \mathrm{ppm}$ within 2 years (Lake et al., 1986). More recent examples include the Ninian Field in the North Sea (Cochrane et al., 1988 ) and the Kuparek Field on the North Alaskan Slope, both cases being associated with massive waterflood operations. Other examples are gas storage fields utilizing either depleted gas fields or aquifers. Examples include depleted gas fields in Oklahoma (Kelley, 1977) and at aquifers at Lussagnet and St Illiers, France and at Redfield, Herscher, and La Clede, U.S. (Lake et al., 1986; Dziewulski et al., 1990). Not all storage field souring incidents are necessarily due to biological activity. For example, natural gas at Chemery and Verlaine, France became sour when gas containing $1.6 \% \mathrm{CO}_{2}$ by volume was stored. It is thought that the $\mathrm{H}_{2} \mathrm{~S}$ is derived from pyrite reduction, and that its release was related to $\mathrm{CO}_{2}$ pressure (and subsequent acidification) in the storage structure (Jauberton and Elgue, 1982). In other cases, temperatures were believed to be too high to support current biological $\mathrm{H}_{2} \mathrm{~S}$ production (Lake et al., 1986).

Although sterile operations are impractical in oil fields (to prevent contamination by sulfatereducing bacteria), control of the extent of biological activities is sometimes feasible using biocide applications, pretreatment of water or drilling muds to remove sulfate-reducing bacterial substrates, or by careful selection of added chemicals and production practices (Lake et al., 1986; Cord-Ruwisch et al., 1987). The application of biocides to waterfloods or storage fields can be costly and the attendant environmental problems need to be considered. It is often a good idea to do sulfur isotope analyses in order to help confirm whether the $\mathrm{H}_{2} \mathrm{~S}$ is due to current biological activity (Herbert, 1986).

Concentrations of biocides found effective in laboratory studies are often insufficient in field practice since strains other than those tested in the laboratory are present, and the bacteria are in consortia which protect them and may even detoxify the active groups of biocides such 
as aldehydes (Cord-Ruwisch et al., 1987). Most claims regarding effectiveness of biocides in reservoirs are not convincing. "Squeeze" treatments have been claimed as effective but are often transitory, and sometimes the biocides used (e.g. aldehydes) may be scavenging $\mathrm{H}_{2} \mathrm{~S}$ rather than inhibiting sulfate-reducing bacteria (Herbert, 1986). According to Herbert (1986), chromatographic effects in reservoirs could separate components of biocide formulations resulting in precipitation of the active ingredients. On the other hand, some biocide activity may actually increase as temperature and pressure increase (Stott and Herbert, 1986). Lake et al. (1986) suggest that water used for injection or for preparing drilling muds or other producing fluids be treated prior to injection. Another possible approach to reducing microbial contamination is to control potential organic electron donors, sulfate, or salt concentrations (Cord-Ruwisch et al., 1987). For example, short chain fatty acids such as acetate, propionate, and n-butyrate are widespread in oilfield production waters with acetate generally present in concentrations 10 times that of others (Herbert et al., 1985). Ammonium ions are also often present in formation waters at levels as high as $250 \mathrm{mg}$ per liter. In North Sea oil fields operated by Shell Expro, fatty acid levels up to 400 $\mathrm{mg}$ per liter carbon and ammonion ion levels up to $87 \mathrm{mg}$ per liter have been measured in formation waters. In contrast, injection waters (e.g. seawater) may be low in potential nutrients but contain sulfate and bacteria (Herbert et al., 1985). Other potential sources of nutrients include chemicals routinely added to production waters (e.g. methanol, citric acid used as a complexing agent, xanthan used in drilling muds, and polyethyleneglycol (used in surfactants) (Cord-Ruwisch et al., 1987). While sulfate-reducing bacteria may not utilize many of these chemicals directly, associated bacteria have been shown to be capable of their degradation into products used by sulfate-reducing bacteria (Bache and Pfennig, 1981; Schink and Stieb, 1983).

Possible preventative methods include chlorination or biocide treatment of waters used in secondary recovery of oil/gas and in the preparation of drilling muds. Heat, ultraviolet light, chlorine, and ozone have also been used to treat such waters. Gamma radiation has been suggested for killing sulfate-reducing bacteria at the bottom of well bores as the water enters the reservoir (Agaev et al., 1985). Cord-Ruwisch et al. (1987) suggest that removing precipitates harboring sulfate-reducing bacteria from oil tanks, removing particles from water by a flotation unit, lowering the $\mathrm{pH}$ to 5.0 by acidification, and avoiding dilution of high salt concentrations were effective methods for controlling bacterial sulfate reduction in an oil field operation. In general, it appears important to understand the characteristics of injected waters, chemical additives, and formation waters in order to avoid creating conditions which could lead to field souring or formation plugging.

\subsection{STATUS OF BASIC AND APPLIED RESEARCH.}

\section{BASIC RESEARCH.}

The correlation of numbers and activities of sulfate-reducing bacteria to $\mathrm{H}_{2} \mathrm{~S}$ levels is difficult due to the reasons mentioned previously, including the influence of production practices on $\mathrm{H}_{2} \mathrm{~S}$ concentrations and the ability of some of the commonly used biocides to scavenge $\mathrm{H}_{2} \mathrm{~S}$. 
As a result, when sulfur isotope ratios are ambiguous, it is difficult to correlate sulfatereducing bacteria with $\mathrm{H}_{2} \mathrm{~S}$ production. Cochrane et al. (1988) working at Chevron's Ninian oilfield reservoir in the North Sea encountered similar problems. Unfortunately, analysis of the sulfur isotope ratios in the $\mathrm{H}_{2} \mathrm{~S}$ showed that the ${ }^{34} \mathrm{~S}:{ }^{32} \mathrm{~S}$ ratios were between -0.6 and $+10.5 \%$, which falls in the range between biological and non-biological generation mechanisms as discussed earlier. In this case, the presence of large numbers of thermophilic SRB's led to conclusions of $\mathrm{H}_{2} \mathrm{~S}$ production, at least, in part, through the biological reduction of sulfate. An examination of the relative proportions of fatty acids measured in the Ninian formation yielded a theoretical maximum of $0.61 \mathrm{mg}$ sulfide for each $\mathrm{mg}$ of total fatty acid converted. An extrapolation from laboratory data suggested that the quantities of $\mathrm{H}_{2} \mathrm{~S}$ measured in the Ninian Field could be generated through the activities of thermophilic sulfate-reducing bacteria growing on carbon sources available in the formation (e.g. acetic, propionic, and butyric fatty acids). The statistical correlation for acetic acid versus hydrogen sulfide was weakly negative. It was suggested that this correlation is difficult to interpret since water flow between injection and production wells is not well-defined. Analysis of bioprobe studs at the front end of the production system suggested that low numbers of thermophilic sulfate-reducing bacteria and other thermophilic anaerobic bacteria enter the system in the produced fluids. It was hypothesized that they attach to surfaces, initiate biofilm formation, and grow into microbial communities (biofilms). Contamination of the rest of the system occurs as a result of mechanical sloughing or biofilm disruption (Cochrane et al., 1988).

Waterflood models proposed by Jones (1987) and Sanders et al. (1987), based on previous studies, are consistent with the Cochrane study. According to this waterflood operation model, injection of seawater into the reservoir creates temperature and nutrient/chemical concentration gradients between the injection well bore and the production well. Temperature gradients occur due to the cooling effect of the seawater on the hot formation. Nutrient and chemical gradients occur through the mixing of seawater with connate water. These gradients are also dependent on the amount of mixing of injection and connate water, the extent of channelling, the degree of faulting of the formation, and the porosity of the rock. It is hypothesized that a specific zone exists between the injection well bore and the production well where sulfate-reducing bacteria thrive (Cochrane et al., 1988). It is suggested that the thermophilic sulfate-reducing bacteria may be ultramicrobacteria as described by Lappin-Scott et al. (1987) under nutrient poor conditions until they migrate in the injected waters to the nutrient rich zone after which they increase in size. This model also suggests that the thermophilic bacteria arise by adaptation or mutation from mesophilic sulfate-reducing bacteria, after initial colonization of the wellbore area where temperatures are cooler. Herbert and Stott (1983) were unable, however, to demonstrate adaptations of mesophilic sulfate-reducing bacteria under laboratory conditions. Eventually, according to this model, the thermophilic sulfate-reducing bacteria would migrate to the production wells and contaminate the production system.

Montgomery et al. (1990) have demonstrated in laboratory experiments that a sulfideresistant strain of Thiobacillus denitrificans, Strain F can prevent the accumulation of sulfide by Desulfovibrio desulfuricans or by a mixed population of sulfate-reducing bacteria enriched 
from an oil field brine when both the organisms are grown in liquid medium or in Berea sandstone cores. Thiobacillus denitrificans is an obligate autotroph and facultative anaerobe which can utilize reduced sulfur compounds as energy sources and oxidize them to sulfate. Under anaerobic conditions, nitrate is used as the terminal electron acceptor and is reduced to molecular nitrogen. The strain used in these experiments is a sulfide-resistant strain since it has been shown by Sublette and Sylvester (1987) that growth of wild-type strains of $T$. denitrificans ATCC 23642 can be inhibited by sulfide concentrations as low as 100-200 uM and completely inhibited by initial sulfide concentrations of $1 \mathrm{mM}$. $T$. denitrificans, Strain $F$ is both sulfide-tolerant (e.g. greater than $1000 \mathrm{uM}$ ) and glutaraldehyde-tolerant $(25-40 \mathrm{ppm})$. Results showed that sulfide concentration with this strain was below detectable levels after 14 to 19 days while the wild-type strain reduced sulfide concentration only marginally (Montgomery et al., 1990). It was also observed that Strain F penetrated Berea sandstone cores at roughly $0.4 \mathrm{~cm} /$ day, which is faster than the rate observed for $D$. desulfuricans and other organisms present in the oil field brine enrichments. While this has been proposed as a possible approach for controlling $\mathrm{H}_{2} \mathrm{~S}$ levels, there are many potential problems and limitations. Limitations include a fairly narrow temperature range. Growth rates at $27^{\circ}$ and $33^{\circ} \mathrm{C}$ are $50 \%$ and $75 \%$, respectively, as compared to growth at $30^{\circ} \mathrm{C}$. Temperatures greater than $40^{\circ} \mathrm{C}$ are totally inhibitory. Montgomery et al. (1990) suggest, therefore, that this approach would be restricted to shallow wells with temperatures less than $45^{\circ} \mathrm{C}$. This organism is also inhibited by salt concentrations greater than $3 \%$. A more serious issue may be the unknown environmental and production impacts of adding a biocide-resistant organism. A major concern could be uncontrolled growth resulting in formation plugging. For these reasons, this approach will require additional research before application to production systems or storage systems..

\section{APPLIED RESEARCH.}

Though the use of Thiobacillus denitrificans will require considerably more work for field applications, other Thiobacillus species have already been applied successfully in commercial systems such as the Dowa-NKK Bio-SR process which uses Thiobacillus ferroxidans to remove $\mathrm{H}_{2} \mathrm{~S}$ from gas streams. In this system, a solution of ferric sulfate contacts sour gas in an absorber. The solution absorbs hydrogen sulfide and oxidizes it to elemental sulfur. At the same time, the ferric sulfate is reduced to ferrous sulfate. The step which uses the bacteria in a bioreactor is the aerobic regeneration of ferrous sulfate to ferric sulfate. The ferric sulfate is then regenerated as part of a closed cycle in which there is no degradation of the solution, no waste, no catalyst, and no special chemical except minor periodic additions of ferric sulfate (Satoh et al., 1988). This process occurs at a $\mathrm{pH}$ of about 2 which is optimum for $T$. ferroxidans and is about 500,000 times faster than the oxidation that would occur in the absence of bacteria (Lacey and Lawson, 1970). There are a number of commercial plants in Japan, including the Kosaka works of Barium Chemicals, Ltd! In this plant, a $70 \% \mathrm{H}_{2} \mathrm{~S}$ stream is reduced in a jet scrubber to $10 \mathrm{ppm}$ or less. This BIO-SR process has been operated continuously and reliably since 1986 (Satoh et al., 1988). This system has also been tested at a Japanese refinery, where a $5 \% \mathrm{H}_{2} \mathrm{~S}$ stream was reduced to 10 to 20 ppm (Satoh et al., 1988). The Bio-SR process is currently being evaluated for other

gas and oil industry applications. An attractive feature of processes like Bio-SR is combining 
the advantages of both chemical and biological processes instead of depending exclusively on a single approach.

Much of the work currently examining in situ biological hydrogen sulfide control has been conducted on a gas storage system in Iowa (Dziewulski et al., 1990). This storage field was known to have potential for biological souring (Kelley, 1977), but operators had been able to control bacterial contamination through biocide applications for over 30 years. Due to reasons which are still unclear, $\mathrm{H}_{2} \mathrm{~S}$ levels began increasing in the early $1980 \mathrm{~s}$ and then doubled between 1986 and 1988. This system has now been modeled and the roles of geological, operational, chemical, and biological factors related to field souring are being investigated. Based on studies of this system, it appears that the nutrients for seasonal bursts of $\mathrm{H}_{2} \mathrm{~S}$ production come principally from the influx of groundwater. Nutrients of special importance are iron and possibly organic carbon and energy sources (Dziewulski et al., 1990). In addition, a complex community of microbes is present in the formation including acetogens, sulfate-reducing bacteria, acid-producing bacteria, and methanogens. During gas withdrawal, when groundwater influx occurs and $\mathrm{H}_{2} \mathrm{~S}$ production is stimulated, the numbers of acetogens appear to decrease while the numbers of acid-producing and sulfate-reducing bacteria increase. Bacterial numbers and $\mathrm{H}_{2} \mathrm{~S}$ production appear to be correlated. Isotope analyses showed "del" values between -9 and -20 , indicating that $\mathrm{H}_{2} \mathrm{~S}$ is derived principally from biological sources.

Work on mitigation techniques is being tested under conditions which closely simulate in situ conditions using cores in on-site, high pressure test systems with actual process fluids and gases. Results with this particular system indicate that traditional biocide treatments, including glutaraldehyde, acrolein, hydrogen peroxide, quaternary amines, and glutaraldehyde-quaternary amine combinations had either no effect or very transitory effects (5-24 hours) on the sulfate-reducing bacteria, acid-producing bacteria, and $\mathrm{H}_{2} \mathrm{~S}$ levels in the cores and effluent materials. Treatment with borate, a known elevator of $\mathrm{pH}$ and inhibitor of RNA polymerase in some bacteria, showed initial promising results with the sulfatereducing bacteria, acid-producing bacteria, and $\mathrm{H}_{2} \mathrm{~S}$ levels being reduced for over 12 days after a single treatment. The additions of nitrate to stimulate nitrate reducing bacteria did not show an effect. However, test systems seeded with Thiobacillus denitrificans resulted in a decline in $\mathrm{H}_{2} \mathrm{~S}$ levels while the numbers of sulfate-reducing bacteria remained steady. These initial results require further confirmation and detailed analysis but suggest that further work on less traditional approaches is needed.

While much of the work to date has been performed with a storage field in an advanced stage of souring, other fields in earlier stages of souring are also being investigated. One possibility is that fields at earlier stages may be more readily mitigated if the bacterial contamination has not spread beyond the well-bore. One study showing that this may be the case is underway at a west Texas production field undergoing alternate water and $\mathrm{CO}_{2}$ injection in order to stimulate production. This formerly sweet field was treated by the injection of molasses into the well bores (in a weighted corrosion inhibitor) which resulted in $\mathrm{H}_{2} \mathrm{~S}$ souring, the accelerated corrosion of well tubulars and sucker rods, and increases in 
viable bacterial numbers. It was found, however, that only those wells having casing leaks allowing communication with a shallow red clay formation had severe corrosion. In this case, treatment of the downhole well bore region with $200 \mathrm{ppm}$ aldehyde twice each week appears to have killed the microbes since they can be observed microscopically but are not viable. There has also been a subsequent decline in $\mathrm{H}_{2} \mathrm{~S}$ which is not believed to be due to the scavenging properties of the aldehyde, and the corrosion rates have dropped to near zero in the 8 months since treatment. There is also an indication that the addition of certain trace elements to the steels can dramatically alter their susceptibility to corrosion and may have applications to reducing costs normally associated with the use of steels developed specifically for sour service.

\subsection{FUTURE RESEARCH DEVELOPMENT AND REQUIREMENTS.}

\section{RELEVANCE AND JUSTIFICATION.}

At present, it is not yet known whether biological souring is a major problem in the gas and oil industries since the extent of such occurrences is presently unknown. There have been major occurrences of biological souring, however, which have had serious economic consequences. Most of these known cases have involved oil production where waterflood practices were used. In addition, a growing number of gas storage fields appear to be experiencing problems though it is not known if the problem is widespread. In general, it would appear that understanding the consequences of mixing injected and formation waters would be useful information in developing production practices which could avoid downstream souring, corrosion, and possibly environmental problems. 


\subsection{RECOMMENDATIONS AND PRIORITIES.}

Near-term high priority research needs include:

- Test promising treatments for mitigating reservoir souring and determine the mechanisms through which such mitigation occurs.

- Develop reservoir models useful in predicting the consequences of mixing injected and formation waters based on geological, chemical and operational parameters.

- Determine reservoir characteristics that are predictive of the initial processes in formation souring and develop on-line or field useable methods to detect such changes.

- Identify production practices which cause souring and establish cost-effective modifications which prevent or delay such processes.

- Develop rapid and economical methods for differentiating between biological and abiological souring.

- Evaluate combined chemical and biological methods of removing $\mathrm{H}_{2} \mathrm{~S}$ at competitive costs.

Longer-term, high priority R\&D includes:

- Determine the mechanism(s) of microbial mobility in formations.

- Investigate how bacteria live in geological formations.

- Develop probes which allow for on-line monitoring of geochemical, chemical, and biological activities in subsurface environments.

- Identify reactions, other than $\mathrm{H}_{2} \mathrm{~S}$ production, which are important to oil or gas recovery operations. 


\section{Chapter 13}

\section{CHEMICALS FROM METHANE.}

\subsection{INTRODUCTION.}

Alternate uses of methane and natural gas liquids $\left(\mathrm{C}_{2} \mathrm{H}_{4}\right.$ and $\left.\mathrm{C}_{3} \mathrm{H}_{6}\right)$ as feedstocks for the production of bulk and specialty chemicals have been extensively evaluated over the past several decades. These exhaustive investigations established the ability of various methaneoxidizing microorganisms to co-oxidize diverse substrates to value-added products (Sariaslani, 1989). However, few, if any, of these products have become established articles of commerce. Today, Provesta, Inc, a subsidiary of Phillips Petroleum Co., manufactures a single-cell protein product derived from methanol for a diverse number of market sectors.

\section{BACKGROUND.}

Microorganisms which grow at the expense of one-carbon compounds as their sole sources of carbon and energy are termed methylotrophs. The last two decades have witnessed significant advances in our understanding of methylotropic microorganisms and the biochemistry involved in the oxidation of one-carbon substrates by this group of microorganisms. Several research groups have studies the biological production of chemicals from methane (Anthony, 1975, 1982; Bohanon et al., 1988; Bussineau and Papoutsakis, 1986, 1988; Higgins et al., 1981; Hou, 1981, 1982, 1984; Hou et al., 1978a, 1978b, 1979, 1981, 1982a, 1982b; Nunn and Lidstrom, 1986; Patel et al., 1979; 1979a, 1979b, 1980; Patt et al., 1974; Sakai and Tani, 1987, 1988; Samuelov, 1988; Schurig and Burkle, 1982). Some of the current research topics include: 1) the biochemical and biophysical nature of the methane monoxygenase enzyme (Habets-Crutzen et al., 1985; Huq et al., 1978; Kelly et al., 1989; Prince et al., 1988), 2) genetic and molecular biology of methylotrophs (Anderson and Lidstrom, 1988; Bewersdorff, 1971; Byrom, 1987; Jones et al., 1988; O'Connor et al., 1977; Patel, 1982; Patel and Hou, 1984; Reed and Dugan, 1987; Tsygankov and Kazakova, 1987; Wackett and Gibson, 1988; Wolf and Hanson, 1980), and 3) bioremediation with methanotrophs (Fox et al., 1988; Large, 1983; Linton and Cripps, 1978; Windass et al., 1980; Woodland and Dalton, 1984). Several review articles (Best and Higgins, 1983; Gleeson and Sudberry, 1988; Haber et al., 1983; Higgins et al., 1981) and books (Anthony, 1982; Hou, 1984, 1988; Large, 1983) have been published which describe the progress in the methanotrophy field.

The studies by Whittenbury and colleagues (1975) on methanotrophs provide a basis for their classification. On the basis of their membrane arrangements the methanotrophs have been divided into two groups. Type 1 organisms were described as having bundle or discshaped membrane vesicles distributed throughout the cell. Type 2 organisms possessed layers of paired membranes localized around the periphery of the cell. However, the role of these internal membranes is not clearly known. 
Lawrence and Quayle (1970), working on the carbon assimilation pathways in a number of methanotrophs, found a correlation between the type of membrane arrangement and the pathway of carbon assimilation. Type 1 organisms incorporated carbon at the level of formaldehyde using the ribulose monophosphate cycle; whereas, Type 2 organisms used the serine pathway. Type 2 methanotrophs had a complete set of enzymes for the tricarboxylic acid cycle; whereas the Type 1 methanotrophs lacked ketoglutarate dehydrogenase. An NADP-specific gluconate-phosphate dehydrogenase was detected in Type 1 but not Type 2 methanotrophs.

Colby et al. (1975) expanded this classification scheme to accommodate two subgroups in each of the Type 1 and Type 2 groups of methanotrophs. Of the Type 1 methanotrophs, subgroup A consists of bacteria with a DNA base ratio of 50 to $54 \mathrm{~mol} \%$ guanine plus cytosine $(\mathrm{G}+\mathrm{C})$ which do not fix carbon dioxide autotrophically. Methylomonas methanica and Methylomonas albus are examples of such organisms. Subgroup B includes bacteria with a DNA base ratio of $65.5 \mathrm{~mol} \% \mathrm{G}+\mathrm{C}$; they possess the ribulose monophosphate cycle for carbon assimilation, as do all Type 2 methanotrophs. However, they also possess some of the enzymes of the serine pathway and Benson-Calvin cycle (phosphoribulokinase and ribulose bisphosphate carboxylase). It is unclear how these pathways contribute to the overall carbon assimilation of these bacteria. Methylomonas capsulatus (Bath) is an example of such an organism and may well represent a third major type of methanotroph, the socalled Type $\mathrm{x}$.

Methanotrophs have the ability to oxidize methane completely to carbon dioxide. Methane is oxidized to methanol, and then to formaldehyde by the enzymes methane monooxygenase and methanol dehydrogenase, respectively. It is at this level that the pathway branches. A series of dehydrogenase reactions oxidize methanol to formaldehyde, formate and $\mathrm{CO}_{2}$, with a net yield of two reducing equivalents per methane molecule. Assimilation of carbon occurs at the level of formaldehyde and/or $\mathrm{CO}_{2}$ by one of the following pathways: 1) serine pathway (Type II), 2) ribulose monophosphate pathway (Type I) or 3) ribulose bisphosphate pathway. The most efficient pathway is the facultative variant of the ribulose monophosphate pathway. Because the serine pathway uses the more reduced formaldehyde and the Calvin cycle uses $\mathrm{CO}_{2}$, predicted yields of these pathways are similar.

Both assimilatory and dissimilatory pathways occur simultaneously in the cell. There is no evidence for the simultaneous functioning of two complete $\mathrm{C}-1$ assimilating pathways in any microorganism, but further work on the alternative $\mathrm{C}-1$ assimilation pathways in Type 1 methanotrophs will hopefully explain their role and importance in the overall carbon metabolism of these organisms.

Methylotrophs can modify chemicals that they cannot use as a source of energy or nutrients. This process is known as cometabolism or co-oxidation and occurs in mixed cultures as well as in pure cultures. A definition of co-oxidation is the gratuitous oxidation of a chemical, from which the organism derives no energy or carbon, coincident with the oxidation of a growth substrate which supplies energy and carbon for the organism's growth. A number 
of organic compounds are co-oxidized, including some of environmental and industrial importance.

A wide range of products can be produced via co-oxidation with methane or methanol (Sariaslani, 1989). These co-oxidation products are not assimilated by the bacteria and cannot serve as growth substrates. They are excreted by the cells until their concentration builds up to inhibitory levels. There are several publications on the epoxidation of olefins by methanotrophs. The production of propylene oxide from propylene has been studied in detail (Hou, 1982, 1984, 1988; Hou et al., 1978a, 1978b, 1980a, 1980b, 1981, 1982a, 1982b). They determined important physiological parameters as well as rate and yield data for several strains, including that growth on methane was essential for this epoxidation activity, but methane would inhibit propylene oxide production if present during the oxidation. Therefore, methane was not used concurrently with propylene but was used to regenerate the culture after oxidizing propylene.

Methylotrophs oxidize methane to methanol by methane monooxygenase as follows:

$$
\mathrm{CH}_{4}+\mathrm{NADH}+\mathrm{H}^{+}+\mathrm{O}_{2} \rightarrow \mathrm{CH}_{3} \mathrm{OH}+\mathrm{NAD}^{+}+\mathrm{H}_{2} \mathrm{O}
$$

Thus, the initial reaction in methane oxidation is not only non-energy producing but requires energy. However, the non-specific nature of this enzyme makes it potentially industrially important.

The methane monooxygenase activity of certain methanotrophs can exist in either a particulate or a soluble form, depending on the conditions under which the organism is grown. Methylosinus trichosporium, grown in a chemostat under oxygen limiting conditions, had $100 \%$ particulate methane monooxygenase activity, under nitrate limitation, $100 \%$ soluble and particulate activities, $78 \%$ and $22 \%$, respectively. Studies on Methylococcus capsulatus (Bath) showed that the intracellular location of the methane monooxygenase depended on the availability of copper and was not dependent on either methane or nitrate limitation. Particulate methane monooxygenase was observed under conditions with copper in excess; whereas under conditions of copper stress a soluble methane monooxygenase was found. Thus, it would be predicted that in nature the particulate methane monooxygenase is predominant.

The soluble methane monooxygenase appears to be more stable than the particulate methane monooxygenase and therefor easier to purify and characterize. There has only been a single particulate methane monooxygenase purified and characterized, although this procedure has failed to yield active enzyme (Huq et al., 1978). In the absence of a repeatable method for the isolation of a particulate methane monooxygenase, it is difficult to assess whether or not the soluble and particulate methane monooxygenases have any components in common or whether they are distinct, unrelated enzymes. However, some insight can be gained from the information already available. 
Methane monooxygenase from several species of methanotrophs has been shown to insert an oxygen atom into a wide range of substrates (Anthony, 1975; Anthony, 1982; Bussineau and Papoutsakis, 1988; Bussineau and Papoutsakis, 1986; Bussineau et al., 1987). These include carbon monoxide, ammonia, n-alkanes, n-alkenes, dimethyl and diethyl ether, alicyclic and aromatic hydrocarbons. Oxidation by methane monooxygenase can produce a molecule that is not further metabolized such as propylene oxide (1-2 epoxypropane) from the oxidation of propylene or a molecule that is further oxidized by other oxidoreductases such as benzyl alcohol from the oxidation of toluene, which is further oxidized to benzoic acid. It is this ability to insert oxygen into a wide variety of chemicals that makes the methaneutilizing bacteria of potential economic importance.

\subsection{STATUS OF BASIC AND APPLIED RESEARCH.}

\section{BASIC RESEARCH.}

Research on the biological production of chemicals from methane is currently conducted in only a few labs throughout the world. Basic research on the taxonomy, genetics and physiology of methane-utilizing bacteria is more common. Researchers are still isolating and characterizing new strains of methanotrophs. However, most of the effort has concentrated on methanol-utilizing bacteria, and methane-utilization is usually considered as a characteristic of these bacteria.

Considerable research has been conducted on the genetics of the methanol dehydrogenase complex (Andersen and Lidstrom, 1988; Bohanon et al., 1988; Haber et al., 1983; Machlin et al., 1988; Nunn and Lidstrom, 1986a, 1986b; O'Connor et al., 1977). These researchers have identified numerous gene products and have clarified the roles of these enzymes. Murrell et al. have identified the structural genes encoding for the soluble methane monooxygenase of Methylococcus capsulatus (Bath) (Cardy and Murrell, 1990). In vitro expression analysis revealed several aspects of the regulation of these methane monooxygenase structural genes. This research has led to the development of many molecular tools for genetic modification of methylotrophic bacteria.

Over the last two decades, there has been significant progress in our understanding of the biochemistry of carbon, phosphate and nitrogen metabolic pathways in methylotrophs. Prince et al. (1988) and Fox (Fox, 1988; Fox et al., 1988, 1989) have significantly advanced our knowledge of the biochemical nature of the oxo-bridged binuclear iron centers at the active site of soluble methane monooxygenase of Methylosinus trichosporium (OB3b).

\section{APPLIED RESEARCH.}

The industrial exploitation of the lack of substrate specificity of methane monoxygenase has been a major incentive for research in this area. Methane monooxygenase from several species of methanotrophs have also been shown to be able to insert an oxygen atom into a wide range of substrates. Methane-oxidizing bacteria have been considered for: single cell 
protein production (Bewersdorff, 1971; Harwood and Pirt, 1970; Molton and Pirt, 1971; Sheehan and Johnson, 1971; Windass et al., 1980), enhanced oil recovery (Hou et al., 1979), polymer production (Byrom, 1987; Linton and Cripps, 1978), and the elimination of methane in coal mines (Silverman, 1964). Several investigators have studied the co-oxidative abilities of methane-oxidizing organisms including: olefins to epoxides (Patel, 1982), alkanes to secondary alcohols (Hou et al., 1981; Hou et al., 1982a, 1982b), alkanes or secondary alcohols to ketones (Hou et al., 1979, 1981, 1982; Patel et al., 1980; Thompson, 1976) and certain aromatic oxidations (Hou et al., 1982). It is noteworthy that the work performed at Kyoto University in Japan on formaldehyde production reported $950 \mathrm{mM}$ formaldehyde in a 9-hour reaction in a continuous culture system (Sakai and Tani, 1986, 1987, 1988). Less attention has been spent on the regioselective nature of these reactions (Hou et al., 1981), and only recently has a group analyzed the stereospecific nature of these reactions (Habetscrutzen, 1985; Schurig and Burkle, 1982; van Ginkel et al., 1987). Weijer et al., (1988) found little stereospecificity by methanotrophs with epoxide formation. In these studies several strains of propane-utilizers as well as some methanotrophs were screened. The propaneutilizers produced ratios of R- to S- forms of propylene oxide from 45:55 to 99:1. The methanotrophs were found to be less stereospecific. In other studies (Kelley et al., 1988, 1989), both the co-oxidative and stereospecific production of propylene oxide and oxidative products of 3-methylcyclohexene were investigated to determine physiological parameters that may be important to these processes. It was found that enhanced stereospecificity occurs under conditions for propylene oxide (1,2-epoxypropane).

Leak et al. (1987) found highly stereoselective hydroxylation of 3-methylcychohexene by cellfree extracts of Methyosinus trichosporium OB3b. Leak et al. (1987) also examined several alkyl-substituted derivatives of cyclohexene and cyclohexane as "active-site probes" of the soluble methane monooxygenase from Methylococcus capsulatus (Bath) and made several conclusions about the methane monooxygenase active site for this organism. Most importantly, conformation and types of substitution can significantly effect the types of products that are produced by the methane monooxygenase enzyme. Further studies in these areas have the potential for the development of new technologies for biocatalytic conversions with methane. The regiospecific and stereospecific nature of biochemical reactions has long been applied in the pharmaceutical industry and recently have become an attractive aspect of biotechnology to the chemical industry.

The majority of the research in this area is conducted outside the U.S. Dalton and Murrell (1990) have concentrated on the methane monooxygenase enzyme, genetic, structural, and biochemical functions; Anthony in England (Anthony, 1975; Anthony and Zatman, 1964) has studied various aspects of methanol-utilizing bacteria. Montfort in New Zealand has investigated the production of various co-oxidative products from lignin-derived substrates. Japanese researchers (Sakai and Tani, 1986, 1987a, 1987b, 1988) have conducted both basic and applied research of the production of several metabolic products from methanol-utilizing bacteria. Finally, Gosh et al. have developed an immobilized bioreactor system for the direct production of methanol from methane (Mehta et al., 1987, 1991). 


\subsection{FUTURE RESEARCH DEVELOPMENTS AND REQUIREMENTS.}

\section{RELEVANCE AND JUSTIFICATION.}

The major advantages of bioprocesses over chemical synthesis are the mild reactions conditions, stereospecificity and regiospecificity. Of the few currently conceived bioprocesses considered for production of heavy, specialty and fine chemicals, stereospecificity and regiospecificity can make bioprocessing economically attractive. Many of these chemicals can be produced by chemical processes, but the products obtained are mixtures of various enantiomers. It is thought that specific enantiomers of certain chemicals can be produced by biocatalysis using methane as the energy source to obtain value-added products.

\section{RESEARCH NEEDS AND LIMITATIONS.}

Research needs include:

- Many aspects of cometabolism (or co-oxidation) at the biochemical and physiological level are not well understood. It is important to determine the biochemical and physiological basis of cometabolism, not only because of its scientific significance but also because of it commercial applications in bioremediation and the production of useful chemicals.

- Because of recent changes in the clean air act, natural gas liquids (e.g. butane and other lower boiling point hydrocarbons) cannot be added to gasoline. New areas of use for natural gas liquids will be needed.

- Determine the biochemical and chemical constraints of the stereo- and regiospecificity of the methane monooxygenase enzyme by screening several diverse groups of chemicals and their related congeners. This information is be used to determine the size and configurational constraints on the methane monooxygenase active site. By identifying the important constraints on stereo- and regiospecificity of the methane monooxygenase enzyme, it will be possible to describe size and configurational (3D) constraints of the active site. The understanding of the methane monooxygenase resulting from the proposed research will aid in establishing the conformation of the active site and this information will be used in predicting the types of compounds amenable to oxidation.

- Identify amino-acid residues involved in the methane monooxygenase active site and determine the significance of these residues on the size, configuration and the activity of the active site. Site-directed mutagenesis will be used to alter the amino acid sequence of the methane monooxygenase enzyme. By identifying the important components of the active site and by determining the effects of various changes in this site, it may be possible to enhance the efficiency of the biological system and/or to develop options for biomimetic pathways to methane activation and conversion. 
These enhancements could include increasing the efficiency of product formation, increasing the stereospecificity, or increasing (or decreasing) the range of products. The understanding of the methane monooxygenase enzyme and the availability of this enzyme with altered active sites resulting from the proposed research will greatly aid in the understanding of methane activation by the methane monooxygenase enzyme.

\subsection{RECOMMENDATIONS AND PRIORITIES STATUS.}

For the natural gas industry, this research is not a high priority in the near-term. This is because such applications will be relatively low volume in the near future, and new chemical methods for mimicking biocatalysts may be developed based, in part, on these studies. In addition, though methane is cheaper than other carbon sources, its lower solubility in liquids puts it at a distinct disadvantage with other carbon sources (e.g. methanol). For the midand long-term, however, there is a possibility that biochemical and/or chemical methods of mimicking biochemical reactions may become major sources of new chemicals with novel properties. For this reason, some interest from major chemical manufacturers would be expected. In addition, the basic research conducted in this project form a fundamental basis for many of the nearer-term applications associated with environmental applications such as halogenated hydrocarbon degradation. For this reason, long-term research is merited, and the research described in the previous section could be helpful in understanding how to control such reactions and is, therefore, considered high priority long-term research.

- Develop expanded databases concerning the co-oxidation of other substrates by methane monooxygenase to added-value chemicals.

- Develop new applications for the use of natural gas liquids. Federal restrictions on the use of natural gas liquids in refined products will create certain initiatives for new applications and markets for these liquids.

- Evaluate the application of methane monooxygenase in bioremediation.

- Evaluate the role of methanotrophs in methane biogeochemical cycles and any relationship to global warming hypotheses. 


\title{
Chapter 14
}

\author{
PHYSICAL DELIVERY OF MICROBLAL ACTIVITY \\ FOR APPLICATION TO FOSSIL FUEL BIOTECHNOLOGY.
}

\subsection{INTRODUCTION.}

A casual inventory of the metabolic activities of microorganisms leads microbiologists to put these organisms forward as potential agents of bioprocessing and/or bioremediation. These metabolic activities are first demonstrated in the laboratory and then optimized to carry out small-scale surface operations for the processing of materials and the degradation of pollutants. The expansion of these conceptual initiatives into large scale applications presumes that microorganisms can be brought effectively into contact with materials to be bioprocessed or pollutants to be biodegraded. If the materials to be contacted by these biological agents are simply adsorbed to particulate material that can be stirred and mixed to facilitate this contact, minimal contact problems exist and the desired reactions proceed at a satisfactory rate.

Recent research into the behaviour of vegetative bacteria in solid matrices has revealed that these full-sized $( \pm 1.0 \mu \mathrm{m})$, metabolically-active bacterial cells show a high level of affinity for available surfaces, adhering to the first surface encountered and penetrating only very small distances into the matrix (Shaw et al., 1985). These data are confirmed by the examination of backflow water from injection wells receiving millions of gallons of injection water of indifferent quality (high organic chemical content) over a period of several years (McKinley et al., 1988). The distribution of microbial biomass in the vicinity of these wells clearly showed that the continuous injection of bacteria and nutrients leads to a very shallow ( $<18$ inch) zone of active bacterial proliferation beyond which nutrients are depleted and microbial growth is extremely sparse. Even the most conservative interpretation of these data indicates it may be extremely difficult to treat materials with microorganisms if these materials are distributed throughout a solid matrix (soil or rock) to which the microbial cells have limited access.

\section{SUMMARY OF THE POTENTIAL USE OF ULTRAMICROBACTERIA IN BIOTRANSFORMATIONS}

The production of ultramicrobacteria is inherently economical and produces a product that can be stored for years without refrigeration. For this reason, ultramicrobacteria represent a convenient means of bacterial inoculation, even in cases where their phenomenal penetrating abilities are not necessary. Ultramicrobacteria now constitute a very valuable means of penetrating solid matrices that cannot be penetrated by vegetative bacterial cells because of their pronounced tendency to adhere to the first available surfaces. These small dormant bacterial cells appear potentially useful in the biotreatment of processed materials in surface deposits (e.g. coal) as well as in the treatment of organic molecules in situ within 
solid matrices. Ultramicrobacteria have the potential to function in the bioremediation of subterranean deposits of organic pollutants as well as to bioprocess fossil fuels in situ prior to recovery.

\subsection{STATUS OF BASIC AND APPLIED RESEARCH.}

\section{STARVED ULTRAMICROBACTERIA AS A PENETRATING INOCULUM.}

In 1977, it was discovered that a large number of natural bacterial species react to starvation by reducing their cell size (from $\pm 1.0 \mu \mathrm{m}$ to $\pm 0.3 \mu \mathrm{m}$ ) and by becoming essentially dormant and non-adherent (Novitsky and Morita, 1977). This starvation behaviour has been examined in detail with most natural groundwater bacterial isolates readily forming these very small ultramicrobacteria (MacLeod et al., 1988). The process of producing ultramicrobacteria by starvation is both simple and feasible, even on the small (ca. 150 litre) industrial fermenter scale. Thus, ultramicrobacteria can be produced by simple starvation, economically, and in large volumes.

The ability of ultramicrobacteria to penetrate solid matrices has been extensively examined in cores and in large scale simulators, with the conclusion that these small dormant cells are easily carried by fluids penetrating into and through natural solid matrices with permeabilities greater than 130 milliDarcies (Singh et al., 1988; Cusack et al., 1990). Extensive examinations of natural groundwaters have shown that large populations of ultramicrobacteria, naturally- derived from vegetative populations at the surface, already exist at considerable depths (eg. $3,000 \mathrm{~m}$ ). Modeling of the movement of ultramicrobacteria through solid matrices, using the "go vs. no go" premise, has led to the prediction that a few of these small dormant cells will be deposited by chromatographic separation onto surfaces within the matrix, while the bulk of their numbers will move through the matrix with the fluid front. Bacterial spores, which are simply larger (ca. $1.0 \mu \mathrm{m}$ ) dormant bacterial cells, have been shown to penetrate very readily through at least $40 \mathrm{~m}$ of Berea sandstone at 500 milliDarcy permeability. It is not expected, therefore, that stringent limitations exist on the penetration ability of non-adherent dormant microbial cells that are substantially smaller than the throat sizes of the solid matrix in question.

In exploiting the myriad of metabolic capabilities of microorganisms in bioprocessing or bioremediation, two concepts concerning ultramicrobacteria are emphasized:

1. These small dormant cells may be potentially valuable in penetrating solid matrices to effect contact with potential microbial substrates.

2. Where natural populations of ultramicrobacteria are already known to be present, simple nutrient stimulation may be sufficient to initiate the desired metabolic activity. 
Microbial Strategies for Biotransformations of Organic Materials

It can be assumed that biological activities will proceed when bacteria encounter their specific organic nutrients under physiologically permissive conditions. Since most natural bacteria are heterotrophs that derive metabolic energy by oxidizing organic substrates, it can be further assumed that these organic nutrients will be transformed to $\mathrm{CO}_{2}$ and $\mathrm{H}_{2} \mathrm{O}$ if conditions remain permissive for all possible bacterial activities. Systems related to fossil fuels differ in the facility with which this essential contact between organisms and nutrients can be achieved, and all of the strategies for the use of these bioprocesses must be conditioned by the realization that material handling costs must be kept down to the minimum while the price of fossil fuel energy is at its current very low level.

\section{Biotransformations in Surface Aquatic Systems.}

Aquatic systems, by definition, have fewer problems of contact and access than are found in solid matrices. Diffusion tends to distribute soluble, potential microbial substrates throughout the aqueous phase. However, even aqueous phases have distinct zones, such as sediments and anoxic areas, within which substrate availability and microbial activity may be modified. Generally, most of the demonstrated metabolic activities of environmental strains of bacteria can be induced and harnessed in either the aerobic or the anaerobic zones of these aqueous systems.

Natural aquatic ecosystems have very large bacterial populations that tend to adhere to surfaces and form biofilms in sediments and on available surfaces (Costerton et al., 1981, 1987). The surface affinity of these bacteria produces very large populations at these solidwater interfaces, and these populations are essentially stationary in relation to the flowing water. Water, containing various amounts of dissolved nutrients, can be visualized as flowing past large populations of bacteria living in exopolysaccharide matrices that have the capability of trapping organic and inorganic molecules. Once trapped, these organic nutrients can be readily transported into the adherent bacterial cells for metabolic processing. In reactor terminology, the bacterial populations of natural water systems constitute a stationary catalytic bed that adsorbs organic molecules from the flowing bulk phase and processes them metabolically. This basic process has been harnessed very effectively in many other industries, since fluids that are already in motion provide the energy to make effective contact between bacteria and nutrients and to effect very useful bioprocessing and/or bioremediation. Applications range from the simple sand filters used to prepare drinking water for domestic consumption to the elaborate reactors used to process cornstarch products. Even in stationary water bodies such as lakes, incidental flow (eg. wind mixing) serves to make contact between stationary bacteria in the sediments and organic nutrients in the bulk water phase and bioprocessing and bioremediation are achieved.

The tar sands plants in Northern Canada have recently announced a proposed biotechnical solution to their most pressing environmental problem, the disposal of billions of tons of tar sand tailings. This problem is inherent in the extraction of oil by surface mining, and it will 
face any oil shale operation that is initiated in the U.S. The solution depends on the kinetic energy of surface waters, involving the establishment of lakes filled with ambient surface water above a very thick sediment of mine tailings (as much as $500 \mathrm{ft}$. thick). Pilot scale experiments have shown that when ambient surface water is layered above tar sands tailings, a layer of enhanced bacterial growth and activity occurs at the water-tailings boundary which bioremediates the toxic components of the tailings (largely napthenic acid) diffusing towards the overlying ambient water. At the beginning of this process, the surface waters must be flushed through the system relatively quickly, because they may acquire unresolved toxicity, and may require further detoxification by incubation with natural napthenic acid-degrading bacterial populations in river sediments before discharge. As the overlying ambient water layer accumulates, a stationary semi-solid body, such as the tailings residue containing dissolved toxic materials, will be gradually detoxified by the passage of ambient water bringing natural nutrients and stimulating intense natural metabolic activity in the upper few inches of the tailings sediments. A much better understanding of the whole tar sands ecosystem will, however, allow for the elimination of the tailings problem completely and the ability to produce oil from tar sands and shale more economically.

The tailings problem arises because of the current environmental policy of total containment in tar sands mining, the zero release policy with respect to the Athabasca River. This river runs through natural tar sands deposits for more than 100 miles of its length. It and its tributaries receive millions of tons of tar sands annually, from which all organic components are removed by leaching and are metabolized by bacteria. There are no complex hydrocarbon residuals in the sediments of this river even a few miles downstream from the last tar sands deposits and the bioprocessing of these very complex polycyclic compounds is obviously complete in the natural river system (Wyndham et al., 1981a, 1981b). Ironically, because of archaic environmental concepts and methods that only examine the flowing phase, regulatory officials have declared that this prime "oil-eating", self-cleaning river is exquisitely sensitive to the hydrocarbons and complex organic acid components of tar sands and have banned the release of tailings. Tailings are the product of a caustic, warm $\left(82^{\circ} \mathrm{C}\right)$ water extraction of tar sands while the river receives millions of tons of tar sands, generating a cold water extract that is completely and naturally bioprocessed. In the new OSLO plant that is proposed for the Athabasca River, the cost of oil production could be reduced by more than $\$ 3 /$ barrel if tailings were not accumulated on site, but were bioprocessed and released seasonally as produced. Biotechnology has the potential for remediation of wastes produced by current oil recovery operations, but by far its greatest potential will be realized when biological principles are involved in the rational design of an effective environmental interface at the time that new operations are conceived and designed.

\section{Biotransformations in Surface Deposits of Processed Material.}

The kinetic energy of water facilitates contact between bacteria and their organic and inorganic nutrients when water is applied to heaps of crushed material and allowed to "trickle leach" their contents. This basic process is used in the recovery of copper from vast piles of mine tailings and low grade ore, and it has a potential for use in the bioprocessing of coal. If the deposit in question has a very open and very homogenous structure, 
complete contact is possible between the permeating water and all solid and soluble elements of the deposit. However, this ideal situation rarely occurs, and usually the more porous areas form zones of preferential water flow, while less porous areas remain virtually unaffected by the water and, therefore, by the biological processes. In the extraction of metals by trickle leaching, this heterogeneity is not an insurmountable problem, because partial recovery from selected zones is economically acceptable. However, partial bioprocessing of large surface deposits (as in coal heap desulfurization), in which certain zones were essentially unaffected, would be less acceptable, creating costly heterogeneity of fuel feed for the operation in question.

A possible solution to the problem of the heterogeneity of surface deposits of processed materials lies in the incorporation of bacteria and/or nutrients into the deposit as it is formed, and the subsequent addition of large amounts of water during and after the formation of the deposit. This simple stratagem will assure biological homogeneity of the surface mass of processed material and water access can be reinforced by some mechanical treatment of the system. Therefore, heap treatment can be considered to be a viable possibility for the bioprocessing and/or bioremediation of organic materials in surface deposits of processed materials.

\section{Biotransformation in situ in Solid Matrices.}

The usefulness of ultramicrobacteria to facilitate the penetration of solid matrices by bacteria is now unequivocally demonstrated in laboratory and large-scale simulator experiments. The simulator is a steel cylinder measuring $45 \mathrm{~cm}$ in diameter by $38 \mathrm{~cm}$ in length (Figure 1). A piston located at the top was used to apply an overburden pressure of 400 PSI and was separated from the test bed by a wax layer and metal sheet. At the top and bottom of the testbed were two saturation distributors (a radial array of perforated pipe) used to inject or withdraw fluids. A single perforated injection probe was located at the top center. The simulator incorporated 8 probes consisting of two concentric tubes with filters spot-welded on one end, strategically positioned throughout the testpack for removing planktonic (liquid) samples. Probe locations are indicated in Figure 2 with probes 1 and 2 being closest to the effluent point, probes 3,4 , and 5 in the middle, and probes 6,7 , and 8 closest to the injection point. Differential pressure across the testpack was measured between the injection point and the effluent withdrawal point using Validyne differential pressure transducers, calibrated with nitrogen. An embedded thermocouple measured temperature in the testpack. The injection fluid was pumped from the reservoir, a sterile $50 \mathrm{~L}$ carboy, to the testbed with a positive displacement pump at a flow rate of $120 \mathrm{cc} / \mathrm{min}$. Flow rates were periodically checked from effluent production collection rates. The pressure and flow rate data were récorded on a Hewlett Packard HP86B computer. To model a homogeneous reservoir, the simulator was packed with $65 \mathrm{~kg}$ (dry weight) of 125 mesh consolidated Ottawa sand. The sandpack was saturated through the bottom saturation distributor with 2 pore volumes of filter sterilized distilled water $(.22 \mu \mathrm{m}$ millipore filter) under vacuum to remove air and stabilize mobile fines. The porosity of the sandpack surrounding the sandstone core was $40 \%$ and permeability was 3.8 Darcies. 


\section{$45 \mathrm{~cm}$ SIMULATOR}

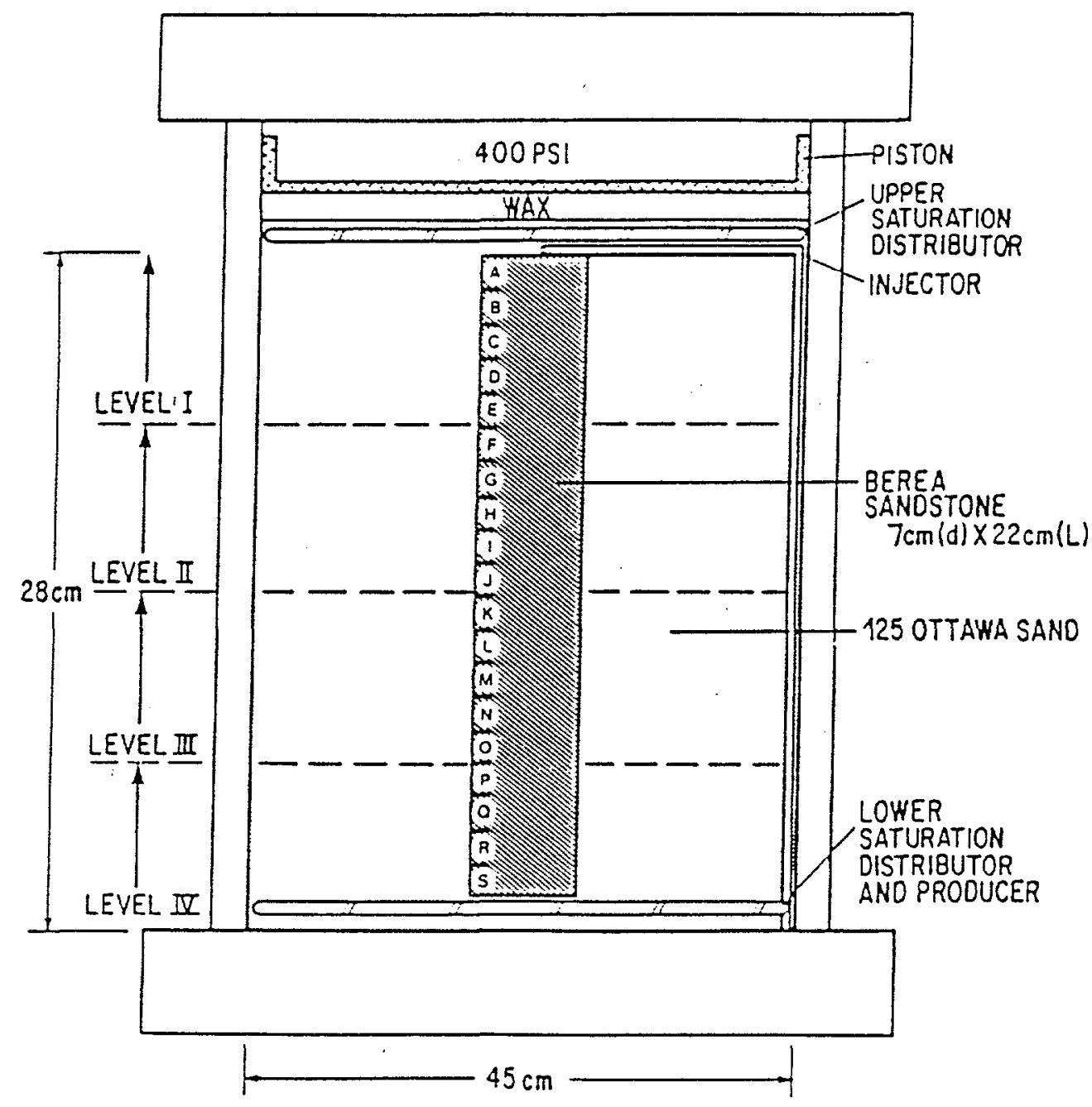

Figure 1. Schematic Diagram of the 3D Reservoir Simulator

The testpacks were placed in the simulator between the upper and lower saturation distributors. This figure shows the heterogenous testpack. 

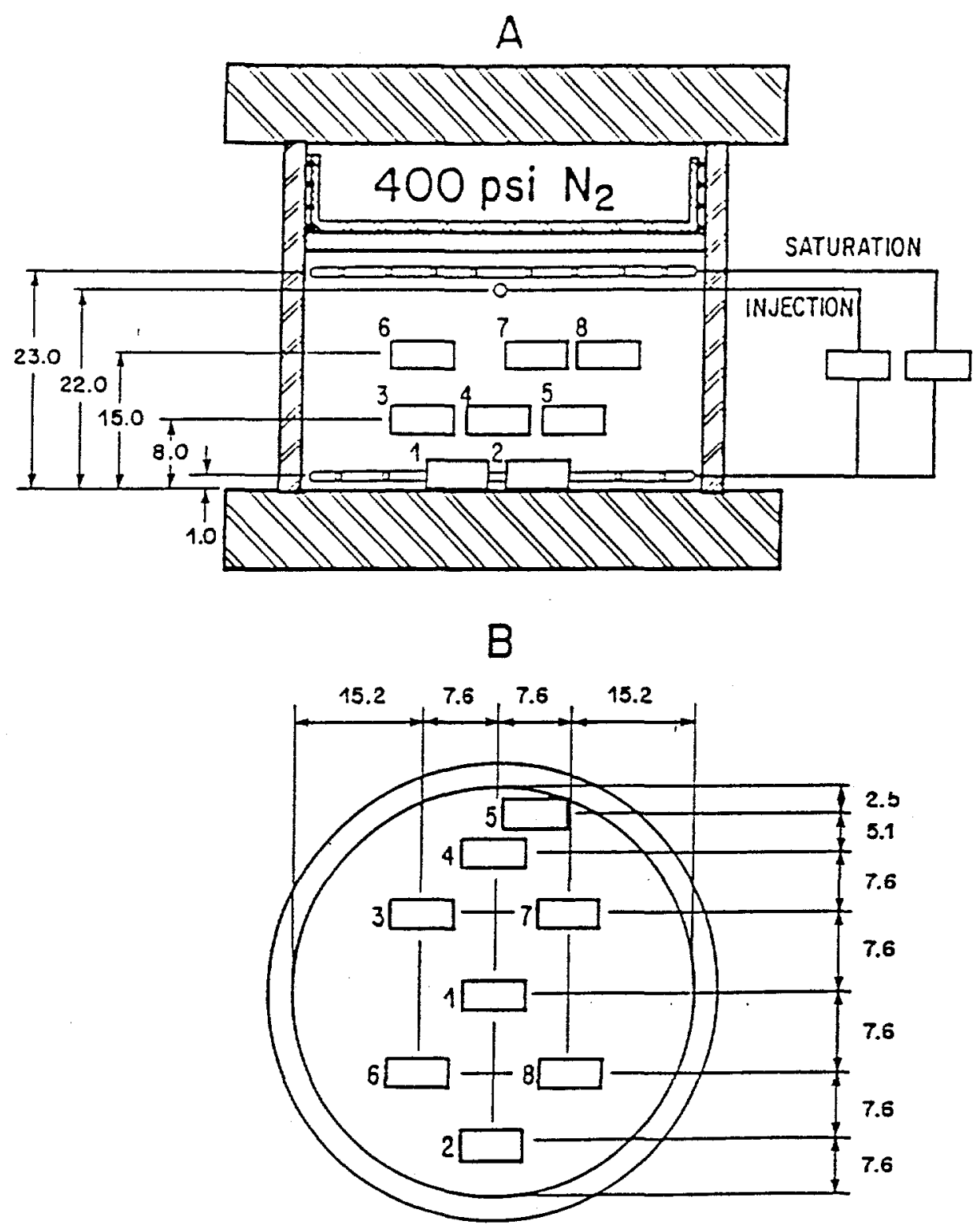

Figure 2. Sample Probe Locations in the Reservoir Simulator

Probes 1 and 2 are closest to the producer, probes 3, 4, and 5 are in the middle and probes 6,7 , and 8 are near the injector. 
In each experiment, the testbed was injected with 1.5 pore volumes of ultramicrobacteria, suspended in phosphate buffered saline at a concentration of $6.8 \times 10^{6}$ colony forming units $/ \mathrm{ml}$, followed by 1.0 pore volume of nutrient. The injectant was pumped from the reservoir into the testbed radially through the central perforated injector at the top of the simulator. The ultramicrobacteria were produced by starvation of bacteria isolated from oilwell water and identified by standard microbiological methods. The organism, FC3, is a facultative anaerobe that produces copious amounts of exopolymer when grown in sodium citrate medium. The cells were harvested and starved for 46 days.

The sodium citrate nutrient medium was injected as per the schedule in Table 1 . A total of 6 pore volumes of nutrient was injected into the homogeneous testbed over 24 days and 6 pore volumes into the heterogeneous testbed over 42 days. Initial pressure was $8 \mathrm{KPa}$ across the homogeneous testbed and $7.68 \mathrm{KPa}$ across the heterogeneous testbed (Table 1). Planktonic samples were collected from all probes and the producer during ultramicrobacteria and nutrient injection, then analyzed for viable cells as described by Cusack et al. (1990). After completion of each experiment, the testbeds were randomly sampled through four horizontal zones. The sessile (solid) samples were analyzed for viable cell numbers, exopolysaccharide production and prepared for scanning electron microscopy.

After ultramicrobacteria injection, the only organism recovered from the testbed was FC3. Fluid samples from the probes demonstrated that ultramicrobacteria entered each area of the sandpack (Table 2). Viable ultramicrobacterial numbers increased from $2.0 \times 10^{4}$ colony forming units $/ \mathrm{ml}$ to $>1.8 \times 10^{5}$ colony forming units $/ \mathrm{ml}$ and saturated every location in the sandpack. During nutrient injection, cell numbers increased ten-fold after 1 pore volume to $10^{6}$ colony forming units/ml, and one hundred-fold after 2 pore volumes (Table 3 ). When treatment was complete, after 6 pore volumes of nutrient, viable cell numbers increased to greater than $10^{8}$ colony forming units $/ \mathrm{ml}$. Differential pressure readings were used as an indication of permeability reduction across the sandpack. The initial differential pressure of $8.0 \mathrm{KPa}$ increased to $16 \mathrm{KPa}$ when ultramicrobacteria were introduced into the sandpack (Table 1). As the ultramicrobacteria formed normal-sized cells with nutrient stimulation, the differential pressure increased to over $137 \mathrm{KPa}$ on day 10 . Daily fluctuations in differential pressure were recorded between day 10 and day 24 . This was attributed to a shift in the plug due to the elastic nature of the polymer when pressure was initially applied. On day 24, the sandpack was dismantled and random sessile samples were removed.

Healthy, resuscitated bacteria were apparent throughout the sand, with polymer and a confluent biofilm formation filling the pores and coating the surfaces of the sand particles, as determined by scanning electron microscopy. Viable cell numbers were highest in levels 1 and 2, with counts ranging from $1.0 \times 10^{6}$ colony forming units/g to $5.0 \times 10^{8}$ colony forming units/g. Carbohydrate production was uniform throughout the sandpack. These results suggest that maximum cell counts are not required to yield maximum polymer production. Injection of FC3 followed by sodium citrate medium promoted uniform growth, polymer production and plugging through the homogenous porous matrix (Table 4.) 
Table 1

SCHEDULE OF TREATMENTS AND DIFFERENTIAL PRESSURE (DP) READINGS IN THE RESERVOIR SIMULATOR EXPERIMENTS

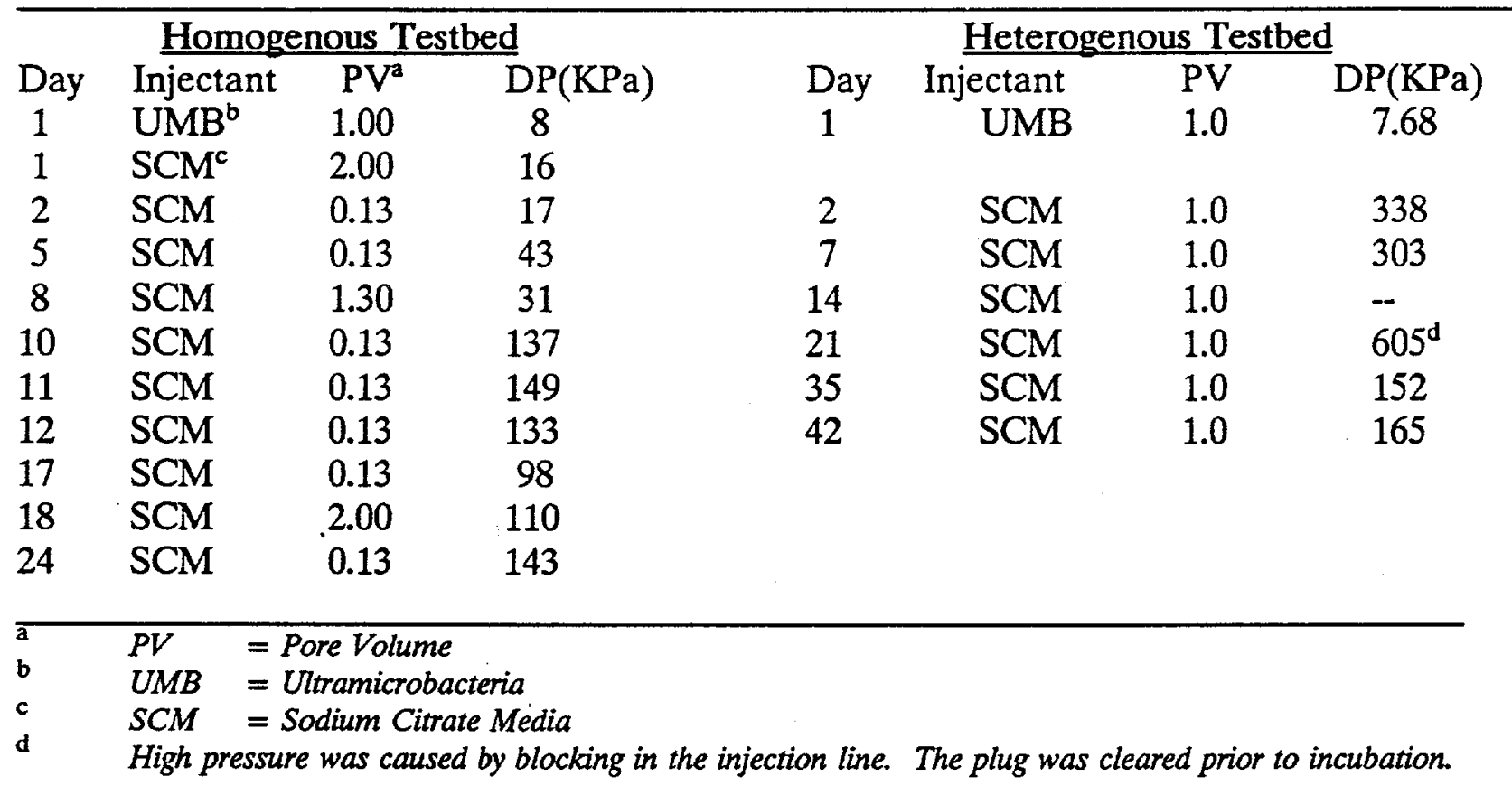

Table 2

VIABLE CELL COUNTS (CFU/ML X 105) DURING UMB PENTRATION THROUGH THE HOMOGENOUS TESTPACK.

$\begin{array}{cccccc}\begin{array}{l}\text { Probe } \\ \text { Number }\end{array} & \begin{array}{c}\text { Pore } \\ \text { Volume }\end{array} & & & & \\ & 0.12 & 0.36 & 0.60 & 0.84 & 1.00 \\ 1 & & & 0.73 & 1.50 & 4.50 \\ 2 & & 0.25 & 0.63 & 1.30 & 5.00 \\ 3 & & & 0.91 & 1.20 & 2.70 \\ 4 & 0.13 & 0.15 & 0.56 & 1.50 & 1.80 \\ 5 & & & 0.12 & 0.15 & 6.50 \\ 6 & 1.30 & 3.20 & 2.20 & 1.53 & 6.50 \\ 7 & 0.91 & 1.90 & 2.00 & 2.10 & 7.00 \\ 8 & 0.81 & 1.90 & 2.50 & 3.60 & 4.00\end{array}$


Table 3

VIABLE CELL NUMBERS IN THE FLUID SAMPLES TAKEN FROM THE PROBES AND THE PRODUCER (PROBE 9) IN THE 3D RESERVOIR SIMULATOR

HOMOGENOUS TESTBED

$\begin{array}{ccccc}\begin{array}{c}\text { SAMPLE } \\ \text { PROBE }\end{array} & \begin{array}{c}\text { UMB } \\ 1 \mathrm{PV}\end{array} & \begin{array}{c}\text { SCM } \\ 1 \mathrm{PV}\end{array} & \begin{array}{c}\text { SCM } \\ 2 \mathrm{PV}\end{array} & \begin{array}{c}\text { SCM } \\ 6 \mathrm{PV}\end{array} \\ 1 & & & & \\ 2 & 4.5 \times 10^{5} & 2.1 \times 10^{6} & 7.1 \times 10^{7} & 2.9 \times 10^{8} \\ 3 & 5.0 \times 10^{5} & 3.3 \times 10^{6} & 1.6 \times 10^{8} & 7.3 \times 10^{8} \\ 4 & 2.7 \times 10^{5} & 3.2 \times 10^{6} & 2.0 \times 10^{7} & 2.3 \times 10^{8} \\ 5 & 1.8 \times 10^{5} & 2.2 \times 10^{6} & 4.2 \times 10^{7} & 7.3 \times 10^{9} \\ 6 & 6.5 \times 10^{5} & 3.0 \times 10^{6} & 1.2 \times 10^{7} & 3.1 \times 10^{8} \\ 7 & 6.5 \times 10^{5} & 2.7 \times 10^{6} & 4.4 \times 10^{7} & 7.3 \times 10^{9} \\ 8 & 7.0 \times 10^{5} & 2.8 \times 10^{6} & 9.1 \times 10^{7} & 7.3 \times 10^{9} \\ 9 & 4.0 \times 10^{5} & 2.9 \times 10^{6} & 5.1 \times 10^{7} & 7.3 \times 10^{9} \\ & 2.4 \times 10^{5} & 2.6 \times 10^{6} & 4.0 \times 10^{7} & 3.5 \times 10^{8}\end{array}$

HETEROGENOUS TESTBED

$\begin{array}{ccccc}\begin{array}{c}\text { SAMPLE } \\ \text { PROBE }\end{array} & \begin{array}{c}\text { UMB } \\ 1 \mathrm{PV}\end{array} & \begin{array}{c}\text { SCM } \\ 1 \mathrm{PV}\end{array} & \begin{array}{c}\text { SCM } \\ 2 \mathrm{PV}\end{array} & \begin{array}{c}\text { SCM } \\ 6 \mathrm{PV}\end{array} \\ 1 & & & & \\ 2 & 9.0 \times 10^{4} & 4.4 \times 10^{6} & 3.2 \times 10^{8} & 1.1 \times 10^{9} \\ 3 & 3.0 \times 10^{5} & 1.5 \times 10^{6} & 3.2 \times 10^{8} & 1.1 \times 10^{9} \\ 4 & 3.2 \times 10^{5} & 2.5 \times 10^{6} & 2.7 \times 10^{8} & 6.6 \times 10^{9} \\ 5 & 2.6 \times 10^{5} & 2.5 \times 10^{6} & 2.9 \times 10^{8} & 1.6 \times 10^{9} \\ 6 & 2.1 \times 10^{5} & 1.5 \times 10^{6} & 3.7 \times 10^{8} & 1.1 \times 10^{9} \\ 7 & 3.2 \times 10^{5} & 1.6 \times 10^{6} & 3.5 \times 10^{8} & 2.3 \times 10^{9} \\ 8 & 5.4 \times 10^{5} & 2.7 \times 10^{6} & 3.8 \times 10^{8} & 1.3 \times 10^{9} \\ 9 & 2.4 \times 10^{5} & 1.8 \times 10^{6} & 3.2 \times 10^{8} & 2.3 \times 10^{9} \\ & 2.0 \times 10^{5} & 1.9 \times 10^{6} & 3.5 \times 10^{8} & 2.6 \times 10^{9}\end{array}$


Table 4

SESSLE CELL NUMBERS (CFU/G X 107) AND POLYMER PRODUCTION (MG/G) IN THE HOMOGENOUS TESTBED AND THE SANDPACK OF THE HETEROGENOUS TESTBED

\begin{tabular}{|c|c|c|c|c|c|c|c|}
\hline \multicolumn{8}{|c|}{ HOMOGENOUS TESTBED } \\
\hline \multicolumn{2}{|c|}{ LEVEL 1} & \multicolumn{2}{|c|}{ LEVEL 2} & \multicolumn{2}{|c|}{ LEVEL 3} & \multicolumn{2}{|c|}{ LEVEL 4} \\
\hline $\mathrm{CFU} / \mathrm{g}$ & $\mu \mathrm{g} / \mathrm{g}$ & $\mathrm{CFU} / \mathrm{g}$ & $\mu \mathrm{g} / \mathrm{g}$ & $\mathrm{CFU} / \mathrm{g}$ & $\mu \mathrm{g} / \mathrm{g}$ & $\mathrm{CFU} / \mathrm{g}$ & $\mu \mathrm{g} / \mathrm{g}$ \\
\hline 19.9 & 242 & 5.10 & 290 & 29.20 & 541 & 0.07 & 223 \\
\hline 5.3 & 284 & 8.00 & 209 & 0.60 & 222 & 0.20 & 281 \\
\hline 5.3 & 190 & 1.80 & 205 & 0.20 & 206 & 9.00 & 202 \\
\hline 14.1 & 480 & 8.90 & 219 & 14.80 & 547 & 0.40 & 300 \\
\hline 50.0 & 200 & 6.70 & 284 & 10.20 & 427 & 2.10 & 237 \\
\hline 15.3 & 211 & 7.40 & 373 & 0.30 & 390 & 1.10 & 234 \\
\hline 7.5 & 256 & 5.10 & 207 & 1.60 & 206 & 3.1 & 230 \\
\hline
\end{tabular}

HETEROGENOUS TESTBED

(High Permeability Sandpack)

LEVEL 1

$\mathrm{CFU} / \mathrm{g}$

7.8

5.4

5.8

3.5

8.9

9.2

20.9

12.4
LEVEL 2

\section{CFU/g $\quad \mu \mathrm{g} / \mathrm{g}$}

$3.10 \quad 137$

$3.10 \quad 246$

$0.28 \quad 131$

$0.16 \quad 145$

$0.34 \quad 153$

$0.29 \quad 422$

$0.10 \quad 858$

$0.06 \quad 202$
LEVEL 3

$\begin{array}{ll}\text { CFU/g } & \mu \mathrm{g} / \mathrm{g} \\ 0.17 & 148 \\ 1.34 & 127 \\ 0.10 & 141 \\ 0.23 & 144 \\ 1.38 & 188 \\ 0.22 & 943 \\ 0.10 & 586 \\ 0.16 & 126\end{array}$

LEVEL 4

$\begin{array}{lc}\text { CFU/g } & \mu \mathrm{g} / \mathrm{g} \\ 1.12 & 281 \\ 0.13 & 83 \\ 0.10 & 85 \\ 0.11 & 104 \\ 0.10 & 124 \\ 0.10 & 220 \\ 0.20 & 117 \\ 0.10 & 86\end{array}$

It is concluded from these simulator experiments that ultramicrobacteria penetrate any solid matrix $>130$ milliDarcies in permeability and resuscitate when provided with suitable nutrients. If plugging is required, a slime-producing strain and a nutrient that favors exopolysaccharide production is selected. If other metabolic activities are required, such as the biotransformation of a given substrate or the bioremediation of a specific pollutant, the ultramicrobacteria can be resuscitated and induced to develop that activity with only minimal plugging of the solid matrix. 


\section{Biobarrier Formation.}

The simplest use of ultramicrobacteria, in the environmental areas that concern the fossil fuels industry, is their application to plug leaking berms and earthen dams. Many oil-contaminated surface waters and tar sands tailings ponds are retained by earthen berms and dams and many of these structures develop dendritic water flow problems that constitute serious leakage into natural ecosystems. If ultramicrobacteria are applied to the origins of these dendritic leaks and allowed to flow with the permeating water into the penetrating water channels, they will react to slime-enhancing nutrients by resuscitating and plugging the leaks. Alternatively, a subterranean body of a poilutant may be poised to enter and contaminate a natural water system. The application of ultramicrobacteria technology to form a "curtain wall" of wells through which ultramicrobacteria and nutrients are injected, forming an effective exopolysaccharide biobarrier, serves to contain the pollutant and protect the natural system. Field trials of this ultramicrobacteria biobarrier technology are presently being undertaken by CARE UMB Ltd. to exploit its use in the solution of environmental problems.

\section{In situ Biotransformations.}

For several years, environmental contractors have pumped vegetative bacteria with the demonstrated capability of degrading specific pollutants (eg. gasoline, PCBs, etc.) into subterranean plumes of these pollutants. While these contractors honestly believed that the active bacteria penetrated these solid sand or soil matrices and bioremediated the pollutants to which they had been adapted, it is known that these vegetative organisms do not penetrate these solid matrices. It is now possible to form ultramicrobacteria from the very same degradative strains and inject them into these pollutant plumes. Simulator data clearly shows that ultramicrobacteria will penetrate deeply with the injected water, and that the availability of specific nutrients will cause these very small, dormant organisms to return to their full-sized, fully-active metabolic state. This method of facilitating the contact between useful bacterial strains and the organic molecules that they are designed to transform removes the last practical barrier for the use of microorganisms in targeted biotransformations in solid matrices.

\subsection{FUTURE RESEARCH DEVELOPMENT AND REQUIREMENTS.}

Exploitation of ultramicrobacteria requires further development of the basic data base concerinig the range of directed physiological and metabolic activities in these dormant cells. Presently, the best-documented physiological activity is in situ slime production following nutrient stimulation. Can ultramicrobacteria be induced to metabolize diverse substrates and, if so, does in situ induction occur in the presence of inducer substrates? The ability of ultramicrobacteria to penetrate solid matrices of various types offers a potentially valuable technology for the development of performance-effective biosystems for applications in in situ biotransformations, biotransformations in surface deposits and aquatic ecosystems and bioremediation strategies.

\subsection{RECOMMENDATIONS AND PRIORITY STATUS}

- Develop an expanded data base on other physiological and metabolic capabilities of ultramicrobacteria. 


\section{Chapter 15}

\section{AN ANALYSIS OF BIOENGINEERING/BIOREACTOR TECHNOLOGY APPLICABLE TO THE BIOPROCESSING OF FOSSIL FUELS.}

\subsection{INTRODUCTION AND SUMMARY.}

\section{INTRODUCTION.}

Applications of bioprocessing to fossil energy resources could include: desulfurization, removal of nitrogen, oxygen and mineral matter, production of oxygenated fuels, chemical feedstocks and fuel additives, conversion to gaseous fuels, viscosity reduction, release of organic materials bound to inorganics and bioremediation of wastes. Bioprocessing and bioreactor technologies that would be relevant could differ from application to application. The size of such applications, however, would be very large, orders of magnitude larger than bioprocess and bioreactor technologies practiced in the pharmaceutical and food industries, and the costs of these processes have to be very low, once again orders of magnitude lower than the pharmaceutical and food applications.

These factors of size and economic constraints create formidable research and development challenges to the development and deployment of bioprocessing and bioreactor technologies for applications in fossil energy resources. Large scale bioprocessing, however, has been developed to economical scale, commercialized and is widely used in the corn wet milling industry, fuel alcohol industry, mining industry for copper extraction, and the wastewater treatment industry. These processes and plants operate at full capacity with minimum downtime and consistently meet product quality specifications. Thus, the bioprocess and bioreactor experiences from these industries could be relevant.

Large scale bioprocesses have three primary cost centers: capital costs, process energy costs and cost of raw materials and supplies. These costs are always present, although their relative magnitude differs from case to case. All potential fossil energy applications are low cost and high volume. Hence, bioprocessing costs will often dictate commercial viability and applicability. Thus, research and development efforts directed towards reduction of cost centers, be it in biocatalysts, enzymes, processing aids, bioreactor design, separations processes, or process integration, would be very important.

\section{SUMMARY.}

There are many potential applications for the bioprocessing of fossil fuels. These would be very large scale applications, and the costs of the processes will need to be very low. These features of size and economic constraints provide unique research and development challenges in bioengineering and bioreactor technology development. Currently, large scale bioprocessing is successfully practiced in several industries such as the corn wet milling, fuel ethanol, copper 
bioleaching and waste treatment, and each of these industries has successfully developed, adapted and integrated technologies to operate economically within a commercial infrastructure.

Large scale bioprocesses have three primary cost centers: capital costs, process energy costs, and cost of raw materials. The relative magnitude of these vary from case to case, but these costs are always present. Research and development efforts directed towards reduction of cost centers will be important for future success.

The two major bioengineering components of the bioprocess are bioreactors and separations processes. Successful development and integration of both components are necessary for viability. Depending on applications, the bioreactor systems could be multiphase or singlephase. Considerable research is occurring in three-phase reactors targeted towards aerobic depyritization of coal. A considerable body of knowledge and experience exists for the design of two-phase (gas-liquid) bioreactors which could be useful for the design of novel fermentations such as conversion of syngas to oxygenated fuels. Single-phase systems in anaerobic processes have also been successfully and economically scaled up to very large scale because of their simplicity. The applicability of large scale aerobic bioreactors for fossil fuel bioprocessing should be approached with a great deal of caution because of energy loss and heat generation considerations.

Separations processes are often the largest cost centers for bioprocesses, and a great deal of effort should be placed on development of low cost separations processes, and their integration with bioconversion. Development of novel integrated separation processes particularly in the area of membrane based processes such as electrodialysis, pervaporation, microfiltration, and ultrafiltration, would be important.

Recent developments have occurred in the construction of conjugated polyaniline polymers which exhibit selectivity for important gas pairs such as hydrogen-nitrogen, oxygen-nitrogen, and carbon dioxide-methane (Anderson et al., 1991). Such selective gas separating films offer potential advantages to bioprocessing and efficient membrane-based gas separations.

Based on the analysis of the status of bioengineering and bioreactor technologies, economic and process constraints and potential cost centers, bioengineering research and development should be directed towards:

- Development of low capital cost bioreactor and bioconversions.

- Development of low energy requiring bioreactors and bioconversions.

- Development and integration of low energy requiring separations processes with bioconversion.

- Development of new oxygenated liquid fuels that can be potentially made from future fossil feedstocks which are likely to be more oxygenated than hydrocarbons.

- Development of integrated processes and systems. 
These research and development initiatives should be targeted with short (5-10 years), mid (1015 years) and long (15-20 years) term programs. Several short to mid term programs should be chosen, and substantial focused effort on research and technology development should be devoted to these so that technical and economic successes are demonstrated within a time frame of 5 to 15 years, respectively.

\subsection{STATUS OF BASIC AND APPLIED RESEARCH.}

\section{BACKGROUND.}

Large scale bioprocesses and bioreactors have been successfully applied in the corn wet milling industry, fuel ethanol industry, production of acetone-butanol solvents, copper bioleaching and wastewater treatment. In the corn wet milling process, multiple bioconversion steps including non sterile fermentation (steeping) and enzymatic processes are integrated with separation processes. This industry currently processes approximately 900 million bushels of corn $(\sim 50$ billion pounds) to produce a variety of products including feedstocks for fuel ethanol. Watson (1977) provides technical details for industrial corn utilization. The fuel ethanol production from corn in the U.S., is approaching 1 billion gallons per year, and numerous process advances have been made to reduce costs and improve efficiency. From 1915 to 1955, acetone and nbutanol solvents were made by carbohydrate fermentation and it was one of the largest industrial fermentation processes, practiced (Beesch, 1953). This process is currently used in China (Lin et al., 1989) to produce 135 million pounds of n-butanol annually. Recently, Marlatt and Datta (1986) have described and evaluated an improved acetone-butanol process. In the area of biohydrometallurgical processes, the in situ bioleaching of copper from low grade ores has been an overwhelming success story, and in 1989 approximately $25 \%$ of all copper produced in the U.S., with a worth of approximately 650 million dollars, was produced by this process (Debus, 1990). In biological waste treatment, significant advances in process intensification have been made by the fluidized bed bioreactors (Jerris et al., 1977; Andrews, 1988) and this has led to successful commercialization.

It is noteworthy that in all of these successful cases of large scale bioprocesses, the bioreactors have been low cost or no cost (as in the case of copper bioleaching), and the total processes have been integrated and operated within an integrated infrastructure. For large scale fermentations (ethanol, acetone-butanol), the processes are anaerobic, and the production fermentors are not operated under sterile conditions. Due to the low power, cooling and pressure demands such fermentors 'cost between $\$ 1$ to $\$ 4$ per gallon of installed fermentation capacity, and the fermentor capital costs are not a major fraction of the total capital cost of the process (Marlatt and Datta, 1986). Moreover, low cost materials of construction such as carbon steel, epoxy-lined steel, spherical tanks, reinforced plastic columns, etc. are often used in the processes to keep capital costs low. The major processing cost center (i.e. excluding raw material costs) for many of these are in the separations process both in terms of capital and energy costs. Debus (1990) has analyzed the economics of the copper ore bioleaching process and has identified several key attributes that were critical to its commercial success. These include: in-situ processing; lower energy, capital and labor costs relative to the alternatives; ability to convert waste product to a resource; passive systems and favorable environmental impact. 


\section{CURRENT STATUS.}

The two major bioengineering components of bioprocesses are bioreactors and separations processes. Successful development and integration of both components are necessary for viable bioprocesses.

\section{Bioreactors.}

There appear to be three general classes of systems that bioreactors will have to handle for future applications in fossil resources: 1) three-phase systems with solid, liquid and gas, 2) twophase systems with solid-liquid, liquid-gas and 3) single-phase systems-liquid only. Examples of the first system would be coal desulfurization in aerobic slurry or leach systems, examples of the second system would be aerobic fermentations (gas liquid) or anaerobic bioconversion of a solid or gas, and examples of the third system would be simple anaerobic bioconversion in liquid media.

Andrews and co-workers have done considerable research work in design and evaluation of bioreactors for three-phase systems with particular attention to coal desulfurization (Andrews, 1989, 1990; Andrews et al., 1990; and Andrews and Quintana, 1990). The particle size of coal has a significant effect on the rate and degree of bacterial depyritization (Andrews, 1990). In coal fired utility boilers the coal is generally pulverized $(-80$ mesh) and $2-3$ months storage of coal is kept in stock. These features may allow microbial depyritization to be conducted within the infrastructure of the coal fired utilities (Andrews, 1989). Several groups of researchers in Europe (Rossi et al., 1989) and the U.S. (Andrews and Quintana, 1990) are evaluating several designs of aerated trough slurry bioreactors for desulfurization of coal. The European work has proceeded to the pilot scale. Major technical problems of mixing and mass transfer, particularly at high slurry concentrations, will need to be solved before these processes can be scaled up. The pile type reactor systems such as leach heaps or ring shaped piles are also being evaluated as a low capital and energy cost alternative for these three-phase bioreactors (Hammack, 1991; Baier, 1987). Since the size of coal in these piles is large, the rate and extent of depyritization is lower than that obtained in slurry reactors. The research on desulfurization of organic sulfur is in the very early stage and no bioreactor work has been performed. However, severe technical problems in contacting and mass transfer are anticipated because the organic sulfur in coal is dispersed throughout the coal polymeric structure.

A considerable body of knowledge exists for the design and operation of two-phase (gas-liquid) bioreactors because these systems have been widely used in the fermentation industry for manufacture of a wide variety of products. Large (100,000 - 150,000 gal) stirred tank aerobic fermentors are used in citric acid production. A very large (400,000 gal) pressure cycle aerobic fermentor was designed and operated by ICI Corporation for production of single cell protein. Many designs of air lift fermentors are available. The waste treatment industry has available many designs of aerobic activated sludge units. Fluidized bed reactors have also been successfully commercialized for aerobic wastewater treatment where the solubility of oxygen, although low, is only one order of magnitude less than the concentration of organic matter, not two or three orders of magnitude less, as is typical of aerobic fermentations designed to 
maximize production of a product. (Andrews, 1988; Jerris et al., 1977). Thus, if large scale twophase gas-liquid bioreactors are needed for fossil fuel bioprocessing, a considerable body of knowledge exists for design of such systems.

The applicability of large scale aerobic bioreactors for fossil fuel bioprocessing should be approached with a great deal of caution because of energy loss considerations. When oxygen (or other oxidized electron acceptors such as nitrate or sulfate) are used there is a loss of available electrons (i.e. chemical combustion energy) in the bioconversion process. Hence, the "bioconverted" product could be more oxidized and have lower energy value, often undesirable where a combustible fuel is the end product. Furthermore, these aerobic processes also produce heat which has to be removed with expensive heat exchange and refrigeration processes. In a recent workshop, rationale of such calculations of mass and energy balances and the applicability of electron balances to bioconversions were provided (Datta and Andrews, 1991). Anaerobic bioprocesses conserve the available electrons and thus chemical combustion energy and produce very little metabolic heat. Thus, such systems could be more easily processable in large scale bioreactors. Recent research advances in anaerobic bioconversion of $\mathrm{C} 1$ gases and liquids $\left(\mathrm{CO}, \mathrm{CO}_{2} / \mathrm{H}_{2}, \mathrm{CH}_{3} \mathrm{OH}\right)$ to longer chain fatty acids and alcohols could be very attractive systems to further develop for production of oxygenated fuel additives (see Chapter 5).

The third and the simplest system, the single-phase bioreactor, is widely applied in large scale bioprocessing in the fuel ethanol industry, in the corn wet milling industry, in acetone-butanol fermentations, and in anaerobic treatment of liquid industrial wastes. As mentioned earlier, the capital and operating costs of these bioreactors are low, and very large volume $(500,000-1$ million gal) vessels are routinely used in the ethanol and corn wet milling industries. The production fermentors or conversion tanks are usually non-sterile, although for certain fermentations the feed stream and smaller seed fermentors are sterilized. Due to their simplicity and low cost such bioreactor systems have been successfully commercialized. It would be worthwhile to target research and development in fossil fuel bioconversion processes towards the use of simple, scalable, low cost bioreactors.

\section{Separations Processes.}

Separations are often the largest cost center for bioprocesses, both in terms of capital and energy costs. It is unfortunate that the development of low cost integrated separations processes is often neglected in the bioprocess research and development agenda. Since most bioprocesses occur in dilute systems, several types of separations processes can play very important roles in the overall system, for example, separations systems for retention and recycle of biocatalysts (organisms, enzymes, processing aids, etc.) and separations processes for recovery and purification of products from dilute solutions. It is beyond the scope of this short treatise to describe and analyze the many separations processes that are developed or will need to be developed for such bioprocesses. Some recent advances, however, particularly in the area of membrane based separations, may impact the future of fossil fuel bioprocessing and a few are highlighted below. 
Microfiltration and ultrafiltration processes could be suitable for retention and recycle of biocatalysts. Development and deployment of large scale systems are occurring in the food and related bioprocessing industries (example, "cold filtered" beers).

Pervaporation systems for removal of water from ethanol/water mixtures are being developed and full scale demonstrations are planned (Flemming, 1989; Rapin, 1988). Such systems could also be developed for recovery of organics from dilute aqueous solutions and provide a low energy requiring alternative to distillation.

Recent developments in electrodialysis and water-splitting electrodialysis membranes can allow low energy and low cost processes for recovery and purification of organic acids from dilute aqueous solutions (Datta, 1989; Van Nispen and Jonker, 1991). Since many anaerobic processes can efficiently make organic acids from a variety of feedstocks (including syn- gas/methanol), these electrodialysis-based recovery processes could lead to economically viable processes to produce oxygenated fuels and fuel additives.

\subsection{FUTURE RESEARCH DEVELOPMENT AND REQUIREMENTS.}

\section{RELEVANCE AND JUSTIFICATION.}

Bioprocesses may become important in several potential applications in fossil energy resources such as: desulfurization; removal of heteroatoms (nitrogen, oxygen, ash) from fuels; bioconversion to oxygenated fuels, fuel additives and chemical feedstocks; conversion to gaseous fuels; enhancement of processability (viscosity reduction, release of trapped organics from inorganics) and waste bioremediation. Since these are low-cost high-volume applications, the capital and operating costs of the processes will play a critical role in their ultimate technical and economic viability. Bioreactors and separations processes are the two major bioengineering components of these processes. Wherever large scale bioprocessing has been successful, for example, in the corn wet milling industry, fuel alcohol industry, wastewater treatment industry, it has been successful because the results of basic and applied research overcame critical cost centers in processes and then integrated processes could be developed. This will also be true for these emerging bioprocesses for fossil fuel applications. Thus, identifying the cost centers of these processes and targeting R\&D efforts (whether it is basic, applied or commercial) towards reduction of these cost centers would be important.

\section{RESEARCH NEEDS AND LIMITATIONS.}

One should be mindful of the fact that in this area bioprocesses are not stand-alone alternatives or solutions. These processes will need to be integrated with an upstream or downstream chemical conversion process, with a combustion process, or with the operation of an engine. Since very large infrastructures with large capital investments are already in place for handling and processing fossil fuels, future bioprocesses should be synergistic to this infrastructure. Furthermore, the constraints of economics and large size create formidable research and development challenges. This is also an area where research and technology are in the early stages of development and not mature (as may be the case of other processing alternatives). 
Hence, significant breakthroughs to overcome many technical barriers and cost centers can be anticipated.

Based on the analysis of the status of bioengineering and bioreactor technologies, the economic and process constraints and potential cost centers, bioengineering research and development resources should be devoted to the following areas:

1. Development of low capital cost bioreactors and bioconversions.

- Non-sterile processes

- Non-corrosive conditions

- Open systems

- Anaerobic bioconversion

- In-situ bioconversion

2. Development of low energy requiring bioreactors and bioconversions.

- Anaerobic processes

- Non-sterile processes

3. Development and integration of low energy requiring separations processes with bioconversion.

- Membrane based processes: electrodialysis, pervaporation, micro and ultrafiltration

- Novel separations integrated with bioconversion

4. Development of other oxygenated liquid fuels and fuel additives (that can be made from future fossil energy feedstocks which are likely to be more oxygenated than hydrocarbons).

5. Development of integrated processes and systems

- Bioconversion with separations

- Bioprocesses within infrastructure

\subsection{RECOMMENDATIONS AND PRIORITY STATUS.}

Research and development initiatives should be developed with short, mid and long-term programs. Since this area is in the early stages of development, short term programs should be able to deliver technically successful products and processes within five years and be economically successful (i.e. first commercialization) within ten years. Mid-term programs should be technically successful within 10 years and economically successful within 15 years, and for long term programs the horizons for technical and economic success should be 15 and 20 years, respectively.

Since this assessment of technology development is based on current knowledge, prediction of those that will become successful is always uncertain. Based on an assessment of the status of 
bioengineering, the following have a good chance of success in the short to mid term if sufficient $R \& D$ resources are devoted to their development.

- Bioprocesses for syngas/methanol to oxygenated fuel/octane enhancers

- Pyritic desulfurization of high sulfur coal

- Anaerobic bioprocessing of oxygenated (low rank) coals

- Bioremediation of toxic wastes from fossil fuel processes 


\section{Chapter 16}

\section{APPLICATION OF ANALYTICAL INSTRUMENTATION TO EVALUATE BENEFICIATION OF FOSSL FUELS BY BIOLOGICAL SYSTEMS.}

\subsection{INTRODUCTION.}

The bioprocessing of fossil fuels offers a potential cost-effective alternative to ever more expensive recovery of the diminishing supplies of high grade oil. Fossil fuels such as coal, heavy oil, shale oils, tar sands, and asphaltenes are a large and relatively untapped domestic resource that does not involve complex interactions with unstable governments in the Middle East and elsewhere. The lack of utilization of these North American resources rests with the cost of beneficiation, environmental problems associated with the recovery and the ability of the oil producing countries to maintain the costs of oil just below that which would stimulate development of these resources. The problem to be addressed herein is the development and utilization of analytical tools to assess the bioprocessing of fossil fuels.

The area of natural gas processing is a special subset of the analytical problems addressed in this section. Instrumentation and technology for identifying components and processing of natural gas and biologically-generated methane are currently available, so significant progress in the application of biotechnology to the resource would not be significantly limited by instrumentation.

\section{SUMMARY.}

Bioprocessing offers potential economic advantages in the beneficiation of fossil fuels and natural gas. To compensate for market price decreases ever more efficient and low-capitalintensive processes must be developed. This requires better analytical structure determinations for these complex polymers so appropriate beneficiation responses can be detected rapidly, quantitatively, and at high sensitivity. If this process can be done non-destructively and on-line, it will be possible to more rapidly determine the specific conditions for optimization of the process streams. These on-line, non-destructive processes require validation by high resolution analyses that are destructive in many cases. An ideal situation subtends if the shifts in microbial ecology or key parameters of the biological consortia can be monitored in the same microcosms (bioreactors) as the beneficiation process itself. The utilization of genetically engineered "reporter" strains containing the lux gene cassette, which bioluminesce when specific genes are activated, offers an on-line means to monitor ecological processes in the same system utilized for the beneficiation processes. These processes can be coupled to on-line electrochemical, mass related, and spectroscopic determinations of a beneficiating microbial consortia. These 
same technologies can be utilized to monitor microbially-influenced corrosion and to provide a multitrophic level of toxicity assessment.

\subsection{STATUS OF BASIC AND APPLIED RESEARCH.}

\section{BACKGROUND.}

The analytical technology for the residue fossil fuels is so immature that much of the research on biodesulfurization is done on surrogates such as dibenzothiophene. Utilizing pure compounds or mixtures of compounds that are not in a complex matrix such as coal means that problems of bioavailability and effects of competition and inhibition are not addressed. This is further complicated by the enormous heterogeneity in the distribution of the various components between different geological horizons and even in the microscale in the samples utilized for analysis. There are markedly different organic/inorganic ratios and degrees of diagenesis with attendant polymerization that add complexity to the analysis. One solution is to triturate the sample and attempt to homogenize the components so some measure of reproducibility can be achieved. Even with homogenization the currently standard techniques defined by ASTM for the analysis of organic sulfur in coal are woefully inadequate, particularly in the reproducible estimation of organic sulfur (Friedman, 1990).

New methods are clearly necessary. This review will first consider the destructive and nondestructive methods for characterizing the residue fossil fuels (substrata). A separate section will be devoted to natural gas. New analytical methodologies will be discussed concerning the on-line monitoring of microbial communities involved in biotechnological processes. Both domestic and foreign techniques will be presented without distinction, together with a review of commercial and non-commercial methods.

\section{SUMMARY.}

This report analyzes the status of current analytical problems and available technology for the non-destructive analysis of the residue fossil fuel substrata, the high resolution destructive analyses of the residue fossil fuel substrates, the non-destructive analyses of the microbial consortia involved in biobeneficiation, the high resolution destructive analysis of the microbiota involved in biobeneficiation, and a special section on the current technology as applied to natural gas. The future for analytical instrumentation is seen in developing on-line nondestructive analysis of the substrata, preferably that which can be modified for application in laboratories conducting the research. Once promising technology is defined, these methods can be moved into pilot plants and then to processing facilities.

Nuclear magnetic resonance imaging represents a very promising on-line technology; X-ray based analysis, particularly with the high energy sources available, should simplify analysis. The on-line methodology for monitoring the ecology of monocultures or, more importantly, for microbial consortia is a second major research need. We see the utilization of various nondestructive devices that can monitor the biomass, community structure, and nutritional status of the consortia coupled with implanted genetically-engineered bacteria containing the lux gene 
cassette in specific operons that have been found to be specific in the biobeneficiation process as a critical need. The detection of these bacteria involve photon imaging detection microscopy. The electrochemical techniques of microbial-influenced corrosion could be of benefit if conducting electrodes can be utilized in the bioreactors. With these systems, the beneficiation effectiveness of specific consortia can be monitored on-line as conditions in bioreactors are modified to optimize the process.

\section{CURRENT RESEARCH DEVELOPMENTS.}

\section{NON-DESTRUCTIVE ANALYTICAL METHODS FOR THE SUBSTRATUM.}

\section{Nuclear Magnetic Resonance Spectrometry.}

The method with the greatest promise is nuclear magnetic resonance. Its principal drawback is the relatively low sensitivity and the high cost. With solid samples, the use of solid-state line narrowing techniques increases the sensitivity and allows for non-destructive analysis of the nuclear environment of active nuclei. New techniques allow examination of the various environments for ${ }^{1} \mathrm{H},{ }^{11} \mathrm{~B},{ }^{13} \mathrm{C},{ }^{15} \mathrm{~N},{ }^{17} \mathrm{O},{ }^{27} \mathrm{Al}$, and ${ }^{29} \mathrm{Si}$. These can often be studied individually, using a whole variety of techniques. Most commonly, the cross polarized, magic angle spinning technology in which the sample is centrifuged rapidly in the magnetic field to compensate for inhomogeneities in the magnetic fields is used to improve resolution. Oxides forming on the sample surfaces can be followed. Electron spin/nuclear spin double resonance, dynamic nuclear polarization when combined with magic angle spinning are good for carbon films and allow useful spectra in minutes to hours on tiny samples (Maciel et al., 1991). Specific analysis of naturally occurring ${ }^{15} \mathrm{~N}$ in the samples under various perturbation conditions can give insight into structures containing the nitrogen (Mathias et al., 1991). The resolution of solid samples is unfortunately about 100 times less than for solutions. The new imaging power coupled with newly stabilized magnetic fields of very high intensity is making this technology increasingly attractive to the study of these complex substrates. They should be ideal for following specific reactions of engineered microbes on the surfaces as they modify specific chemical bonds in processes such as desulfurization.

Cross polarized, magic angle spinning-nuclear magnetic resonance spectrometry has been used for demonstration of fungal activity (Trametes versicolor and Penicillium sp.) in the solubilization of low-rank coals to show that the process involves formation of carboxylic acids at methylene carbons (Linehan, 1990). The resulting acids are below 20,000 Daltons in molecular weight, as determined by gel permeation chromatography. Block decay ${ }^{13} \mathrm{C}$-nuclear magnetic resonance is more accurate than cross polarized, magic angle spinning-nuclear magnetic resonance spectrometry for low rank coals.

\section{Optical Spectrascopy.}

Unfortunately, the fossil fuel residue substrates are black. The blackness means that little electromagnetic energy is recovered upon excitation with photons. This is particularly critical for low energy radiation such as the infrared. The wonderful advances with Fourier transform 
infrared spectrometry (FTIR) are difficult to apply to coal, tar sands, and oil shales. Photoacoustic spectroscopy (PAS), however, is becoming increasingly more powerful. In FTIRPAS, particles of the material are irradiated in a helium atmosphere, and the spectra of the energy that re-radiates is transferred as acoustic waves to a microspeaker as the detector. With new computerized technology, this has become increasingly attractive as the shape of the particles is totally irrelevant to PAS (McClelland et al., 1991). New solid state devices may replace microphones in photoacoustic spectroscopy extending applications to liquid solutions (K. J. Schlaber, Biotronics Technology, Inc. Milwaukee, WI, personal communication).

\section{$X$-Ray Spectroscopy.}

X-ray fluorescence is an elegant means to determine heavy elemental contamination of the energy substrates. These devices are now applicable to field use, requiring a source of gamma radiation and a detector, both of which can be modified to gain sensitivity (Schindler and Tisdale, 1991). The major problem is the relatively low sensitivity of the technique; it is sensitive at levels down to tens of parts per million which is considerably above the limits for exposure set by the EPA. Capturing the vapors from filters with various types of destructive procedures is another utility for X-ray fluorescence. In this system the sensitivity is of the order of 0.2 to $1.0 \mathrm{ug} / \mathrm{cm}^{2}$ (Piorek, 1991). This corresponds to 2 to $10 \mathrm{ug} / \mathrm{m}^{3}$ of air which is below industrial standards for most metals. The most practical way to gain sensitivity is to increase the time of exposure.

The sensitivity and specificity of X-ray analysis can be increased by utilizing X-ray absorption near edge structure spectroscopy (XANES) which has been used for coal and asphaltenes (Gorbaty et al., 1990a; 1990b). These can be combined with X-ray photoelectron spectroscopy to determine directly the form of the bound sulfur in the presence of inorganic sulfur utilizing the sulfur $2 \mathrm{p}$ electrons at $164.2 \mathrm{eV}$ as the sum of thiophenes, sulfides and mercaptans. The sensitivity comes from using the high energy source at the National synchrotron light source line $\mathrm{X}-10 \mathrm{C}$. Pyrite interferences can be removed from the XANES data by subtracting the third derivative spectrum of iron pyrite from the third derivative spectrum of the fossil fuel residues. These techniques show clear evidence that the thiophenic sulfur content increases with the increase in rank of coal samples.

\section{$X$-Ray Absorption Fine Structure Spectroscopy (XAFS).}

XAFS provides insight into the electronic state and local atomic environment of the specific element in question. In theory, any element can be examined. The utilization of the synchrotron radiation source enables the utilization of a very intense X-ray source which greatly increases the sensitivity. XANES is utilized with "Edges" corresponding to $\pm 20-30 \mathrm{eV}$ of absorption edge which is unusually rich in structure with sharp peaks of electron transitions to bound levels just below the continuum, and from broader peaks from low-energy resonant scattering of photoelectrons by neighboring atomic shells. The region of XAFS is from 30 to $1500 \mathrm{eV}$ above the edge and is the extended X-ray absorption fine structure. This has the greatest potential for non-destructive, non-invasive determination of the forms of organic sulfur 
in various fossil fuel residues (Huggins et al., 1990). Various deconvoluting techniques are now being applied to fully utilize this technology.

\section{Mossbauer Spectroscopy.}

${ }^{57} \mathrm{Fe}$ Mossbauer spectroscopy provides another non-destructive means to determine the organic and inorganic sulfur content of coals and other fossil fuel residues, allowing for accurate determinations of the pyritic sulfur in coals and other products (Huggins et al., 1990). The technique is sensitive to the valence, spin, and magnetic states of iron atoms or ions.

${ }^{57} \mathrm{Fe}$ Mossbauer spectroscopy has shown that bacterial desulfurization of coal with Sulfolobus brierleyi and Thiobacillus ferrooxidans exclusively removes pyritic sulfur while the organic sulfur is not affected. With the fungus Polyporous versicolor the solubilization of coal involved calcium, chlorine and iron, while failing to show much effect on the organic sulfur (Huggins et al., 1990).

\section{DESTRUCTIVE ANALYTICAL METHODS FOR THE SUBSTRATUM.}

There have been significant advances in means of preparation or extraction of various components that can be applied to coals, tars or oil shales.

\section{Supercritical Fluids.}

A most exciting new development is the application of supercritical fluid extraction. Supercritical fluids have low viscosity and high diffusivity with properties more like gases than liquids. The most used agent is supercritical-carbon dioxide which, unfortunately, is relatively non-polar, exhibiting the solvating power of hexane. There is significant research on making supercritical$\mathrm{CO}_{2}$ more effective by adding modifiers such as alcohols, aldehydes, and surfactants in various combinations. Many of these adjuvants and modifiers, however, compromise the utility of the flame ionization detector. The major utility of the flame ionization detector is that it sees analytes but not products of combustion such as carbon dioxide or water. Many of these additives will also interfere with ultra violet detection. The volatility of the supercritical fluids make them ideal for various types of "smart detectors" such as flame ionization detectors, photoionization detectors, inductively-coupled plasma detectors, mass spectrometers, matrixassisted FTIR, surface enhanced Raman spectrometry (SERS), near infrared, atomic emission detectors, sulfur chemiluminescence detectors, and induced fluorescence detectors.

\section{Thermal Analysis.}

There is new life in thermal destruction techniques such as thermal analysis, with the coupling to various of the smart detectors in place of the traditional thermogravimetric analysis. Coupling multiple non-destructive instruments in series provides an information density that increases with the power of the number of different stages rather than a simple additive relationship. It should be possible to couple thermal analysis to gas chromatography, FTIR, atomic emission spectrometers or mass spectrometers, for example. Thermal analysis has been made more reproducible by carefully controlling the pressure (Kehl et al., 1991). The utilization 
of the exponentially multiplicative power from directly coupled techniques has drawbacks. Utilization of the enormous power in these coupled techniques requires extremely sophisticated computer programming. As an example of the computer programming requirements, Hewlett Packard required 4 years to manufacture a gas chromatography-FTIR-mass spectrometer data system able to integrate information from each technique into a single report. The system, when finally marketed, required a more sophisticated computer than their powerful "chem station". Thermal analysis after pyrolysis with smart detectors also gives structural insights (Carangelo et al., 1991; Dawes et al., 1991; Wiebolt et al., 1991).

\section{Laser Desorption.}

In vacuum or with specifically controlled atmospheres, new technologies such as laser desorption with ultra violet specific lasers can selectively volatilize aromatics hydrocarbons at surfaces. Fast atoms or ions focused by a gun onto surfaces may be utilized to liberate ionized molecules from materials such as phospholipids or neutral molecules that can subsequently be ionized by laser pulses. This technology is most often applied in mass spectrometry. Fast atom bombardment takes advantage of matrix effects to provide a continuous stream of ionized molecular ions and fragments from tiny surface targets. These techniques have been utilized to map surfaces with raster controlled ion guns and time-of-flight mass spectrometers. Organic secondary ion mass spectrometry (SIMS) may be important in defining the heterogeneity at surfaces of tars and coals.

The application of classical chemical depolymerization with careful chromatography and simple detectors can yield incisive information about structural changes mediated by biological processes (Carlson et al., 1991). Dry standard coals were extracted with tetrahydrofuran and the soluble products fractionated into aliphatics, aromatics, and polar components on alumina. The residue was depolymerized with ferric chloride intercalated and heated in $10 \% \mathrm{KOH}$ in methanol at $250-275^{\circ} \mathrm{C}$. The residue was an ash. The solubilized material was again fractionated into aliphatics, aromatics, and polar fractions. Each fraction was analyzed by capillary gas chromatography with flame ionization detection. As the rank of tested Argonne standard coals increased, progressively less biological markers appeared in the extracts, and more of the components were linked in the depolymerized fractions. As the coal rank increased, there were progressively more aliphatic carbons. Application of smart detectors to these types of studies could yield much greater structural insight into transformations wrought by biological agents.

\section{Separation Technologies.}

Capillary gas chromatography leads all technologies in its diverse applicability. It requires that the analyte be made volatile. A new high temperature gas chromatograph, the Varian 3410 , operates at temperatures greater than $500^{\circ} \mathrm{C}$. Unfortunately, column technology limits exploitation of this temperature range.

Smart detectors make capillary gas chromatographic technology ever more valuable. Little can displace the flame ionization detector with its 7 orders of magnitude of linear response plus low cost and reliability. 
High pressure liquid chromatography is more effective with less volatile materials, but the relatively low volatility of the liquid mobile phase presents problems with many of the "smart detectors". One elegant solution to removal of the liquid (mobile phase) is the particle beam apparatus. The sample is nebulized upon elution into a stream of gas that is surrounded by an annular inert gas flow. The analyte stream is drawn into an evacuated chamber, and the solvents and gases are skimmed by differentially pumped skimmers as inertia draws heavier analytes through narrow openings into a high vacuum environment. Recent design modifications have increased the efficiency of the particle beam interface so it now allows regular subnanogram sensitivities when used with liquid chromatographic electron impact mass spectrometry.

Possibly the most powerful new technology in mass spectrometry is the electrospray technique. J. B. Fenn of Yale discovered that, when aqueous solutions were nebulized into a chamber with a KV potential, charged droplets were generated. These droplets could be stripped of water when passed through inertial skimmers with the formation of microparticles, most of which contained a single molecule of the analyte. The microparticulates concentrated the charges generated by the potential, so multiple charged molecules were drawn into the vacuum of the mass spectrometer. Since the mass range of mass spectrometers is actually mass/charge, it was suddenly possible to investigate macromolecules of high molecular weight. It proved very simple to define the actual charge, and so the mass could be determined. This made it possible to determine the mass to one AMU of polymers with molecular weights of up to 150,000 with quadrupole and ion trap mass spectrometers. It is possible to sequence peptides with mass spectrometers. The effects of substrate binding to enzymes and mass changes in enzyme substrate complexes are now readily determined by the electrospray technique. Biochemistry has now become the province of mass spectrometrists.

Supercritical fluid chromatography allows for a compromise between the liquid chromatographic and gas chromatographic resolutions. Supercritical fluid chromatography can use both liquid chromatography and gas chromatography detectors. The problems with supercritical fluid chromatography have been in releasing the high pressure prior to detection. The tendency to plug with the expansion induced cooling has been alleviated by using heated uniform restricters just prior to the detectors. Capillary supercritical chromatography can be directly introduced into a double pumped mass spectrometer (one that allows chemical ionization). Column supercritical chromatography eluents can be readily introduced into mass spectrometers with the particle beam apparatus.

Another powerful new separation technique is capillary zone electrophoresis. This relies on the lack of parabolic solvent front in sufficiently small capillaries to develop the highest theoretical plates for separation ever achieved. The problems are that it operates on such tiny amounts of analyte that detection becomes a problem. The use of laser fluorescence or quenching has led to attomolar sensitivities at the end of the capillary with this technique. The application of atmospheric pressure inlet mass spectrometer with glow discharge ionization has made the smart detector couple with this technology. There is still no automated way to couple the releasing technologies for the solid or semisolid tar or coals to capillary zone electrophoresis technology. 
There are other new or improved detectors to use on analytes desorbed from coal or other materials.

\section{Resonance Raman Spectroscopy.}

Resonance Raman Spectroscopy is ideal for aromatics and the excitation at $190 \mathrm{~nm}$ precludes most fluorescence (Page et al., 1991). Surface enhanced Raman spectrometry on silver microbases on an electrode offers insight as to surface orientation of specific molecules.

\section{Inductively Coupled Plasma Spectrometry.}

Inductively coupled plasma provides information on multiple ions and can be detected by spectrometry or mass spectrometry. Supersonically treating the nebulizer enhances the feasibility of analyzing oils and tars (Chan and Kwan, 1991). Inductively coupled plasma mass spectrometry allows for isotopic specificity and increases sensitivity to parts per million for multiple elements as each isotope of each element yields a single line. Supercritical fluid chromatography-inductively coupled plasma spectrometry seems to be an increasingly attractive technique. The coupling of an atomic emission detector to a capillary gas chromatograph offers data on the elemental composition of each component. The system is sensitive to $\mathrm{H}, \mathrm{C}, \mathrm{N}, \mathrm{O}$, $\mathrm{S}, \mathrm{As}, \mathrm{Ni}, \mathrm{V}, \mathrm{Fe}$, and $\mathrm{Pb}$, among others. Hewlett Packard will offer a supercritical fluid chromatography, gas extraction, FTIR, mass spectrometry, and atomic emission detector instrumentation with complete computer coupling in the future. This instrumentation, without the supercritical fluid extraction, has been used successfully in complete flavor analysis (Olson et al., 1991). Near infrared spectrometry is becoming popular, as it has windows where water interference is minimal. The near infrared is where the new charge transfer device detectors are most sensitive, and the compilations of the multiple harmonics and overlaps in this region for the various functional groups are slowly being resolved.

\section{Sulfur Chemiluminescence.}

The major new detector for the analysis of coal, oil sands, and tars is the specific sulfur chemiluminescence detector. The sulfur chemiluminescence detector fits on the flame ionization and takes the heated products into a chamber for reaction of the sulfur oxides generated in the flame ionization detector with ozone to generate the chemiluminescent SO radical. The sulfur chemiluminescence detector produces a dual flame ionization-sulfur chemiluminescent trace that allows detection of sulfur in capillary chromatography peaks. The sulfur chemiluminescence detector rejects carbon at least a million fold, becoming quite specific to sulfur. This detector is more sensitive than the flame ionization detector with linearity over several orders of magnitude. Comparisons of sulfur content in heavy oils measured by X-ray fluorescence and sulfur chemiluminescence with an internal standard showed essentially no differences. Operational parameters relating to maximum detector sensitivity are column bleed which reduces sensitivity, probe position, flame ionization detector temperature, gas flow rates, and "conditioning". These operational parameters can be controlled with sulfur chemiluminescence detectors representing a significant advance in instrumentation (Drushel et al., 1991). 


\section{TECHNOLOGIES FOR NON-DESTRUCTIVE ANALYSIS OF MICROBIOTA INVOLVED IN BIOPROCESSING.}

\section{Quartz Crystal Microbalance.}

It has been a goal to design a probe that could non-destructively monitor the formation, stability and activity of microbial biofilms in situ for on-line control of mechanical and chemical processes. The quartz crystal microbalance is an extremely sensitive device that utilizes an AT cut quartz crystal to detect thin film deposits in vacuum systems with sensitivities up to 18 $\mathrm{ng} / \mathrm{cm}^{2}-\mathrm{Hz}$. This system has been adapted to a flow-through system and has been shown to detect bacterial colonization non-destructively (White et al., 1990).

\section{Infrared Spectrometry.}

The attenuated total reflectance-Fourier transform infrared spectrometer (ATR-FTIR) determines the spectrum of adsorbent materials next to the surface of a germanium crystal that fall within the envelop of the evanescent wave. This technique has been used to detect microbial biofilms (Nichols et al., 1985; Nivens et al., 1990). The ATR-FTIR system provides both biomass estimates and evidence that under specific conditions the relative concentrations of components can change (Mittelman et al., 1990). Shifts in nutritional status by the biofilm can be readily detected with the formation of poly beta-hydroxyalkanoate by ATR-FTIR (White et al., 1990).

\section{Reporter Bacteria.}

It is possible to genetically engineer bacteria such as those involved in microbially-influenced corrosion to contain the lux cassette of genes which will exhibit bioluminescence under specific conditions (King et al., 1990). Bioluminescence is detected non-destructively as an on-line "reporter" for the presence and specific activity of that microbe in an adherent biofilm. Engineered bacteria containing the lux gene cassette in critical operons of processes that are involved in biobeneficiation of fossil energy residues will be used as "reporters" to monitor these processes, as parameters of the systems are manipulated. The engineered organisms can be incorporated into multi-species microbial consortia in biofilms on metallic surfaces and simultaneously monitored electrochemically, as the nutrient composition and electron donor/acceptors are manipulated concurrent with the biodegradation of specific components of fuel residues, be they carbon rich (toluene, benzene, xylene) or fortuitously metabolized contaminants (trichloroethylene and products). These can be monitored semicontinuously by capillary gas chromatography/mass spectrometry. The effects of these processes on the mobilization/immobilization of inorganic elements $(\mathrm{S}, \mathrm{Hg}, \mathrm{Cr}, \mathrm{Pb}, \mathrm{Cu})$ or radioactive surrogates (Sr, Co, Cs) can be monitored by inductively coupled plasma atomic absorption. "Reporter" bacteria with lux in naphthalene biodegradation pathways are available (King et al., 1990). New genetic constructs can be sought in toluene or methane oxygenases involved in fortuitous degradation, in the synthesis of the endogenous storage material poly beta-hydroxy alkanoate (PHA), or the uronic acid containing extracellular polysaccharide polymers. The systems shown to be effective in biodegradation/immobilization in the flow-through microcosms can be isolated 
in flow-through chambers which would be separated from the environment. The bioluminescence in the isolation chamber will be monitored remotely through a fiberoptic cable and photon counting system. These techniques would be utilized in wells or bioreactors to provide continuous in situ "reporting" for effects of manipulations of nutrients, water, and electron donors/acceptors in situ subsurface treatment systems for beneficiation techniques.

The genetically engineered bacteria with the lux gene cassette in a specific operon involved in a biobeneficiation process such as the hydrolysis of polynuclear aromatic hydrocarbons provides a means to test the bioavailability of these insoluble hydrocarbons to the enzymes of the bacteria under the conditions of the processing technology. This technology is totally nondestructive and represents a convenient means for optimizing the conditions during the bioremediation process.

\section{Potentiometry.}

The colonization of a mild steel electrode by bacteria results in a 300 to $500 \mathrm{mv}$ more negative potential relative to a standard calomel electrode (Dowling et al., 1989). In a flowing, continuous culture apparatus the increasingly negative open circuit potential paralleled the increase in bacterial colonization of the electrode (Jack, 1990).

Corrosion rates of metals in terms of the corrosion current density can be determined by the polarization resistance that is traditionally measured by perturbing the system above and below the corrosion potential. Linear polarization measurements assume there are no capacitive effects and, unfortunately, irreversibly damage microbial biofilms. Electrochemical impedance spectroscopy, if performed as $\pm 5 \mathrm{mV}$ (rms) sinusoidal potential perturbation over a frequency range of $10 \mathrm{KHz}$ to $3 \mathrm{mHz}$, does no detectable damage to the biofilm (Dowling et al., 1988), provides insight into both resistive and capacitive aspects of surface electrochemical activity, and gives indications of localized pitting corrosion by shifts of the maximum phase angle between applied potential and induced current to lower frequencies (Dowling et al., 1989; Oltra and Keddam, 1988). Electrochemical impedance spectroscopy is a non-destructive measure of the average corrosion rate based on polarization resistance as well as indications of localized corrosion. This technique offers a non-destructive indicator of microbial activity by the biofilm attached to the electrode.

\section{DESTRUCTIVE TECHNOLOGIES FOR THE DETECTION OF MICROBIAL COMMUNITY STRUCTURE, BIOMASS AND NUTRITIONAL STATUS.}

Techniques have been developed and validated for assays of the microbial biofilms utilizing gas chromatography-mass spectrometry to measure "signature" lipid biomarkers to define microbial consortia in which the bias of cultural selection of the classical plate count is eliminated. Since the total community is examined in these procedures, without the necessity of removing the microbes from surfaces, the microstructure of multi-species consortia is preserved.

The gas chromatography-mass spectrometry method involves the measurement of biochemical properties of the cells and their extracellular products. Those components generally distributed 
in all life forms are utilized as measures of biomass. Components restricted to subsets of the microbial communities are utilized to define the community structure. The concept of "signatures" for subsets of the community based on the limited distribution of specific components has been validated by using antibiotics and cultural conditions to manipulate the community structure. The resulting changes agreed both morphologically and biochemically with the expected results (White et al., 1980). Other validation experiments involved isolation and analysis of specific organisms and finding them in appropriate mixtures, utilization of specific inhibitors and noting the response, and changes in the local environment, such as the light intensity, are summarized in reviews (White et al., 1985, White, 1983, White, 1986a, White, 1986b).

Phospholipids are found in the membranes of all cells. Under the conditions expected in natural communities, the bacteria contain a relatively constant proportion of their biomass as phospholipids (White et al., 1979c). Phospholipids are not found in storage lipids and have a relatively rapid turnover in some sediments, so the assay of these lipids offers a measure of the "viable" cellular biomass (White et al., 1979b).

The ester-linked fatty acids in the phospholipids (PLFA) are both the most sensitive and the most useful chemical measures of microbial biomass and community structure thus far developed (Bobbie and White, 1980, Guckert et al., 1985). The specification of fatty acids that are ester-linked in the phospholipid fraction of the total lipid extract greatly increases the selectivity of this assay as most of the anthropogenic contaminants, as well as the endogenous storage lipids, are found in the neutral or glycolipid fractions of the lipids. By isolating the phospholipid fraction for fatty acid analysis, it proved possible to show bacteria in the sludge of crude oil tanks. The specificity and sensitivity of this assay has been greatly increased by the determination of the configuration and position of double bonds in monoenoic fatty acids (Edlund et al., 1985, Nichols et al., 1985, Nichols et al., 1986) and by the formation of electron capturing derivatives which, after separation by capillary gas chromatography, can be detected by negative chemical ionization mass spectrometry at femtomolar sensitivities (Odham et al., 1985). This makes possible the detection of specific bacteria in the range of 100 to 1000 organisms. By utilizing fatty acid patterns of bacterial monocultures, Myron Sasser of the University of Delaware, in collaboration with Hewlett Packard, has been able to distinguish between over 8000 strains of bacteria (Sasser, 1985). Thus, analysis of the fatty acids can provide insight into the community structure of microbial consortia as well as an estimate of the biomass.

The nutritional status of certain bacteria in biofilms can be related to shifts in the metabolic activities that could potentiate corrosion processes. The nutritional status of microbial consortia can be estimated by monitoring the proportions of specific endogenous storage compounds relative to the cellular biomass. Certain bacteria form the endogenous lipid poly betahydroxyalkanoate (PHA) under conditions when the organisms can accumulate carbon but have insufficient total nutrients to allow growth with cell division (Nickels et al., 1979). PHA is readily detected non-destructively and on-line by ATR-FTIR (White et al., 1990).

A second measure of community nutritional status is the formation of extracellular polysaccharide glycocalyx. Uronic acid-containing glycocalyx forms maximally in the marine 
Pseudomonas atlantica under conditions of nutritional stress (Uhlinger and White, 1983). Uncontaminated subsurface aquifer sediments contain microbiota with very high levels of extracellular polysaccharides, indicating poor nutrient conditions (White, 1983). Excessive amounts of these exopolymers are not formed when nutrients are added to sub-surface sediment microcosms (Balkwill and White, 1987). These polymers form on the surfaces of metals exposed to rapidly flowing seawater and may be responsible for inducing reversible acceleration of corrosion (Nivens et al., 1986).

Starvation induces the formation of minicells in some marine bacteria. There is a loss of cell components, including the membrane lipids, but there is a marked increase in the proportion of monoenoic PLFA with the double bond in the trans configuration (Guckert et al., 1986; Hood et al., 1986). The accumulation of this trans monoenoic PLFA synthesized from ${ }^{14} \mathrm{C}$ acetate has been shown in natural communities of pelagic marine organisms (Guckert et al., 1987).

\section{SPECIFIC ANALYSES OF COMPONENTS IN NATURAL GAS.}

Natural gas provides a distinctive substratum for biotechnological manipulation. The components are volatile and thus are available for capillary gas chromatographic analysis. A most exciting technology in terms of sensitivity, resolution, and information is the combined technologies of capillary gas chromatography with FTIR in which the components are deposited on a liquid nitrogen cooled germanium plate in microspots for analysis with transmission by a FTIR microscope. The cold temperature provides matrix assistance. The non-destructive nature of the analysis means that the system can gather signal over as long a time as is necessary for the analysis. This allows for signal recovery from noise and provides enormous sensitivity. The sharp bands from the cooled spectra give great structural information.

Capillary gas chromatography can be coupled to the new ion trap mass spectrometer which now provides a more sensitive and less expensive means for mass spectral information. Both the FTIR and the ion trap mass spectrometer (ITMS) provide the Fellgate advantage by monitoring all mass units or spectral frequencies continuously (not one band at a time as with classical technologies). The ITMS also makes possible $\mathrm{MS}^{\mathrm{n}}$ which gives detailed structural information as well. The new technologies available in this exciting development are reviewed by Cooks et al. (1991). These instruments will be developed to the point that they can be utilized as dedicated monitoring devices. The ITMS system has been utilized for the identification and quantification of volatile components in the air by passing a helium stream through a soil sample with the detection of traces of specific organic compounds (Wise et al., 1990).

\subsection{FUTURE RESEARCH DEVELOPMENTS AND REQUIREMENTS IN ANALYTICAL TECHNOLOGIES.}

\section{RELEVANCE AND JUSTIFICATION.}

The principal limitation in current technology involving the beneficiation of coal, tar sands, heavy oils, shale oils, asphaltenes, and resin oils is the inability to determine the quantitative effects of various treatments or processes on the complex substrata. Without accurate estimates 
of organic sulfur there can be no demonstration that specific processes are effective. The great potential of genetic manipulation cannot be realized unless there is a means to quantitatively assess the results of each experiment.

The paucity of adequate methodology for analysis has been emphasized in the EPRI sponsored First International Symposium on the Biological Processing of Coal (see Friedman, 1990).

\section{RESEARCH NEEDS, JUSTIFICA1'ION AND LIMITATIONS.}

There is a specific need for non-destructive analysis of the complex substrata that can provide a comprehensive analysis of the substratum. The marked heterogeneity of the system, particularly in the solid residue samples like coals, tar sands, or shale oils, make this analysis particularly difficult as the conditions and the concentrations of specific contaminants or inhibitors have a widely varying distribution. New technologies that provide for imaging the distribution of specific components in the samples are particularly important. The powdering of samples is often inadequate to provide the homogeneity necessary for analysis. The new developments in nuclear magnetic resonance imaging offer a particularly important new field for research as the technology can follow on-line chemical processes, provided the concentrations are high enough. Research on ever-stronger and better controlled magnetic fields is of prime importance.

The new X-ray techniques are valuable for specific specimens. The requirement for synchrotron $\mathrm{X}$-ray source is a marked limitation. The possibilities of new, more sensitive detectors and radioactive sources of gamma irradiation could lead to the development of this technology, so it could be used in the laboratory or even in the field with suitable precautions.

The advent of new extraction techniques such as supercritical fluid extraction with specific additives and polar modifiers and for specific reactions in the supercritical state could make analyses more feasible. The power of the new hyphenated technologies already offer exciting possibilities for extracted components.

In the analysis of the microbiota involved in the biobeneficiation process, the genetic engineering of bacteria to contain the lux cassette of genes in specific operons offer a powerful new technology if it can be coupled to the detection of the individual bacteria. This would provide specific on-line information of the process activity in specific sites of the heterogeneous substrata. Such an apparatus is now possible. The instrument is based on a microscope with long focal length objectives that will focus photons from bioluminescence produced when the lux gene cassette is activated onto an enhanced photon-counting imaging (PCI) camera with associated image processing computer. The computer will process the image to map the localization of the active bacteria in time and space. Epifluorescence and reflective Normarski will allow other components of the consortia to be monitored. The substratum could be supplied in a system containing a working electrode surface in a laminar flow chamber for concomitant electrochemical analysis, as the biofilm activities are manipulated by changes in the bulk phase chemistry. 
The PCI microscope system would allow for the on-line monitoring of the effects of specific localization of different types of bacteria in consortia on the biobeneficiation for the first time. In most research to date, the inappropriate analytical chemistry on the substratum is coupled with utilization of monocultures of bacteria. Monocultures are essentially not found in natural systems. These organisms, including genetically engineered organisms, should be used in consortia as they exist in nature. This provides the wide metabolic versatility and the resilience that is necessary for the wide application of biotechnology to biobeneficiation.

Consortia recovered from the natural sites of fossil fuel residues would be a prime candidate. The biodegrading consortia from the tar-sands of Canada and Alaska would be suitable first candidate.

The various consortia could be examined using a microscope such as a Zeiss Axioplan microscope with long focal length objectives for precise focusing onto the biofilm holder. Epifluorescent illumination for acridine orange and DAPI stained cells as well as tetramethylrhodamine and fluorescein labeled oligonucleotides complementary to 16S RNA sequences and reflection Normarski allow for the mapping and identification of biofilm organisms which are not bioluminescent. Phase transmission optics are available for examination of the biofilm after embedding in plastic and recovery from the metal coupon. This system is a highly stable platform with sharp focus and the best light gathering system for the photon counting imaging camera, and it is capable of simultaneous epifluorescent and reflective Normarski.

The Hamamatsu C24000-20 photon counting imaging ( $\mathrm{PCI}$ camera is designed for applications that visualize light levels too low for ordinary vidicon cameras (Wick, 1989) and require readout speeds too fast for charge transfer device cameras. In experimental situations where photon flux is very low, two approaches have been utilized to detect incident photons with imaging cameras. The approach utilized in a charged transfer camera is to collect electrons or holes generated by the incident photons. This process involves cooling the charged transfer device chip to reduce dark currents, allowing the system to integrate charge over long periods of time. The second approach, which is unique to the PCI cameras, requires the incident photons to generate photoelectrons which are amplified by a two channel microplate for conversion to photons on a phosphorscreen. The photons are then counted with a low lag vidicon camera only if the charge packets are greater than a threshold value. The quantum efficiency of the PCI system is about 0.2 compared to 0.6 for a cooled charged transfer device. This relative inefficiency for $\mathrm{PCI}$ is more than compensated for by the much higher processing speed. Liquid nitrogen cooled charged transfer device cameras (which essentially cost the same) are more effective if higher photon fluxes can be integrated over time. If the photon flux is less than the noise, it will not be detected. In astronomy, the slower speeds of charged transfer devices are compensated for by allowing longer times for accumulation of charges in each component. The break-point for a charged transfer device versus a PCI is in terms of minutes at reasonable photon flux levels. Microbes in biofilms move in position or change the photon flux in times of minutes in the system under consideration here. The chemiluminescence utilized to detect the position of specific bacteria with the ester-linked acridinium DNA probes for 16S RNA lasts $\sim 2$ seconds. 
The Hamamatsu PCI consists of a photocathode with a two stage microchannel plate intensifier capable of $\sim 10^{8}$ amplification which projects the amplified cascade of photoelectrons onto a phosphorscreen on which a low lag vidicon camera is focused. When the output of the luminescence is so low that the image is no longer continuous but consists of individual temporally and spatially distinct photons, it is essentially impossible to detect light as an analogue quantity. In this system, each point of light represents a single photon and the image is acquired by recording the number of photons at each point in the image, over a period of time. In this system, each photon is not counted as a voltage (intensity) but as the presence or absence of a photon in the same way as the eye records images. The PCI system requires a digital imaging processor which allows for the signal to accumulate the image over time and allows analysis functions for quantitative evaluation of images, grey level manipulation, pseudocolor display, and image superposition. Preprocessing the video signal provides two important functions. First, it allows discrimination between the photon signal and the low amplitude noise contribution from the image intensifier and the video system. By digitizing the video signal to a significant number of bits, the threshold can be set to discriminate against the noise. The discriminator also increases the spatial resolution of the system, as the output phosphor displays a Gaussian intensity profile which represents multiple pixels in the image memory. Increasing the discrimination decreases the pixels for each spot intensity. To fully utilize the single photon detection capability of the system, high speed computer processing must be utilized.

The bioluminescent bacteria have an output in a broad band between 478 and $505 \mathrm{~nm}$ (maximum $497 \mathrm{~nm}$ ) with a yield of between $10^{3}$ to $10^{5}$ quanta/s/cell (in all directions). In the past, mixed bacterial type biofilms in flow chambers have been about 10-15 um thick and the biofilm essentially transparent. The chemiluminescent system that is used in the Gen-probe acridinium-ester-labeled DNA probes to 16S RNA sequences with the addition of base has a spectral band between 400 and $450 \mathrm{~nm}$ with a maximum at $430 \mathrm{~nm}$ with between 20 to 1000 photons/s/cell with a $2 \mathrm{~s}$ reaction time after flooding with base and hydrogen peroxide. This is based on their being between 1000 and $10^{5}$ acridinium moieties intercalated per bacterial cell and a $10 \%$ quantum efficiency during a $2 \mathrm{~s}$ time course. The Hamamatsu PCI system has been utilized to detect individual bioluminescent bacteria (Wick, 1989).

The Hamamatsu Argus-50 image processor integrates through an RS-232C interface to a IBM PS/2 80486 computer. This consists of a M4414 frame memory board, a M4416 large storage capacity board and center of gravity detector board, the photon counting software, and a macro imaging chamber. The macro imaging chamber allows the direct observation of a field $200 \mathrm{x}$ $200 \mathrm{~mm}^{2}$. This software/hardware allows for calculation of the centroid or center of gravity of the output spots. This calculation further increases the spatial resolution and provides for a quantitative relationship between the photons detected and the pixels addressed. The center of gravity processing system, when used with a Zeiss microscope, provides excellent resolution with the 40x planneofluor objective (Wick, 1989).

\subsection{RECOMMENDATIONS AND PRIORITIES.}

It is clear that there are some research areas that seem to be less productive than others. The utilization of surrogates for specific compounds such as dibenzothiophene for organic 
sulfur in coals seems to be a less than critical pathway for major breakthroughs. The utilization of monocultures for the complex requirements seems to be also a less productive process.

Clear needs are for support of on-line, non-destructive analytical methods to detect and monitor changes occuring in fossil fuels which are effected by biological agents. Nuclear magnetic resonance spectrometry appears very promising, as does the continued development of X-ray technologies for substratum characterization. Use of flow systems where products can be identified on-line are critical as conditions for biobeneficiation are modified. The ion trap mass spectrometry with capability for $\mathrm{MS}^{\mathrm{n}}$ needs development and implementation. On-line capillary gas chromatography with the FTIR collection system for matrix assisted analysis would be excellent. The specific analysis of sulfur with capillary gas chromatography-sulfur chemiluminescence detectors is immediately applicable. The new technologies of inductively coupled plasma detectors-mass spectrometers or gas chromatographic-atomic emission detectors for on-line monitoring could be applied immediately if the resources were available.

The monitoring of the active consortia involved in the biobeneficiation could also be improved significantly by resource application to the development of genetically engineered "reporter" strains with the $l u x$ cassette in the proper operons (with the subsequent validation that the bioluminescence indicates the specific activity and not others). This needs to be coupled with technologies that allow on-line monitoring of the bioluminescent light such as the photon counting microscope. Other non-destructive monitoring devices such as the quartz crystal microbalance, ATR-FTIR, the open circuit potential, electrochemical noise, and the electrochemical impedance spectroscopy can be readily done. Specific optrodes in which dyes sensitive to $\mathrm{E}_{\mathrm{h}}$ or $\mathrm{pH}$ can be covalently linked to fiberoptic probes, and the local environment around the optrode monitored by the fluorescence changes resulting from microbe induced changes in the microenvironment could be developed based on on-going research. These could help develop critical parameters associated with successful biobeneficiation.

The potential of surface enhanced Raman spectroscopy could be very useful in determining the molecular interrelationships between the effective bacteria and the complex residues involved with these fossil fuels. We have the opportunity to apply innovative biotechnology if the appropriate analytical tools are available. 
- Improve non-destructive techniques and analytical instrumentation for direct on-line analysis of complex substrata undergoing biological modification(s).

- nuclear magnetic resonance imaging spectrometry (NMR)

- X-ray fluorescence spectrometry (XRF)

- X-ray absorption near-edge structure spectroscopy (XANES)

- quartz crystal microbalance (QCM)

- attenuated total reflectance - FTIR spectrometry (ATR-FTIR)

- "reporter" bacteria coupled to enhanced photon-imaging/photon image processing computer

- electrochemical impedance spectroscopy (EIS)

- Improve destructive techniques coupled to "smart-detector" analytical systems for on- line analysis of complex substrata undergoing biological modification(s).

- supercritical fluid extraction (SFE)

- flame-ionization detectors (FID)

- photoionization detectors (PD)

- inductively-coupled plasma detectors (IPC)

- mass spectrometry (MS)

- secondary ion mass spectrometry (SIMS)

- matrix-assisted FTIR

- surface enhanced Raman spectrometry (SERS)

- near infrared spectrometry (NIR)

- atomic emission detectors (AED)

- sulfur chemiluminescent detectors (SCD)

- induced fluorescence detectors (IFD)

- capillary gas chromatography (CGC)

- thermal analysis (TA)

- Develop sophisticated "smart" analytical systems through the coupling of non-destructive and/or destructive instrumentation in series to provide information densities that increase with the power of the number of different stages rather than simply additive relationships.

- thermal analysis/gas chromatography/FTIR/mass spectrometry

- gas chromatography/FTIR/mass spectrometry

- capillary gas chromatography/ion trap mass spectrometry (CGC/ITMS)

- capillary gas chromatography/FTIR (CGC/FTIR)

- capillary gas chromatography/sulfur chemiluminescence (CGC/SCD)

- inductively coupled plasma/mass spectrometry (ICP/MS)

- capillary gas chromatography/atomic emission (CGC/AED)

- enhanced fiber optic detectors 


\section{REFERENCES}

Abbott, B. J. and W. E. Gledhill (1971). The extracellular accumulation of metabolic products by hydrocarbon-degrading microorganisms. Adv. Appl. Microbiol. 14:249-388.

Abramowicz, D. A. (1990). Aerobic and anaerobic biodegradation of PCBs: a review. Crit. Rev. Biotechnol. 10:241-251.

Abril, M. A., C. Michan, K. N. Timmis, and J. L. Ramos (1989). Regulator and enzyme specificities of the TOL plasmid-encoded upper pathway for degradation of aromatic hydrocarbons and expansion of the substrate range of the pathway. J. Bacteriol. 171:6782-6790.

Agaev, N. M., A. E. Smorodin, and M. M. Guseinov (1985). Influence of gamma radiation on the metabolic activity of sulphate-reducing bacteria. Protein Metabol. 21:11-113.

Ahlert, R. C., D. S. Kosson, W. V. Black, and J. E. Brugger (1991). Slurry-based biotreatment of contaminants sorbed onto soil constituents. Abstracts of the Battelle Symposium, In Situ and On-Site Bioreclamation, San Diego, CA.

Akin, D. F. (1980). Attack on lignified grass cell walls by a facultatively anaerobic bacterium. Appl. Environ. Microbiol. 40: 809-820.

Al-Bashir, B., R. Leduc, T. Cseh, and R. Samson (1990). Effect of soil/containment interactions on the biodegradation of naphthalene in flooded soil under denitrifying conditions. Appl Microbiol. Biotech. 34:414-419.

Aldercreutz, P. and B. Mattiason (1987). Aspects of biocatalyst stability in organic solvents. Biocatalysis. 1:99-103.

Amy, G. L., R. M. Narbaitz, and W. J. Cooper (1987). Removing VOC's from groundwater containing humic substances by means of coupled air stripping and adsorption. J. Am. Water Works Assoc. 49:54.

Amos, D.A. and M. J. McInerney (1991). Composition of poly- $\beta$-hydroxyalkanvate from Syntrophomonas, Wolfei grown on unsaturated fatty acid substrates. Arch. Microbiol. 155:103-106.

Anderson, AJ. and E. A. Dawes (1990). Occurrence, metabolism, metabolic role and industrial uses of bacterial PHA. Microbiol. Rev. 54:450-472.

Anderson, D. J. and M. E. Lidstrom (1988). The moxFG region encodes four polypeptides in the methanol-oxidizing bacterium Methylobacterium sp. Strain AM1. J. Bacteriol. 170:2254-2262.

Anderson, M., R., B. R. Mattes, H. R'eiss, and R. B. Kaner (1991). Conjugated polymer films for gas separations. Science 252: 1412-1415.

Andrews, G. (1988). Fluidized-bed bioreactors. Biotechnol. Genet. Engin. Rev. 6:151-178. 
Andrews, G. (1989). Minimizing the cost of coal biodesulfurization. 6th Annual Pittsburgh Coal Conference.

Andrews, G. (1990). Large scale bioprocessing of solids. Biotechnol. Prog. 6:225-230.

Andrews, G., C. J. Stevens, J. Quintana, and P. R. Dugan (1990). Oxygen transfer problems in coal processing bioreactors. Proc. of 7 th Annual Pittsburgh Coal Conference.

Andrews, G. and J. Quintana (1990). Mixing and mass transfer in the aerated trough bioreactor. Proceedings First International Symposium on the Biological Processing of Coal. Electric Power Research Institute. pp. 5.71-5.85.

Andrews, G. (1989). Reactors for scaling-up coal bioprocessing. Proceedings 1989 Symposium on biological processing of coal and coal-derived substances, Electric Power Research Institute, Palo Alto, CA. pp. 2.1-2.16

Andrews, G., M. Darroch, and T. Hansson (1989). Bacterial removal of pyrite from concentrated coal slurries. Biotech. Bioeng. 32:813-820.

Anthony, C. (1975). The microbial metabolism of C1 compounds: the cytochromes of Pseudomonas AM1. Biochem. J. 146:289-298.

Anthony, C. (1982). The biochemistry of methylotrophs. Academic Press, London.

Anthony, C. and L. J. Zatman (1964). The microbial oxidation of methanol 2: The methanoloxidizing enzyme of Pseudomonas sp. M27. Biochem. J. 92:614-621.

Antonini, E., G. Carrea, and P. Cremonesi (1981). Enzyme catalyzed reactions in water-organic solvent two-phase systems. Enzyme Microb. Technol. 3:291.

Armstrong, J.M., R. H. Douglass, and W. M. Korreck (1991). Design of a packed column bioreactor for on-site treatment of air stripper off-gas. Abstracts of the Battelle Symposium, In Situ and On-Site Bioreclamation. San Diego, CA.

Atlas, R. M. (1984). Petroleum Microbiology. MacMillan Publishing Co., New York, N.Y. Chapters $8,9,10,11,12,14,15$.

Bache, R. and N. Pfennig (1981). Selective isolation of Acetobacterium woodii on methoxylated aromatic acids and determination of growth yields. Arch. Microbiol 130:255-261.

Baedecker, M. J., D. I. Siegel, P. C. Bennett, and I. M. Cozzarelli (1989). The fate and distribution of crude oil in a shallow aquifer. I. The distribution of chemical species and geochemical facies. In: U. S. Geological Survey Toxic Substances Hydrology Program --(G. E. Mallard and S. E. Ragone, eds.). U. S. Geological Survey Water Resources Investigation Report 88-4220. pp. 13-20.

Bailey, J.E. (1991). Towards a science of metabolic engineering. Science, in press.

Bak, F. and F. Widdel (1986a). Anaerobic degradation of indolic compounds by sulfate-reducing enrichment cultures, and description of Desulfobacterium indolicum gen. nov. sp. nov. Arch. Microbiol. 146:170-176. 
Bak, F. and F. Widdel (1986b). Anaerobic degradation of phenol and phenol derivatives by Desulfobacterium phenolicum sp. nov. Arch. Microbiol. 146:177-180.

Bakker, G. (1977). Anaerobic degradation of aromatic compounds in the presence of nitrate. FEMS Lett. 1:103-108.

Balba, M. T. and W. C. Evans (1977). The methanogenic fermentation of aromatic compounds. Biochem. Soc. Trans. 5:302-304.

Balba, M. T. and W. C. Evans (1979). The methanogenic fermentation of $\Omega$-phenylalkanecarboxylic acids. Biochem. Soc. Trans. 7:403-405.

Balba, M. T. and W. C. Evans (1980a). Methanogenic fermentation of the naturally occurring aromatic amino acids by microbial consortium. Biochem. Soc. Trans. 8:625-627.

Balba, M. T. and W. C. Evans (1980b). The methanogenic biodegradation of catechol by a microbial consortium: evidence for the production of phenol through cis-benzenediol. Biochem. Soc. Trans. 8:452-454.

Balba, M. T., E. Senior, and D.B. Nedwell (1981). Anaerobic metabolism of aromatic compounds by microbial associations isolated from saltmarsh sediment. Biochem. Soc. Trans. 9:230-231.

Baldwin, B. C., M. F. Bray, and M. J. Geogdegan (1966). The microbial decomposition of paraquat. Biochem. J. 101:15.

Balkwill, D. L., F. R. Leach, J. T. Wilson, J. F. McNabb, and D. C. White (1987). Equivalence of microbial biomass measures based on membrane lipid and cell wall components, adenosine triphosphate, and direct counts in subsurface sediments. Microbial Ecology. 16:73-84.

Ball, H. A., M. Reinhard, and P. L. McCarty (1991). Biotransformation of monoaromatic hydrocarbons under anoxic conditions. Abstracts of the Battelle Symposium In situ and on-site bioreclamation, San Diego, CA.

Ballard, D. G. H., A. Courtis, I. M. Shirley, and S. C. Taylor (1983). A biotech route to polyphenylene. J. Chem. Soc. Chem. Commun. 634:945-955.

Barbaro, J. R., J. F. Barker, C. I. Mayfield, and L. Lemon (1991). A lab and field evaluation of nitrate addition as an alternate electron acceptor for the remediation of anaerobic, BTEX-contaminated groundwaters. Abstracts of the Battelle Symposium, In situ and on-site bioreclamation, San Diego, CA.

Barik, S., W. J. Brulla, and M. P. Bryant (1985). PA-1. a versatile anaerobe obtained in pure culture, catabolizes benzenoids and other compounds in syntrophy with hydrogenotrophs and P-2 plus Wolinella sp. degrades benzenoids. Appl. Environ. Microbiol. 50:304-310.

Barik, S., S. Prieto, S. B. Harrison, E. C. Clausen, and J. L. Gaddy (1988). Biological production of alcohols from coal through indirect liquefaction. Appl. Biochem. Biotechnol. 18:363-378.

Barik, S. (1990). Biological gasification of coals. Draft Final Report to US DOE. DOE-METC Contract No DE-AC21-87MC23285. 
Barik, S., J. L. Vega, E. R. Johnson, E. C. Clausen, and J. L. Gaddy (1990). Methanation of synthesis gas using biological processes. In: Bioprocessing and Biotreatment of Coal. (D.L. Wise, ed.). Marcel Dekker, Inc. New York, NY. pp. 375-392.

Barik, S., S. Prieto, S. B. Harrison, E. C. Clausen, and J. L. Gaddy (1990). Biological production of ethanol from coal synthesis gas. In: Bioprocessing and Biotreatment of Coal. (Wise, D. L. ed.). Marcel Dekker, Inc., New York, N.Y. pp. 131-154.

Barker, J. F., G. C. Patrick, and D. Major (1989). Natural attenuation of aromatic hydrocarbons in a shallow sand aquifer. Ground Water Monitoring Review. 7:64-71.

Bartha, R. (1986). Biotechnology of petroleum pollutant biodegradation. Microbiol. Ecology, 12:155172.

Bartha, R. and I. Bossert (1984). The treatment and disposal of petroleum wastes. In: Petroleum Microbiology (R. M. Atlas, ed.). MacMillan Publishing Co., New York, N.Y. pp. 553-577.

Bartseh, H., C. Malaveille, A. Barbı, and G. Planche (1979). Mutagenic and alkylating metabolism of haloethylenes, chlorobutadienes and dichlorobutenes produced by rodent or human liver tissues: Evidence for oxirane formation by cytochrome P450 linked microsomal monooxygenases. Arch. Toxicol. 41:249-278.

Batterman, G. and P. Werner (1984). Beseitigung einer Untergrundkontamination mit Kohlenwasserstoffen durch mikrobiellen Abbau. GWF - Wasser / Abwasser 125:366-377.

Bauer, J. E. and D. G. Capone (1988). Effects of co-occurring aromatic hydrocarbons on degradation of individual polycyclic aromatic hydrocarboons in marine sediment slurries. Appl. Environ. Microbiol. 54:1649-1655.

Bauman, B. J. (1989). Soils contaminated by motor fuels: research activities and perspectives of the American Petroleum Institute. In: Petroleum Contaminated Soils (Kostecki, P.T. and Calabrese, E.J., eds.). 1:3-20.

Beesch, S. (1953). A microbiological process report-acetone-butanol fermentation of starches. Appl. Microbiol. 1:85-95.

Belkin, S. and H. W. Jannasch (1985). A new extremely thermophilic sulfur-reducing heterotrophic marine bacterium. Arch. Microbiol. 141:181-186.

Benckiser, G. and J. C. G. Ottow (1982). Metabolism of the plasticizer di-n-butylphthalate by Pseudomonas pseudoalcaligenes under anaerobic conditions, with nitrate as the only electron acceptor. Appl. Environ. Microbiol. 44:576-78.

Benner, R. and R. E. Hodson (1985). Thermophilic anaerobic biodegradation of $\left({ }^{14} \mathrm{C}\right)$-lignin, $\left({ }^{14} \mathrm{C}\right)-$ cellulose and $\left({ }^{14} \mathrm{C}\right)$-lignocellulose preparations. Appl. Environ. Microbiol. 50:971-976.

Benner, R., A. E. Maccubbin, and R. E. Hodson (1984). Anaerobic biodegradation of the lignin and polysaccharide components of lignocelluiose and synthetic lignin by sediment microflora. Appl. Environ. Microbiol. 47:998-1004. 
Berry, D. F., A. J. Francis, and J. M. Bollag (1987). Microbial metabolism of homocyclic and heterocyclic aromatic compounds under anaerobic conditions. Microbiol. Rev. 51:43-59.

Berry, D. F., E. L. Madsen, and J. M. Bollag (1987). Conversion of indole to oxindole under methanogenic conditions. Appl. Environ. Microbiol. 53:180-182.

Bertrand, J. C., P. Caumette, G. Mille, M. Gilewicz, and M. Denis (1989). Anaerobic biodegradation of hydrocarbons. Sci. Prog. 73:333-350.

Best, D. J. and I. J. Higgins (1983). Methane-utilising organisms (methanotrophs) as biocatalyts. Top. Enzyme Ferment. Biotechnol. 7:38-75.

Bewersdorff, M. (1971). The use of methane for production of bacterial protein. Biotech. Bioengr. 13:49-62.

Bhadra, A., J. M. Scharer, and M. Moo-Young (1987). Microbial desulfurization of heavy oils and bitumen. Biotechnol. Adv. 5:1-27.

Bhatnagar, L., J. A. Krzycki, and J. G. Zeikus (1987). Analysis of hydrogen metabolism in Methanosarcina barkeri: Regulation of hydrogenase and role of CO-dehydrogenase in $\mathrm{H}_{2}$ production. FEMS Microbiol. Lett. 41:337-343.

Bhatnagar, L., S. P. Li, M. K. Jain, and J. G. Zeikus (1989). Growth of methanogenic and acidogenic bacteria with pentachlorophenol as co-substrate. In: Biotechnology Applications in Hazardous Waste Treatment (Lewandowski, G., A. Armenante and B. I. Baltzis, eds.). New Jersey Institute of Technology, Newark, N.J. pp. 383-393.

Bhatnagar, L., M. K. Jain, and J. G. Zeikus (1991). Methanogenic bacteria. In: Variations in Autotrophic Life (Shively, J. M., and L. L. Barton, eds.). Academic Press, Inc. New York, N.Y. pp. 251-270.

Bird, C. W. and P. M. Molton (1972). The production of fatty acids from hydrocarbons by microorganisms. Top. Lipid Chem. 6:125-169.

Bleakley, W. B. (1972). Wilmington attacks water problems. Oil and Gas J. 70:71-72.

Block, R. N., T. P. Clark, and M. Bishop (1990). Biological treatment of soils contaminated by petroleum products. In: Petroleum Contaminated Soils (Kostecki, P. T. and Calabrese, E. J., eds.). 3:167-175.

Bobbie, R. J. and D. C. White (1980). Characterization of benthic microbial community structure by high-resolution gas chromatography of fatty acid methyl esters. Appl. Environ. Microbiol. 39:12121222.

Bohanon, M. J., C. A. Bastien, R. Yoshida, and R. S. Hanson (1988). Isolation of auxotrophic mutants of Methylophilus methylotrophus by modified-marker exchange. Appl. Environ. Microbiol. 54:271-273.

Bokranz, M. and A. Klein (1987). Nucleotide sequence of the methyl coenzyme M reductase gene cluster. Nucleic Acids Res. 15:4350-4351. 
Bokranz, M., G. Baumer, R. Allmanoberger, Dankel-Fuchs, and A. Klein (1988). Cloning and characterization of the methyl coenzyme $\mathrm{M}$ reductase genes. J. Bacteriol. 170:568-577.

Bollag, J. M. and S. Russel (1976). Aerobic versus anaerobic metabolism of halogenated anilines by a Paracoccus sp. Microb. Ecol. 3:65-73.

Boogerd, F. C., P. Bos, J. G. Kuenen, J. J. Heijnen, and R. G. J. M. Van der Lane (1990). Oxygen and carbon dioxide mass transfer and the aerobic, autotrophic cultivation of moderate and extreme thermophiles: a case study related to the microbial desulfurization of coal. Biotechnol. Bioeng. 35:1111-1119.

Booth, G. H., L. Elford, and D. S. Wakerly (1968). British Corrosion 3:242.

Bos, P. and J. G. Kuenen (1990). Microbial treatment of coal. In: Microbial Mineral Recovery (Ehrlich, H.L. and Brierley, C.L., eds.). McGraw-Hill, New York, N.Y. pp. 343-377.

Bos, P., F. C. Boogerd, and J. G. Kuenen (1990). The use of moderately thermophilic sulfur-oxidizing bacteria in the desulfurization of high-sulfur coals. Proceedings First International Symposium on the Biological Processing of ,Coal. Electric Power Research Institute 3.63-3.75.

Bossert, I. and Bartha, R. (1984). The fate of petroleum in soil ecosystems. In: Petroleum Microbiology (R. ‥ Atlas, ed.). MacMillan Publishing Co., New York, N.Y. pp. 435-473.

Bossert, I. D. and L. Y. Young (1986). Anaerobic oxidation of $p$-cresol by a denitrifying bacterium. Appl. Environ. Microbiol. 52:1117-1122.

Bossert, I. D., M. D. Rivera, and L. Y. Young (1986). p-Cresol biodegradation under denitrifying conditions: isolation of a bacterial coculture. FEMS Microbiol. Ecol. 38:313-319.

Bourgeois, J. P., N. Aupaix, R. Bloise, and J. L. Millet (1979). Proposition d'explication de la formation d'hydrogene sulfure dans les stockages souterrains de gaz natural par Reduction des sulfures mineraux de la rocke magasin. Revuew de l'Institut Francais du Petrole 34:371-386.

Bouwer, E. J., B. E. Rittmann, and P. L. McCarty (1981). Anaerobic degradation of halogenated 1and 2-carbon organic compounds. Env. Sci. Technol. 15:596-599.

Bouwer, E. J. and P. L. McCarty (1984). Transformation of 1- and 2-carbon halogenated aliphatic organic compounds under methanogenic conditions. Appl. Environ. Microbiol. 45:1286-1294.

Boyd, S. A., D. R. Shelton, D. Berry, and J. M. Tiedje (1983). Anaerobic biodegradation of phenolic compounds in digested sludge. Appl. Environ. Microbiol. 46:50-54.

Braun, K. and D. T. Gibson (1984). Anaerobic degradation of 2-aminobenzoate (anthranilic acid) by denitrifying bacteria. Appl. Environ. Microbiol. 48:102-107.

Briganti, G., M. Adami, G. Di Giorgio, G. Levi, and M. Vian (1990). A biodesulfurization process for coal. Proceedings First International Symposium on the Biological Processing of Coal. Electric Power Research Institute 3.15-3.23. 
Broholm, K, B. K. Jensen, T. H. Christensen, and L. Olsen (1990). Toxicity of 1,1,1,-trichloroethane and trichlorethene on a mixed culture of methane-oxidizing bacteria. Appl. Environ. Microbiol. 56:2488-2493.

Bronchart, R. D. E., J. Cadron, A. Charlier, A. A. R. Gillot, and W. Verstraete (1985). A new approach in enhanced biodegradation of spilled oil: development of an oil dispersant containing oleophilic nutrients. Proceedings of the 1985 International oils spill conference, American Petroleum Institute, Washington D.C. pp. 453-462.

Buchner, W., R. Schliebs, G. 'Winter, and K. H. Buchel (1989). Industrial Inorganic Chemicals, VCH Publishers, New York, N.Y.

Buhler, M. and J. Schlinder (1984). Aliphatic hydrocarbons. In: Biotechnology, Vol 6a, (H.-J. Rehm and G. Reed, eds.). Verlag Chimie. pp. 329-385.

Bull, A. T. and D. J. Hardmann (1991). Microbial diversity - approaches to explore and biotechnological potential. In: Current Opinion in Biotechnology, 2. (K. Horikishi and KN. Timmis, eds.). in press.

Bussineau, C. M. and E. T. Papoutsakis (1986). Intracellular reaction rates; enzyme activities and biomass yields in Methylomonas L3: Growth rate and substrate composition effects. Appl. Microbiol. Biotechnol. 24:435-442.

Bussineau, C. M., T. A. Keuer, I. M. Chu, and E. T. Papoutsakis (1987). Effect of growth conditions on enzyme activities, intracellular kinetics and biomass yields of a new RuMP-type methylotroph (T15). Appl. Microbiol. Biotechnol. 26:61-69.

Bussineau, C. M. and E. T. Papoutsakis (1988). Evidence suggesting energy-dependent formaldehyde transport in an RuMP-type methylotroph (T15). Arch. Microbiol. 149:214-219.

Butler, J. H. A. and J. C. Buckerfield (1979). Digestion of lignin by termites. Soil Biol. Biochem. 11:507-513.

Button, D. K. B. R. Robertson, and K. S. Craig (1981). Dissolved hydrocarbons and related microflora in a fjordal seaport: sources, sinks, concentrations and kinetics. Appl. Environ. Micro. 42:708-719.

Byrom, D. (1987). Polymer synthesis by microorganisms: Technology and economics. Trends Biotechnol. 5:246-250.

Cain, R. B. (1980). Transformations of aromatic hydrocarbons. In: Hydrocarbons in Biotechnology. (D. E. F. Harrison, I. J. Higgins and R. Watkinson, eds.). Heyden \& Sons, London. pp. 99-132.

Cain, R. B. (1981). Microbial degradation of surfactants and "builder" components. In: Microbial Degradation of Xenobiotics and Recalcitrant Compounds. (Leisinger, T., A. M. Cook, R. Hütter and J. Nüesch J., eds.). Academic Press, New York, N.Y. pp. 325-370.

Carangelo, R. M., M. A. Serio, P. R. Solomon, S. Charpenay, Z. Z. Yu, and R. Bassilakis (1991). Coal pyrolysis: measurements and modeling of product evolution kinetics and char properties. Abstracts 1991 Pittsburgh Conference and exposition, Pittsburgh, PA. \# 665. 
Cardy, D. L. N. and J. C. Murrell (1990). Cloning, sequencing and expression of the glutamine synthetase structural gene ( $g \ln \mathrm{A}$ ) from the obligate methanotroph Methylococcus capsulatus (Bath). J. Gen. Microbiol. 136:343-352.

Carlson, R. E., W. P. Vorkink, M. Lee, Y. Zang, and J. Shabtai (1991). Analysis of depolymerization products of various rank coals using high resolution chromatographic techniques. Abstracts 1991 Pittsburgh Conference and Exposition, Pittsburgh, PA. \# 579.

Carrea, G., S. Riva, R. Bovara, and P. Pasta (1988). Enzymatic oxidoreduction of steroids in twophase systems: effects of organic solvents on enzyme kinetics and evaluation of the performance of different reactors. Enzyme Microb. Technol. 10:333-338.

Cerniglia, C. E. (1984). Microbial transformation of aromatic hydrocarbons. In: Petroleum Microbiology. (R. M. Atlas, ed.). MacMillan Publishing Co., New York, N.Y. pp. 99-128.

Chairprasert, A. U. Stahl, and K. Esser (1987). Life cycle, meiotic recombination and unilateral gene transfer in methanotrophic yeasts of the genus Pichia. Appl. Microbiol. Biotechnol. 27:265-271.

Chan, S. K. and W. N. Kwan (1991). Analysis of crude oils using an inductively coupled plasma with ultrasonic nebulization. Abstracts Pittsburgh Conference and Exposition. Pittsburgh, PA. \# 971.

Chandra, D., A. K Mishra, S. G. Chaudhuri, J. N. Chakrabarti, N. K. Prasad and P. Roy (1980). Removal of sulfur from coal by Thiobacillus ferroxidans and by mixed acidophilic bacteria present in coal. Fuel 59:249-252.

Chemielowski, J., A. Grossman and T. Wegrzynowaka (1964). The anaerobic decomposition of phenol during methane fermentation. Zesz. Nauk. Politech. Slask. Inz. Sanit. 8:97-122.

Chen, W., K. Ohmiya, S. Shimizu and H. Kawakami (1985a). Degradation of dehydrodivanillin by anaerobic bacteria from cow rumen fluid. Appl. Environ. Microbiol. 49:211-216.

Chen, W., K. Supanwong, K. Ohmiya, S. Shimizu and H. Kawakami (1985b). Anaerobic degradation of veratrylglycerol- $\beta$-guaiacyl ether and guaiacoxyacetic acid by mixed rumen bacteria. Appl. Environ. Microbiol. 50:1451-1456.

Chianelli, R. R., T. Aczel, R. E. Bare, G. N. George, M. W. Genowitz, M. J. Grossman, C. E. Haith, F. J. Kaiser, R. R. Lessard, R. Liotta, R. L. Mastracchio, V. Minak-Bernero, R. C. Prince, W. K. Robbins, E. I. Stiefel, J. B. Wilkinson, S. M. Hinton, J. R. Bragg, S. J. McMillen and R. M. Atlas (1991). Bioremediation technology development and application to the Alaskan spill. Proceedings of the 1991 International oils spill conference, American Petroleum Institute, Washington D.C. pp. 549-558.

Chiang, C. Y., J. P. Salanitro, E. Y. Chai, J. C. Colthart and C. L. Klein (1989). Anaerobic biodegradation of benezene, toluene, and xylene in a sandy aquifer - data analysis and computer modelling. Ground Water. 27:823-834.

Chibata, I., T. Tosa and T. Sato (1985). Immobilized biocatalysts to produce amino acids and other organic compounds. In: Enzymes and Immobilized Cells in Biotechnology. (Laskin, A.1., ed.). Benjamin-Cummings, Menlo Park, CA. Chap. 3. 
Clark, D. P. (1989): Genetic approach to microbial coal desulfurization; final report Jan-Dec, 1988. DOE Report DE89009581.

Cochrane, W. J., P. S. Jones, P. F. Sanders and M. J. Mosley (1988). Studies on the thermophilic sulfate-reducing bacteria from a souring north sea oil field. SPE European Petroleum Conference, London, UK. October 16-19. p. 301-316.

Cohen, M. S. (1990). Enzymatic solubilization of coal. In: Bioprocessing and Biotreatment of Coal (D. Wise, ed.). Marcel Dekker, Inc. New York, N.Y. pp. 253-273.

Colberg, P. J. and L. Y. Young (1982). Biodegradation of lignin-derived molecules under anaerobic conditions. Can. J. Microbiol. 28:886-889.

Colberg, P. J. and L. Y. Young (1985a). Anaerobic degradation of soluble fraction of $\left({ }^{14} \mathrm{C}\right.$-lignin) lignocellulose. Appl. Envrion. Microbiol. 49:345-349.

Colberg, P. J. and L. Y. Young (1985b). Aromatic and volatile acid intermediates observed during anaerobic metabolism of lignin-derived oligomers. Appl. Envrion. Microbiol. 49:350-358.

Colberg, P. J. (1988). Anaerobic microbial degradation of cellulose, lignin, oligolignols and monoaromatic lignin derivatives. In: Environmental Microbiology of Anaerobes. (A. J. B. Zehnder, ed.). John Wiley, New York, N.Y. pp.333-372.

Colby, J., H. Dalton and R. Whittenbury (1975). An improved assay for bacterial methane monooxygenase: Some properties of the enzyme from Methylomonas methanica. Biochem. J. 151:459-462.

Collman, J. P. and L. S. Hegedus (1980). Principles and Applications of Organotransition Metal Chemistry. University Science Books, Mill Valley, CA. pp. 454-457.

Cook, A. M., H. Grossenbacher and R. Hütter (1984). Bacterial degradation of Ncyclopropylmelamine (the steps to ring cleavage). Biochem J. 222:315-320.

Cooks, R. G., G. L. Gish, S. A. McLuckey and R. E. Kaiser (1991). Ion trap mass spectrometry. Chem. and Engineering. News. 69:26-41.

Cooper, D. G. and J. E. Zajic (1980). Surface-active compounds from microorganisms. Adv. Appl. Microbiol. 26:229-253.

Cord-Ruwisch, R. and J. L. Garcia (1985). Isolation and characterization of anaerobic benzoatedegrading spore-forming sulfate-reducing bacterium Desulfotomaculum sapomandens sp. nov. FEMS Microbiol. Lett. 29:325-330.

Cord-Ruwisch, R., W. Kleinitz and F. Widdel (1987). Sulfate-reducing bacteria and their activities in oil production. Petroleum Technol. 97:106.

Cos, D.P. and A. L. Williams (1980). Biological process for converting naphthalene to cis-1,2dihydroxy-1,2-dihydroxynaphthalene. Appl. Environ. Microbiol. 39:320-326.

Costerton, J. W. (1987). Bacterial biofilms in nature and disease. Ann. Rev. Microbiol. 41:435-464. 
Costerton, J.W., R. T. Irwin and K. J. Cheng (1981). The bacterial glycocalyx in nature and disease. Ann. Rev. Microbiol. 35:299-324.

Couch, G. R. (1990). Biotechnology and coal: a European perspective. In: Bioprocessing and Biotreatment of Coal (D. Wise, ed.). Marcel Dekker, Inc. New York, N.Y. pp. 29-55.

Crawford, D. L. (1981). Microbial conversion of lignin to useful chemicals using a lignin-degrading Streptomyces. Biotechnol. Bioeng. Symp., 11:275-291.

Crawford, D. L., R. K. Gupta, L. A. Deobald and D. J. Roberts (1990). Proceedings; Biotransformation of coal and coal substructure model compounds by bacteria under aerobic and anaerobic conditions. First International Symposium on the Biological Processing of Coal. EPRI, 4-27.

Cunningham, J. M., K A. Schatjian, C. Meyers, G. Yoshiok and J. M. Jordan (1991). Use of dispersants in the United States: perception or reality? Proceedings of the 1991 International oils spill conference, American Petroleum Institute, Washington D.C. 389-393.

Cusack, F., H. M. Lappin-Scott, S. Singh, M. de Rocco and J.W. Costerton (1990). Advances in microbiology to enhance oil recovery. Appl. Biochem. Biotech. 24:885-897.

Dagley, S. and P. A. Johnson (1963). Microbial oxidation of kynurenic, xanthurenic and picolinic acids. Biochem. Biophys. Acta 78:577-587.

Dailey, N. S. (1981). Process effluents: quantities and control technologies. In: Environmental health, and control aspects of coal conversion--an information overview, Vol. 1 (H. M. Braunstein, E. D. Conephaver and .H. A. Pfuderer, eds.). Ann Arbor Science Publ., Ann Arbor, MI. pp. 1-157.

Daniels, L., G. Fuchs, R. K. Thauer and J. G. Zeikus (1977). Carbon monoxide oxidation by methanogenic bacteria. J. Bacteriol. 132:118-126.

Darymple, D. A., F. D. Skinner and N. P. Meserole (1991). Investigation of U.S. Natural Gas Reserve Demographics and Gas Treatment Processes, Topical Report GRI-91/0019, Chicago, IL.

Datta, R. (1989). Recovery and purification of lactate salts from whole fermentation broth by electrodialysis. U.S. Patent \#4,885,247.

Datta, R. and G. Andrews (1991). Mass and energy balances for coal based microbial system. In: Second International Symposium on the Biological Processing of Coal, Workshop \#2, EPRI/DOE.

Datta, R. and J. G. Zeikus (1983). Anaerobic bioconversion of one-carbon compounds. Dev. Ind. Microbiol. 23:131-140.

Datta, R., G. Andrews, M. Worden, D. Quigley and M. K. Jain (1991). Mass and energy balances for coal-based microbial systems. Second International Conference on Coal Bioprocessing, Electric Power Research Institute, San Diego, CA. in press.

Davison, B. H., D. M. Nicklaus, A. Misra, S. N. Lewis and B. D. Faison (1991). Utilization of microbially solubilized coal; Preliminary studies on anaerobic conversion. Appl. Biochem. Biotechnol., in press. 
Dawes, P., M. Cumbers and E. Evans (1991). Applications of microfurnace pyrolysis sytems to geochemical analysis. Abstracts 1991 Pittsburgh Conference and Exposition, Pittsburgh, PA. \# 666.

de Zeeuw, W. (1988). Granular sludge in UASB reactors. In: Granular Anaerobic Sludge: Microbiology and Technology. (Lettinga, G. ed.). Pudoc, Wageningen, Netherlands. pp. 132-145.

De Lorenzo V., M. Herrero, U. Jakubzik, K N. Timmis (1990). Mini-Tn5 transposon derivatives for insertion mutagenesis, promoter probing, and chromosomal insertion of cloned DNA in Gramnegative eubacteria. 'J. Bacteriol. 172:6568-6572.

Debus, K. H. (1990). The economic hurdles to commercialization of biological coal desulfurization. Proceedings First International Symposium on the Biological Processing of Coal. Electric Power Research Institute 5.89-5.103.

Deetz, J. S. and J. D. Rozzell (1988). Enzyme-catalyzed reactions in non-aqueous media. Trends Biotechnol. 6:15-18.

deSmet, M., G. Eggink, B. Witholt, J. Kingma and H. Wynberg (1983). Characterization of intracellular inclusions formed by Pseudomonas oleovorans during growth on octane. J. Bacteriol. 154:870-878.

DeWeerd, K. A., A. Saxena, D. P. Nagle, Jr. and J. M. Suflita (1988). Metabolism of the ${ }^{18} \mathrm{O}$ methoxy substituent of 3-methoxybenzoic acid and other unlabeled methoxybenzoic acids by anaerobic bacteria. Appl. Environ. Microbiol. 54:1237-1242.

Dias, O. C. and M. C. Bromel (1989): Case history of microbially induced organic acid underdeposit attack in a gas pipeline. Corrosion 89 , Paper \#194, NACE.

Diekert, G. and M. Ritter (1983). Carbon monoxide fixation into the carboxyl group of acetate during growth of Acetobacterium woodii on $\mathrm{H}_{2}$ and $\mathrm{CO}_{2}$. FEMS Microbiol. Lett. 17:299-302.

Diekert, G., E. Schrader and W. Harder (1986). Energetics of CO formation and CO oxidation in cell suspensions of Acetobacterium woodii. Arch. Microbiol. 144:386-392.

Diekert, G., M. Hansch and R. Conrad (1984). Acetate synthesis from $\mathrm{CO}_{2}$ in acetogenic bacteria: Is carbon monoxide an intermediate? Arch. Microbiol. 138:224-228.

Diekert, G., G. Fuchs and R. K. Thauer (1985). Properties and function of carbon monoxide dehydrogenase from anaerobic bacteria. In: Microbial Gas Metabolism. (R. K. Poole and C. S. Dow, eds.). Academic Press, London. pp. 115-130.

Diels, L., D. Springael, S. Kreps and M. Mergeay (1991). Construction and characterization of heavy metal resistant PCB degrading Alcaligens sp. strains. Abstracts of the Battelle Symposium In situ and on-site bioreclamation. San Diego, CA.

Diks, R. M. M. and S. P. P. Ottengraf (1991). A biological treatment system for the purification of waste gases containing xenobiotic compounds. Abstracts of the Battelle Symposium In situ and on-site bioreclamation. San Diego, CA. 
Dimroth, P. (1987). Sodium ion transport decarboxylases and other aspects of sodium ion-cycling bacteria. Microbiol. Rev. 51:320-340.

Dineen, D., J. P. Slater, P. Hicks, J. Holland and L. D. Clendening (1990). In situ biological remediation of petroleum hydrocarbons in unsaturated soil. In: Petroleum Contaminated Soils (Kostecki, P. T. and Calabrese, E. J., eds.). 3:177-187.

Doddema, H. J. (1988). Site-specific hydroxylation of aromatic compounds by polyphenol oxidase in organic solvents and in water. Biotechnol. Bioeng. 32:716-722.

Doi, Y., A. Tamaki, M. Kunioka, and M. Soga (1987). Biosynthesis of an unusual copolyester (10 mol\% 3-hydroxy butyrate and 30 mol\% 3-hydroxyvalerate units) in Alcaligenes eutrophus from pentanoic acid. J. Chem Soc. Chem. Commun. 1635-1636.

Dosoretz, C., and U. Marchaim (1990). Methanogenic fermentation by halophilic anaerobic bacteria in the hypersaline environment of the Dead Sea. In: Bioprocessing and Biotreatment of Coal, (Wise, D. L. ed.). Marcel Dekker, Inc., New York, N.Y. pp. 437-448.

Dott, W., D. Feidieker, P. Kampfer, H. Schleibinger and S. Strechel (1989). Comparison of autochthonous bacteria and commercially available cultures with respect to their effectiveness in fuel oil degradation. J. Ind. Microbiol. 4:365-374.

Dowling, N. J. E., J. Guezennec, M. L. Lemoine, A. Tunlid and D. C. White (1988). Corrosion analysis of carbon steels affected by aerobic and anaerobic bacteria in mono and coculture using $\mathrm{AC}$ impedance and DC techniques. Corrosion 44:869-874.

Dowling, N. J. E., E. E. Stansbury, D. C. White, S. W. Borenstein and J. C. Danko (1989). On-line electrochemical monitoring of microbially induced corrosion. In: Microbial Corrosion: 1988 Workshop Proceedings (G. J. Licina, ed.). EPRI R-6345, Research Project 8000-26, Electric Power Research Institute, Palo Alto, CA. pp. 5-1 5-17.

Drozd, J. W. (1980). Whole cell transformations. In: Hydrocarbons in Biotechnology. (D. E. F. Harrison, I. J. Higgins and R. Watkinson, eds.). Heyden \& Sons, London. pp. 75-83.

Drushel, H. V. and G. D. Dupre (1991). Sulfur compounds in petroleum by GC/SCD: detector evaluation/optimization and $\mathrm{BP} / \mathrm{T}_{\mathrm{r}}$ correlations. Abstracts 1991 Pittsburgh Conference and Exposition, Pittsburgh, PA. \# 575.

Duarte, J. C. (1988). Bioconversions in organic solvents. In: Perspectives in biotechnology (J. C. Duarte, L. J. Archer, A. T. Bull and G. Holt, eds.). Plenum Press, Inc., London. pp. 22-41.

Dugan, P. (1986). 'Microbiological desulfurization of coal and its increased monetary value. In: Workshop on Biotechnology for the Mining, Metal-Refining and Fossil Fuel Industries (H. L. Erhlich and D. S. Holmes,eds.). J. Wiley \& Sons, New York, N.Y. pp. 185-204.

Dunlop, K. R. and J. J. Perry (1975). Fatty acids from alkane-grown mycobacteria. J. Bacteriol. 121, 250-257. 
Dutton, P. L. and W. C. Evans (1966). Dissimilation of aromatic substrates by Rhodopseudomonas palustris. Biochem. J. 104:30-37.

Dutton, P. L. and W. C. Evans (1968). The photometabolism of benzoic acid by Rhodopseudomonas palustris. Biochem. J. 107:28-36.

Dutton, P. L. and W. C. Evans (1969). The metabolism of aromatic compounds by Rhodopseudomonas palustris: a new reductive method of aromatic ring metabolism. Biochem. J. 113:525-536.

Dwyer, D. F., M. L. Krumme, S. A. Boyd and J. M. Tiedje (1986). Kinetics of phenol biodegradation by an immobilized methanogenic consortium. Appl. Environ. Microbiol. 52:345-351.

Dziewulski, D. M., S. P. Fraleigh, D. H. Pope, S. Thomas, P. Puente and G. Annexstad (1990). Microbial production of hydrogen sulfide in gas storage and production fields: Field studies, preliminary modeling and control. Corrosion 90, Paper \#35.

Eaton, D. C. (1985). Mineralization of polychlorinated biphenyls by Phanerochaete chrysosporium: a ligninolytic fungus. Enzyme Microb. Technol. 7:194-199.

Eaton, R. W. and K. N. Timmis (1986). Characterization of a plasmid-specified pathway for the catabolism of isopropylbenzene in Pseudomonas putida RE204. J. Bacteriol. 168:123-131.

Eckart, V., M. Köhler and W. Hieke (1986). Microbial desulfurization of petroleum and heavy petroleum fractions. 5. Anaerobic desulfurization of Romashkino petroleum. Zbl. Mikrobiol. 141:291300 .

Edlund, A., P. D. Nichols, R. Roffey and D. C. White (1985). Extractable and lipopolysaccharide fatty acid and hydroxy acid profiles from Desulfovibrio species. J. Lipid Res. 26:982-888.

Edwards, E. A., L. E. Wolls, D. Grbic'-Galic' and M. Reinhard (1991). Anaerobic degradation of toluene and xylene - implications of sulfate as the terminal electron acceptor. Abstracts of the Battelle Symposium, In Situ and On-site Bioreclamation, San Diego, CA.

Ehhalt, D. H. (1974). The atmospheric cycle of methane. Tellus 25:57-70.

Ehrlich, H. L. (1990). Geomicrobiology, 2nd edition. Marcel Dekker, New York, N.Y.

Ehrlich, G. G., E. M. Godsy, D. F. Georlitz and M. F. Hult (1982). Degradation of phenolic contaminants in ground water by anaerobic bacteria: St. Louis, MN. Ground Water 20:703-710.

Ehrlich, G. G., E. M. Godsy, D. F. Goerlitz and M. F. Hult (1983). Microbial ecology of a creosotecontaminated aquifer at St. Louis Park, MN. Dev. Ind. Microbiol. 24:235-245.

El-Zeky, M. and Y. A. Attia (1986). Coal slurries desulfurization by flotation using thiophilic bacteria for pyrite depressions. Proc. 8th Int. Symp. Coal Slurry Fuels Prep. Util. 242-261.

Eliuk, S. E. (1984). A hypothesis for the origin of hydrogen sulphide in Devonian crossfield member dolomite, Wabamun Formation, Alberta, Canada. Conference Proceedings, Canadian Soc. Petrol. Geol. Carbonate in Sub Surface and Outcrop Core. pp. 245-289. 
Ellis, D. B., P. F. Brust, P. J. Kountz, A. F. Water, M. Harpold and T. R. Gingeras (1985). Isolation of alcohol oxidase and two other regulatable genes from the yeast Pichia pastoris. Mol. Cell Biol. 5:1111-1121.

Engelhardt, G. and P. R. Wallnofer (1978). Metabolism of di- and mono-n -butyl phthalate by soil bacteria. Appl. Environ. Microbiol. 35:243-246.

Ensley, B. D., D. T. Gibson and A. L. Laborde (1982). Oxidation of naphthalene by a multicomponent enzyme system from Pseudomonas sp. strain NCIB9816. J. Bacteriol. 149:948-954.

Ensley, B. D., B. J. Ratzkin, T. D. Osslund, M. J. Simon, L. P. Wackett and D. T. Gibson (1983). Expression of naphthalene oxidation genes in Escherichia coli results in the biosynthesis of indigo. Science 222:167-171.

Ensley, B. D., T. D. Osslund, M. Joyce and M. J. Simon (1988). Expression and complementation of naphthalene dioxygenase activity in Escherichia coli. In: Microbial Metabolism and the Carbon Cycle (Hagadorn, S. R., Hansen, R. S. and Kunz, D.A eds.). Harwood Academic Publishers, New York, N.Y. pp. 437-455.

Erlich, G. G., D. F. Goerlitz, E. M. Godsy and M. F. Hult (1982). Degradation of phenolic contaminants in ground water by anaerobic bacteria: St. Louis Park, MN. Ground Water 20:703-710.

Evans, W. C. (1977). Biochemistry of the bacterial catabolism of aromatic compounds in anaerobic environments. Nature 270:17-22.

Evans, W. C. and G. Fuchs (1988). Anaerobic degradation of aromatic compounds. Ann. Rev. Microbiol. 42:289-317.

Evans, P. J., W. Ling and L. Y. Young (1991). Anaerobic degradation of toluene and $m$-xylene by denitrifying pure cultures. Abstracts of the Battelle Symposium In situ and on-site bioreclamation, San Diego, CA.

Fedorak, P. M. (1990). Microbial metabolism of organosulfur compounds in petroleum. In: Geochemistry of Sulfur in Fossil Fuels (Orr, W. L. and White, C. M., eds.). American Chemical Society Symposium Series 429, 93-112.

Faison, B. D., C. A. Woodward and R. M. Beam (1990). Microbial solubilization of a preoxidized subbituminous coal; product characterization. Appl. Biochem. Biotechnol. 24:831-841.

Fedorak, P. M. and S. E. Hrudey (1984). The effects of phenol and some alkyl phenolics on batch anaerobic methanogenesis. Water Res. 18:361-367.

Fedorak, P. M., and S. E. Hrudey (1986). Anaerobic treatment of coal conversion wastewaters in semicontinuous cultures. Water Res. 20:113-122.

Ferry, J. G. and R. S. Wolfe (1976). Anaerobic degradation of benzoate to methane by a microbial consortium. Arch. Microbiol. 107:33-40.

Fina, L. R. and A. M. Fiskin (1960). The anaerobic decomposition of benzoic acid during methane fermentation. II. fate of carbons one and seven. Arch. Biochem. Biophys. 91:163-165. 
Fina, L. R., R. L. Bridges, T. H. Coblenz and F. F. Roberts (1978). The anaerobic decomposition of benzoic acid during methane fermentation. III. The fate of carbon four and the identification of propionic acid. Arch. Microbiol. 118:169-172.

Finnerty, W. R. (1987). Application of Microbial Processes to Viscosity Reduction of Heavy Crude Oil. DOE/BC/10507 pp. 1-23.

Finnerty, W. R. and M. E. Singer (1983). Microbial enhancement of oil recovery. Biotechnol. 1:47-54.

Finnerty, W. R. and M. E. Singer (1984). A microbial biosurfactant. Genetics, physiology and applications. Develop. Ind. Microbiol. 45:31-40.

Finnerty, W. R. and M. Robinson (1986). Microbial desulfurization of fossil fuels. In: Workshop on Biotechnology for the Mining, Metals Refining and Fossil Fuel Industries (H. L. Erhlich and D. S. Holmes, eds.). J. Wiley \& Sons, New York, N.Y. pp. 205-221.

Fischer, A. J., E. A. Rowan and R. F. Spalding (1987). VOC's in groundwater influenced by large scale withdrawals. Groundwater 25:407-413.

Flemming, H. L. (1989). Membrane pervaporation-separation of organic/aqueous mixtures. Int'l. Conf. on Fuel Alcohol and Chemicals, Feb. 2, Guadalajara, Mexico.

Fliermans, C. B., T. J. Phelps, D. Ringelberg, A T. Mikell and D. C. White (1988). Mineralization of trichloroethylene by hetertrophic enrichment cultures. Appl. Environ. Microbiol. 54:1709-1714.

Fogel, M. M., A. R. Taddeo and S. Fogel (1986). Biodegradation of chlorinated ethenes by a methane-utilizing mixed culture. Appl. Environ. Microbiol. 51:720-724.

Fogel, S., M. Findlay and A. Moore (1989). Enhanced bioremediation techniques for in situ and onsite treatment of petroleum contaminated soils and groundwater. In: Petroleum Contaminated Soils (Calabrese, E. J. and Kostecki, P. T., eds.). 2:201-210.

Foght, J. M., D. L. Gutnick and D. W. S. Westlake (1989). Effect of emulsan on biodegradation of crude oil by pure and mixed bacterial cultures. Appl. Environ. Microbiol. 55:36-42.

Foght, J. M., P. M. Fedorak, M. R. Gray and D. W. S. Westlake (1990). Microbial desulfurization of petroleum. In: Microbial Mineral Recovery (Ehrlich, H.L. and Brierley, C.L., eds.). McGraw-Hill, New York, N.Y. pp. 379-407.

Flyvbjerg, J., E. Arvin, B. K. Jensen and S. K. Olsen (1991). Biodegradation of oil and creosote related aromatic compounds under nitrate reducing conditions. Abstracts of the Battelle Symposium In situ and on-site bioreclamation, San Diego, CA.

Foster, J. W. and R. H. Davis (1966). A methane dependent coccus with notes on classification and nomenclature of obligate, methane-utilizing bacteria. J. Bact. 91:1924-1931.

Fox, B. G. (1988). Purification of a high specific activity methane monooxygenase component from a Type II methanotroph. Biochem. Biophys. Res. Comm. 154:165-170. 
Fox, B. G., K. K. Surerus, E. Munck and John D. Lipscomb (1988). Evidence for a u-oxo bridged binuclear iron cluster in the hydroxylase component of methane monooxygenase: Mossbauer and EPR Studies. J. Biol Chem. 234:1150-1158.

Fox, B. G., W. A. Froland, J. E. Dege and J. D. Lipscomb (1989). Methane monooxygenase from Methylosinus trichosporium OB3b. J. Biol. Chem. 264:10023-10033.

Franklin, M. J., D. C. White and H. S. Isaacs (1989). The use of current density mapping in the study of microbial influenced corrosion. In: Corrosion 90, Paper 90-104, NACE, Las Vegas, NV.

Frazer, A C. and L. Y. Young (1985). A gram-negative anaerobic bacterium that utilizes O-methyl substituents of aromatic acids. Appl. Environ. Microbiol. 49:1345-1347.

Frazer, A. C. and L. Y. Young (1986). Anaerobic C1 metabolism of the O-methyl- ${ }^{14} \mathrm{C}$-labeled substituent of vanillate. Appl. Environ. Microbiol. 51:84-87.

Frey, J. and K. N. Timmis (1985). ColD-derived cloning vectors that autoamplify in the stationary phase of bacterial growth. Gene 35:103-111.

Friedman, S. (1990). Sulfur analyses of coal - a critical evaluation. Proceedings First International Symposium on the Biological Processing of Coal. Electric Power Research Institute 1.3-1.14.

Fuchs, G., U. Schnitker, and R. K. Thauer (1974). Carbon monoxide oxidation by growing cultures of Clostridium pasteurianum. Eur. J. Biochem. 49:111-115.

Fuchs, G., A. Kröger and R. K. Thauer (1990). Mechanism of anaerobic degradation of aromatic compounds in Texas lignite by bacteria. In: Bioprocessing and Biotreatment of Coal (Wise, D. L. ed.). Marcel Dekker, Inc., New York, N.Y. pp. 245-252.

Fukui, S. and A. Tanaka (1980). Production of useful compounds from alkane media in Japan. $A d v$. Biochem. Eng. 17:1-35.

Fukui, S. and A. Tanaka (1982). Immobilized microbial cell. Ann. Rev. Microbiol. 36:145-157.

Fusillo, T. V., J. J. Hochreiter and D. G. Lord (1985). Distribution of volatile organic compounds in a New Jersey coastal plain aquifer system. Groundwater 23:354-360.

Gates,G. L. and C. F. Parent (1976). Water-quality control presents challenge in giant Wilmington field. Oil and Gas J. 74:115-126.

Gawdzik, A and J. Farbiszewska-Bajer (1990). Application of biotechnology for coal prepurification from sulfur. Przem. Chem. 69:214-216.

Geerligs, G., H. C. Aldrich, W. Harder and G. Diekert (1987). Isolation and characterization of a carbon monoxide utilizing strain of the acetogen Peptostreptococcus products. Arch. Microbiol. 148:305-313.

Geigert, J., S. L. Neidleman and S. H. DeWitt (1984). Further aspects of wax ester synthesis by Acinetobacter sp. HO1-N. J. Am. Oil Chem. Soc. 61:1747-1750. 
Geissler, J. F., C. S. Harwood and J. Gibson (1988). Purification and properties of benzoatecoenzyme A ligase: a Rhodopseudomonas palustris enzyme involved in the anaerobic degradation of benzoate. J. Bacteriol. 170:1709-1714.

Genthner, B. R. S. and M. P. Bryant (1982). Growth of Eubacterium limosum with carbon monoxide as the energy source. Appl. Environ. Microbiol. 43:70-74.

George, G. N. and M. L. Gorbaty (1989). Sulfur K-edge X-ray absorption spectroscopy of petroleum asphaltenes and model compounds. J. Am. Chem. Soc. 111:3182-3186.

George, G. N., M. L. Gorbaty and S. R. Kelelman (1990). Sulfur K-edge X-ray absorption spectroscopy of petroleum asphaltenes and model compounds. In: Geochemistry of Sulfur in Fossil Fuels. (Orr, W. L. and White, C. M., eds.). American Chemical Society Symposium Series 429. pp. 220-230.

George, G. N., M. L. Gorbaty, S. R. Kelelman and M. Sansone (1991). Direct determination and quantification of sulfur forms in coals from the Argonne Premim Sample program. Energy and Fuels 5:93-97.

Gersberg, R. M., W. J. Dawsey and H. F. Ridgway (1989). Biodegradation of dissolved aromatic hydrocarbons in gasoline-contaminated groundwaters using denitrification. In:Petroleum Contaminated Soils (Calabrese, E.J. and Kostecki, P.T., eds.). 2:211-218.

Giam, C. S., H. S. Chan, G. S. Neff and E. L. Atlas (1978). Phthalate ester plasticizers: a new class of marine pollutants. Science 199:419-21.

Gibson, S. A. and J. M. Suflita (1986). Extrapolation of biodegradation results to groundwater aquifer: Reductive dehalogenation of aromatic compounds. Appl. Environ. Microbiol. 52:681-688.

Gibson, D. T., M. Hensley, H. Yoshioka and T. J. Mabry (1970). Formation of (+)-cis-2,3-dihydroxy1-methylcyclohexa-4,6-diene from toluene by Pseudomonas putida. Biochemistry 7:3795-3802.

Gibson, D. T., and L. Y. Young (1986). Anaerobic degradation of xenobiotics by microbial consortia. In: Microbial Degradation of Organic Compounds. Marcel Dekker, New York, N.Y. pp. 487-523.

Gibson, D. T., G. J. Zylstra and S. Chauhan (1990). Biotransformations catalysed by toluene dioxygenase from Pseudomonas putida F1. In: Pseudomonas: Biotransformations, Pathogenesis, and Evolving Technology (S. Silver, A.M. Chakrabarty, B. Iglewski and S. Kaplan. eds.). American Society for Microbiology, Washington D.C. pp. 121-132.

Gleeson, M. A. and P. E. Sudbery (1988). The methylotrophic yeasts. Yeast 4:1-15.

Glockler, R. R. Tschech and G. Fuchs (1989). Reductive dehydroxylation of 4-hydroxybenzoyl-CoA in a denitrifying, phenol-degrading Pseudomonas species. FEBS Lett. 251:237-240.

Godsy, E. M., D. F. Goerlitz and G. G. Erlich (1983). Methanogenesis of phenolic compounds by a bacterial consortium from a contaminated aquifer in St. Louis Park, MN. Bull. Environ. Contamin. Toxicol. 30:261-268. 
Godsy, E. M., D. F. Goerlitz and D. Grbic'-Galic' (1987). Anaerobic biodegradation of creosote contaminants in natural and simulated ground water ecosystems. In: U. S. geological survey program on toxic waste-ground water contaimination, (B. J. Franks, ed.). U. S. Geological Survey, Tallahassee, FL. pp. A-17 - A-19.

Godsy, E. M. and D. Grbic'-Galic' (1989). Biodegradation pathways for benzothiophene in methanogenic microcosms. In: U. S. Geological Survey Toxic Substances Hydrology Program Proceedings of the Technical Meeting (G. E. Mallard and S.E. Ragone, eds.). U.S. Geological Survey Water Resources Investigation Report 88-4220. Reston, VA. pp.559-564.

Goerlitz, D. F., D. E. Troutman, E. M. Godsy and B. J. Franks (1985). Migration of wood-preserving chemicals in contaminated groundwater in a sand aquifer at Pensacola, Florida. Environ. Sci. Technol. 19:955-961.

Gorbaty, M. L., G. N. George and S. R. Keleman (1990a). Direct determination and quantification of sulfur forms in heavy petroleum and coals. 2. The sulfur K-edge X-ray absorption spectroscopy approach. Fuel 69:945-949.

Gorbaty, M. L., G. N. George and S. R. Keleman (1990b). Chemistry of organically bound sulfur forms during the mild oxidation of coal. Fuel 69:1065-1068.

Grbic'-Galic', D. (1983). Anaerobic degradation of coniferyl alcohol by methanogenic consortia. Appl. Environ. Microbiol. 46:1442-1446.

Grbic'-Galic', D. N. Churchman-Eisel and I. Mrakovic (1990). Microbial transformation of styrene by anaerobic consortia. J. Appl. Bacteriol. 69:247-260.

Grbic'-Galic', D. (1986). O-Demethylation, dehydroxylation, ring reduction and cleavage of aromatic substrates by Enterobacteriaceae under anaerobic conditions. J. Appl. Bacteriol. 61:491-497.

Grbic'-Galic', D. (1989). Microbial degradation of homocyclic and heterocyclic aromatic hydrocarbons under anaerobic conditions. Dev. Ind. Microbiol. 30:237-253.

Grbic'-Galic', D. (1990). Anaerobic microbial transformation of nonoxygenated aromatic and alicyclic compounds in soil, subsurface, and freshwater sediments. Soil Biochem. 6:117-189.

Grbic'-Galic', D. (1991). Anaerobic microbial degradation of aromatic hydrocarbons. In: Microbial enhancement of oil recovery - recent advances. (E.C. Donaldson, ed.). Elsevier Science Publishers, Amsterdam, Netherlands. pp.145-161.

Grbic'-Galic', D. and T. M. Vogel (1987). Transformation of toluene and benzene by mixed methanogenic cultures. Appl. Environ. Microbiol. 53:254-260.

Grbic'-Galic', D. and L. Y. Young (1985). Methane fermentation of ferulate and benzoate: Anaerobic degradation pathways. Appl. Environ. Microbiol. 50:292-297.

Greene, T.C. (1991). The Apex barges spill, Galveston Bay, July 1990. Proceedings of the 1991 International oils spill conference, American Petroleum Institute, Washington D.C. pp. 291-297. 
Grethlein, A. J., R. M. Worden, M. K. Jain and R. Datta (1990). Continuous production of mixed alcohols and acids from carbon monoxide. Appl. Biochem. Biotechnol. 24/25:875-884.

Grethlein, H. E. and L. R. Lynd. U.S. Patent \#4,626,321. December, 1986.

GRI Field Guide, 2nd Edition (1990). Microbiologically Influenced Corrosion (MIC): Methods of Detection in the FIeld, Gas Research Institute, Chicago, IL.

Grinenko, V. A. and M. V. Ivanov (1983). Principal reactions of the global biogeochemical cycle of sulfur. In: The Global Biogeochemical Sulfur Cycle (M. V. Ivanov and J.R. Freney, eds.). J. Wiley and Sons. pp. 1-23.

Groudev, S. N. and F. N. Genchev (1979). Microbial coal desulfurization; effect of cell adaptation and mixed cultures. Compt. Rend. Acad. Bilg. Sci. 32:353-355.

Guckert, J. B., C. B. Antworth, P. D. Nichols and D. C. White (1985). Phospholipid, ester-linked fatty acid profiles as reproducible assays for changes in prokaryotic community structure of estuarine sediments. FEMS Microbiol. Ecology. 31:147-158.

Guckert, J. B., M. A. Hood and D. C. White (1986). Phospholipid, ester-linked fatty acid profile changes during nutrient deprivation of Vibrio cholerae: increases in the trans/cis ratio and proportions of cyclopropyl fatty acids. Appl. Environ. Microbiol. 52:794-801.

Guckert, J. B., D. B. Ringelberg and D. C. White (1987). Biosynthesis of trans membrane fatty acids from acetate in the bacterium Pseudomonas atlantica. Can. J. Microbiol. 33:784-754.

Gundlach, E. R., P. D. Boehm, M. Marchand, R. M. Atlas, D. M. Ward and D. A. Wolfe (1983). The fate of Amoco Cadiz oil. Science 221, 122-129.

Guyer, M. and G. Hegeman (1969). Evidence for a reductive pathway for the anaerobic metabolism of benzoate. J. Bacteriol. 99:906-907.

Haber, C. L., L. N. Allen, S. Zhao and R. Hanson (1983). Methylotrophic bacteria: biochemical diversity and genetics. Science 221:1147-1153.

Habets-Crutzen, A. Q. H., L. E. S. Brink, C. G. van Ginkel, J. A. M. de Bont and J. Tramper (1984). Production of epoxides from gaseous alkenes by resting-cell suspensions and immobilized cells of alkene-utilizing bacteria. Appl. Microbiol. Biotechnol. 20:245-252.

Habets-crutzen, A. Q. H., S. J. N. Carlier, J. A. M. de Bont, D. Wistuba, V. Schurig, S. Hartmans and J. Tramper (1985). Sterospecific formation of 1,2-epoxypropane, 1,2-epoxybutane and 1-chloro-2,3epoxypropane by alkene-utilizing bacteria. Enzyme Microb. Technol. 7:17-21.

Haddock, J. D. and J. G. Ferry (1990). Anaerobic metabolism of aromatic chemicals. In: Bioprocessing and Biotreatment of Coal (D. Wise, ed.). Marcel Dekker, Inc. New York, N.Y. pp. 393416.

Haggin, J. (1989). Applications of biotechnology to fossil fuels explored. Chem. Eng. News. 67:28. 
Hanson, R. S. (1980). Ecology and diversity of methylotrophic organisms. In: Microbial Oxidation of Gaseous Hydrocarbons, (C.T. Hou, ed.). pp. 3-39.

Harary, I. (1957). Bacterial fermentation of nicotinic acid. J. Biol. Chem. 226:815-831.

Harborn, S., B. W. Smith and M. D. Lilly (1986). Two-liquid phase biocatalysis: epoxidation of 1,7 octadiene by Pseudomonas putida. Enzyme Microb. Technol. 8:85-90.

Harding, R., R. Wyza, J. Isbister and A. DeSouza (1990). Pathway studies on microbial coal desulfurization. Proceedings First International Symposium on the Biological Processing of Coal. Electric Power Research Institute P-11.

Harrison, O. R. (1991). An overview of the Exxon Valdez oil spill. Proceedings of the 1991 International oils spill conference, American Petroleum Institute, Washington D.C. pp. 313-320.

Hartdegen, F. J., J. M. Coburn and R. L. Roberts (1984). The microbial desulfurization of petroleum. Chem. Eng. Progr. 80:63-67.

Harwood, J. H. and S. J. Pirt (1972). Quantitative aspects of growth of the methane oxidizing bacterium Methylococcus capsulatus on methane in shake flack and continuous chemostat culture. J. Appl. Bact. 35:597-607.

Harwood, C. S. and J. Gibson (1986). Uptake of benzoate by Rhodopseudomonas palustris grown anaerobically in light. J. Bacteriol 165:504-509.

Harwood, C. S and J. Gibson (1988). Anaerobic and aerobic metabolism of diverse aromatic compounds by the photosynthetic bacterium Rhodopseudomonas palustris. Appl. Environ. Microbiol. 54:712-717.

Hatcher, H. J. and L. J. Johnson (1990). Economic factors in the bioprocessing of coal. In: Bioprocessing and Biotreatment of Coal (D. Wise, ed.). Marcel Dekker, Inc. New York, N.Y. pp. 5772.

Hazen, T. C. (1990). Deep subsurface bacterial responses to contaminants. In: Proceedings of the First international Symposium on Microbiology of the Deep (C. B. Fliermans and T. C. Hazen, eds.). pp. 6-45 to 6-53.

Healy, J. B., Jr. and L. Y. Young (1978). Catechol and phenol degradation by a methanogenic population of bacteria. Appl. Environ. Microbiol. 35:216-218.

Healy, J. B., Jr. and L. Y. Young (1979). Anaerobic biodegradation of eleven aromatic compounds to methane. Appl. Environ. Microbiol. 38:84-89.

Healy, J. B., Jr., L. Y. Young and M. Reinhard (1980). Methanogenic decomposition of ferulic acid, a model lignin derivative. Appl. Environ. Microbiol. 39:436-444.

Hegeman, G. (1987). Anaerobic growth of bacteria on benzoate under denitrifying conditions. In: Microbial metabolism and the Carbon Cycle. (S. R. Hagedorn, R. Hanson and D. A. Kunz, eds.). Gordon and Breach, New York, N.Y. 
Henry, S. M. and D. Grbic'-Galic' (1991). Influence of endogenous and exogenous electron donors and trichloroethylene oxidation toxicity on trichloroethylene oxidation by methanotrophic cultures from a groundwater aquifer. Appl. Environ. Microbiol. 57:236-244.

Henson, J. M., M. V. Yates, J. W. Cochran and D. L. Shackleford (1988). Microbial removal of halogenated methanes, ethanes, and ethylenes in an aerobic soil exposed to methane. FEMS Microbiol. Ecol. 53:193-201.

Heptinstall, J. and J. R. Quayle (1970). Pathways leading to and from serine during growth of Pseudomonas AM1 on C1 compounds or succinate. Biochem. J. 117:563-572.

Herbert, B. N. (1987). Reservoir souring. In: Microbial Problems in the Offshore Oil Industry, (E. C. Hill, J. L. Shennan and R. J. Watkinson, eds.). J. Wiley and Sons, New York, N.Y. pp. 63-72.

Herbert, B. N. and J. F. D. Stott (1983). The effects of pressure and temperature on bacteria in oilfield water injection systems. In: Microbial Corrosion, Metals Society, London.

Herbert, B. N., P. D. Gilbert, H. Stockdale and R. J. Watkinson (1985). Factors controlling the activity of sulphate-reducing bacteria in reservoirs during water injection. SPE Paper \#13978.

Hergenroeder, R., G. F. Parkin and R. E. Speece (1976). Methane fermentation of coal conversion wastewater constituents. Environmental Studies Institute. Drexel University, Philadelphia, PA.

Herrero, M., V. Lorenzo and K. N. Timmis (1990). Transposon vectors containing non-antibiotic resistance selection markers for cloning and stable chromosomal insertion of foreign genes in Gramnegative bacteria. J. Bacteriol. 172:6557-6567.

Higgins, I. J., D. J. Best, R. C. Hammond and D. Scott (1981). Methane-oxidizing microorganisms. Microbiol. Rev. 45:556-589.

Hill, F. F., I. Venn and K. L. Lukas (1986). Studies on the formation of long-chain dicarboxylic acids from pure n-alkanes by a mutant of Candida tropicalis. Appl. Microbial Biotechnol. 24:168-174.

Hilpert, W., B. Schink and P. Dimroth (1984). Life by a new decarboxylation-dependent energy conservation mechanism with $\mathrm{Na}^{+}$as coupling ion. EMBO. J. 3:1665-1670.

Hirschberg, R. and J. C. Ensign (1971). Oxidation of nicotinic acid by a Bacillus species: Source of oxygen atoms for the hydroxylation of nicotinic acid and 6-hydroxynicotinic acid. J. Bacteriol. 108:757759.

Ho, C. -H., C. Y. Ma, B. R. Clark, M. R. Guerin, T. K. Rao and J. L. Epler (1980). Separation of neutral nitrogen compounds from synthetic crude oils for biological testing. Environ. Res. 22:412-422.

Holcenberg, J. S. and E. R. Stadtman (1969). Nicotinic acid metabolism. III. Purification and properties of a nicotinic acid hydroxylase. J. Biol. Chem. 244:1194-1203.

Hood, M. A., J. B. Guckert and D. C. White (1986). The effect of nutrient (carbon) deprivation on the levels of lipids, carbohydrates, DNA, RNA, and protein of Vibrio cholerae. Appl. Environ. Microbiol. 52:788-793. 
Hopper, D. J. (1978). Incorporation of $\left[{ }^{18} \mathrm{O}\right]$ water in the formation of $p$-hydroxybenzyl alcohol by the p-cresol methylhydroxylase from Pseudomonas putida. Biochem. J. 175:345-347.

Hou, C. T. (1984). Methylotrophs: Microbiology, Biochemistry and Genetics (C. T. Hou, ed.). CRC Press, Boca Raton, FL.

Hou, C. T. (1985). 'Oxidation of gaseous hydrocarbons by methanotrophs: Heterogeneous bioreactor. Ann. N.Y. Acad. Sci. (Enzyme Engin.). 434:541-548.

Hou, C. T. (1988). Enzyme dynamics and regulation. In: Topics in Petroleum Biotechnology. SpringerVerlag, New York. pp. 261-267.

Hou, C. T. and A. I. Laskin (1976). Microbial conversion of dibenzothiophene. Develop. Ind. Microbiol. 17:351-362.

Hou, C. T., A. I. Laskin and R. N. Patel (1978). 'Growth and polysaccharide production by Methylocystis parvus' OBBP on methanol. Appl. Environ. Microbiol. 37:800-804.

Hou, C. T., R. Patel, A. I. Laskin, N. Barnabe and I. Marczak (1979). Microbial oxidation of gaseous hydrocarbons: Production of methyl ketones from their corresponding secondary alcohols by methaneand methanol-growth microbes. Appl. Environ. Microbiol. 38:135-142.

Hou, C. T., R. N. Patel, A. I. Laskin and N. Barnabe (1980). Microbial oxidation of gaseous hydrocarbons: Oxidation of lower $n$-alkanes and $n$-alkanes by resting cell suspensions of various methylotrophic bacteria, and the effect of methane metabolites. FEMS Microbiology Letters. 9:267270.

Hou, C. T., R. Patel, N. Barnabe and I. Marczak (1981). Spectrospecificity and other properties of a novel secondary-alcohol dehydrogenase. Eur. J. Biochem. 119:359-364.

Hou, C. T., R. N. Patel, A. I. Laskin and N. Barnabe (1982). Epoxidation of alkenes by methane monoxygenase: Generation and regeneration of cofactor, NADH, by dehydrogenase. J. Appl. Biochem. 4:379-383.

Hou, C. T., R. Patel, A. I. Laskin, I. Marczak and N. Barnabe (1982). Production of terminal and subterminal oxidation products from n-alkanes by methylotrophic bacteria. Dev. Indust. Microbiol. 22:467-478.

Hsu, T., S. L. Daniel, M. F. Lux and H. L. Drake (1990). Biotransformations of carboxylated aromatic compounds by the acetogen Clostridium thermoaceticum: generation of growth-supportive $\mathrm{CO}_{2}$ equivalents under $\mathrm{CO}_{2}$-limited conditions. J. Bacteriol. 172:212-217.

Hsu, T. S. and R. Bartha (1976). Interaction of pesticide-derived chloroaniline residues with soil organic matter. Soil Sci. 116:444-452.

Hubley, J. H., J. R. Mitton and J. F. Wilkinson (1974). The oxidation of carbon monoxide by methane-oxidizing bacteria. Arch. Microbiol. 95:365-368.

Hubley, J. H., A. W. Thomson and J. F. Wilkinson (1975). Specific inhibitors of methane oxidation in Methylosinus trichosporium. Arch. Microbiol. 102:199-202. 
Hudlicky, T., H. Luna, G. Barbieri and L. D. Kwart (1988). Enantioselective synthesis through microbial oxidation of arenes. I. Efficient preparation of terpene and prostanoid synthons. J. Am. Chem. Soc. 110:4735-4741.

Huffman, G.P., F. E. Huggins, S. Mitra, N. Shah, R. J. Pugmire, B. Davis, F. W. Lytle and R. B. Greegor (1989a). Investigation of the molecular structure of organic sulfur in coal by XAFS spectroscopy. Energy \& Fuel 3:200-205.

Huffman, G. P., N. Shah and F. Huggins (1989b). Characterization of inorganic constituents and heteroatoms in coal by advanced analytical techniques. Proceedings 1989 Symposium on biological processing of coal and coal-derived substances, Electric Power Research Institute, Palo Alto, CA. pp. 1.1-1.12.

Huggins, F.E., G. P. Huffman, N. Shah, S. Mitra, B. Ganguly, A. Shah, M. M. Taghiei and S. Vaidya (1990). Structural characterization of important elements in bioprocessed coal. Proceedings First International Symposium on the Biological Processing of Coal. Electric Power Research Institute 1.45-1.65.

Humenick, M. J., L. N. Britton and C. F. Mattox (1982). Natural restoration of ground water in UCG. In Situ 6:107-125.

Hunt, A. L., D. E. Hughes and J. M. Lowenstein (1958). The hydroxylation of nicotinic acid by Pseudomonas fluorescens. Biochem. J. 69:170-173.

Huq, M. N., B. J. Ralph and P. A D. Rickard (1978). The extracellular polysaccharide of a methylotrophic culture. Aust. J. Biol. Sci. 31:311-16.

Hutber, D. W. and D. W. Ribbons (1983). Involverment of coenzyme A esters in the metabolism of cyclohexane-carboxylic acid by Rhodopseudomonas palustris. J. Gen. Microbiol 129:2413-2420.

Hutchins, S.R. and J. T. Wilson (1991). Laboratory and field studies on BTEX biodegradation in a fuel-contaminated aquifer under denitrifying conditions. Abstracts of the Battelle Symposium In situ and on-site bioreclamation, San Diego, CA.

Hutchins, S. R., G. W. Sewell, D. A. Kovacs and G. A. Smith (1991). Biodegradation of aromatic hydrocarbons by aquifer microorganisms under denitrifying conditions. Environ. Sci. Technol. 25:6876.

Hutton, W. E. and C. E. ZoBell (1949). The occurrence and characteristics of methane oxidizing bacteria in marine sediments. J. Bacteriol. 58:463-473.

Hyman, D., R. Hammack, D. Finseth and K. Rhee (1990). The bacteria-mediated leaching of pyrite from coarse coal. Proceedings First International Symposium on the Biological Processing of Coal. Electric Power Research Institute 3.101-3.111.

Inoue, A and K. Horikoshi (1989). A Pseudomonas thrives in high concentrations of toluene. Nature, 338:264. 
Isbister, J. B. and E. A. Kobylinski (1985). Microbial desulfurization of coal. In: Coal Science and Technology: Processing and Utilization of High Sulfur Coals (Y.A. Attia ed.). Elsevier Publishing Co., New York, N.Y. pp. 627-641.

Ishikura, T., H. Nishida, K. Tanno, N. Miyachi and A. Ozaki (1968). Microbial production of salicylic acid from naphthalene. Agr. Biol. Chem. 32:12-20.

Iverson, W. P. and G. J. Olson (1983). Microbial Corrosion. The Metals Society, London. pp. 46-53.

Iverson, W. P. (1974). Microbial corrosion of iron. In: Microbial Iron Metabolism (J. B. Neilands, ed.). Academic Press, New York, N. Y. pp. 475-513.

Jack, R. F. (1990). The effects of increased bacterial metabolic diversity on the corrosion of carbon steel. M.S. Thesis, University of Tennessee, Graduate Program in Ecology, Knoxville, TN 37996. pp. 1-102.

Jack, T. R., M. McD. Francis and R. G. Worthingham (1989). External Corrosion of Line Pipe Part II: Laboratory study of cathodic protection in the presence of sulfate-reducing bacteria. In: Biologically Induced Corrosion(S. C. Dexter, ed.). NACE, Houston. pp.339-350.

Jain, M. K., R. Datta and J. G. Zeikus (1989). High-value organic acids fermentation emerging processes and products. In: Bioprocess Engineering: The First Generation. (T. K. Ghose, ed.). Ellis Harwood Limited, Chichester, England. pp. 366-398.

Jain, M. K., L. Bhatnagar and J. G. Zeikus (1990). Biochemical pathways for methane formation and use of granulated biomass for high-rate anaerobic digestion. Proc. Indo-German Joint Steering Committee Report on Int. Conf. on Biogas Technologies and Implementation Strategies, Pune, India. pp. 498-514.

Jannasch, H. W. (1979). Chemosynthetic production of biomass: an idea from a recent oceanographic discovery. Oceanus 22:59-63.

Jauberton, G. and J. Elgue (1982). Selective desulphurisation of gas withdrawn from an underground storage reservoir. Rev. Inst. fr. Petrole 37:207-223.

Jenneman, G. E., M. J. McInerney, R. M. Knapp, J. B. Clark, M. M. Feero, D. E. Revus and D. F. Menzie (1983). A halo-tolerant, biosurfactant-producing Bacillus species potentially useful for enhanced oil recovery. Dev. Ind. Microbiol. 24:485-492.

Jeris, J. W., R. W. Owens and R. Hickey (1977). Biological fluidized bed treatment for BOD and nitrogen removal. Water Pollut. Cont. Fed. 49:816-831.

Jewell, W. J., Y. M. Nelson, D. E. Fennell, S. Underhill, M. S. Wilson and T. E. White (1991). Methanotrophs for biological pollution control: Feasibility of developing an attached microbial film reactor and kinetics of TCE removal. Final Report (July 1987-March, 1989), Gas Research Institute Report \#GRI-91-0012.

Johansen, N. G. and J. W. Birks (1991). Determination of sulfur compounds in difficult matrices by capillary column GC with sulfur chemiluminescence detection. Amer. Lab. 112-119. 
Johnston, D. P. (1969). Control of corrosion in gas storage wells. In: NACE Short Course on Fundamentals and Field Practices of Corrosion Control. Houston, January 1969.

Johnston, J. B. and Rengathan (1987). Production of substituted catechols from substituted benzenes by a Pseudomonas sp. Enzyme Microbiol Technol. 9:706-710.

Jones, P. J. (1987). Hydrogen sulphide in an operating North Sea oilfield. Presented at SPE Aberdeen Section Seminar:Produced Water Problems. May 1987, Aberdeen, Scotland.

Jones, J. L., W. S. Fong, P. Hall and S. Cometta (1988). Whither bioprocesses for volume chemicals? Chemtech 4:304-309.

Jones, M. A. and J. H. Greenfield (1991). In situ comparison of bioremediation methods for a number 6 fuel oil spill in Lee County, Florida. Proceedings of the 1991 International oils spill conference, American Petroleum Institute, Washington D.C., pp. 533-540.

Jorgensen, C., E. Mortensen, B. Jensen and E. Arvin (1991). Biodegradation of toluene by a denitrifying enrichment culture. Abstracts of the Battelle Symposium In situ and on-site bioreclamation, San Diego, CA.

Josephson, J. (1983). Subsurface contaminants. Environ. Sci. Technol. 17:518A-521A.

Kaserer, H. (1905). Ueber die oxydation des wasserstofes und des methane durch mikroorganism. Z. Landw. Versuchsw. Deut. Oesterr. 8:789.

Kaiser, J. P. and K. W. Hanselmann (1982a). Aromatic chemicals through anaerobic micobial conversion of lignin monomers. Experientia 38:167-176.

Kaiser, J. P. and K. W. Hanselmann (1982b). Fermentative metabolism of substituted monoaromatic compounds by a bacterial community from anaerobic sediments. Arch. Microbiol. 133:185-194.

Kaneyuki, H. , H. Deno, J. Hiratsuka, T. Matsuyoshi and T. Furukawa (1980). Production of sebacic acid from n-decane by mutants derived from Torulopsis candida. J. Ferment. Technol. 58:405-410.

Kargi, F. (1987). Biological oxidation of thianthrene, thioxanthene and dibenzothiophene by the thermophilic organism. Biotechnol. Lett. 9:478-482.

Kasahara, K. and F. Kajiyama (1985). Role of sulfate-reducing bacteria in the localized corrosion of buried pipes. In: Biologically Induced Corrosion-NACE-8 (S. C. Dexter, ed.). NACE, Houston. pp.172183.

Kawatra, S. K., T. C. Eisele and S. Bagley (1987). Coal desulfurization by bacteria. Mineral. Metall. Process. 4:189-192.

Kehl, T. A., G. Widmann and D. S. McMorran (1991). A new equipment for pressure DSC applications. Abstracts 1991 Pittsburgh Conference and Exposition, Pittsburgh, PA. \# 121

Keith, C. L., R. L. Bridges, L. R. Fina, K. L. Iverson and J. A. Cloran (1978). The anaerobic decomposition of benzoic acid during methane fermentation IV. Dearomatization of the ring and volatile fatty acids formed on ring rupture. Arch. Microbiol. 118:173-176. 
Kelley, J. (1980). Bugs can eat your pipes. In: 16th Heart of America Annual Pipeline Operation and Maintenance. Liberal, Kansas, November 18, 1980.

Kelley, R. L., J. R. Conrad, D. E. Hoefer, A. Desai, V. J. Srivastava and C. Akin (1988). Important Factors in Biotechnological Processes Involving Methanotrophs. IGT's First International Symposium on Gas, Oil and Coal Biotechnology.

Kelley, R. L., D. E. Hoefer, J. R. Conrad, V. J. Srivastava and C. Akin (1989). Stereospecificity and physiology of co-oxidative production of chemicals by methanotrophic bacteria. In Press.

Kerby, R. and J. G. Zeikus (1987). Catabolic enzymes of the acetogen Butyribacterium methylotrophicum grown on single-carbon substrates. J. Bacteriol. 169:5605-5609.

Kerby, R. and J. G. Zeikus (1983). Growth of Clostridium thermoaceticum on $\mathrm{H}_{2} / \mathrm{CO}_{2}$ or $\mathrm{CO}$ as energy source. Curr. Microbiol. 8:27-30.

Kerby, R., W. Niemczura and J. G. Zeikus (1983). Single carbon catabolism in acetogens: Analysis of carbon flow in Acetobacterium woodii and Butyribacterium methylotrophicum by fermentation and ${ }^{13} \mathrm{C}$-nuclear magnetic resonance measurement. J. Bacteriol. 155:1208-1218.

Khalid, A. M., D. Bhattacharyya and M. I. H. Aleem (1989). Sulfur metabolism and the coal desulfurization potential of Sulfolobus brierleyi and Thiobacilli. Proceedings 1989 Symposium on biological processing of coal and coal-derived substances, Electric Power Research Institute, Palo Alto, CA. pp. 2.19-2.36

Khalil, M. A. K and R. A. Rasmussen (1983). Sources, sinks, and seasonal cycles of atmospheric methane. J. Geophys. Res. 88:5131-5144.

Kilbane, J. J. (1990). Sulfur-specific microbial metabolism of organic compounds. Resources, Conser. Recycling. 3:69-79.

Kilbane, J., A. Maka and C. Akin (1989). Microbial removal of organic sulfur from coal. Paper presented at First Electric Power Research Institute Symposium, Palo Alto, CA.

Kilbane, J. J. and B. A. Bielaga (1990). Genetic study of biodesulfurization. Proceedings First International Symposium on the Biological Processing of Coal. Electric Power Research Institute 2.17-2.32.

Kim, B. H. and J. G. Zeikus (1985). Importance of hydrogen metabolism in regulation of solventogenesis by Clostridium acetobutylicum. Dev. Ind. Microbiol. 26:549-556.

Kim, B. H., P. Bellows, R. Datta and J. G. Zeikus (1984). Control of carbon and electron flow in Clostridium acetobutylicum fermentations: Utilization of carbon monoxide to inhibit hydrogen production and to enhance butanol yields. Appl. Environ. Microbiol. 48:764-770.

Kim, T. S., H. Y. Kim and B. H. Kim (1990). Petrole equivalent. Biotechnol. Lett. 12:757-760.

Kim, H. Y., T. S. Kim and B. H. Kim (1990). Degradation of organic sulfur compounds and the reduction of dibenzothiophene to biphenyl and hydrogen sulfide by Desulfovibrio desulfuricans M6. Biotechnol. Lett. 12:761-764. 
King, R. A. and J. D. A Miller (1971). Corrosion by the sulphate-reducing bacteria. Nature 233:491.

King, J. M. H,. P. M. DiGrazia, B. Applegate, R. Burlage, J. Sanseverio, P. Dunbar and G. S. Sayler (1990). Rapid and sensitive bioluminescent reporter technology for naphthalene exposure and biodegradation. Science 249:778-781.

Kinoshita, S. and K. Nakayama (1978). Amino acids. In: Economic Microbiology, Vol. 4 (A. H. Rose, ed.). Academic Press, New York, N.Y. pp. 209-261.

Kirkpatrick, N. and J. M. Palmer (1987). Semi-continuous ligninase production using foamimmobilized Phanerochaete chrysosporium. Appl. Microbiol. Biotechnol. 27:129-136.

Klemps, R., H. Cypionka, F. Widdel and N. Pfennig (1985). Growth with hydrogen, and further physiological characteristics of Desulfotomaculum species. Arch. Microbiol. 143:203-208.

Kletsova, L. V., E. S. Chibisova and Y. D. Tsygankov (1988). Mutants of the Obligate Methylotroph Methylobacillus flagellatum KT defective enzymes of the ribulose monophophate cycle of formaldehyde fixation. Arch. Microbiol 149:441-446.

Klibanov, A. M. (1986). Enzymatic reactions in organic media. In: Protein Engineering (Inouye, M. and R. Sarma, eds.). Academic Press, New York, N.Y. Chap. 21.

Klibanov, A. M. (1989). Biocatalysis in organic solvents. Trends in Biochem. Sci. 14:141-144.

Kluyver, A. J. and C. G. Schnellen (1947). On the fermentation of carbon monoxide by pure cultures of methane bacteria. Arch. Biochem. 14:57-70.

Knackmuss, H. J., M. Helwig, H. Lackner and W. Otting (1976). Cometabolism of 3-methylbenzoate and methylcatechols by a 3-chlorobenzoate utilizing Pseudomonas: accumlation of ( + )-2,3-dehydro-4methyl-and (+)-2,5-dehydro-2-methyl-5-oxo-furan-2-acetic acid. Eur. J. Appl. Microbiol. 2:267-276.

Knezovich, J. P., D. S. Bishop, T. J. Kulp, D. Grbic-Galic and J. DeWitt (1990). Anaerobic microbial degradation of acridine and the application of remote fiber spectroscopy to monitor the transformation process. Environ. Toxicol. Chem. 9:1235-1243.

Knoll, G. and J. Winter (1987). Anaerobic degradation of phenol in sewage sludge. Appl. Microbiol. Biotechnol. 25:384-391.

Knoll, G. and J. Winter (1989). Degradation of phenol via carboxylation to benzoate by a defined obligate syntrophic consortium of anaerobic bacteria. Appl. Microbiol. Biotechnol. 30:318-324.

Knott, J. A and R. D. Sproull (1989). Bioleaching of coal in a fluidized bed. Proceedings 1989 Symposium on biological processing of coal and coal-derived substances, Electric Power Research Institute, Palo Alto, CA. pp. 2.39-2.50.

Knowles, R. (1982). Denitrification. Microbiol. Rev. 46:43-70.

Köhler, M., I. L. Genz, B. Schicht and V. Eckart (1984). Microbial desulfurization of petroleum and heavy petroleum fractions. 4. Anaerobic degradation of organic sulfur compouns of petroleum. $\mathrm{Zbl}$. Mikrobiol. 139:239-247. 
Konheiser, U., B. Pasti, C. Bollschweiler and A. Klein (1984). Mol. Gen. Genet. 198:146-152.

Kosaric, N., W. L. Cairns and N. C. C. Gray (eds.) (1987). Biosufactants and Biotechnology. Marcel Dekker, New York, N.Y.

Krishna, C. R. and A. J. Francis (1988). Microbial treatment of coals and its effect on ash fusion properties. ACS Div. Fuel Chem. Preprints 35:587-589.

Krouse, H. R., C. A. Viau, L. S. Eliuk, A. Ueda and S. Halas (1988). Chemical and isotopic evidence of thermochemical sulphate reduction by light hydrocarbon gases in deep carbonate reservoirs. Nature 333:415-419.

Krumholz, L. R. and M. P. Bryant (1985). Clostridium pfennigii sp. nov. uses methoxyl groups of monobenzenoids and produces butyrate. Int. J. Syst. Bacteriol. 35:454-456.

Krumholz, L. R. and M. P. Bryant (1986a). Eubacterium oxidoreducens sp. nov. requiring $\mathrm{H}_{2}$ or formate to degrade gallate, pyrogallol, phloroglucinol and quercetin. Arch. Microbiol. 144:8-14.

Krumholz, L. R. and M. P. Bryant (1986b). Syntrophococcus sucromutans sp. nov. gen. nov. uses carbohydrates as electron donors and formate, methoxymonobenzenoids or Methanobrevibacter as electron acceptor systems. Arch. Microbiol. 143:313-318.

Krumholz, L. R. and M. P. Bryant (1988). Characterization of the pyrogallol-phloroglucinol isomerase of Eubacterium oxidoreducens. J. Bacteriol. 170:2472-2479.

Krumholz, L. R., R. L. Crawford, M. E. Hemling and M. P. Bryant (1987). Metabolism of gallate and phloroglucinol in Eubacterium oxidoreducens via 3-hydroxy-5-oxohexanoate. J. Bacteriol 169. 1886-1890.

Krzycki, J. A., L. J. Lehman and J. G. Zeikus (1985). Acetate catabolism by Methanosarcina barkeri: Evidence for the involvement of carbon monoxide dehydrogenase, methyl coenzyme $M$ and methylreductase. J. Bacteriol. 163:1000-1006.

Kuhn, E. P., P. J. Colberg, J. L. Schnoor, O. Wanner, A. J. B. Zehnder and R. P. Schwarzenbach (1985). Microbial transformations of substituted benezenes during infiltration of river water to ground water: laboratory column studies. Environ. Sci. Technol. 19:961-968.

Kuhn, E. P., J. Zeyer, P. Eicher and R. Schwarzenbach (1988). Anaerobic degradation of alkylated benzenes in denitrifying laboratory aquifer columns. Appl. Environ. Microbiol. 54:490-496.

Kuhn, E. P., J. M. Suflita, M. D. Rivera and L. Y. Young (1989). Influence of alternate electron acceptors on the metabolic fate of hydroxybenzioate isomers in anoxic aquifer slurries. Appl. Environ. Microbiol. 55:590-598.

Kuhn, E. P. and J. M. Suflita (1989a). Anaerobic biodegradation of nitrogen-substituted and sulfonated benzene aquifer contaminants. Haz. Waste Haz. Mater. 6:121-133.

Kuhn, E. P. and J. M. Suflita (1989b). Microbial degradation of nitrogen, oxygen, and sulfur heterocyclic compounds under anaerobic conditions: studies with aquifer samples. Env. Toxicol. Chem. 8:1149-1158. 
Kula, M. R., Y. Aharonowitz, J. Bu'Lock, A. M. Chakrabarty, D. A. Hopwood, B. Mattiasson, J. G. Norris, O. M. Neijssel, H. Sahm, J. H. Sobieszczanski, U. Stahl and K. N. Timmis (1986). Microbiology and Industrial Products. In: Biotechnology: Potentials and Limitations (S. Silver, ed.). Springer Verlag, Berlin. pp. 71-81.

Kurita, S., T. Endo, H. Nakamura, T. Yagi and N. Tamiya (1971). Decomposition of some organic sulfur compounds in petroleum by anaerobic bacteria. J. Gen. Appl. Microbiol. 17:185-198.

Laane, C. and J. Tramper (1990). Tailoring the medium and reactor for biocatalysis. Chemtech. 20:502.

Laane, C., S. Boeren, K. Vos and C. Veeger (1987). Rules for optimization of biocatalysis in organic solvents. Biotechnol. Bioeng. 30:81-84.

Lacey, D. T. and F. Lawson (1970). Kinetics of the liquid phase oxidation of acid ferrous sulfate by Thiobacillus ferroxidans. Biotech. Bioeng. 12:29-50.

Ladousse, A. and B. Tramier (1991). Results of twelve years of research in spilled oil bioremediation: Inipol EAP22. Proceedings of the 1991 International oils spill conference, American Petroleum Institute, Washington D.C. pp. 577-581.

Lake, E. A., P. A. S. Rae and E S. Pankhurst (1986). Biological aspects of bringing gas ashore. 123rd Annual General Meeting of the Institution of Gas Engineers, May 15, 1986. Communication 1291.

Lapin, D. and J. V. Matson (1990). Bioconversion of solubilized lignite: pilot reactor studies. In: Bioprocessing and biotreatment of coal (D. Wise, ed.). Marcel Dekker, Inc. New York, N.Y. pp. 211243.

Later, D. W., M. L. Lee, K. D. Gartle, R. C. Kong and D. L. Vasillaros (1981). Chemical class separation and characterization of organic compounds in synthetic fuels. Anal Chem. 53:1612-1620.

Lawes, B.C. (1990). Soil-induced decomposition of hydrogen peroxide: preliminary findings. In: Petroleum Contaminated Soils (Kostecki, P. T. and Calabrese, E. J., eds.). 3:239-249.

Lazaroff, N., J. E. Wey and P. R. Dugan (1990). Bacterioelectric deashing of coals. ACS Div. Fuel Chem. Preprints 35:926-942.

Leahy, J. G. and R. R. Colwell (1990). Microbial degradation of hydrocarbons in the environment. Microbiol. Revs. 54:305-315.

Lee, H. K. and K. L. Sublette (1990). Reduction of nitric oxide to elemental nitrogen by Thiobacillus denitrificans. Appl. Biochem. Biotechnol. 24/25:441-445.

Lee, H. K. and K. L. Sublett (1991). Simultaneous combined microbial removal of sulfur dioxide and nitric oxide from a gas stream. Appl. Biochem. Biotechnol. 28/29:623-634.

Lee, K. and E. M. Levy (1991). Bioremediation: waxy crude oils stranded on low energy shorelines. Proceedings of the 1991 International oils spill conference, American Petroleum Institute, Washington D.C. pp. 541-547. 
Leeper, S. A. and G. F. Andreus (1991). A Critical review and evaluation of bioproduction of organic chemicals. Appl. Biochem. Biotechnol. 28/29:499-511.

Lehrbach, P. R., J. Zeyer, W. Reineke, H. J. Knackmuss and K. N. Timmis (1984). Enzyme recruitment in vitro: use of cloned genes to extend the range of haloaromatics degraded by Pseudomonas sp. B13. J. Bacteriol 158:1025-1032.

Lettinga, G., A. F. M. van Velsen, S. Hobma, W. de Zeeuw and A. Klapwijk (1980). Use of the upflow sludge blanket (USB) reactor concept for biological wastewater treatment, especially for anaerobic treatment. Biotechnol. Bioeng. 22:699-734.

Lettinga, G., S. W. Homa, L. W. Hulshoff Pol, W. de Zeeuw, P. de Jong, D. Grain and R. Roersma (1983). Design, operation and economy of anaerobic treatment. Water Sci. Technol. 15:177-196.

Leuschner, A. P., D. J. Trantolo, E. E Kern and D. L. Wise (1985). Biogasification of Texas lignite. Dynatech R/D Company, Cambridge, Mass and Houston Lighting and Power, Houston, TX.

Leuschner, A. P., M. J. Laquidara and A. S. Martel (1990). Biological methane production from Texas lignite. In: Bioprocessing and Biotreatment of Coal (D. L. Wise, ed.). Marcel Dekker, Inc., New York, N.Y. pp. 109-130.

Levine, S. and W. Ghiorse (1990). Analysis of environmental factors affecting abundance and distribution of bacteria, fungi, and protozoa in subsurface sediments of the upper atlantic coastal plain. In: Proceedings of the First International Symposium on Microbiology of the Deep (C. B. Fliermans and T. C. Hazen, eds.). pp. 5-31 to 5-47.

Ley, S. V., F. Sternfeld and S. Taylor (1987). Microbial oxidation in synthesis: a six step preparation of $(+)$-pinitol from benzene. Tetrahedron Lett. 28:225-228.

Ley, S. V. and F. Sternfeld (1988). Microbial oxidation in synthesis: preparation from benzene of the cellular secondary messenger myo-inositol-1,4,5-triphosphate $\left(\mathrm{IP}_{3}\right)$ and related derivatives. Tetrahedron Lett. 29:5305-5307.

Lidstrom-O'Connor, M. (1982). A Study of the Genetics and Regulation of Methane Oxidation. DOE/ER/10680-2.

Lin, S., X. Zhou and R. Traxler (1989). Acetone butanol fermentation in China. Society for Industrial Microbiology News 39:209-210.

Lindstrom, J. E. and E. J. Brown (1989). Supplemental carbon use by microorganisms degrading toxic organic compounds, and the concept of specific toxicity. Haz. Waste Haz. Mats. 6:195-200.

Linehan, J. C. (1990). Characterization of the coal biosolubilization process using gel permeation chromatography and CPMAS NMR. In: Proceedings: 1990 First International Symposium on the Biological Processing Coal, Electric Power Research Institute GS-6970, September 1990, Palo Alto, CA. pp. 1-75 - 1-86.

Linko, S. (1988). Production and characterization of extracellular lignin peroxidase from immobilized Phanerochaete chrysosporium in a 10-L bioreactor. Enzyme Microb. Technol. 10:410-416. 
Linko, Y. Y., M. Leisola, N. Lindholm, J. Troller, P. Linko and A. Fiechter (1986). Continuous production of lignin peroxidase by Phanerochaete chrysosporium. J. Biotechnol. 4:283-290.

Linton, J. D. and R. E. Cripps (1978). The occurrence and identification of intracellular polyglucose storage granules in Methylococcus NCIB 11083 grown in chemostat culture on methane. Arch. Microbiol. 117:41-48.

Little, B., P. Wagner and D. Duquette (1987). Microbiologically induced cathodic depolarization. In: Corrosion 87, Paper No. 370, NACE, Houston.

Little, B., P. Wagner, S. M. Gerchakov, M. Walch and R. Mitchell (1986). Involvement of a thermophilic bacterium in corrosion processes. Corrosion 42:533-536.

Little, B. J., P. A. Wagner, W. G. Characklis and W. Lee (1990). Microbial corrosion. In: Biofilms (W. G. Characklis and K. C. Marshall, eds.). John Wiley and Sons, Inc., New York, N.Y.

Little, C. D., A. V. Palumbo, S. E. Herbes, M. E. Lidstrom, R. L. Tyndall and P. J. Gilmer (1988). Trichloroethylene biodegradation by a methane-oxidizing bacterium. Appl. Environ. Microbiol. 54:951-956.

Liu, S., L. N. Liang and J. M. Suflita (1991). The metabolism of the ground water contaminant 2hydroxybiphenyl under sulfate-reducing bacterial conditions. Curr. Microbiol. 22:69-72.

Lorowitz, W. H. and M. P. Bryant (1984). Peptostreptococcus productus strain that grows rapidly with $\mathrm{CO}$ as the energy source. Appl. Environ. Microbiol. 47:961-964.

Lovitt, R. W., B. H. Kim, G. J. Shen and J. G. Zeikus (1988). Solvent production by microorganisms. Critical Rev. Biotechnol. 7:107-186.

Lovley, D. R. (1987). Organic matter mineralization with the reduction of ferric iron: a review. Geomicrobiol. J. 5:375-399.

Lovley, D. R. and E. J. P. Phillips (1988). Novel mode of microbial energy metabolism: organic carbon oxidation coupled to dissimilatory reduction of iron or manganese. Appl. Environ. Microbiol. 54:1472-1480.

Lovley, D. R. and D. J. Lonergan (1990). Anaerobic oxidation of toluene, phenol and p-cresol by the dissimilatory iron-reducing organism, GS-15. Appl. Environ. Microbiol. 56:1858-1864.

Lunden, K. C. and T. M. Stastny (1985). Sulphate-reducing bacteria in oil and gas production. In: Corrosion 85 Conference, Paper 296, Boston, MA., NACE.

Lynd, L. H., R. Kerby and J. G. Zeikus (1982). Carbon monoxide metabolism of the methylotrophic acidogen Butyribacterium methylotrophicum. J. Bacteriol. 149:255-263.

Machlin, S. M., P. E. Tam, C. A. Bastien and R. S. Hanson (1988). Genetic and physical analyses of Methylobacterium organophilum XX. Genes encoding methanol oxidation. J. Bacteriol. 170:141-148. 
Maciel, G. E., P. S. Marchetti, S. F. Dec, I. S. Chuang, H. Lock, R. H. Lewis and C. E. Bronnimann (1991). Applications of solid-state NMR to inorganic materials. Abstracts 1991 Pittsburg Conference \& Exposition, Pittsburgh, PA. \# 391.

MacLeod, F. A., H. M. Lappin Scott and J. W. Costerton (1988). Plugging of a model rock system by using starved bacteria. Appl. Environ. Microbiol. 54:1365-1372.

Madsen, E. L., A. J. Francis, and J. M. Bollag (1988). Environmental factors affecting indole metabolism under anaerobic conditions. Appl. Environ. Microbiol. 54:74-78.

Major, D. W., C. I. Mayfield and J.F. Barker (1988). Biotransformation of benzene by denitrification in aquifer sand. Ground Water 26:8-14.

Maka, A. (1990). Microbial removal of $\mathrm{H}_{2} \mathrm{~S}$ from gas streams. Proceedings First International Symposium on the Biological Processing of Coal. Electric Power Research Institute. pp. 19-24.

Maka, A, V. McKinley, J. R.Conrad and K. F. Fannin (1987). Degradation of benzothiophene and dibenzothiophene under anaerobic conditions by mixed cultures. Abst. Annu. Meet. Am. Soc. Microbiol. O-54. pp. 269.

Makula, R. A. and W. R. Finnerty (1968). Microbial assimilation of hydrocarbons. I. Fatty acids derived from normal alkanes. J. Bacteriol. 95:2102-2107.

Makula, R. A., P. J. Lockwood and W. R. Finnerty (1975). Comparative analysis of the lipids of Acinetobacter species grown on hexadecane. J. Bacteriol. 121:250-258.

Malashenko, Y. R., Y. Khaier, E.N. Budkova, Y. Isagulova, U. Berger, T. P. Krishtab, D. V. Chernhyshenko and V. A. Romanovskaya (1987). Methane-oxidizing microflora in bodies of fresh and salt water. Plenum Publishing Corporation. pp. 115-120.

Manowitz, B. and F. W. Lipfert (1990). Environmental aspects of the combustion of sulfur-bearing fuels. In: Geochemistry of Sulfur in Fossil Fuels (Orr, W. L. and C. M. White, eds.). American Chemical Society Symposium Series 429. pp. 53-67.

Mara, D. D. and D. J. A. Williams (1970). The evaluation of media used to enumerate sulphate reducing bacteria. J. Appl. Bact. 33:543.

Marlatt, J. A. and R. Datta (1986). Acetone-butanol fermentation process development and economic evaluation. Biotechnology Progress. 2:23-28.

Martin, A K (1982). The origin of urinary aromatic compounds excreted by ruminants. 3. The metabolism of phenolic compounds to simple phenols. Brit. J. Nutrit. 48:497-507.

Mathias. L. J., D. G. Powell, A. M. Sikes and G. Johnson (1991): 15-N solid state NMR of polymers: a new method for examining composition, conformation, and motion. Abstracts 1991 Pittsburg Conference \& Exposition, Pittsburgh, PA. \# 392

Mathur, S. P. (1974). Phthalate esters in the environment: pollutants or natural products? $J$. Environ. Qual. 3:189-97. 
May, S. W. (1979). Enzymatic epoxidation reactions. Enzyme Microbiol. Technol. 1:15-22.

Mayer F. L., D. L.Stalling and J. L.Johnson (1972). Phthalate esters as an environmental contaminant. Nature 238:411-413.

McClelland, R. W. Jones, and S. Lug (1991). Recent advances in photoacoustic FTIR. Abstracts 1991 Pittsburg Conference \& Exposition, Pittsburgh, PA. \# 367.

McCormick, N. G., F. E. Feeherry and H. S. Levinson (1976). Microbial transformation of 2,4,6trinitrotoluene and other nitroaromatic compounds. Appl. Environ. Microbiol. 31:949-958.

McKinley, V.L., J.W. Costerton and D.C. White (1988). Microbial biomass activity and community structure of water and particulates retrieved by backflow from a waterflood injection well. Appl. Environ. Microbiol. 54:1383-1393.

Mehta, P. K, S. Mishra and T. K. Ghose (1987). Methanol accumulation by resting cells of Methylosinus trichosporium (I). J. Gen. Appl. Microbiol. 33:221-229.

Mehta, P.K., S. Mishra and T. K. Ghose (1991). Methanol biosynthesis by covalently immobilized cells of Methylosinus trichosporium: Batch and continuous studies. Biotechol. Bioeng. 37:551-556.

Merkel, S.M., A.E. Eberhard, J. Gibson and C.S. Harwood (1989). Involvement of coenzyme A thioesters in anerobic metabolism of 4-hydroxybenzoate by Rhodopseudomonas palustris. 171:1-7.

Mermod, N., Harayama and K. N. Timmis (1986a). New route to bacterial production of indigo. BIO/TECHNOLOGY 4:321-324.

Mermod N., J.-L., Ramos, P. R. Lehrbach, K. N. Timmis (1986b). Vector for regulated expression of cloned genes in a wide range of Gram-negative bacteria. J. Bacteriol. 167:447-454.

Metzler, T., R. Marquardt, P. Prave and E.-L. Winnacker (1987). Characterisation of a promoter Methylosinus trichosporium (IP) J. Gen. Appl. Microbiol. 33:221-229.

Miall, L. M. (1978). Organic acids. In: Economic Microbiology,

Vol 2 (A. H. Rose, ed.). Academic Press, New York, N.Y. pp. 47-119.

Mihelcic, J. R. and R. G. Luthy (1988a). Degradation of polycyclic aromatic lydrocarbon compounds under various redox conditions in soil-water systems. Appl. Environ. Microbiol. 54:1182-1187.

Mihelcic, J. R. and R. G. Luthy (1988b). Microbial degradation of acenaphthene and naphthalene under denitrification conditions in soil-water systems. Appl. Environ. Microbiol. 54:1188-1198.

Miklaucic, E. A. and J. Saseen (1989). The Ashland oil spill, Floreffe, Pa - case history and response evaluation. Proceedings of the 1989 International oils spill conference, American Petroleum Institute, Washington D.C. pp. 45-51.

Miller, J. D. A. and R. A. King (1975). Biodeterioration of metals. In: Microbial Aspects of the Deterioriation of Materials (D. W. Lovelock and R. J. Gilbert, eds.). Academic Press, New York, N.Y. 
Mittelman, M. W., D. E. Nivens, C. Low and D. C. White (1990). Differential adhesion, activity, and carbohydrate:protein ratios of Pseudomonas atlantica monocultures attaching to stainless steel in a linear shear gradient. Microbial Ecology 19:269-278.

Mizuno, S., N. Yoshikawa, M. Seki, T. Mikawa and Y. Imada (1988). Microbial production of cis, cis-muconic acid from benzoic acid. Appl. Microbiol. Biotechnol. 28:20-25.

Modrzakowski, M. C. and W. R. Finnerty (1980). Metabolism of symmetrical dialkyl ether by Acinetobacter species HO1-N. Arch. Microbiol. 126:285-290.

Modrzakowski, M. C., R. A. Makula and W. R. Finnerty (1977). The metabolism of the alkane analogue, di-octyl ether, by Acinetobacter species. J. Bacteriol. 131:92-97.

Mohan, R. R., M. Li Robbins, A. I. Laskin and L. A. Naslund (1979). Use of microorganisms in combination with surface active agents to synergistically disperse oil slicks. U.S. Patent 4,146,470.

Molnaa, B. A. and R. B. Grubbs (1989). Bioremediation of petroleum contaminated soils using a microbial consortia as inoculum. In: Petroleum Contaminated Soils (Calabrese, E. J. and Kostecki, P. T., eds.). 2:219-232.

Molton, P. M. and B. J. Pirt (1971). A chromatographic method for analysis of the gaseous phase in shake flask cultures and its application to the study of methane utilization. J. Appl. Bact. 34:535-54.

Mondello, F. J. (1989). Cloning and expression in Escherichia coli of Pseudomonas strain LB400 gene encoding polychlorinated biphenyl degradation. J. Bacteriol. 171:725-729.

Montgovery, A. D., M. J. McInerney and K. L. Sublette (1990). Microbial control of the production of hydrogen sulfide by sulfate-reducing bacteria. Biotech. Bioeng. 35:553-539.

Monticello, D. J. and W. R. Finnerty (1985). Microbial desulfurization of fossil fuels. Ann. Rev. Microbiol. 39:371-389.

Monticello, D, D. Bakker, M. Schell and W. R. Finnerty (1985a). Plasmid-borne Tn5 insertion mutation resulting in accumulation of gentisate from salicylate. Appl. Environ. Microbio. 49:761-766.

Monticello, D., D. Bakker and W. R. Finnerty (1985b). Plasmid-mediated degradation of dibenzothiophene by Pseudomonas species. Appl. Environ. Microbiol. 49:756-760.

Moreton, R. S. (1989). Technical and economic aspects and feasibility of single cell oil production using yeast technology. In: World Conference on Biotechnology for the Fats and Oil Industry (T. H. Applewhite, ed.). American Oil Chemists Society, Urbana, IL. pp. 148-152.

Mountfort, D. O. and M. P. Bryant (1982). Isolation and characterization of an anaerobic syntrophic benzoate-degrading bacterium from sewage sludge. Arch. Microbiol. 133:249-256.

Mountfort, D. O. and R. A. Asher (1986). Isolation from a methanogenic ferulate degrading consortium of an anaerobe that converts methoxyl groups of aromatic acids to volatile fatty acids. Arch. Microbiol. 144:55-61. 
Mountfort, D. O., W. J. Brulla, L. R. Krumholtz and M. P. Bryant (1984). Syntrophus buswelli gen. nov. sp. nov.: a benzoate catabolizer from methanogenic ecosystems. Int. J. Systematic Bacteriol. 34:216-217.

Nakhla, G. F., M. T. 'Suidan and J. T. Pfeffer (1990). Control of anaerobic GAC reactors treating inhibitory wastewaters. Res. J. WPCF 62:65-72.

Narayan, R. and N. W. Y. Ho (1988). Objectives of coal bioprocessing and objectives. ACS Div. Fuel Chem. Preprints 35:487-495.

National Academy of Sciences (1985). Oil in the sea; inputs, fates and effects. Washington, D.C.

National Research Council Committee (1945). Chemistry of coal utilization. J. Wiley and Sons, New York, N.Y. pp. 1370-1457.

Neilson, A. H., A-S. Hynning and M. Remberger (1988). Transformation of halogenated aromatic aldehydes by metabolically stable anaerobic enrichment cultures. Appl. Environ. Microbiol. 54:22262236.

Ngaisa, O. G. and D. L. Wise (1988). Process evaluation for the enzymic removal of organic sulfur from coal. AIChE Ann. Meeting Preprint N.65f.

Nichols, P. D., W. R. Mayberry, C. P. Antworth and D. C. White (1985a). Determination of monounsaturated double bond position and geometry in the cellular fatty acids of the pathogenic bacterium Francisella tularensis. J. Clin. Microbiol. 21:738-740.

Nichols, P. D.; J. M. Henson, J. B. Guckert, D. E. Nivens and D. C. White (1985b). Fourier transform-infrared spectroscopic methods for microbial ecology: analysi of bacteria, bacteria-polymer mixtures and biofilms. J. Microbiol. Methods 4:79-94.

Nichols, P. D., J. B. Guckert and D. C. White (1986). Determination of monounsaturated fatty acid double-bond position and geometry for microbial monocultures and complex consortia by capillary GC-MS of their dimethyl disulphide adducts. J. Microbiol. Methods 5:49-55.

Nichols, P. D., G. A. Smith, C. P. Antworth, R. S. Hanson and D. C. White (1987a). Phospholipid and lipopolysaccharide normal and hydroxy fatty acids as potential signatures for methane-oxidizing bacteria. FEMS Microbiol. Ecol. 31:327-335.

Nichols, P. D., C. A. Mancuso and D. C. White (1987b). Assessment of methanotrophic and methanogenic biomass and community structure from environmental samples using signature phospholipids. Organic Geochemistry. 11:451-461.

Nickels, J. D., J. D. King and D. C. White (1979). Poly beta-hydroxybutyrate metabolism as a measure of unbalanced growth of the estuarine detrital microbiota. Appl. Environ. Microbiol. 37:459. 465.

Nivens, D. E., P. D. Nichols, J. M. Henson, G. G. Geesey and D. C. White (1986). Reversible acceleration of corrosion of stainless steel exposed to seawater induced by the extracellular secretions of the marine vibrio Vibrio natriegans. Corrosion 41:204-210. 
Nivens, D. E., J. Q. Chambers and D. C. White (1990). Non-destructive monitoring of microbial biofilms at the solid-liquid interfaces using on-line devices. Proceedings of the Intemational Congress of Microbially Influenced Corrosion (N. J. E. Dowling and M. W Mittelman, eds.). Knoxville, TN.

Nochur, S. V. and J. P. Kitchell (1990). Enzymatic desulfurization of coal. Proceedings First International Symposium on the Biological Processing of Coal. Electric Power Research Institute. pp. 33-36.

Norris, P. R. (1990). Acidophilic bacteria and their activity in mineral sulfide oxidation. In: Microbial Mineral Recovery (Ehrlich, H. L. and Brierley, C. L., eds.). McGraw-Hill, New York, N.Y. pp. 3-28.

Novelli, G. D. and C. E. Zobell (1944). Assimilation of petroleum hydrocarbons by sulfate-reducing bacteriol. J. Bacteriol. 47:447-448.

Novitsky, J.A and R.Y. Morita (1977). Survival of a psychrophilic marine Vibrio under long-term nutrient starvation. Appl. Environ. Microbiol. 33:635-641.

Novotny, M., J. W. Strand, S. L. Smith, D. Wiesler and F. J. Schwende (1981). Compositional studies of coal tar by capillary gas chromatography-mass spectrometry. Fuel 60:213-220.

Nunn, D. N. and M. E. Lidstrom (1986a). Isolation and complementation analysis of 10 methanol oxidation mutant classes and identification of the methanol dehydrogenase structural gene of Methylobacterium sp. Stain AM1. J. Bacteriol. 166:581-590.

Nunn, D. N. and M. E. Lidstrom (1986b). Phenotypic characterization of 10 methanol oxidation mutant classes in Methylobacterium sp. Strain AM1. J. Bacteriol. $4166 \quad$ :591-597.

O'Brien, J. M., R. W. Wolkin, T. T. Moench, J. B. Morgan and J. G. Zeikus (1984). Association of hydrogen metabolism with unitrophic or mixotrophic growth of Methanosarcina barkeri on carbon monoxide. J. Bacteriol. 158:373-375.

O'Connor, M., A. Wopat and R. S. Hanson (1977). Genetic transformation in Methylobacterium organophilium. J. Gen. Microbiol. 98:265-272.

O'Connor, C. D., and K. N. Timmis (1987). Highly repressible expression system for cloning genes that specify potentially toxic proteins. J. Bacteriol. $169: 4457-4462$.

Oberbremer, A., R. Muller-Hurtig and F. Wagner (1990). Effect of the addition of microbial surfactants on hydrocarbon degradation in a soil population in a stirred reactor. Appl. Microbiol. Biotechnol. 32:485-489.

Odham, G., A. Tunlid, G. Westerdahl, L. Larsson, J. B. Guckert and D. C. White (1985). Determination of microbial fatty acid profiles at femtomolar levels in human urine and the initial marine microfouling community by capillarygas chromatography-chemical ionization mass spectrometry with negative ion detection. J. Microbiol. Methods. 3:331-344.

Odom, C. B., M. Coole and N. C. Mishra (1990). Genetics of coal biosolubilization by fungi. Proceedings: 1990 First International Symposium on the Biological Processing of Coal. EPRI. pp. 4-17. 
Oil Spill Intelligence Report International Oil Spill Control Directory (1991). 11th edition, Cutter Information Corp. Arlington, MA.

Oldenhuis, R., J. Y. Oedzes, J. J. Van der Waarde and D. B. Janssen (1991). Kinetics of chlorinated hydrocarbon degradation by Methylosinus trichosporium OB3b and toxicity of trichlorethylene. Appl. Environ. Microbiol. 57:7-14.

Olsen, R. H., M. D. Mikesell and J. J. Kukor (1991). Stratification of anoxic BTEX-degrading bacteria at three petroleum contaminated sites. Abstracts of the Battelle Symposium In Situ and On-site Bioreclamation, San Diego, CA.

Olson, J. S., H. W. Diehl and J. J. Worman (1991). Analysis of complex organic reaction product mixtures by GC/FTIR/MS/AED. Abstracts 1991 Pittsburgh Conference and Exposition, Pittsburgh, PA. \# 695.

Olsson, G., L. Larsson, O. Holst and H. T. Karlsson (1989). Microorganisms for desulfurization of coal; the influence of leaching compounds on their growth. Fuel 68:1270-1274.

Oltra, R. and M. Keddam (1988). Application of impedance technique to localized corrosion. Corrosion Science 28:1-18.

Oremland, R. S. (1988). Biochemistry of methanogenic bacteria. In: Biology of Anaerobic Microorganisms. (A. J. B. Zehnder, ed.). J. Wiley, New York, N.Y. pp. 641-705.

Oremland, R. S., L. G. Miller and M. J. Whiticar (1987). Sources and flux of natural gases from Mono Lake, CA. Geochim. Cosmochim. Acta 51:2915-2929.

Oren, A. (1990a). Anaerobic degradation of organic compounds in hypersaline environments: possibilities and limitations. In: Bioprocessing and Biotreatment of Coal (D. Wise, ed.). Marcel Dekker, Inc., New York, N.Y. pp. 155-175.

Oren, A. (1990b). Microbial formation of methane from pretreated lignite at high salt concentrations. In: Bioprocessing and Biotreatment of Coal (D. Wise, ed.). Marcel Dekker, Inc., New York, N.Y. pp. 449-463.

Orr, Wilson L. (1974). Changes in sulfur content and isotopic ratios of sulfur during petroleum maturation - Study of Big Horn Basin Paleozoic Oils. The American Association of Petroleum Geologists Bulletin 58:2295-2318.

Orton, M. D. (1978). Sulphate reducing bacteria corrosion control. In: American Gas Association Transmission Conference Proceedings, Montreal, Quebec. May 1978.

Ozcengiz, G., G. N. Alaeddinoglu and N. Gurdal (1988). Microbial removal of sulfur compounds from Turkish Cannakkale-Can lignites. Turk. Biyol. Derg. 12:114-122. (Turkish, CA 110, 157384).

Page, S. H., S. R. Goates and M. L. Lee (1991). Effects of phase behavior in supercritical fluid chromatography with polar modifiers. Abstracts 1991 Pittsburgh Conference and Exposition, Pittsburgh, PA. \# 887. 
Palowitch, E. R. and F. E. Deurbrouck (1979). Wet concentration of coarse coal. 1. Dense medium separation. In: Coal Preparation (Leonard, J.W., ed.). 4th edition. American Institute of Mining, Metallurgical and Petroleum Engineers, New York, N.Y. pp. 9.1-9.36.

Pankhurst, E. S. (1968). Bacteriological aspects of the storage of gas underground. J. Appl. Bact. 31:311-322.

Pastan, I., L. Tsai and E. R. Stadtman (1964). Nicotinic acid metabolism. J. Biol. Chem. 239:902-906.

Patel, R. N. Oxidation of hydrocarbons by methane utilizing bacteria. In: Catalysis of Organic Reactions (R. L. Augustine, ed.).

Patel, R. N. and C. T. Hou (1982). Enzymatic transformation of hydrocarbons by methanotrophic organisms. In: Symposium on Biotechnology of Chemical Production. Chapter 11. pp. 141-163.

Patel, R. N., C. T. Hou and A. Felix (1979). Microbial oxidation of methane and methanol: Purification and properties of a heme-containing adehyde dhydrogenase from Methylomonas methylovora. Arch. Microbiol. 122:241-247.

Patel, R. N., C. T. Hou, A. I. Laskin, P. Derelanko and A. Felix (1979). Microbial production of methyl ketones. Eur. J. Biochem. 191:401-406.

Patel, R. N., C. T. Hou, P. Derelanko and A. Felix (1980). Purification and properties of a hemecontaining ahldehyde dehydrogenase from Methylosinus trichosporium. Arch. Biochem. Biophys. 203:654-662.

Patel, T. R., K. G. Jure and G. A. Jones (1981). Catabolism of phloroglucinol by the rumen anaerobe Coprococcus. Appl. Environ. Microbiol. 42:1010-1017.

Patt, T., G. C. Cole, J. Bland and R. S. Hanson (1974). Isolation and characterization of bacteria that grow on methane and organic compounds as sole sources of carbon and energy. J. Bacteriol. 120:955-964.

Peakall, D. B. (1975). Phthalate esters: occurrence and biological effects. Residue Rev. 54:1-41.

Peeples, T. L., G. J. Olson, S. Hirosue, V. Muralidharan and R. M. Kelly (1990). Coal sulfur transformations monitored by hyperthermophilic archaebacteria. ACS Div. Fuel Chem. Preprints 35:907-915.

Pereira, W. E., C. E. Rostad, D. M. Updegraff and J. L. Bennett (1987a). Anaerobic microbial transformations of azaarenes in ground water at hazardous waste sites. In: Chemical Quality of Water and the Hydrologic Cycle (R. C. Averett and D. M. McKnight, eds.). Lewis Publishers, Chelsea, MI. pp. 111-123.

Pereira, W. E., C. E. Rostad, D. M. Updegraff and J. L. Bennett (1987b). Fate and movement of azaarenes in an aquifer contaminated by wood-treatment chemicals. Environ. Toxicol. Chem. 6:163167. 
Pereira, W. E., C. E. Rostad, T. J. Leiker, D. M. Updegraff and J. L. Bennett (1988). Microbial hydroxylation of quinoline in contaminated ground water: evidence for incorporation of the oxygen atom of water. Appl. Environ. Microbiol. 54:827-829.

Perry, J. J. (1979). Microbial cooxidations involving hydrocarbons. Microbiol. Rev. 43:59-72.

Phelps, T. J. and D. C. White (1990). Activities of microorganisms in deep, unconsolidated eastern coastal plain sediments. In: Proceedings of the First International Symposium on Microbiology of the Deep (C. B. Fliermans and T. C. Hazen, eds.). pp. 4-125 to 4-135.

Phelps, T. J., J. J. Niedzielske, R. M. Schram, S. E. Herbes and D. C. White (1990). Biodegradation of trichloroethylene in continuous-recycle expanded-bed bioreactors. Appl. Environ. Microbiol. 56:1702-1709.

Phelps, T., R. M. Schram, D. B. Ringolberg, N. T. F. Dowling and D. C. White (1991). Hydrogen mediated acetogenesis as a possible mechanism for microbially influenced corrosion of natural gas transmission lines. Biofouling 2:114-120.

Phillips Petroleum Company (1976). United States Patent 3,975,234.

Pieper, D. H., K. H. Engesser, and H.-J. Knackmuss (1990). (+)-4-carboxymethyl-2,4-demethylbut-2en-4-olide as dead end metabolite of 2,4-dimethylphenoxyacetic acid or 2,4-dimethyl-phenol by Alcaligenes eutrophus JMP 134. Arch. Microbiol. 154:600-604.

Piet, G. J. and J. G. M. M. Smeek (1985). Behavior of organic pollutants in pretreated Rhine water during dune infiltration. In: (C. H. Ward, W. Giger and P. L. McCarty, eds.). Ground Water Quality. John Wiley \& Sons, New York, N.Y. pp. 122-144.

Pietropaolo, V., C. Danzet, A. Zecchin, P. Trois, G. Rossi, P. Valenti and N. Orsi (1990). Organic sulfur removal by microorganisms isolated from an Italian coal mine. Proceedings First International Symposium on the Biological Processing of Coal. Electric Power Research Institute 2.3-2.14.

Piorek, S. (1991). Application of a field portable X-ray analyzer to on-site analysis of workplace air contaminants. Abstracts 1991 Pittsburg Conference \& Exposition, Pittsburgh, PA. \# 183.

Pirnik, M. P., R. M. Atlas and R. Bartha (1974). Hydrocarbon metabolism by Brevibacterium erythrogenes: normal and branched alkanes. J. Bacteriol. 119:868-878.

Pope, D. H. and T. P. Zintel (1987). Methods for the investigation of under-deposit corroison. In: Corrosion 88, Paper No. 249, NACE, St. Louis, MO.

Pope, D. H., T. P. Zintel, A. K Kuruvilla and O. W. Siebert (1987). Organic acid corrosion of carbon steel: A mechanism of microbiologically influenced corrosion. In: Corrosion 88, Paper No. 76, NACE, St. Louis, $\mathrm{MO}$.

Pope, D. H., D. Dziewulske, T. P. Ziritel, H. Aldrich and J. Frank (1989a). Microbiologically influenced corrosion and hydrogen sulfide production in gas industry facilities. In: American Gas Association 1989 Operating Section Proceedings, Paper 89-DT-71: 578-584. 
Pope, D. H., T. P. Zintel, B. A. Cookingham, R. G. Morris, D. Howard, R. A. Day, J. R. Frank and G. E. Pogemiller (1989b). Mitigation strategies for microbiologically influenced corrosion in gas industry facilities. In: Corrosion 89, Paper No. 192, NACE.

Pope, D. H., D. Dziewulski and J. R. Frank (1990a). Recent advances in understanding microbiologically influenced Corrosion in the Gas industry and New approaches to mitigation. In: AGA Operating Section Proceedings 1990, Paper 90-DT-62, AGA pp.495-502.

Pope, D. H., T. P. Zintel, H. Aldrich and D. Duquette (1990b). Laboratory and field tests of efficacy of biocides and corrosion inhibitors in the control of microbiologically influenced corrsion. In: Corrosion 90, Paper No. 34, NACE.

Preslo, L., M. Miller, W. Suyama, M. McLearn, P. Kostecki and E. Fleischer (1989). Available remedial technologies for petroleum contaminated soils. In: Petroleum contaminated soils (Kostecki, P. T. and Calabrese, E. J., eds.). 1:115-127.

Pridham, J. B. (1965). Low molecular weight phenols in higher plants. Ann. Rev. Plant Physiol. 26:13-36.

Prince, R. C., G. N. George, J. C. Savas, S. P. Cramer and R. N. Patel (1989). Spectroscopic properties of the hydroxylase of methane monooxygenase. Biochem. Biophys. Acta 952:220-229.

Prince, R. C., J. R. Clark and J. E. Lindstrom (1990). Bioremediation monitoring program, report to the US Coastguard, Alaska Dept. of Environmental Protection, Anchorage, AK 99503. pp. 1-85.

Pritchard, P. H. and C. F. Costa (1991). EPA's Alaska oil spill bioremediation project. Environ. Sci. Technol. 25:372-379.

Procter, M. H. and S. Scher (1960). Decomposition of benzoate by a photosynthetic bacterium. Biochem. J. 76:33P.

Rai, C. (1986). Microbial desulfurization of bituminous coals to determine the effectiveness of Thiobacillus ferroxidans under simulated coal slurry pipeline conditions. Fossil Fuel Utilization; Environmental Concerns. ACS Symp. 319:86-96.

Ramanand, K and J. M. Suflita (1991). Anaerobic degradation of m-cresol in anoxic aquifer slurries: carboxylation reactions in a sulfate-reducing bacterial enrichment. Appl. Environ. Microbiol. In press.

Ramos, J. L., A. Stolz, W. Reineke and K. N. Timmis (1986). Altered effector specificities in regulators of gene expression TOL plasmid $x y l S$ mutants and their use to engineer expansion of the range of aromatics degraded by bacteria. Proc. Nat. Acad. Sci. USA. 83:8467-8471.

Ramos J. L., A. Wasserfallen and K. N. Timmis (1987). Redesigning metabolic routes: manipulation of TOL plasmid pathway for catabolism of alkylbenzoates. Science 235:593-596.

Ramos, J. L., Gonzalez-Carrero and K. N. Timmis (1988). Broad-host range expression vectors containing manipulated meta-cleavage pathway regulatory elements of the TOL plasmid. FEBS Lett. 226:241-246. 
Rapin, J. L. (1988). In: Third International Conference on Pervaporation Process. Nancy, France.

Ratledge, C. (1980). Microbial lipids derived from hydrocarbons. In: Hydrocarbons In Biotechnology (D. E. F. Harrison, I. J. Higgins and R. Watkinson, eds.). Heyden \& Sons, London. pp. 133-153.

Ratledge, C. (1984). Microbial fats and oils-an overview. In: Biotechnology in the Oils and Fats Industry (C. Ratledge, P. S. S. Dawson and J. B. M. Rattray, eds.). American Oil Chemists Society, Urbana, IL. pp. 119-127.

Ratledge, C. (1989). Biotechnology of oils and fats. In: Microbial Lipids, Vol 2 (C. Ratledge and J. Wilkinson, eds.). Academic Press, New York, N.Y. pp. 567-668.

Raymond, R. L., R. A. Brown, R. D. Norris and E. T. O'Neill (1986). Stimulation of biooxidation processes in subterranean formations. U.S. Patent 4,588,506.

Reed, W. and P. R. Dugan (1987). Isolation and characterization of the facultative methylotroph Mycobacterium ID-Y. J. Gen. Microbiol. 133:1389-1392.

Reeve, J., G. Beckler, P. Cram, P. Hamilton, J. Brown, J. Krzycki, A. Kolodziej, L. Alex, W. OrmeJohnson and C. Walsh (1989). Proc. Natl. Acad. Sci. USA 86:3031-3035.

Reineke W. and H.-J. Knackmuss (1978). Chemical structure and biodegradability of halogenated aromatic compounds. Substituent effects on 1,2-dioxygenation of benzoic acid. Biochim. Biophys. Acta 542:412-423.

Reineke W. and H.-J, Knackmuss (1979). Construction of haloaromatics utilising bacteria. Nature 277:285-286.

Reinhard, M., N. L. Goodman and J. F. Barker (1984). Occurrence and distribution of organic chemicals in two landfill leachate plumes. Environ. Sci. Technol. 18:953-961.

Reinhard, M., L. E. Wills, H. A. Ball, P. L. McCarty, D. W. Phipps, H. F. Ridgway and M. P. Eisman (1991). A field experiment for the anaerobic biotransformation of aromatic hydrocarbon compounds at Seal Beach, California. Abstracts of the Battelle Symposium In Situ and On-site Bioreclamation, San Diego, CA.

Renganathan, V. (1989). Possible involvement of toluene-2,3-dioxygenase in defluorination of 3fluoro-substituted benzenes by toluene-degrading Pseudomonás sp. strain T-12. Appl. Environ. Microbiol. 55:330-336.

Rengpipat and J. G. Zeikus (1990). Physiology and biotechnology of halophilic anaerobes for application to Texas lignite. In: Bioprocessing and Biotreatment of Coal (Wise, D. L., ed.). Marcel Dekker, Inc., New York. N.Y. pp. 429-436.

Requejo, A. G. and H. I. Halpern (1989). An unusual hopane biodegradation sequence in tar sands from the Pt. Arena (Monterey) formation. Nature (Lond.) 342:670-673.

Ribbons, D. W., S. C. Taylor, C. T. Evans, S. D. Thomas, J. T. Rossiter, D. A. Widdowson and D. J. Williams (1984). Biodegradations yield novel intermediates for chemical synthesis. In: Advances 
in Applied Biotechnology, Vol. 4, Biotechnology and Biodegradation, eds. D. Kamely, A. Chakrabarty and G.S. Omenn Port folio Publishing Company, The Woodlands, TX. pp. 213-245.

Riley, D., B. V. Tucker and W. Wilkinson (1976). Biological unavailability of bound paraquat residues in soil. In: D. D. Kaufman, F. F. Still, F. D. Paulson, and S. K. Bandal (eds.), Bound and conjugated pesticide residues. ACS Symp. Ser. No. 29, American Chemical Society, Washington, D. C. pp. 301-353.

Roberto, F. F., A. W. Glenn, D. Bulmer, D. F. Bruhn and T. E. Ward (1990). Genetic manipulation of acidophilic bacteria which are potentially applicable in coal beneficiation. ACS Div. Fuel Chem. Preprints 35:868-874.

Roberts, D. J., P. M. Fedorak and S. E. Hrudey (1987). Comparison of the fates of the methyl carbons of $m$-cresol and $p$-cresol in methanogenic consortia. Can. J. Microbiol. 33:335-338.

Roberts, D. J., P. M. Fedorak and S. E. Hrudey (1988). Culture methods for obtaining $m$-cresoldegrading methanogenic consortia. Can. J. Microbiol. 17:83-87.

Roberts, D., J. James-Hagstrom, D. Garvin, C. Gorst, J. Reinquist, J. Baun, F. Hasse and S. Ragsdale (1989). Proc. Natl. Acad. Sci. USA 86:32-36.

Roberts, D. J., P. M. Fedorak and S. E. Hrudey (1990). $\mathrm{CO}_{2}$ incorporation and 4-hydroxy-2methylbenzoic acid formation during anaerobic metabolism of $m$-cresol by a methanogenic consortium. Appl. Environ. Microbiol. 56:472-478.

Roberts, P. V., L. Semprini, G. D. Hopkins, D. Grbic'-Galic', P. L. McCarty and M. Reinhard (1989). In-situ Aquifer Restoration of chlorinated aliphatics by methanotrophic bacteria. EPA Report 600/289/033.

Rogers, J. E., R. G. Riley, S. W. Li, M. W. O'Malley and B. L. Thomas (1985). Microbial transfomation of alkylpyridines in groundwater. Water Air Soil Pollut. 24:443-454.

Rokem, J. S., I. Goldberg and R. I. Mateles (1978). Maintenance requirements for bacteria growing on C1-compounds. Biotech. Bioeng. 20:1557-1564.

Rosanova, E. P. and T. N. Nazina (1979). Occurrence of thermophilic sulphate-reducing bacteria in oil bearing strata of Apsheron and Western Siberia. Microbiology 129:907-911.

Rossiter, J. T., S. R. Williams, A. E. Cass and D. W. Ribbons (1987). Aromatic biotransformations 2: production of novel chiral fluorinated 3,5-cyclohexadiene-cis-1,2-diol-1-carboxylates. Tetrahedron Lett. 28:5173-5176.

Rostrup-Nielsen, J. R. (1971). Some principles relating to the regeneration of sulfur-poisioned nickel catalyst. J. Catalysis 21:171.

Runnion, K. N. and J. D. Combie (1990). Microbial removal of organic sulfur from coal. Proceedings First International Symposium on the Biological Processing of Coal. Electric Power Research Institute 2.63-2.76. 
Russell, H. H., J. E. Matthews and G. W. Sewell (1991). Remediation of sites contaminated with TCE. Remediation (Winter 1990/91):167-181.

Safferman, S. I. (1991). Selection of nutrients to enhance biodegradationfor the remediation of oil spilled on beaches. Proceedings of the 1991 International Oils Spill Conference, American Petroleum Institute, Washington D.C. pp. 571-581.

Sakai, Y. and Y. Tani,(1986). Formaldehyde production by cells of a mutant of Candida boidinii S2 grown in methanol-limited chemostat culture. Agric. Biol. Chem. 50:2615-2620.

Sakai, Y. and Y. Tani (1987a). Formaldehyde production with heat-treated cells of methanol yeast. J. Ferm. Tech. 65:489-491.

Sakai, Y. and Y. Tani (1987b). Production of acrolein, acetaldehyde and propionaldehyde by cells of a methanol yeast, Candida boidinii S2. Agric. Biol. Chem. 51:2617-2620.

Sakai, Y. and Y. Tani (1988). Production of formaldehyde by detergent-treated cells of a methanol yeast, Candida boidinii S2 Mutant Strain AOU-1. Appl. Environ. Microbiol. 54:485-489.

Samain, E., G. Albagnac and H. C. Dubourguier (1986). Initial steps of catabolism of trihydroxybenzenes in Pelobacter acidigallici. Arch. Microbiol. 144:242-244.

Sambrook, J., Fritsch and T. Maniatis (1989). Expression of cloned genes in Escherichia coli. In: Molecular Cloning - A Laboratory Manual, 2nd Edition. Cold Spring Harbor Laboratory Press, Cold Spring Harbor.

Samuelov, N. S. (1988). Kinetics and regulation of B-lactamase formation in methylotrophic bacterium. Biotech. Bioengr. 31:125-129.

Sanders, P. F. and J. F. D. Stott (1987). Assessment, monitoring, and control of microbiological corrosion hazards in offshore oil production system. In: Corrosion '87 Conference, Paper No. 367, San Francisco, NACE.

Sanders, P. F., D. M. Holt and M. J. Mosley (1987). Corrosion by thermophilic sulphide producing bacteria in hot oilfield environments. In: Proceedings of the 7th International Biodeterioration Symposium, Cambridge. Elsevier Applied Science Publishers Ltd., London.

Sariaslani, F. S. (1989). Microbial enzymes for oxidation of organic molecules. Crit. Rev. Biotechnol. 9:170-257.

Sasser, M. (1985). Identification of bacteria by fatty acid composition. Am. Soc. Microbiol. Meet. March 3-7.

Satoh, H., J. Yoshizawa and S. Kametani (1988). Bacteria help desulfurize gas. Hydrocarbon Processing. 12:10-15.

Schauder, B., H. Blöcker, R. Frank and J. E. G. McCarthy (1987). Inducible expression vectors incorporating the Escherichia coli atpE translation initiation region. Gene 52:279-283. 
Schennen, U., K. Braun and H.J. Knackmuss (1985). Anaerobic degradation of 2-fluorobenzoate by benzoate-degrading bacteria. J. Bacteriol. 161:321-325.

Schindler, J. S., and R. C. Tisdale (1991). Application of X-ray fluroesence tecniques to environmental measurements. Abstracts 1991 Pittsburgh Conference and Exposition, Pittsburgh, PA. \# 151.

Schink, B. and N. Pfennig (1982). Fermentation of trihydroxybenzenes by Pelobacter acidigallici gen. nov. sp. nov., a new strictly anaerobic, non-sporeforming bacterium. Arch. Microbiol. 133:195-201.

Schink, B. and M. Stieb (1983). Fermentative degradation of polyethylene glycol by a strictly anaerobic, gram-negative nonsporeforming bacterium, Pelobacter venetianus sp., nov. Appl. Environ. Microbiol. 45:1905-1913.

Schnell, S., F. Bak and N. Pfennig (1989). Anaerobic degradation of aniline and hydroxybenzenes by newly isolated sulfate-reducing bacteria and description of Desulfobacterium anilini. Arch. Microbiol. 152:556-563.

Schnell, S. and B. Schink (1991). Anaerobic aniline degradation via reductive deamination of 4aminobenzoyl-CoA in Desulfobacterium anilini. Arch. Microbiol. 155:183-190.

Schurig, V. and W. Burkle (1982). Extending the scope of enantiomer resolution by complexation gas chromatography. J. Am. Chem. Soc. 104:7573-7580.

Schwartz, D. (1990). Isolation of microorganisms which can extract organic sulfur from coal humic acids. Proceedings First International Symposium on the Biological Processing of Coal. EPRI, 2-95, 1990.

Schwartz, D., J.R. Mattoon, P. Neus and M. Mooney (1990). Isolation of microorganisms which can extract organic sulfur from coal humic acids. Proceedings First International Symposium on the Biological Processing of Coal. Electric Power Research Institute 2.93-2.101.

Schwarzenbach, R. P., E. Hoehn, and J. K. Schneider (1983). Behavior of organic compounds during infiltration of river water to ground water. Environ. Sci. Technol. 17:472-479.

Scott, C.D., G.W. Strandberg and S.N. Lewis (1986). Microbial depolymerization of coal. Biotechnol. Prog. 2:131-139.

Scott, C. D., C.A. Woodward, and B.D. Faison (1990). Solubilization of coal by reducing enzymes in organic and aqueous medium. Proceedings First International Symposium on the Biological Processing of Coal. EPRI, 4-45.

Sembiring, T. and J. Winter (1989). Anaerobic degradation of $o$-phenylphenol by mixed and pure cultures. Appl. Microbiol. Biotechnol. 31:81-92.

Semprini, L., P.V. Roberts, G.D. Hopkins and D.M. Mackay (1987). A field evalutation of in-situ biodegradation methodologies for the restoration of aquifers contaminated with chlorinated aliphatic compounds: Results of a Preliminary demonstration. Stanford Technical Report No. 302. 
Senior, E., and M.T.M. Balba (1984). The use of single-stage and multi-stage fermentors to study the metabolism of xenobiotic and naturally occurring molecules by interacting microbial associations. In: Microbiological Methods for Environmental Biotechnology (Grainger, J.M. and J.M. Lynch, eds). Society for Applied Bacteriology, Academic Press, Inc., Orlando, FL. pp.275-293.

Sharak-Genthner B.R. and M.P. Bryant (1987). Additional characteristics of one-carbon-compound utilization by Eubacterium limosum and Acetobacterium woodii. Appl. Environ. Microbiol. 53:471-476.

Sharak-Genthner, B.R., W. A. Price, II and P. H. Pritchard (1989a). Anaerobic degradation of chloroaromatic compounds in aquatic sediments under a variety of enrichment conditions. Appl. Environ. Microbiol. 55:1466-1471.

Sharak-Genthner, B. R., W. A. Price, II and P. H. Pritchard (1989b). Characterization of anaerobic dechlorinating consortia derived from aquatic sediments. Appl. Environ. Microbiol. 55:1472-1476.

Sharak-Genthner, B. R., G. T. Townsend and P. J. Chapman (1989c). Anaerobic transformation of phenol to benzoate via para-carboxylkation: use of fluorinated analogues to elucidate the mechanism of transformation. Biochem. Biophys. Res. Commun. 1262:945-951.

Shaw, J.C., B. Bramhill, W.C. Wardlaw and J.W. Costerton (1985). Bacterial fouling of a model core system. Appl. Environ. Microbiol. 49:693-701.

Shay, L.K and G. Wegner (1985). Improved fermentation process for producing Torula yeast. Food Technol. 39:61-66.

Shay, L.K. and G. Wegner (1986). Nonpolluting conversion of whey permeate to food yeast protein. J. Dairy Sci. 69:676-683.

Sheehan, B. T. and M. J. Johnson (1971). Production of bacterial cells from methane. Appl. Microbiol. 21:511-515.

Shelton, D. R. and J. M. Tiedje (1984). General method for determining anaerobic biodegradation potential. Appl. Environ. Microbiol. 47:850-857.

Shelton D.R., S.A. Boyd and J.M .Tiedje (1984). Anaerobic biodegradation of phthalic acid esters in sludge. Environ. Sci. Technol. 18: 93-97.

Shennan, J.L. (1984). Hydrocarbons as substrates in industrial fermentations. In: Petroleum Microbiology, ed. R. M. Atlas. MacMillan Publishing Company, New York. pp. 643-683.

Sheppard, J.C., H. Westberg, J.F. Hopper and K. Ganesan (1982). Inventory of global methane sources and their production rates. J. Geophys. Res. 87:1305-1312.

Shima, H., Kudo, T. and Horikoshi, K. (1991). Isolation of toluene-resistant mutants from Pseudomonas putida PpG1 (ATCC17453). Agric. Biol. Chem. 55:1197.

Shlomi, E. R., A. Lankhorst and R. A. Prins (1978). Methanogenic fermentation of benzoate in an enrichment culture. Microbiol. Ecol. 4:249:261. 
Shuttleworth, K.L. and J.M. Bollag (1986). Soluble and immobilized laccase as catalysts for the transformation of substituted phenols. Enzyme Microb. Technol. 8:171-179.

Sieburth, J.M., P.W. Johnson, M.A. Eberhardt, M.E. Sieracki, M. Lindstrom, and D. Laux (1987). The first methane-oxidizing bacterium from the upper mixing layer of the deep ocean:Methylomonas pelagica sp. nov. Current Microbiology 14:285-293.

Silverman, M. P. (1964). Methane-oxidizing bacteria: A review of the literature. U.S.Bureau of Mines, 8246.

Simpson, F.Y., G.A. Jones, E.A. Wolin (1969). Anaerobic degradation of some bioflavanoids by microflora of the rumen. Can. J. Microbiol. 15:972-974.

Singer, J.T. and W.R. Finnerty (1984a). Genetics of hydrocarbon utilizing microorganisms. In: Petroleum Microbiology (R.M. Atlas, ed.). MacMillan Publishing Company, New York. pp. 299-354.

Singer, M.E. and W.R. Finnerty (1984b). Microbial metabolism of normal and branched alkanes. In: Petroleum Microbiology (R.M. Atlas ed.). MacMillan Publishing Company, New York. pp. 1-50.

Singer, M.E. and W.R. Finnerty (1990). Physiology of Biosurfactant synthesis by Rhodococcus species H-13A. Can. J. Microbiol. 36:741-745.

Singer, M.E., S. Tyler, and W.R. Finnerty (1985). Growth of Acinetobacter species HOl-N on nhexadecanol. Physiological ultrastructural characteristics. J. Bacteriol. 162:162-169.

Singer, M.E., W.R. Finnerty and A. Tunelid (1990). Physical and chemical properties of a biosurfactant synthesized by Rhodococcus species H-13A. Can. J. Microbiol. 36:746-750.

Singh, S., D. Nguyen, J. Grieco, M. de Rocco, J.W. Costerton, F. Cusack and H.M. Lappin-Scott (1988). Reservoir plugging/blocking using ultramicrobacteria:three-dimensional physical simulator results. IV Unitar Conference. AOSTRA publication. pp.1-14.

Sleat, R. and J. P. Robinson (1983). Methanogenic degradation of sodium benzoate in profundal sediments from a small eutrophic lake. J. Gen., Microbiol. 129:1412-152.

Sleat, R. and J.P. Robinson (1984). The bacteriology of anaerobic degradation of aromatic compounds. J. Appl. Bacteriol 57:381-394.

Smolenski, W.J. and J. M. Suflita (1987). Biodegradation of cresol isomers in anoxic aquifers. Appl. Environ. Microbiol. 53:710-716.

Snellman, E.A, R.P. Collins and J.C. Cooke (1988). Utilization of fuel oils by fungi isolated from oceanic tar balls. Lett. Appl. Microbiol. 6:105-107.

Somerville, H.J. (1987). North sea oil exploration ad production: interactions with the environment. Institute of petroleum Annual Conference. Aberdeen, Scotland. Paper STJ337.

Song, H., X. Wang, and R. Bartha (1990). Bioremediation potential of terrestrial fuel spills. Appl. Environ. Microbiol. 56:652-656. 
Spain, J.C. and D.T. Gibson (1988). Oxidation of substituted phenols by Pseudomonas putida F1 and Pseudomonas sp., strain JS6. Appl. Environ. Microbiol. 54:1399-1405.

Speight, J.G. and S.E. Moschopedis (1981). On the molecular nature of petroleum asphaltenes. In: Chemistry of Asphaltenes (J. W. Bunger and N.C. Li, eds.). American Chemical Society, Washington, D.C. pp. 1-16.

Stegmann, R., S. Lotter and J. Heerenklage (1991). Biological treatment of oil contaminated soils in bioreactors. Abstracts of the Battelle Symposium In Situ and On-site Bioreclamation, San Diego, CA.

Stephens, R. L., M. G. Haygood, and M. E. Lidstrom (1988). Identification of putative methanol dehydrogenase (moxF) structural genes in methylotrophs and cloning of moxF genes from Methylococcus capsulatus Bath and Methylomonas albus BG8. J. Bacteriol. 170:2063-2069.

Stetter, K.O., H.Konig,and E. Stackebrandt (1983). Pyridictium gen. nov., a new genus of submarine disc-shaped sulphur-reducing Archaebacteria growing optimally at 105 degrees C. System. Appl. Microbiol. 4:535-551.

Stock, L.M. and R. Wolny (1990). Elemental sulfur in bituminous coals. In: Geochemistry of Sulfur in Fossil Fuels(Orr, W.L. and White, C.M., eds). American Chemical Society Symposium Series 429, pp. 241-248.

Stott, J.F.D. (1987). Petroleum reservoir souring. In: Sour Service in the Oil, Gas, and Chemical Industry. CAPCIS and IBC Technology.

Stott, J. and B.N. Herbert (1986). The effect of pressure and temperature on sulphate-reducing bacteria and the action of biocides in oilfield water injection systems. J. Appl. Bact. 61:57-66.

Streitwieser A., Jr. and C. H. Heathcock (1976). Introduction to Organic Chemistry. Macmillan Publishing Company, New York.

Stümer, D. H., D. J. Ng, and C. J. Morris (1982). Organic contaminants in groundwater near an underground coal gasification site in northeastern Wyoming. Environ. Sci. Technol. 16:582-585.

Sublette, KL. (1988). Biological removal of hydrogen sulfide from coal-derived synthesis gas. $A C S$ Div. Fuel Chem. Preprints 35: 665-678.

Sublette, K.L., P. Plumb, B.N. Dasu and K. Lee (1990). Microbial reduction of sulfur dioxide as a means of by-product recovery from regenerable processes for flue gas desulfurization. Proceedings First International Symposium on the Biological Processing of Coal. Electric Power Research Institute 5.51-5.64.

Suflita, J. M. and G. D. Miller (1985). Microbial metabolism of chlorophenolic compounds in ground water aquifers. Environ. Tox. Chem. 4:751-758.

Suflita, J.M., L.-N. Liang, and A. Saxena (1989). The anaerobic biodegradation of o-, m- and p-cresol by sulfate-reducing bacterial enrichment cultures obtained from a shallow anoxic aquifer. $J$. Ind. Microbiol. 4:225-266. 
Suidan, M. T., J. T. Pfeffer, and G. F. Nakhla (1988). In: Anaerobic Digestion 1988 (Hall, E. R. and P. N. Hobson, eds.). Pergamon Press, Oxford. pp. 249-257.

Suzuki, O. (1989). Production of gamma-linolenic acid by fungi and its commercialization. In: World Conference on Biotechnology for the Fats and Oils Industry (T. H. Applewhite, ed.). American Oil Chemists Society, Urbana, Ill. pp. 110-116.

Szewzyk, R. and N. Pfennig (1987). Complete oxidation of catechol by a stricly anaerobic sulfatereducing Desulfobacterium catecholicum. sp. nov. Arch. Microbiol. 147:163-168.

Szewzyk, U. and B. Schink (1989). Degradation of hydroquinone, gentisote, and benzoate by a fermenting bacterium in pure or defined benzoate by a fermenting bacterium in pure or defined mixed culture. Arch. Microbiol. 151:541-545

Szewzyk, U., R. Szewzyk, and B. Schink (1985). Methanogenic degradation of hydroquinone and catechol via reductive dehydroxylation to phenol. FEMS Microbiol. Ecol. 31:79-87.

Tabak, H.H., J.R. Haines, A.D. Venosa, J.A. Glaser, S. Desai and W. Nisamaneepong (1991). Enhancement of biodegradation of Alaskan weathered crude oil components by indigenous microbiota with the use of fertilizers and nutrients. Proceedings of the 1991 International Oils Spill Conference, American Petroleum Institute, Washington D.C. pp. 583-592.

Tanaka, A. and S. Fukui (1985). Bioconversion of lipophilic compounds by immobilized biocatalysts in the presence of organic solvents. In: Enzymes and Immobilized Cells in Biotechnology (ed. A. Laskin). Benjamin-Cummings Publishing Co., London. pp. 175-199.

Tanner, R. S., and D. Yang (1990). Clostridium ljungdahlii PETC sp. nov., a new, acetogenic, Grampositive, anaerobic bacterium. ASM Abstracts R21, Anaheim, CA.

Tarvin, D. and A. M. Buswell (1934). The methane fermentation of organic acids and carbohydrates. J. Amer. Chem. Soc. 56:1751-1755.

Tatnall, R.E., K.M. Stanton, and R.C. Ebersole (1988). Testing for the presence of sulfate-reducing bacteria. Materials Peirformance. Taylor, B. F., W. L. Campbell and I. Chinoy (1970). Anaerobic degradation of the benzene nucleus by a facultative anaerobic microorganism. J. Bacteriol. 102:430437.

Taylor, B. F. (1983). Aerobic and anaerobic catabolism of vanillic acid and some other methoxyaromatic compounds by Pseudomas sp. strain PN-1. Appl. Environ. Microbiol. 46:1286-1292.

Taylor, S.C. (1985). Enzymes in organic synthesis, Ciba Found. Symp. 111:71-80.

Taylor, S.C., D.W. Ribbons, A.M.Z. Slawin, D.A. Widdowson, and D.J.Williams (1987). Biochemically generated chiral intermediates for organic synthesis: the absolute sterochemistry of 4bromo-cis-2,3-dihydroxycyclohexa-4,6-diene-1-carboxylic acid formed from 4-bromobenzoic acid by a mutant Pseudomonas putida. Tetrahedron Lett. 28:6391-6394.

Thauer, R. K., K. Jungerman, and K. Decker (1977). Energy conservation chemotrophic anaerobic bacteria. Bacteriol. Rev. 41:100-180. 
Thiele, J. H., and J. G. Zeikus (1988a). The anion-exchange substrate shuttle process: A new approach to two-stage biomethanation of organic and toxic wastes. Biotechnol. Bioeng. 31:521-535.

Thiele, J. H., and J. G. Zeikus (1988b). Substrate shuttle process for high rate biomethanation. J. Adv. Water Pollution Control 5:165-172.

Thiele, J. H., and J. G. Zeikus (1988c). Interactions between hydrogen and formate-producing bacteria and methanogens during anaerobic digestion. In: Erickson, L. E. and D. Y. C. Fung (eds.) Handbook on Anaerobic Fermentations, Marcel Dekker, New York. pp.537-595.

Thiele, J. H., W.-M. Wu, M. K. Jain, and J. G. Zeikus (1990). Ecoengineering high rate anaerobic digestion systems: Analysis of improved syntrophic biomethanation catalysts. Biotechnol. Bioeng. 35:990-999.

Thompson, A. W., J. G. O'Neill and J. F. Wilkinson (1976). Acetone production by methylobacteria. Arch. Microbiol. 109:243-246.

Tiller, A.K. (1985). A review of the European research effort on microbial corrosion between 1950 and 1984. In: Biologically Induced Corrosion Nace-8 (ed. S.C. Dexter). NACE, Houston. pp. 8-30.

Tsai,C.G. and G.A. Jones (1975). Isolation and identification of rumen bacteria capable of phloroglucinol degradation. Can. J. Microbiol. 21:794-801.

Tsai, L., I. Pastan, and E. R. Stadtman (1966). Nicotinic acid metabolism. J. Biol. Chem. 241:18071813.

Tschech, A. and G. Fuchs (1987). Anaerobic degradation of phenol by pure cultures of newly isolated denitrifying Pseudomonas. Arch. Microbiol 148:213-217.

Tschech, A. and N. Pfennig (1984). Growth yield increase linked to caffeate reduction in Acetobacter woodii. Arch. Microbiol. 137: 163-167.

Tschech, A. and B. Schink (1985). Fermentative degradation of resorcinol and resorcylic acids. Arch Microbiol. 143:52-59.

Tschech, A. and B. Schink (1986). Fermentative degradation of monohydroxybenzoates by defined syntrophic co-culture. Arch. Microbiol. 145:396-402.

Tschech, A and B. Schink (1988). Methanogenic degradation of anthranilate(2-aminobenzoate). Sys. Appl. Microbiol. 11:9-12.

Tsygankov, Y. D. and S. M. Kazakova (1987). Development of gene transfer systems in Methylobacillus flagalatum KT: Isolation of auxotrophic mutants. Arch. Microbiol. 149:112-119.

Tu, A.S., T.A. Murray, K.A. Hutch, A. Sivak, and H.A. Milman (1985). In-vitro transformation of Balb c-3T3 cells by chlorinated ethenes and ethylenes. Cancer Lett. 28:85-92.

Uemura, N., A. Taoka and M. Takagi (1989). Production of dicarboxylic acids by fermentation. In: World Conference on Biotechnology for the Fats and Oils Industry (ed. T.H. Applewhite). American Oil Chemists Society, Urbana, Ill. pp. 148-152. 
Uffen, R. L. (1976). Anaerobic growth of Rhodopseudomonas species in the dark with carbon monoxide as a sole carbon and energy substrate. Proc. Natl. Acad. Sci. USA 73:3298-3302.

Uhl, W., H.J. Hone, M. Beyer and J. Klein (1989). Continuous microbial desulfurization of coal application of a multistage slurry reactor and analysis of the interactions of microbial and chemical kinetics. Biotech. Bioeng. 34:1341-1356.

Uhlinger, D. J., and D. C. White (1983). Relationship between the physiological status and the formation of extracellular polysaccharide glycocalyx in Pseudomonas atlantica. Appl.

Environ. Microbiol. 45:64-70.

Van den Munckhof, P.M. and M.F.X. Veul (1991). Production-scale trials on the decontamination of oil-polluted soil in a rotating bioreactor at field capacity. Abstracts of the Battelle Symposium In Situ and On-site Bioreclamation, San Diego, CA.

Van Ginkel, C. B., A.Q.H. Habets-Cutzen, A.R.M. vander Last and J.A.M. DeBout (1987). A description of microbial growth on gaseous alkenes in a chemostat culture. Biotech. Bioeng. 30:799804.

Van Eldere, J., J. Robben, B. DePauw, R. Merckx and H. Eyssen (1988). Isolation and identification of intestinal steroid-desulfating bacteria from rats and humans. Appl. Environ. Microbiol. 54:2112-2117.

Van Afferden, M., S. Schacht, J. Klein, and H.G. Truper (1990). Degradation of dibenzothiophene by Brevibacterium sp. DO. Arch. Microbiol. 153:324-328.

Van Nispen, J. G. M. and R. Jonker (1991). Process for the fermentative separation of organic acids. U.S. Patent \#5,002,881.

Vecchioli, G.I., M.T. Del Danno and M.T. Painceira (1990). Use of selected autochthonous soil bacteria to enhance degradation of hydrocarbons in soil. Environ. Pollut. 67:249-258.

Vega, J. L., S. Prieto, B. B. Elmore, E. C. Clausen, and J. L. Gaddy (1989). The biological production of ethanol from synthesis gas. Appl. Biochem. Biotechnol. 20/21:781-797.

Venosa, A.D., J.R. Haines, W. Nisamaneepong, R. Govind, S. Pradham and B. Siddique (1991). Protocol for testing bioremediation products against weathered Alaskan crude oil. Proceedings of the 1991 International Oils Spill Conference, American Petroleum Institute, Washington D.C. pp. 563-570.

Vogel, T. M. and D. Grbic'-Galic' (1986). Incorporation of oxygen from water into toluene and benzene during anaerobic fermentative transformation. Appl. Environ. Microbiol. 52:200-202.

Vogels, G.D. and C. Van der Drift (1976). Degradation of purines and pyrimidines by microorganisms. Bacteriol. Rev. 40:403-468.

Von Wolzogen Kuhr, C.A. and I.S. van der Vlugt (1934). The graphitization of cast iron as an electrochemical process in anaerobic soils. Water 18:147-165.

Vrvic, M.M., V. Djordjevic, O. Savkovic, J. Vucetic and D. Vitorovic (1988). Preparation of rich kerogen concentrates: removal of pyrite with Thiobacillus ferroxidans. Org. Geochem. 13: 1109-1114. 
Wackett, L. P. and D. T. Gibson (1988). Degradation of tricholoroethylene by toluene dioxygenase in whole-cell studies with Pseudomonas putida F1. Appl. Environ. Microbiol. 54:1703-1708.

Wagener, S. and B. Schink (1987). Anaerobic degradation of nonionic and anionic surfactants in enrichment cultures and fixed-bed reactors. Wat. Res. 21:615-622.

Wang, Y. -T., M. T. Suidan, and J. T. Pfeffer (1984). Anaerobic biodegradation of indole to methane. Appl. Environ. Microbiol. 48:1058-1060.

Ward, D.M., R.M. Atlas, P.D. Boehm and J.A. Calder (1980). Microbial biodegradation and chemical evolution of oil from the Amoco spill. AMBIO, J. Human Environ. Res. Manag. Royal Swedish Acad. Sci. 9:277-283.

Ward, B., Quigley, D.R. and Dugan, P.R (1990). Relationship between natural weathering and lignite solubility or alkali solubility. Proceedings of the Institute of Gas Technology Ist Int. Gas, Oil and Coal Biotechnology Symposium. pp. 65-79.

Watson, S. A. (1977). Industrial utilization of corn. G. F. Sprague (Ed.) Corn and Com Improvement. Agronomy 18. American Society of Agronomy, Madison, WI.

Weaver, A. A and M. E. Lidstrom (1985). Methanol dissimilation in Xanthobacter H4-14: Activities, induction and comparison to Pseudomonas AM1 and Paracoccus denitrificans. J. Gen. Microbiol. 131:2183-2197.

Weijer, A.C.L.M. et al (1988). Enantiomeric composition of lower epoxy alkanes produced by methane -, alkane - and alkene utilizing bacteria. Enz. Microbial. Technol. 10:214-218.

Westrick, J.J., J.W. Mello, and R.F. Thomas (1984). The groundwater supply survey. J. Am. Water Works Assoc. 76:52-59.

White, D. C. (1983). Analysis of microorganisms in terms of quantity and activity in natural environments. Society for General Microbiology Symposium. 34:37-66.

White, D. C. (1986b). Environmental effects testing with quantitative microbial analysis: Chemical signatures correlated with in situ biofilm analysis by FT/IR. Toxicity Assessment 1:315-338.

White, D. C. (1988). Validation of quantitative analysis for microbial biomass, community structure, and metabolic activity. Advances in Limnology 31:1-18.

White, D. C., W. M. Davis, J. S. Nickels, J. D. King and R. J. Bobbie (1979b). Determination of the sedimentary microbial biomass by extractable lipid phosphate. Oecologia 40:51-62.

White, D. C., R. J. Bobbie, J. S. Herron, J. D. King and S. J. Morrison (1979c). Biochemical measurements of microbial mass and activity from environmental samples. In: Native Aquatic Bacteria: Enumeration, Activity and Ecology ASTM STP 695. American Soc. for Testing and Materials, Philadelphia, PA. pp.69-81.

White, D. C., R. J. Bobbie, J. S. Nickels, S. D. Fazio and W. M. Davis (1980). Nonselective biochemical methods for the determination of fungal mass and community structure in estuarine detrital microflora. Botanica Marina 23:239-250. 
White, D. C., G. A Smith, M. J. Gehron, J. H. Parker, R. H. Findlay, R. F. Martz, and H. L. Fredrickson (1983). The ground water aquifer microbiota: biomass, community structure and nutritional status. Developments in Industrial Microbiol. 24:201-211.

White, D. C., D. E. Nivens, P. D. Nichols, A. T. Mikell, B. D. Kerger, J. M. Henson, G. G. Geesey and C. K. Clarke (1985). Role of aerobic bacteria and their extracellular polymers in the facilitation of corrosion: use of Fourier transforming infrared spectroscopy and "signature"phospholipid fatty acid analysis. Proced. NACE International Conf. on Biol. Induced Corrosion, Gaithersburg, MD, June 1012, pp. 1-11.

White, J. M., D. D. Jones, D. Huang and J. J. Gauthier (1988). Conversion of cyanide to formate and ammonia by a pseudomonad obtained from industrial wastewater. J. Ind. Microbiol. 3:263-272.

White, D. C., D. E. Nivens, M. W. Mittelman, J. Q. Chambers, J M. King, and G. S. Sayler (1991). Non-destructive on-line monitoring of MIC. Corrosion/91, Paper 114 National Association of Corrosion Engineers, Houston, TX.

Whited, G.M. (1986). Metabolism of toluene and aromatic acids by strains of Pseudomonas. Ph.D. dissertation. University of Texas, Austin TX, 1986.

Whittle, P. J., D. O. Lunt, and W. C. Evans (1976). Anaerobic photometabolism of aromatic compounds by Rhodopseudomonas sp. Biochem. Soc. Trans. 4:490-491.

Wick, R. A. (1989). Advances in Microscopy - Part II: Photon counting imaging: applications in biomedical research. BioTechniques 7:262-268.

Widdel, F. (1988). Microbiology and ecology of sulfate-and sulfur-reducing bacteria. In: A.J.B. Zehnder (ed.). Biology of anaerobic microorganisms. Wiley, New York. pp. 469-585.

Widdel, F. and N. Pfennig (1984). Dissimilatory sulfate- or sulfur-reducing bacteria. In: Bergey's Manual of Systematic Bacteriology Volume 1 (Eds. N.R. Krieg and J.G. Holt). Williams and Wilkins, Baltimore. pp. 663-679.

Wiebolt, R. C. M. C. Garry, F. J. Weesner, and M. P. Fuller (1991). Pyrolysis FT-IR as an alternative to TGA/IR. Abstracts 1991 Pittsburgh Conference and Exposition, Pittsburgh, PA. \# 667.

Wiegel J., X. Zhang, D. Dalton. and G. W. Kohring (1990). Degradation of 2,4-dichlorophenol in anaerobic freshwater lake sediments. In: Tedder, W. and F. G.Pohland (eds.) Emerging technologies for Hazardous Waste Treatment. ACS-Symposium Books, Washington, D. C. pp. 119-141.

Williams, R. J. and W. C. Evans (1973). Anaerobic metabolism of aromatic substrates by certain microorganisms. Biochem. Soc. Trans. 1:186-187.

Williams, R. J. and W. C. Evans (1975). The metabolism of benzoate by Moraxella species through anaerobic nitrate respiration. Biochem. J. 148:1-10.

Wilson, J.T. and B.H. Wilson (1985). Biotransformation of trichloroethylene in soil. Appl. Environ. Microbiol. 29:242-243. 
Wilson, B.H., G. B. Smith and J.F. Rees (1986). Biotransformation of selected alkylated benzenes and halogenated aliphatic hydrocarbons in methanogenic aquifer material: a microcosm study. Environ. Sci. Technol. 20:997-1002.

Wilson, B. H., B. Bledsoe, and D. Kampbell (1987). Biological processes occurring at an aviation gasoline spill site. In: R. C. Averett and D. M. McKnight (eds.), Chemical Quality of Water and the Hydrologic Cycle. Lewis Publ., Chelsea, MI. pp. 125-137.

Wilson, J. S., J. Halow, and M. R. Ghate (1988). Chemtech. February, 123-128.

Windass, J. D. (1980). Improved conversion of methanol to single-cell protein by Methylophilus methylotrophus. Nature 287:396-401.

Winter, R.B., Yen, K.N., B.D., Ensley (1989). Efficient degradation of trichloroethylene by a recombinant Escherichia coli. Bio/Technology 7:282-285.

Wise, M. B., M. V. Buchanan, and M. R. Guerin (1990). Rapid determination of target compounds in environmental samples using direct sampling ion trap mass spectormetry. Proceed. 38th ASMS Conference on Mass Spectrometry and Allied Topics. Tuscon, AZ, pp. 619-620.

Witholt, B., J. Sijtsema, M. Kok and G. Eggink (1990). In: Pseudomonas: Biotransformations, Pathogenesis and Evolving Biotechnology. Eds. S. Silver, A.M. Chakrabarty, B. Iglewski and S. Kaplan. American Society for Microbiology Publications, Washington, D.C. pp. 141-150.

Wolf, H. and R. Hanson (1979). Isolation and characterization of methane-utilizing yeasts. J. Gen. Microbiol. 114:187-194.

Wolf, H. J. and R. S. Hanson (1980). Identification of methane-utilizing yeasts. FEMS Microbiol. Letts. 7:177-179.

Wolf, H. M. Christiansen and R. Hanson (1980). Ultrastructure of methanotrophic yeasts. J. Bacteriol. 141:1340-1349.

Wood, H. G. and L. G. Ljungdahl (1991). In: Shively, J. M., and L. L. Barton (eds.), Variations in Autotrophic Life, Academic Press. pp. 201-250.

Woodland, M. P. and H. Dalton (1984). Purification and characterization of component A of the methane monooxygenase from Methylococcus capsulatus (Bath). J. Biol. Chem. 259:53-59.

Worden, R. M., A. J. Grethlein, J. G. Zeikus, R. Datta (1989). Butyrate production from carbon monoxide by Butyribacterium methylotrophicum. Appl. Biochem. Biotechnol. 20/21:687-698.

Worthingham, R.G, T.R. Jack, and V. Ward (1985). External Corrosion of Line Pipe Part I: Identification of Bacterial Corrosion in the Field. In: Biologically Induced Corrosion Nace-8 (ed. S.C. Dexter). NACE, Houston. pp.330-338.

Wright L. and J. Kepley (1967). Bactericide application in an Oriskany storage pool. In: Regional Meeting of the SPE, Evansville, Indiana, September 1967. 
Wubbolts, M.G. and KN. Timmis (1989). Engineering Pseudomonas spp. for the production of cisdiols by biotransformation. In: Genetics and Molecular Biology of Industrial Microorganisms. eds C.L. Hershberger, S.W. Queener and G. Hegeman, A.S.M. Washington DC., pp. 194-199.

Wubbolts, M.G. and K.N. Timmis (1990). Biotransformation of substituted benzoates to the corresponding cis-diols by an engineered strain of Pseudomonas oleovorans producing the TOL plasmid-specified enzyme toluate-1,2-dioxygenase. App. Environ. Microbiol. 56:569-571.

Wuhrmann, K, K. Mechsner and T. Kappeler (1980). Investigations on rate-determining factors in the microbial reduction of azo-dyes. Eur. J. Appl. Microbiol. Biotechnol. 9:325-338.

Wyndham, R.C. and J.W. Costerton (1981a). Heterotrophic potentials and hydrocarbon degradation potentials of sediment microorganisms within the Athabasca oil sands deposit. Appl. Environ. Microbiol. 41:783-790.

Wyndham, R.C. and J.W. Costerton (1981b). In vitro microbial degradation of bituminous hydrocarbons and in situ colonization of bitumen surfaces within the Athabasca oil sands deposit. Appl. Environ. Microbiol. 41:791-800.

Wyza, R.E., A.E. DeSouza, and J.D. Isbister (1987). Depolymerization of low-rank coals by a unique microbial consortium. Proc. Workshop on the biological treatment of coal. US/DOE/INEL. Tysons Corner, VA.

$\mathrm{Xu}, \mathrm{Y} ., \mathrm{H}$. Zhong and W. Cai (1990). Microbial removal of pyritic sulfur from coal. Weishengwu Xuebao 30:134-40 (Chinese, CA 113, 155548)

Yale, B.S. (1991). A comparison of solid-phase and slurry-phase bioremediation of PNA-containing soils. Abstracts of the Battelle Symposium In Situ and On-site Bioreclamation, San Diego, CA.

Yen, K.M. and C.M. Surdar (1988). Genetics of naphthalene catabolism in Pseudomonas. CRC Critical Reviews in Microbiol 15:247-167.

Yi, Z.-H. and H.-J. Rehm (1982a). Degradation pathway from n-tridecane to 1,13 -tridecanedioic acid in a mutant of Candida tropicalis. Eur. J. Appl. Biotechnol 14:144-146.

Yi, Z.-H. and H.-J. Rehm (1982b). Metabolic formation of dodecanedioic acid from n-dodecane by a mutant of Candida tropicalis. Eur. J. Appl. Biotechnol 14:254-258.

Yi, Z.-H. and H.-J. Rehm (1982c). A new metabolic pathway from n-dodecane to 1,12 dodecanedioic acid in a mutant of Candida tropicalis. Eur. J. Appl. Biotechnol. 15:175-179.

Yi, Z.-H, and H.-J. Rehm (1982d). Formation of 1,12 -dodecane dioic acid and 1,13 -tridecanedioic acid from different substrates by immobilized cells of a mutant of Candida tropicalis. Eur. J. Appl. Biotechnol. 16:1-4.

Ying, A., J. Duffy, G. Shepherd and D. Wright (1990). Bioremediation of heavy petroleum oil in soil at a railroad maintenance yard. In: Petroleum Contaminated Soils (Kostecki, P.T. and Calabrese, E.J., eds.) 3:227-238. 
Yokochi, T and O. Suzuki (1984). Japanese Patent 59 l30191-A.

Yoon, R.H., C.I. Basilio and M.L. Stallard (1990). Microbial removal of ash from coal. Proceedings First International Symposium on the Biological Processing of Coal. Electric Power Research Institute 3.79-3.97.

Young, L. Y. (1984). Anaerobic degradation of aromatic compounds. In: D. T. Gibson (ed.), Microbial degradation of organic compounds. Marcell Dekker, Inc., New York. pp. 487-523.

Young, L. Y. and A. C. Frazer (1987). The fate of lignin and lignin-derived compounds in anaerobic environments. Geomicrobiol. J. 5:261-293.

Young, D. N., E. B. Vale, and E. R. Hall (1988). In: Scholze, R. J., E. D. Smith, J. T. Bandy, Y. C. Wu, J. V. Basilico (eds.) Biotechnology for Degradation of Toxic Chemicals in Hazardous Wastes. Noyes Data Corporation, Park Ridge, New Jersey. pp. 542-572.

Young, L. Y. and M. D. Rivera (1985). Methanogenic degradation of four phenolic compounds. Water Res. 19:1325-1332.

Zajic, J.E. and A. Y. Mahomedy (1984). Biosynthesis of surface active agents. In: Petroleum Microbiology. ed. R.M. Atlas. MacMillan Publishing Co., New York. pp. 221-298.

Zajic, J.E. and C. J. Panchal (1976). Bioemulsifiers. CRC Crit. Rev. Microbiol. 5:39-66.

Zehnder, A.J.B. and W. Stumm (1988). Geochemistry and biogeochemistry of anaerobic habitats. In: A.J.B. Zehnder (ed.). Biology of anaerobic microorganisms. Wiley, New York, p. 1-38.

Zeikus, J. G. (1980). Chemical and fuel production by anaerobic bacteria. Ann. Rev. Microbiol. 34:423-464.

Zeikus, J. G. (1981). Lignin metabolism and the carbon cycle: Polymer biosynthesis, biodegradation and environmental recalcitrance. Adv. Microbial Ecol. 5:211-243.

Zeikus, J. G. (1983a). Metabolism of one carbon compounds by chemotrophic anaerobes. $A d v$. Microbiol. Phys. 24:216-297.

Zeikus, J. G. (1983b). Chemical and fuel production from one carbon fermentations: A microbiological assessment. In: Organic Chemicals from Biomass, Addison-Wesley. pp. 359-383.

Zeikus, J. G. (1983c). Metabolic communication between biodegradative populations in nature. Microbes in their natural environment. 34:423-462.

Zeikus, J.G., A. L. Wellstein, and T. K. Kirk (1982). Molecular basis for the recalcitrance of lignin in anaerobic environments. FEMS Microbiol. Lett. 15:193-197.

Zeikus, J. G., R. Kerby and J. A. Krzycki (1985). Single-carbon chemistry of acetogenic and methanogenic bacteria. Science. 227:1167-1173.

Zeikus, J. G., S. Lowe, and B. C. Saha (1990). Biocatalysis in anaerobic extremophiles. In: Abramowicz, D. A. (ed.) Biocatalysis. Van Nostrand Reinhold, New York. pp.255-276. 
Zerubina, N.N., N.N. Lyalikova and E.I. Shmuk (1959). Investigations of microbial oxidation of iron pyrite. Invest. Akad. Nauk. Sr Otedl. Tekh. Mauk. Me. Toplivo. 1:117-119.

Zeyer, J., P.R. Lehrbach and K.N. Timmis (1985). Use of cloned genes of Pseudomonas TOL plasmid to effect biotransformation of benzoate to cis-dihydrodiols and catechols by Escherichia coli cells. Appl. Environ. Microbiol. 50:1409-1415.

Zeyer, J., A. Wasserfallen and K.N. Timmis (1985). Microbial mineralization of ring-substituted anilines through an ortho-cleavage pathway. App. Environ. Microbiol. 50:447-453.

Zhang, X. and J. Wiegel (1990). Isolation and partial characterization of a clostridium species transforming para-hydroxybenzoate and 3,4-dixydroxybenzoate and producing phenols as the final transformation products. Microb. Ecol. 20:103-121.

Zhang, X, T. V. Morgan and J. Wiegel (1990). Conversion of ${ }^{13} \mathrm{C}-1$ phenol to ${ }^{13} \mathrm{C}-4$ benzoate, an intermediate step in the anaerobic degradation of chlorophenols. FEMS Microbiol. Lett 67:63-66.

Ziegler, K., Braun, K, Böckler, A, and G. Fuchs (1987). Studies on the anaerobic degradation of benzoic acid and 2-aminobenzoic acid by a denitrifying Pseudomonas strain. Arch. Microbiol. 149:6269.

Ziegler, K, R. Buder, J. Winter and G. Fuchs (1987). Activation of aromatic acids and aerobic 2aminobenzoate metabolism in a denitrifying Pseudomonas strain. Arch. Microbiol. 151:171-176.

Ziomek, E and R.E. Williams (1989). Modification of lignins by growing cells of the sulfate-reducing anaerobe Desulfovibrio desulfuricans. Appl. Environ. Microbiol. 55:262-2266.

Zobell, C.E. (1946). Action of microorganisms on hydrocarbons. Bacteriol. Rev. 10:1-49.

Zobell, C.E. (1957). Ecology of sulphate-reducing bacteria. In: Symposium on Sulfate-Reducing Bacteria-Their Relationship to the Secondary Recovery of Oil. St. Bonaventure University.

Zobell, C.E. (1958). The ecology of sulphate-reducing bacteria. Producers'Mon. Penn. Oil Prod. Ass. 22:12-29. 


\section{APPENDLX 1 \\ PRIORITTZED PROGRAM RECOMMENDATIONS}

\section{BIOREMEDIATION OF LIQUID FOSSIL FUELS AND REFINED PRODUCTS (Chapter 3)}

A. Establish "proof of principle" for various bioremediation strategies by providing test sites for the thorough testing and documentation on the effectiveness of these biological-based technologies in terrestrial, fresh water, and marine environments.

B. Identify internal marker standards and establish standard protocols for estimating rates of biodegradation and bioremediation effectiveness. This type of standardization will aid in the direct comparison of results obtained by different investigators.

C. Establish protocols to be used for the testing of bioremediation products.

D. Determine fundamental limits of oil biodegradation.

E. Define the role(s) of synthetic surfactants and biosurfactants in bioremediation strategies for terrestrial, fresh-water and marine environments.

F. Provide basic answers to the question "is there a role for inducers or alternative growth substrates?" in bioremediation technologies.

G. Investigate alternative delivery systems for the addition of nutrients serving to stimulate rates of biodegradation.

H. Analyze possible adverse ecological effects resulting from implementation of bioremediation strategies.

I. Evaluate the potential for the use of microorganisms as nongrowing, immobilized biocatalysts in bioremediation.

J. Assess anaerobic biodegradation of crude oil and refined products. 


\section{BIODESULFURIZATION OF FOSSIL FUELS. (Chapter 4)}

A. Accelerate R\&D efforts in the analytical characterization of organosulfur in complex fossil fuels.

B. Develop programs into the basic physiology and biochemistry of microbial interactions with high-sulfur coals and oils. The major objectives are to establish large culture collections of aerobic and anaerobic microorganisms that upgrade fossil fuels through biodesulfurization, biodenitrogenation, bioleaching, biodeashing and bioliquefaction and are available to the scientific community.

C. Correlate the physical/chemical forms of organosulfur existing in fossil fuels to specific biological systems that catalyze "biodesulfurization". It is essential to understand whether a biodesulfurization process removes all types organosulfur in a fuel, or only specific sulfur species.

D. Foster R\&D programs that integrate biology with chemistry.

E. Establish the absolute chemistry and enzymology involved in microorganisms which catalyze beneficial reactions.

F. Evaluate biobeneficiation of high-sulfur coals and oils with defined solvent-tolerant microorganisms where biocatalysis proceeds in an organic solvent reaction medium.

G. Evaluate "soluble coal" for large volume bioprocessing of coal. Enzymatic reactions involving hydrogenase in a hydrogen atmosphere solubilize bituminous and subbituminous coals.

H. Address technical issues concerning mass transfer on industrial scales, and separation of biomass from the fuel. Immobilized desulfurization biocatalysts functioning in a $100 \%$ organic solvent-based reaction medium may prove beneficial to bioprocessing strategies.

I. Design new bioreactor systems consisting of immobilized biocatalysts which function in $100 \%$ organic solvent systems.

J. Develop strategies for disposal of sulfur wastes that will be generated in large scale biodesulfurization technologies. 


\section{BIOCONVERSION OF COAL AND LIGNITE PYROLYSIS GAS AND WASTE STREAMS (Chapter 5)}

A. Develop anaerobic processes for conversion of synthesis gas and methanol to higher value organic solvents, organic acids, and methane.

B. Develop fluidized bed-biofilm reactors and UASB reactor systems with active granular sludge for treatment of coal pyrolysis gas wastes with preference for UASB systems.

C. Develop microbial consortia that anaerobically degrade phenolic coal-based gasification wastes and which form stable biofilms or granules.

D. Develop new biocatalysts by isolation or genetic improvements of existing strains that convert syngas and methanol to economically recoverable levels of organic alcohols, organic acids, or methane.

E. Isolate anaerobic acetogens (i.e., sulfate reducers or syntrophiles) that degrade phenolics, coal-based soluble aromatics and $\mathrm{HCN}$ into organic acids and $\mathrm{H}_{2}$.

F. Develop bioreactor technologies for retention and recycling of biocatalysts.

G. Develop advanced separation technology for recovery of organic acids or alcohols from dilute solutions.

H. Identify physiobiochemical tolerance mechanisms of syngas fermenting organisms to organic solvents and acids.

I. Identify biochemical rate-limiting steps in anaerobic digestion of phenolic-based coal pyrolysis wastes. 


\section{ANAEROBIC BIOTRANSFORMATION OF FOSSIL FUEL RELATED AROMATIC CHEMICALS (Chapter 6)}

\section{HIGH-PRIORITY}
A. Explore the limits of anaerobic metabolism, and its potential in the liquefaction, desulfurization, denitrogenation, and deoxygenation of fossil fuels.
B. Identify metabolic pathways and their regulation.
C. Focus on bioconversions that retain the fuel value of the product.
D. Explore in situ methodologies for the beneficiation of fossil fuels.
E. Correlate structure of fossil fuel substrates with their susceptibility to anaerobic decay.
F. Develop solubilization with the aim of increasing the susceptibility of the products to methanogenic fermentation.

\section{LOWER-PRIORITY}

G. Isolate effective microorganisms and/or consortia

a) select for efficient fossil fuel utilization

b) nutritionally characterize the isolates.

H. Economic assessment of aerobic versus anaerobic beneficiation processes.

I. Explore the direct conversion of soft coals to methane. 


\section{BIOCONVERSION OF HYDROCARBONS TO ADDED VALUE PRODUCTS (Chapter 7)}

NEAR-TO MID-TERM.

A. Alkanes \& Alkenes------> Fatty Acids, Fatty Alcohols, Fatty Aldehydes, Mono- \& Poly-unsaturated Fatty Acids, Hydroxy Fatty Acids, Saturated and Unsaturated Wax Esters, Short \& LongChain Dicarboxylic Acids, Methyl Ketones, Alkoxy Fatty Acids, Polyhydroxy Fatty Acids, Biosurfactants, Amino Acids, Vitamins, Flavor Chemicals, TCA Cycle Intermediates, Epoxyalkanes, Glycols

B. Simple Aromatics----> 1,3,5-Trihydroxybenzene, Benzene Catechol, Muconic Acid, Toluene Phenol, Succinic Acid, Anthracene Polyphenylene, 1- \& 2-Naphthols, Phenanthrene 1,2Dihydroxy Naphthalene, Salicylic Acid, Salicylaldehyde, Coumarin, Naphthoquinones, Hydroxy Naphthoic Acids, Benzyl Alcohol, Benzylaldehyde, 1,2- Dihydroxy Toluene, Benzoic Acid, Poly(Methyl)Toluene, 3-Methyl Catechol

C. Alkyl-Substituted Aromatics---> Phenylacetic Acid, Cinnamic Acid (Alkylbenzene) Phenylpropionic Acid

D. Expedite the development of hydrocarbon biotransformations in organic media through "solvent engineering".

E. Initiate focused programs for the further development of definitive databases in the genetics and enzymology of long-chain alkane and aromatic hydrocarbon oxidations for production of value added chemicals.

F. Generate expanded databases on all types of oxidoreductases with potential for fossil fuels beneficiation.

G. Develop biosurfactant technology for such applications in fossil energy heavy oil pipeline transportation, bioremediation, emulsifiers/deemulsifiers, wetting/dewetting agents, flocculation/deflocculation, solubilization/detergency, foaming/defoaming agents, and corrosion control chemicals.

H. Evaluate the potential for high cell density petro-chemical feedstock fermentations (single cell protein) for the production of specialty chemicals and enzymes.

I. Analyze the growth of fungi on petro-chemicals for the production of extremely highvalue added polyenoic fatty acids such as gamma-linolenic acid, eicosapentenoic acid, and arachidonic acid. 


\section{GENETIC STRATEGIES FOR THE DESIGN AND CONSTRUCTION OF MICROORGANISMS ABLE TO EFFICIENTLY BIOCONVERT AROMATIC HYDROCARBONS TO ADDED-VALUE CHEMICALS (Chapter 8)}

\section{NEAR-MID-LONG TERM.}

A. Develop greater insights into global microbial and metabolic diversity to better exploit biochemical reactions in targeted biotechnological applications.

B. Develop and characterize microbial metabolic networks, their control and the consequences of deliberate alteration of metabolite levels and balances, so that manipulation of metabolic flow for biotechnological purposes moves increasingly from empirical to predictive science.

C. Extend our knowledge on the utility and drawbacks of laboratory strains for carrying out interesting biotransformations.

D. Develop new genetic tools that are useful for the analysis and manipulation of groups (rather than individuals) of poorly characterized but biotechnologically interesting organisms.

E. Design new metabolic routes using different biosynthetic and degradative pathways to obtain novel products that are impossible to synthesize chemically - for example, indigo production from four different pathways: glucose assimilation, tryptophan biosynthesis, tryptophanase and naphthalene oxidation. Such strategies are applicable to any assimilatable organic molecule whose carbon skeleton can be disassembled and reassembled into new products.

F. Develop high level enzyme(s) synthesis which is uncoupled from biomass production.

G. Construct new metabolic routes for product synthesis from either known pathways or non-existing pathways.

H. Develop the coordinated expression of genes originating from different pathways.

I. Improve metabolite flow by inactivation of key enzymes acting at branchpoints. 


\section{STRATEGIES AND DEVELOPMENT OF NEW MICROORGANISMS POSSESSING SPECIALIZED PHYSIOLOGICALATTRIBUTES FOR THE BENEFICIATION OF FOSSIL FUELS (Chapter 9)}

\section{NEAR-TERM.}

A. The isolation and characterization of stable solvent-tolerant microorganisms which exhibit broad tolerance to organic solvents.

B. Genetic engineering of solvent-tolerant microorganisms.

\section{MID-TERM.}

The application of solvent-tolerant microorganisms in biotransformations and bioremediation technologies should be considered as mid-term initiatives, since these fields offer significant potential for commercial exploitation. Solvent-tolerant microorganisms will allow higher efficiences in bioprocessing technologies with higher substrate concentrations and improved product yields. Most importantly, such reaction systems may likely develop new reactions and products not before possible. The development of suitably gene-engineered solventtolerant microorganisms represents priority status.

\section{LONG-TERM.}

A. Biodesulfurization of fossil fuels.

B. Biodesulfurization of coal. 


\section{USE OF METHANE IN WATER TREATMENT (Chapter 10)}

\section{NEAR-TERM.}

A. Determine the technical goals needed to achieve economic competitiveness of methanotrophic systems.

B. Develop systems which achieve low effluent concentrations of pollutant either by adding a granulated activated carbon component or by developing the granulated activated carbon fluidized reactor.

C. Establish pollutant degradation rates of methanotrophic systems at ambient temperatures.

D. Improve gas mass transfer in above-ground bioreactors designed for methanotrophic systems.

E. Design above-ground and in situ bioreactors for methanotrophic systems that release zero methane to the atmosphere.

F. Develop systems capable of gas phase methanotrophic reactions with air stripping and vacuum extraction.

G. Develop new methods for on-line measurement of in situ pollutants and nutrient concentrations.

\section{MID AND LONG-TERM.}

H. Develop improved methods for the detection of microorganisms and targeted chemicals.

I. Initiate $R \& D$ programs for developing a better understanding of the biochemistry and genetics of microbial-mediated pollutant biodegradation.

J. Develop improved models for groundwater hydrology and biogeochemical reactions.

K. Establish a better definition of priority pollutants and risk assessment. 


\section{MICROBIOLOGICALLY INFLUENCED CORROSION \\ IN THE NATURAL GAS INDUSTRY (Chapter 11)}

\section{NEAR-TERM.}

A. Develop on-line methods for the measurement of corrosion rates and associated chemical reactions.

B. Improve the understanding of MIC mechanisms to identify other target chemicals or bacteria.

C. Develop biochemical and genetic probes to increase the speed and decrease the cost of field detection of MIC.

D. Test and develop alternatives to biocide applications for the control of MIC.

E. Evaluate the environmental effects of biocides and other chemicals used to control MIC.

\section{MID-TERM AND LONG-TERM.}

F. Develop biochemical and genetic on-line probes for key environmental and bacterial targets - high priority.

G. Develop methods to modify microbial populations in actual field situations - high priority.

H. Develop realistic models of biofilms in the natural environment which can be used diagnostically - high priority.

I. Identify methods of corrosion treatment which apply chemicals only to the affected sites (e.g. antibody carriers). 


\section{SUBSURFACE MICROBIOLOGY IN THE NATURAL GAS INDUSTRY (Chapter 12)}

\section{NEAR-TERM.}

A. Test promising treatments for mitigating reservoir souring and determine the mechanisms through which such mitigation occurs.

B. Develop reservoir models useful in predicting the consequences of mixing injected and formation waters based on geological, chemical and operational parameters.

C. Determine reservoir characteristics that are predictive of the initial processes in formation souring and develop on-line or field useable methods to detect such changes.

D. Identify production practices which cause souring and establish cost-effective modifications which prevent or delay such processes.

E. Develop rapid and economical methods for differentiating between biological and abiological souring.

F. Evaluate combined chemical and biological methods of removing $\mathrm{H}_{2} \mathrm{~S}$ at competitive costs.

\section{LONG-TERM.}

G. Determine the mechanism(s) of microbial mobility in formations.

H. Investigate how bacteria live in geological formations.

I. Develop probes which allow for on-line monitoring of geochemical, chemical, and biological activities in subsurface environments.

J. Identify reactions, other than $\mathrm{H}_{2} \mathrm{~S}$ production, which are important to oil or gas recovery operations. 


\section{CHEMICALS FROM METHANE (Chapter 13)}

\section{MID-TO LONG-TERM}

A. Develop expanded databases concerning the co-oxidation of other substrates by methane monooxygenase to added value chemicals.

B. Develop new applications for the use of natural gas liquids. Federal restrictions on the use natural gas liquid in refined products will create certain initiatives for new applications and markets for these liquids.

C. Evaluate the application of methane monooxygenase in bioremediation.

D. Evaluate the role of methanotrophs in methane biogeochemical cycles and any relationship to global warming hypothesis. 


\section{PHYSICAL DELIVERY OF MICROBIAL ACTIVITY AND APPLICATION TO FOSSIL FUEL BIOTECHNOLOGY (Chapter 14)}

A. Develop an expanded data base on other physiological and metabolic capabilities of ultramicrobacteria. 


\section{ANALYSIS OF BIOENGINEERING/BIOREACTOR TECHNOLOGY APPLICABLE TO THE BIOPROCESSING OF FOSSIL FUELS (Chapter 15)}
A. Bioprocesses for syn gas/methanol to oxygenated fuel/octane enhancers.
B. Pyritic desulfurization of high sulfur coal.
C. Anaerobic bioprocessing of oxygenated (low rank) coals.
D. Bioremediation of toxic wastes from fossil fuel processes.
E. Integration of separations with bioconversions. 


\section{APPLICATION OF ANALYTICAL INSTRUMENTATION TO FOSSIL FUELS (Chapter 16)}

A. Improve non-destructive techniques and analytical instrumentation for direct on-line analysis of complex substrata undergoing biological modification(s).

nuclear magnetic resonance imaging spectrometry (NMR)

$\mathrm{X}$-ray fluorescence spectrometry (XRF)

$\mathrm{X}$-ray absorption near-edge structure spectroscopy (XANES)

$\mathrm{X}$-ray fine structure spectroscopy (XAFS)

quartz crystal microbalance (QCM)

attenuated total reflectance - FTIR spectrometry (ATR-FT/IR)

"reporter" bacteria coupled to enhanced photon-imaging/photon

image processing computer

electrochemical impedance spectroscopy (EIS)

B. Improve destructive techniques coupled to "smart-detector" analytical systems for online analysis of complex substrata undergoing biological modification(s). supercritical fluid extraction (SFE)

flame-ionization detectors (FID)

photoionization detectors (PID)

inductively-coupled plasma detectors (IPC)

mass spectrometry (MS)

secondary ion mass spectrometry (SIMS)

matrix-assisted FT/IR

surface enhanced Roman spectrometry (SERS)

near infra red spectrometry (NIR)

atomic emission detectors (AED)

sulfur chemiluminescent detectors (SCD)

induced fluorescence detectors (IFD)

capillary gas chromatography (CGC)

thermal analysis (TA)

C. Develop sophisticated "smart" analytical systems through the coupling of nondestructive and/or destructive instrumentation in series to provide information densities that increase with the power of the number of different stages rather than simply additive relationships.

thermal analysis/gas chromatography/FTIR/mass spectrometry

gas chromatography/FTIR/mass spectrometry

capillary gas chromatography/ion trap mass spectrometry (CGC/TTMS)

capillary gas chromatography/FTIR (CGC/FTIR)

capillary gas chromatography/sulfur chemiluminescence (CGC/SCD)

inductively coupled plasma/mass spectrometry (ICP/MS)

capillary gas chromatography/atomic emission (CGC/AED)

enhanced fiber optic detectors

D. Biosensors 


\section{APPENDLX 2 \\ FEDERAL PROGRAMS IN FOSSIL ENERGY BIOTECHNOLOGY}

\section{OAK RIDGE NATIONAL LABORATORY}

Oak Ridge National Laboratory (ORNL) is one of the nation's largest multipurpose R\&D installations. It is operated by Martin Marietta Energy Systems, Inc. for the U.S. Department of Energy. ORNL is a national energy laboratory whose charge is the development of safe, economical, and environmentally acceptable technologies for efficient production and use of energy from various forms. ORNL operates three biology-based divisions with $R \& D$ programs in fossil resource technologies: Chemical Technology Division, Environmental Sciences Division, and Biology Division.

Chemical Technology Division. Current research programs in the Chemical Technology Division address biotechnological issues in fossil resources ranging from bench-scale to pilotplant demonstration projects. Current areas of biotechnology development include: advanced bioreactor systems, bioprocessing of fossil fuels, advanced separation systems, and biocatalysis in organic media.

Bioprocessing efforts in the Chem Tech Division have concentrated on the production of useful fuels and chemicals and the degradation or isolation of environmental pollutants. Early accomplishments include the development of bioreactor systems for producing ethanol and other chemicals, removing nitrates and phenols from industrial wastewaters, treating municipal wastewaters, and removing toxic metals such as lead and cadmium from waste streams. Other contributions in the biotechnology program involve new bioanalytical techniques, tissue culture, protein engineering, and genetic engineering.

A biotreatment process that degrades the organic chemicals in wastewater from coal gasification processes shows potential for reducing capital and operating costs to as much as $50 \%$ of those of a conventional biotreatment process. This bioprocess uses a fixed-film, fluidized-bed bioreactor containing thin films of microorganisms that are attached to the surface of coal particles which are $<1 \mathrm{~mm}$ in diameter.

Advanced bioreactor systems are being developed to improve the efficiency of the fermentation process in which sugar substrates are converted to ethanol. Using immobilized Zymomonas mobilis organisms to maintain high cell concentrations without washout, production rates have far exceeded those of conventional fermentation methods, offering a potential commercial process for efficient production of this valuable chemical feedstock and gasoline extender-octane booster.

As the immobilization of enzymes and cell systems is a key factor in conducting many successful advanced bioprocesses, Chem Tech has focused on developing this technique for use in several different bioconversion processes. Chem Tech researchers have incorporated 
biocatalysts (microorganisms or enzymes) and adsorbents (microbial, plant, or animal biomass) in monodispersed beads formed of hydrocolloidal gels such as carrageenan and alginate. This allows a highly concentrated biological reagent to be used in advanced bioreactors without washout.

Biophotochemical phenomena that have been under investigation includes the use of algae or other biological reagents that utilize light photons to photosynthetically split water into oxygen and hydrogen. Photosynthetic water splitting by platinized chloroplasts is an intriguing approach to the production of hydrogen for use as a renewable gaseous fuel. Hydrogen also has potential applications as a possible addition to or substitute for natural gas.

Bioprocessing concepts are beginning to have an important impact on the use of fossil fuels, particularly our plentiful coal supply. Microbial systems have now been shown to beneficiate coal by the removal of sulfur and other heteroatoms. In one of the most innovative approaches to date, a Chem Tech research team is involved in the development of bioprocesses for the solubilization and gasification of coal. Such systems utilize either microorganisms or isolated enzymes to carry out the bioconversion process at mild operating conditions with the potential for significant economy and less environmental hazard than present thermochemical methods. 'Bioprocesses are also under development for the removal of pollutants from the wastewater of coal conversion processes. It is perhaps also possible to use biological techniques for the removal of hazardous materials from coal-derived liquids and petroleum products, and a recent Chem Tech development may allow the ultimate removal and recycle of $\mathrm{CO}_{2}$ from coal and petroleum combustion processes.

Other biological processes are under development for the enhanced recovery of oil by injecting microbial populations directly into exhausted petroleum reservoirs where they carry out interactions in situ. Similar techniques may be useful for the processing of oil shale and tar sands. Advanced environmental control technology based on bioprocesses will also be important for these applications.

The nationally recognized accomplishments in the field of biotechnology are further supported at ORNL by the establishment of the Oak Ridge Bioprocessing Research Facility, a user resource open to university, national laboratory, and industrial scientists and engineers. It includes laboratories for investigation of advanced bioprocessing concepts using stirred-tank and columnar bioreactors, ranging in size from bench-scale to $500 \mathrm{~L}$. Advanced columnar systems can be operated as fixed-bed or fluidized-bed bioreactors and are equipped to accommodate a variety of process monitoring and control equipment. The user resource also offers several stirred-tank fermentors of various sizes. Research opportunities available at the facility include feedstock pretreatment and fractionation, microbial culture selection and improvement, genetic manipulation, microbial and enzyme immobilization, advanced bioreactor concepts, process feasibility and scaleup, bioprocess monitoring and control, and biochemical separation.

The bioprocessing research program at ORNL has been strengthened and expanded through collaboration with a number of outstanding academic institutions. The University of Tennessee has recently established a graduate program in biotechnology in which the ORNL staff and facilities play a major role. Future collaborative efforts will focus on creating a 
consortium, composed of representatives from academia, industry, and ORNL, that will expand the capabilities of this exciting research area.

International collaboration is evidenced by the numerous exchanges of visits and information among ORNL researchers and academic and research institutions throughout the world. ORNL staff members have established contacts in biotechnology programs in many countries, including the United Kingdom, Israel, Italy, Germany, Belgium, Holland, Sweden, and Spain. An alliance has been formed with leading laboratories and academic institutions in Spain that will ensure future collaborative efforts in biotechnology.

Environmental Sciences Division.' The Environmental Sciences Division of ORNL conducts environmental research and systems analyses to evaluate the effects that energy generation technologies have on the environment and to understand complex environmental relationships. Assessing and predicting effects of environmental changes are essential to reducing environmental risks and impacts, and to managing natural resources wisely. ESD is involved in basic and applied research, environmental assessments, environmental engineering and demonstrations of advanced technology, in addition to providing both technical guidance for regulatory compliance and program management for DOE, other federal and state agencies, and industry. Research currently underway addresses major environmental issues of public and scientific concern:

- global environmental changes

- ecological risks and responses to contaminants

- implications of disturbances to forests and water resources

- safe management of chemical and radioactive wastes

- environmental bioremediation

- development of renewable biomass energy systems

\section{IDAHO NATIONAL ENGINEERING LABORATORY}

The Idaho National Engineering Laboratory (INEL) is a U.S. Department of Energy owned facility conducting basic research in biotechnology, chemical sciences, environmental and earth sciences, material sciences, physics and electronic engineering. INEL is also a center for basic nuclear physics and radiochemistry research, nuclear reactor safety research, defense programs, nuclear waste technology, and the development of advanced energy concepts. The INEL Center for Biological Processing Technology provides for multidisciplinary approaches devoted to research and scale-up activity directed to the innovative bioprocessing of energy resources and other natural resources for the purpose of improving the usefulness and value of those relatively low value-high volume resources.

Bioprocessing technology makes use of living organisms, sub-cellular components and cellular products in processing systems and builds upon the more fundamental information derived from biotechnology. A distinguishing feature of bioprocessing, in comparison to the multidisciplinary biotechnology field, is one of magnitude and scale-up as well as bioreactor design. 
Examples of material being bioprocessed include fossil fuels (coals, oils, natural gas, shales, tar sands), mineral ores, for both release and recovery of metals, hazardous and nonhazardous organic and mineral wastes including processes for metal biosorption, waste degradation and "greenhouse" and combustion gases as well as noxious vapors.

Center staff are also conducting fundamental and applied research on microbially induced corrosion (MIC) in collaboration with material scientists, and they are investigating means of inhibiting MIC.

In addition to the center's permanent scientific and engineering staff, collaborative programs are conducted with scientists at universities as well as with industrial and governmental laboratories. The center also maintains a student participation program through the Association of Western Universities (AWU) in addition to a program for visiting scientists from universities and industry.

The center is also actively involved in the organization and conduct of symposia, workshops, conferences, and other technology transfer activities, frequently in cooperation with other scientific organizations.

R\&D units within INEL are: Bioprocessing Technology Unit, Bioprocessing Engineering Remediation Technologies, Degradation Processes, Microbially Enhanced Oil Recovery (MEOR), Environmental Biotechnology Unit, Biohydrometallurgy, Subsurface Microbiology, Coal Liquefaction and Desulfurization, Phosphate Solubilization and Biodegradation of Organics, Molecular Genetics, Geosciences Unit, Modeling, Hydrology, Geochemistry, Geology/Seismology, and NPR Geoscience Unit.

Research programs currently under development at the center are: Bioremediation and Bioreclamation of Contaminated Soils and Sediments, Biohydrometallurgy, Development of Gas/Vapor Phase Reactors for Bioconversion of Gases and Vapors, Microbial Remediation of Uranium Mill and Mine Tailing Contaminant Migration Hazards, Development of Genetic Engineering Capability for Biomining Bacteria, Selenium Detoxification, Isolation and Genetic Characterization of Coal Desulfurizing Bacteria, Study of a Newly Discovered Bacteriophage in Acidophilic Bacteria, Production of Biopolymers Using Microbial Enzymes, Interfacial Phenomena of Microorganisms of Metal Surfaces, Biocorrosion in Nuclear Power Systems and Waste Storage Canisters, Solubilization and Modification of Low Rank Coals, Biological Separation of Phosphate From Ore, Resistance of Solidified Ion Exchange Resin Wastes to Biological Degradation, Continuous Bioprocessing of Organic Solvents, Biodegradable Industrial Solvents, Microbially Enhanced Oil Recovery (MEOR) and Wettability Research, Coal Bio-Desulfurization, Biochemical Engineering, INEL Subsurface Microbiological and Geochemical Investigations and Biodegradation of Chlorinated Solvents. 


\section{PITTSBURGH ENERGY TECHNOLOGY CENTER}

The Pittsburgh Energy Technology Center (PETC) is the nation's largest and oldest federal laboratory devoted solely to a technology-based coal research and development program. The PETC mission is to develop cost-effective and environmentally sound technologies that promise better use of the nation's abundant supply of coal. In addition to in-house R\&D projects, PETC manages joint government-industry projects in the multibillion dollar Clean Coal Technology Program, which has as a primary goal the reduction of pollutants contributing to acid rain. A recently initiated Combustion 2000 program was established to improve the environmental performance and significantly increase the efficiency of the next generation of coal-fired power plants. Near-term goals target the development of a lowemission boiler system that integrates numerous retrofit technologies being developed and demonstrated through Fossil Energy R\&D and Clean Coal Technology programs. The Flue Gas Cleanup Program at PETC focuses on meeting the requirements of the 1990 Clean Air Act, particularly the more stringent emission requirements to take effect after the year 2000. Biotechnological initiatives under program management by PETC include:

\section{Coal Preparation and Solids Transport Division}

- Biological depyritization of coal

- Enhanced coal biodesulfurization through genetic modification of bacterial strains

- Molecular biology of coal desulfurization

- Molecular biological enhancement of coal biodesulfurization technique: organic sulfur removal

- Cloning and expression of the sulfoxide/sulfone/sulfonate/sulfate genes in pseudomonas and thiobacilli

- Genetic engineering of sulfur-degrading Sulfolobus

- Combined chemical and microbiological removal of organic sulfur from coal

- Bioconversion of coal-derived synthesis gas to liquid fuels

- Evaluation of sulfur-reducing microorganisms for organic desulfurization

- The effect of moderate coal-cleaning on microbial removal of organic sulfur

- Microbial strain improvement for organosulfur removal from coal

\section{Advanced Utilization Division}

- Microbial desulfurization of coal.

- Microbial flue-gas cleanup

\section{Liquid Fuels Division}

- Biological production of ethanol from coal

- Microbiological metal recovery from spent coal liquefaction catalysts

- Bioprocessing of coal

- Anaerobic bioprocessing of low rank coals

- High pressure synthesis gas fermentation

- Biological upgrading of coal liquids

- Biological conversion of coal 


\title{
Environmental Control Division
}

- Biological capture of carbon dioxide from flue gas

\author{
University of Coal Research \\ - Thiophene metabolism in Escherichia coli \\ - Bioprocessing of lignite coals using reductive microorganisms \\ - Electrochemistry of Thiobacillus ferrooxidans reaction with pyrite \\ - Genetics of coal bioliquifaction by Neurospora crassa \\ - A study of microbial enzymes and coal liquefaction \\ - Applications of micellar enzymology to clean coal technology \\ - Microbial mineralization of coal-derived hydrophobic organic contaminants
}

\section{Small Business Innovation Research Program}

- No current SBIR projects

- Phase I: A heat flow probe to measure total sediment metabolic activity

- Phase II: Biological production of methanol from methane

- Phase III: Nonaqueous enzymatic processing of coal

\section{In-House R\&D}

\author{
Coal Preparation Division: Heap Leaching \\ Organic sulfur oxidation \\ Biodecarboxylation
}

\section{MORGANTOWN ENERGY TECHNOLOGY CENTER}

The Morgantown Energy Technology Center (METC) is an implementation facility for the Department of Energy's fossil energy program, focusing on the development of systems to utilize domestic fossil fuels efficiently with concomitant high environmental performance standards. The mission of the surface coal gasification advanced research program is to develop energy systems based on coal gasification technology that have the potential to provide a cost-effective and environmentally superior means for meeting the needs of the utility, industrial and commercial energy sectors. Objectives of the R\&D initiatives are to advance the state-of-the-art of coal gasification based systems to produce energy and chemicals. Of interest is the examination of new and novel approaches that might have application to improving or enhancing coal gasification technology. Advanced research projects focus on long-range, high-risk research. These projects are efforts which industry would not normally pursue but which are essential to the continued advancement of surface coal gasification technology. METC houses engineering research capabilities, laboratories, and on-site facilities and has the lead role in implementation responsibilities for 14 fossil energy technology program areas. In addition to on-site research, METC manages projects 
with industry, academia and R\&D organizations. Technologies to develop from METC's research is the integrated gasification combined cycle system, a technology option for new electric power plants. METC monitors nine of DOE's Clean Coal Technology projects which are focused on commercialization of advanced generations of environmentally clean, coal-based technologies. Projects addressing recovery of gas from low permeability formations include horizontal drilling, the development of measurement-while drilling instrumentation, and improved simulation methods.

Biotechnology initiatives address advances in bioprocessing technology that offer potential improvements for the direct conversion of coal to methane or for the indirect conversion of synthesis gas to methane and hydrogen. Bioprocessing could potentially reduce capital and operating costs for conversion of coal to gaseous products. Program objectives are to develop bioprocesses for the efficient, cost-effective and environmentally superior conversion of coal or lignite to methane-rich products for use as a synthetic natural gas, and to develop bioprocesses for the conversion of synthesis gas derived from coal gasification to hydrogen. Current projects are: 1) development of microbial gas processes, 2) biological conversion of synthesis gas, and 3) biological production of hydrogen (SBIR).

\section{OFFICE OF BASIC ENERGY SCIENCES}

The Energy Biosciences program of the Office of Basic Energy Sciences has as its mission the generation of fundamental information about biological processes in plants and microorganisms that may ultimately be used in the development of new biotechnologies. As such the program covers topics that relate to fossil energy. An example is the basic understanding of sulfur metabolism that impinges on fuel contamination. The emphasis is on comprehending the biochemistry, genetics and physiology in a way that could open the door to producing organisms that may aid in improving operations by avoiding or reducing contamination. It is clear that much remains to be learned about different organisms that have previously been unstudied that may be used for transforming fossil resources into more environmentally acceptable and usable products. The use of microorganisms for conversion of fossil fuel combustion products such as carbon monoxide into useable products such as acetate and methane is one of the areas of investigation sponsored by the Energy Biosciences program. 


\section{External Peer Reviewers \\ For \\ "Assessment of Research Needs for Fossil Energy Biotechnology"}

A final draft version of this report was sent to ten outside reviewers, representing industry and academics. The reviewers were selected for their in-depth knowledge and experience in hydrocarbon-petroleum microbiology. The following scientists served as peer reviewers of this report for Consultec Scientific, Inc.

\section{$\underline{\text { Academic }}$}

1. Dr. Ananda Chakrabarty Department of Microbiology Univ. of Illinois Medical Center Chicago, IL 60612

2. Dr. Robert Kelly Department of Chem. Engineering North Carolina State University Raleigh, NC 27695

3. Dr. Michael McInerney Department of Microbiology University of Oklahoma Norman, OK 73019-0245

4. Dr. David Updegraff Department of Chemistry Colorado School of Mines Golden, CO 80401

5. Dr. Donald Westlake

Department of Microbiology

University of Alberta

(Westec Microbes, Ltd)

Victoria, British Columbia

CANADA V9C $1 \mathrm{X} 4$

\section{Industry}

1. Dr. Robert Huddleston

Conoco, Inc.

1000 South Pine

Ponca City, OK 74603

2. Dr. Thomas Jack

Nova Husky Research Corporation 2928 16th Street, N.E.

Calgary, Alberta, CANADA T2E 7K7

3. Dr. Richard Raymond

1801 Eugene Court

Wilmington, DE 19810

4. Dr. Beverly McFarland

Chevron Research \& Technology

100 Chevron Way, Bldg. 30.1234

Richmond, CA 94802-0627

5. Dr. Joseph Salanitro

W. Hollow Research Center

Shell Development Company

P.O. Box 1380

Houston, TX 70001 


\section{Special Reviewer:}

Dr. Donald Hitzman

Geo-Microbial Technologies, Inc.

Ochelata, OK 74051

Phone: 918-535-2281

Dr. Hitzman served as a consultant to the subpanel meeting held on November 4 and 5 , 1991 in Knoxville, TN. 


\section{PEER REVIEW COMMENTS}

As far as possible, the reviewers comments, particularily those concerning specific changes or corrections, were incorporated into the report. Excerpts from the reviewers, covering general comments, policy concerns, recommendations, and alternate views are presented here, along with a response from the principal investigator, when appropriate.

A. Chakrabarty. The report addresses the major areas of research in fossil energy biotechnology, providing a factual and useful assessment of current status and future potential. A concern addresses the absence of an in-depth discussion concerning the potential usefulness of genetically-engineered microorganisms in fossil energy biotechnology, particularly bioremediation. Overall, an excellent report on the current status of fossil fuel biotechnology with insights into the future trend of research. The recommendations are timely, precise, and trendsetting.

PI Response. The genetic manipulation of microorganisms is discussed in Chapter 8 with respect to the important potential for such genetic tools in the construction of improved biocatalysts. Multienzyme pathways involved in the degradation of simple aromatic hydrocarbons served as the primary focus for this discussion, for reasons that the fundamental information base is further advanced and more sophisticated than knowledge about the genetic systems and ability to manipulate genes in alkane-utilizing or condensed, polycyclic aromatic hydrocarbon-utilizing microorganisms. Once process specific microorganisms are identified, then genetic engineering will become of prime importance in the development of production strains for superior industrial performance properties.

R. Kelly. In general, the most comprehensive and thoughtful discussion of this subject I have seen.

M. McInerney. This document provides the first comprehensive overview of the role of biotechnology in fossil energy and will serve as the handbook to develop creative commercial applications of biotechnology in this area. Other areas not covered in the report include global climate changes in relationship to burning of fossil fuels and the role of biological processes in diagenesis of fossil resources. The panel recognizes the metabolic potential of anaerobic processes in the degradation of hydrocarbons. Non-aqueous biocatalysis may represent the needed breakthrough to make fossil fuel biotechnology economical. Panel rightfully recommends the study of metabolic diversity, particularly as it relates to targeted beneficiation of fossil fuels. Bioremediation. One area in need of further work is the fate of complex polynuclear aromatic hydrocarbons. The degradation of these compounds is not well understood. Syngas Bioconversions. The value in converting syngas to methane is not apparent, considering the surplus of natural gas. Anaerobic Biotransformations. A comprehensive overview of anaerobic processes, indicating the potential for this technology. Added Value Products. Recommendations are sound and organic solvent based technology sounds promising. Genetic Strategies. Relevance not apparent to fossil fuel biotechnology. 
Solvent Tolerant Microorganisms. A large literature on ethanol and butanol tolerance was not discussed. Methane/Water Treatment. Still unclear as to whether methane oxidation is beneficial. An area where combinations of aerobic and anaerobic biotransformations might improve technology. MIC. Improved methods to detect and monitor biocorrosion needed. Subsurface. Microbial ecology of subsurface environments needs high priority status. UMB. Reservoirs contain a diverse and rich microflora. Methods to stimulate the indigenous microflora to produce beneficial activities needed. Recommend the study of the metabolic potential of subsurface microorganisms.

D. Updegraff. This is an exceedingly thorough and well-prepared report covering all currently foreseeable research needs. The report is inspiring.

D.W.S. Westlake. I agree with the evaluation of subjects discussed in this report. The development of organic solvent-tolerant microorganisms is considered of primary importance for the effective and economic exploitation of biological activities directed to fossil energy technologies. Bioremediation. This chapter is very narrowly focused, primarily addressing catastrophic oil spills. Point spills are of greater importance to the environment and society. Biodesulfurization. An accurate statement of current status. Future initiatives should be directed to the use of organic solvent based biocatalytic systems. Anaerobic Biotransformations. A role for anaerobic bacterial transformations of low molecular weight fossil fuel substrates. Bioconversions. The emphasis in this chapter on the use for solvent engineering of bioconversions of fossil fuels is timely and innovative. Genetic Strategies. A major lack of knowledge exists in the physiology, biochemistry, and genetics of microorganisms which degrade high molecular weight polycyclic aromatic hydrocarbons. Solvent Tolerant Microorganisms. A very important direction with very interesting and economically important potential. MIC. An area of major economic importance. Suggest upgrading the development of on-line probes to near-term. Subsurface Microbiology. The problem of reservoir souring is a major problem in the oil industry. UMB. Unproven conceptual technology. Bioreactor Design. Premature technology which needs to be based on characteristics of the organisms and processes involved. Analytical Instrumentation. Good chapter. Unfortunately analytical systems discussed are expensive and only available to large laboratories.

R. Huddleston. An excellent report which addresses the issues outlined as targets and does so in reasonably comprehensive fashion. The specification of PROBLEMS in Chapter 2 is not employed in a consistent manner. A large number of $R \& D$ recommendations are made, which should be prioritized and research goals specified

PI Response. The "Problems" category in Chapter 2 is used to specify either basic needs or to identify limitations in the application of more advanced biotechnology options. The programs identified are at different levels of technical development and, accordingly, the problems which characterize each option are different. The large number of R\&D recommendations listed more accurately reflects our lack of understanding and insight into most of the biotechnology options addressed in this report. Prioritization of so many 
recommendations did not serve any useful purpose in identifying good or bad targets of focus. The organization of these diverse topics into 3 primary foci and identification of unifying priniciples which serves to integrate this diversity appeared to be of greater value in identifying and specifying R\&D goals of scientific merit.

T. Jack. I found the report interesting, thoughtful, and thought provoking. Prefer a ranking of the three primary programs in the order of environmental research, upgrading of fossil fuels, and chemicals production with a priority ranking of bioremediation, biocorrosion, upgrading of fossil fuels, added value products, anaerobic biotransformations, and syngas bioconversions. Bioremediation. The viewpoint and scope is narrow, although many valid observations are made. Biodesulfurization. A quality review of this topic. Solvent tolerant Microorganisms. Chapter has narrow focus. Methane/Water Treatment. Chapter well written with a good balance of practical and fundamental work. MIC. The area is economically important and presents an opportunit; for advances in understanding the composition and behavior of mixed communities. Subsurface. Straightforward recommendations. Bioreactors. A mixture of sensible analysis and rather general information.

R. Raymond. This report is very comprehensive, it accurately describes the present status of biotechnology, and the research initiatives suggested are appropriate and "sorely" needed to bring about applications that are socially and economically demanding for the future.

B. McFarland An ambitious project to provide technically sound advice to DOE for future program development. "This document does a good job of providing an update on the overall status of several key areas of biotechnology related to fossil fuels." What constitutes a definition of "success" in context of targeted research area: technology or economics?" It appeared the focus of the report was more towards "technology" rather than to process "economics". Barriers to the implementation of biotechnology options should be added to the report.

PI Response. The panel addressed fossil fuel biotechnology primarily from a technology perspective, focusing on the status of definable knowledge in broad areas of fossil resource biology. The panel charge was to assess the current status of fossil energy biotechnology and to provide forward-thinking recommendations to DOE for the improved use of fossil resources through biotechnological options. This independent assessment was conducted over a period of nine months to determine the research needs concerning the application of biotechnology to the conversion and use of U.S.-based fossil energy resources. The direction, content, and priority of research activities were addressed in the long term (15-30 years), with emphasis on the identification of new applications and potential opportunities, including radically different approaches from the direction of current biotechnology initiatives in fossil resources research programs. The panel recognized and discussed the issue of "economic drivers". There was, however, general consensus that the status of information and knowledge about fossil energy biotechnology was so immature that development of economic feasibility projections would be totally speculative and of little value to program development. The panel does agree, however, that the early economic 
evaluation of any bioprocessing option becomes of importance to the eventual viability of the program. The large number of recommendations listed in the Appendix for each technical area illustrates clearly that most of the fossil energy biotechnology areas identified requires significantly more in-depth basic research. Bioremediation. General agreement with stated recommendations. Not a good development of roadblocks for implementing bioremediation strategies. Biodesulfurization. General agreement of biocatalysis. Milestones were useful adjuncts to priority research needs. Anaerobic Biotransformations. The level of detail much greater than in some of the other chapters. Recommendations on screening methods, enrichment techniques, and lessons learned would have been useful. The sections under each of the chemicals were complete and did a good job of pointing out methods and problems along with results from the reviewed literature. Added Value Products. A strong endorsement for the high priority of non-aqueous biocatalysis directed to fossil fuels. Genetic Strategies. General agreement on recommendations. Solvent Tolerant Microorganisms. The development or isolation of solvent tolerant microorganisms should be a high priority for DOE funding. MIC. The development of a fundamental understanding of MIC is critical. Subsurface. Why not petroleum subsurface microbiology?

J. Salanitro. A strong concern is expressed as to whether bioprocesses could ever handle the large volumes of gas, liquids and solids processed by the energy industry on a daily basis as well as the inadequacies of biotechnological options to function economically with competing chemical processes. The panel lacked industry representation to provide input into process engineering requirements and economic evaluations regarding fossil fuel utilization and/or treatment. Biotechnology options in bioremediation were discussed in context of the heavy hydrocarbon fractions and the lack of definitive evidence that such compounds are subject to biodegradation. Again cost-effectiveness and applicability of bioremediation strategies must be compared to and competitive with existing process technologies 